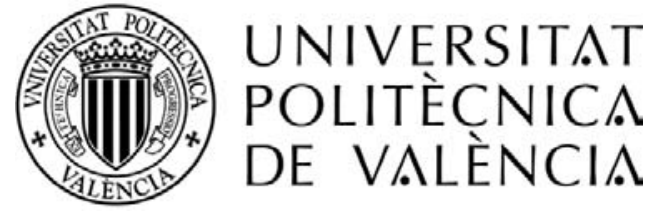

\author{
Facultad de Bellas Artes de San Carlos \\ Departamento de Pintura
}

Programa de Doctorado

Artes Visuales e Intermedia

Tesis Doctoral:

Electroacústica: la expresión del gesto sonoro

Presentado por:

Carlos David Perales Cejudo

Dirigida por:

Dr. Francisco Javier Sanmartín Piquer

Dra. Cristina Portalés Ricart 

El vínculo que existe entre la percepción sonora y la visual en entornos de creación musical ha constituido uno de los argumentos más recurrentes y naturales en cuanto a comprensión, análisis y valoración estética de una obra musical. Desde el origen de la más remota producción sonora se encuentra el factor humano y por tanto, la expresión gestual que de esta se desprende. Desde la aparición de los primeros dispositivos que permitieron el desarrollo de la música producida mediante medios mecánicos, la figura del intérprete pasó de ser una prima donna a un mero tramoyista entre bambalinas. En el caso preciso de la música electroacústica que no está asociada a este componente interpretativo humano - a través de instrumentos acústicos o mediante intervenciones visuales asociadas - el oyente se encuentra en un nuevo estadio de percepción y cognición. Parámetros referentes al espacio, manipulación sensorial y cognitiva y gestualidad interpretativa, a través de dispositivos de registro e interacción, como sensores, establecen un marco renovado en los planteamientos de expresión musical. En cualquier caso y dada la multidisciplinariedad a 
la que viene asociado el arte que tiene que ver con el sonido en el último siglo, sigue habiendo correspondencias sonido-imagen que propician una semántica renovada respecto a la herencia musical y la interpretación con los instrumentos acústicos decimonónicos que aún conforman la mayor parte de plantillas orquestales.

En esta tesis, cuyo título es 'Electoacústica: la expresión del gesto sonoro' se exploran los nuevos brotes que han salido durante los últimos 70 años a raíz de la aparición de los primeros experimentos de Pierre Schaefer en el Groupe de Recherche de Musique Concrète (GRMC) en la radio francesa y la fundación del Estudio de Música Electrónica de la radio de Colonia en la década de los 50 donde Karlheinz Stockhausen exploró las posibilidades de expresión sonora a partir de sistemas de producción electrónica. La investigación se ha realizado en 6 partes: en el ensayo $O$ se presenta el contexto teórico, que definirá los caminos por los que discurrirá la investigación y en el que se acotarán los conceptos y planteamientos que servirán como cimiento en los siguientes 5 capítulos. En este tema se hace una panorámica en la definición y la terminología de este lenguaje así como una revisión de los principales descubrimientos y avances que han propiciado el estadio actual de la música electroacústica. Los siguientes 5 capítulos conforman la parte práctica. En cada uno de ellos se aborda un planteamiento específico y concreto que permite investigar y extraer conclusiones en los diferentes perfiles que plantea el título de esta tesis.

En el primer ensayo titulado Contrapunto Acusmático en Vivo se aborda el diseño y composición de una obra para soporte grabado (cinta) de tipo abierto en el que se cuestiona la flexibilidad y adaptabilidad de los medios fijados (fixed media) y el análisis de 
parámetros ajenos a la producción sonora. En este caso, una persona lee un poema asociado a una temática concreta (cultura Peranakan en Singapur); una aplicación programada en Max MSP analiza algunos parámetros que tienen que ver con las propiedades de la voz de dicho usuario; al término de la lectura se puede oír el resultado de la obra. Así pues, la configuración final de la obra estará condicionada por los parámetros extraídos del análisis de la voz del lector. En el siguiente ensayo, TanGram, se investiga el escenario interpretativo de un cuarteto de percusión con electroacústica; en este se desarrolla una obra para 4 tam tams y 4 mandos de control remoto Wii de Nintendo, que los 4 intérpretes llevan asido al brazo y que permite explorar la gestualidad y las posibilidades expresivas en una interpretación musical para grupo instrumental con electrónica en vivo. En el tercer ensayo, Sonido Aumentado, se propone una instalación visual que reacciona al sonido y movimiento de los intérpretes de una formación jazzística; en este caso se crea un entorno de Realidad Aumentada para visualizar el sonido de estos intérpretes a partir de una Jam session, precedido por una fase de aprendizaje mediante un taller. En el cuarto ensayo, Electroacústica y video-performanza, se investiga la creación musical electroacústica para una video-danza con un planteamiento y un perfil específico como es el site-specific. En el último ensayo, Espectromorfología y gesto visual, se investigan las concordancias y coherencias entre imagen y sonido a partir de los postulados de la espectromorfología del lenguaje electroacústico; el resultado de este ensayo dará lugar a la composición de la parte sonora de un video-documental titulado 'Manos que dan forma'.

Finalmente, y aparte de las conclusiones que se extraen directamente en cada ensayo, se presentan unas conclusiones en las que no sólo se establecen criterios a partir de cada uno de los temas tratados, sino 
que además, se comparan los distintos ensayos realizados para evaluar de forma crítica los resultados obtenidos, tanto de la adecuación de los dispositivos utilizados como del éxito alcanzado a nivel artístico y/o conceptual. 
El vincle que hi ha entre la percepció sonora i la visual en els entorns de creació musical ha constituït un dels arguments més recurrents $i$ naturals quant a la comprensió, l'anàlisi i la valoració estètica d'una obra musical. A l'origen fins i tot de la més remota producció sonora es troba el factor humà i, per tant, l'expressió gestual que se'n desprèn. Des de I'aparició dels primers dispositius que van permetre el desenvolupament de la música produïda mitjançant mitjans mecànics, la figura de l'intèrpret va passar de ser una prima donna a un mer tramoista entre bastidors. En el cas precís de la música electroacústica que no està associada a aquest component interpretatiu humà - a través d'instruments acústics o mitjançant intervencions visuals asociades - l'oïdor es troba en un nou estadi de percepció i cognició. Paràmetres referents a l'espai, la manipulació sensorial i cognitiva i la gestualitat interpretativa, a través de dispositius de registre $\mathrm{i}$ interacció, com ara sensors, estableixen un marc renovat en els plantejaments d'expressió musical. En qualsevol cas, i atesa la multidisciplinaritat a la qual s'associa l'art que té a veure amb el so en I'últim segle, continua havent-hi correspondències so-imatge que propicien una semàntica renovada respecte a l'herència musical i la 
interpretació amb els instruments acústics vuitcentistes que encara conformen la major part de les plantilles orquestrals.

En aquesta tesi, el títol de la qual és 'Electroacústica: la expresión del gesto sonoro', s'exploren els nous brots que han eixit durant els últims 70 anys arran de l'aparició dels primers experiments de Pierre Schaefer al Groupe de Recherche de Musique Concrète (GRMC) a la ràdio francesa i de la fundació de l'Estudi de Música Electrònica de la ràdio de Colònia en la dècada del 1950, on Karlheinz Stockhausen va explorar les possibilitats de l'expressió sonora a partir de sistemes de producció electrònica. La investigació s'ha fet en sis parts: en l'assaig $O$ es presenta el context teòric, que definirà els camins pels quals discorrerà la investigació i en el qual es delimitarà els conceptes i plantejaments que serviran com a fonament dels cinc capitols següents. En aquest assaig introductori es fa una panoràmica de la definició i la terminologia d'aquest llenguatge, així com una revisió dels principals descobriments i avanços que han propiciat l'estadi actual de la música electroacústica. Els cinc capítols següents conformen la part pràctica de l'estudi. En cadascun d'aquests s'aborda un plantejament específic i concret que permet investigar i extraure conclusions quant als diferents perfils que planteja el títol d'aquesta tesi.

En el primer assaig, titulat Contrapunto Acusmático en VIvo, s'aborda el disseny i la composició d'una obra per a suport gravat (cinta) de tipus obert en el qual es qüestiona la flexibilitat i l'adaptabilitat dels mitjans fixats (fixed media) i l'anàlisi de paràmetres aliens a la producció sonora. En aquest cas, una persona llig un poema associat a una temàtica concreta (la cultura Peranakan de Singapur); una aplicació programada en Max MSP analitza alguns paràmetres que tenen a veure amb les propietats de la veu d'aquesta persona; al final de la 
lectura es pot sentir el resultat de l'obra. Així doncs, la configuració final de l'obra estarà condicionada pels paràmetres extrets de l'anàlisi de la veu del lector. En l'assaig següent, TanGram, s'investiga l'escenari interpretatiu d'un quartet de percussió amb electroacústica; en aquest es desenvolupa una obra per a quatre tam-tams i quatre comandaments de control remot Wii de Nintendo, que els quatre intèrprets porten agafats al braç i que permeten explorar la gestualitat i les possibilitats expressives en una interpretació musical per a grup instrumental amb electrònica en viu. En el tercer assaig, Sonido aumentado, es proposa una instal-lació visual que reacciona al so i el moviment dels intèrprets d'una formació jazzística; en aquest cas es crea un entorn de realitat augmentada per a visualitzar el so d'aquests intèrprets a partir d'una Jam session, precedida d'una fase d'aprenentatge mitjançant un taller. En el quart assaig, Electroacústica y video-performanza, s'investiga la creació musical electroacústica per a una videodansa amb un plantejament $\mathrm{i}$ un perfil específics (sitespecific). En l'últim assaig, Espectromorfología y gesto visual, s'investiguen les concordances i coherències entre imatge i so a partir dels postulats de l'espectromorfologia del llenguatge electroacústic; el resultat d'aquest assaig donarà lloc a la composició de la part sonora d'un videodocumental titulat Manos que dan forma.

Finalment, i a part de les conclusions que s'extrauen directament en cada assaig, es presenten unes conclusions generals en les quals no solament s'estableixen criteris a partir de cadascun dels temes tractats, sinó que a més es compara els diferents assajos que s'han portat a terme per a avaluar de forma crítica els resultats obtinguts, tant quant a l'adequació dels dispositius utilitzats com a l'èxit aconseguit a nivell artístic i/o conceptual. 



\section{SUMMARY OF THE DOCTORAL THESIS}

The link that exists between sound and visual perception in musical creation environments has been one of the most recurring and natural arguments in terms of understanding, analysis and aesthetic appreciation of a musical work. From the beginning of the most remote sound production is the human factor and thus, the gestural expression that from this comes off. Since the appearance of the first devices that enabled the development of the music produced by mechanical means, the human component went from being a prima donna to a mere backstage sceneshifter. In the specific case of electroacoustic music that is not associated with human interpretive component through acoustic instruments or associated visual interventions, the listener is in a new stage of cognitive perception. Parameters of space, cognitive and sensory manipulation and interpretive gestures through interaction and recording devices such as sensors, establishing a new framework in the approach to musical expression. In any case, given the multidisciplinary approach that is associated with art that has to do with sound in the last century, there still remains sound-image correlations that creates a renewed semantic with regard to the musical heritage and performance with 
nineteenth acoustic instruments that still make up the majority of orchestral templates.

In this doctoral thesis, entitled 'Electoacoustic: the expression of sonic gesture' there have been explored the new shoots that have emerged over the past 70 years following the onset of the first experiments of Pierre Schaefer in the el Groupe de Recherche de Musique Concrète (GRMC) in French radio and the founding of the Electronic Music Studio of Radio Cologne in the 50 s where Karlheinz Stockhausen explored the possibilities of sonic expression from electronic production systems. The research has been structured in six chapters: in part o the theoretical context is presented, which will identify the roads that will run the investigation and in which the concepts and approaches that will serve as a foundation in the following five chapters will be delimited. This part provides an overview on the definition and terminology of this language as well as a review of the major discoveries and advances that have led to the current stage of electroacoustic music. The following five chapters (essays 1 to 5 ) make up the practice part. Each of them addresses a specific and focused approach that allows to investigate and draw conclusions on the different profiles that raises the title of this thesis.

Essay 1 entiteled Contrapunto Acusmático en Vivo deals with the design and composition of a work for recorded media (tape) of opentype, in which the flexibility and adaptability of the fixed media and the analysis of sound production unconnected parameters are questioned. In this case, a person reads a poem associated with a specific theme (Peranakan culture in Singapore); an application programmed in Max MSP analyzes some parameters that have to do with that user's voice; at the end of the reading, the result of the work 
can be heard. Thus, the final characteristics of the work are conditioned by the parameters extracted from the analysis of the voice of the reader. The following essay, TanGram, investigates the interpretive stage of electro-acoustic percussion quartet; in this it is developed a work for 4 tam tams and 4 Nintendo Wii remote controls that the 4 players have fastened to their arms, allowing exploring the gestures and expressive possibilities in a musical performance for instrumental ensemble with live electronics. In the third essay, Augmented Sound, a visual installation that reacts to the sound and movement of jazz interpreters is proposed; in this case an Augmented Reality scenario is created to visualize the sound of these performers from a Jam session, preceded through a phase of learning by means of a workshop. In essay 4, Electroacoustic and video-performanza, it is investigated the electroacoustic music creation for a video-dance with an approach and a specific profile such as site-specific. In the last essay, Spectromorphology and visual gesture, the consistency and coherence between sound and image from the postulates of the electroacoustic language spectromorphology are investigated; the results of this part will lead to the composition of the sound part of a video documentary entitled 'Manos que dan forma'.

Finally, and apart from the conclusions drawn directly from each essay, some conclusions are presented in which not only criteria from each of the covered topics are stablished, but also the different parts are compared in order to critically evaluate the obtained results, both the adequacy of the devices used and the reached success in the artistic and/or conceptual levels. 



\section{AGRADECIMIENTOS}

En estas primeras líneas quisiera trasmitir mi gratitud y agradecimiento a todas aquellas personas que de un modo directo o indirecto han propiciado el desarrollo de esta tesis doctoral. El trabajo descrito en esta memoria es fruto de una estrecha relación entre distintos campos del conocimiento y la expresión artística, por lo que en algunos casos se ha trabajado en colaboración con distintos investigadores y profesionales pertenecientes a diferentes disciplinas.

En primer lugar quisiera mostrar mi agradecimiento hacia mis directores de tesis, los doctores Francisco Sanmartín Piquer y Cristina Portalés Ricart. A Paco por su inestimable cercanía, apoyo y entusiasmo en todos los planteamientos que han ido surgiendo a lo largo de esta tesis. Su talante y savoir faire me han permitido contar con la flexibilidad y libertad necesaria para dirigir mis inquietudes hacia aquellos aspectos que he ido considerando más relevantes para una investigación artística musical en el ámbito universitario. A Cristina por su incansable apoyo y paciencia, por su excelencia personal y profesional y por compartir mi vida, haciendo que desde aquel frío noviembre vienés de 1999 mi gran pasión y prioridad, la música, pasara a un plano absolutamente secundario. Su tesis 
'Entornos multimedia de realidad aumentada en el campo del arte' se ha convertido en la tesis de referencia para cualquier investigador que desee realizar una investigación en disciplinas de ciencia y arte. En colaboración con ella he realizado el segundo ensayo de esta tesis, así como la publicación de varios artículos de investigación en revistas internacionales.

A todos y cada uno de los miembros e investigadores del Mixed Reality Lab de la Universidad Nacional de Singapur con los que pude realizar proyectos de investigación artística. Al Centre for Arts de la misma Universidad, que me permitió contar con sus instalaciones e instrumental. En especial a Eng-Tat Khoo, ingeniero malayo que me ayudó y acompañó en mis inolvidables peripecias administrativas en la ciudad de Singapur. También a su director Adrian Cheok por permitirme formar parte activa de su laboratorio y acogerme con entusiasmo.

Al Laboratorio de Luz por recibirme como uno más del grupo en las ocasiones que he necesitado alguna ayuda o indicación. A Maria José Martínez de Pisón, su directora, por dirigir mi memoria docente para la obtención de mi DEA y ofrecerme su apoyo durante mi etapa investigadora.

A Maica Ontiñano, junto a la cual realicé el cuarto ensayo, por contar conmigo en la creación y diseño del sonido de su video-danza 'porque la perdí y ofrecerme toda su confianza en el planteamiento y desarrollo del proyecto.

A Mamen Marcos y Carlos Barragán, autores del video-documental 'Manos que dan forma' por ofrecerme toda la libertad para realizar la parte sonora de dicho proyecto, permitiéndome investigar y proponer 
soluciones atrevidas y arriesgadas al planteamiento común en el sonido para un video-documental.

Por último, quisiera dar las gracias a Joaquín Lambíes, gran percusionista y amigo. Con él pude explorar todas las posibilidades sonoras de la familia de la percusión en el quinto ensayo de esta tesis; así mismo agradecer su apoyo en mi labor como compositor y ofrecerme incondicionalmente su capacidad artística en solitario y como miembro del grupo de percusión Kontakte, con el cual he realizado proyectos de innovación artística tan importantes como el tercer ensayo de esta tesis y otros proyectos que se recogen en el primer anexo de esta memoria. 



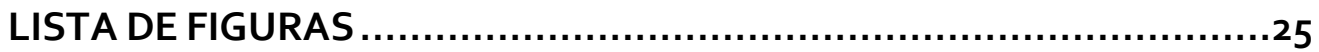

INTRODUCCIÓN................................................................ 35

o. CONTEXTO TEÓRICO .....................................................55

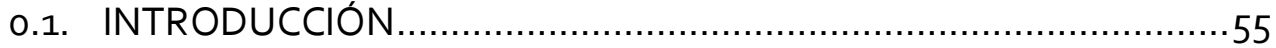

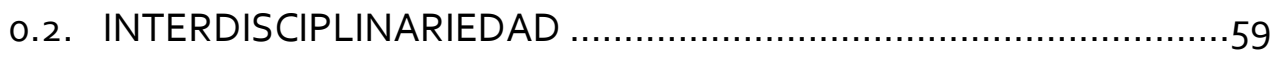

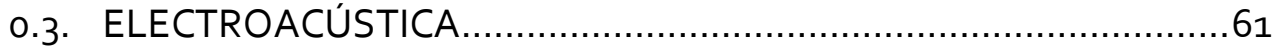

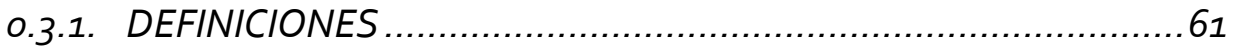

0.3.1.1. ANTECEDENTES: MÚSICA PROCESADA ........................61

o.3.1.2. ACUSMÁTICA - CONCRETA ....................................... 62

0.3.1.3. MÚSICA ELECTRÓNICA .............................................65

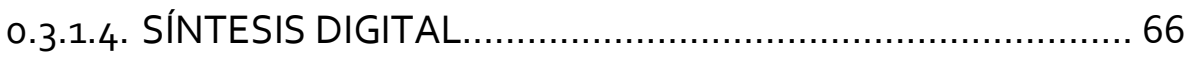

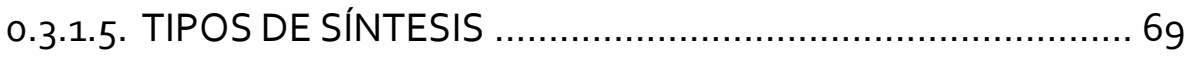

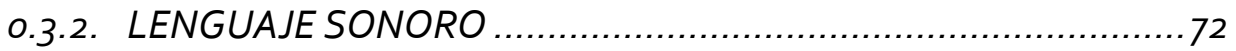

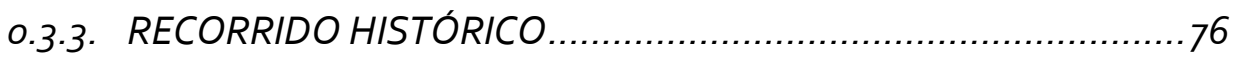

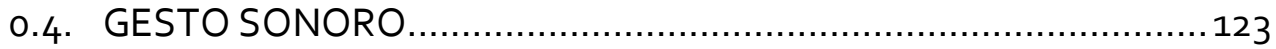

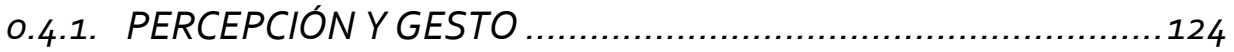

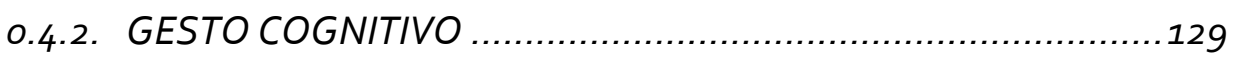

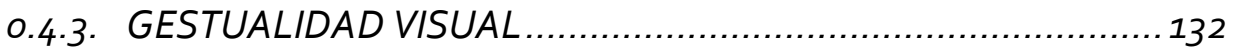




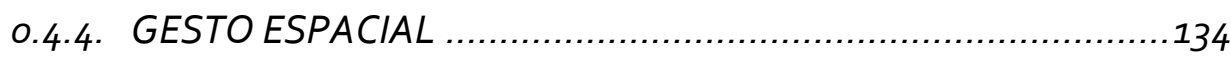

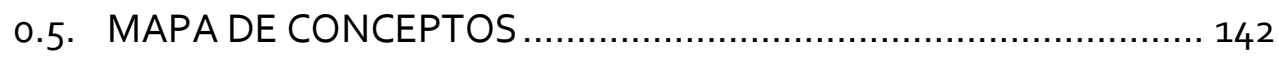

1. CONTRAPUNTO ACUSMÁTICO EN VIVO ..........................145

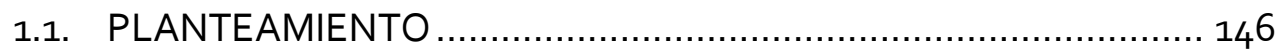

1.1.1. MARCO EN EL QUE SE INSCRIBE EL ENSAYO .....................146

1.1.2. MARCO HISTÓRICO-CULTURAL .....................................148

1.1.3. MARCO TEÓRICO ......................................................150

1.1.3.1. METODOLOGÍA .................................................152

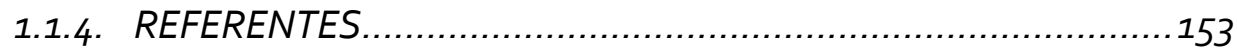

1.2. DESCRIPCIÓN TÉCNICA ….............................................159

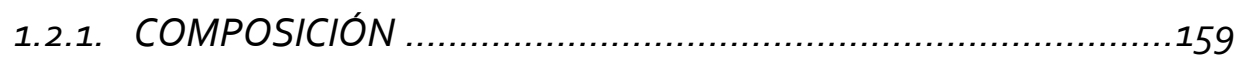

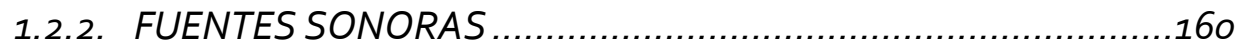

1.2.3. PROCESAMIENTO LIVE / NON LIVE ...............................161

1.2.3.1. DESCRIPCIÓN DEL RANGO ….................................. 164

1.2.3.2. REQUERIMIENTOS TÉCNICOS ..................................... 166

1.2.3.3. ANALISIS DE LOS POEMAS ......................................... 168

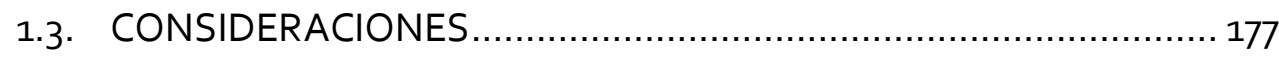

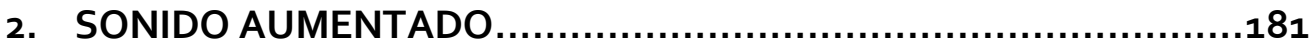

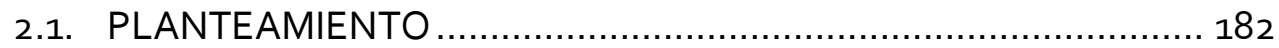

2.1.1. MARCO EN EL QUE SE INSCRIBE EL ENSAYO ......................184

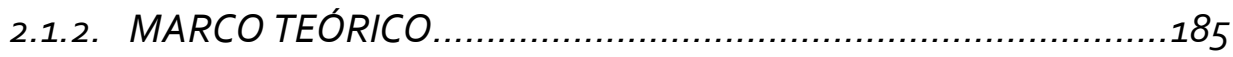

2.1.2.1. EL CONTÍNUO DE MILGRAM ....................................... 188

2.1.2.2. CLASIFICACIÓN DE LOS SISTEMAS DE REALIDAD

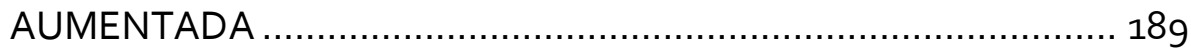

2.1.2.3. CAMPO DE APLICACIÓN ........................................193

2.1.2.4. SISTEMAS DE COORDENADAS TERRENO/OBJETO ........ 196

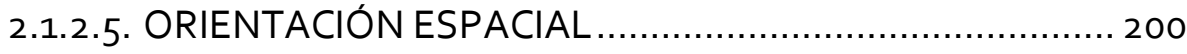

2.1.2.6. DISPOSITIVOS DE REGISTRO / CONTROLADORES ........ 200

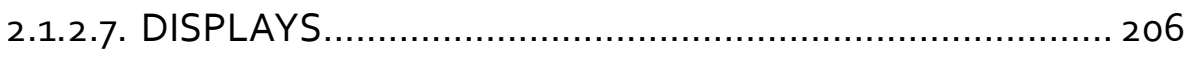

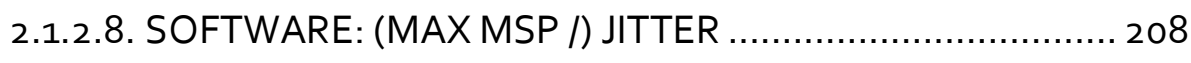




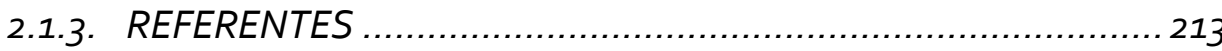

2.2. DESCRIPCIÓN TÉCNICA ...................................................... 216

2.2.1. COMPONENTES DE LA APLICACIÓN...................................216

2.2.1.1. DISPOSITIVOS FÍSICOS ................................................216

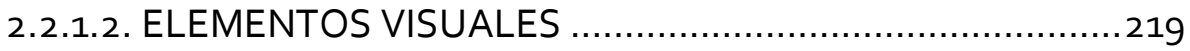

2.2.2. DESARROLLO, PROCESO ...........................................220

2.2.3. CONSIDERACIONES / RESTRICCIONES TÉCNICAS ................224

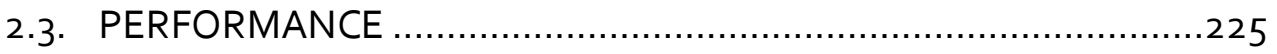

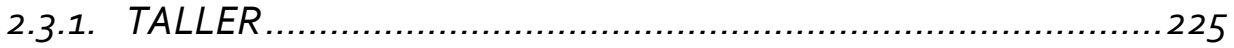

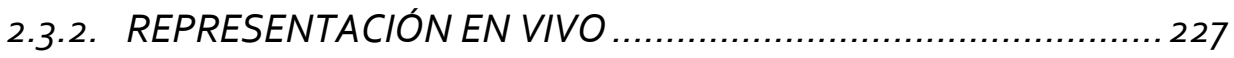

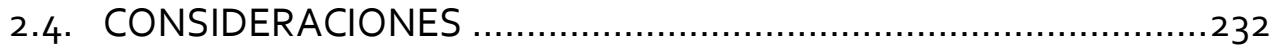

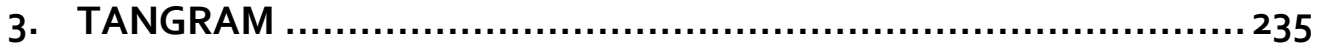

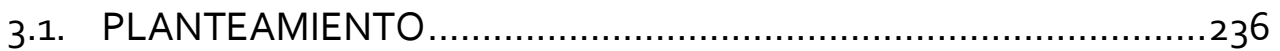

3.1.1. MARCO EN EL QUE SE INSCRIBE EL ENSAYO...................... 239

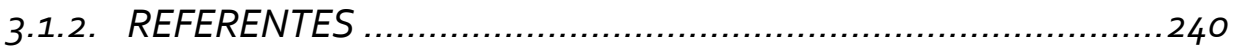

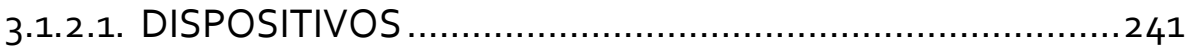

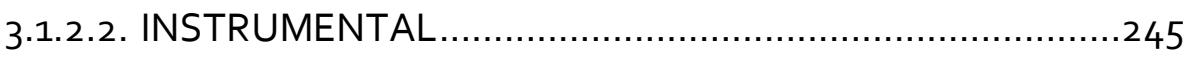

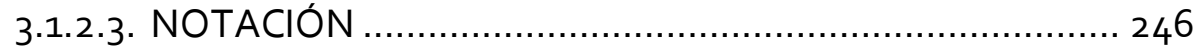

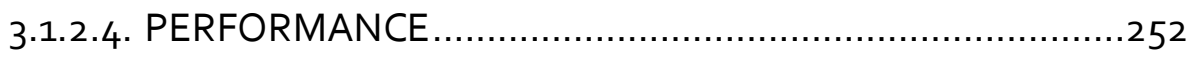

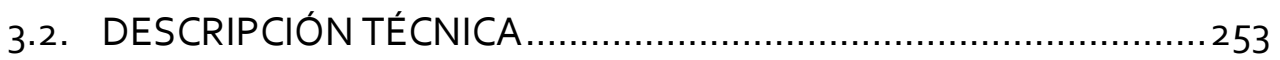

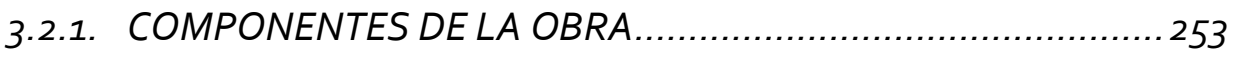

3.2.1.1. METODOLOGÍA NOTACIONAL ................................... 253

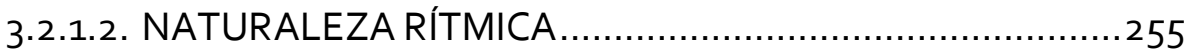

3.2.1.3. ANÁLISIS FORMAL DE LA OBRA................................. 257

3.2.1.4. ELEMENTOS ACÚSTICOS …........................................260

3.2.1.5. DEL GESTO A LA NOTACIÓN SONORA ........................ 262

3.2.1.6. AUTONOMÍA INTERPRETATIVA .................................. 264

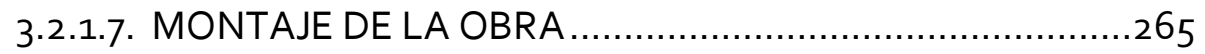

3.2.2. DESARROLLO, PROCESOS DE ELECTRÓNICA EN VIVO .........268

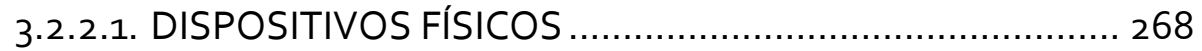

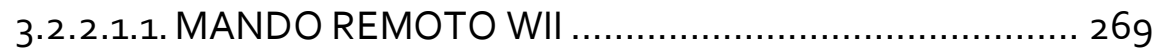


3.2.2.1.2. GESTIÓN DE DATOS VIA BLUETOOTH.....................271

3.2.2.2. Discurso en tiempo real sobre DSP ................................ 275

3.2.3. PATCH DE CONCIERTO …........................................... 284

3.2.4. RECURSOS ADICIONALES EN CONCIERTO........................ 286

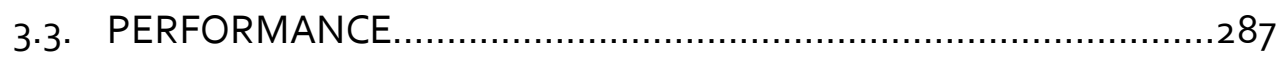

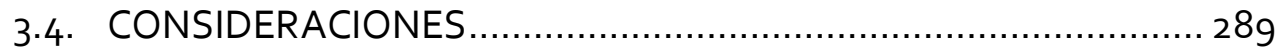

4. ELECTROACÚSTICA Y VIDEO-PERFORMANZA .......................293

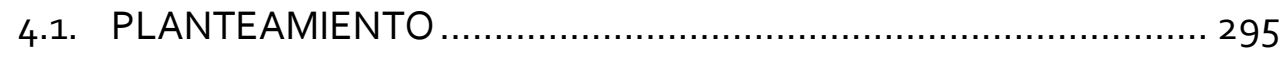

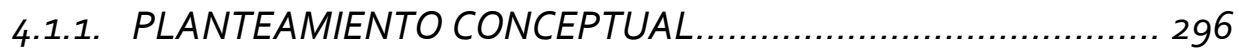

4.1.2. MARCO EN EL QUE SE INSCRIBE EL ENSAYO .................... 298

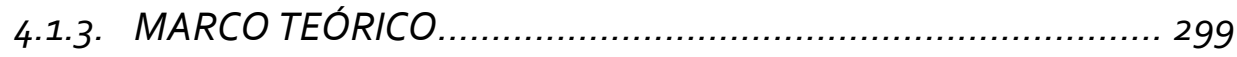

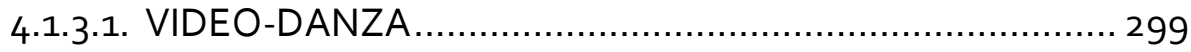

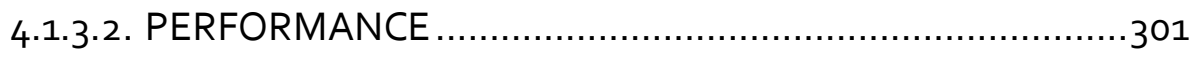

4.1.3.3. IMPROVISACIÓN SITE-SPECIFIC ............................... 302

4.1.3.3.1. INTRODUCCIÓN ................................................ 302

4.1.3.3.2. HISTORIA DE LA PERFORMANCE SITE-SPECIFIC ..... 304

4.1.3.3.3. PERFORMANCE SITE-SPECIFIC: PÚBLICO .................305

4.1.3.3.4. SITE-SPECIFIC FRENTE A SITE-GENERIC .................. 306

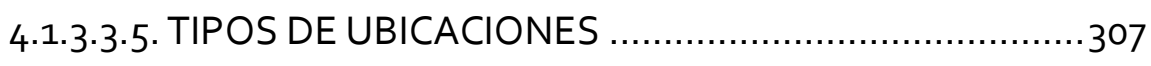

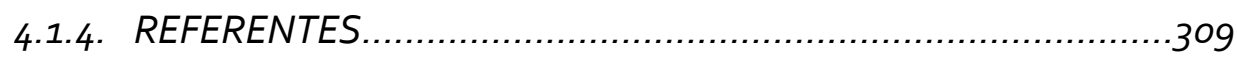

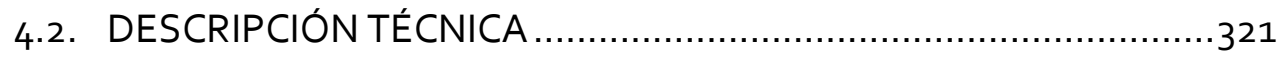

4.2.1. GRABACIÓN Y EDICIÓN DE MUESTRAS..............................324

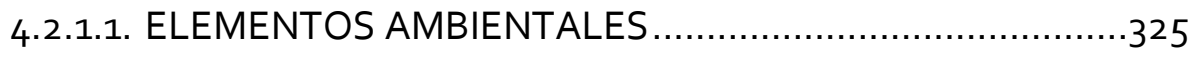

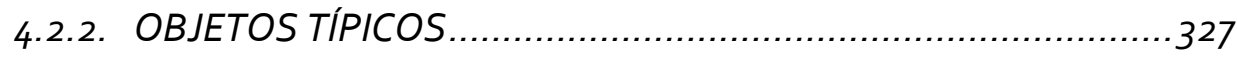

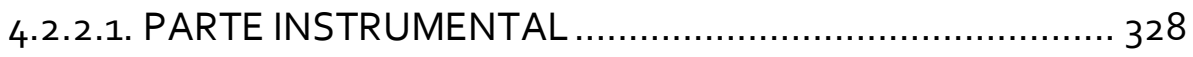

4.2.2.2. PARTE ELECTRÓNICA ............................................. 329

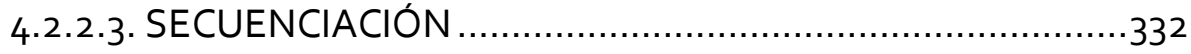

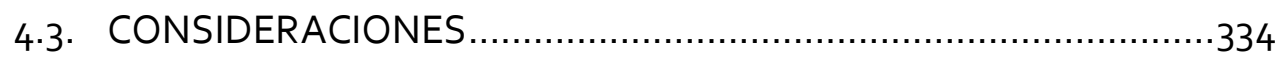

5. ESPECTROMORFOLOGÍA Y EL GESTO VISUAL....................... 335

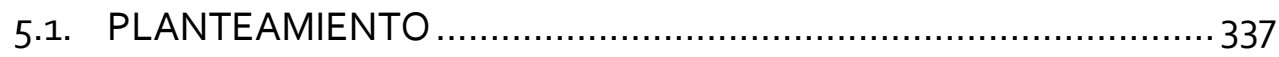


5.1.1. MARCO EN EL QUE SE INSCRIBE EL ENSAYO. 338

5.1.2. MARCO TEÓRICO 339

5.1.2.1. METODOLOGÍA ESPECTROMORFOLÓGICA 339

5.1.2.1.1. ESTRUCTURACIÓN DE TÉRMINOS 344

5.1.2.1.2. METODOLOGÍA. .344

5.1.2.1.3. FUNCIONES ESTRUCTURALES 345

5.1.2.1.4. ELECCIÓN DEL MATERIAL SONORO EN FUNCIÓN DE

LA TERMINOLOGÍA. .345

5.1.2.1.5. ELECCIÓN DEL MATERIAL SONORO EN FUNCIÓN DEL TRAZADO 346

5.1.2.1.6. ELECCIÓN DEL MATERIAL SONORO A PARTIR DE LA ESTRUCTURA .346

5.1.2.1.7. COMPONIENDO MOVIMIENTOS 348

5.1.2.1.8. DISEÑANDO COMPORTAMIENTOS ..........................350

5.1.2.1.9. PRECISIÓN TERMINOLÓGICA................................. 352

5.1.2.1.9.1. TERMINOLOGÍA ADICIONAL ............................. 352

5.1.2.1.9.2. META-DATOS............................................. 353

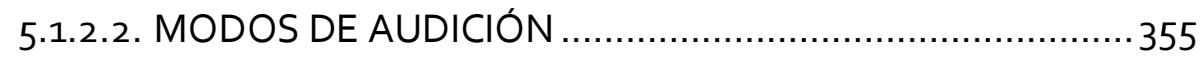

5.1.2.2.1. MODOS SCHAEFFERIANOS DE AUDICIÓN................ 355

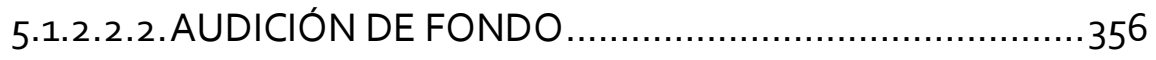

5.1.2.2.3. AUDICIÓN REDUCIDA …....................................... 357

5.1.2.2.4. MODOS AUDITIVOS SEGÚN SMALLEY .................... 357

5.1.2.2.5. MODOS AUDITIVOS SEGÚN DELALANDE .................358 5.1.2.3. COMPORTAMIENTO DE LA PERCEPCIÓN

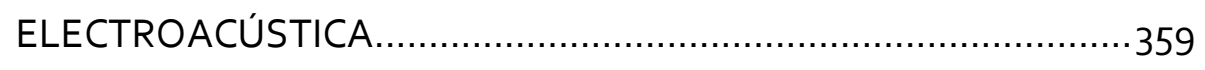

5.1.2.3.1. PERSPECTIVA AMBIENTAL ................................... 360

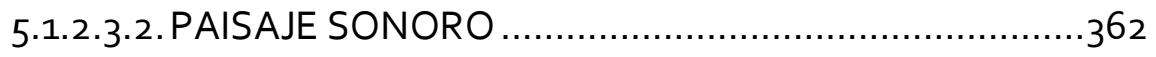

5.1.2.3.3. AUTOCENTRICIDAD Y ALOCENTRICIDAD ..................364

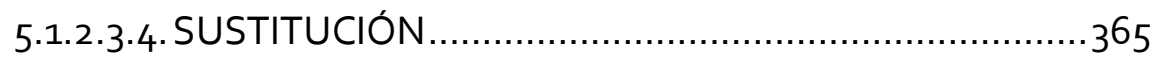

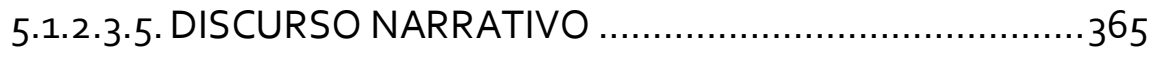

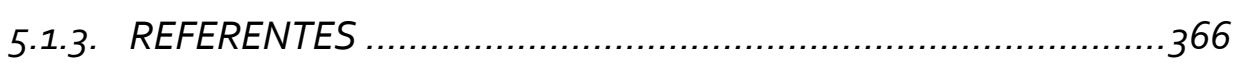

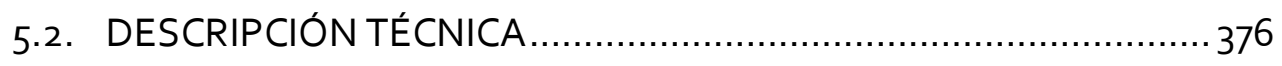


5.2.1. FUENTES INSTRUMENTALES 376

5.2.1.1. NATURALEZA PLÁSTICA: INSTRUMENTOS ACÚSTICOS 378 5.2.1.1.1. PLASTICIDAD SONORA 378

5.2.1.1.2. CORRESPONDENCIA SUBJETIVA O META-SONORA 379

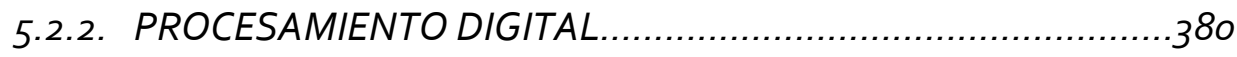

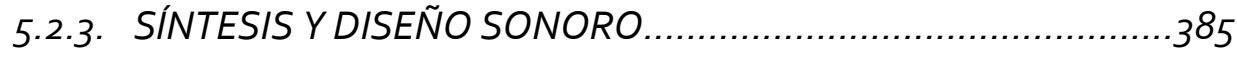

5.2.4. SECUENCIACIÓN ................................................ 87

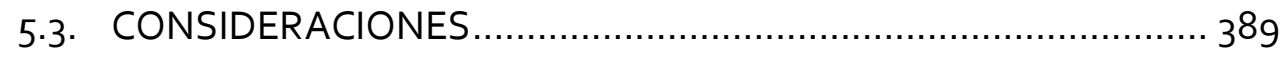

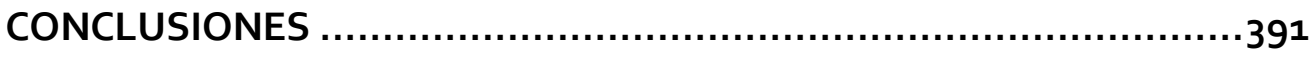

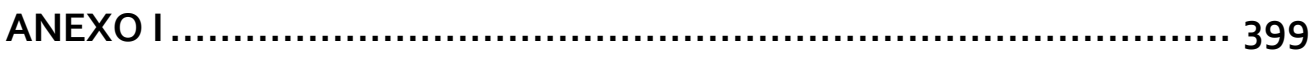

ANEXO II .......................................................................413

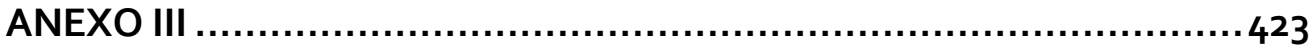

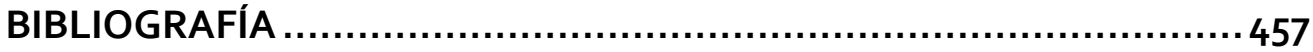




\section{LISTA DE FIGURAS}

Fig. 1 Evolución cronológica de los ensayos de la tesis, y composiciones, publicaciones y conferencias dentro del periodo de duración de la tesis..........52 Fig. 2 Territorios interdisciplinarios, en (Climent, 2006).............................56

Fig. 3 Continuo Sonido/Imagen ................................................... 58 Fig. 4 Pierre Schaeffer en la ORTF (Estudio de la Radio Francesa), y Chromatic Phonogene, 1953. 63

Fig. 5 Fragmento de la paritura Studie I, K. Stockhausen, (Köln, 1954).... 66

Fig. 6 Max Mathews tocando y sampleando un violín conectado al sistema IBM

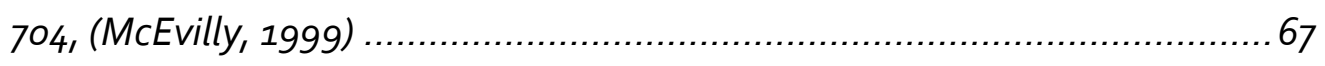

Fig. 7 Hydraulis, en (Grups.blanquerna, 2010) ....................................... 77

Fig. 8 Arpa eólica, en (Britannica, 2010) ............................................. 77

Fig. 9 Mano de Guido, en (Wikipedia, 2010i) ......................................... 78

Fig. 10 Zanfona, en (ElMusiquiatra, 2010) ........................................... 79

Fig. 11 Archicembalo, en (Wikipedia, 2010a)......................................... 80

Fig. 12 Arca Musarithmica, en (ElMusiquiatra, 2010) ...............................80

Fig. 13 Pascalina, en (LoyolaUniversityChicago, 2006) .............................82

Fig. ${ }_{14}$ Clavecin Electrique, en (ElMusiquiatra, 2010) ................................ 82

Fig. 15 Musikalisches Wurfelspiel, en (ISMLP, 2010) ............................... 83 
Fig. 16 Music Box, en (Wikipedia, 2010q) ......................................... 83

Fig. 17 J. N. Maelzel con un Panharmonicon, en (ElMusiquiatra, 2010) ......... 84

Fig. 18 Telégrafo-Piano, en (EbrisaOnline, 2010) ................................... 85

Fig. 19 T. A. Edison junto a uno de sus primeros Fonógrafos en 1878, en

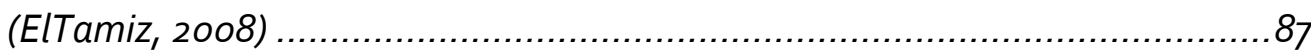

Fig. 20 Comptómetro, en (IBM, 2010a) .............................................. 88

Fig. 21 Pianola; Votey a la derecha de la imagen, en

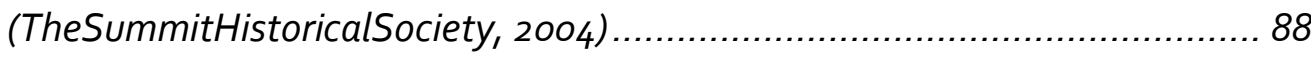

Fig. 22 Telarmonio, en (ElMusiquiatra, 2010)........................................... 89

Fig. 23 Luigi Russolo y Ugo Piatti con el Intonarumori, 1913, en (IntuitiveMusic,

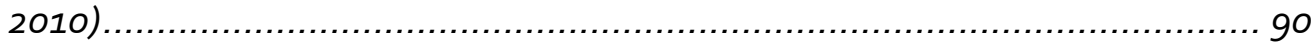

Fig. 24 L. Theremin, en (Noctamina, 2009) ............................................. 92

Fig. 25 J. Mager con su Spharophon, en (PhotographersDirect, 2010) .......... 93

Fig. 26 M. Martenot, en (IntuitiveMusic, 2010)..................................... 93

Fig. 27 Trautonium, en (AnalogArtEnsemble, 2010) ................................ 94

Fig. 28 Órgano Hammond, modelo B3 con la caja del altavoz Leslie, en

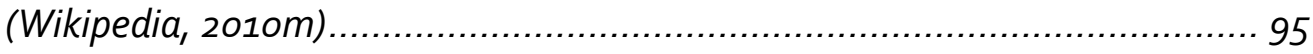

Fig. 29 Novachord, en (DiscreteSynthesizers, 2006) ................................ 96

Fig. 30 Ondiolline, en (Member.tde, 2010) ...........................................97

Fig. 31 Solid-state trasistor en 1958, en (IBM, 20106)............................. 98

Fig. 32 Solovox, en (Hammond-organ, 2010) y Clavioline, en (120years, 2010) 98

Fig. 33 H. Lecaine tocando el Sackbutt, en (Lecaine, 2010)......................... 99

Fig. 34 H. Bode tocando un Melochord en 1948, en (120years, 2010)............100

Fig. 35 Partitura de 4' 33" de J. Cage, en (Cage, 1999)...............................101

Fig. 36 Harry F. Olson y Herbert Belar con el primer Sintetizador de Sonido, en (Pennstate, 2010) …................................................................ 103

Fig. 37 Pabellón Philips, 1958, en (Arq-lab-vox, 2010) ..............................105

Fig. 38 El sintetizador Mark II en el Estudio Columbia-Princeon, 1985. De izquierda a derecha: Milton Babbitt, Meter Mazuey y Vladimir Ussachevsky, en (IntuitiveMusic, 2010) 108 
Fig. 39 San Francisco Tape Music Center, 1965. De izquierda a derecha: Tony Martin, Hill Maginnis, Ramon Sender, Morton Subotnick y Pauline Oliveros, en (IntuitiveMusic, 2010)... 108

Fig. 40 Robert Moog con una de las versiones de Moog, en (IntuitiveMusic, 2010)

Fig. 41 John Eaton con un Synket, en (KeyboardMuseum, 2010) 111

Fig. 42 Mellotron, 1974 en (Wikipedia, 2010l) 115

Fig. 43 Captura de los créditos de Max MSP (Cycling74, 2010) 120

Fig. 44 Mac Il de Apple, en (HistoriaGlobalOnline, 2010). 121

Fig. 45 Esquema en 3 dimensiones para el análisis del objeto sonoro, en (Schaeffer, 1952). 125

Fig. 46 Espectrograma de un fragmento de Chansos de gestes, $R$. Cochini, en (Justel, 2000) 126

Fig. 47 Espectrograma de un fragmento de Chiaroscuro, F. Dhomont, en (Justel, 2000) 127

Fig. 48 Análisis de frecuencia en $3 D$ de un objeto sonoro, en (Climent, 2001) 127 Fig. 49 Captura de e-RRATUM, en (Climent, 2001).... 128

Fig. 50 Esquema de colocación de los 60 altavoces del Cybernephone durante el Festival Synthese'og (Bourges-Francia) y El autor durante el estreno de Hydra (2009) (ver Anexo I). 135

Fig. 51 Fraçois Baile utilizando el Acousmonium en Salle Olivier Messiaen, Maison de Radio France, Paris 1980, en (EMF, 2006), e instalado en Roma en 2008, en (Cipriani, 2008). 136

Fig. 52 Fachada principal y Figura Baba 148

Fig. 53 Entrada principal de la casa Baba 149

Fig. 54 Tablas de movimientos y partitura del Concierto para piano preparado y orquesta de cámara de J. Cage, en (Díaz de la Fuente, 2005) 154

Fig. 55 Matriz de intensidades y Partitura de Estructuras para dos piano, $P$.

Boulez, en (Díaz de la Fuente, 2005) 157

Fig. 56 Fragmento musical del Poema Sayang Airwell. 160 
Fig. 57 De izquierda a derecha y de arriba a abajo: Er Hu, Gu Qin, Yang Qin, Shimian Luo, Viñas Hong y Pien Ching, en (CIIC, China Internet Information

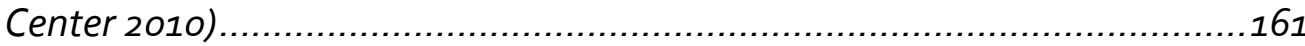

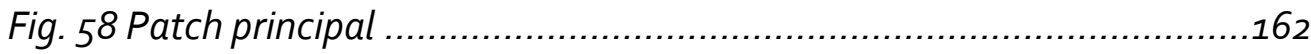

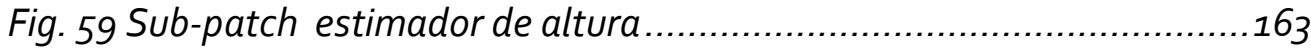

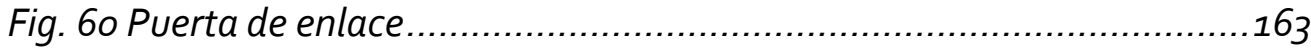

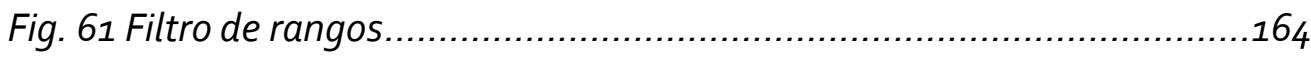

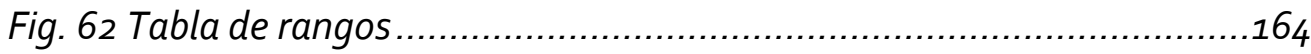

Fig. 63 Conversión de alturas a índice MIDI..........................................165

Fig. 64 Recreación de un posible resultado final en el programa Audacity.....166

Fig. 65 Sub-patch sfplay , Reproductor de archivos.................................166

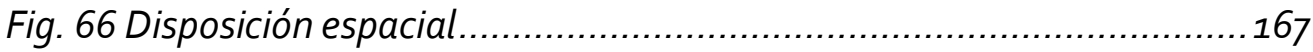

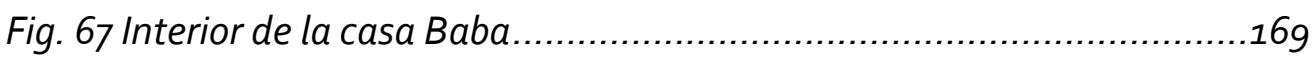

Fig. 68 Manipulando el interior de un piano .......................................... 175

Fig. 69 El autor manipulando el cordaje de un piano en el Centre for Arts de Singapur.

Fig. 70 Ejemplo de entorno de RA mediante las librerías BazAR, en (CVLAB -

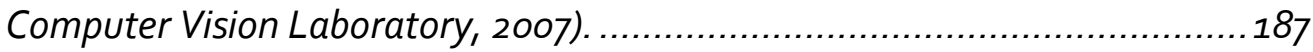

Fig. 71 Continuo de Milgram. A partir de (Milgram y Kishino, 1994).............189

Fig. 72 Continuo de Milgram ampliado con otros conceptos. ......................189

Fig. 73 Sistemas de coordenadas: a) Terrestre global: b) Terrestre local; c)

Centrado en objetos, (Portalés, 2008)

Fig. 74 Comparación de dispositivos de registro, en (Neumann, 2001). 199

Fig. 75 Sensor inercial MT9 de Xsens y su representación virtual, en (XSens, 2007). 204

Fig. 76 Aplicación de RA en la que el usuario lleva GPS y un sensor inercial para el registro de su posición y orientación, y marcas para el reconocimiento de gestos de las mano, en (Piekarski, 2006). 204

Fig. 77 Ejemplo de cambio de posición y dirección del eje óptico de la cámara virtual 210 Fig. 78 Objeto jit.gl.model 211 
Fig. 79 Modelo obj modificado mediante jit.gl.model: a) Mapeado de vídeo; b) Modo de alambres; c) Transparencia (blend activado); d) Salida matricial.... 211 Fig. 80 Objeto mtg para Jitter 213

Fig. 81 a) Piano - as image media; b) Telesymphony, en (Paul, 2003)...........214

Fig. 82 Messa di Voice, en (Levin, 2006). 215

Fig. 83 Usuarios interactuando con The Hidden Worlds of Noise and Voice, en (Levin y Collaborators, 2008). 216

Fig. 84 Esquema de los componentes y distribución espacial de Sonido

Aumentado. 218

Fig. ${ }_{5}$ NURBS cilíndrico a partir de js jitaudioznurbs.js, donde: a) Con textura;

b) Representación alámbrica; c) Con textura y deformaciones a partir de un audio; d) Representación alámbrica y deformaciones a partir de un audio.... 219 Fig. 86 Patch principal de Sonido Aumentado ........................................ 221

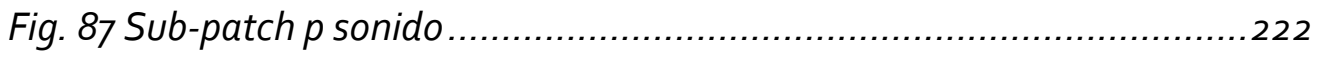

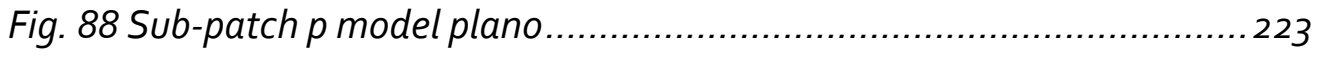

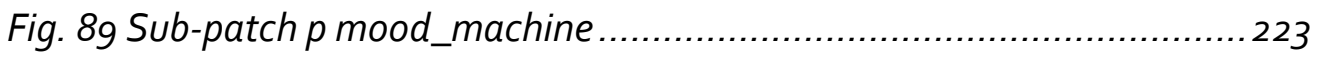

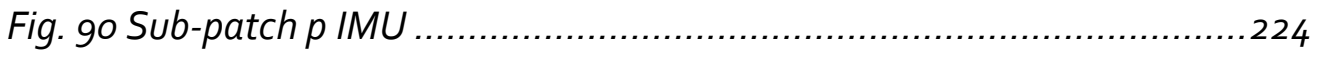

Fig. 91 Imágenes tomadas durante el taller de Sonido Aumentado ..............226

Fig. 92 Visualizaciones del sonido de acuerdo al instrumento utilizado y a la

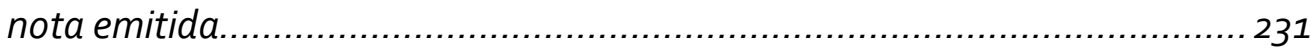

Fig. 93 Imágenes tomadas durante la Jam session................................ 232

Fig. 94 Placa Arduino, en (Cuartielles y Banzi, 2006) .............................. 238

Fig. 95 Captura de concierto, Kontakte, grupo de percussió, en (Kontakte, 2009)

Fig. 96 Despliegue de dispositivos para DSP-bop, en (Climent, 2001) ...........242

Fig. 97 Captura del Patch Los Misterios de Mitra de G. Jiménez ...................242

Fig. 98 Captura durante el estreno de Fragments de G. Jiménez .................243

Fig. 99 Ricardo Climent probando la inclinación de los guantes, Méjico, 2003

Fig. 100 Placa BASIC STAMP y Sensores para baquetas para Agravidade Liberta, en (Climent, 2003)..... 
Fig. 101 Captura del Patch Le Gyrosbone y Carlos Gil durante el estreno de 'Le Gyrosbone'. 245

Fig. 102 Sistema La Kroonde, en (Coduys et al., 1999) ............................. 245

Fig. 103 Fragmento de Mikrophonie (1964) en (http://brainiac-

conspiracy.typepad.com/my_weblog/2007/12/stockhausen.html) ............. 246

Fig. 104 Indicaciones de tiempo y cinta magnética, en (Berenguer, 1974) .....247

Fig. 105 Fragmento de Poème Électronique de E. Varèse, en (Varèse, 1957-58)

Fig. 106 Fragmento de Unsound Objects, Harrison (1995) en (Berezan, 2009)

Fig. 107 Fragmento de Vortex (1982) en (Samlley, 1982) ......................... 250

Fig. 108 Fragmento de la leyenda de Acute, en (Climent, 2008)...................251

Fig. 109 Fragmento de Le Gyrosbone (2005), R. Climent ..........................251

Fig. 110 Fragmento de TanGram ..................................................... 254

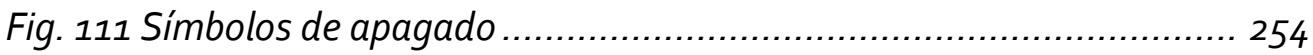

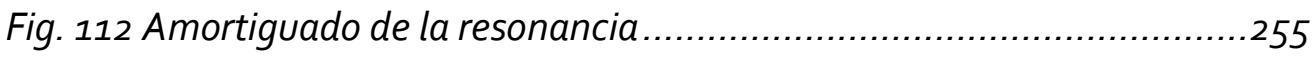

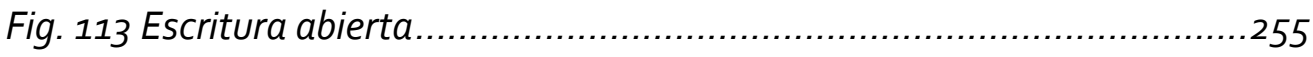

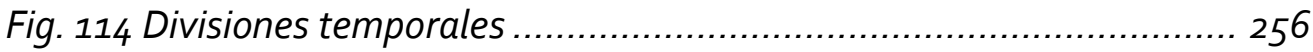

Fig. 115 Simbología de baquetas y utensilios ...................................... 262

Fig. 116 Kontakte ensayando TanGram................................................ 264

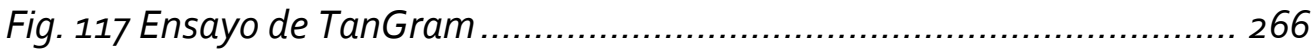

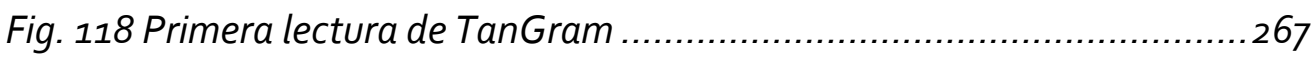

Fig. 119 Interior del mando Wii, en (Seidle, 2006).................................... 269

Fig. 120 Acelerómetro ADXL 330, en (Seidle, 2006)................................. 270

Fig. 121 Ejemplo de valores de aceleración en los 3 ejes, a partir de (Xiig19o,

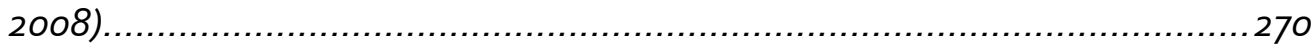

Fig. 122 Inductores y Bluetooth BCM 4042, en (Seidle, 2006)..................... 271

Fig. 123 Acelerómetro y EEPROM, en (Seidle, 2006) ................................ 271

Fig. 124 Activación de eventos en la partitura de TanGram ......................... 273

Fig. 125 Objeto aka.wiiremote, en (Akamatsu, 2009)............................. 274

Fig. 126 Escalado y Envío de los valores y botones desde el objeto

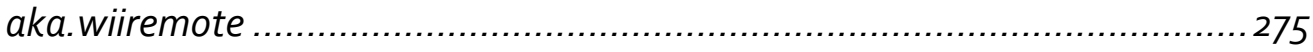


Fig. 127 Fragmento de la partitura ................................................. 276

Fig. 128 Mando Wii................................................................. 276

Fig. 129 Prueba del mando Wii durante un ensayo de TanGram..................276

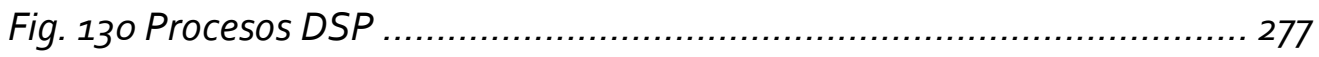

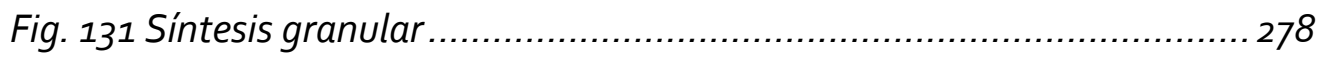

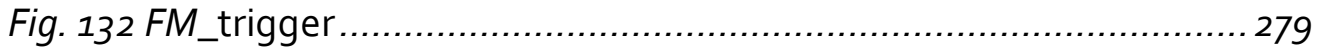

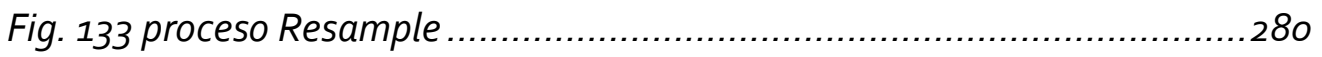

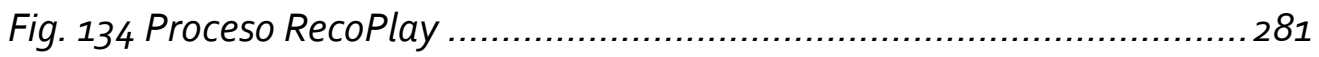

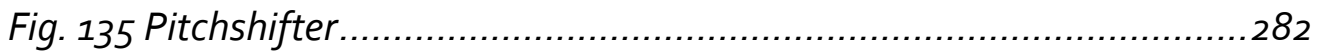

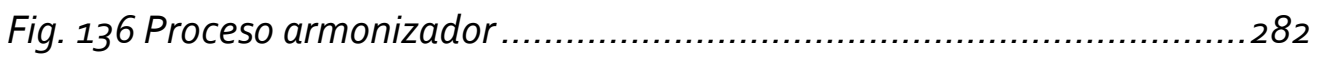

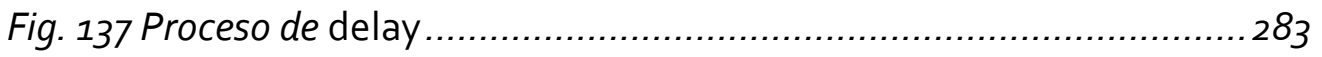

Fig. 138 Matriz de datos en Max MSP.................................................284

Fig. 139 Captura del Patch principal TanGram.......................................28

Fig. 140 Sub-patch encargado de la gestión de la entrada y salida de micros. 286

Fig. 141 Sub-patch para controlar los datos vía MIDI ............................. 287

Fig. 142 Espacio escénico para TanGram, Badajoz 2009...........................28

Fig. 143 Mesa de control: controlador MIDI UC33, PowerBook G4, Tarjeta de Audio MOTU Traveller 828 MkIl. ....................................................289

Fig. 144 Saluda en el estreno de TanGram, 2009 .................................... 291

Fig. 145 Captura de Porque la perdí................................................ 297

Fig. 146 Captura de Degustación de Titus Andronicus, en (Baus, 2010) .........309

Fig. 147 Captura de One flat thing, reproduced, en (Forsythe, 2010) ............310

Fig. 148 Captura de Hodoku, en (Patrian, 2008) ..................................... 312

Fig.149 Captura de Sleepness

Fig. 150 Armónica de Cristal.. 313

Fig. 151 Capturas de Ma Mère l'Oye, en (Mey, 2008) ................................ 314

Fig. 152 Captura de Rosas danst Rosas, en (Mey, 1997) ............................ 315

Fig. 153 Captura de Fase, en (Mey, 2002) ........................................... 316

Fig. 154 Capturas de Here After, en (Vandekeybus, 2010a) ....................... 317

Fig. 155 Capturas de Mirror Mirror in the Wall, en (Lee, 1986) ..................... 318

Fig. 156 Esquema de Remote Dancing, en (Lee, 2010a) ............................318

Fig. 157 Capturas de Remote Dancing, en (Lee, 2010a)............................319 
Fig. 158 Seis bailarines virtuales en Remote Dancing, en (Lee, 2010a) .........319

Fig. 159 Instalación Stereo Dances, en (Lee, 2010b)................................320

Fig. 16o Instalación Volume para Lightwalking, en (UVA, 2010)..................321

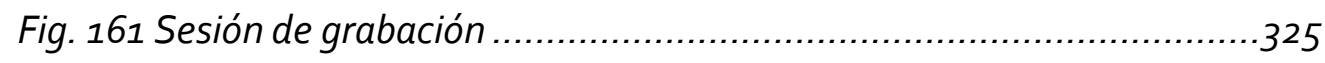

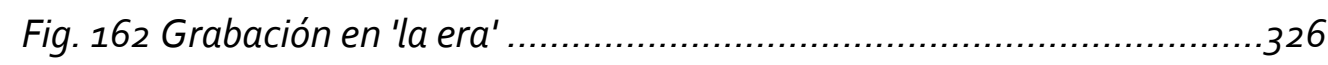

Fig. 163 Grabación de sonidos de respiraciones...................................... 327

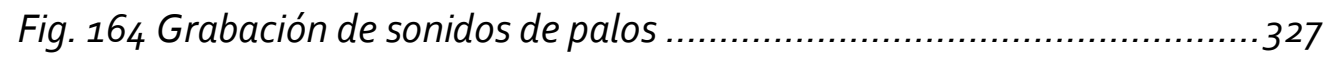

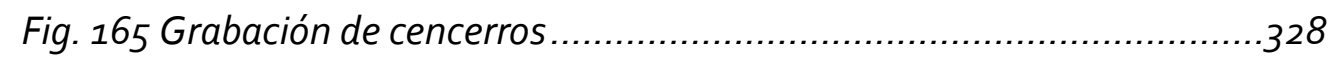

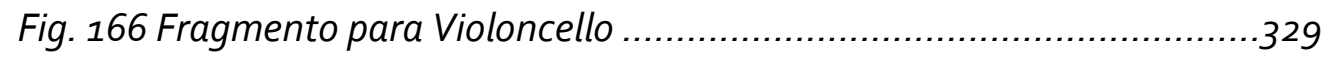

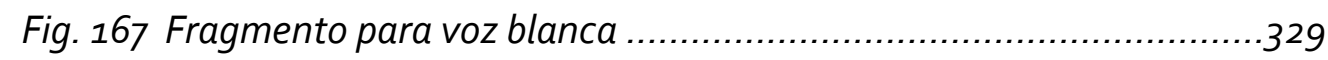

Fig. 168 Utensilios de labranza y cocina típicos de Gavín............................330

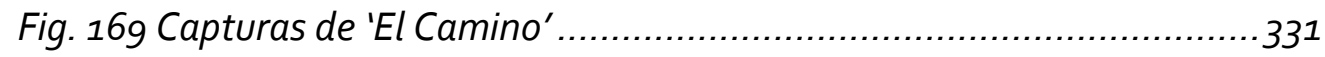

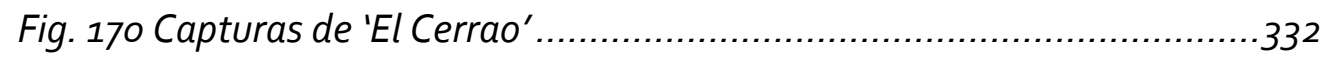

Fig. 171 Modulos AU utilizados, Space designer, en (Apple, 2010C) y

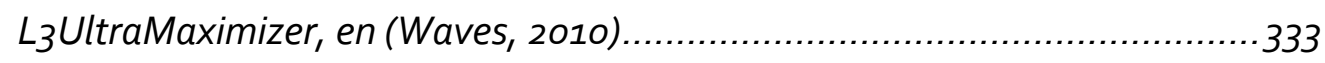

Fig. 172 Materiales sonoros en Porque la perdí......................................... 333

Fig. 173 Procesos estructurales, en (Smalley, 1997) ...............................345

Fig. 174 Equivalencia visual de un objeto emergente y otro que desaparece, en

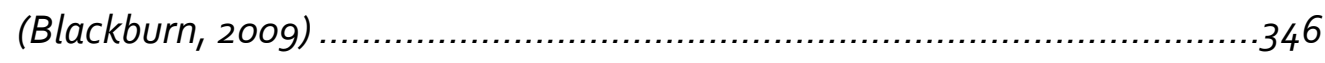

Fig. 175 Construcción de una Unidad sonora, en (Blackburn, 2009).............347

Fig. 176 Cadena Morfológica creada a partir de dos Unidades Sonoras y

funcionalidades duales del sonido ' $C^{\prime}$ ', en (Blackburn, 2009) ........................348

Fig. 177 Movimiento y Procesos de evolución, en (Smalley, 1997) ................349

Fig.178 Mov. compuesto: Multi-direccional Fig. 179 Textura compuesta:

Masa 349

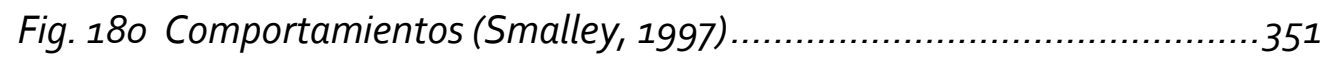

Fig.181 Comportamiento apresurado Fig. 182 Comportamiento voluntario

351

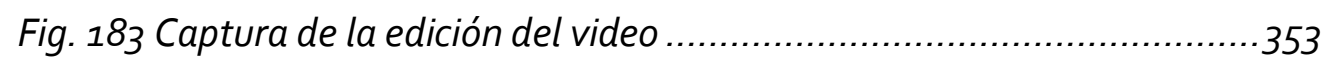

Fig.184 Captura de SpotMeta Fig. 185 Captura de Punakea...................353

Fig. 186 Captura de Gaia, en (Rekalde, 2010a).......................................367

Fig. 187 Captura de Vuelos migratorios, en (Rekalde, 2010b).....................369 
Fig. 188 Captura de Portrait d'une femme, en (Gauthier, 2010)................... 370

Fig. 189 Capturas de Nord/Sud, en (Gauthier, 2010) ............................... 370

Fig. 190 Captura de Perg, en (Scarani, 2010) .......................................... 372

Fig. $19160 \times 60$ A Circle of Sound, White Fungus Productions, en (60x60, 2008)

Fig. 192 Captura de 'no entry (no exit)', en (Koop et al., 2010)..................... 374

Fig. 193 Captura del procesamiento de señal de video, en (Tannenbaum, 2010) 375

Fig. 194 Captura del video Viscous Meanderings, en (Tannenbaum et al., 1985) 376

Fig. 195 Instrumentos de percusión grabados ....................................... 377

Fig. 196 Captura de la edición de sonido................................................. 379

Fig. 197 Captura de la edición de sonido ..............................................380

Fig. 198 Captura de Granular 2.5 de Nobuyasu Sakonda, en (Sakonda, 2010) 382

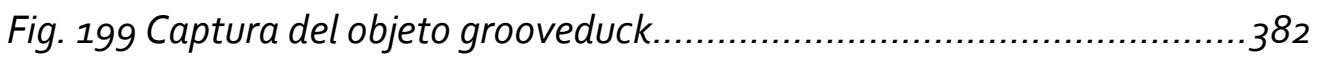

Fig. 200 Captura del programa Csound 5, en (Csound, 2010a) .....................384

Fig. 201 Captura del código basado en Alan Lee, en (Boulanger, 2000) ........385

Fig.202 Captura de Reaktor Fig. 203 Carptura de Absynth ......................386

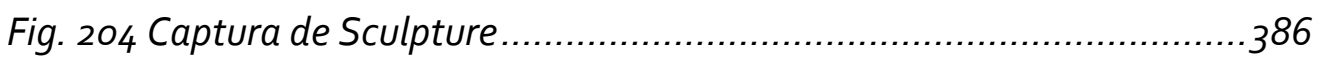

Fig. 205 Captura de Ultrabeat Fig. 206 Captura de ESX24 .................... 387

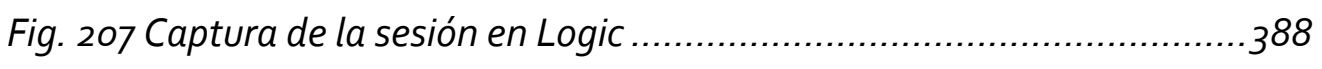

Fig. 208 Comparación entre los distintos programas utilizados en esta tesis.

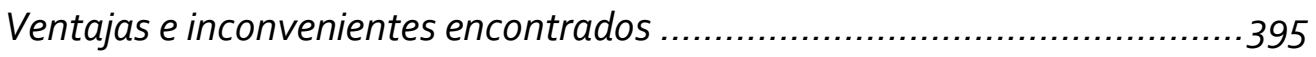

Fig. 209 Comparación entre los distintos métodos de registro utilizados en esta

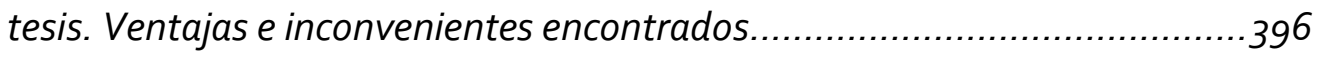

Fig. 210 Portada del CD del VI Concurso Internacional de Composición Miniaturas Electroacústicas, Huelva, 2008.......................................... 402

Fig. 211 Portada del CD 60 Aniversario 2' 49" AMEE, Valencia, 2008 ........... 403 Fig. 212 Presentación del triple CD AMEE Vol. I, Valencia, 2009; de izquierda a derecha Enrique Mateu, Manuel Bonino, Daniel Roca, Jacco van den Hoek, 
David Alarcón, El autor, Miguel Molina, Gregorio Jiménez y Josep Lluís Galiana. 405

Fig. 213 Reproducción del Clavicordio modelo NM264785a Anónimo, Collection Musikseet de Estocolmo, y El autor durante el estreno de Clavichord_IO en el Club Diario Levante (Valencia)..... 407

Fig. 214 Paritura de Jeu, y S. Aparisi, J. Francés y El autor durante el estreno de Jeu, 2009 . 408

Fig. 215 Partitura de Theatrique y foto del estreno, de izquierda a derecha, El autor, Xelo Giner y Andrés Lewin Richter, 2009 410 Fig. 216 Partitura de Dans y Kontakte, grupo de percusión durante el estreno de la obra, 2010 411 


\section{INTRODUCCIÓN}

'Los niños y los animales entienden mejor mi música' (Stravinsky, 1961) ${ }^{1}$

La música, como otras manifestaciones artísticas ha evolucionado en función de los acontecimientos que han ido sucediendo a lo largo de la historia. Es evidente que la relación entre compositor y público no ha sido siempre la misma. Así como para la nobleza de los siglos XVII y XVIII era esencial el dominio de la expresión artística y sus manifestaciones, y para la burguesía del siglo XIX significaba un elemento de distinción, en el s. XX y sobre todo después de la lla Guerra Mundial la expresión artística musical perdió el 'dueño' que siempre tuvo.

Beethoven (1770-1827) se entiende como el primer compositor que consiguió vivir de sus obras y publicaciones al margen de mecenas y

\footnotetext{
${ }^{1}$ 'My music is best understood by children and animals'.
} 
acreedores. Hasta Vivaldi (1678-1741) la música de nueva creación no se entendía como algo necesario. Bach (1685-1750) acostumbraba a reutilizar su propio material para obras de nueva factura. Esta intratextualidad perdió su sentido con el romanticismo, ya que el compositor se definía en términos de inspiración salvaje e irrepetible. La composición musical pasó de entenderse como un bien de uso a ser entendido como una manifestación trascendente.

Estos dos factores pueden explicar la situación en la que quedó la música a principio del s. XX. Compositores como Mahler (1860-1911), Debussy (1862-1918), o Schoenberg (1874-1951) consiguieron marcar nuevos caminos en lo referente a la estética musical pero el estadio de orfandad en el que quedaba el objeto musical iba a desviar la trayectoria hacia un nuevo dueño: el pueblo. Es en este punto y junto a los nuevos lenguajes musicales afroamericanos cuando nace el jazz, y la música pasa a un estadio de ludicidad importante.

Después de la lla Guerra Mundial la comunidad artística musical se erigió en torno a varios epicentros creativos. Los cursos de verano de Darmstadt en los que coincidieron los más importantes compositores del momento dieron claves importantes en la innovación de lenguajes estéticos y creativos. Sin embargo, la disociación entre música clásica y público ya se había producido. Aunque el término 'música clásica' se acuño por primera vez en el Oxford English Dictionary en 1836, señalando las composiciones europeas más destacadas del siglo anterior ((ed) Simpson y (ed) Weiner, 2009), con el tiempo significó lo opuesto a la música popular y empezó a utilizarse en el lenguaje corriente. 
En la actualidad existen planteamientos musicales extraídos de todas y cada una de las situaciones descritas. Existen manifestaciones absolutamente escolásticas y herederas de la formación academicista decimonónica y expresiones artísticas más modernas. En el grupo de las primeras podemos ver como un escaso porcentaje de la programación de las grandes salas de concierto la forman obras de nueva creación. Una gran parte de los conciertos de abono y grandes festivales de música han convertido sus sesiones en verdaderos museos donde se venera la antigüedad y se ningunea la novedad. En el plano académico existe algo parecido: la formación con la que termina un estudiante de grado superior en un conservatorio no llega apenas a los años 50 del s. XX. Es en ambientes diferentes a la formación musical tradicional donde se pueden desarrollar investigaciones y expresiones artísticas más innovadoras. El lenguaje musical asistido mediante medios electrónicos, como es la electroacústica, mantiene relaciones con ambos mundos. Por un lado, el músico interesado en la composición puede acercarse a la creación electroacústica, pero al mismo tiempo debe seguir planteamientos estéticos anteriores al s. XX.

En la actualidad la llamada 'música clásica' se ha convertido en un gueto elitista y excluyente que reivindica la poca formación e interés del gran público, pero por otro lado ignora que su propia naturaleza estética y planteamientos son ajenos y están voluntariamente desvinculados de la condición social actual. En este sentido, y aunque en ciertas plataformas culturales pase lo contrario, la electroacústica está sirviendo en estos días para unir de nuevo los intereses sonoros del público y ofrecer planteamientos transversales a la propia creatividad y expresión del arte. 


\section{Motivación personal}

Con apenas 12 años mi futuro profesional estaba más que marcado. Ya en el vientre de mi madre formaba parte inevitable de conciertos en los que ella interpretaba arias de Bellini, Donizzetti, Puccini, Arrieta, Sorozabal, Vives, etc. Con 17 años ya tenía una inclinación clara por la composición y la innovación de los lenguajes musicales. Durante mis estudios de Composición y Piano en el Conservatorio Superior de Música de Sevilla pude conocer personalmente a compositores y nuevos creadores andaluces: Antonio J. Flores, J. Burgos, Enrique Rueda, Manuel Castillo e intérpretes como J. C. Garvayo, Javier Perianes, etc. En 1999 recibí soporte económico de la Junta de Andalucía para estudiar en la Universidad de Música y Arte Dramático de Viena las carreras de Dirección de Orquesta y Composición. En esta mítica escuela conocí y aprendí directamente de personas tan ilustres en el mundo de la música como Günter Kahowetz, Dietmar Schermann, Wolfwang Suppan, Roswitha Heintze, Konrad Leitner, Michael Jarrell y Leopold Hager entre otros. Como parte de mi formación en los estudios de Composición, asistí a los cursos en electroacústica en el laboratorio de Dieter Kaufmann, pero aún no me motivaba el empleo de máquinas en la composición musical.

En Junio de 2002 fuí seleccionado para cubrir una plaza de Director Asistente en la Jove Orquesta de la Generalitat Valenciana bajo la dirección artística de Manuel Galduf. Durante 3 años pude compartir trabajo con el compositor valenciano afincado actualmente en Reino Unido, Ricardo Climent, quien ocupaba la plaza de Compositor Residente. Juntos llevamos a cabo el montaje de los encargos de obras que el Instituto Valenciano de la Música realizó a Climent para la JOGV: 
obras para orquesta con electroacústica. En este contexto de colaboración estrecha con un compositor especializado en el lenguaje electroacústico es cuando se despertó en mi interior la necesidad de renovar mi planteamiento estético en lo concerniente a la composición musical.

\section{Contexto académico}

En 2006 recibí la invitación por el Mixed Reality Lab de la Universidad Nacional de Singapur para realizar una estancia como compositor residente e intervenir en varios proyectos de investigación en el área de la Human-Computer Interaction (Interacción humano-computador).

En dicho laboratorio pude dar forma a mi proyecto de investigación titulado 'Contrapunto Acusmático en Vivo' a partir del proyecto Peranakan Sound Design, realizado en Singapur.

Cuando conocí el programa de doctorado 'Artes visuales e intermedia' en la facultad de Bellas Artes de la Universidad Politécnica de Valencia se me abrió un campo muy fértil en cuanto a la investigación artística del sonido y la composición musical en un marco universitario; hasta hace pocos años no era posible hablar de investigación en el contexto de la formación musical de los conservatorios españoles.

Es por todo esto que cuando tuve la oportunidad de desarrollar un trabajo de investigación y embarcarme en una tesis doctoral dentro del mundo de las Artes descubrí una oportunidad excelente de completar mi formación académica y mis inquietudes de creación e investigación musical. La temática de la tesis - Electroacústica: el gesto sonoro - me facilita el nexo de unión entre las disciplinas de investigación y documentación rigurosa del marco universitario y la interpretación y creación de mundo musical. A veces, el intérprete 
describe trayectorias errantes e intuitivas dado que en la mayoría de los casos, la experimentación musical no se ha regido por un rigor documental y severo, ha estado por el contrario sujeto a condiciones culturales, políticas y sociales concretas y casi siempre desfavorecedoras.

\section{Contexto científico}

En los días que corren la interpretación y composición musical se haya vinculada a multitud de corrientes y disciplinas artísticas, sin embargo pocas de ellas conocen los detalles que han propiciado su estado actual. Desde la aparición de los primeros dispositivos electrónicos que permiten la manipulación del sonido (ver Tema O) el artista ha ido adaptando la forma de expresión a las prestaciones de estos. Así pues, a veces, la propia naturaleza de la expresión sonora se ha ido formando dependiendo del progreso científico de los dispositivos electrónicos. A partir del desarrollo del primer sistema de circuitos integrados creado por Robert Moog en 1963, se crearán modelos portátiles para adquirir un uso más práctico en concierto, y así fueron surgiendo instrumentos como el VCS3, utilizado por Roxy Music, la primera banda musical que experimentó con la música electrónica en 1971.

Después de analizar la evolución de la electrónica asociada a los instrumentos musicales, es difícil establecer una clara correspondencia con el avance estético que supuso la música concreta a mediados de los 40 y la electrónica en los 50. Evidentemente los planteamientos en la manipulación del sonido por parte de los compositores formados en una tradición musical escolástica, fue distinta al uso que hicieron los artistas dedicados a lenguajes musicales herederos de las músicas populares de principios del s. XX 
como el jazz o el blues, y aunque siempre hubieron expresiones artísticas que vivían entre ambos límites, como el ecléctico compositor Frank Zappa (1940-1993) o el extravagante pianista Friedrich Gulda (1930-2000), el término 'electroacústica' ha derivado en nuestros días a una parcela elitista de la música llamada clásica o culta.

En este punto querría detenerme a reflexionar sobre una forma de arte con sonido llamado 'Arte sonoro'. Como argumenta Miguel Molina (1960):

'la práctica siempre antecede al concepto, de no ser así la historia del Arte Sonoro no empezaría apenas hace treinta o cuarenta años a lo sumo (...) Encontrar los precedentes de una práctica actual es meterse en el túnel del tiempo, en el eterno presente ¿quién dudaría que el arte de las cavernas no era una pionera práctica multimedia?, en la cueva confluía, como en el ordenador, simultáneamente todos los medios: la imagen, grafía, sonido, movimiento y otros que desconocemos. Pero a pesar de ello, no podemos confundirlos, los conceptos son históricos y muchas cosas han cambiado que nos hace encontrar sus conexiones $y$ divergencias.' (Molina, 2006).

Desde esta reflexión podríamos ver en esta forma de arte cualquier manipulación que se hiciera con el sonido, independientemente del objetivo y los resultados que se obtuvieran, y por ende desde que el primer homo sapiens-sapiens soplara por un tubo hueco o golpeara dos piedras por mero placer lúdico existiría un arte sonoro. Pero como termina diciendo Molina, para diferenciar los conceptos históricos de los artísticos tendremos que entender los significados que se desprenden de su definición en nuestros días. En (Molina, 2008) se apunta: 
'El vocablo 'Arte Sonoro' (Sound Art, Audio Art, Klangkunst o Art Sonore), va siendo ya común su uso y conocimiento en los últimos años, aunque la aparición de este término es relativamente reciente de poco más de veinte años, que hace que su definición y amplitud todavía se encuentre abierta y aún genere ciertas ambivalencias. En primer lugar hay que señalar que la aparición de un término nuevo en el campo del arte, no significa necesariamente que comience su desarrollo desde su denominación, ya que habitualmente la práctica antecede a su concepto y en el caso del arte sonoro se ha producido así, ya que a partir del empleo de este término, se ha englobado propuestas artísticas que se remontan a comienzos del siglo pasado e incluso podríamos situarla mas atrás'.

Aunque ya a mediados del s. XX aparecieron muestras pioneras que proponían la relación entre lo sonoro y lo visual (Molina, 2008), como la exposición For Eyes \& Ears ('Para los ojos y los oídos') en la Cordier \& Ekstrom Gallery de New York (1964); con objetos sonoros dadaístas de Marcel Duchamp y Man Ray, audio-instalaciones de Klüver y Rauschenberg, obras cinéticas sonoras de Jean Tinguely y Takis, y otras obras en colaboración entre artistas, compositores e ingenieros; y en el ámbito europeo, se realizaron dos muestras que ya son históricas de este género en 1980 con títulos similares, como Für Augen und Ohren ('Para Ojos y Oídos') en la Akademie der Künste de Berlin, y Écouter par les yeux ('Escuchar por los ojos') en el Musée d'Art Moderne de la Ville de Paris, el primer empleo documentado del término 'Arte sonoro' como una disciplina novedosa se recoge en el comentario que hace el historiador Don Gorddard para el catálogo de la muestra realizada en 1983 que es denominada precisamente Sound/Art, exhibida en The Sculpture Center de la ciudad de New York, 
comisariada por William Hellerman y promovida por The Sound Art Foundation:

'Puede ser que el arte sonoro se adhiera a la opinión del comisario Hellermann, que la escucha es otra forma de ver, donde este sonido tiene significación únicamente cuando su conexión con una imagen se entiende... La conjunción del sonido y de la imagen insiste en la implicación del espectador, forzando su participación en el espacio real y concreto, en lugar de responder a un espacio imaginado y pensado' (Hellerman y Goddard, 1983).

Como señala Molina a propósito de este espacio real y concreto, nos hace recordar lo que sería el espacio imaginado y pensado en los lenguajes audiovisuales proyectados y en la música de concierto (Molina, 2008).

En cualquier caso, el llamado Arte sonoro tiene una naturaleza transversal a otras manifestaciones artísticas. Según J. Iges, el arte sonoro es un arte claramente híbrido, nacido en la intersección, y no puede extrañar por tanto que los autores que lo han venido realizando hayan pertenecido al mundo literario, al tecnológico, al musical, al arte visual, al teatral o a campos situados 'entre sillas' como la poesía experimental, el arte de acción o las prácticas intermedia (Iges, 2010).

Después de otear el horizonte artístico del sonido y sus expresiones artísticas, la temática y planteamientos que se dan en esta tesis parten desde un punto concreto. Mi formación como músico, intérprete y compositor, formado en la tradición de la música clásica me sitúa en una posición que cuestiona constantemente la idoneidad y evolución estética de los lenguajes electroacústicos en el ámbito de la creación artístico-musical actual y la gestualidad. 


\section{Límites de la investigación}

- Naturaleza de la investigación. Esta tesis tiene carácter principalmente práctico. De otro modo, y aunque se ha centrado en la elaboración de una serie de ensayos y casos prácticos, también se ha hecho una revisión bibliográfica, extrayendo aquellos conceptos, metodologías, conclusiones, etc. que se han considerado relevantes para el entendimiento de los términos técnicos del gesto sonoro y el lenguaje electroacústico, estado actual de desarrollo y posibles planteamientos artísticos futuros. Se han elaborado un total de cinco ensayos para la exploración de diversas cuestiones planteadas a partir del contexto teórico descrito en el tema o.

- Acotación del área de estudio. El área de estudio en la que se basa esta tesis es el lenguaje musical electroacústico, otorgando especial atención a la implicación de la gestualidad y las distintas lecturas que se pueden generar a partir de la exploración musical, dispositivos y software que se utilizan, consideraciones referentes al intérprete, y las distintas alternativas tecnológicas y metodológicas que han aportado diversos investigadores y creadores.

- Ensayos realizados. En esta tesis se han elaborado un total de cinco ensayos, algunos de ellos consistentes en varias fases. El número y temática no se había planteado en un principio, sino que han ido surgiendo durante la investigación llevada a cabo y se han visto condicionados por distintas circunstancias, explicadas en cada uno de ellos. 
- Acotación metodológica. En el tema o se ha empleado una metodología de búsqueda bibliográfica y puesta en común de investigaciones y desarrollos aportados por distintos autores, compositores e intérpretes. En los ensayos, temas 1 al 5, se han seguido los siguientes pasos: en primer lugar se ha planteado una situación artística; a continuación se ha contextualizado dentro de un marco teórico más específico y se ha realizado una revisión bibliográfica para ver cómo los distintos autores han aportado soluciones a situaciones similares; después se ha diseñado y creado un resultado propio; a continuación se han estrenado las obras en concierto o difundido mediante soportes digitales dependiendo de las características de cada una de las obras; por último, y en algunos casos se han redactado escritos para su presentación en congresos especializados de ámbito internacional.

- Acotación bibliográfica. La bibliografía consultada en esta tesis ha sido extensa y variada, aunque se han consultado en mayor medida artículos publicados en congresos. Ello es debido en primer lugar a que la novedad relativa de la música electroacústica no ha dado lugar todavía a una extensa bibliografía editada de otro modo; por otra parte, a que éstos son el medio normal de difusión de los últimos avances e investigaciones, que han sido especialmente numerosos en los últimos 30 años. Es por ello que la mayoría de bibliografía consultada está en inglés. En la medida de lo posible, estos documentos bibliográficos se han recopilado en formato pdf, para insertarlos a continuación en una base de datos bibliográfica elaborada con el programa Endnote (Endnote, 2010). 
- Actualidad de la investigación. Esta tesis se basa en un lenguaje musical que está actualmente en continuo desarrollo y exploración. Este hecho tiene la ventaja de que la temática tratada es actual y novedosa; sin embargo, tiene la desventaja de que quizá, en el momento de lectura de esta memoria, hayan acontecido nuevos planteamientos o creaciones que no estén aquí contemplados.

\section{Objetivos}

El objetivo del tema o ó contexto teórico, es el de establecer un marco concreto de definiciones y significados acerca de la creación musical electroacústica y su evolución desde el primer indicio histórico en la exploración artística asistida por medios mecánicos y digitales. Se han aportado en este apartado una gran cantidad de reflexiones y referencias por parte de autores vinculados al pensamiento, interpretación y composición musical electroacústica que nos sitúan en un estadio gestual de la expresión musical. A partir de esto se puede enumerar una serie de objetivos generales:

- Estudiar el significado y contextos en los que se utiliza el término electroacústico.

- Investigar y definir el significado e implicaciones de la gestualidad en una composición musical electroacústica.

- Mediante la práctica en los ensayos se persigue estudiar la viabilidad y adecuación de ambos términos a la escena artística de la composición e interpretación con medios electroacústicos. 


\section{Hipótesis}

Los componentes semánticos, visuales, cognitivos, estructurales y espaciales en la gestualidad de la música electroacústica pueden desarrollarse y abarcar disciplinas artísticas diferentes a las vinculadas a la propia naturaleza sonora, generando marcos de actuación interdisciplinares y proyectos asociados a la imagen.

\section{Metodología}

El contenido del tema o se ha realizado durante la fase de redacción de la memoria de la tesis (ver Fig. 1), por lo que la metodología empleada en esta parte ha consistido en una búsqueda bibliográfica y posterior contraste con distintos autores; la elaboración de una base de datos bibliográfica ha facilitado el proceso en gran medida.

De otro modo en los temas 1 al 5 (ensayos) se ha seguido la siguiente metodología:

- En primer lugar se ha planteado una situación artística; algunos de los ensayos han surgido a partir de encargos específicos por parte de artistas o intérpretes que ofrecían un margen artístico flexible para la investigación musical en el lenguaje electroacústico.

- Se ha contextualizado cada ensayo dentro de un marco teórico más específico atendiendo a los parámetros de investigación descritos en el tema 0.

- Revisión bibliográfica para ver cómo los distintos autores han aportado soluciones a situaciones similares.

- Se han extraído conclusiones a partir del análisis de los resultados, aceptando las limitaciones o condicionantes en 
cada caso. Los resultados artísticos rara vez se analizan o se exponen a conclusiones concretas, pero el formato de una tesis doctoral, aun en un marco puramente práctico, exige una coherencia entre planteamientos y resultados.

- Todos los ensayos se han estrenado en concierto o difundido mediante soportes digitales dependiendo de las características de cada una de las obras. Con ello no sólo se difunde entre la comunidad artística sino que se establece un feedback mutuo que propicia situaciones o planteamientos complementarios. Así mismo plantea la oportunidad de entablar ciertos debates estéticos y cuestiones concretas sobre los caminos actuales en la investigación artística. En el Anexo II de esta tesis se incluye la partitura de concierto de la obra TanGram que aún se encuentra en trámites de edición.

- Por último, y en algunos casos se han redactado escritos para Su presentación en congresos especializados de ámbito internacional. En el Anexo III de esta tesis se adjuntan los artículos que han sido publicados durante el periodo que abarca la realización de esta tesis.

En paralelo a la investigación que se presenta en esta tesis, se ha desarrollado también una actividad como compositor de obras para electroacústica con y sin instrumentos acústicos que por sus características no se ha considerado oportuno incluirlas como ensayos, aunque se han incluido en el Anexo I una descripción de cada una de ellas y aparecen cronológicamente en la Fig. 1. Estas composiciones han completado mi formación y han ido definiendo otras vías de investigación que se pueden presentar en el campo de la composición electroacústica. 
A continuación se hará una breve descripción del desarrollo de mis estudios de doctorado, la realización de los ensayos, las obras compuestas que no se inscriben en la redacción de esta tesis, y la redacción propia de esta tesis.

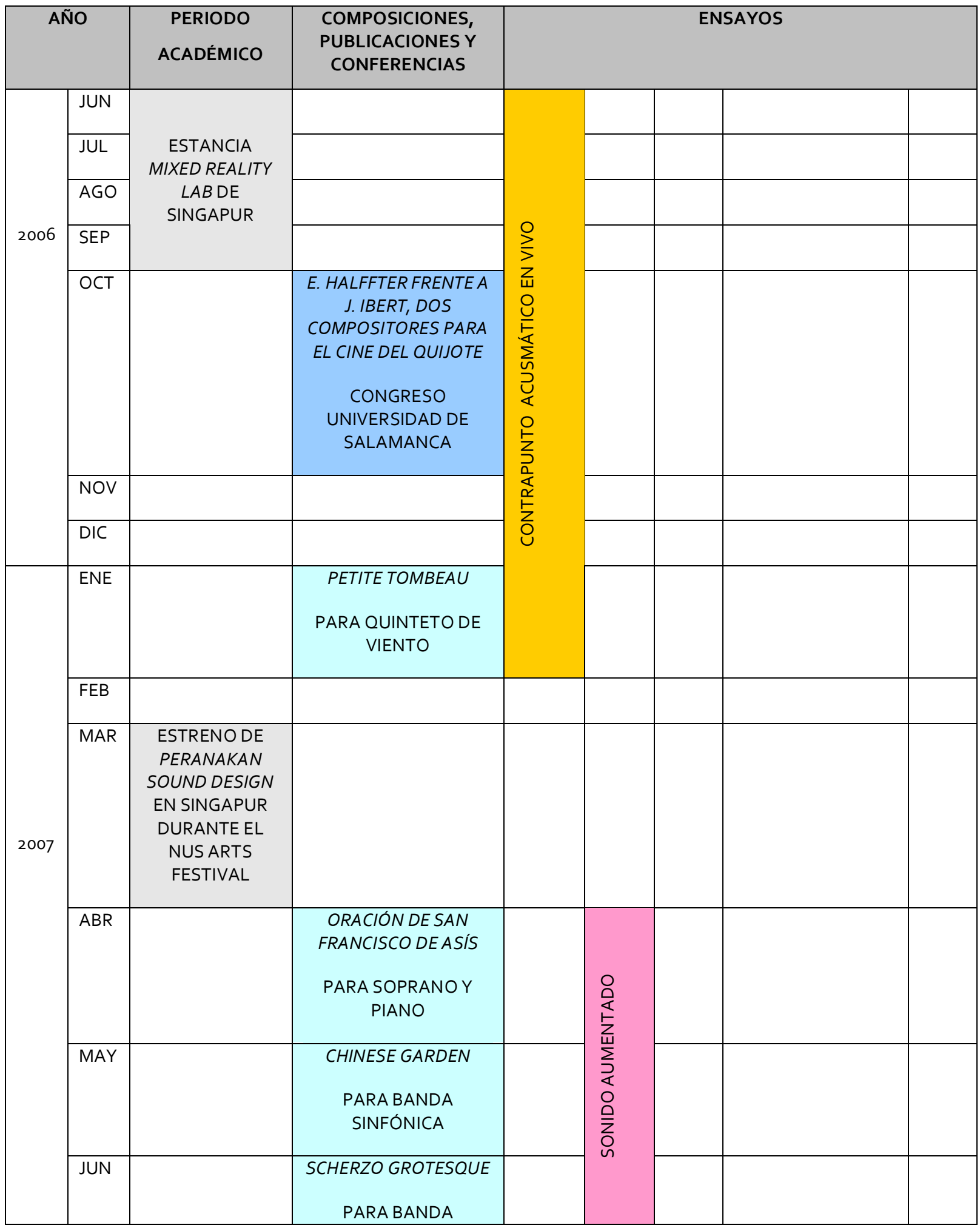




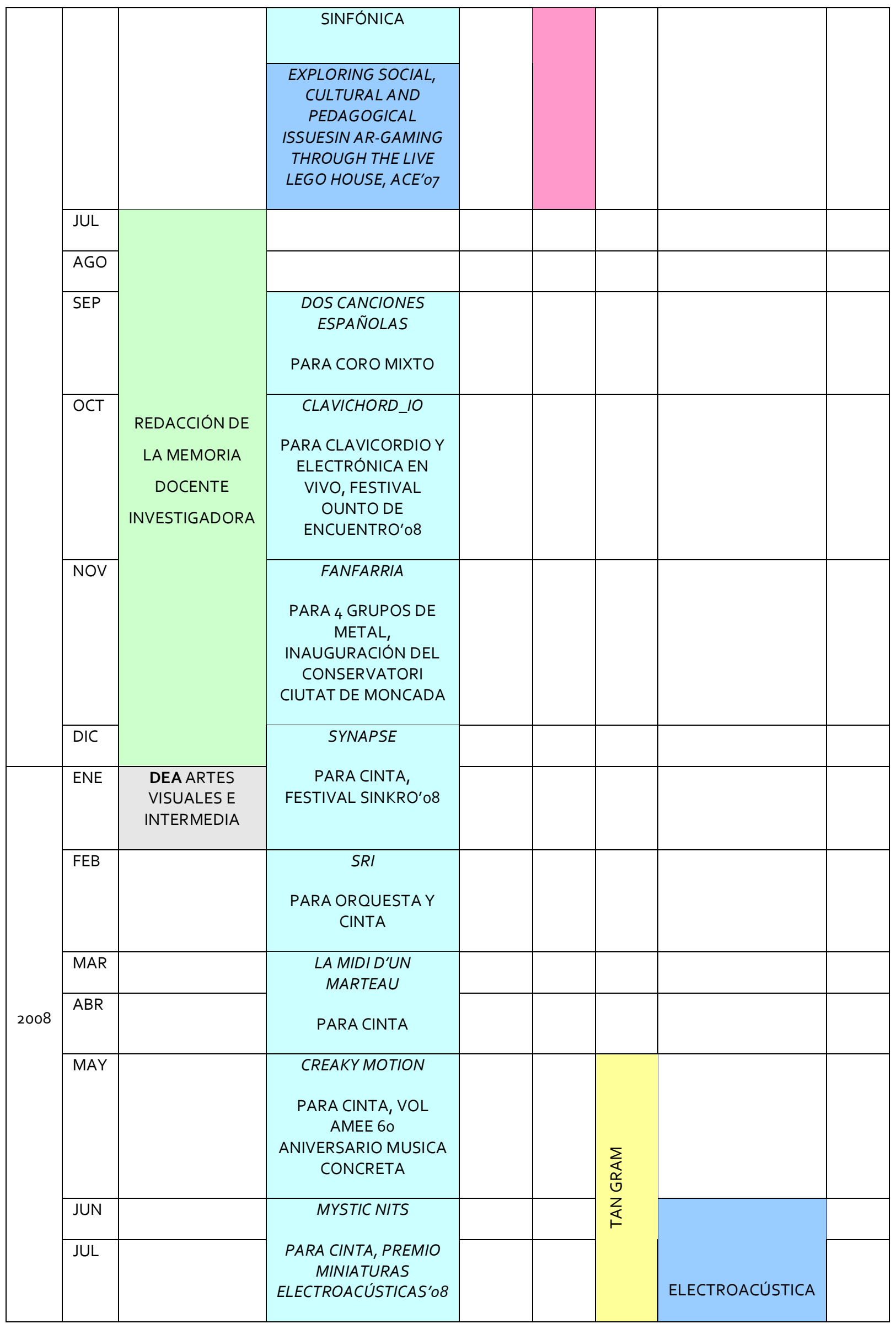




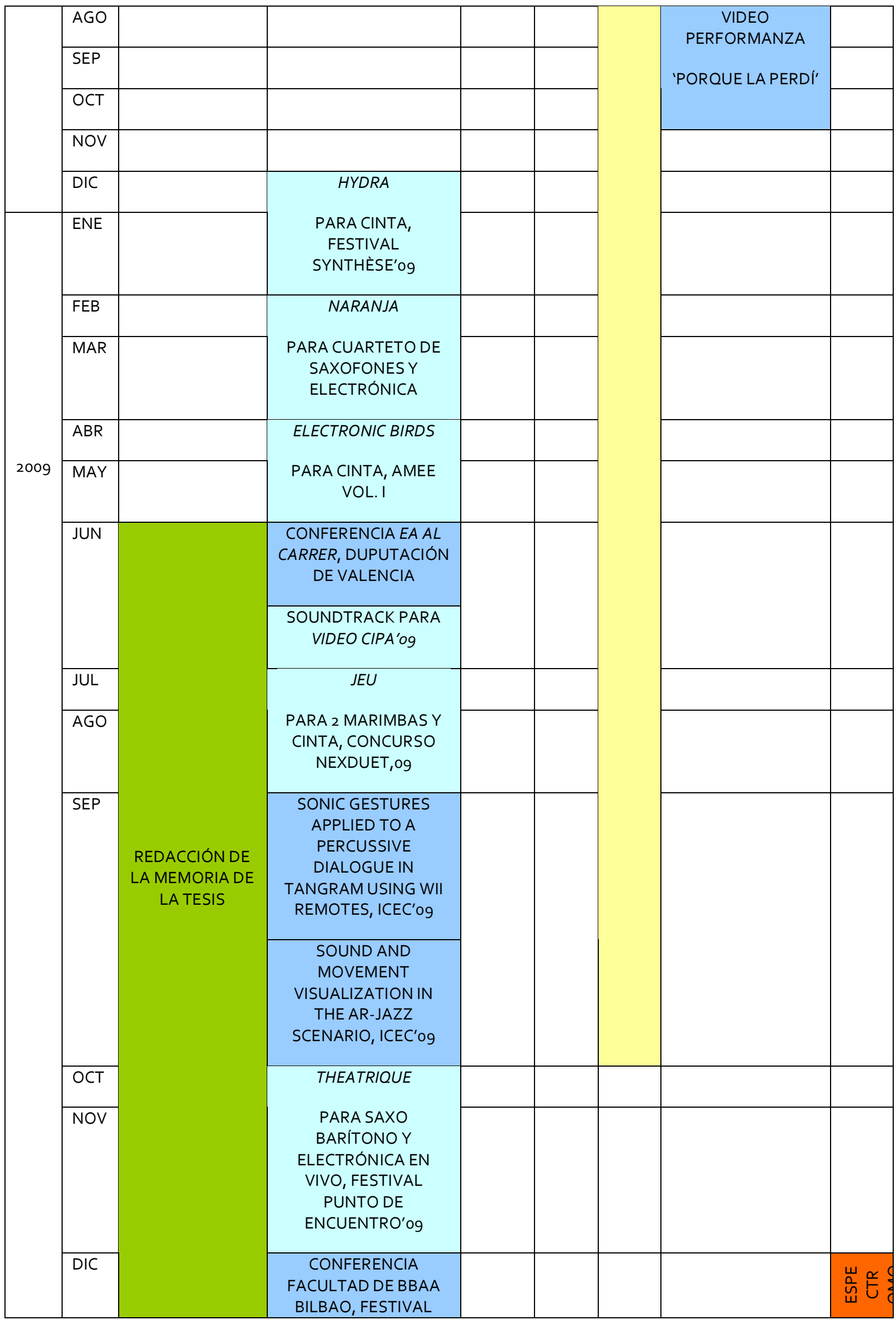




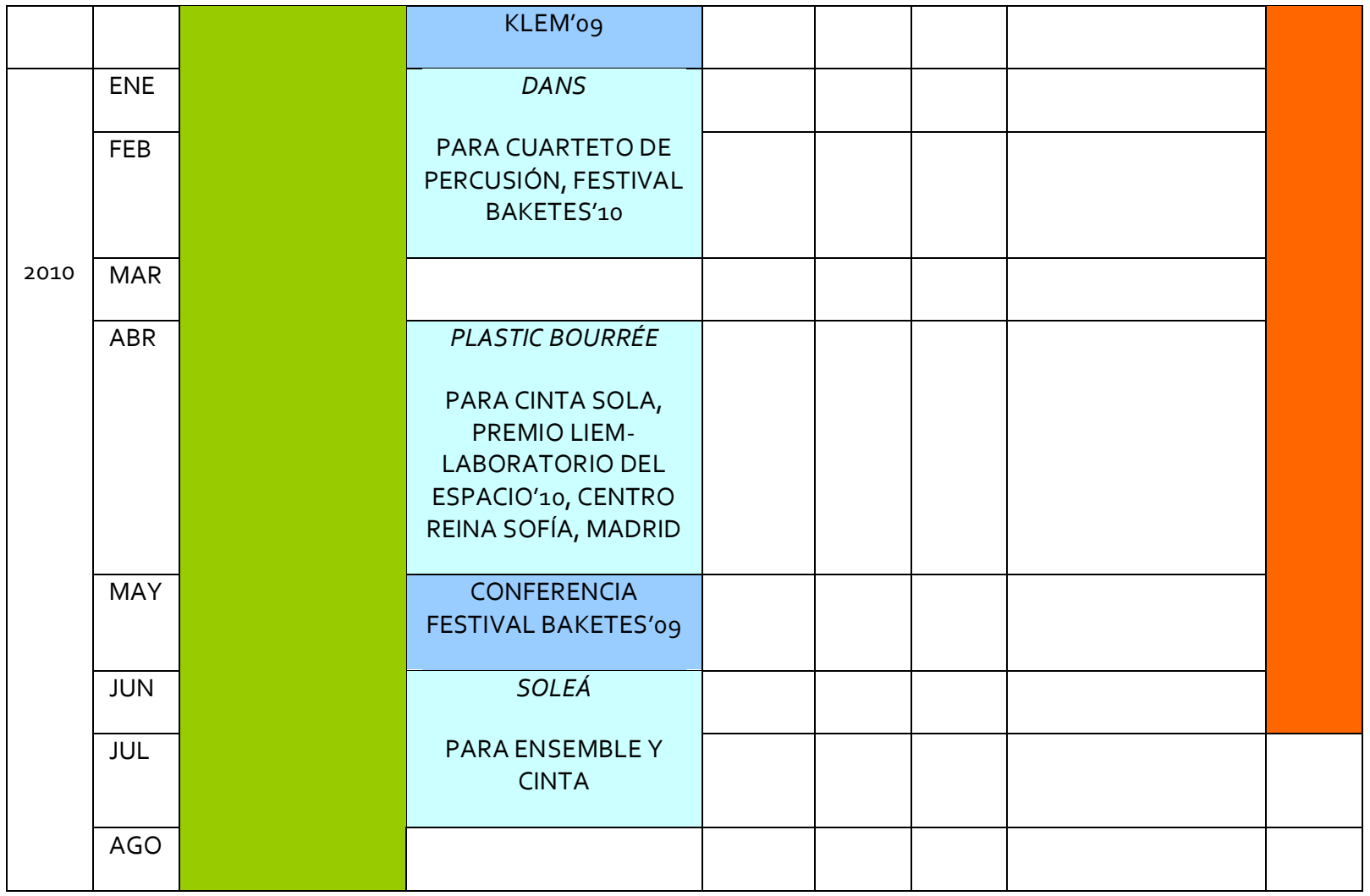

Fig. 1 Evolución cronológica de los ensayos de la tesis, y composiciones, publicaciones y conferencias dentro del periodo de duración de la tesis

\section{Estructura de la memoria}

En el tema o ó tema introductorio, a modo de marco teórico, se repasan los paradigmas y postulados que para un músico con formación específica en composición e interpretación musical como yo, plantean un punto de arranque en la investigación del lenguaje electroacústico. En los temas 1 al 5 se plantean casos de experimentación basados en dichos planteamientos, obteniendo resultados específicos aplicados al mundo de la composición musical relacionada con el gesto y el lenguaje electroacústico. A continuación se explican los contenidos de cada capítulo.

En el tema 1, llamado 'Contrapunto Acusmático en Vivo', se recoge la investigación y la composición de 4 poemas para cinta realizados durante mi estancia en el Mixed Reality Lab de Singapur a partir del 
proyecto de investigación llamado Peranakan Sound Design en el que se diseñó una obra electroacústica abierta para cinta que toma forma en base al análisis que se realiza de la voz del poeta cuando este recita un poema.

En el tema 2 se explica el ensayo 'Sonido Aumentado', una instalación elaborada para representaciones en vivo en la que se ofrece una visualización del sonido y del movimiento a partir de las interpretaciones de un combo ${ }^{2}$ de jazz. Este ensayo ha sido elaborado para el evento Jazz \& Arts Meeting, en el que también se ha ofrecido un taller dirigido a los músicos que intervienen a continuación en una Jam session ${ }^{3}$.

En el tema 3, 'TanGram', se aborda la composición de una obra para 4 percusionistas y 4 sensores de movimiento como es el mando remoto Wii de Nintendo. En este ensayo se exploran las posibilidades de transformación del sonido a partir de la gestualidad del intérprete en un obra para instrumentos de percusión y electrónica en vivo.

En el tema 4 se explica el desarrollo del proyecto musical para 'porque la perdi', realizado a partir de la video-performanza de su autora, Maica Ontiñano, en Huesca durante el verano de 2008. En este ensayo se aborda la composición en paralelo del sonido para el video de una improvisación de danza enmarcada en una performance Site-specific (lugar concreto).

El tema 5 contiene el trabajo de composición realizado para el video 'Manos que dan forma', realizado por Mamen Marcos y Carlos

\footnotetext{
${ }^{2}$ Combo: agrupación reducida de músicos de Jazz.

3 Jam session: improvisación sobre una melodía, sin mucha preparación y arreglos definidos.
} 
Barragán sobre artistas y artesanos valencianos y mexicanos. En este ensayo se aborda la espectromorfología como una manera de entender el gesto sonoro en la electroacústica, asociado a una imagen visual.

Se ha definido una estructura similar en los 5 ensayos prácticos: en primer lugar se realiza una introducción donde se resume el trabajo realizado y la motivación personal que da lugar al ensayo. A continuación se explica el planteamiento o idea general. Dentro de este apartado se ubican los parámetros que definen la naturaleza de cada ensayo con un índice de conceptos descritos en el tema o, un marco teórico con los planteamientos que rigen cada investigación y una descripción de los referentes que han propiciado algunos de los planteamientos de cada ensayo. El siguiente apartado contiene la descripción técnica del proceso realizado en cada proyecto, procesos, medios, dispositivos y pautas de actuación que configuran la naturaleza de cada uno de ellos.

Una vez abordados todos los temas se aporta un apartado de conclusiones, en el que se resumen, discuten y valoran cada uno de los ensayos, aportando además un análisis comparativo entre los distintos dispositivos y programas utilizados en ellos.

Finalmente, en los anexos se aporta una parte donde se describen las obras que han discurrido en paralelo como resultado de mi actividad como compositor, la partitura que resulta del tercer ensayo, TanGram, para 4 tam-tams y 4 mandos Wii de Nintendo y las publicaciones de investigación que se han elaborado durante el transcurso de esta investigación. 


\section{o. CONTEXTO TEÓRICO}

En un marco artístico de creación e interpretación puramente musical, el propio término 'Electroacústica' plantea de entrada posturas enfrentadas en cuanto a su significado, origen y definición. Aunque su empleo, como término que define un tipo de lenguaje sonoro, tiene una trayectoria bastante joven, hoy en día se ha extendido junto a otras artes y formas de expresión. Debido a esta corta trayectoria y a la multitud de espacios artísticos a los que puede vincularse se puede encontrar variada y a veces contradictoria bibliografía. Es por ello que se ha procurado unificar criterios y definir los significados que han propiciado esta tesis doctoral.

\section{o.1. INTRODUCCIÓN}

En el interés por el desarrollo y avance del arte, a lo largo de la historia se puede encontrar continuamente la presencia tecnológica. En concreto, la evolución de la música depende en cierta medida del 
desarrollo tecnológico y científico y de las implicaciones de otras artes (Fig. 2).

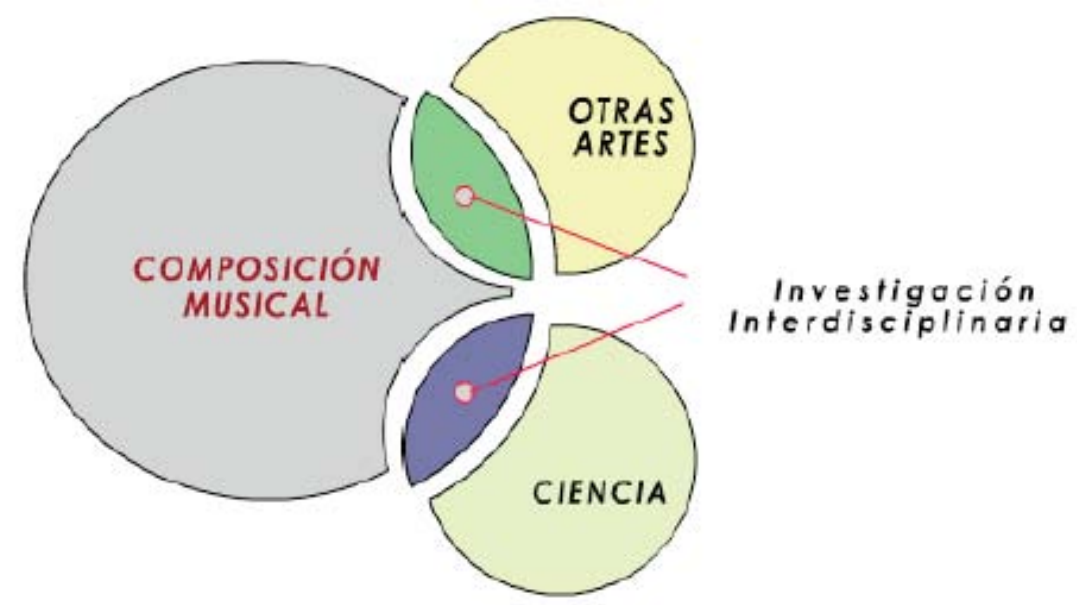

Fig. 2 Territorios interdisciplinarios, en (Climent, 2006)

Como ejemplo, se podría observar esta sinergia en la construcción de cualquier instrumento musical: nuevas técnicas, nuevos materiales, ampliación de la tesitura y de la potencia sonora, etc. El perfeccionamiento del instrumento también es debido a una exigencia técnica que se encuentra en la partitura: el compositor pide al interprete un esfuerzo interpretativo que puede traducirse en que el fabricante dote al instrumento de una nueva característica técnica (García de la Torre, 2006), y este avance va ligado a las necesidades acústicas de un recinto concreto (salas de concierto, auditorios, espacios religiosos, palacios, etc.).

Podríamos aplicar el mismo proceso a aquellos instrumentos musicales basados en la electrónica y la informática. En este caso es esencial la colaboración entre compositores, interpretes, ingenieros, programadores, y por último, fabricantes que concentren todo este esfuerzo multidisciplinar en el diseño de nuevos instrumentos de expresión musical. 
Desde comienzos del s. XX, emerge en el área de la composición musical una inquietud por la exploración de nuevos dominios sonoros. Después de la superación de la intratable tonalidad por parte de Debussy (1862-1918) o Mahler (1860-1911) y la nueva ordenación serial de Schoenberg (1874-1951) comienza una intención de renovar los conceptos de jerarquías sonoras (Berenguer, 1974). Con Russolo 1885-1947) y Cage (1912-1992) comienza la incorporación del 'ruido' como un elemento sonoro con identidad propia. Con el desarrollo de la electrónica y los avances en el campo de la física acústica se pudieron estudiar los parámetros que definen la forma del sonido y con esto el desarrollo de plataformas que propiciaran su exploración: la radio, sistemas de grabación, reproducción, amplificación, generación y transformación.

Habría que remontarse a principios del s. XX para encontrar así mismo, a músicos que pedían un avance cualitativo ya que consideraban necesario incorporar nuevos timbres y destrezas a la paleta orquestal (Boulez, 2001). Como respuesta, en aquella época se intentaron incorporar nuevos sonidos a un orden musical de diversas formas: aparecen nuevos instrumentos mecánicos (Theremin, Ondas Martenot...), la percusión orquestal pasa a un primer plano (Ionisation de E. Varese), se preparan los instrumentos acústicos tradicionales de tal forma que se obtengan o resalten ruidos ajenos a su funcionamiento habitual (Threnody for the Victims of Hiroshima de K. Penderecki), etc.

Después de la lla Guerra Mundial, y frente a la heterogeneidad de estilos propia de la primera parte del s. XX, hubo una intención implícita de sistematizar esta exploración del sonido. En el estudio de la radio de Colonia, Pierre Schaeffer (1910-1995) comenzó a mitad de 
la década de los 40, a explorar un lenguaje artístico que llamó en un principio 'música concreta', donde las notas musicales eran sustituidas por objetos sonoros, grabados del medio ambiente y registrados sobre una cinta magnética, sometidos o no a procesos de tratamiento mecánico o desnaturalización, y compuestos $u$ organizados con criterios musicales mediante técnicas de montaje de grabación.

En este instante nacieron dos importantes planteamientos en un entorno de creación sonora:

- El compositor se convierte a su vez en intérprete.

- La obra queda fijada en una única versión.

Estos dos nuevos conceptos van a condicionar no sólo la propia naturaleza de composición musical sino las atribuciones que resultan de la colaboración con los diferentes lenguajes de expresión artística.

Teniendo en cuenta la figura del intérprete, la implicación de artes ajenas a la propia producción del sonido y la utilización de medios electrónicos podemos dibujar el continuo de conceptos empleados en esta tesis (Fig. 3):

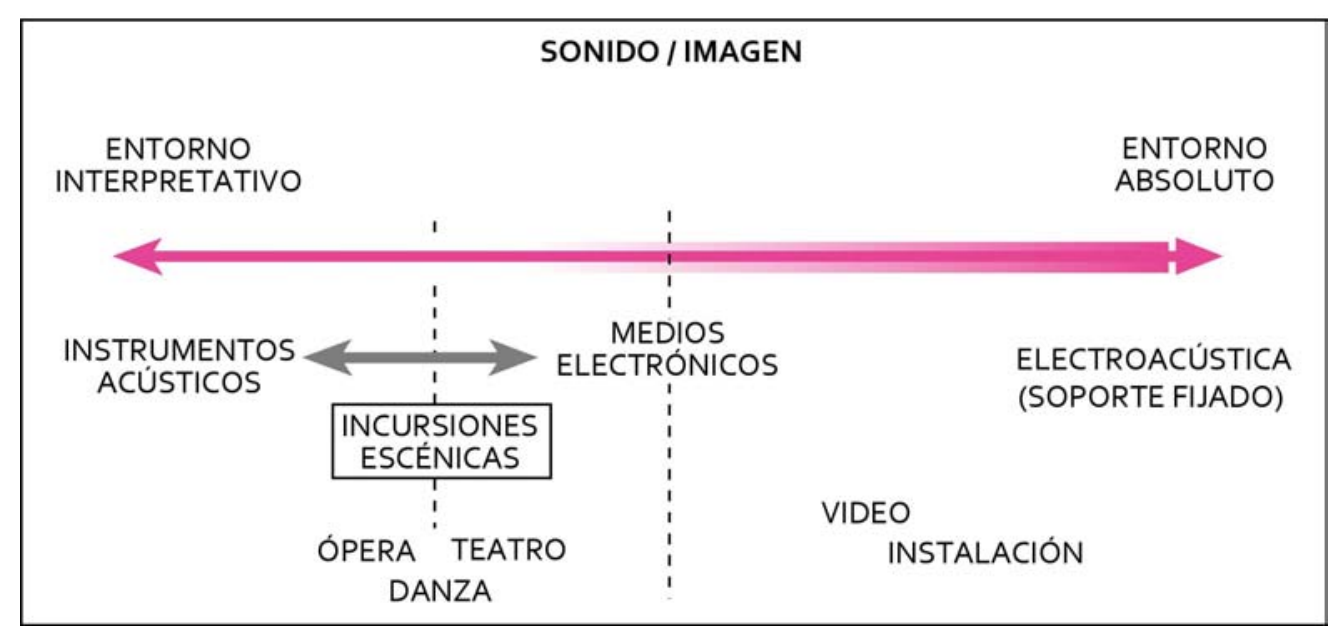

Fig. 3 Continuo Sonido/Imagen 
En la figura anterior podemos ver la continuidad que un entorno interpretativo o carente de tal, confiere al arte hecho con sonido. Entorno absoluto se refiere a los medios de expresión fijada: obras pensadas para su reproducción mediante sistemas de amplificación o altavoces.

Teniendo en cuenta el componente visual en un entorno de creación sonora tendremos que considerar los campos artísticos que contienen parámetros visuales, ya sean en directo o en formato fijado, y que atribuyen un planteamiento interdisciplinar al resultado artístico.

\section{o.2. INTERDISCIPLINARIEDAD}

Preguntarse acerca de la influencia que la tecnología pueda tener en la mentalidad de la creación implica preguntarse acerca del pasado y del futuro de la creación. Como apunta (Berenguer, 1996), no es posible separar el desarrollo tecnológico del desarrollo de la creación, porque tanto la tecnología como la creación son actividades que caracterizan marcadamente al ser humano. En cierta medida, todo hombre crea y usa para ello la tecnología que encuentra a su alcance, a veces incluso como una caja negra, sin comprenderla verdaderamente. Recursivamente, uno de los productos distinguidos del proceso de creación es la tecnología.

Desde el prisma de la estética musical, y como podemos ver en (Climent, 2006) la existencia de la práctica interdisciplinar está justificada por la imposibilidad de resolver en su totalidad determinadas cuestiones en el entorno de la investigación o en áreas creativas y socio-culturales cuando se opera en el seno de una disciplina única. Al abandonar los límites de determinadas áreas del 
conocimiento, sus prácticas y métodos, y aventurarse en otros adyacentes, se pueden en principio encontrar respuestas a problemas de gran complejidad. Dichas soluciones serían difícilmente alcanzables de abordarse exclusivamente en compartimentos del pensamiento y la práctica.

Así mismo, y como comenta la compositora Elsa Justel (Argentina, 1945) el propio elemento tecnológico contribuye a aportar una nueva forma de articulación que conducirá probablemente a cambios radicales de lenguaje, acercando cada vez más los conceptos de ciencia, tecnología y arte. Un dominio sólido de esos medios tecnológicos será pues indispensable para manejar mejor los elementos de orden artístico (Justel, 2000).

Por contra, en la práctica multidisciplinar, a pesar de que individuos provenientes de disciplinas diferentes trabajan por un objetivo común, nunca llegan a cruzar sus respectivas áreas de experiencia al abordarlo. La investigación transdisciplinar aparece cuando individuos que trabajan por una meta conjunta intercambian metodologías, pensamiento y herramientas entre ellos y sus diferentes disciplinas (Ellis y Fouts, 2001).

En el entorno de la innovación, se ha afirmado que 'la investigación transdisciplinar es un imperativo del mundo contemporáneo' (Grigg et al., 2003) y se ha definido esta investigación entre disciplinas como: 'buena, deseable, e inevitable' (Sanz-Menendez et al., 2001). Muchas de las conclusiones de este estudio son extrapolables entre diversos entornos disciplinares, de hecho el eje central de esta tesis aborda intersecciones y colaboraciones entre géneros musicales (composición e interpretación) y otras artes (danza, arte digital) u otras ciencias 
(visión por computador: realidad aumentada, integración de sensores).

\section{o.3. ELECTROACÚSTICA}

Aunque cualquier análisis terminológico y acercamiento conceptual puede dar lugar a múltiples discusiones y debates, se va a tratar en este capítulo de desentrañar los aspectos más relevantes que han propiciado y colocado el término 'Electroacústica' en el panorama de composición musical actual y en el contexto de los ensayos abordados. Como se ha citado en la introducción de esta tesis, existen estéticas o maneras de entender el arte construido con sonido muy importantes y de gran repercusión, como es el 'Arte sonoro' o la industria del cine, que sin embargo no han sido objeto de estudio en esta investigación, dada la naturaleza de los ensayos que se abordan en esta tesis y del interés personal y profesional del autor.

\subsubsection{DEFINICIONES}

A continuación se hará una panorámica sobre los conceptos que ha definido la creación sonora desde la aparición de sistemas físicos de procesado, tratamiento y control de datos; y las reflexiones estéticas que surgieron alrededor esta nueva manera de creación.

\subsubsection{ANTECEDENTES: MÚSICA PROCESADA}

Con los primeros experimentos de Pierre Schaefer en el Groupe de Recherche de Musique Concrète (GRMC) en la radio francesa, y la fundación del Estudio de Música electrónica de la radio de Colonia en la década de los 50 donde Karlheinz Stockhausen (1922-2007) exploró las posibilidades de expresión sonora a partir de sistemas de 
producción electrónica, se abrieron nuevas rutas en la exploración de la expresión sonora y musical.

Compositores principalmente instrumentales como E. Varése (18831965), K. Stockhausen, G. Ligeti (1923-2006), así como algunos más cercanos en el tiempo como J. Harvey (*1939) y J. Harrison (*1952), y artistas interdisciplinares actuales como Cecile le Prado (*1956), R. Climent (*1965), han explorado los recursos acústicos mediante el tratamiento de fuentes sonoras grabadas o simplemente la reproducción y edición de sonido mediante sistemas electrónicos.

Dependiendo del enfoque que se le de al tratamiento y al origen de las fuentes sonoras han ido surgiendo diferentes opciones terminológicas, que cada compositor y cada ámbito de creación e investigación ha ido adecuando a sus intereses artísticos. Así pues tenemos que detenernos a analizar los conceptos de música concreta o acusmática y música electroacústica, y las implicaciones que sendos términos confieren a un proceso y un resultado sonoro.

\subsubsection{ACUSMÁTICA - CONCRETA}

Como podemos ver en (Berenguer, 1974; Palombini, 1993; Dhomont, 1996; Justel, 2000; Aguilar, 2006; Minsburg, 2008), el origen de la palabra 'Acusmática' se remonta a los discípulos de Pitágoras, que escuchaban sus lecciones sin verlo: la idea era que se concentraran en su voz y no en su imagen. Esta situación dio lugar a la utilización de la palabra 'acusmática' como aquella en donde se escucha un sonido sin ver, sin reconocer su fuente. Esto implica un cambio radical en la forma de escuchar. Sin darnos cuenta, solemos escuchar un sonido e inmediatamente pensamos en qué o quien lo está generando (referente conceptual y visual). 
Según (EARS, 2010) el término pitagórico se vuelve a poner en uso en un contexto musical en 1955 por Jérôme Peignot (*1926), quien lo considera la distancia que separa a los sonidos de su origen, es decir, una presentación únicamente sonora, propia de la música electroacústica (Peignot, 1960).

El término 'musica concreta' (en francés: 'real', 'concreto'), acuñado en 1948 por P. Schaeffer (Kennedy, 2006) (Fig. 4), puede confundirse con una simple manera de hacer música a partir del sonido ambiente en el mundo real que no implique la mediación del componente humano e instrumental. Mientras que este aspecto se podría asociar al desarrollo de la música de Schaeffer, se ha de ver como un término que describe algo más que la simple grabación y manipulación de ruidos corrientes (Robert, 1999).
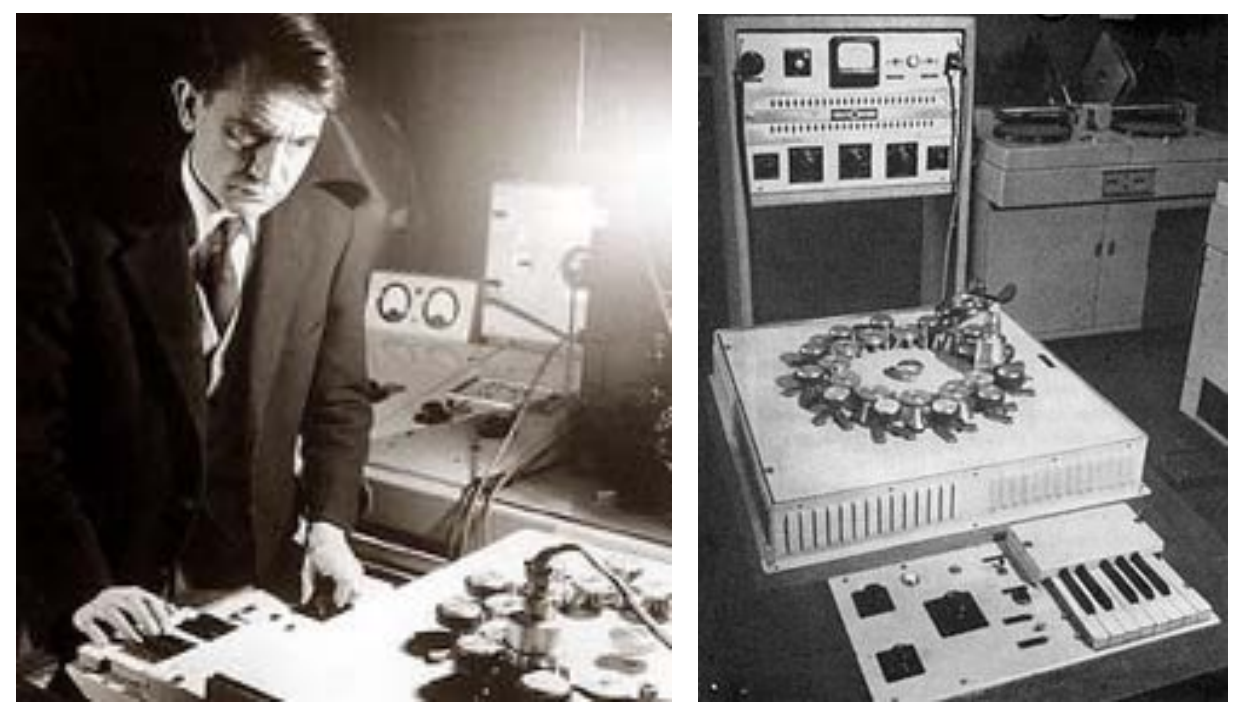

Fig. 4 Pierre Schaeffer en la ORTF (Estudio de la Radio Francesa), y Chromatic Phonogene ${ }^{4}, 1953$

\footnotetext{
${ }^{4}$ Herramienta desarrollada para controlar la velocidad en aplicaciones de diseño sonoro. Fueron desarrollados tres prototipos: El primero llamado 'Chromatic Phonogene' (controlado por un teclado con una octava), el segundo llamado 'Sliding Phonogene' y el tercero desarrollado en la propia radio francesa llamado 'Universal'.
} 
Para (Climent, 2006), el término de música acusmática es aquella en la que el oyente percibe el objeto sonoro sin adivinar el origen que lo produjo. Esta naturaleza abstracta hace del lenguaje puramente acusmático una vía de expresión exenta de conceptualismos, así pues el objeto sonoro, en términos estrictos, es un fin en si mismo.

En (McEvilly, 1999) la música concreta se puede definir simplemente como aquella música compuesta mediante la manipulación de fuentes sonoras grabadas. De todos modos, para Pierre Schaeffer y como se ha visto anteriormente, el término no sólo describe la grabación de sonidos sino el modo específico de composición. La música concreta representa un gran cambio en la técnica de composición desde la práctica tradicional (Schaeffer, 1966). El compositor comenzó entonces con lo concreto (el sonido grabado) y procedió hacia la abstracción (estructura musical). Cualquier grabación sonora puede utilizarse para la composición.

Schaeffer acuñó el término l'objet sonore (el objeto sonoro) para el sonido grabado. Para entender cómo el compositor consigue dar forma a las estructuras musicales utilizando este método es necesario explicar otras consideraciones propias de Schaeffer - Ėcoute reduite (escucha reducida) (ver Apartado 5.1.2.2). Él mismo insiste en una nueva conducta de escucha para la música concreta. Propone la escucha reducida en tanto el oyente localizaría en la estructura interna aquellos sonidos desnudos de su contexto social. Esto conecta al oyente en la eliminación de tal connotación social y propone una escucha abstracta en cuanto al sentido musical y las propiedades acústicas del sonido, ej.: comportamiento dinámico, densidad, volumen, etc. Este enfoque se planteó quasi imposible a priori para el oyente, ya que todo el entorno cultural, los conocimientos 
involuntarios adquiridos y la asociación convencional hace muy difícil la abstracción pura del sonido. Tal y como se verá en el apartado 0.4, la escucha asociativa o referencial (con su componente visual) fue, y es aún hoy, una característica indisoluble en el proceso de escucha musical.

Posteriormente veremos en el Apartado 5.1.2.2.4, que según varios autores (Denis Smalley (Smalley, 1986) Delalande (Delalande, 1998), Truax (Truax, 2001), etc.), existen varios modos de percepción sonora derivados de los tipos de audición y en función de si la atención sonora se centra en el sujeto o en el objeto.

\subsubsection{MÚSICA ELECTRÓNICA}

La tecnología y estética de la primera música electrónica ofrece un gran contraste a los planteamientos de factura de la musica concreta. El Estudio de Música de la Radio de Colonia fue creado para la síntesis de sonido desde sus principios más básicos. Primeramente se desarrolló los generadores de Sine-Tone (onda sinusoidal). Compositores como K. Stockhausen o Herbert Eimert (1897-1972) creyeron que el desarrollo de un serialismo electrónico puro generaría una nueva música completamente desligada de timbres y formas tradicionales. Eimert en particular, no encontró razón para crear timbres que imitaran sonidos naturales o instrumentales, sino que buscó la ejecución de una síntesis musical basada en nuevos timbres (Manning, 1993). Así pues, en este nuevo entorno tímbrico, los parámetros compositivos pueden ser controlados por medio de procedimientos seriales extraordinariamente definidos. 

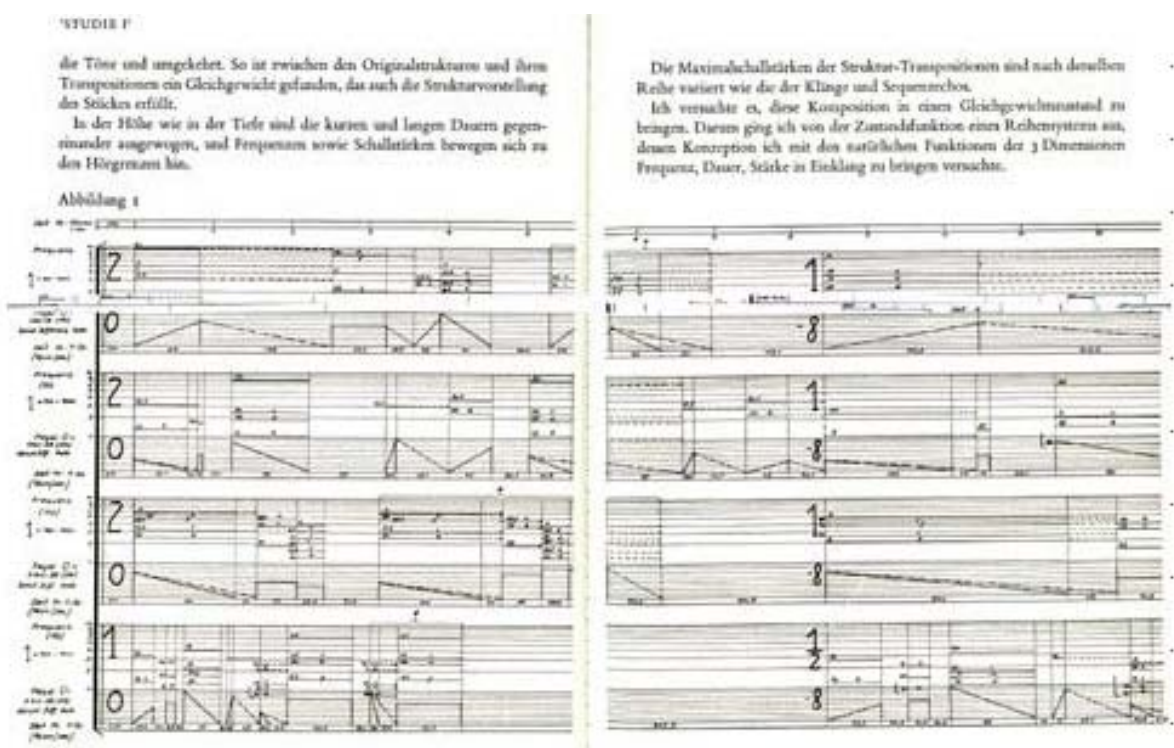

Fig. 5 Fragmento de la paritura Studie I, K. Stockhausen, (Köln, 1954)

En las obras tempranas Studie 1 (Fig. 5) y Studie 2, Stockhausen, utiliza procedimientos seriales de control y progresión tímbrica. En el Studie 2 utiliza procedimientos seriales para controlar los parámetros de espacio y timbre. El mundo sonoro de estas primeras obras estuvo fuertemente asociado con el gusto del timbre de campanas. La reverberación sonora está tratada como un constituyente integral del timbre, sujeta al control serial y similar al que aplicó en otros parámetros musicales (López, 1989).

\subsubsection{SIINTESIS DIGITAL}

Según (Justel, 2010), la Música Acusmática (como término genérico) nació de la unión de varias corrientes musicales: la música concreta inventada por Schaeffer, la música electrónica descubierta por Stockhausen y la síntesis digital desarrollada por Max Mathews (Nebraska, 1926).

En un artículo histórico que apareció en la revista Science el año 1963, (Mathews, 1963) mostraba una visión muy optimista del ordenador como instrumento musical. El autor (Fig. 6), un pionero de la música 
con ordenadores, decía que generar sonidos a partir de números era una forma completamente general de sintetizar sonidos, ya que el ámbito de frecuencias y dinámicas del oído está acotado y que por tanto cualquier sonido que podamos percibir puede ser generado de esta forma.

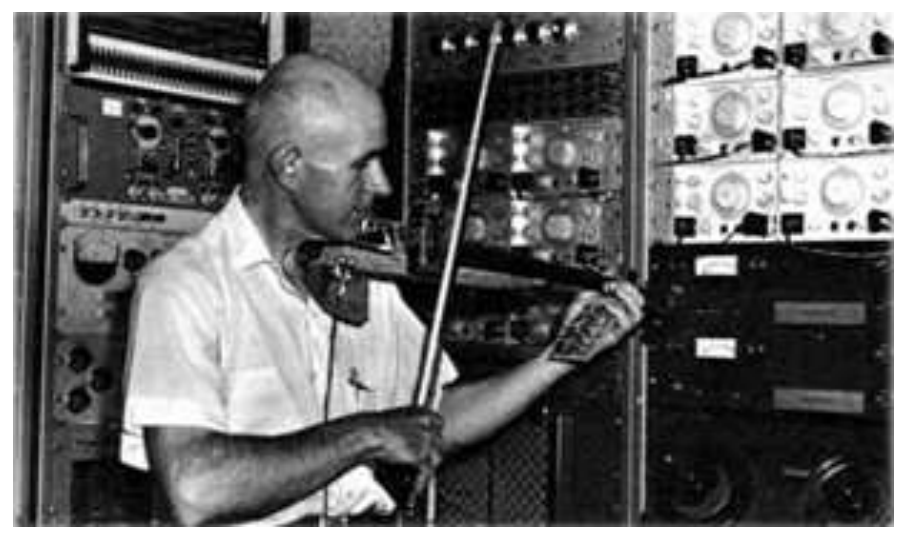

Fig. 6 Max Mathews tocando y sampleando un violín conectado al sistema IBM 704, (McEvilly, 1999)

La promesa de la música con ordenadores era que el ordenador es capaz de generar cualquier sonido que pueda salir por un altavoz. Unos años más tarde, el mismo Max Mathews, en su libro sobre la tecnología de la música con ordenadores (Mathews et al., 1969) escribía:

'Los dos problemas fundamentales en la síntesis del sonido son (1) la gran cantidad de datos necesarios para definir una onda acústica -por tanto la necesidad de un programa muy rápido- y (2) la necesidad de un lenguaje simple y potente con que describir una secuencia compleja de sonidos'.

El problema (1) ya ha sido resuelto en gran medida por la evolución tecnológica, ya que la velocidad de los procesadores digitales se ha ido incrementando de forma exponencial durante los últimos veinte años. El problema (2) y según se comenta en (Serra, 2010) sigue sin tener 
una solución satisfactoria por el hecho de que es imposible describir los sonidos si se ha de definir cada uno de los números que representan una onda acústica. Se ha de poder describir el sonido a partir de menos números o se ha de partir de sonidos grabados. Afortunadamente la mayor parte de ondas no son musicalmente interesantes y muchas ondas físicamente diferentes, son perceptualmente iguales. Por tanto, no es necesario generar todas las ondas posibles y el objetivo se centra en encontrar un grupo reducido de técnicas de síntesis y de control que nos permitan explorar todo el espacio tímbrico de interés musical.

El adjetivo 'sintético' se define según la (R.A.E., 2010d) como: 'que procede componiendo, o que pasa de las partes al todo'. No es lo mismo que decir artificial, es decir, no natural, sintético.

Uno de los programas que actualmente se utilizan en la creación, edición y manipulación del sonido es el Csound (utilizado en el Ensayo 5). Las rutinas de Csound derivan de los programas desarrollados a partir de los algoritmos recopilados por Max Mathews (Music, Music1, Music2, Music3 y Music4, Music4B. Music4B se tradujo completamente al lenguaje Fortran para favorecer su transportabilidad a otros sistemas de computación). Hubert Howe () escribió el nuevo programa Music4BF y posteriormente Howe y Godfrey Winham lo alteraron y expandieron. Después de algún tiempo Barry Vercoe desarrolló un sistema para el IBM System/360, este es el Music11. Es el primer programa de este tipo desarrollado para microcomputadores, siendo el antecesor de Csound (Csound, 2010b).

Podemos diferenciar dos tipos de síntesis: la síntesis analógica y la digital. La síntesis analógica trabaja con un conjunto continuo de valores (señales analógicas). Los sintetizadores analógicos tienen la 
función básica de generar sonido desde cero utilizando dispositivos electrónicos capaces de producir este tipo de señales adecuadas para la vibración de altavoces. La síntesis analógica se inicia a mediados de los años 6o, y se encuentra en su mayor auge hasta principios de los años 80 (Serra, 2010).

Sin embargo, los ordenadores son máquinas digitales y no analógicas, es decir, sus operaciones se basan en matemáticas discretas 5 . La síntesis digital trabaja en el dominio discreto, y no continuo. La síntesis digital se inicia como hemos visto en 1957 con Max Mathews, pero no se populariza hasta principios de los 80 , desbancando a la síntesis analógica (Gómez Gutiérrez, 2009). Debido a su versatilidad, la síntesis digital permite el uso de infinitas técnicas, además de permitir emular cualquier método de síntesis analógica (Miranda, 2002).

\subsubsection{TIPOS DE SÍNTESIS}

Ya que en esta tesis se van a aplicar distintos procesos de síntesis en la creación, transformación y manipulación de sonido, se hará una panorámica por los principales tipos de síntesis sonora:

- Síntesis aditiva: consiste en la combinación de varios osciladores para conseguir un nuevo sonido o timbre. En este tipo de síntesis es muy importante la utilización de diferentes

\footnotetext{
${ }^{5}$ La Matemática discreta es la parte de la matemática encargada del estudio de los conjuntos discretos: finitos o infinitos numerables. En oposición a la matemática continua, que se encarga del estudio de conceptos como la continuidad y el cambio continuo, la matemática discreta estudia estructuras cuyos elementos pueden contarse uno por uno separadamente. Es decir, los procesos en matemática discreta son contables, como por ejemplo, los números enteros, grafos y sentencias de lógica (Wikipedia, 2010k).
} 
envolventes (ataque, caída, parte sostenida y extinción) para cada oscilador que le dan dinámica y expresividad al sonido resultante. Es la más utilizada para emular sonidos de instrumentos reales.

- Síntesis substractiva: una señal rica en armónicos es generada por uno o varios osciladores que poseen diferentes tipos de forma de onda en referencia a su forma. Esta señal es después filtrada para substraer (de ahí su nombre) las frecuencias que no queramos reflejar en la señal final con el fin de buscar la sonoridad deseada. La forma de filtrar estas frecuencias es usando filtros controlados por tensión (VCF).

- Síntesis granular: síntesis experimental por tiempo y frecuencia a nivel cuántico de tal forma que cambios en la señal relacionados con el tiempo alteran el timbre de un sonido y viceversa. De ahí se obtienen altas densidades de 'cuantos $\operatorname{acústicos}^{6}$ que se pueden llamar 'granos'. Un grano sonoro es un fragmento sonoro de muy corta duración (entre 5 y $100 \mathrm{~ms}$ ) a los cuales se les aplica envolventes suaves (graduación de volumen) para evitar chasquidos. Al repetir varios granos en una sucesión a una tasa mayor a $20 \mathrm{~Hz}$, los granos se funden produciendo un sonido continuo. El compositor lannis Xenakis fue el primero en explicar una teoría explícita para la composición con granos de sonido ya en la década de los 60 (Xenakis, 2001):

\footnotetext{
${ }^{6}$ En física, el término cuanto o cuantio (del latín Quantum, plural Quanta, que representa una cantidad de algo) denotaba en la física cuántica primitiva tanto el valor mínimo que puede tomar una determinada magnitud en un sistema físico, como la mínima variación posible de este parámetro al pasar de un estado discreto a otro (Wikipedia, 2010k).
} 
'Todos los sonidos, inclusive en una variación continua, se conciben como un ensamblaje de un gran numero de sonidos elementales que están adecuadamente dispuestos en su lugar en el tiempo. En el ataque, cuerpo y desvanecimiento de un sonido, miles de sonidos mas puros aparecen en un intervalo de tiempo mas o menos corto' (Prieto y Reyes, 2001-2004).

- Síntesis mediante tabla de ondas: o Wavetable es una técnica de síntesis de sonido utilizando sistemas de muestreo digital almacenando sonido de alta calidad y reproduciéndolo cuando se solicite. Dado que las tablas de onda pueden ser sintéticas, pero también proceder de sonidos reales, la síntesis por tabla de ondas se utiliza frecuentemente para emular instrumentos reales. Este método se acerca mucho al sampleo diferenciándose en los métodos de compresión.

- Síntesis mediante modulación de frecuencias (FM): consiste en variar la frecuencia de una señal portadora con respecto a una segunda (denominada moduladora), generando finalmente una 'onda modulada'. La FM puede generar salidas de señal complejas que contengan múltiples frecuencias con sólo dos osciladores.

- Síntesis por modulación de amplitud (AM): De igual manera que la síntesis mediante modulación de frecuencias (FM), la señal portadora es, ahora, modificada en amplitud por la moduladora.

- Síntesis por modulación en anillo (RM): Aunque también es una modulación en amplitud, lo que realmente se hace es 
multiplicar la portadora por la moduladora, generando así sonidos más chirriantes.

- Síntesis mediante modelado físico: Destinada a la emulación de instrumentos existentes se basa en las propiedades físicas de cada instrumento a emular. Requiere el uso de microprocesadores específicos debido al cálculo en tiempo real generando así sonidos muy realistas.

- Síntesis mediante distorsión de fase: Basándose en osciladores digitales, trata de reproducir aleatoriamente una forma de onda previamente almacenada, consiguiendo así saltos de fase y, por tanto, adición y/o eliminación de armónicos a la señal de salida (Dodge y Jerse, 1997).

Actualmente se siguen investigando y desarrollando las posibilidades de todos estos procesos de síntesis, especialmente combinando las posibilidades de cada uno de ellos para conseguir prestaciones y resultados novedosos (Musicalwars, 2007). Los diferentes programas que existen en el mercado ofrecen multitud de recursos en cuanto a la manipulación de sonido por síntesis digital.

\section{o.3.2. LENGUAJE SONORO}

El impacto tecnológico es claramente evidente en la composición electroacústica: el sonido es grabado, sintetizado y editado antes de ser manipulado para crear directamente la estructura musical. El compositor interactúa con el material musical en un modo determinado. Acerca de las acepciones y matices del término, (Harrison, 1996) enfatiza que esta nueva relación entre compositor y 
material es una dimensión de la musica concreta de Schaeffer que a menudo se ignora en el ámbito de habla inglesa:

'En el ámbito de habla inglesa, el término 'musica concreta' se ha tomado normalmente para designar la utilización de sonidos reales, grabados de fuentes sonoras por medio de micrófono. En francés, es ampliamente comprendido como una dimensión en la que concreto, más allá de la Musica concreta, es el empleo de un método de trabajo.'

En el siguiente comentario podemos ver como Francis Dhomont acuña el término 'método de composición Schaefferiano':

'Este original método compositivo comienza con lo concreto (evento sonoro puro) y procede hacia su abstracción (estructura musical) - de ahí el término de música concreta - en oposición a los que se considera escritura instrumental, donde se empieza con el concepto (abstracto) y se concluye con la representación (concreto).' (Dhomont, 1996).

Está claro, por la consideración de Dhomont que la percepción auditiva adquiere un gran significado, no sólo para aquellos que se consideran discípulos de Schaeffer, sino también para la música electroacústica. Independientemente de las particularidades entre escuelas de composición electroacústica, la notación de las ideas sobre el papel deberían ser, y a menudo son, completamente atajadas como materiales que se acercan a los compositores en un aspecto más concreto basado en criterios de percepción. La creciente importancia de la inmediatez de la escucha se ha hecho evidente desde el comienzo de este método. Sólo hay que recordar el primer postulado 
de Schaeffer por la creación de la musica concreta: Primautè de l'oreille! (Primacía a la escucha) (Schaeffer, 1966).

El oído es elevado a una posición de honor. La música de cinta es considerada más perceptiva que la música del pasado. Harrison refuerza esta postura en el siguiente comentario:

'El árbitro en este proceso es el oído, el compositor comprometido en un constante proceso de revisión con el material y el contexto en el que se halla en todo momento. Si algo "funciona" o suena correcto no necesita justificación posterior en dicho contexto musical, tanto como la especulación musical se ha probado experimentalmente (experimentalmente, perceptiblemente).' (Harrison, 1996)

Estas consideraciones son imprescindibles para la composición y el desarrollo del lenguaje electroacústico en el discurso musical. El mismo medio demanda un método de trabajo que asegure que el compositor experimenta su música en un sentido concreto (Palmer, 198gb). Otro parámetro de este estilo es que este análisis 'fuera del tiempo', aun escrito en partitura, es imposible. La percepción auditiva se convierte en la máxima autoridad y funciona para desarmar la tendencia a ver el análisis como lo inverso a la composición (McEvilly, 1999).

Otro reclamo de Schaeffer fue la búsqueda de un lenguaje 'Recherche d'un language' (Schaeffer, 1966). Las nuevas estructuras musicales deben asegurar la comunicación entre compositor y oyente. La naturaleza propia de este medio presenta un reto para los compositores en la búsqueda de un lenguaje musical coherente. EI medio electroacústico (cinta) exige una nueva experiencia de escucha 
que a la vez demanda una nueva práctica musical. El entorno auditivo también cambia. La fuente sonora permanece ahora invisible. Los ejecutantes no son necesarios. Así mismo, la obra existe en un medio fijo y concreto, normalmente utilizando altavoces. Se pueden utilizar varios ordenadores y representaciones gráficas, que resultan del empleo tecnológico en la composición de obras electroacústicas análogas a las partituras tradicionales. De todos modos, mientras este tipo de datos es intrínseco a la creación de una obra electroacústica, no se requiere para una representación musical.

El término 'música electrónica' en contraposición a la definición específica que hacían los compositores del círculo de París, se ha ido generalizando también en su uso. La definición del término según Otto Luening aclara estos planteamientos:

'Música electrónica' es un término genérico que describe el uso del sonido electrónico generado o modificado por medios electrónicos, acompañado o no, por voces o instrumentos en directo, reproducido a través de altavoces.' (Luening, 1975).

Esta definición es acertada ya que cubre la gran variedad de géneros que existen en el medio electrónico. Sin embargo choca con la segunda categoría que vemos en (Vande Gorne, 1996): el término 'Instrumental'. Música de cinta y reproducción en tiempo real son los dos principales modos de expresión. Estos están lejos de ser géneros independientes ya que a menudo coexisten en la composición musical. La música de cinta, género original (musica concreta), crea el objeto artístico grabando y manipulando sonidos en la cinta. La representación en tiempo real concierne a la modificación en vivo o transcrita de sonidos naturales y/o el uso de material pregrabado 
La definición de Luening también presenta ciertos problemas en el sentido del componente instrumental, ya que distingue entre material sintético y natural, y describe que la música electroacústica en el sentido de la retransmisión, las cualidades de percepción del sonido, como experiencia en la escucha, no están localizadas (Luening, 1975).

\subsubsection{RECORRIDO HISTÓRICO}

A fin de entender las inquietudes y necesidades de los artistas, compositores y creadores en la expresión musical, y ofrecer una perspectiva coherente sobre la historia que ha propiciado la situación de la electroacústica en nuestros días, en este capítulo se hará un recorrido por los descubrimientos e inventos más significativos en cuanto a instrumentos y composición asistida por medios mecánicos y dispositivos analógicos o digitales (Appleton y Perera, 1975; Deutsch, 1976; Griffiths, 1978; Bermúdez Acosta, 1980; Sadie, 1984; Chapel Hinojosa, 1995; Dodge y Jerse, 1997; Kurzweil, 1999; Burns, 2010; Wikipedia, 2010e; Wikipedia, 2010g; Wikipedia, 2010f).

Siglo VI - V a. C., Pitágoras descubrió las relaciones numéricas correspondientes a los intervalos de la escala musical. Estos ratios de correspondencia es lo que él llamó la Armonía de las Esferas. 
Siglo II, a. C. El Hydraulis fue inventado por Ktesibios, el hijo de un peluquero griego, que estaba fascinado por la neumática y escribió un tratado de principios sobre el uso de sistemas hidráulicos para la alimentación de los dispositivos mecánicos. Su invento más famoso, el Hydraulis (Fig. 7), utiliza el agua para regular la presión del aire dentro de un órgano. Funciona mediante una pequeña cisterna llamada pnigeus colocada dentro de un barril de agua, una serie de bombas de

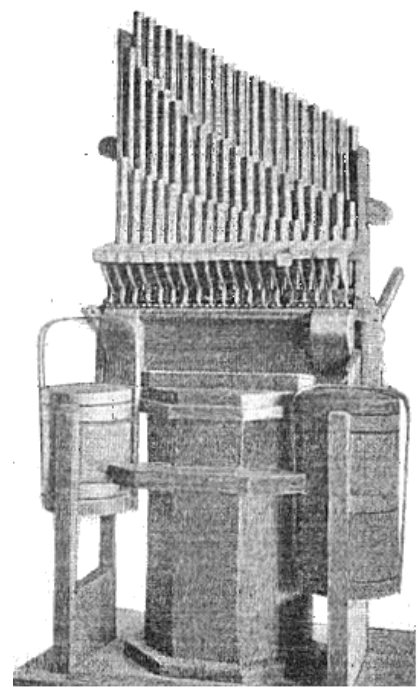

Fig. 7 Hydraulis, en (Grups.blanquerna, 2010) impulsión de aire que forman un depósito canalizado para accionar el órgano.

Arpa eólica griega (Fig. 8): Se puede considerar el primer instrumento automático. Fue creado para Eolo, el dios griego del viento. El instrumento tenía dos puentes sobre los que se pasan las cuerdas. El instrumento se colocaba en una ventana para aprovechar la corriente de aire. Todas las cuerdas tenían la misma longitud y estaban afinadas en la misma altura, pero tenían diferentes calibres, consiguiendo reproducir diferente afinación.

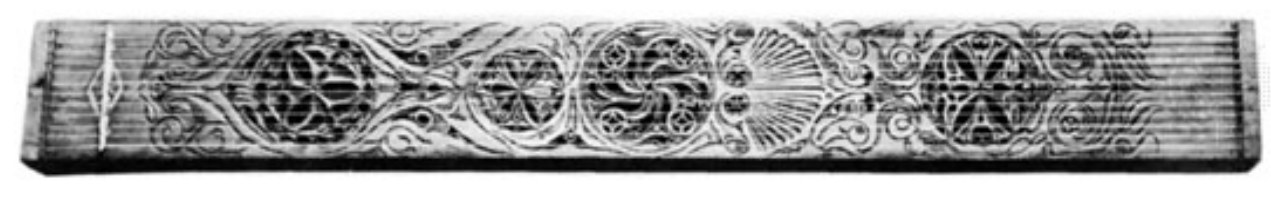

Fig. 8 Arpa eólica, en (Britannica, 2010)

Año 89o, Banu Musa fue un constructor de órganos, dejando la primera documentación escrita de un instrumento automático. 
ca. 995 - 1050, El compositor Guido de Arezzo (995-1050), desarrolló una forma rudimentaria de solfeo, llamada solmisación, que utilizaba un sistema mnemotécnico para aprender canciones anónimas. El método consiste en la asignación de las representaciones alfabéticas, las sílabas, en diferentes articulaciones de la mano humana (Fig. 9). Este sistema mnemotécnico al parecer, se basó en la técnica utilizada por los

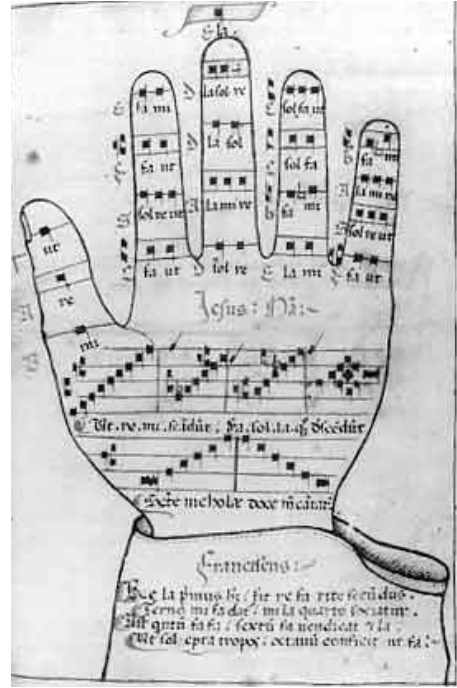

Fig. 9 Mano de Guido, en (Wikipedia, 2010i) fabricantes de almanaques de la época.

1400 se desarrolló la Zanfona, Zanfoña o Vielle. La zanfona se asemeja a un violín mecánico en el que varias cuerdas vibran por la fricción de una rueda enresinada (situada en la caja de resonancia del instrumento) que gira gracias a un manubrio. Las notas cambian al presionar las teclas de un teclado dotado de unas espadillas que acortan la cuerda melódica. La zanfona común (Fig. 10) tiene dos o tres cuerdas melódicas o cantantes, de las que se obtienen varias notas (alrededor de dos octavas de un piano), y dos o tres bordones a los lados, que emiten una sola nota (generalmente más grave). Esta nota sostenida independiente de la melodía es la que le ha valido el sobrenombre de gaita zamorana o de pobre, debido a la nota sostenida o bordón de la gaita, y debido a esta particularidad es intercambiable por la gaita en muchos estilos de música popular, especialmente en Francia y Hungría. Las zanfonas actuales pueden llegar a tener 23 cuerdas, agrupadas en cuatro categorías: melódicas, 
bordones, rítmicas (o trompetas) y simpáticas (que vibran sin necesidad de tañerlas porque entran en resonancia).

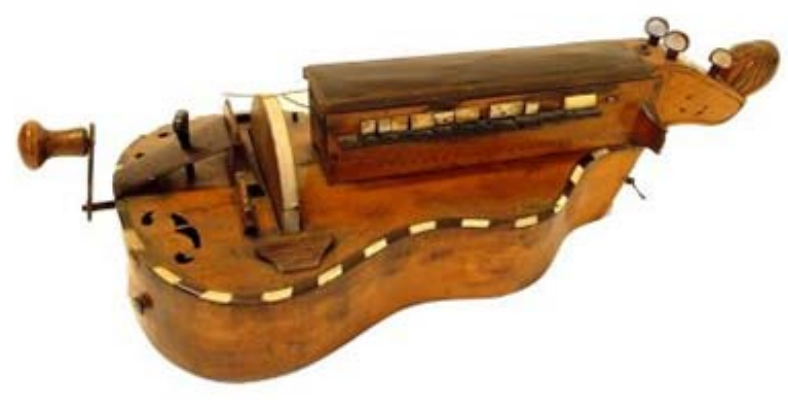

Fig. 10 Zanfona, en (ElMusiquiatra, 2010)

Se desarrollaron los motetes llamados isorrítmicos. Estas canciones hacían uso de patrones rítmicos y alturas para definir la composición. Compositores como Machaut (siglo 14), Dufay y Dunstable, (siglo 15), compusieron multitud de motetes isorrítmicos. La técnica musical que sigue consiste en un patrón fijo de altura que repite un ritmo característico a lo largo de una obra musical, aunque las notas cantadas sean distintas. Se utilizó en el análisis de la estructura de los motetes de la escuela polifónica Ars Nova de los siglos XIV y XV, cuyos tenores o cantus firmus se distinguían por la continuidad de un esquema rítmico, denominado talea, constituido por células idénticas que se aumentaban o disminuían, y que con el tiempo se extendería también a otras voces

Aparece el Soggetto cavato, una técnica de mapeo de las letras del alfabeto en alturas. Esta técnica fue utilizada en la Misa de Josquin Desprez, basada en el nombre de Hércules, el duque de Ferrara. Una aplicación de soggetto cavato implicaría tomar las vocales del nombre Hércules de la siguiente manera: $\mathrm{e}=\mathrm{re}=\mathrm{D} ; \mathrm{u}=\mathrm{ut}(\mathrm{Do})=\mathrm{C}$; etc. Este 
patrón de mapeo vocal se podría aplicar a nombres, apellidos, así como pueblos y ciudades.

1500 Se empezaron a construir los primeros órganos de accionamiento mecánico, los órganos de agua llamados hydraulis ya estaban en vigor.

Don Nicola Vicentino (1511-1572), compositor italiano y teórico, inventa el Archicembalo, un antecesor del clave, con hasta seis teclados y treinta y una medidas para una octava (Fig.

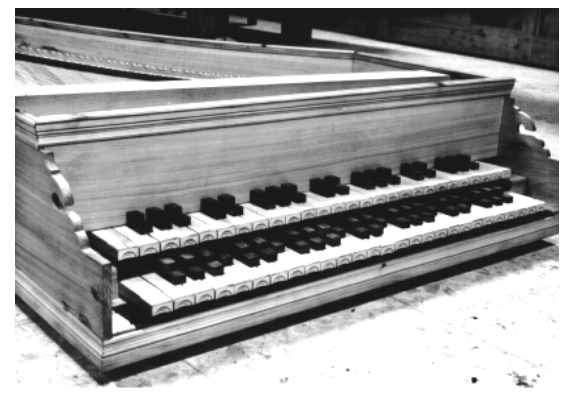
11).

Fig. 11 Archicembalo, en (Wikipedia, 2010a)

1600 Athanasius Kircher describe en su libro, Musurgia Universalis (1600), un dispositivo mecánico llamado Arca Musarithmica (Fig. 12), que ideó para hacer música. Aplicó relaciones numéricas aritméticas para representar las escalas, el ritmo y las relaciones de tempo.

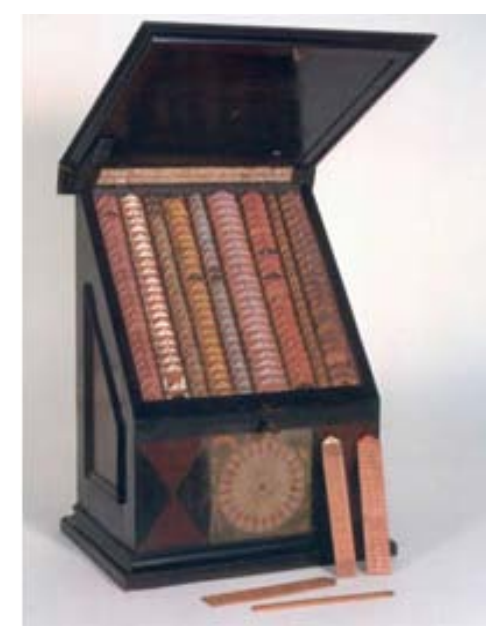

Fig. 12 Arca Musarithmica, en (ElMusiquiatra, 2010)

1627 El filósofo y ensayista Inglés, Francis Bacon escribió sobre una utopía científica en su libro La Nueva Atlántida. En este relata un viaje 
de unos navegantes que, partiendo de Perú, se dirigen a China y Japón, y empujados por un fuerte vendaval van a parar a las costas de un imaginario estado con un ordenamiento social sui generis, basado en el desarrollo de la ciencia. En un pasaje del libro, uno de los sabios que gobierna La Nueva Atlántida, revela lo siguiente:

'Tenemos cámaras sonoras, donde practicamos y demostramos toda clase de sonidos y sus derivados. Diversos instrumentos originales de música, algunos de los cuales producen sonidos más suaves que ninguno de los vuestros, tañidos de campanas y campanillas de exquisita delicadeza. Podemos producir sonidos casi imperceptibles, amplios y profundos, prolongados, atenuados y agudos. Imitamos las voces de las bestias y pájaros y toda clase de sonidos articulados. Tenemos ciertos aparatos que aplicados a la oreja aumentan notablemente el alcance del oído. También diversos y singulares ecos artificiales que repiten la voz varias veces como si rebotara, y otros que la devuelven más alta de como la reciben.'

1641 Pacaline, también conocida como Pascalina (Fig. 13). Fue un invento del gran genio francés Blaise Pascal (1623-1662). Era una máquina sumatoria mecánica o una especie de calculadora. Obviamente este invento no creaba música pero se puede considerar como precursor de los ordenadores modernos y los sintetizadores digitales. 


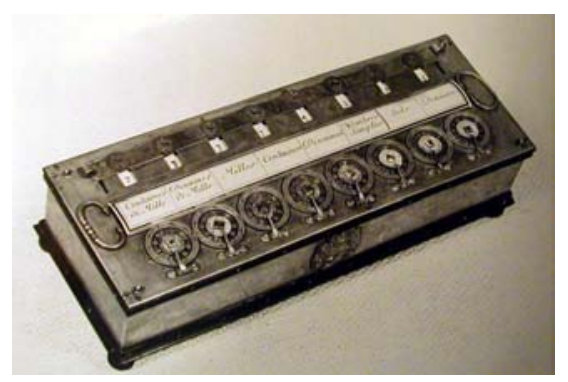

Fig. 13 Pascalina, en (LoyolaUniversityChicago, 2006)

1644 The nouvelle invention de Lever, o El Nuevo Invento de Subida. Fue un motor hidráulico en el que se producían sonidos musicales. No se tiene datos de quien lo inventó pero se supone que De Lever es el apellido del inventor, o es un término pseudo musical que significa De Subida, o sea, sonidos 'que suben', como en el órgano de tubos.

1761 Abbe Delaborde construye el Clavecin Electrique en Paris (Fig. 14).

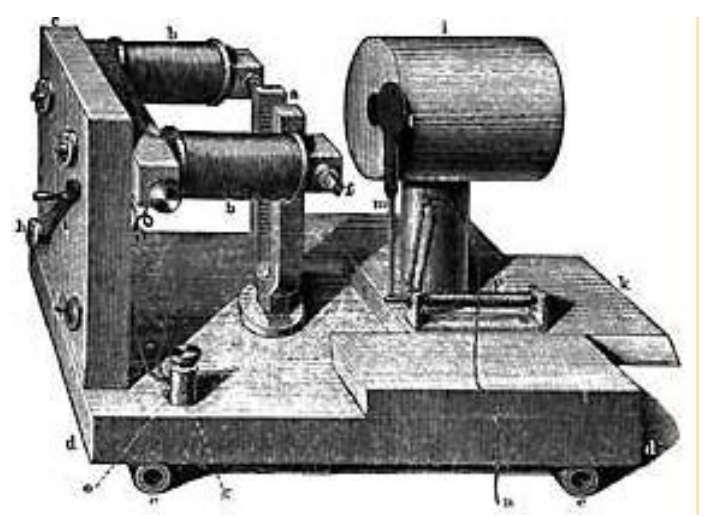

Fig. ${ }_{14}$ Clavecin Electrique, en (ElMusiquiatra, 2010)

Benjamin Franklin perfecciona la Armónica de Cristal (ver Tema 4).

1787 Mozart compuso la Musikalisches Wurfelspiel (Juego musical de dados). Esta composición consiste en preparar una serie de compases compuestos que se disponen en un orden aleatorio de 8 compases en una tabla. Cada lanzamiento con dos dados genera 2 números 
individuales, de modo que después de ocho tiradas, se van formando las frases musicales (Fig. 15).
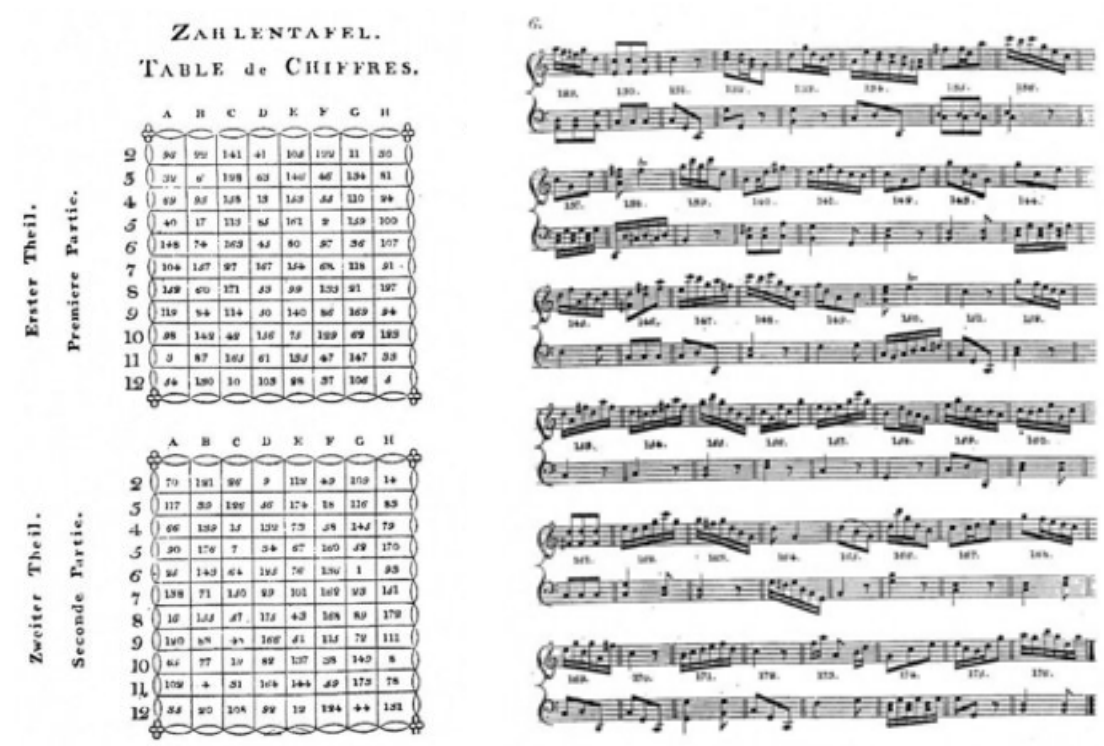

Fig. 15 Musikalisches Wurfelspiel, en (ISMLP, 2010)

1796 Caja de música (Music Box): Su inventor fue el relojero suizo Antoine Favre. Poseía unos 15 cilindros, de los cuales salían tres diferentes melodías con una combinación de 72 tonos (Fig. 16).

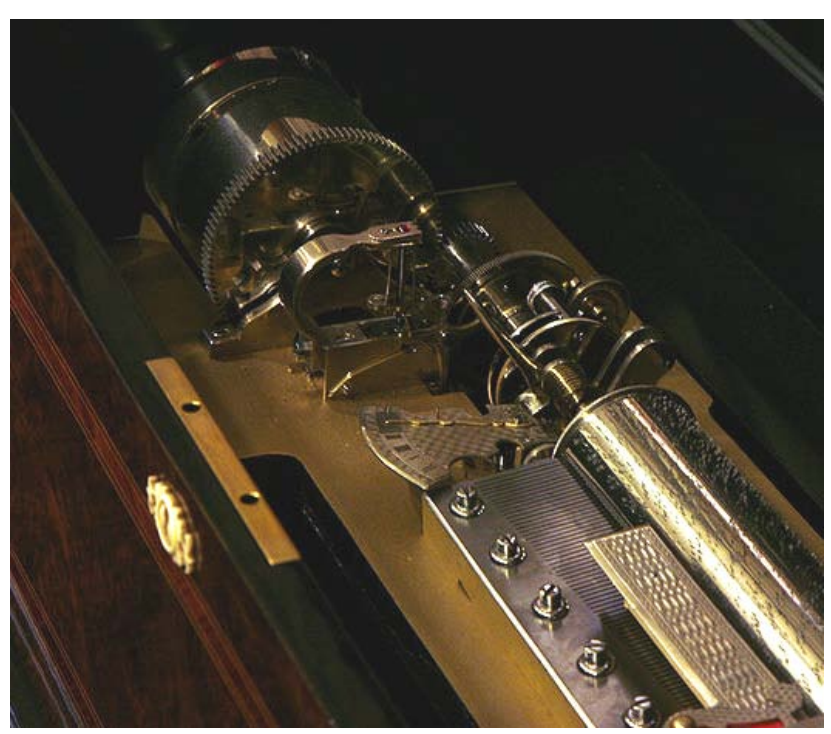

Fig. 16 Music Box, en (Wikipedia, 2010q) 
1813 Panharmonicon, o Panarmónico (Fig. 17), haciendo referencia al dios Pan, el 'creador' del Syrinx o la flauta de Pan. Fue inventado por Johann Nepomuk Maelzel (1772-1838), quién también creó el Metrónomo. Era una especie de teclado mecánico o más bien, una orquesta militar mecánica que automatizaba los sonidos de flautas, clarinetes, trompetas, violines, cellos, percusión, címbalos, entre otros (el primer prototipo de Mellotron o máquina de sampleo). Se menciona que su inventor convenció de cierta manera a Beethoven para que compusiera algo para dicho instrumento, llegando este a componer una sonata llamada La victoria de Wellington y empezar a escribir una sinfonía llamada La Batalla de Victoria, pero por diferencias con Johann, las descartó completamente.

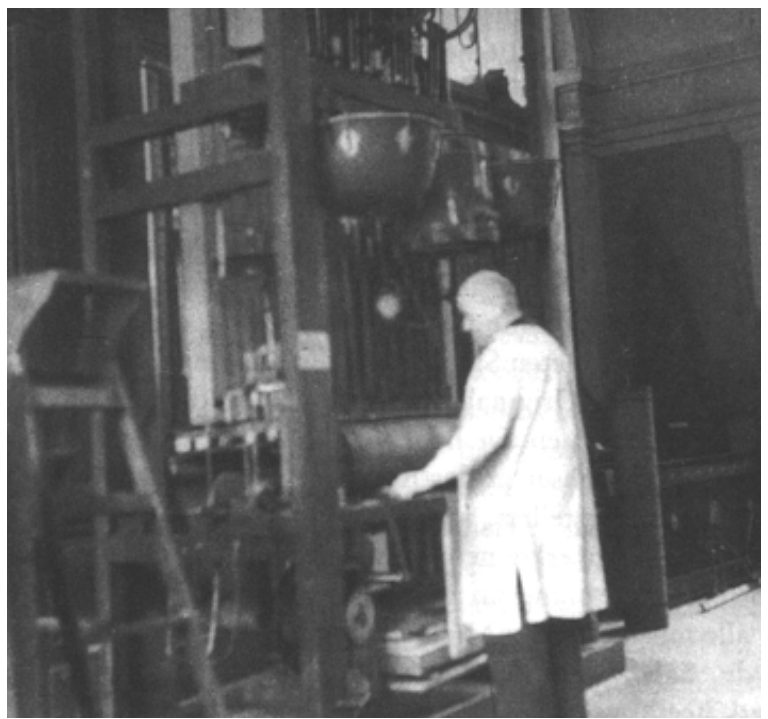

Fig. 17 J. N. Maelzel con un Panharmonicon, en (ElMusiquiatra, 2010)

1830 Robert Schumann compone las Variaciones Abegg, op. 1. El tema principal está basado en las letras que forman el nombre de una antigua novia: A-B-E-G-G; una aplicación tardía de la técnica anteriormente descrita como Soggetto cavato.

1832 Samuel Morse (1791-1872) inventa el Telégrafo. 
1833-34 The Direfference Engine, o Motor Diferenciado (método de diferenciación). Su inventor fue el científico británico Charles Babbage. Su invento era una especie de máquina para trabajar con tablas matemáticas libres de error; se puede decir que fue la primera sumadora automática digital programable por ende, precursora de las máquinas de sampling, sintetizadores digitales, secuenciadores, etc.

1835 Robert Schumann compone su obra Carnaval, op. 9 , 21 piezas breves para piano. Cada pieza se basa en un personaje diferente.

1850 D. D. Parmelee patentó la primera máquina capaz de sumar manejada por teclas.

1859 Telégrafo-Piano (Fig. 18): Se trata de un especie de telégrafo que utilizaba para su funcionamiento un teclado muy parecido al del piano, de esa forma su mecanismo de pulsos rítmicos funcionaba mejor. Su inventor fue David E. Hughes.

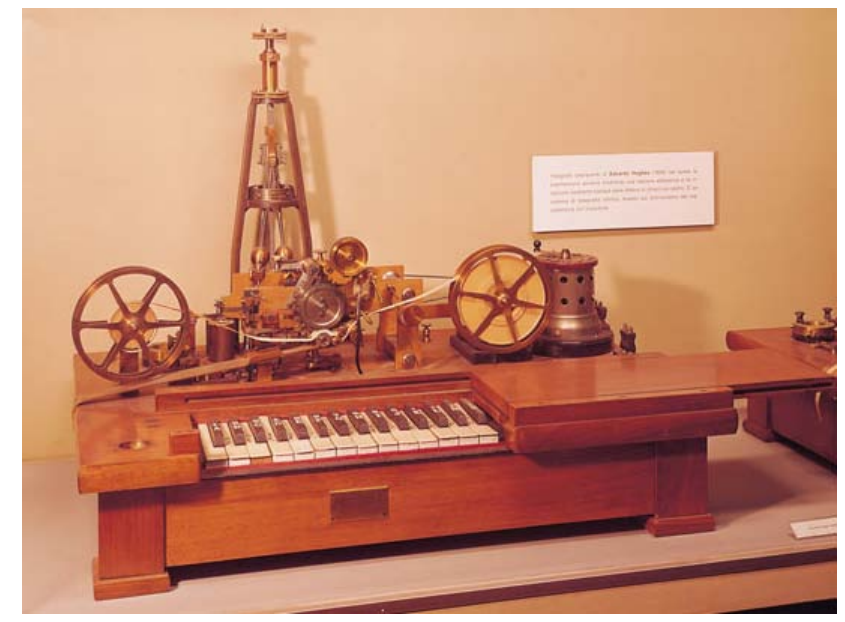

Fig. 18 Telégrafo-Piano, en (EbrisaOnline, 2010)

1863 Hermann Helmholtz escribe su libro On the Sensations of Tone as a Physiological Basis for the Theory of Music (sobre las sensaciones del sonido como base fisiológica para la teoría musical). Históricamente 
este libro fue uno de los fundadores de la acústica moderna (completando el trabajo anterior de Joseph Sauveur).

1867 Piano Electromecánico, o también llamado Piano Electromagnético. Fue desarrollado por un individuo de apellido Hipp, quien fuera director de una fábrica telegráfica suiza. Este invento se trataba de un teclado tipo piano que activaba una serie de mecanismos electromagnéticos y que a su vez activaban unos dinamos (pequeños generadores eléctricos) para de esa forma generar tonos y producir sonidos.

1876 Electrohamonic, también Ilamado Telégrafo Electromusical o Armónico. Su inventor fue Elisha Gray (junto con Bell, inventor del teléfono). En este instrumento, también en forma de teclado, aparece por vez primera el oscilador (circuito electromagnético autovibratorio), el cual se encontraba en cada tecla y se denominaba oscilador de frecuencia simple. Con el Electroarmónico se podían transmitir sonidos musicales a través de una línea telefónica; luego Gray construyó en modelos posteriores un pequeño amplificador para que los sonidos fueran más audibles sin necesidad de usar la línea telefónica.

Aparece el Tonametric de Koenig. Este instrumento está dividido en cuatro octavas con 670 partes iguales, siendo uno de los primeros que hicieron uso del microtuning (micro intervalos).

1877 El Fonógrafo, uno de los inventos mas interesantes de Thomas A. Edison (1847-1931) (Fig. 19); inventor de la electricidad (en 1882). Para grabar, se practica una muesca por medio de un diafragma con una aguja en una cinta móvil de papel recubierto con parafina. El 
Fonógrafo era capaz de transformar las ondas acústicas en eléctricas y fue el precursor de la industria de la música grabada.

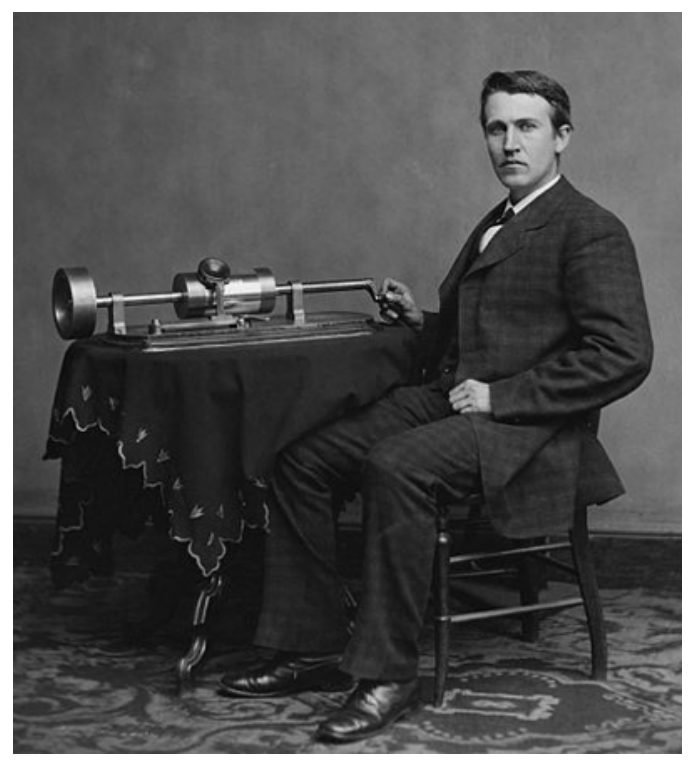

Fig. 19 T. A. Edison junto a uno de sus primeros Fonógrafos en 1878, en (ElTamiz, 2008)

Se inventa el altavoz, también llamado amplificador (Loudspeaker). Fue inventado por el alemán Ernst Wermer de Siemens, aunque fue patentado por el inglés Oliver Lodge. Obviamente sin este invento no existirían los instrumentos eléctricos, en este caso, los diversos sintetizadores.

Emile Berliner (1851-1929) desarrolló y patentó el sistema cilíndrico y fonográfico del disco, al mismo tiempo que Edison.

Dorr E. Felt (1862-1930), perfeccionó una calculadora llamada Comptómetro (Fig. 20), accionada por teclas con ruedas de trinquete que podían ser movidas por uno o más dientes a la vez. 


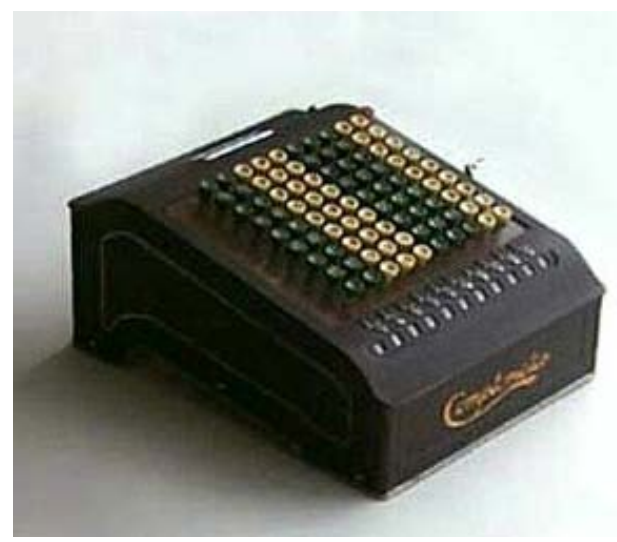

Fig. 20 Comptómetro, en (IBM, 2010a)

1880 Alexander Graham Bell (1847-1922) financió su propio laboratorio en Washington DC. Junto con Charles S. Tainter, Bell ideó y patentó varios medios de transmisión y grabación de sonido.

1895 Julián Carrillo desarrolló unas teorías de microtonos basadas en escalas con 96 tonos. Sus instrumentos estaban construidos para reproducir divisiones de $1 / 16$ partes de un tono. Mostró sus instrumentos en Nueva York en 1926. Estos incluyen una Octavina para los tonos de una octava y una Citera Arpa para los tonos en relación $1 / 16$.

1897 E. S. Votey inventó la Pianola (Fig. 21), un instrumento que utiliza un rollo de papel perforado que se mueve sobre un puente. Los agujeros en el papel corresponden a las 88 notas del teclado.

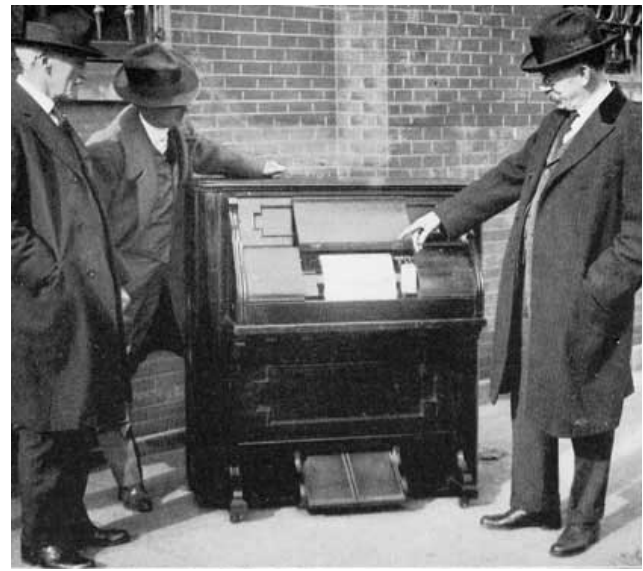

Fig. 21 Pianola; Votey a la derecha de la imagen, en

(TheSummitHistoricalSociety, 2004) 
1898 Valdemar Poulson (1869-1942) patentó su Telegraphone, la primera máquina de grabación magnética.

1906 Thaddeus Cahill inventó el Dynamophone, una máquina que produce música a partir de la corriente alterna de unos dinamos. Este fue el primer dispositivo de la síntesis aditiva. El Dynamophone también era conocido como el Telarmonio (Fig. 22). El instrumento pesaba más de 200 toneladas y fue diseñado para transmitir el sonido a través de cables de teléfono; sin embargo, los cables eran demasiado delicados para todas las señales. Los generadores producen tonos puros a partir de frecuencias variadas e intensidad, el control de volumen genera la dinámica. Puede considerarse el padre de Muzak'.

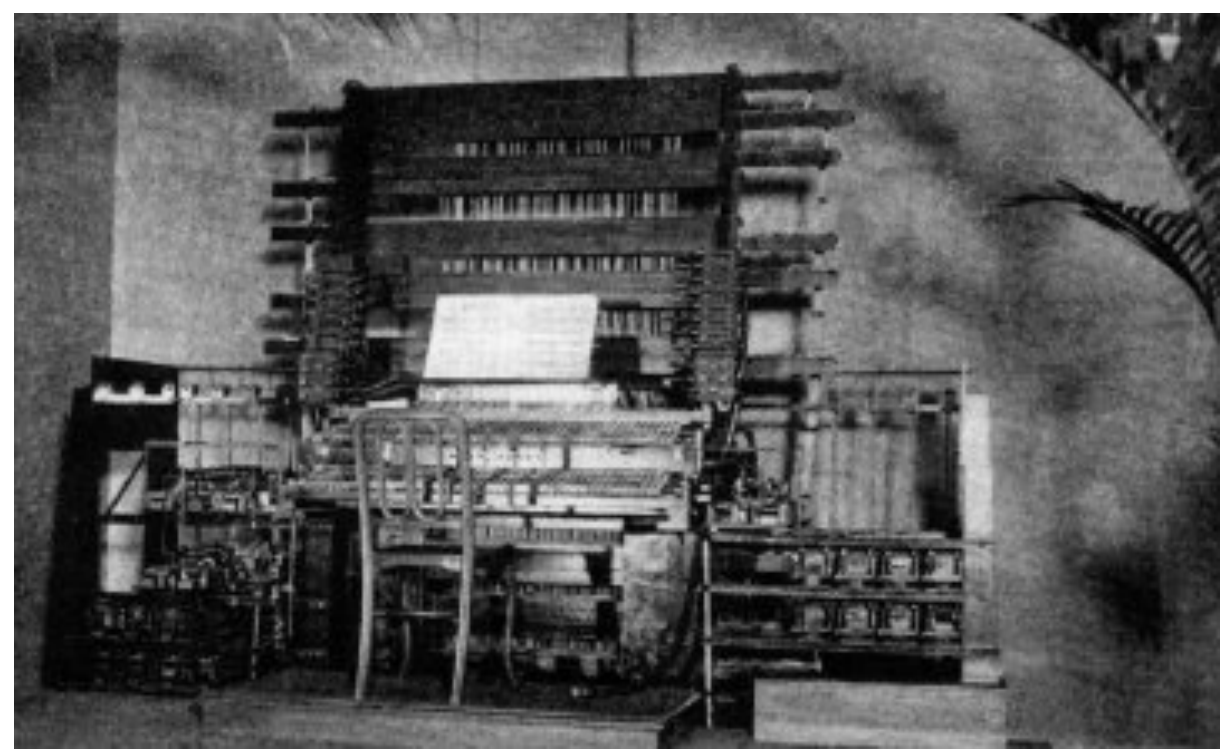

Fig. 22 Telarmonio, en (ElMusiquiatra, 2010)

Lee De Forest (1873-1961) inventó el Triodo o Tubo de Audion, el primer tubo de aspiradora.

\footnotetext{
${ }^{7}$ Muzak Corporation es el nombre de una compañía estadounidense fundada en los años 30 y de las primeras que se dedicó a enlatar música y vender el producto para que las tiendas la emitiesen por los altavoces.
} 
1907 El compositor Ferruccio Busoni (1866-1924) creyó que el sistema musical actual era muy limitado, por lo que afirmó que la música instrumental estaba muerta. Su tratado sobre la estética, Sketch of a New Music (Boceto de una nueva música), planteó un debate sobre el futuro de la música.

1910 La primera emisión radiofónica en Nueva York (la primera estación de radio fue construida en 1920, también en Nueva York).

1912 El movimiento futurista italiano fue fundado por el pintor Luigi Russolo (1885-1947), y el poeta Marinetti Filippo (Fig. 23). Marinetti escribió el manifiesto 'Música Futurista'; el credo del Movimiento Futurista fue:

'Presentar el alma musical de las masas, de las grandes fábricas, de los ferrocarriles, de los trasatlánticos, de los acorazados, de los automóviles y aviones. Agregar a los grandes temas centrales del poema musical el dominio de las máquinas y el reino victorioso de la electricidad'.

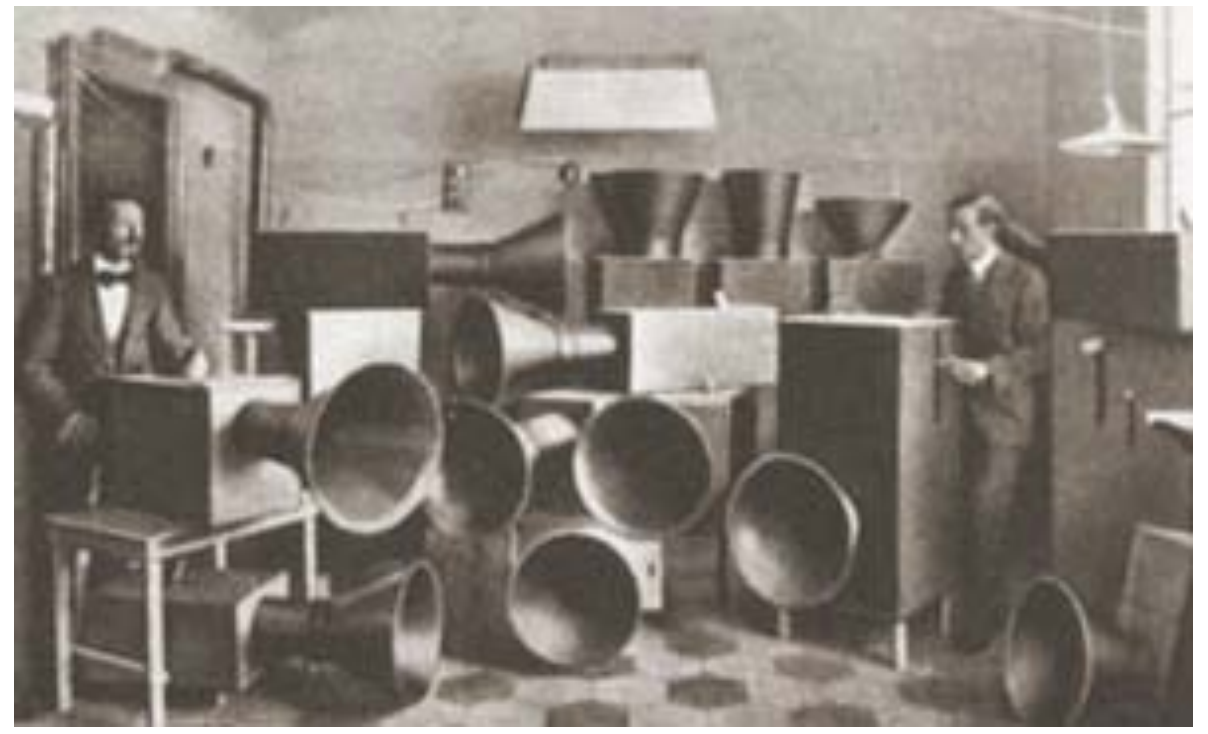

Fig. 23 Luigi Russolo y Ugo Piatti con el Intonarumori, 1913, en (IntuitiveMusic, 2010) 
Henry Cowell (1897-1965) introdujo clústers en la música de piano. Las obras Banshee y Aeolic Harp son buenos ejemplos.

1914 Se presentó el primer concierto de música futurista. El concierto, llamado Arte de los ruidos, fue presentado por Marinetti y Russolo en Milán, Italia.

1920 Lev (Leon) Theremin, Rusia (Fig. 24), inventó el Aetherophone (más tarde llamado el Theremin o Thereminovox). El diseño clásico consiste en una caja con dos antenas. Se ejecuta acercando y alejando la mano de cada una de las antenas correspondientes, sin llegar a tocarlas. La antena derecha suele ser recta y en vertical, y sirve para controlar la frecuencia o tono: cuanto más cerca esté la mano derecha de la misma, más agudo será el sonido producido. La antena izquierda es horizontal y con forma de bucle, y sirve para controlar el volumen: cuanto más cerca de la misma esté la mano izquierda, más baja el volumen, y viceversa. Muchos compositores del s. XX utilizan este instrumento en sus obras: Varese, Honegger, etc. 


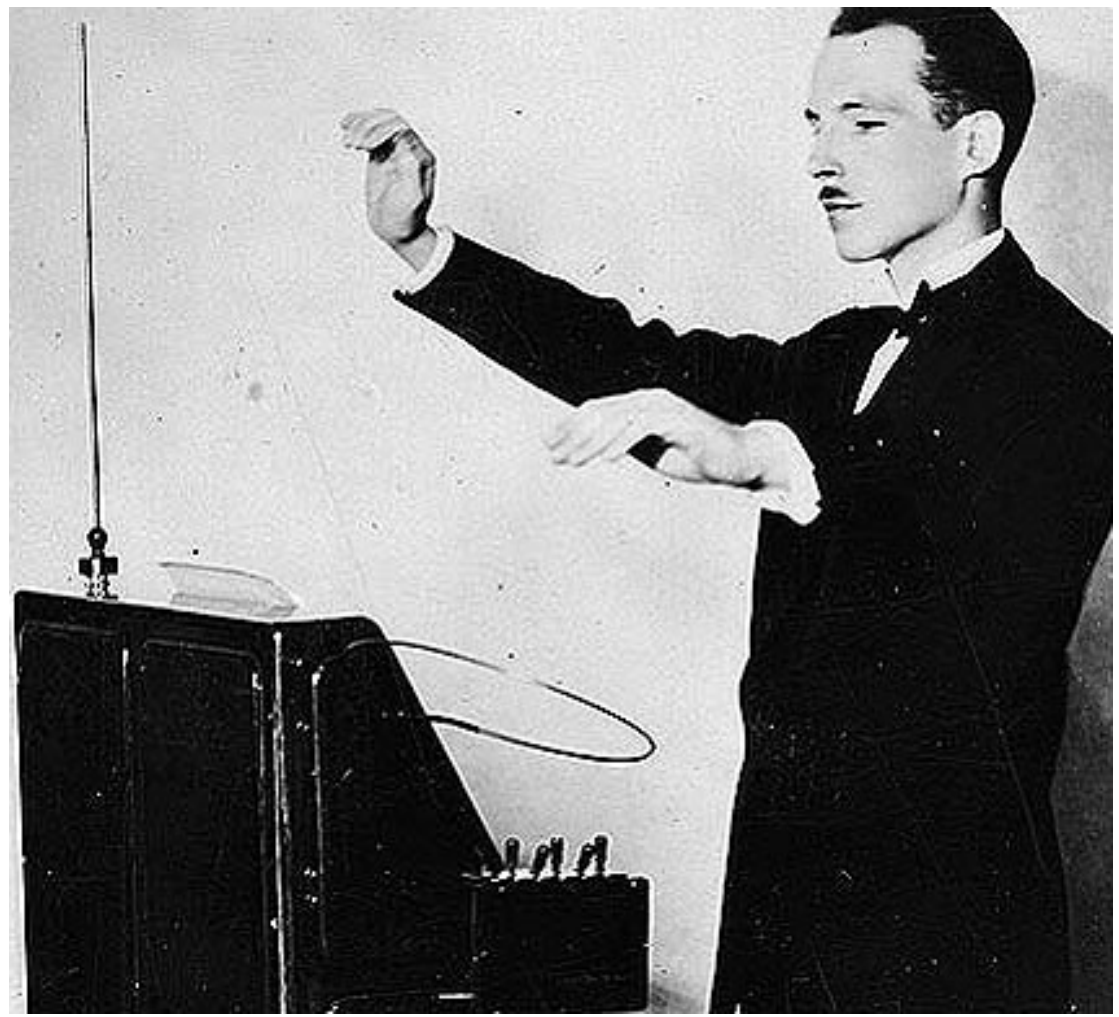

Fig. 24 L. Theremin, en (Noctamina, 2009)

1922 Darius Milhaud (1892-1974) experimentó con la transformación vocal del fonógrafo a partir de cambios de velocidad.

Ottorino Respighi (1879-1936) exige en su obra Pini di Roma, una grabación de ruiseñores en fonógrafo.

1926 Jorg Mager (Fig. 25) construye un instrumento electrónico, el Spharophon, presentado por primera vez en el Festival de Donaueschingen (Georgy Rimsky-Korsakov, nieto de Nikolái RimskiKorsakov, compuso algunas obras experimentales para este instrumento). Mager más tarde desarrolló una Partiturophon y un Kaleidophon, ambos utilizados en producciones teatrales. Todos estos instrumentos fueron destruidos en la $2^{a}$ Guerra Mundial. 


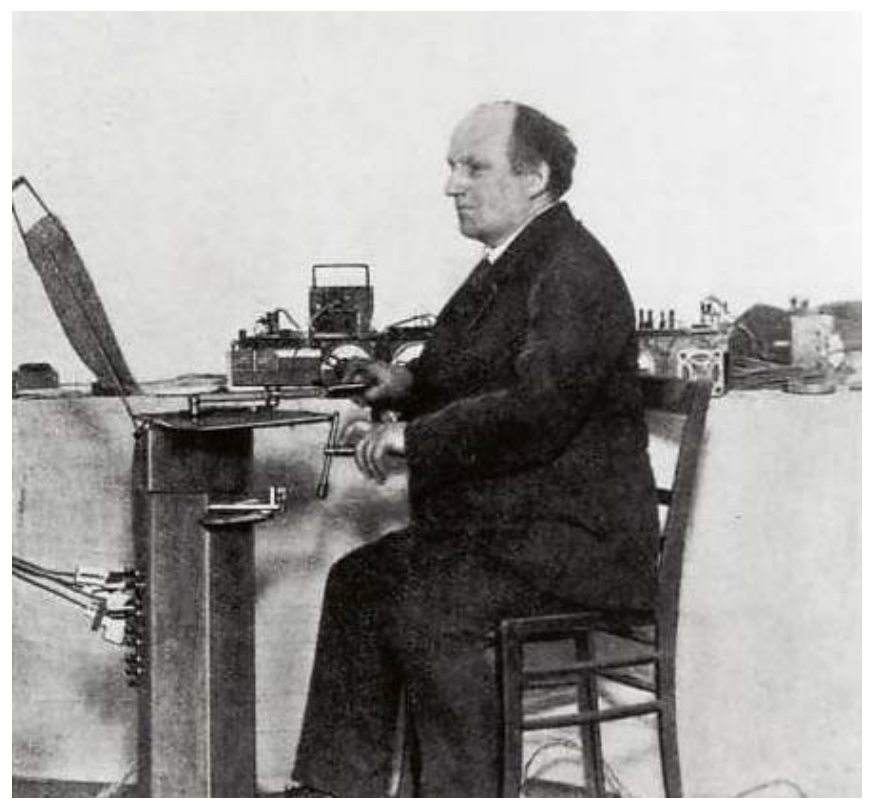

Fig. 25 J. Mager con su Spharophon, en (PhotographersDirect, 2010)

George Antheil (1900-1959) compone Ballet Mechanique. Antheil era un expatriado americano que vivía en Francia. La obra fue orquestada para pianos, xilófonos, pianola, timbres (de puerta), y un avión de hélice.

1928 Maurice Martenot (1898-1980) construyó el Ondes Martenot. El instrumento está formado por un teclado, un altavoz y un generador de baja frecuencia. Es un instrumento monofónico, es decir, que no produce notas simultáneas. El instrumento utilizaba síntesis sustractiva (Fig. 26). Compositores como Honegger, Messiaen, Milhaud, Dutilleux, y Varese componen obras para este instrumento.

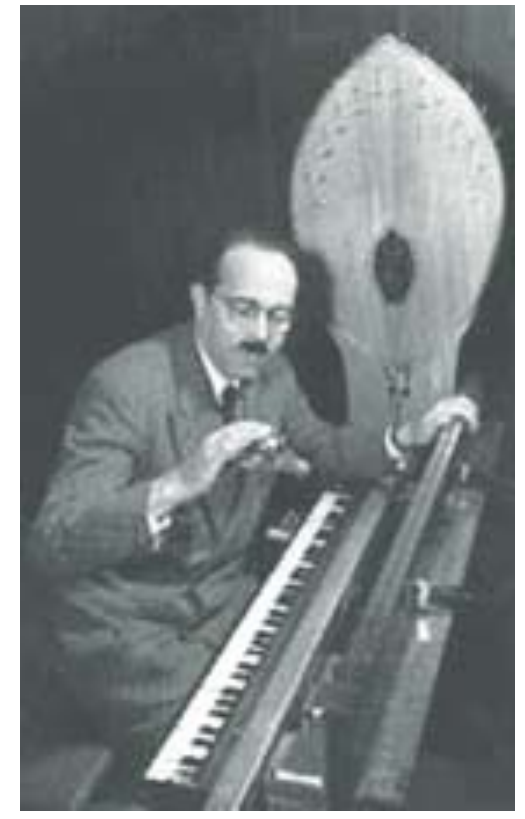

Fig. 26 M. Martenot, en (IntuitiveMusic, 2010) 
Friedrich Trautwein (1888-1956), construyó el Trautonium (Fig. 27). Compositores tales como Hindemith, Richard Strauss, y Varese escribieron para este instrumento, aunque no existen grabaciones históricas.

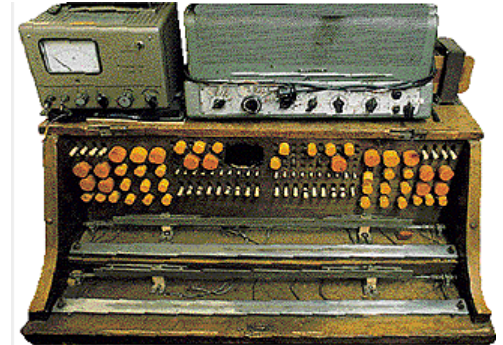

Fig. 27 Trautonium, en (AnalogArtEnsemble, 2010)

1929 Laurens Hammond (1895-1973) construye instrumentos como el Órgano Hammond (Fig. 28), Novachord, Solovox, así como dispositivos que generan efectos de reverberación. Como características principales, el órgano Hammond presenta un mueble de madera, cerrado o con cuatro patas, de aspecto sobrio con un sistema de 25 ó 32 pedales para los sonidos del bajo. En la consola hay dos teclados de cinco octavas y encima de éstos, hay cuatro juegos de nueve drawbars o barras deslizantes que permiten añadir armónicos (generados mediante ruedas fónicas - Tone Wheels, por su nombre en inglés) a los sonidos fundamentales del instrumento. Cuenta con un altavoz giratorio acabado en dos trompetas (una de ellas muda) instalado sobre un motor que gira a dos diferentes velocidades: Slow-Fast (Lento-Rápido) / Tremolo-Chorale. Este sistema de amplificación, llamado Leslie, es en gran parte responsable de su característico timbre, pero no fue nunca vendido por Hammond, ya que Leslie y Hammond fueron (durante el período dorado de la marca) empresas totalmente separadas y rivales, puesto que Laurens Hammond nunca fue partidario de la utilización de este tipo de altavoz. 


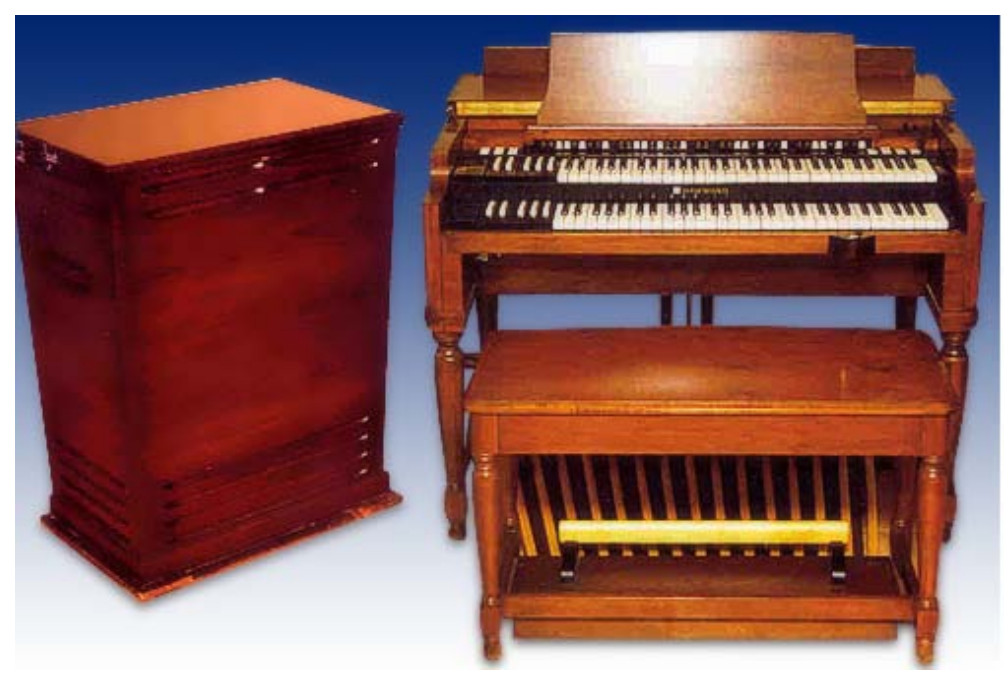

Fig. 28 Órgano Hammond, modelo B3 con la caja del altavoz Leslie, en (Wikipedia, 2010m)

1931 Se compone el Cuarteto del compositor Ruth Crawford Seeger. Esta es una de las primeras obras que emplea el serialismo extendido, una organización sistemática de sonido, ritmo, dinámica y articulación.

Henry Cowell trabajó con Leon Theremin para construir el Rhythmicon, un instrumento que podría desempeñar combinaciones métricas de complejidad prácticamente ilimitada. Con este instrumento compuso el Concierto llamado Rhythmicana.

El alemán Jorg Mager fue contratado para crear sonidos electrónicos de campana para la producción de Parsifal de Wagner en el festival de Bayreuth.

1935 La compañía Allegemeine Elektrizitäts Gesellschaft (AEG), construye y desarrola el primer Magnetophon (grabadora).

1937 La guerra de los mundos fue dirigida por Orson Welles, el primer director en usar la técnica de atenuación y disolución por primera vez en la película Ciudadano Kane. Hasta la fecha, la mayoría de los directores de cine utilizaban en su lugar empalmes contundentes. 
Se construye el Electrochord (piano electroacústico).

1938 Se construye el Novachord (Fig. 29).

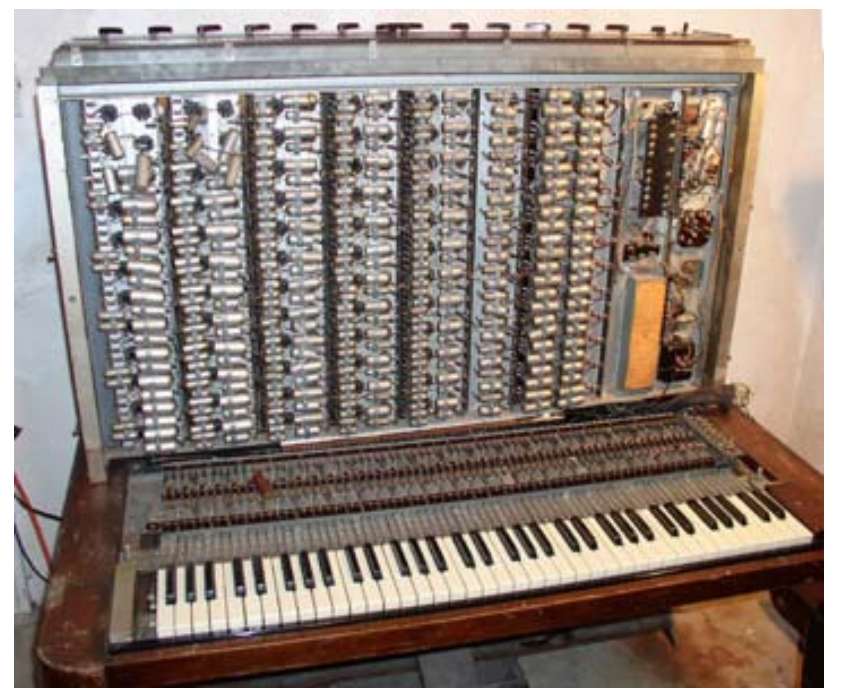

Fig. 29 Novachord, en (DiscreteSynthesizers, 2006)

John Cage (1912-1992) comenzó a experimentar con la indeterminación. En su composición, Imaginary Landscape No. 1, se les pide a los artistas, intérpretes o ejecutantes que realicen cambios de los ajustes de velocidad en los reproductores de disco.

Durante la década de 1930 se desarrollan las cintas de plástico.

Se construye The Sonorous Cross (un instrumento parecido a un Theremin).

1940 Los siguientes instrumentos fueron construidos: el Pi Electronium (utilizado por unos pocos compositores alemanes, entre ellos: Brehme, Degen, y Jacobi), la Multimónica, el órgano Polychord, el Tuttivox, el órgano Marshall, y otros órganos eléctricos pequeños.

1941 Joseph Schillinger escribió el Sistema de composición musical Schillinger. Este libro ofrece recetas para la composición: ritmos, 
sonidos, armonías, etc. Entre sus estudiantes estaban George Gershwin y Glenn Miller.

Georges Jenny idea y construye la Ondioline (Fig. 30). Se trata de un instrumento monofónico, que incorporaba un sencillo oscilador de lámparas y un teclado de tres octavas, ampliable a siete por medio de un conmutador electrónico. Hay que anotar que el mencionado teclado era sensible a la fuerza de la ejecución, y al vibrato que el interprete pudiera imprimir a cada nota.

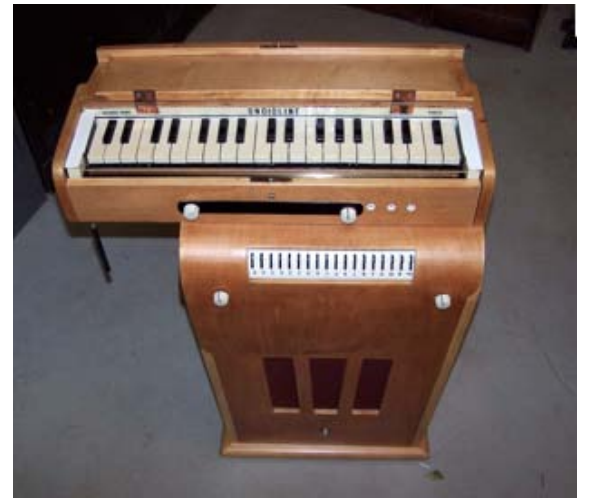

Fig. 30 Ondiolline, en (Member.tde, 2010)

1944 Percy Grainger y Cruz Burnett patentaron una máquina que 'liberó' a la música de las limitaciones de los sistemas convencionales de ordenación rítmica y de las limitaciones físicas de los artistas e intérpretes. La invención mecánica para componer lo que llamaron Musica Libre, utiliza ocho osciladores y un equipo de sincronización, además de un papel de gráfico foto-sensible con la intención de que la notación proyectada, se pudiera convertir en sonido.

1947 Bell Labs desarrolló y produjo el solid state transistor (transistor de estado sólido) (Fig. 31). 


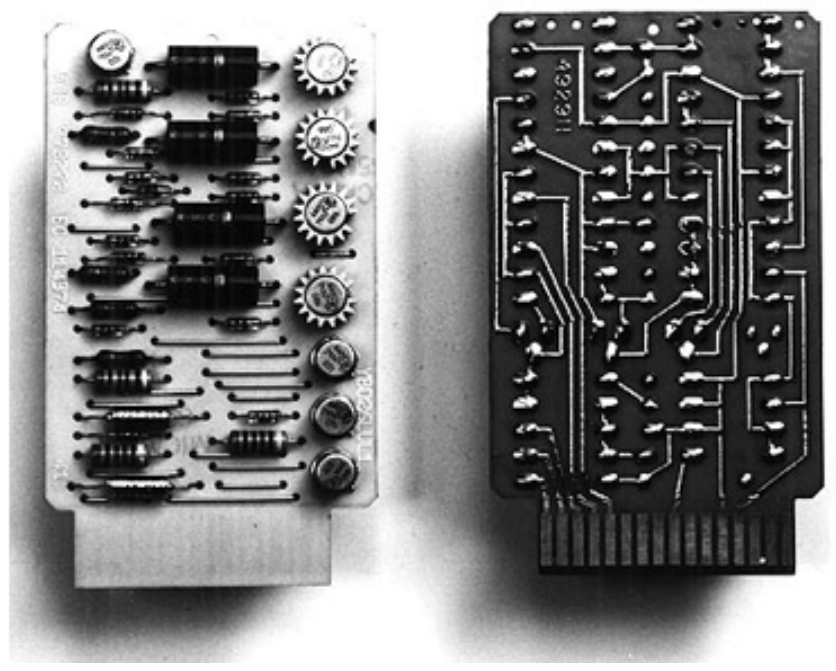

Fig. 31 Solid-state trasistor en 1958, en (IBM, 2010b)

En la obra Three compositions for Piano, Milton Babbitt serializó todos los aspectos de altura, el ritmo, dinámica y articulación.

En este mismo año aparecerían en el mercado instrumentos de características comparables, pero menos versátiles y con diferentes principios a la hora de generar el sonido. Se trataba del Solovox y la Clavioline (Fig. 32), algunos de cuyos timbres, similares a los del Ondioline, han llevado a confundir en ocasiones a críticos y a oyentes.
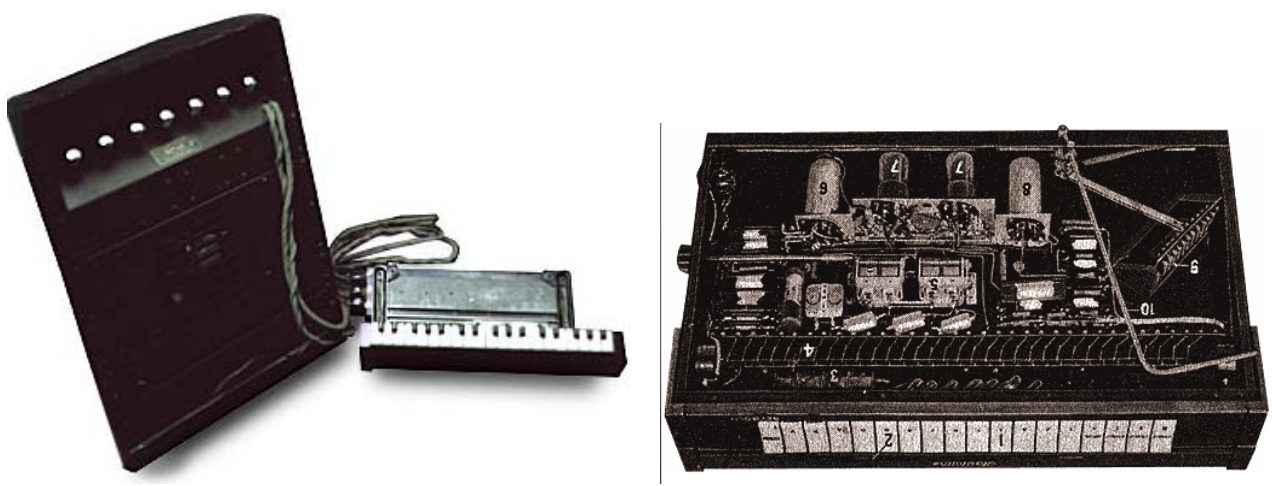

Fig. 32 Solovox, en (Hammond-organ, 2010) y Clavioline, en (120years, 2010)

John Scott Trotter, construye en 1948 una máquina para componer música popular. 
El canadiense Hugh LeCaine (1945-1973) construyó

el Sackbutt electrónico (Fig. 33), un instrumento que en realidad sonaba como un cello.

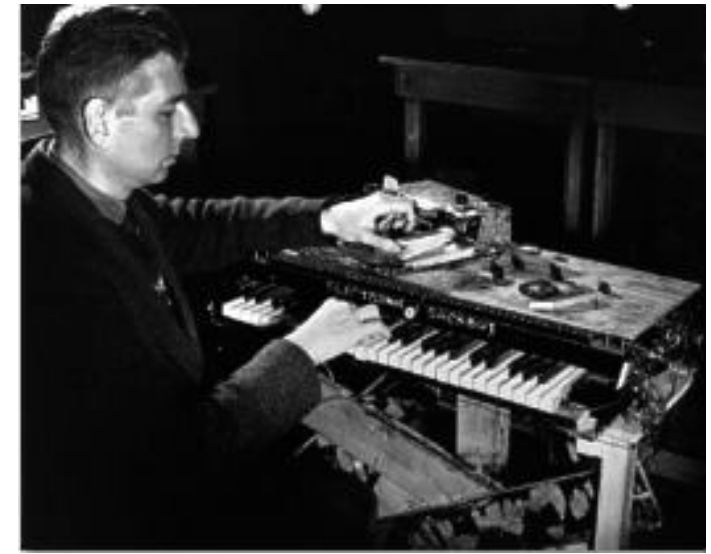

Fig. 33 H. Lecaine tocando el Sackbutt, en (Lecaine, 2010)

Pierre Schaeffer (1910-1995), un técnico de sonido que trabajaba en Radio-difusión-Televisión Francesa (RTF) en París, produjo varios estudios cortos, que llamó música concreta. En octubre de 1948, los primeros estudios de Schaeffer difundidieron estos trabajos en los llamados Concerts de Bruits (Concierto de ruidos).

Joseph Schillinger escribió la base matemática de las Artes.

1949 Pierre Schaeffer y el ingeniero Jacques Poullin trabajaron en experimentos de sonido, llamados musica concreta. Entre 1949 y 1950 Schaeffer y Pierre Henry (1927-1996), junto con Poullin componen Symphonie pour un homme seul (Sinfonía para un Solo Hombre); la obra se estrenó en realidad el 18 de marzo de 1950.

Olivier Messiaen compuso una obra para piano llamada Mode de valeurs et d'intensités (Modo de duraciones e intensidades), un trabajo que estableció escalas no sólo de la altura, sino también de duración, intensidad, y ataque.

El Melochord (Fig. 34) fue inventado por Haral Bode. 


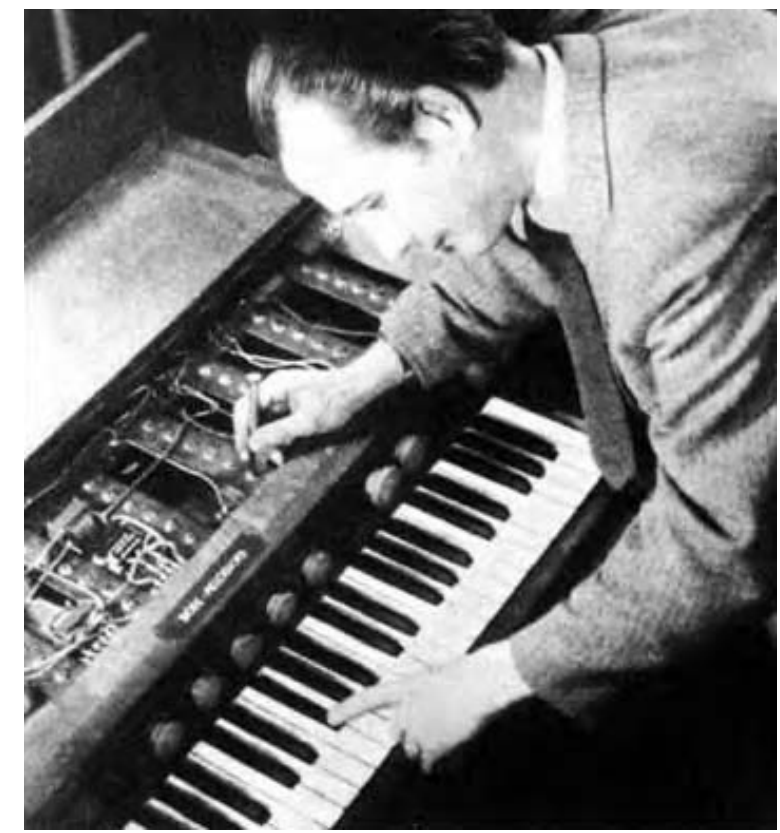

Fig. 34 H. Bode tocando un Melochord en 1948, en (120years, 2010)

1950 El Estudio de Milán fue creado por Luciano Berio (1925-2003).

1951 Clara Rockmore realiza conciertos por todo el mundo con el Theremin.

El estudio RTF se estableció formalmente como el Groupe de Musique Concrete. El grupo se abrió a otros compositores, incluyendo Messiaen y sus alumnos, Pierre Boulez, Karlheinz Stockhausen y George Barraqué. Boulez y Stockhausen lo dejaron poco después debido a que Schaeffer no estaba interesado en el uso de sonidos generados electrónicamente, sino que quería basarlo todo en las grabaciones.

Uso de la indeterminación por John Cage, que culminó con Music of Changes, un trabajo basado en las permutaciones numéricas de libro I Ching, el libro chino de los oráculos.

'Estructuras, Libro la', fue uno de los primeros intentos de Pierre Boulez por emplear una pequeña cantidad de materia musical, llamadas células (ya sea para su uso como alturas, duraciones, 
dinámica, o formas de ataque), en una estructura complejamente serializada.

1951-53 Eimert y Beyer produjeron las primeras composiciones con alturas generadas electrónicamente. Las piezas utilizan un dispositivo mecanizado que producían melodías basadas en el análisis de Markov sobre canciones de Stephen Foster.

1952 La estación de radio de Colonia, Nordwestdeutscher Rundfunk (más tarde Westdeutscher Rundfunk) fue fundada por Herbert Eimert. Pronto se le unió Stockhausen, quien se propuso crear lo que ellos Ilamaban Elektronische Musik.

John Cage compone la obra 4' 33" (Fig.

35). El compositor estaba tratando de liberar al intérprete y al compositor de tener que tomar ninguna decisión consciente, por lo tanto, los únicos sonidos en esta pieza son los producidos por el público.

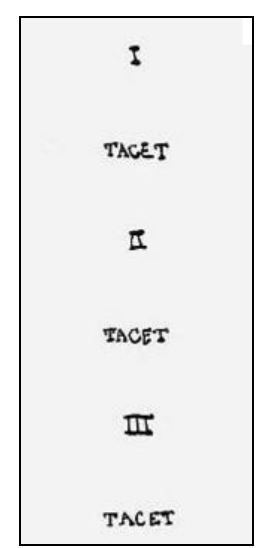

Fig. 35 Partitura de 4'33" de J. Cage, en (Cage, 1999)

1953 Robert Beyer, Werner Meyer-Eppler y Eimert comenzaron a experimentar con sonidos generados electrónicamente. Eimert y Meyer-Eppler dieron cursos en la Escuela de Verano de Darmstadt (Alemania), e hicieron presentaciones de su trabajo en París.

Louis y Bebe Barón establecieron un estudio privado en Nueva York, y produjeron las bandas sonoras de películas de ciencia ficción como Planeta prohibido (1956) y Atlántida, que utilizan material electrónico de sonido. 
Otto Luening (1900-1996) y Vladimir Ussachevsky (1911-1990), presentarán por primera vez un concierto en el Museo de Arte Moderno de Nueva York, el 28 de octubre. El programa incluyó Sonic Contours de Ussachevsky (creado a partir de grabaciones de piano), y Fantasía en el espacio (mediante grabaciones flauta) de Luening. Después del concierto, se les pidió estar en el Today Show con Dave Garroway. La organización Músicos Local 802 levantó un alboroto porque Luening y Ussachevsky no eran miembros del sindicato de músicos.

1953-54 Karlheinz Stockhausen utilizó las investigaciones numéricas de Helmholtz como base de su Studie I y Studie II. Trató de crear sonidos sintetizados cada vez más complejos a partir de las ondas más simples (sinusoidales).

1954 La serie Música de Nuestro Tiempo, de la Radio de Colonia (19 de octubre) utilizó exclusivamente sonidos electrónicos, generados por Stockhausen, Eimert, Pousseur, etc. Las piezas utilizaban técnicas estrictas de serialización.

Dripsody fue compuesto por Hugh LeCaine. La única fuente de sonido para esta pieza es un goteo de agua.

1955 Harry Olson y Belar, ambos trabajando para el sello RCA, inventaron el Sintetizador de Música Electrónica, también conocido como Sintetizador de Sonido Olson-Belar (Fig. 36). Este sintetizador utiliza ondas diente de sierra que se filtran para obtener otros tipos de timbres. El usuario puede programar el sintetizador con el teclado de una máquina de escribir que perfora comandos en una cinta de papel con 40 canales con código binario. 


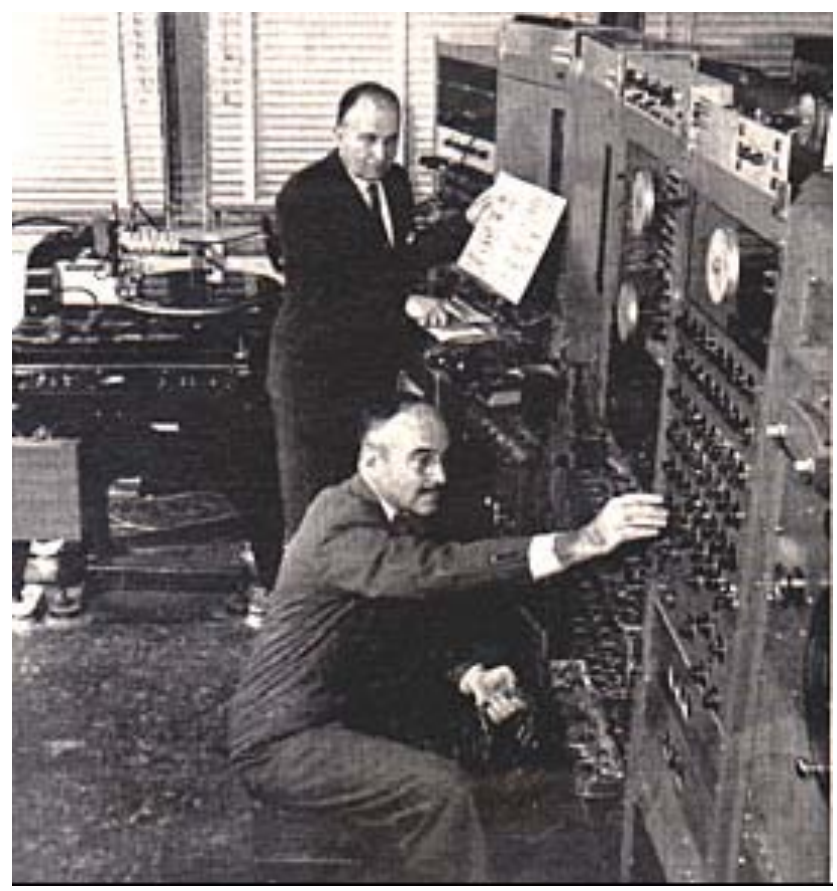

Fig. 36 Harry F. Olson y Herbert Belar con el primer Sintetizador de Sonido, en (Pennstate, 2010)

El Columbia-Studio se funda, siendo sus inicios la sala de estar de Ussachevsky y luego el apartamento de Luening.

Lejaren Hiller (1924-1992) y Leonard Isaacson, de la Universidad de Illinois componen el Cuarteto de Cuerdas Illiac, la primera pieza de la música generada por ordenador. La pieza fue llamada así debido a que utiliza un ordenador Univac y fue compuesta en la Universidad de Illinois.

1955-56 Karlheinz Stockhausen compone Gesang der Junglinge. Este trabajo utiliza dos grabaciones de voces de niños y sonidos sintetizados. La versión original fue compuesta para cinco altavoces, pero finalmente se redujo a cuatro. El texto corresponde a la Benedicite, que aparece en el libro de Daniel donde Nabucodonosor lanza a Sadrac, Mesac y Abednego a un horno de fuego de donde milagrosamente salen ilesos, y se ponen a cantar alabanzas a Dios. 
1956 Martin Klein y Bolitho Douglas utilizaron un ordenador Datatron llamado Push-Button Bertha para componer música. Este equipo fue utilizado para componer canciones populares; las melodías se obtienen de una secuencia aleatoria de datos numéricos que se asignan a un esquema tonal preestablecido.

Se funda un estudio electrónico en Tokio, en el seno de la radio de Japón.

Luening y Ussachevsky escribieron música incidental para El Rey Lear de Orson Welles, Nueva York.

1957 De madera y latón, obra compuesta por Luening. Utiliza fuentes de ruido que incluyen: trompetas, trombones y marimbas.

Scambi, compuesta por Henri Pousseur, fue creada en el estudio de Milán, Italia.

Se establece un estudio de electrónica en Varsovia, en la Radio Polaca.

Se establece en Munich la empresa Siemens, y en Eindhoven la empresa Philips, ambos estudios de electrónica.

David Seville creó Chipmunk, unas marionetas con forma de ardilla que sonaban mediante un reproductor de grabaciones de la voz humana a doble velocidad mediante manipulación electrónica. 
1958 Edgard Varese (1883-1965) compone Poeme Electronique para la Exposición Mundial de Bruselas. La obra fue compuesta para el Pabellón Philips (Fig. 37), un edificio diseñado por el famoso arquitecto Le Corbusier, que fue asistido por lannis Xenakis. El trabajo se realizó con alrededor de 425 altavoces acompañado por imágenes proyectadas. Esta fue realmente una

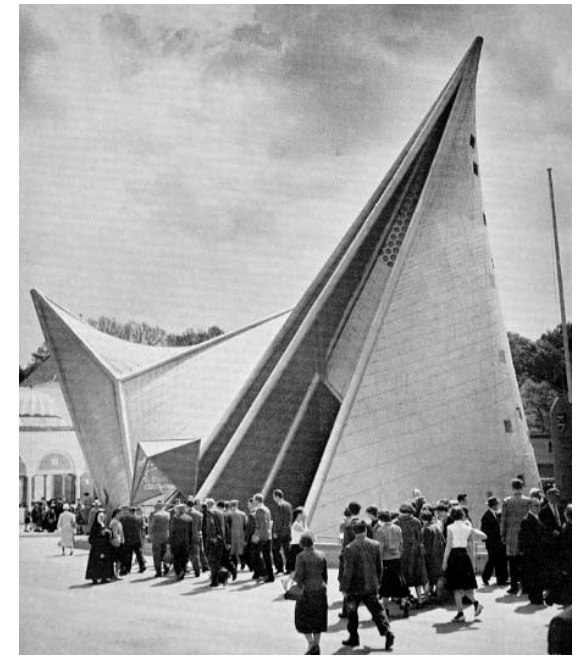

Fig. 37 Pabellón Philips, 1958, en (Arq-lab-vox, 2010) de las primeras producciones multimedia a gran escala.

lannis Xenakis (1922-2001), compone Concret Ph, un interludio de duración: 2' 42"; compuesta también para la Exposición Universal de Bruselas. Hizo uso de una sola fuente sonora: carbón quemándose amplificado.

Max Mathews, de los Laboratorios Bell, generó música a partir de computadoras.

John Cage compone Fontana Mix en el estudio de Milán.

Se funda en Londres, el Taller Radiofónico de la BBC, un estudio de electrónica.

Se establece en Estocolmo, un estudio de electrónica en la Radio Sueca.

Se funda el Estudio de Música Experimental en la Universidad de Illinois, dirigido por Lejaren Hiller. 
Pierre Henry sale del Group de Musique Concrete, estos se reorganizarán como el Groupe de Recherches Musicales (GRM).

Gordon Mumma y Robert Ashley fundaron el Estudio Cooperativo de Música Electrónica en Ann Arbor, Universidad de Michigan.

Luciano Berio compone Thema-Omaggio a Joyce. La fuente de sonido consiste en una mujer leyendo el Ulises de Joyce.

1958-6o Stockhausen compone Kontakte para cinta con cuatro canales. Hubo una segunda versión para piano, percusión y cinta.

1958-59 Mauricio Kagel, un compositor argentino, compone Transición II, la primera pieza en la que pide una grabadora en vivo como parte de la actuación. El trabajo fue realizado en Colonia. La obra trabaja en tres niveles. En vivo: El pianista toca en el teclado mientras otro realiza recursos percusivos dentro del piano. Cinta 1: Antes de realizar la pieza, se graban previamente algunas secciones que se van a reproducir durante la representación. Cinta 2: la interpretación en vivo también se graba con la banda sonora. La repetición de cualquier parte del material musical no está permitido en su lugar, mientras los intérpretes siguen tocando para llevar a cabo el tiempo presente, las cintas pueden recordar la música que ya ha sonado. Además, las cintas se pueden manipular para cambiar el timbre y las frecuencias con el fin de hacer imposible el reconocimiento de los sonidos originales.

Max Mathews, en los Laboratorios Bell, comenzó a experimentar con programas de computadora para crear materiales sonoros de buena calidad. Mathews y Joan Miller también en los Laboratorios Bell, escriben Music4, el programa de la primera computadora extendida para síntesis de sonido. Las versiones I a III fueron escritas como 
versiones experimentales en un lenguaje integrado. Music $I V$ y Music $V$ fueron escritas en el lenguaje FORTRAN. Music4 no permitía comportarse como un instrumentos polifónico (sonar más de 1 nota a la vez). Music5 solucionó este problema.

El Columbia-Princeton Electronic Music Center fue fundado formalmente. El grupo se había gestionado a través de la Fundación Rockefeller, dando lugar a la creación del Consejo de la Universidad de Música Electrónica. Para este proyecto se estableció un espacio con asistentes técnicos, equipos electrónicos y materiales a disposición de otros compositores de forma gratuita. Con una donación de 175.000 dólares en cinco años se llevó a cabo para Columbia y Princeton. En enero de 1959, bajo la dirección de Luening y Ussachevsky (de Columbia) y con Milton Babbitt y Roger Sessions (de Princeton), el Centro fue establecido formalmente.

El sintetizador RCA Mark II (Fig. 38) fue construido en la mencionada Columbia-Princeton Electronic Music Center (la versión original fue construida para la creación artificial del habla humana). El Mark II funcionaría con osciladores y generadores de ruido. El operador introducía las instrucciones en el sintetizador mediante un rollo de papel perforado para controlar la altura, volumen, duración y timbre. El sintetizador utiliza una escala convencional de doce notas. 


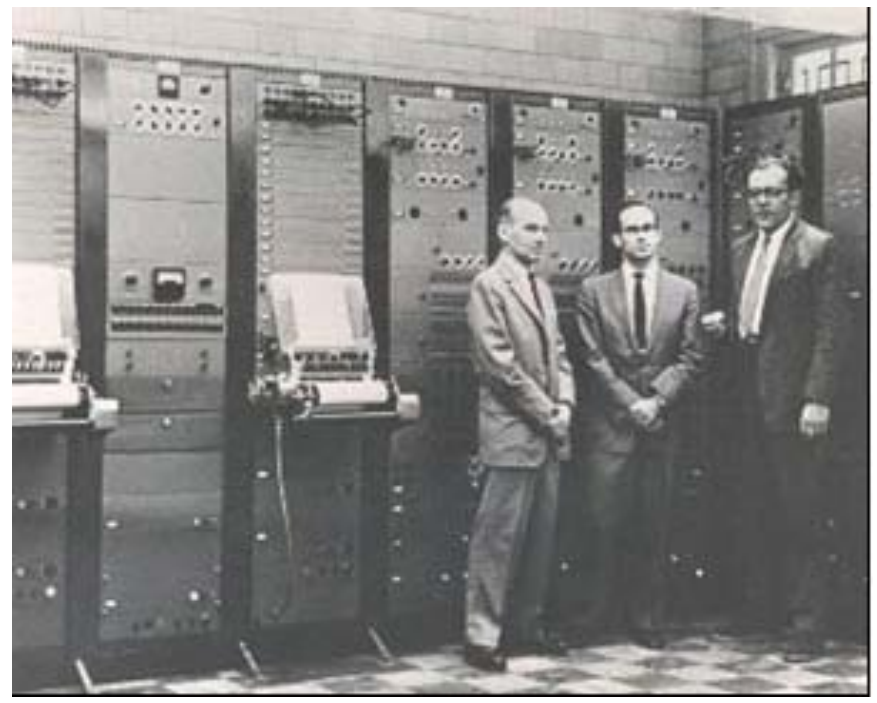

Fig. 38 El sintetizador Mark II en el Estudio Columbia-Princeon, 1985. De izquierda a derecha: Milton Babbitt, Meter Mazuey y Vladimir Ussachevsky, en (IntuitiveMusic, 2010)

1960 Los compositores del ámbito de la música orquestal más tradicional comenzaron a rebelarse. Algunos trataron de obtener sonidos cuasi-electrónicos a partir de instrumentos tradicionales. Bruno Bartelozzi, escribió un nuevo libro sobre técnicas instrumentales extendidas.

Morton Subotnick, Pauline Oliveros, y Ramón Sender fundaron el San Francisco Tape Music Center (Fig. 39).

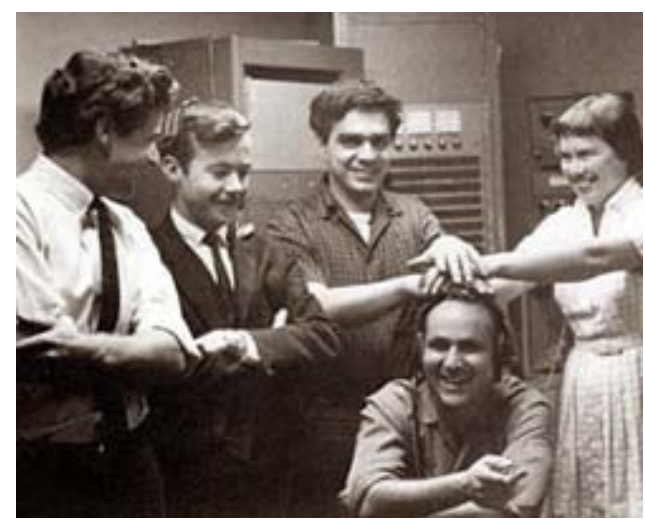

Fig. 39 San Francisco Tape Music Center, 1965. De izquierda a derecha: Tony Martin, Hill Maginnis, Ramon Sender, Morton Subotnick y Pauline Oliveros, en (IntuitiveMusic, 2010) 
John Cage compone Cartridge Music, una composición de duración indeterminada para varios intérpretes utilizando cartuchos de gramófono y micrófonos de contacto en diversos objetos.

1961 Se llevaron a cabo los primeros conciertos de música electrónica en el estudio de Columbia-Princeton. La música fue recibida con mucha hostilidad por parte de otros miembros del profesorado.

Varese finalizó su obra Deserts, en el estudio de Columbia-Princeton.

Music IV, basado el lenguaje FORTRAN, fue utilizado en la composición de Bicycle Built for Two de Max Mathews.

Se distribuyó a escala mundial la producción de circuitos integrados VLSI (Very Large Scale Integration).

Robert Moog y Herbert Deutsch crearon un sintetizador controlado por voltaje (Fig. 40).

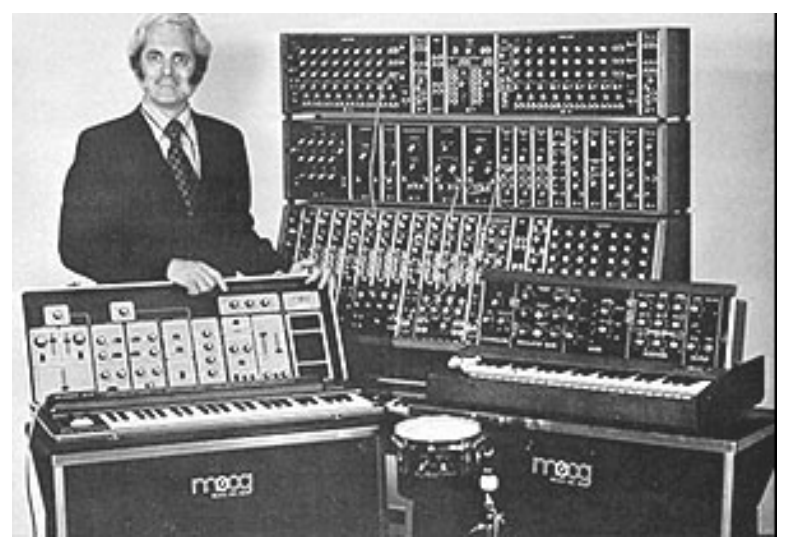

Fig. 40 Robert Moog con una de las versiones de Moog, en (IntuitiveMusic, 2010)

Luciano Berio compone Visage. Esta composición de radio se basa en la idea de la comunicación no verbal. Hay muchos pasajes basados en palabras, pero sólo se dice una palabra durante toda la composición 
(en realidad dos veces): parole (en italiano, palabra). Cathy Berberian, esposa del compositor, fue la intérprete.

Se escribe el trabajo teórico Meta + Hodos, escrito por James Tenney (más tarde aparecerá META Meta + Hodos, escrito en 1975).

1962 Bell Labs, produce transistores en masa, amplificadores profesionales y componentes.

PLF 2 fue desarrollado por James Tenney. Este programa de ordenador fue utilizado para escribir Cuatro estudios estocásticos, Ergodos y otros.

lannis Xenakis compone Bohor compuesta por ocho pistas de sonido.

Milton Babbitt compone Ensembles for Synthesizer (1962-64) en el estudio de Columbia-Princeton.

En la Universidad de Illinois, Kenneth Gaburo compone Antiphony III, para coro y cinta.

Paul Ketoff (Fig. 41) construyó el Synket. Este sintetizador fue construido para el compositor John Eaton y fue diseñado específicamente como un instrumento para representaciones en vivo. 


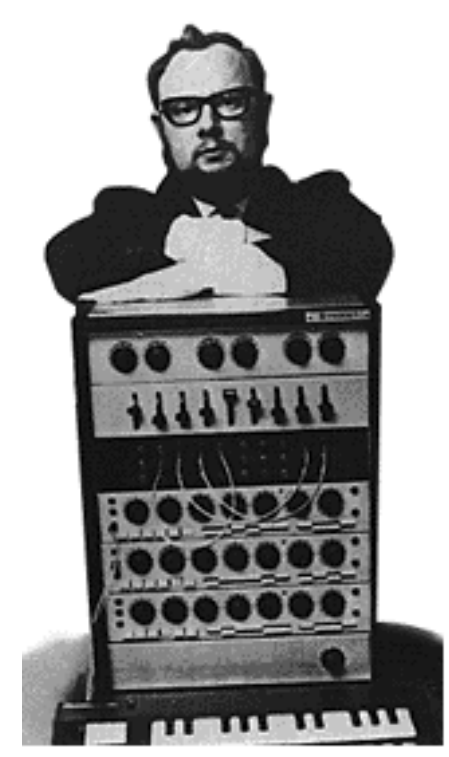

Fig. 41 John Eaton con un Synket, en (KeyboardMuseum, 2010)

$\mathbf{1 9 6 3}$ Lejaren Hiller y Robert Baker componen la Computer Cantata.

Pierre Henry compone la obra Variaciones sobre una puerta y un suspiro.

Milton Babbitt compone Philomel en el estudio de ColumbiaPrinceton. La historia trata de Filomela, una mujer sin lengua, que se transforma en un ruiseñor (basado en un cuento de Ovidio).

Mario Davidovsky compone Synchronism I para flauta y cinta. Davidovsky escribe numerosos Sincronismos. Todas estas obras están escritas para uno o varios instrumentos en vivo y cinta. En ellos se explora la sincronización de eventos entre el directo y la cinta grabada. 1964 El ordenador Moog se desarrolla por completo. La idea modular de este sistema viene de la miniaturización de la electrónica.

Gottfried Michael Koenig usa el PR-1 (Proyecto 1), un programa de computador que fue escrito en FORTRAN e implementado a una computadora IBM 7090. El propósito del programa era proporcionar 
datos para calcular la estructura en una composición musical; escrito para realizar operaciones algorítmicas en serie a partir de datos de entrada. La segunda versión del PR-1 se completará en 1965.

Karlheinz Stockhausen compone Mikrophonie I, una pieza que requiere seis músicos. Dos intérpretes tocan un tam-tam grande, mientras que otros dos se mueven alrededor del instrumento con micrófonos para recoger diferentes timbres; los dos últimos artistas manejan el control de la tramitación electrónica

Ilhan Mimaroglu, un compositor turco-estadounidense, escribió Bowery Bum. Se trata de una obra concreta, en la que usa una goma de borrar como única fuente sonora. Se basaba en una pintura de Dubuffet.

1965 Se producen de forma comercial engranajes de alta fidelidad.

Se comercializa el primer ordenador Moog.

Karlheinz Stockhausen compone Solo. La composición utiliza una grabadora con cabezas móviles para redefinir las variaciones en el retardo entre la grabación y la reproducción y la manipulación en directo durante la ejecución.

Karlheinz Stockhausen compone Mikrophonie II para coro, órgano Hammond, electrónica y cinta.

Steve Reich compone It's gonna rain, una composición para cinta. Dura aproximadamente 17 minutos y 50 segundos. Fue la primera gran obra de Reich y un hito en el minimalismo musical y la música procesada.

1966 El Cuarteto Moog ofrece conciertos en todo el mundo. Fue el primer grupo en interpretar música electrónica en el Carnegie Hall. 
Herbert Brun compone Non sequitur VI.

Steve Reich compone Come out, otra obra minimalista.

1967 Walter Carlos (más tarde Wendy), compone Switched on Bach usando un sintetizador Moog.

Iannis Xenakis escribie Musiques Formelles (Música formalizada). La primera discusión de la síntesis granular; las nubes y los granos de sonido se describen en este libro.

León Kirschner compone su Cuarteto de cuerdas No. 3, la primera pieza con electrónica en ganar el Premio Pulitzer.

Kenneth Gaburo compone Antiphony IV, una obra para trombón, piccolo, coro y cinta.

Morton Subotnick compone Silver Apples of the Moon, el primer trabajo encargado específicamente para un medio grabado.

El grupo The Grateful Dead lanzaron Anthem of the Sun and Frank Zappa y The Mothers of Invention, Uncle Meat. Ambos álbumes hicieron un amplio uso de la manipulación electrónica.

1968 Lejaren Hiller y John Cage componen HPSCHD, obra de duración indeterminada, para hasta 7 clavecines y hasta 52 bandas magnéticas. La interpretación incluye asimismo 7 pre-amplificadores, 208 cintas generadas por ordenador, 52 projectores, 64 proyectores con 6400 diapositivas, 8 projectores de video con 40 películas, una pantalla circular de 103 metros y varias pantallas rectangulares de $3 \times 12$ metros. Morton Subotnick compone The Wild Bull (El Toro Salvaje).

Hugh Davies compila un catálogo internacional de la música electrónica. 
1969 Terry Riley compone Rainbow in Curved Air.

A Finales de la década de los 60 se construye la Sal-Mar. El instrumento diseñado por el compositor Salvatore Martirano. Consistía en circuitos analógicos que eran controlados por circuitos digitales internos, manipulados por el compositor, artista o intérprete a través de un teclado de control con 291 teclas sensibles al tacto.

Godfrey Winham y Hubert Howe adaptaron Music IV para el IBM 7094 como MUSIC4B, este último como lenguaje integrado; MUSIC4BF (la adaptación del lenguaje Fortran-MUSIC4B, fue escrita por Winham y Howe).

Music $V$ incluyó variantes como MUSIC 360 y MUSIC11 para los ordenadores IBM360 y el PDP11, estos fueron escritos por Barry Vercoe, Roger Hale, y Carl Howe en el MIT, respectivamente.

Groove fue desarrollado por Max Mathews y Richard F. Moore en los Laboratorios Bell, y fue utilizado para controlar los sintetizadores analógicos.

1970 Charles Wuorinen, con su obra Times Encomium, fue el primer ganador del Premio Pulitzer con composición totalmente electrónica.

Charles Dodge escribe Earths Magnetic Field. Este es un gran ejemplo de la cartografía numérica en las estadísticas de datos musicales.

Steve Reich compone de Four Organs.

1972 El álbum de Pink Floyd The Dark Side of the Moon fue lanzado al mercado. En él se utilizan conjuntos de sintetizadores y pistas concretas como interludios entre las canciones. 
1973 Sawdust, obra para cinta programada en un lenguaje escrito por Herbert Brun.

1974 Se construye El Mellotron (Fig. 42). Este instrumento fue ejemplo temprano de reproductor de muestras que utilizan bucles de cinta. Hubo versiones con sonidos de cuerda y flauta; el instrumento fue utilizado en bandas sonoras de películas y grabaciones.

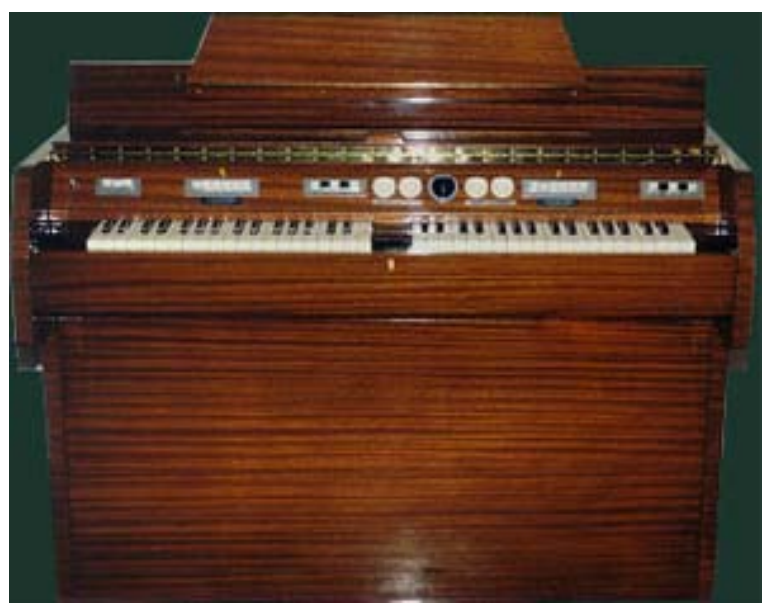

Fig. 42 Mellotron, 1974 en (Wikipedia, 2010l)

Clara Rockmore edita grabaciones con un Theremin.

1976 El compositor Philip Glass, en colaboración con el libretista Robert Wilson compone Einstein on the Beach, una ópera multimedia a gran escala de el estilo minimalista.

1977 Se funda el Institut de Recherche et de Coordinación Acoustique / Musique (IRCAM) de París, bajo la dirección de Pierre Boulez.

Aparece el Systems Concepts Digital Synthesizer (SCDS), construido por Peter Samson. Consiste en un generador de señal con elementos de proceso de ejecución en paralelo, y capaz de funcionar en tiempo real. Tiene 256 osciladores digitales, 128 modificadores de la señal (filtros, reverbs, escaladores de amplitud), una memoria para la 
comunicación de valores entre los elementos de proceso, y una gran capacidad de memoria de reverberación y almacenamiento.

1979 El disco compacto fue creado por el holandés Kees Immink, de Philips, y el japonés Toshitada Doi, de Sony. Las primeras aproximaciones a lo que hoy en día se conoce como disco compacto se realizaron a finales de los años 70. Durante esta época aparecieron diversos sistemas de video-disco de lectura mecánica, pero de estos prototipos el único que ha persistido hasta la actualidad ha sido el videoscopio óptico, mayormente conocido ahora como Laser Vision (LV).

1980 Sony y Philips habían desarrollado el sistema de audio digital Compact Disc, su duración de más de 70 minutos se debe a que se quería lograr grabar la novena sinfonía de Beethoven entera sin ningún corte o sin dividirla en dos discos. Comenzaron a distribuir discos compactos, pero las ventas no tuvieron éxito por la depresión económica de aquella época, entonces decidieron abarcar el mercado de la música clásica, de mayor calidad. Así pues, comenzaba el lanzamiento del nuevo y revolucionario formato de grabación audio.

El sistema óptico fue desarrollado por Philips, mientras que la lectura y codificación digital fue desarrollada por Sony, se lanzó en junio de 1980 a la industria y se adhirieron al nuevo producto 40 compañías de todo el mundo mediante la obtención de las licencias correspondientes para la producción de reproductores y discos. Los primeros prototipos de tocadiscos LV (nada que ver con los reproductores de discos de vinilo) aparecieron en los laboratorios alrededor de los años 1970, y en los años siguientes varias empresas como Philips, Disco Vision y Pionner, invirtieron para desarrollar un producto viable, que se presentó en 1978. 
Philip Glass compone Satyagraha, otra ópera a gran escala en estilo minimalista.

$1981 \mathrm{El}$ director de orquesta Herbert von Karajan convencido del valor de los discos compactos, los promovió durante el festival de Salzburgo y desde ese momento empezó su éxito. Los primeros títulos grabados en discos compactos en Europa fueron la Sinfonía Alpina de Richard Strauss, los valses de Frédéric Chopin interpretados por el pianista chileno Claudio Arrau y el álbum The Visitors de ABBA. El diámetro de la perforación central de los discos compactos fue determinado en 15 $\mathrm{mm}$, ya que los creadores se inspiraron en el diámetro de la moneda de 10 centavos del florín holandés. En cambio, el diámetro de los discos compactos, que es de $12,00 \mathrm{~cm}$, corresponde a la anchura de los bolsillos superiores de las camisas para hombres, porque según la filosofía de Sony, todo debía caber allí.

Larry Austin compone Canadian Coastlines, una composición que utiliza un mapa de tierras de Canadá a fin de determinar la textura rítmica, melódica y el contenido de la obra.

Aparecen variantes de Music V: los nuevos desarrollos incluyen Cmusic (por F. R. Moore), llamado así porque está escrito íntegramente en lenguaje de programación $C$.

1982 Aparece el $D A S H$, un nuevo formato digital, que en sus siglas traducidas al español indica que es un magnetofón con cabeza estacionaria, o sea, que tanto en la grabación como en la reproducción solo la cinta se mueve (como también lo es el S-DAT, en cinta de casete). En 1988, Sony y Tascam adoptaron el formato DASH como formato estándar para el magnetófono multipista digital. El DASH, en su funcionamiento básico, es similar a los magnetófonos multipista 
analógicos, permitiendo tanto la edición física 'a tijera' como la edición electrónica. El DASH proporciona grandes prestaciones dirigidas al campo profesional. Permite desde las 2 hasta las 48 pistas de sonido, con una sincronización fiable, y admite una variación en la velocidad de $12,5 \%$, por encima o por abajo. Los DASH multipista han sido muy aceptados por los estudios de grabación, donde todavía están en uso.

1983 Se produciría el primer Disco Compacto en los Estados Unidos por CBS (hoy Sony Music) siendo el primer título en el mercado un álbum de Billy Joel. La producción de discos compactos se centralizó por varios años en los Estados Unidos y Alemania de donde eran distribuidos a todo el mundo. Ya entrada la década de 1990 se instalaron fabricas en diversos países, como ejemplo en 1992 Sonopress produjo en México el primer CD de título De Mil Colores de Daniela Romo.

1985 Fue desarrollado Hierarchical Music Specification Language (HMSL). La organización básica de HMSL es una serie de estructuras de datos llamada morphs (llamado así por ser un software con un diseño flexible o morfológico). Dentro de la superestructura de estos morphs existen otras subestructuras llamadas shapes: colecciones, estructuras, trabajos, tareas y acciones. Estos tipos secundarios de morphs se utilizan para controlar aspectos de la programación de nivel superior y las rutinas.

Interactor, por Morton Subotnick y Coniglio Marcos, fue diseñado específicamente para actuaciones en directo capaces de seguir una partitura. 
1986 Otra variante de Music V - CSound, fue diseñada por Barry Vercoe, del MIT (Massachusetts Institute of Technology).

Jam Factory fue escrito por el programador David Zicarelli. Estaba tratando de crear un programa que escucha a la entrada MIDI permitiendo gestionar esa información.

Joel Chadabe, Offenhartz, Widoff y Zicarelli comenzaron a trabajar en un programa algorítmico que se podría utilizar como un entorno de improvisación. El intérprete podría estar sentado en la computadora y modelar datos en tiempo real por medio de un conjunto de barras de desplazamiento que cambió los parámetros de este algoritmo, tales como el tamaño de los intervalos, la nota mínima y máxima, etc. La versión original iba a ser llamada Master y luego RMan (Random Manager), $\mathrm{y}$ finalmente, ' $\mathrm{M}$ '.

Music Mouse, escrito por Laurie Speigel, fue diseñado para ser un sistema interpretación individual. Podía ser utilizado como un controlador MIDI o como una plataforma de interpretación mediante el sonido interno del Macintosh. A diferencia de otros programas para el entorno Macintosh, Music Mouse no estaba destinado a ser utilizado como un programa grabador/reproductor. En su lugar, el programa permite al programador 'tocar' el ordenador.

Nace el programa Max, escrito en el lenguaje $C$ y desarrollado en el IRCAM por Miller Puckette. Estaba previsto para su distribución posterior por Intelligent Music (la empresa que también distribuía M y Jam Factory), pero fue la empresa Opcode la que eventualmente lo lanzó. La intención original de Miller Puckette era construir un lenguaje que pudiera controlar el sintetizador $4 X$ del IRCAM, y que no fuera necesario para la aplicación gráfica. Los gráficos fueron añadidos 
después de una versión de Max para el ordenador Macintosh con MIDI. Desde 1989, David Zicarelli ha actualizado y ampliado el programa para el entorno Macintosh (Fig. 43).

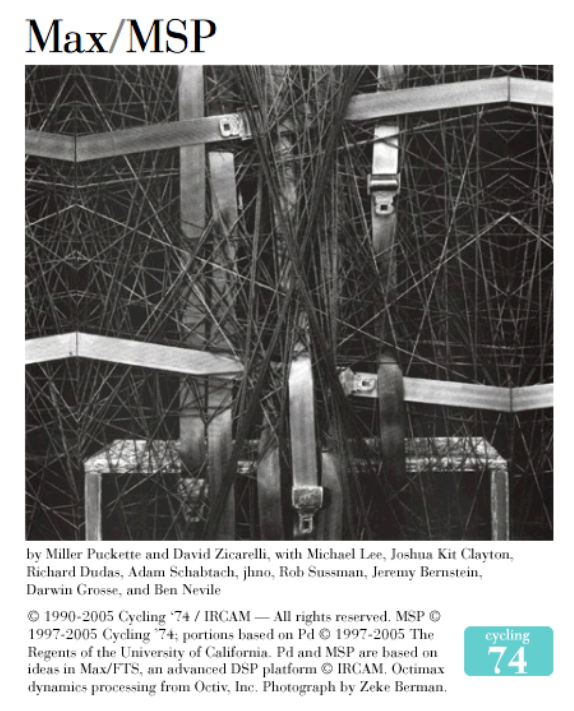

Fig. 43 Captura de los créditos de Max MSP (Cycling74, 2010)

Aparece el Dolby Surround, el R-DAT

Se funda Mackie Designs Inc y Sonic Solutions.

La tecnología del formato de audio $\mathrm{MP}_{3}$ fue desarrollada en Alemania por tres científicos del instituto tecnológico de Fraunhofer, Brandenburg director de tecnologías, Popp y Gril, en Llemenau.

1987 Apple introduce Mac Il (Fig. 44).

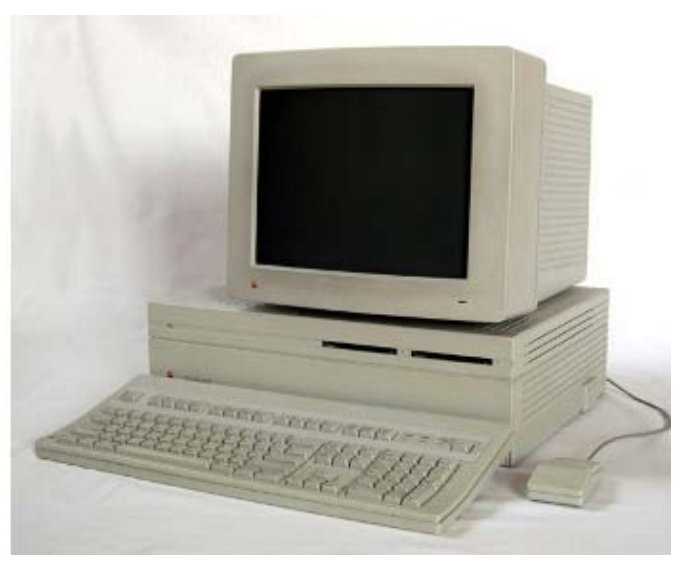


Fig. 44 Mac II de Apple, en (HistoriaGlobalOnline, 2010)

Disponible el primer DAT.

1988 Steve Reich compone Different Trains para cuarteto de cuerda y cinta.

1989 Digidesign introduce Sound Tools

Aparece el sistema de mezcla Mackie 1604.

1990 Sony introduce el CD grabable.

1991 Sony desarrolla el MiniDisc.

Aparece el Alesis ADAT.

1992 Sony anuncia el CD-ROM multimedia.

La Moving Picture Experts Group (de allí el famoso MPEG) aprobó oficialmente la tecnología del $\mathrm{MP}_{3}$.

Se funda Emagic y Macromedia.

1994 Se introduce el DVD.

1995 Fue cuando Karlheinz Brandenburg usó por primera vez la extensión .mp3 para los archivos relacionados con el $\mathrm{MP}_{3}$ que guardaba en su ordenador. Un año después su instituto ingresaba en concepto de patentes 1,2 millones de euros. Diez años más tarde esta cantidad ha alcanzado los 26,1 millones.

El formato $\mathrm{MP}_{3}$ se convirtió en el estándar utilizado por la compresión de audio de alta calidad (con pérdida en equipos de alta fidelidad) gracias a la posibilidad de ajustar la calidad de la compresión, proporcional al tamaño por segundo (bitrate), y por tanto el tamaño 
final del archivo, que podía llegar a ocupar 12 e incluso 15 veces menos que el archivo original sin comprimir.

Fue el primer formato de compresión de audio popularizado gracias a Internet, ya que hizo posible el intercambio de ficheros musicales. Los procesos judiciales contra empresas como Napster y AudioGalaxy son resultado de la facilidad con que se comparten este tipo de ficheros.

Al principio el formato $\mathrm{mp} 3$ se utilizaba por su difusión en redes de intercambio de música, como Internet. Pero más tarde cuando los reproductores de $\mathrm{mp} 3$ se hicieron más populares, el público empezó a conocer más el formato mp3 y sus ventajas. Con los reproductores de mp3 y la versatilidad de Internet, este formato se estandarizó en la sociedad.

1996 Se introduce el primer MiniDisc multipista.

1997 Se desarrolla el Standard del DVD-Audio.

2000 Además del CD y el DVD-Audio, y a partir de este año 2000 se desarrollaron más formatos digitales, con más duración y calidad como el Blu-ray. Además se inventaron varios reproductores autónomos como el iPod de Apple, uno de los reproductores autónomos más vendidos.

2005 El disco Blu-ray empezó a desarrollarse a partir del 19 de mayo, cuando TDK anunció un prototipo de disco Blu-ray de cuatro capas de $100 \mathrm{~GB}$.

2007 El 3 de octubre de este año Hitachi anunció que había desarrollado un prototipo de CD-ROM de 100 GB que, a diferencia de la versión de TDK y Panasonic, era compatible con los lectores disponibles en el mercado y solo requerían una actualización de 
firmware. Hitachi también comentó que está desarrollando una versión de 200 GB. Pero el reciente avance de Pioneer le permitió crear un disco Blu-ray de 20 capas con una capacidad total de 500 GB, aunque no sería compatible con las unidades lectoras ya disponibles en el mercado, como haría Hitachi.

Estos discos se usaron para la consola de video juegos Playstation 3. Los discos Blu-ray incorporan cinco sistemas anticopia: AACS, BD+, Rom Mark, SPDG e ICT.

\subsection{GESTO SONORO}

En (Molina, 2007) se plantea una interesante pregunta:

¿¿Por qué nos empeñamos en ver el sonido?', una pregunta que no tendría sentido para un murciélago, pero sí en cambio lo tiene para nosotros que hemos desarrollado la vista como órgano sensorial primordial en detrimento de los demás sentidos, llegando a tener también un valor epistemológico y metafísico donde el acto de 'ver', es también un acto de conocimiento de la verdad, de 'iluminación', de poder, de hacer visible lo 'oculto' mediante la creación (poiesis).

Es inevitable que el título de esta tesis tienda a asociar como gesto una identidad visual de la creación sonora, pero el comportamiento gestual que se abordará en los ensayos (temas 1 al 5), pretende aportar otras lecturas de 'gesto' a la creación musical con lenguaje electroacústico. A continuación se describirán los parámetros que han definido el comportamiento compositivo electroacústico en los ensayos prácticos. 


\subsubsection{PERCEPCIÓN Y GESTO}

A menudo se habla de la importancia del gesto en la música electroacústica (Justel, 2000; Climent, 2001; Hirst, 2004; Landy, 2007; McKinon, 2007; Kendall, 2009). Es innegable que el término puede asociarse tanto a manifestaciones visuales (representaciones físicas, corporales...) como musicales (comportamiento sonoro).

En (Justel, 2010), podemos ver como el componente visual en el sonido puede definir patrones de exploración artística:

'La experiencia muestra que la percepción del sonido está a menudo dominada por el aspecto visual de una representación musical. Liberándose de ello, la audición acusmática permite desarrollar imágenes abstractas en nuestra imaginación.'

Es curioso que aún 'liberándose de ello' se desarrollen imágenes en nuestra imaginación, durante la escucha acusmática.

El término 'gesto' es definido por la (R.A.E., 2010a) como:

(Del lat. gestus).

1. m. Movimiento del rostro, de las manos o de otras partes del cuerpo con que se expresan diversos afectos del ánimo.

2. m. Movimiento exagerado del rostro por hábito o enfermedad.

3. m. Contorsión burlesca del rostro.

4. m. Semblante, cara, rostro.

5. m. Acto o hecho.

6. m. Rasgo notable de carácter o de conducta.

7. m. ant. Aspecto o apariencia que tienen algunas cosas inanimadas. 
Las primeras acepciones del término están definidas desde una perspectiva visual, pero la $5^{a}$ acepción del término considera un matiz del gesto asociado a la acción o al acto.

Tanto en los planteamientos cognitivos de la expresión artística, como en la propia creación musical, el gesto podría estar asociado con una imagen, y como tal estar así mismo asociado a una representación visual (Drake y Palmer, 1991). En la estética más pura y abstracta del objeto sonoro se recurre a la visualización de esquemas, figuras o ilustraciones de lo que pretende ser una realización o análisis del comportamiento del sonido (Palmer, 1989a).

Como podemos ver en la Fig. 45 (Schaeffer, 1952), la propia descripción terminológica que hace del comportamiento sonoro tiene referentes visuales.

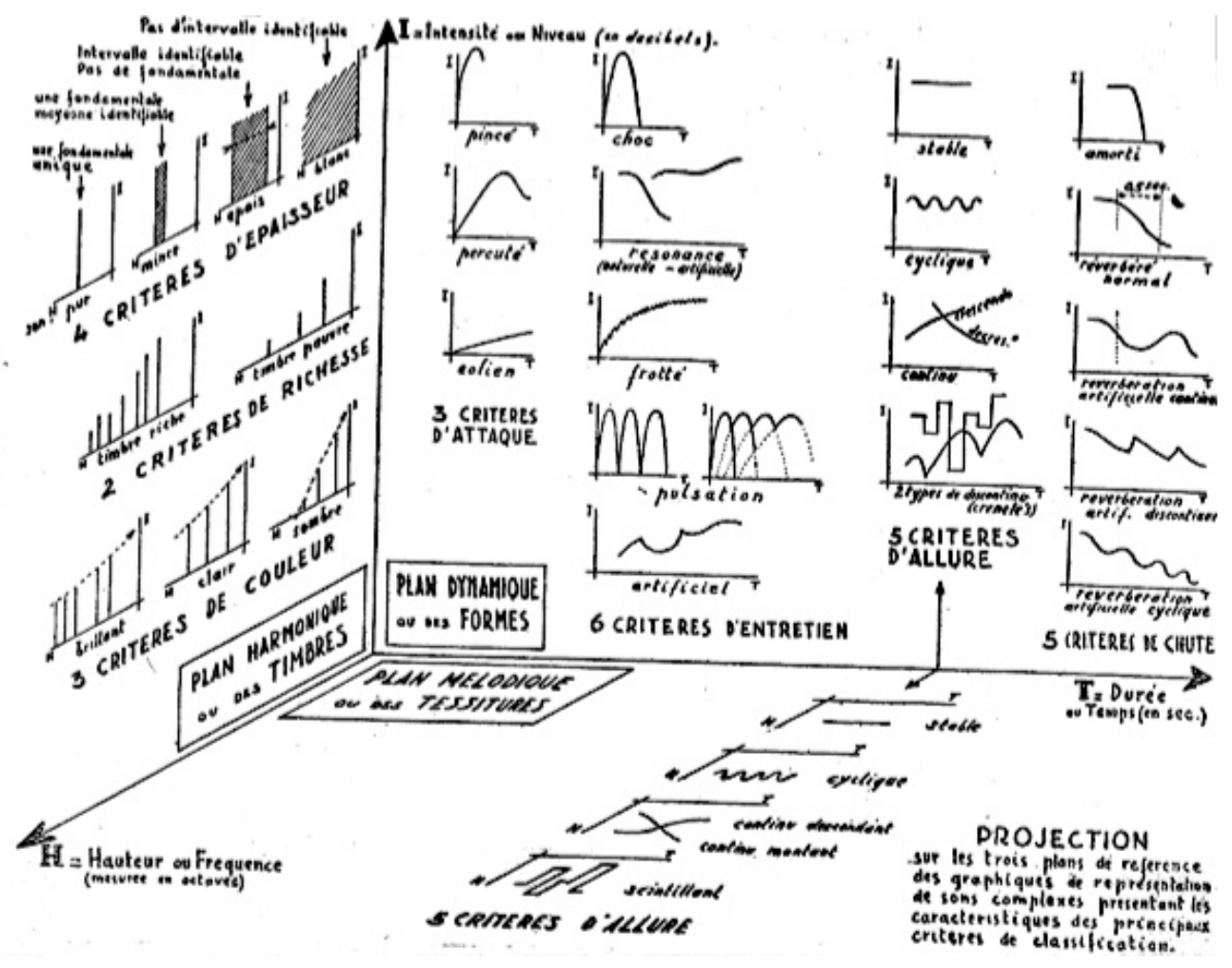

Fig. 45 Esquema en 3 dimensiones para el análisis del objeto sonoro, en (Schaeffer, 1952) 
El propósito del análisis gestual en obras de producción electroacústica ha funcionado en ocasiones partiendo desde la comparación de la imagen de sonogramas y espectrogramas ${ }^{8}$ con el resultado sonoro. En (Justel, 2000), acerca de la obra Chansos de gestes (1977) de Roger Cochini, podemos ver como el análisis descriptivo y la justificación que hace de ciertos objetos sonoros se asemeja a su correspondiente imagen visual (Fig. 46):

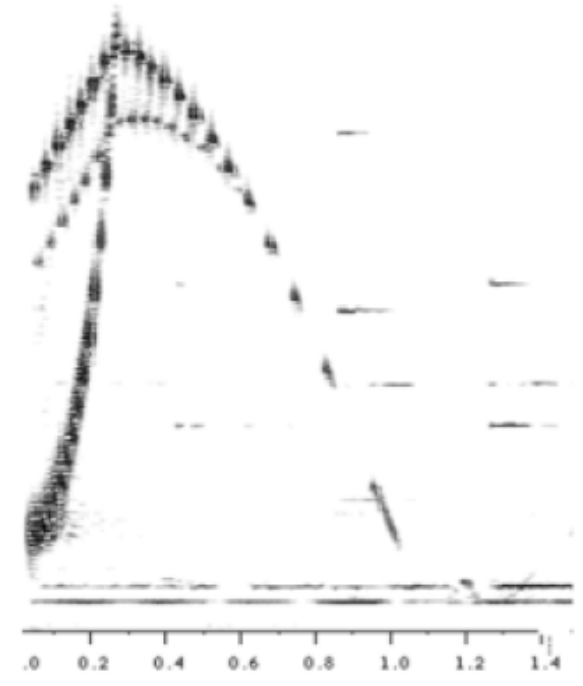

'Gesto ondulatorio integrado por tres estratos sonoros imbricados de la misma clase. Dos de estos estratos dibujan una curva ascendente y descendente y la tercera capa forma una línea ascendente muy punteada. Cada una de las curvas del gesto está construida por puntos de frecuencias fijas'.

Fig. 46 Espectrograma de un fragmento de Chansos de gestes, $R$.

Cochini, en (Justel, 2000)

Así mismo, la misma compositora acerca de Chiaroscuro (1987) de Francis Dhomont argumenta:

'...Esas cuatro secuencias denotan con claridad el gesto amplio y sombreado característico de Dhomont (Fig. 47). El espectrograma define con justeza el título de la pieza. Los contornos de los objetos sonoros se encuentran envueltos por un claroscuro que

\footnotetext{
${ }^{8}$ Representación gráfica bidimensional o tridimensional que representa la energía del contenido de frecuencias de la señal, según va variando ésta a lo largo del tiempo.
} 
nos permite imaginar la importancia de la reverberación que les ha sido aplicada.' (Justel, 2000).

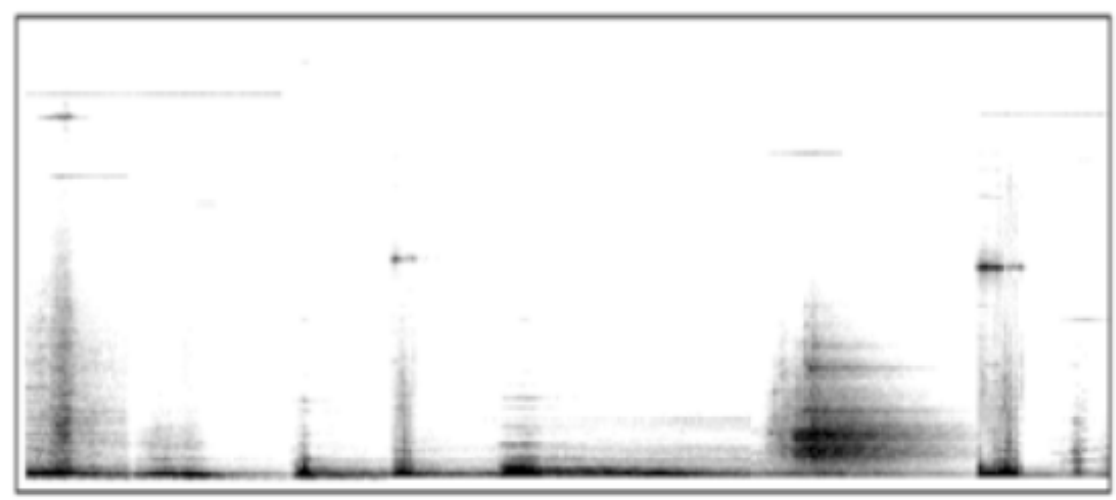

Fig. 47 Espectrograma de un fragmento de Chiaroscuro, F. Dhomont, en (Justel, 2000)

En (Climent, 2001) se justifican y muestran resultados sonoros a partir de la visualización del sonido a través de las herramientas utilizadas (Fig. 48).

'Me aproveché de las posibilidades de Snd de Schoadtedt (Common Lisp) para reproducir un análisis sonoro preciso de frecuencia, una ayuda visual incalculable para tomar decisiones intuitivas en la escucha.' (Climent, 2001)

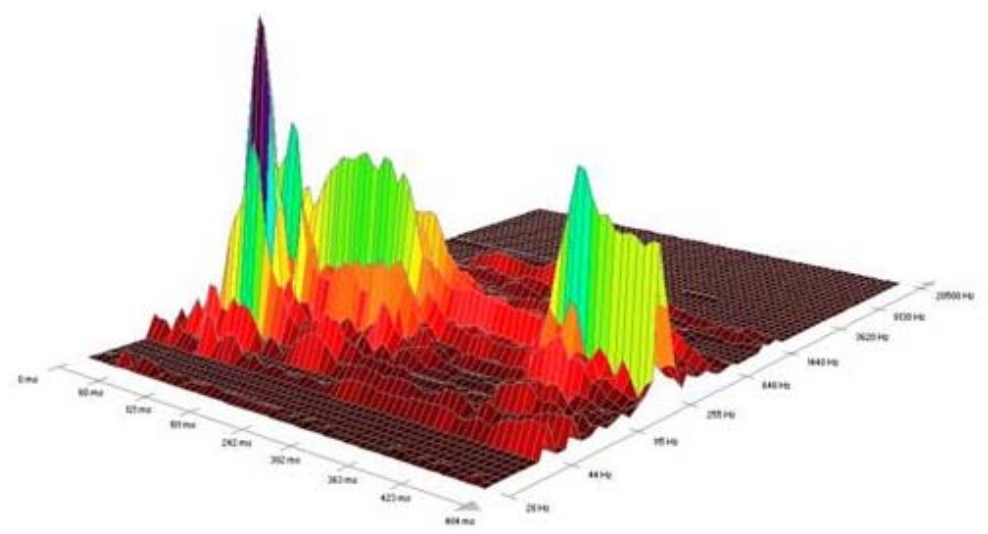

Fig. 48 Análisis de frecuencia en 3D de un objeto sonoro, en (Climent, 2001) 
Así mismo, se toma de referencia un visor de la onda sonora desde una perspectiva lineal para describir los eventos de una obra (Fig. 49).

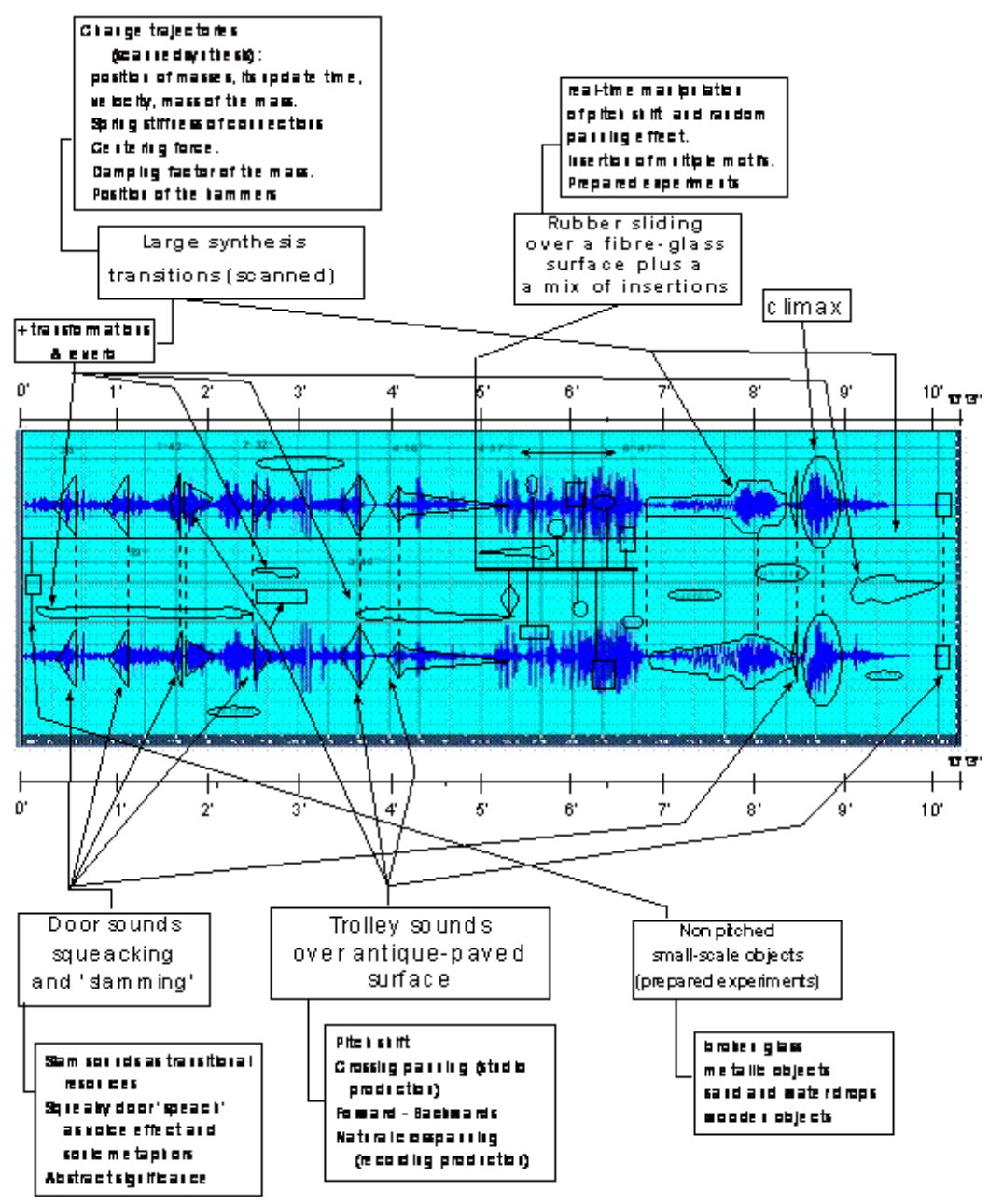

Fig. 49 Captura de e-RRATUM, en (Climent, 2001)

Como se verá en el tema 4 , existen multitud de ejemplos en los que la planificación de una obra con elementos visuales (performáticos o grabados) y diseño sonoro, la factura de la parte de sonido no responde a los mismos criterios de planteamiento que la imagen; mientras el video se diseña en torno a una temática concreta y un estilo definido, el audio parece estar extraído de un contexto ajeno.

Al margen de esta metodología de análisis y herramientas para extraer conclusiones estilísticas y patrones de coherencia con el 
comportamiento sonoro, la intención de esta tesis es de ir más allá en las correspondencias visuales y sonoras en una obra de creación electroacústica. Para ello es necesario detenernos a reflexionar sobre aspectos de percepción cognitiva y gestualidad visual.

\subsubsection{GESTO COGNITIVO}

Como se apunta en (Berenguer, 1996), la música es una manera de relacionar el pensamiento, la actividad mental, con los sonidos que ocurren en el mundo físico. Hacer música conlleva la modificación y la transformación de objetos sonoros, la actuación sobre ellos. La memoria es el medio mental donde tal actividad tiene lugar. No sería posible relacionar los objetos sonoros con el pensamiento, ni de concebirlos como tales, si no fuera por el hecho de que el hombre, aunque poca, tiene memoria: las imágenes sensoriales tan sólo impactan las primeras instancias perceptivas durante unos pocos cientos de milisegundos. A pesar de ello, algunas consiguen llegar, con cierto retraso, a niveles más altos del sistema nervioso. Esos retardos llamados por (Leipp, 1977) 'espesor del presente', son síntoma de la actividad de la unidad funcional conocida como memoria inmediata. Por la poca capacidad de éste y de otros circuitos cerebrales, llamados reverberantes, como el hipocampo-mamilo-talámico, la nueva información, en flujo constante, va desplazando a su predecesora, de manera que se pierde aquello que no ha conseguido pasar esa barrera hacia estructuras cerebrales más complejas, con capacidades de almacenamiento mayores.

Así mismo y según (Leipp, 1984) se conoce que no somos conscientes de las cosas en el instante en que ocurren. Lo experimentado, el fenómeno, se genera algo después del hecho desencadenante, como 
resultado de la interacción de patrones de actividad mental. Aún más : ni el orden en el que los datos sensoriales llegan al cerebro es el mismo en que las cosas se perciben y, en su caso, se hacen conscientes, ni es posible distinguir entre los datos sensoriales que se hacen conscientes y los que no. En cualquier caso, sólo tomamos una poca cantidad de material para hacernos una idea del mundo. Nuestra atención trabaja por tanto con imágenes sonoras efímeramente almacenadas en la memoria: se deterioran a medida que nuevos instantes sonoros son acogidos, y la música existe en el hombre mientras las imágenes sonoras pugnan por un espacio en la memoria.

Durante siglos, la partitura ha sido una prótesis de valor incalculable, ya que palia este problema al facilitar el acceso constante y repetido a la representación de algunos aspectos del flujo de la información musical. No siendo la representación de fenómenos que ocurren en un ámbito perceptivo enteramente extrapolable a otro, la escritura musical presenta lógicas limitaciones. Seguramente, ese aspecto no será jamás superado, pero con la presencia del lenguaje electrónico, la escritura musical se expande hacia nuevas posibilidades de percepción y análisis. Desde sus inicios hasta mediados los 80, la representación de la mayor parte de música electroacústica, al margen de algunas representadas gráficamente, se hallaba en el soporte magnético analógico. Esa información no era muy manipulable ni fácilmente expresable en forma gráfica, pero la posibilidad de repetición exhaustiva de los sonidos musicales permitió no pocos avances, debido precisamente a la inmediatez de acceso a la sucesión de sonidos responsables de las ilusiones musicales (Berenguer, 1996).

Desde estos postulados cognitivos, podemos argumentar que no somos rigurosamente conscientes de las cosas en el instante en que 
ocurren (Palmer, 1989c). Lo experimentado, el fenómeno, se genera algo después del elemento desencadenante, como resultado de la interacción de patrones de actividad mental. En cualquier caso y dada la naturaleza de esta tesis, es aventurado incurrir en hipótesis sobre los complejos procesos de percepción y cognición, sobre todo en campos no excesivamente cercanos a la ciencia cognitiva como es la práctica artística musical.

A propósito de los procesos de transformación a los que se ve sometido un fragmento sonoro mediante ciertos mecanismos de cognición podemos recuperar a Pierre Schaeffer cuando en referencia a su obra Etude aux chemins de fer (1948), escribe el 10 de mayo de 1948:

'Mi composición duda entre dos partes : secuencias dramáticas y secuencias musicales. La secuencia dramática restringe la imaginación. Se asiste a eventos; arranque, parada. Se ve. La locomotora se desplaza, la vía esta desierta o alguien la atraviesa. La máquina sufre, sopla, se detiene - antropomorfismo. Todo esto es lo contrario de la música. Mientras tanto he conseguido aislar un ritmo y oponerlo a sí mismo en un color sonoro diferente. Oscuro, claro, oscuro, claro. Este ritmo puede muy bien permanecer inmutable durante mucho tiempo. De esta forma se crea una especie de identidad y su repetición hace olvidar que se trata de un tren.' (Schaeffer, 1966)

¿Puede esta secuencia que comenta Schaeffer ser calificada de musical? Si se extrae un elemento sonoro cualquiera y se repite sin considerar su forma pero haciendo variar su materia, se anula prácticamente su forma, pierde su significación, su imagen; sólo emerge su variación de materia, y con ella, el fenómeno musical. 
Todo fenómeno sonoro puede pues ser tomado - de la misma manera que las palabras - por su significación relativa o por su sustancia propia. Mientras predomine la significación, y se juegue con ella, habrá literatura y no música (Berenguer, 1996).

\subsubsection{GESTUALIDAD VISUAL}

El gesto humano está en la base de toda percepción musical. Quien oye música, vehiculadas por su forma dinámica, recibe señales del gesto que podría haberla producido y la imagen que subyace tras él (Arroyo Almaraz, 2003). Con ello alimenta el imaginario y piensa. En la música electrónica, el conflicto se hace patente cuando nadie ha sido el responsable inmediato de un sonido o de un cierto comportamiento musical.

'El gesto, entonces, es el de un fantasma que vive, de la misma manera que un virus informático, en el soporte físico utilizado por el medio técnico en el que se desarrolla' (Berenguer, 1996).

Cualquiera que sea el procedimiento por el cual se codifica algún aspecto formal de un determinado objeto, el código (partitura, espectrograma, etc.), el almacenamiento del resultado de la codificación en un soporte, es una cosa totalmente distinta del objeto en cuestión. Más aún, como apunta (Berenguer, 1996) nunca la forma de un código coincide con la del objeto que representa. Si coincidiera un ápice, en ese sentido sería su réplica, y como código tendería a la trivialidad. Un código sólo puede ser considerado como una huella del objeto codificado, más o menos detallada, acaso impresa en algún medio que actúa de soporte. 
En el proceso cognitivo de un proceso audio-visual y después de un largo y complejo orden de procesos neuronales, la energía vibratoria llega a las estructuras cerebrales, éstas ya están esperando, ya están configuradas de una determinada forma y esto, no cabe ninguna duda, influye en la manera en cómo se experimenta el fenómeno. ¿Dónde está la música?, ¿en el objeto?, ¿en el fenómeno?, ¿en su experiencia consciente? Como irónicamente apunta John Cage (Cage, 1999)

¿¿Qué es más musical, un camión pasando por delante de una fábrica o un camión pasando por delante de un conservatorio?.

La música, como cualquier arte u otra actividad del intelecto, es a la vez experiencia, comportamiento, sistema de conocimientos y significaciones, cultura, hecho psico-social. Lejos de poder ser considerada objeto físico, es sobre todo una emergencia de la interacción del sonido con la mente. Se trata, por tanto, de un espacio mental y por tanto tiene inevitablemente atribuciones visuales complejas (Wishart, 1994).

Los compositores Igor Stravinsky y John Cage se habían referido a la imposibilidad de separar la escucha de otros sentidos. Según Cage esa separación era solo imaginaria (Cage, 1999). En sentido inverso, desde las artes visuales, muchos artistas (Milan Knizak, Cristian Marclay, Stuart Sherman, Joseph Beuys, entre otros), han producido obras que enfatizan visualmente el concepto de un objeto que potencialmente contiene sonido, desde los soportes de grabación hasta aquellos que representan algún tipo de universo sonoro. Estas obras tienen la particularidad de ser objetos visuales silenciosos. Como podemos ver en (Haro, 2004), el sonido es en ellas, un elemento poético intrínseco que surge a partir de una lectura visual, dando como 
resultado una relación sinestésica entre la vista y el oído. Una realidad perceptiva dialéctica, que se remite a un planteamiento poético más que sonoro.

\subsubsection{GESTO ESPACIAL}

La difusión espacial en la que la música de producción electroacústica se inscribe nos coloca frente a una gran variedad de posibilidades en cuanto a entornos y espacios físicos, y nos proporciona gran variedad de conceptos estéticos relativos a la propia naturaleza de la creación sonora.

A propósito del diseño espacial y el espacio de interpretación en una obra electroacústica, Curtis Roads señala:

'La coreografía del sonido implica que cada escena en una composición puede ser puesta en relieve por una imagen espacial única.' (Roads, 1997).

De este comentario se puede desprender que un sistema de difusión debe estar constituido de manera que sea posible ofrecer una amplia gama de imágenes espaciales contrastantes. Los primeros sistemas de amplificación de altavoces múltiples estaban concebidos de tal forma que el sonido conservaba sus cualidades físicas idénticas, en todos los ángulos de la sala. Es decir, todos los altavoces poseían las mismas características de construcción. Estos tipos de dispositivos se buscan actualmente para la difusión de obras multicanal. Sin embargo, en el caso de la difusión de obras en formato stereo (2 canales), donde el compositor-intérprete trata de realzar imágenes espaciales diferentes para cada momento de la obra, es más aconsejable utilizar sistemas de proyección dotados de grupos de altavoces de diferentes calidades 
(Justel, 2000). De este modo cada tipo de altavoz tendrá una sonoridad particular, permitiendo articular una textura musical específica. Tales sistemas requieren una preparación técnica elaborada y minuciosa.

Los dos dispositivos más importantes de este género en Europa son el Cybernephone (Fig. 50) y el Acousmonium $^{10}$ (Fig. 51).
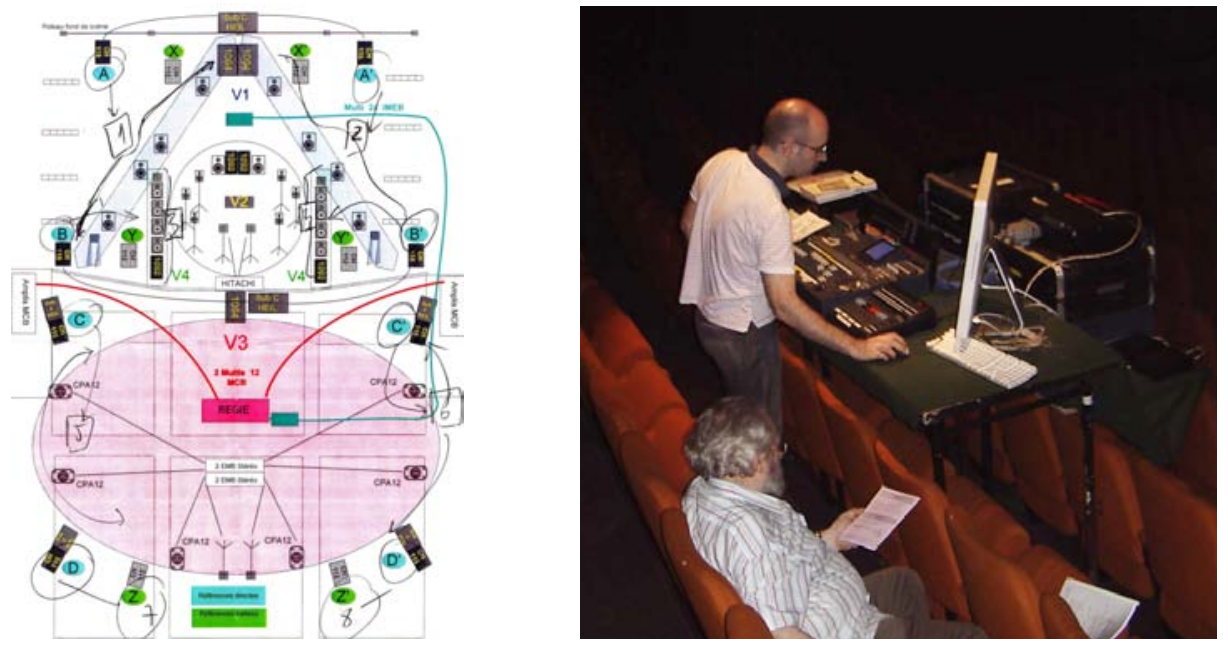

Fig. 50 Esquema de colocación de los 60 altavoces del Cybernephone durante el Festival Synthese'og (Bourges-Francia) y El autor durante el estreno de Hydra (2009) (ver Anexo I)

9 Sistema de dispositivos (amplificadores, altavoces y consola de gestión) diseñado, construido y desarrollado desde 1973 por el IMEB (Institut International de Musique Electroacoustique de Bourges) para la difusión y representación de obras electroacústicas. El Gmebaphone (nombre original) permite simular diferentes tipos de espacio, timbres y tiempo (IMEB, 2010).

${ }^{10}$ Orquesta de altavoces creada y desarrollada por François Baile en 1974 en el GRM de Paris (Groupe de Recherches Musicales), constituida por 80 altavoces, colocados en alturas distintas lo largo de un escenario. La colocación de cada uno depende en sus rangos, potencias, cualidades y sus características direccionales (EMF, 2006). 

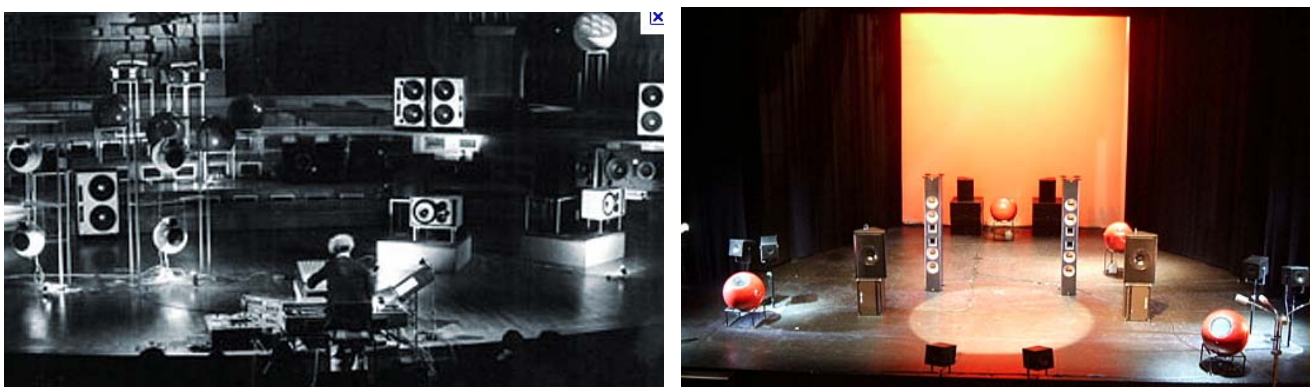

Fig. 51 Fraçois Baile utilizando el Acousmonium en Salle Olivier Messiaen, Maison de Radio France, Paris 1980, en (EMF, 2006), e instalado en Roma en 2008, en (Cipriani, 2008)

A propósito de ambos sistemas de difusión, el compositor francés Jean-Claude Risset comenta en (Risset, 1997):

'...la escuela francesa ha mostrado la vía con el Gmebaphone (más tarde llamado Cybernephone) y el Acousmonium. Ese tipo de dispositivos compuestos por numerosos altavoces, permite colorear y espacializar la difusión: ellos pueden, más allá de un rol puramente espectacular, contribuir a profundizar el sentido de la obra. Sin embargo, si bien ellos valorizan un sonido espectralmente cargado, induciendo aeración y vida por medio de la reacción diversificada de los diferentes altavoces, ellos no convienen a todas las músicas.'

Aparte de las características propias de los sistemas de difusión, las condiciones de la sala y su diseño arquitectónico determinan otros parámetros esenciales en la exploración sonora:

'En tales condiciones, la difusión puede entonces dar a entender verdades figuras espaciales casi visuales, que no se reducen a efectos decorativos o dramáticos, Sería por otra parte abusivo, decir que los aspectos espaciales no pueden ser morfofógicos portadores de flujos y perturbar las figuras melódicas y rítmicas.' (Risset, 1997). 
En este sentido y dependiendo de las características del espacio en el que se produce una difusión de música electroacústica, el compositor aconseja prever dos versiones diferentes de la pieza: una con reverberación (o un procesado de señal concreto) para la difusión en una sala absorbente y otra 'seca' para dejar que el sonido se despliegue en la acústica de la sala, sin conflictos con la reverberación impresa en el soporte.

Teniendo en cuenta las características de una sala y las características técnicas de un sistema de difusión se produce una correlación / interacción entre la composición y el proceso de difusión. El inventor y desarrollador del Cybernephone, Chrsitian Clozier, apunta que el proceso comienza en el momento de la grabación de los sonidos originales y continúa por pares: composición-difusión y difusióninterpretación:

'...el acto esencial de la mezcla, donde el total de los timbres, de los tiempos y de los espacios ha transmutado todas las partes y resuelto las contracciones de singularidad de las partes, es concebido y realizado en el proyecto de manera que todas sus partes marcadas de sus propios valores de gravitación, de atracción constitutiva de sus núcleos, liberadas, puestas en el espacio-tiempo, van a desplegar sus campos, sus expansiones, en el movimiento de la música.' (Clozier, 1997)

Como apunta Emmanuel Nunes (Nunes, 1994), el espacio es también un factor determinante en la estructuración estética de una obra electroacústica. De hecho, en la concepción espacial se conjugan dos dimensiones: la 'dimensión acústica' y la 'dimensión musical'. Entre las dos deben producirse 'transmutaciones que servirán para crear la 
consolidación del discurso'. Es decir, es necesario considerar dos factores de correlación:

- La interacción entre los componentes de la emisión (parámetros de la fuente, tales como el timbre, las duraciones, la intensidad...) y las condiciones de la propagación (características de la sala, como reflexión, distancia, reverberación, etc.) - dimensión acústica (Rowe, 1993).

- La implicación de esos factores en la organización estructural de la música ó, como el propio Nunes define 'La adecuación del proyecto musical al conjunto de esas interacciones'.

En (Castanet, 1988) podemos ver tres formas derivadas de la espacialización del sonido:

- Como ornamento estético. El autor cita como ejemplos los efectos obtenidos en el espacio de difusión, como las trayectorias circulares y los espacios construidos como en los ejemplos de Little boy (1968), Trois mouvements newtoniens (1978) y Dérives (1985) de J. C. Risset así como en Gesang der Jünglinge (1955-56) de Stockhausen.

- Como elemento contractivo. En este caso ubica obras instrumentales basadas sobre cálculos logarítmicos para crear una sensación perceptiva de tipo espiral. El efecto se manifiesta en la macro-estructura. Sin embargo, las consecuencias reales de los fenómenos micro-espectrales restan siempre fuera del alcance de esta escritura instrumental. Es solamente a partir del advenimiento de los medios digitales, que el compositor logrará dominar la materia sonora en su realidad física. La informática hace posible la creación de espacios sonoros cada 
vez más refinados, sobre la base por supuesto, de un conocimiento preciso de las propiedades acústicas del fenómeno sonoro.

'Al contrario de la nota (musical) (que es un símbolo atómico precomposicional), el objeto sonoro se define como un múltiplo, una entidad no-atómica, que comporta una pluralidad de eventos que forman una unidad perceptiva, pero sin embargo, articulada...' 'La novedad de ese trabajo reside en el hecho de que él se apoya sobre datos del espacio sonoro real'(Vaggione, 1991).

- Como metáfora, con el fin de crear imágenes sonoras:

'Ahora bien, para mí, la imagen es aún y todavía un objeto relevante de la realidad: una materia nueva, propia a una música figurativa'. ... 'La imagen se distingue entonces de los objetos naturales, pero ella no se puede confundir con una virtualidad que no haría de la experiencia; la imagen es un objeto, un nuevo objeto'. (Vaggione, 1991)

A partir de las últimas reflexiones expuestas se comprende hasta qué punto los espacios interno y externo se hallan interrelacionados. Resulta evidente que la legibilidad espacial, está ligada a los fenómenos perceptivos y a las condiciones acústicas, puesto que la proyección contribuye a una mejor apreciación de la estructura sonora (Justel, 2000).

'Es así que el sonido cobre vida, que los planos - los múltiples grados de energía contenidos en las morfologías compuestas - se manifiestan a la percepción. La legibilidad de las morfologías se desprende de su puesta en movimiento, de una cinemática de la proyección sonora'. (Vaggione, 1991) 
Por último señalaremos lo que Clozier pone de manifiesto a partir de la electroacústica y el significado integral que alcanza en el momento de su difusión en la interpretación de concierto:

'No son los múltiples canales reunidos y constitutivos de la mezcla final de la obra los que son difundidos, es la obra madre que, diversificada y multiplicada bajo diferentes ángulos, es reconfigurada durante el concierto, resintetizada, cargada de sentido por la interpretación'. (Clozier, 1997)

Estas aserciones se pueden probar mediante un ejemplo histórico: la obra Kontakte (1958-60) de Stockhausen. En ella se aplica una técnica de grabación basada en efectos Doppler ${ }^{11}$, de delay y cambios de fase en la señal, para crear un movimiento espiral (Castanet, 1988). Con el añadido de manipulaciones en la consola, en el momento de la difusión, el compositor refuerza la espacialización interna por la acción directa del espacio real.

Son muchas y muy variadas las obras que vinculan el sonido con el espacio. Piezas que plantean cuestiones de circulación y respuesta acústica, otras que indagan sobre el paisaje, el contexto social, la idea de entorno, etc (Davis, 2003). Las relaciones entre arquitectura y sonido pueden exceder lo estrictamente funcional para alcanzar dimensiones poéticas. Tal es el caso de Tonhaus (sound building) proyecto desarrollado por Francisco López y Klaus Schuwerk entre 1992 y 1993. Los autores destacan que su trabajo no es una sala de

\footnotetext{
${ }^{11}$ El efecto Doppler, llamado así por el austríaco Christian Andreas Doppler, es el aparente cambio de frecuencia de una onda producido por el movimiento de la fuente respecto a receptor. Doppler propuso este efecto en 1842 en su tratado Über das farbige Licht der Doppelsterne und einige anderdae Gestirne des Himmels (Sobre el color de la luz en estrellas binarias y otros astros) (Wikipedia, 2010d).
} 
conciertos sino 'un lugar para experimentar el sonido desde una perspectiva musical'. Mas allá de la forma en que los sonidos circulan en un lugar determinado existe la posibilidad de construir espacios a partir de recorridos únicos e individuales (Davidson, 1991). La experiencia acústica en instalaciones que utilizan sonido puede ser multifocal y envolvente no solo desde la propuesta artística sino también a partir de la participación activa del audio-espectador. No se trata solo de escuchar sino también de construir un recorrido espacial para esa escucha (Doherty, 1998). Cualquier intervención del sonido en el espacio redefine ese lugar y le otorga una connotación plástica, muchas veces enfatizada por elementos técnicos (reproductores, cables, etc.) que son integrados a la experiencia como esculturas. Max Neuhaus, Rulf Julius o Cristina Kubisch han trabajado en este sentido (Haro, 2004). Para muchos artistas las ciudades también pueden ser un escenario o un hyper-instrumento. Se han realizado muchas obras con el sonar y las resonancias de una ciudad a partir de conceptos y técnicas muy distintas. Desde el proyecto World soundscape del canadiense Murray Schafer a la serie Metrópolis de la radio WDR de Colonia (Alemania), pasando por las Derivas de Pedro Elías Mamou y los conciertos plurifocales de ciudad del español Llorenç Barber.

Como se ha apuntado en el apartado 0.2, en todas estas interacciones entre los parámetros artísticos y de espacio - de creación e interpretación (difusión) respectivamente - vemos una vez más la interdisciplinariedad intrínseca que necesariamente emerge en el contexto artístico de una obra de producción electroacústica.

En el último apartado de esta tesis se retomarán algunas de estas reflexiones y se extraerán conclusiones basadas en los ensayos realizados. 


\subsection{MAPA DE CONCEPTOS}

A continuación se presentará un índice de categorías que ayudará a ubicar la naturaleza de cada ensayo y los elementos que intervienen y definen cada uno de ellos.

- Sensores: Un sensor es un dispositivo capaz de medir magnitudes físicas o químicas, llamadas variables de instrumentación, y transformarlas en variables eléctricas (Wikipedia, 20100). Dependiendo de las necesidades y planteamiento de los ensayos así como de los costes, se utilizarán distintas clases de sensores.

- Electrónica en vivo: Se entiende como el procesamiento de los parámetros sonoros durante la representación de una obra, excluyendo cualquier material que haya sido grabado con anterioridad (Sutherland, 1994).

- Tiempo real: Se entiende como aquellos procesos que están sujetos a una restricción de tiempo; la reacción de un sistema a eventos externos debe ocurrir durante su evolución. En (Gillies, 1996) podemos ver una definición canónica de un sistema de tiempo real:

'Un sistema de tiempo real es aquel en el que para que las operaciones computacionales sean correctas no solo es necesario que la lógica e implementación de los programas computacionales sea correcto, sino también el tiempo en el que dicha operación entregó su resultado. Si las restricciones de tiempo no son respetadas el sistema se dice que ha fallado.'

- Obra cerrada/abierta: Se ha definido esta dualidad para situar aquellas obras artísticas que tienen una naturaleza fija o por el 
contrario, pueden presentar diferentes resultados. Así pues se presentarán casos en los cuales existe un margen de resultados en cuanto al producto final.

- Partitura: Elemento gráfico que sostiene las indicaciones para la realización de una obra musical. En esta tesis existen algunos ensayos que necesitan de este soporte gráfico para ser realizadas.

- Intérprete: Se entiende como cualquier persona que se encargue de ejecutar una pieza musical mediante canto o instrumentos, ejecutar un baile con propósito artístico y siguiendo pautas coreográficas o representar una obra teatral, cinematográfica, etc (R.A.E., 2010c).

- Performance: Una performance es una muestra escénica, muchas veces con un importante factor de improvisación, en que la provocación o el asombro, así como el sentido de la estética, juegan un rol principal (Wikipedia, 2010n). En esta tesis el componente performático se entiende tanto en intérpretes musicales como en aquellas personas que son ajenas a la producción directa del sonido.

- Instrumentos acústicos: Conjunto de piezas dispuestas de modo que sirvan para producir sonidos musicales (R.A.E., 2010b).

- Improvisación: Se entiende como el hecho de transmitir o generar de forma espontánea una idea o sentimiento a través de la imaginación y la aplicación de recursos asociados al objeto de la obra (Wikipedia, 2010h). 
- Entorno o medio de reproducción: Conjunto de condiciones extrínsecas que necesita una obra para su ejecución. De este modo podremos hablar de salas de concierto, teatro, espacios abiertos o de otro modo, de medios fijados (fixed media), tales como reproductores de Compact Disk, DVD, memorias digitales, computadoras, etc.

- Procesamiento digital imagen/sonido: Cualquier proceso generado por medios digitales que propicia la propia naturaleza y definición de la obra.

- Software: Se entiende como el equipamiento o soporte lógico de una computadora digital; comprende el conjunto de los componentes lógicos necesarios que hacen posible la realización de tareas específicas, en contraposición a los componentes físicos del sistema o hardware. (Wikipedia, 2010p)

En cada ensayo se aplicará esta clasificación y proporcionará una perspectiva panorámica de los conceptos y parámetros a los que responden cada uno de ellos, extrayendo conclusiones concretas a partir de los resultados obtenidos y en base a la hipótesis planteada en esta tesis. 


\section{CONTRAPUNTO ACUSMÁTICO EN VIVO}

En este ensayo se describe el proyecto realizado en el Mixed Reality Lab (MXRLab) de la Universidad Nacional de Singapur (NUS), durante mi estancia como investigador invitado en dicho centro. Este trabajo sirvió como proyecto de investigación para la obtención del Diploma de Estudio Avanzados en el mismo departamento y programa de doctorado en el que se inscribe esta tesis. Se ha realizado una revisión y ampliación de aquel trabajo para adecuarlo al formato y estilo de esta tesis.

\section{MOTIVACION}

Con motivo de mi estancia como compositor en el citado laboratorio MXRLab llevé a cabo el proyecto Peranakan Sound Design para la apertura de una Casa-Museo llamada Baba en Singapur. Para tal evento la NUS encargó la redacción de unos poemas a cuatro poetas sobre dicha Casa Baba ('Patriarca', en chino) y la cultura Peranakan (herencia histórica de las culturas malaya y china en la isla de Singapur). 
La indagación en los conceptos de contrapunto, disciplina asociada a la técnica escolástica de la composición instrumental, y la exploración del concepto de obra abierta asociado a la filosofía china del I-Ching, me llevó a la creación de las cuatro composiciones desarrolladas para este ensayo.

Este proyecto supuso mi incorporación a la creación musical asistida por medios electrónicos y la investigación del lenguaje electroacústico.

\subsection{PLANTEAMIENTO}

Para cada poema se compuso una obra para cinta, que tendrá su forma final después del procesamiento sonoro en vivo de la voz de cada uno de los poetas. Así se genera una composición para cinta abierta diseñada a partir del análisis de parámetros Live (directo) + Non Live (grabado). Este aspecto particular de la composición musical será el núcleo central de este ensayo.

Al tratarse de una investigación práctica, el objetivo de este ensayo es aportar información detallada sobre los procesos y técnicas que han sido aplicados de forma directa para su producción musical. Se ha pretendido realizar una investigación secuenciada y ordenada dentro de la elaboración de una obra de carácter electroacústico.

\subsubsection{MARCO EN EL QUE SE INSCRIBE EL ENSAYO}

Siguiendo las descripciones que se han hecho en el mapa de conceptos (ver apartado 0.5) se puede presentar un marco general de este ensayo: 
- Sensores: Micrófono.

- Electrónica en Vivo: No se requiere.

- Tiempo real: Procesamiento de los datos que recoge el micrófono, aunque el resultado sonoro se produce después de la lectura de los poemas.

- Obra abierta/cerrada: Obra abierta.

- Partitura: No se requiere en el momento de la ejecución, aunque para la composición de las partes instrumentales existe una partitura.

- Intérprete: No se requiere en el resultado final, aunque para la grabación de muestras se utilizó un piano e instrumentos tradicionales chinos.

- Performance: El usuario que realiza la lectura de los poemas.

- Instrumentos acústicos: No se requiere en el resultado final, aunque para la grabación de muestras se utilizó un piano e instrumentos tradicionales chinos.

- Improvisación: No se requiere.

- Entorno o medio de reproducción: Lectura de los Poemas en vivo y reproducción del resultado mediante soporte digital.

- Procesamiento digital imagen/sonido: Sonido.

- Software: Audacity (Audacity, 2010), Max MSP (Cycling74, 2010). 


\subsubsection{MARCO HISTÓRICO-CULTURAL}

En la calle Neil Road, $N^{0} 157$, se encuentra quizás la última casa superviviente Peranakan de Singapur (Fig. 52). Es citada y celebrada hoy como la expresión más significativa del patrimonio arquitectónico.
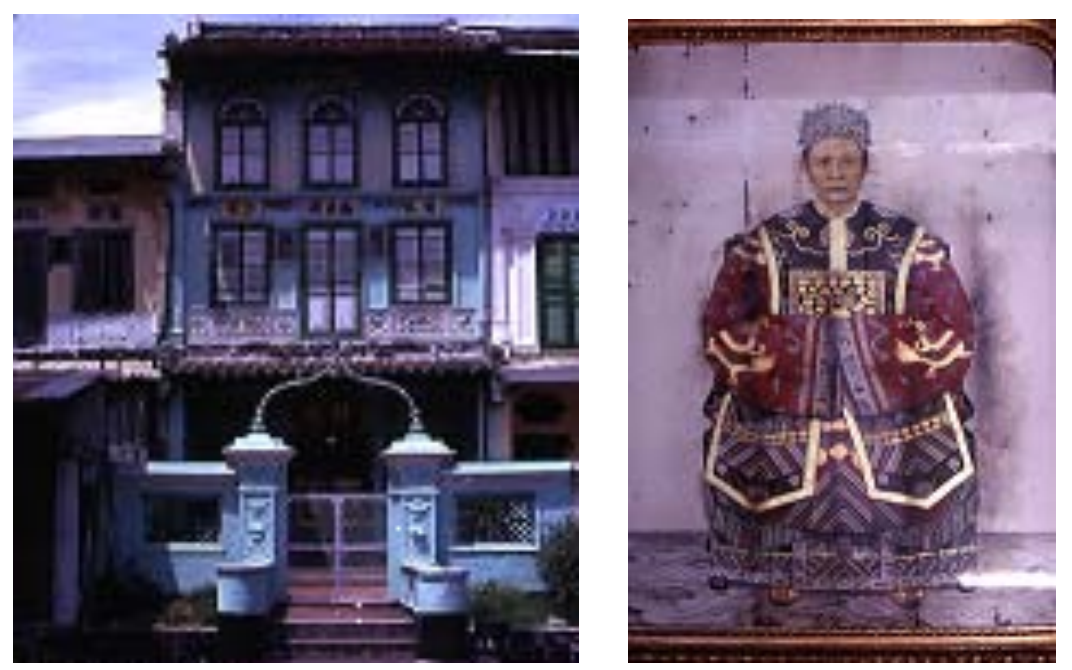

Fig. 52 Fachada principal y Figura Baba

La casa Baba de Tan Cheng Lock juega un importante papel en la conservación de la tradición Peranakan, así como en la conservación de la memoria del respetable líder de la comunidad Peranakan. La cultura Peranakan es el resultado de la fusión entre los primeros colonos chinos que se asentaron en Singapur, Malaca y Penang, con la población indígena malaya. Estos nuevos chinos conocidos como Peranakan, desarrollaron costumbres, gastronomía y lenguajes distintos. La mezcla se completó con los portugueses, ingleses, holandeses y demás occidentales que dominaron aquellas tierras en el siglo XVI, y aún hoy en día se puede encontrar a numerosos personas que llevan los apellidos de sus antepasados (Fernándes, Smith, etc)

La clase dirigente china más antigua está constituida por los Baba, descendientes de los primeros inmigrantes chinos y de mujeres 
malayas. Conocidos como 'chinos del estrecho', fueron los primeros en hacer fortuna y a pesar de su reducido número ejercieron una gran influencia en la política y los negocios de la isla hasta finales de los años cuarenta.

En la casa de Tan Cheng Lock, los visitantes pueden apreciar el gran trabajo de restauración y conservación de la estructura auténtica así como la exposición de objetos y material típico. También tendrán cabida en la casa Baba expositores que podrán ofrecer aspectos típicos de este legado histórico, exquisitos ornamentos, chinoseries, ropas y vestidos típicos de la cultura Peranakan.

Tan Cheng Lock (1883-1960) nacido en Malacca, fue el fundador y primer presidente de la Asociación Malayo-China (MCA) así como líder y responsable en Malasia y Singapur. Durante su mandato, la MCA jugó un papel decisivo en la negociación de la independencia británica.

La casa-museo Peranakan fue posible gracias a la donación por parte de la NUS (Universidad Nacional de Singapur) de 4 millones de dólares a su última descendiente Agnes Tan. La casa sita en el 157 de Neil Road, es la antigua casa de la familia Wee (Fig. 53). La familia Wee tiene una conexión histórica con Singapur prontamente conectada a los esfuerzos por la comunidad en la isla. Entre sus ilustres antepasados se encuentra Wee Bin (1823-1868), un importante magnate y mercader. La casa ha pertenecido a la familia desde 1860.

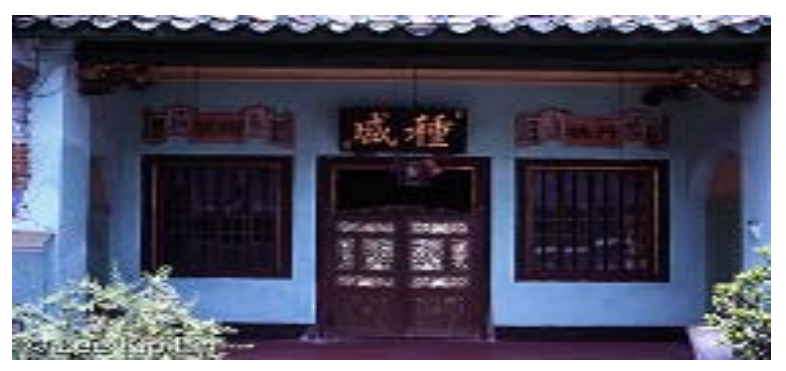

Fig. 53 Entrada principal de la casa Baba 
El estilo ornamental asociado a las casas con terraza Peranakan está estrechamente conectado con el patrimonio histórico y cultural de los Peranakan. Esto incorpora características de la cultura del sur de China, Malasia, así como la arquitectura colonial holandesa y británica. Esta fusión ecléctica de culturas se aprecia con nitidez en la casa Baba de Tan Cheng Lock.

Durante mi visita a la casa pude experimentar sensaciones encontradas. La primera impresión fue la de estar en un recinto con una tradición filosófica y cultural mucho más rica que la de cualquier otro lugar de occidente. Las dinastías milenarias y los grandes pensadores habían sido los padres de esta cultura, sin embargo estos inquilinos sentían debilidad por adquirir hábitos y costumbres europeas. La modernidad se medía por la adquisición de protocolos occidentales. Estos protocolos podrían chocar de frente con los dogmas orientales, pero el exotismo de lo novedoso fascinó a los Peranakan. Esto me hizo comprender que la cultura y la expresión artística es una pura y anecdótica expresión del ser humano en sí mismo y en abstracto.

\subsubsection{MARCO TEÓRICO}

Por Contrapunto Musical entendemos el arte de combinar varias líneas melódicas al mismo tiempo (Sadie, 1984). Esta disciplina arranca en Europa desde el s. XIII, cuando a las líneas melódicas del canto gregoriano, Ilamado Cantus Firmus, se le fueron sumando otras superiores o inferiores a distancias distintas. A partir de este momento nacieron estilos de composición como el Organum, Conductus, Motete, Madrigal, que fueron evolucionando hasta configurar una disciplina en 
sí misma, condicionando el planteamiento y la forma de los estilos a lo largo de los siglos (Pérez, 1981).

Como hemos visto en el tema o, 'acusmático' según (Larousse, 2010): 'nombre dado a los discípulos de Pitágoras que durante cinco años escucharon sus lecciones escondidos tras una cortina, sin verle, $y$ observando el silencio más riguroso'. Como se ha descrito con anterioridad, alrededor de la década de los 40 fue enarbolado en el seno del Estudio de Música Electrónica de la Radio de Paris por Pierre Schaeffer.

La concepción de obra musical cerrada y absolutamente controlada en todos sus factores no es más que una simple utopía. A diferencia de otras disciplinas artísticas, los factores de notación, acústicos y humanos condicionan cualquier intervención musical (Mila, 2003). Tras una fuerte renuncia a aquellos compositores que se esforzaban por controlar todos los factores posibles, compositores como John Cage apostaron por el concepto de obra abierta (Cage, 1999), en la que la improvisación era el plato fuerte de la obra musical. Esta apuesta por la libre decisión del artista no fue ningún descubrimiento. Sólo doscientos años antes a nuestros días, el estilo de bajo acompañado (técnica semi-improvisada de acompañamiento a una melodía) era la estética más habitual de creación musical (Grout y Palisca, 1988).

Con el nacimiento del procesamiento analógico o digital se abriría un nuevo horizonte en el deseo de controlar el máximo número posible de elementos en la creación (emisión y recepción) de una obra sonora. 


\subsubsection{METODOLOGÍA}

El carácter puramente práctico de este ensayo ha requerido una metodología abierta y flexible a los resultados que se van obteniendo en cada paso del proceso creativo.

En cualquier caso no existe un solo método específico en un proceso musical compositivo. Si bien, el planteamiento de la obra y su resultado final, a nivel conceptual, sí requieren unas pautas de orden metodológico que consigan dar coherencia al planteamiento del proyecto y al resultado final.

Se pueden establecer varias etapas en el orden de actuación que se ha llevado en este ensayo:

- Desarrollar un planteamiento novedoso dentro del panorama de creación musical. Búsqueda de caminos que puedan remover los cimientos de la composición electrónica y el protocolo escénico. Análisis del material y componentes técnicos requeridos.

- Recopilación de fuentes sonoras en campo. Grabación de rituales chinos y malayos en sitios de Singapur. Posterior edición, limpieza y masterización en laboratorio para su uso posterior en diferentes herramientas de composición y edición digital.

- Diseño y configuración de una aplicación para el proceso electrónico: programación en Max MSP (Cycling74, 2010) del patch baba . Análisis e integración posterior de las fuentes sonoras en diferentes sub-patchs que harán la reproducción final de cada poema. 
- Clasificación de las fuentes en conjuntos de orden semántico (ver apartado 5.2.1).

- Indagación y exploración de nuevas fuentes sonoras en el estudio, con instrumentos típicos chinos y malayos.

- Análisis de cada poema con su autor y discusión sobre las necesidades semánticas, niveles sonoros, espacialización e instrumentación y estructuración de cada uno.

- Doble línea inductiva/deductiva durante el proceso de creación sonora. Cada proceso digital establece una cualidad en el sonido que condicionará el siguiente, ya sea en combinación, yuxtaposición, integración u ósmosis de este. Así pues, cada gesto sonoro conforma una línea simple que puede relacionarse con las demás en el discurso contrapuntístico de la obra.

\subsubsection{REFERENTES}

Como se ha comentado anteriormente, este trabajo supuso $\mathrm{mi}$ incorporación a la composición e investigación en el lenguaje de la electroacústica. Los primeros puntos de referencia presentaban dos vertientes: el componente conceptual y el componente técnico.

Como obras de referencia conceptual podemos destacar algunas composiciones con formato abierto que ciertos compositores han diseñado como respuesta a la creación musical común. Entre ellas podemos citar la Musikalische Wurfelspiel (ver Apartado 0.3.3), un entretenimiento diseñado por Mozart en el que prepara una tabla con números que tienen correspondencia con compases individuales de música previamente compuestos. Al tirar los dados se va configurando 
una partitura, dando lugar a múltiples soluciones, y por tanto planteando una obra 'abierta'.

El compositor americano John Cage, fue uno de los revolucionarios de la música contemporánea en el s. XX, dotándola de un lenguaje en apariencia caótico. Según dijo en 1970:

'intenté hacer como Satie y Webern, esto es, aclarar la estructura bien con los sonidos, bien con los silencios' (Cage, 2002).

Sin embargo, su gran influencia fue el budismo zen, y el concepto musical de extremo oriente, el cual persigue la liberación del tiempo. En su Concierto para piano preparado y orquesta de cámara planifica una tabla numérica que irá determinando el material musical 'según métodos azarosos y espontáneos' (Fig. 54), como la consulta al oráculo del l-Ching mediante tiradas de monedas (Díaz de la Fuente, 2005).
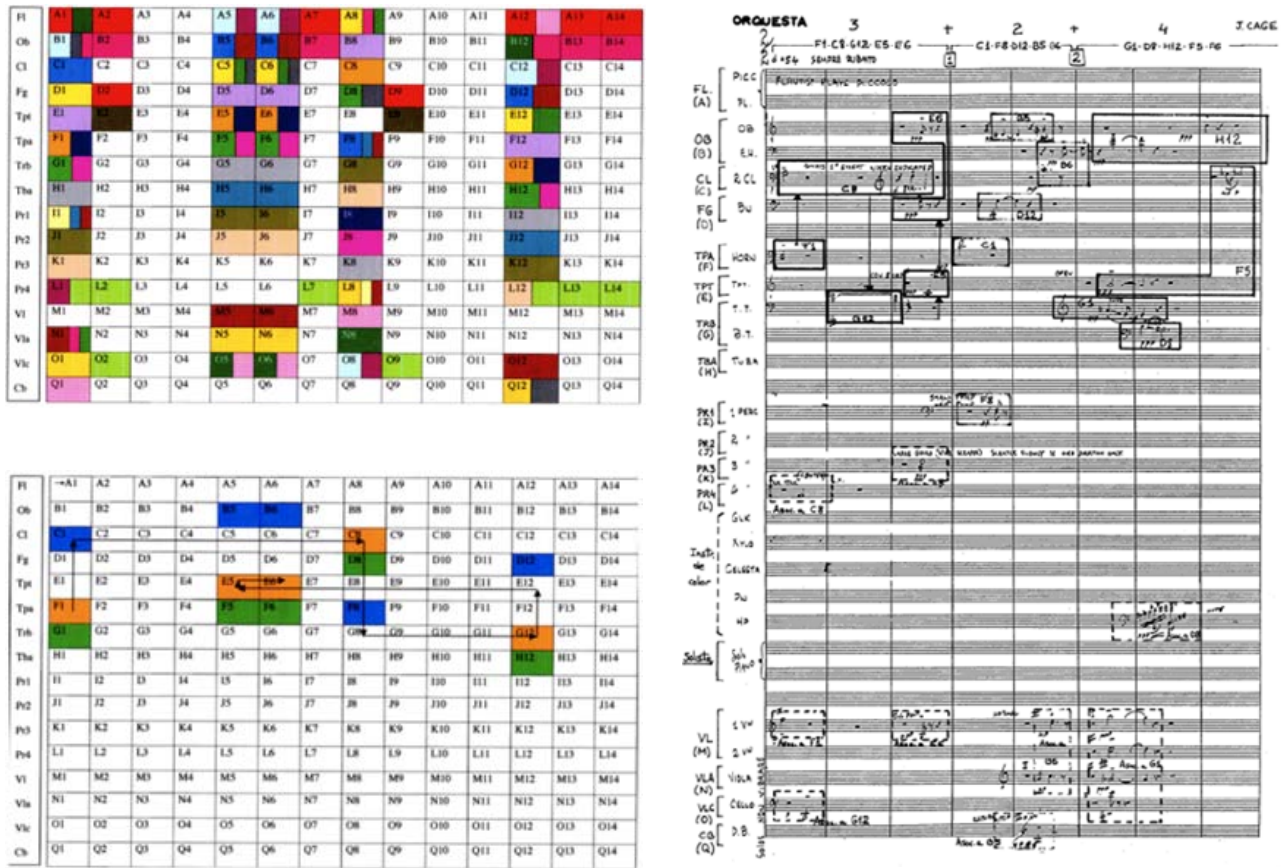

Fig. 54 Tablas de movimientos y partitura del Concierto para piano preparado y orquesta de cámara de J. Cage, en (Díaz de la Fuente, 2005) 
Para entender el funcionamiento de este método podemos remitirnos a la carta del 22 de mayo de 1951 en la que Cage explica a Boulez las características generales del proceso compositivo. En ella explica su pretensión de ordenar los elementos no en una gama (linealmente) sino en un cuadro de $14 \times 16$ en el que procedería a realizar movimientos 'de naturaleza temática'. Refiriéndose al cuadro, comenta:

'En este caso el tamaño de la tabla es de 14 por 16. Es decir: 14 sonidos diferentes producidos por un número de instrumentos ( $a$ veces sólo uno, y a menudo incluyendo percusión) constituye la parte superior de la serie de la tabla y corresponde (hablando cualitativamente) la flauta. La segunda serie en la tabla favorece al oboe y así sucesivamente (...). Los últimos cuatro corresponden a la cuerda. Cada sonido es descrito minuciosamente en la tabla: ej.: un sonido particular, sul ponticello en la $2^{a}$ cuerda del 1er violín, con un sonido particular de flauta, por ejemplo con una caja china (...) Así voy haciendo movimientos en la tabla con una 'naturaleza temática' pero, como verás fácilmente, con un resultado atemático. El movimiento entero usa dos movimientos, ej. 2 abajo, 3 sobre, 4 arriba, etc. (...) La orquesta (en el primer mvt.) fue tratada rigurosamente, mientras que el piano se mantuvo libre, sin tabla, sólo con preparación (...)'. ((Ed) Nattiez, 1995)

Con esta metodología, Cage no renunció a su derecho de tomar decisiones sino que quiso abrirlas al infinito campo de la espontaneidad, la improvisación y el azar.

En el caso anterior hemos visto que el interlocutor de J. Cage fue otro gran compositor del s. XX, el francés Pierre Boulez, uno de los 
máximos pensadores musicales y continuador del serialismo integral. En su obra Estructuras para dos pianos (dos libros, 1951-1952 y 19561961 respectivamente) representa un rigor serial que puede ser considerado el más claro exponente de hiperformalización sonora de la música europea. Es interesante resaltar que Boulez está conectado a los postulados del pintor Paul Klee; ambos se referían a la obra artística en términos de 'estructura':

'el cuadro es el todo, las partes hay que valorarlas en relación al todo, por tanto, en relación al cuadro'. (Klee, 1990)

Antes de ilustrar la metodología y técnicas de Boulez y para entender sus planteamientos seriales y su particular automatismo, tanto desde la génesis lingüística como desde la percepción, tendremos que remitirnos a su libro Hacia una estética musical; en él dedica todo un capítulo a la cuestión del azar en la composición musical. Distingue entre el azar 'por inadvertencia' y el azar 'por automatismo'. Del primero dice:

'La inadvertencia es original, al comienzo, pero uno se fatiga rápidamente de ella, tanto más rápido cuanto está condenada a no renovarse jamás'

Acerca del segundo tipo de azar comenta:

'En primer término, en lo que concierne a la estructura de la obra, el rechazo de una estructura preestablecida, la voluntad legítima de construir una suerte de laberinto con muchos circuitos; por otra parte el deseo de crear una complejidad cambiante (...). En un universo musical en el cual toda la noción de simetría tiende a desaparecer, donde una idea de densidad variable ocupa un lugar cada vez más primordial en todos los peldaños de la construcción 
- desde el material hasta la estructura - es lógico buscar una forma que no se fije'.

La obra está diseñada a partir de la planificación de series con los parámetros musicales más importantes: alturas, duraciones, intensidades y ataques. A partir de estas series y calculando todas las interacciones de valores construye una serie de matrices. Después establece itinerarios diagonales o caminos que considera oportunos para fabricar los materiales descritos (Fig. 55).
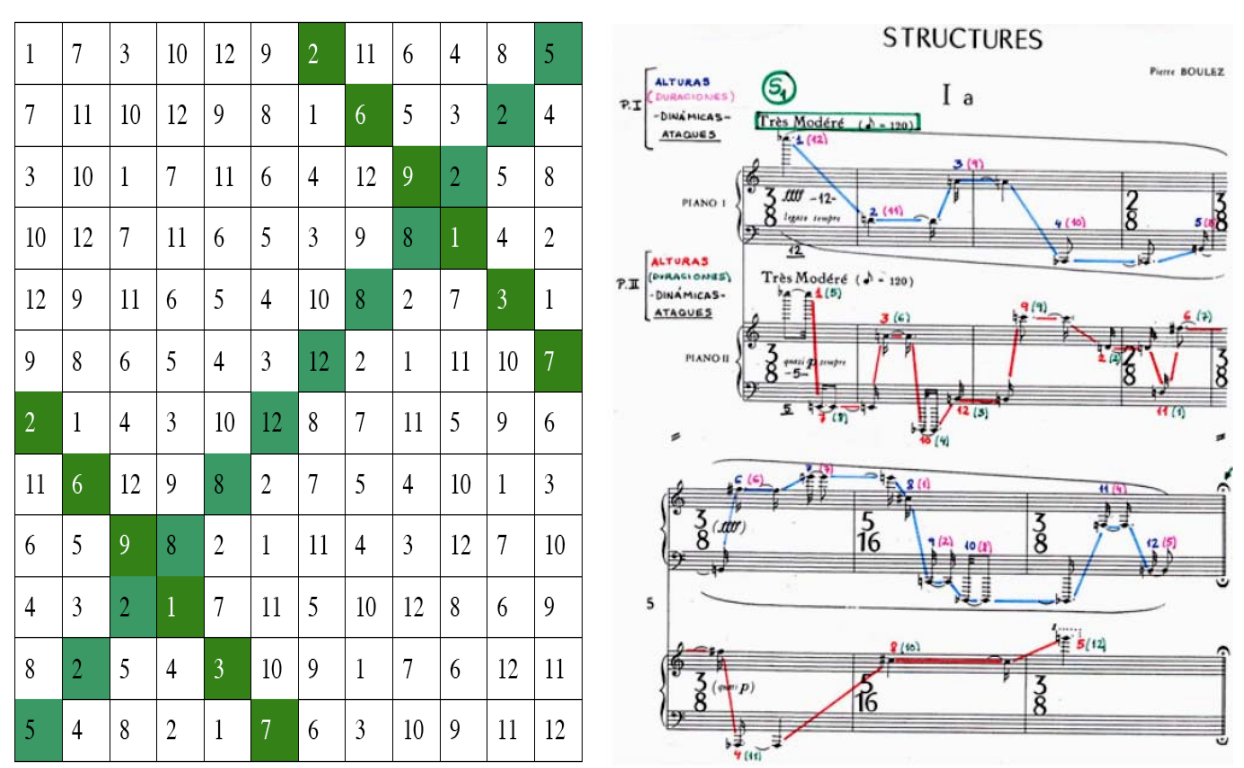

Fig. 55 Matriz de intensidades y Partitura de Estructuras para dos piano, $P$. Boulez, en (Díaz de la Fuente, 2005)

En una entrevista concedida a Jesús Martínez Vargas, Pierre Boulez contesta a la pregunta de Vargas acerca de la dificultad de la comprensión del material sonoro y el papel que juega la memoria en una obra de esta factura. Boulez responde argumentando la necesidad de hacer tabula rasa en el inicio de la década de los años 50 para así poder 'reconstruir completamente el universo'. Más adelante Vargas cuestiona a Boulez sobre su interés por 'cambiar los puntos de vista' de la obra artística, a lo que Boulez responde: 
'Es ud. quien (...) tiene un punto de la vista sobre ella (la obra), y no es la obra la que tiene un punto de vista sobre ud. Lo que es interesante es que esta obra sea lo suficientemente rica para ser portadora de diversos puntos de vista. La obra esencial, para mí, es la obra que se modifica bajo la mirada, y las obras que no son lo suficientemente ricas no se modifican bajo la mirada, y carecen de interés.' (V.V.-A.A., 1991)

Boulez explica que ciertas obras, como las de algunos compositores menores del Barroco, no incitan la mirada; probablemente porque, de algún modo, son demasiado previsibles. Es decir, el interés de una obra se deriva de la sorpresa que un oyente recibe al contemplarla, siempre, claro está, dentro de unos límites que impone la propia comprensibilidad humana. En este sentido, Boulez, otorga una cierta parcela de razón a Meyer, el cual cifra el interés emotivo de una pieza en el modo como crea, cumple o frustra las expectativas sonoras (Meyer, 2001).

Además de estos postulados organizativos en el planteamiento de una obra musical y dado que esta investigación me acercó al lenguaje electroacústico, las obras de Ricardo Climent, compositor residente en la Jove Orquesta de la Generalitat Valenciana (JOGV) durante mi estancia como Director Asistente en dicha Orquesta (2002-2005) fueron decisivas en mi aproximación al estilo. Con Climent pude trabajar y dirigir varios estrenos de obras para Instrumentos y Electrónica con la JOGV: Sons etouffes (2004) para Orquesta y electrónica, 3 Simetrías (2004) para ensemble, cajón amplificado y electrónica en vivo. 
Las obras para electrónica grabada (cinta) que además pude comentar y analizar con el autor fueron: e-RRATUM (2001), Sonic Tsunami (2003) y The last castrati (2004).

Otra influencia y referencia decisiva en mi evolución como compositor de música electroacústica fueron las obras de la compositora francesa Cecile Le Prado (b. 1956), interesada especialmente en el paisaje sonoro, el sonido para videojuegos y la instalación sonora. Durante mi estancia en Singapur (2006) pude conocerla personalmente, conocer su obra y recibir consejos muy valiosos sobre la composición electroacústica. Las obras que pude analizar y discutir con ella fueron: A l'Alba d'un Erable, Elles y Le triangle d'incertitude (1996), y Lisboa (2007).

\subsection{DESCRIPCIÓN TÉCNICA}

\subsubsection{COMPOSICIÓN}

Para cada poema se ha compuesto un material musical correspondiente a la abstracción de cada uno de los textos. No se ha buscado una correspondencia lineal de cada poema, sino una recreación artística y musical de la esencia global de cada texto. Por su escasa naturaleza abstracta, cada poema necesita de más o menos recurrencia visual. El empleo de elementos electrónicos o puramente sonoros responde al análisis y a la discusión previa que se planteó con los autores y a la necesidad de integración de estos con cada poema. El primer y segundo poema contienen más elementos instrumentales que efectos sonoros artificiales. Esto se debe al grado de simbolismo abstracto y a la interpretación artística de cada uno de estos textos. 
A continuación vemos un ejemplo del material musical compuesto (Fig. 56).

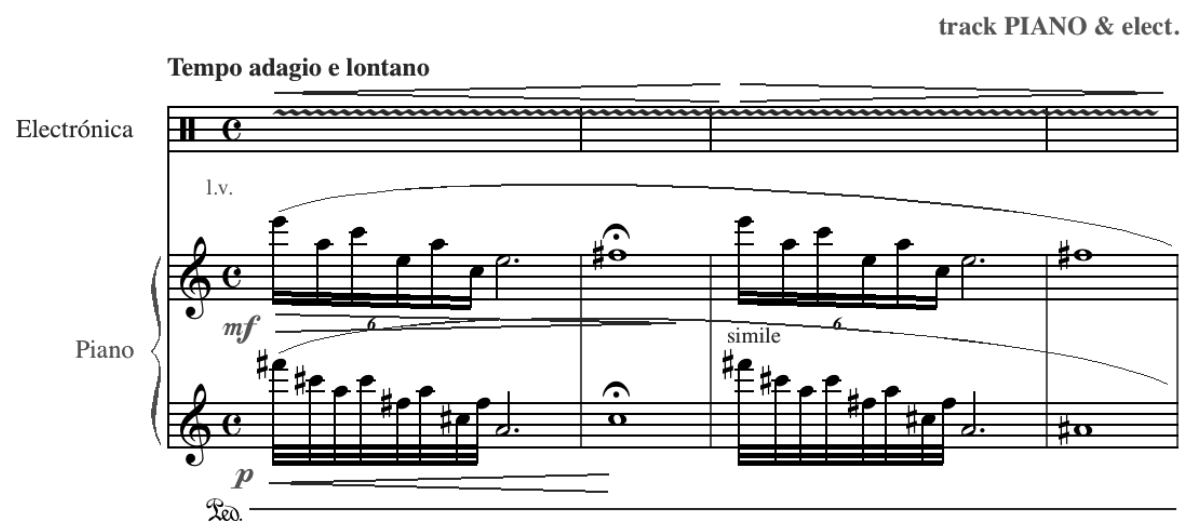

Fig. 56 Fragmento musical del Poema Sayang Airwell

\subsubsection{FUENTES SONORAS}

La composición final de cada una de las obras ha sido el diseño sonoro de distintas fuentes grabadas. Se han utilizado sonidos producidos por instrumentos, ruidos generados por diferentes objetos y la mezcla de ambos. Los instrumentos utilizados han sido excepto el piano, de origen oriental. De la familia de la cuerda se han utilizado el ErHu, Gu Qin, Yang Qin. De la familia de la percusión el Shimia nLuo, Bianz Hong y Pien Ching. Frecuentemente se han mezclado mecánicamente con varias fuentes: la manipulación con monedas chinas (I-Ching), bolas chinas, alambres, llaves y otros objetos han servido como generadores de sonidos en dichos instrumentos. Cada uno de los instrumentos se ha utilizado para explorar efectos y timbres específicos (Fig. 57). Los registros explorados son frecuentemente extremos en cuanto al timbre y la altura. El procesamiento electrónico final en el estudio mediante distintas plataformas de edición de sonido ha sido el factor determinante en el diseño de todos los poemas. 

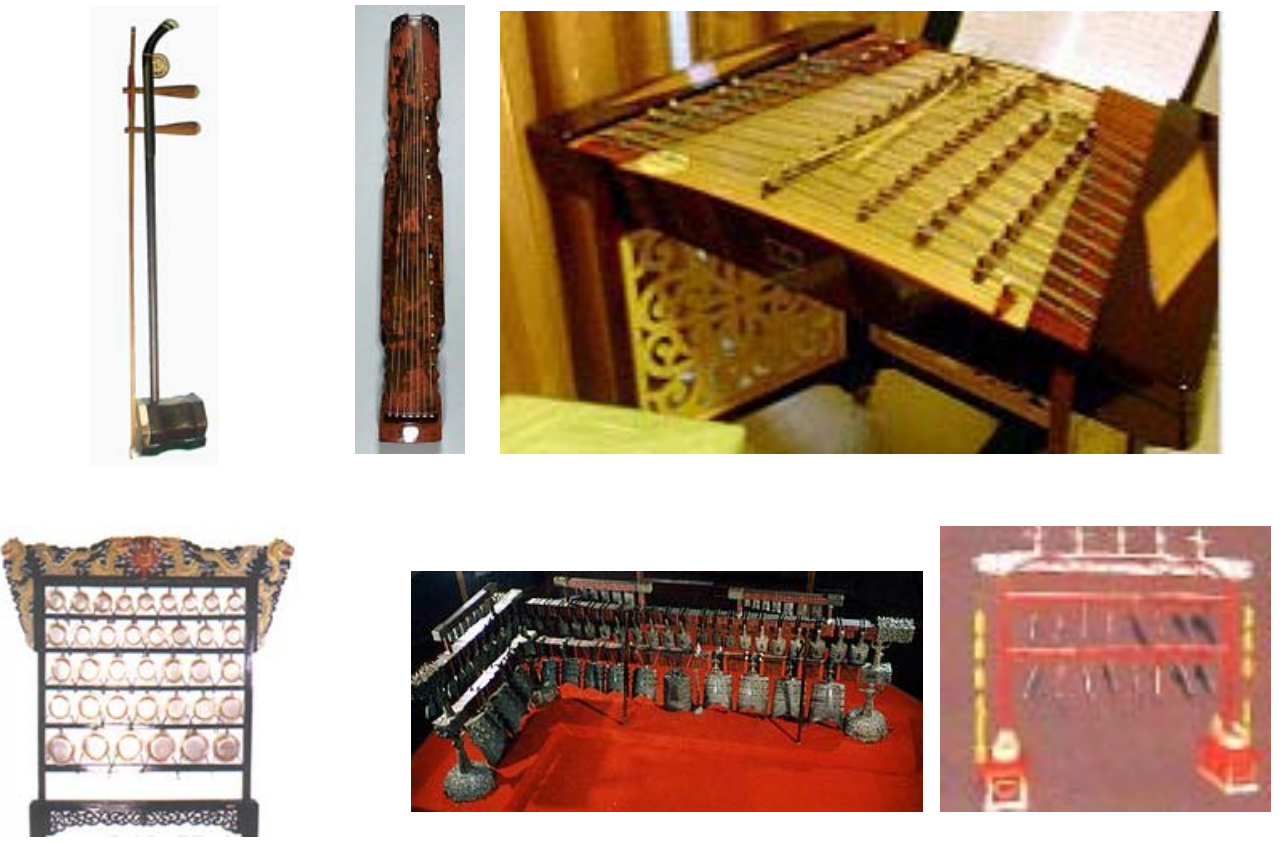

Fig. 57 De izquierda a derecha y de arriba a abajo: Er Hu, Gu Qin, Yang Qin, Shimian Luo, Viñas Hong y Pien Ching, en (CIIC, China Internet Information Center 2010)

\subsubsection{PROCESAMIENTO LIVE / NON LIVE}

Preocupado por los factores del azar y la indeterminación era mi deseo diseñar una aplicación autómata que gestionara los valores de un análisis de voz y lo correlacionara con unas probabilidades de sonidos prediseñadas. Para cada poema se ha compuesto una pista principal (non Live) que se verá complementada por otras capas sonoras, dependiendo de los valores analizados en vivo. Esto conformará la idea de un contrapunto abierto diseñado a partir del vivo (live). No se han seguido las líneas de los Learning Interactive Systems (Music cognition and Al) de compositores como Robert Rowe (Rowe, 2010) ó Norbert Schnell (Schnell, 2010), sino más bien una aplicación que gestione el procesamiento de cuerpo sonoro final de la obra. 
El software utilizado para el procesamiento de la señal y para la posterior reproducción final ha sido Max MSP (Cycling74, 2010); para la edición de sonido: Csound (Csound, 2010a), Supercollider (Supercollider, 2010) y BiasPeak (Bias, 2010). En la Fig. 58 vemos la apariencia del patch principal.

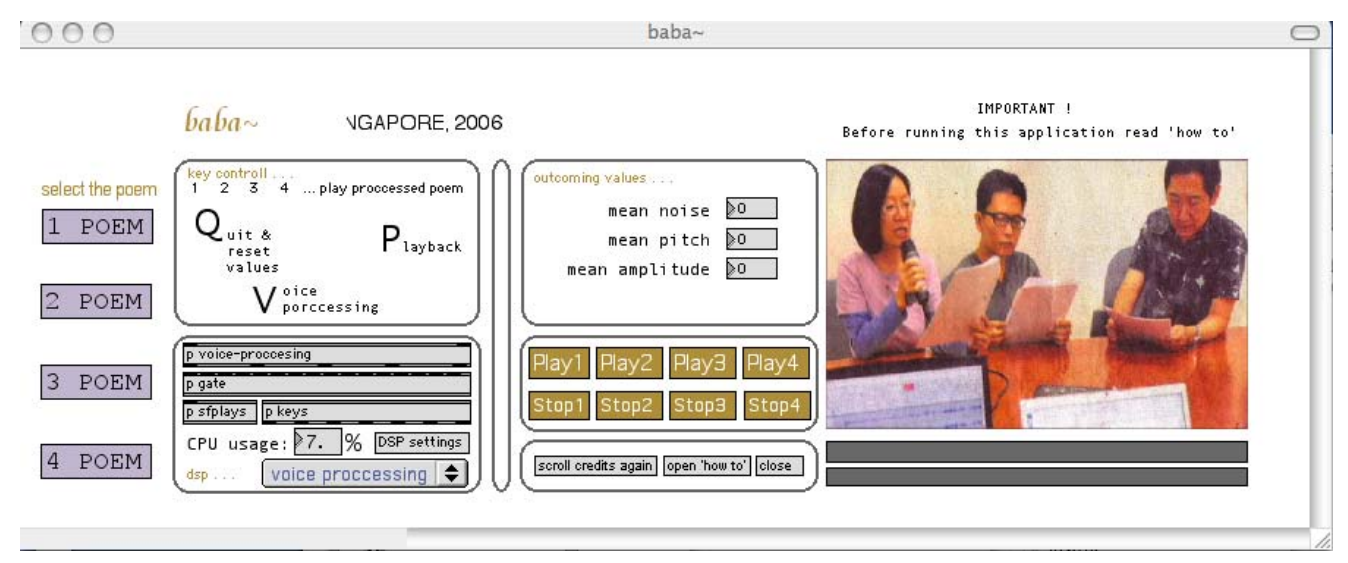

Fig. 58 Patch principal

Para el análisis y procesamiento de la señal del usuario se ha diseñado un objeto en Max MSP llamado baba , basado en el estimador de altura fiddle . Este objeto nos permite conocer en vivo los valores de

- Altura - Pitch Estimator, basado en el objeto fiddle , detecta la cantidad de armónicos de una señal de audio. Si la señal supera el análisis de un número determinado de armónicos, esta es considerada como altura real. Si no, lanza un bang ${ }^{12}$ y nos indica que la señal es considerada como ruido (Fig. 59).

${ }^{12}$ Según (Cycling74, 2010) un bang es una palabra mágica en Max. Es un mensaje especial que significa '¡hazlo!', lo que hace que un objeto haga aquello que se supone que tiene que hacer. 


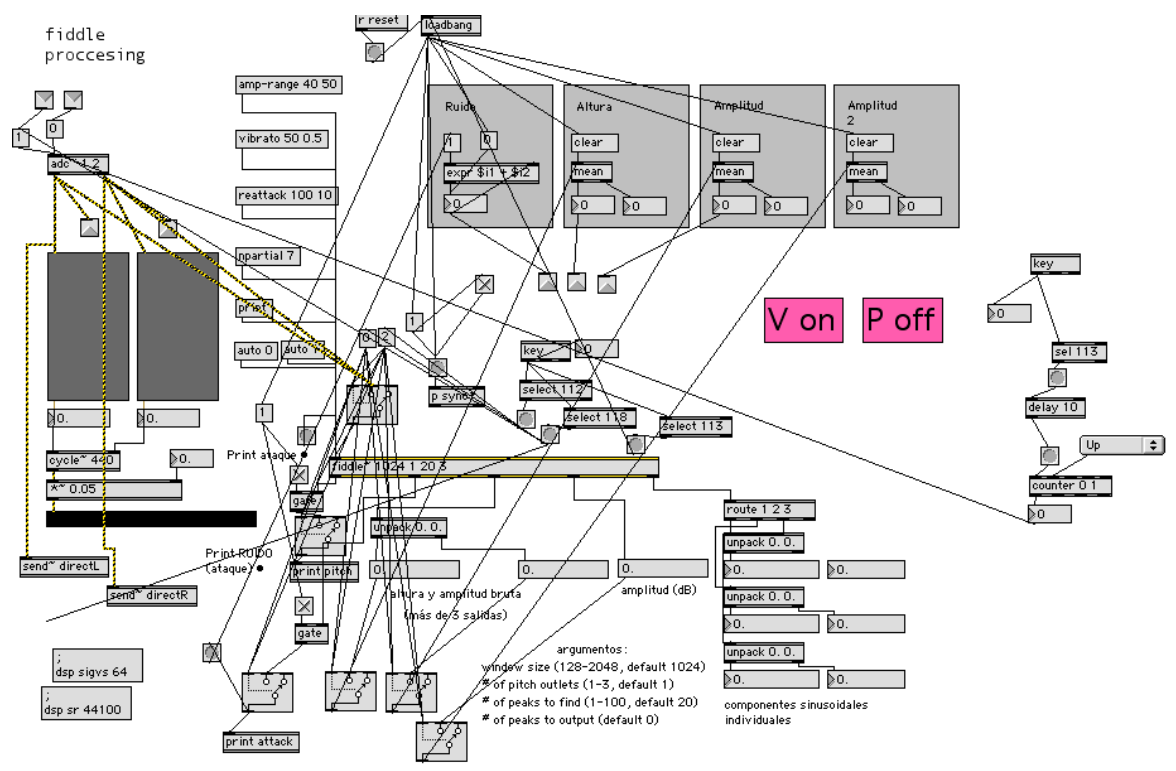

Fig. 59 Sub-patch estimador de altura

- Ruido - Sonidos Asonantes (SA), las señales descartadas por el pitch estimator nos indican la cantidad de fonemas asonantes que el usuario produce al hablar.

- Intensidad - expresada en dB (decibelios), nos indica la media de la amplitud de onda que el usuario produce al hablar.

Mean - Los parámetros anteriores se van almacenando durante el procesamiento en vivo y nos dan una estimación media al final de la lectura de cada poema. Mediante esta estimación media se evitan los picos que el análisis espectral pueda ocasionar al capturar la señal (Fig. 60 y Fig. 61).
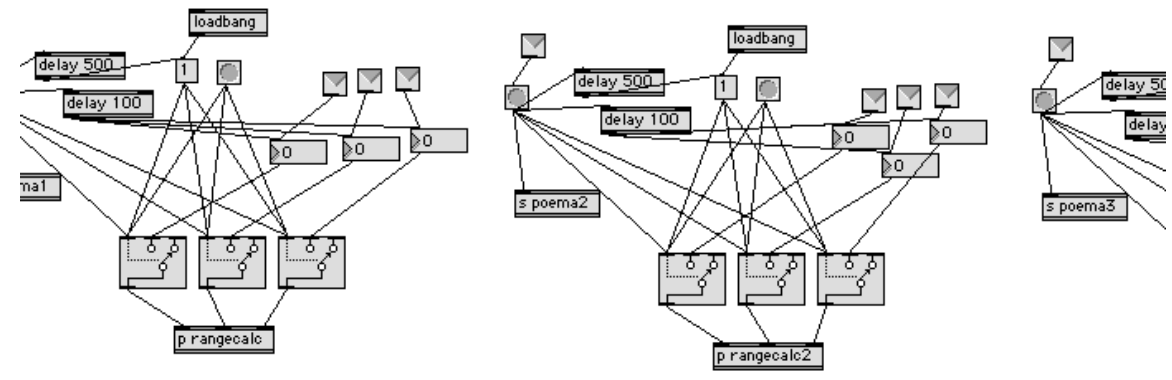

Fig. 60 Puerta de enlace 


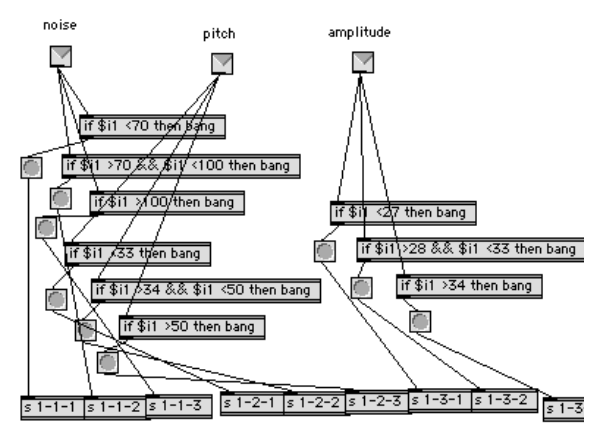

Fig. 61 Filtro de rangos

Después, y mediante la asignación de los diferentes rangos a los determinados bancos de pistas, se reproduce la pista principal de cada poema con sus respectivos resultados del análisis en vivo. Cada uno de los parámetros tiene un comportamiento distinto, y es por ello que la asignación sonora que se les da a cada uno depende de tales rangos.

Para cada parámetro se han compuesto tres posibilidades: baja, media y alta (Fig. 62). El rango asignado a cada parámetro es el siguiente (ver apartado 1.2.3.1).

\begin{tabular}{|c|c|c|c|}
\hline Parámetros/Asignación & baja & media & alta \\
\hline Altura & $0-33$ & $34-50$ & $>50$ \\
\hline Intensidad & $0-27$ & $28-33$ & $>34$ \\
\hline Ruido & $0-70$ & $70-100$ & $>100$ \\
\hline
\end{tabular}

Fig. 62 Tabla de rangos

\subsubsection{DESCRIPCIÓN DEL RANGO}

La altura en el lenguaje hablado tiene un margen muy pequeño entre personas del mismo sexo. Así pues, la nota media para la voz 
masculina en general es un sol $2^{13}$ ( 43 en valor MIDI), para el sexo femenino está alrededor del mi 3 (52 en valor MIDI) (Fig. 63).

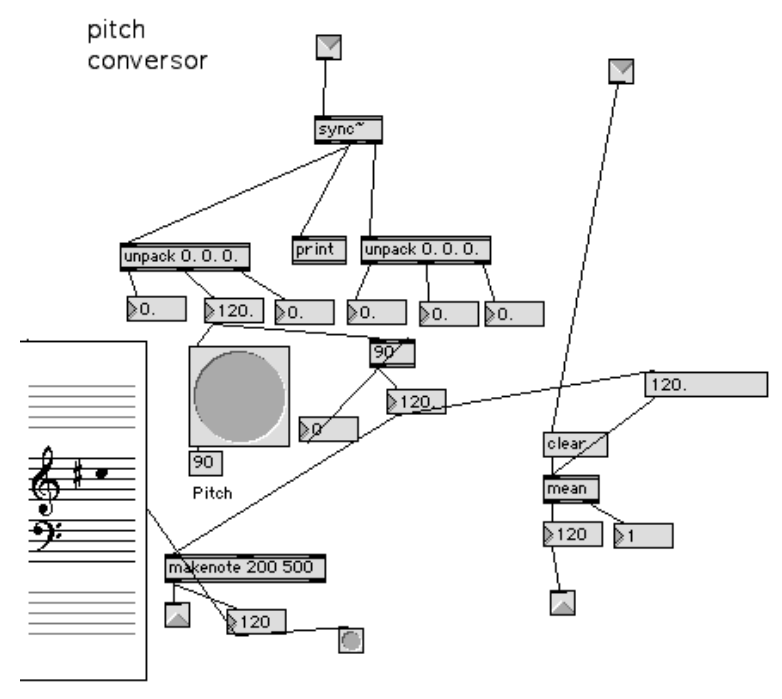

Fig. 63 Conversión de alturas a índice MIDI

La intensidad es muy variable, pues depende también de la distancia a la que el usuario se coloca del micro. Este parámetro por lo tanto, tiene que ser utilizado de modo más flexible que el de altura.

La medición del ruido o señales asonantes nos permite asignar a cada manera de hablar distintas bases de datos sonoros.

En Singapur una de las cuatro lenguas oficiales es el Inglés, y todos los niños aprenden inglés desde pequeños. Por la influencia de la lengua china, la fonética que utilizan al hablar inglés los hace muy particulares. Frecuentemente se habla del Singlish, el inglés pronunciado a la manera de la fonética china en Singapur. Por esta razón el parámetro SA tiene un diseño específico para la fonética de Singapur. En cualquier otro lugar del mundo el análisis fonético condicionaría variando la asignación de nuestra base de datos sonora (Fig. 64).

${ }^{13}$ Índice acústico Franco-Belga. $440 \mathrm{~Hz}=57$ en valor MIDI. 


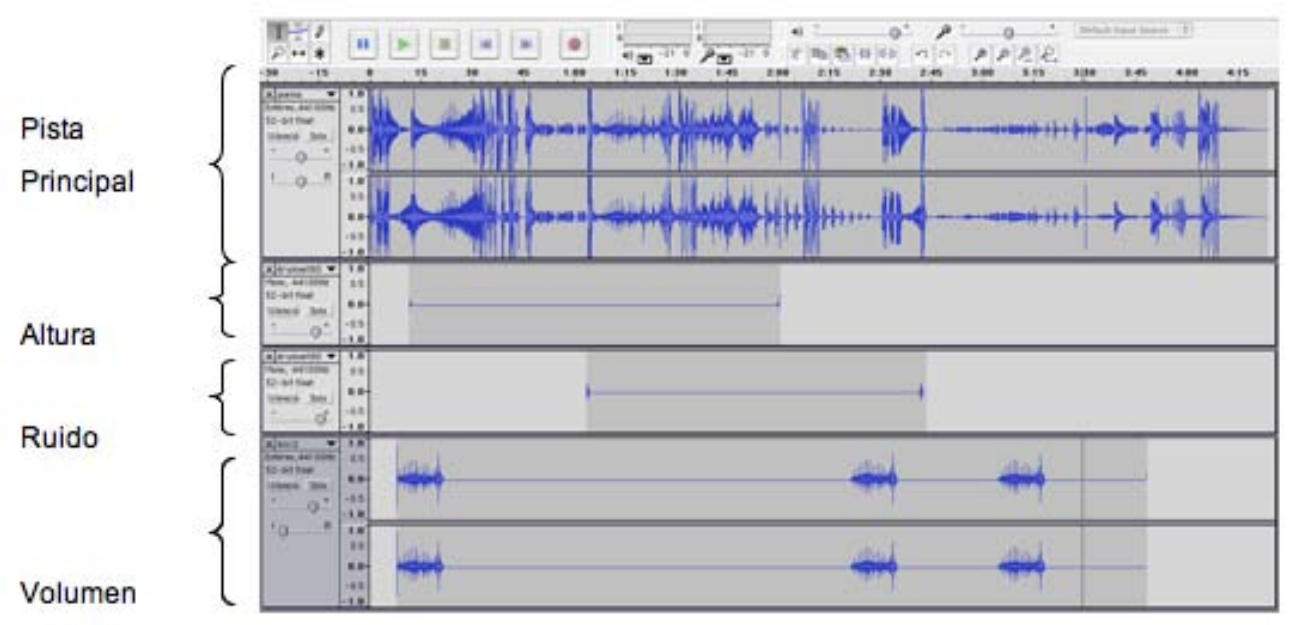

Fig. 64 Recreación de un posible resultado final en el programa Audacity

Cada poema tendrá como resultado 4 pistas mezcladas: 3 posibilidades (parámetros procesados en vivo) más la pista principal (Fig. 65).

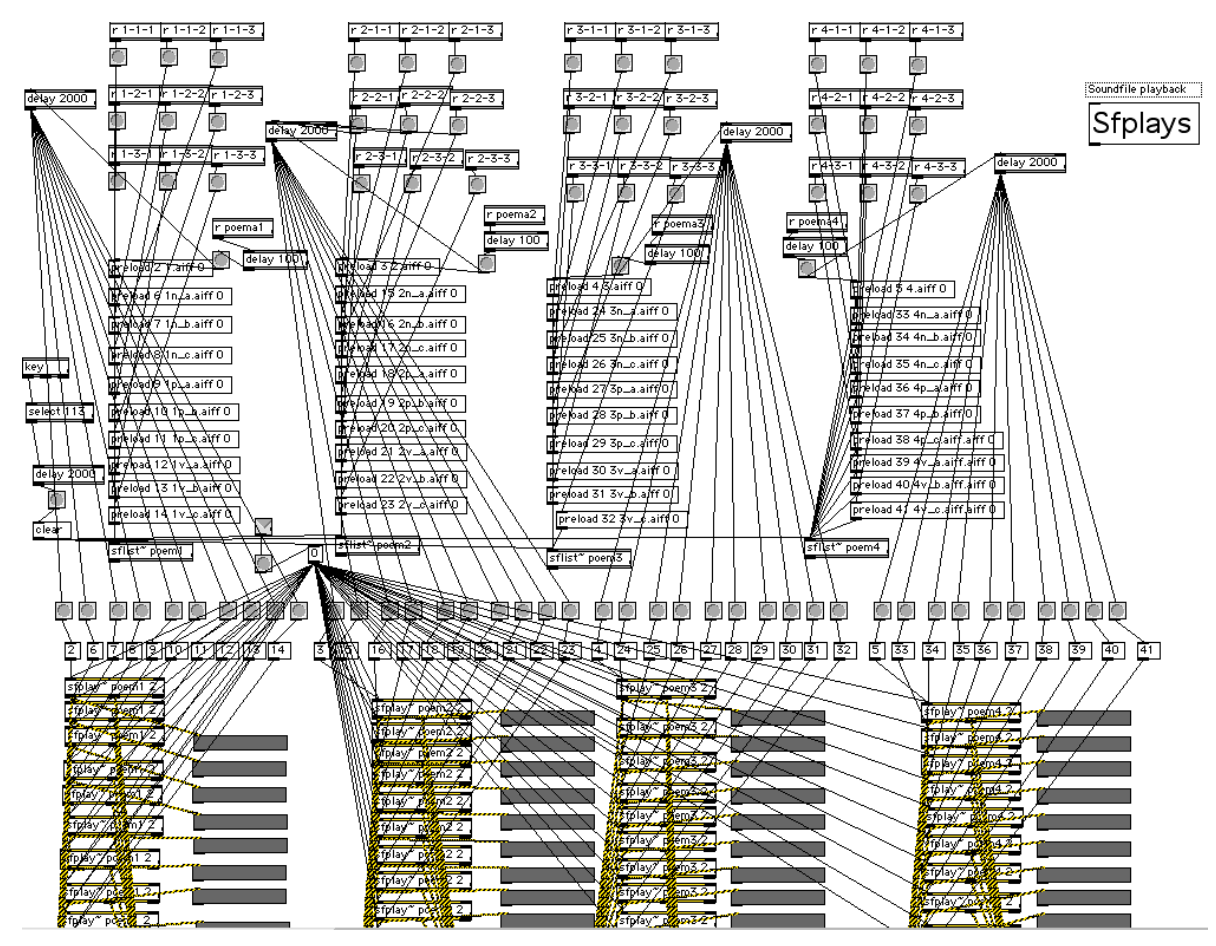

Fig. 65 Sub-patch sfplay , Reproductor de archivos

\subsubsection{REQUERIMIENTOS TÉCNICOS}


La reproducción de los poemas está diseñada en base a los tres factores del análisis en vivo, más la pista principal. Así pues se ha dispuesto la colocación de 4 altavoces en cada esquina de la sala. De este modo la estereofonía adquiere doble dimensión, ya que la dirección del sonido se podrá controlar desde atrás hacia delante y viceversa.

La tarjeta de sonido empleada será de 4 canales, permitiendo el control de todos los parámetros.

El lector (en este caso el poeta) se situará frente a la audiencia y junto al equipo de procesamiento. Este conectará la señal de audio (entrada) al programa de procesamiento de señal (Max MSP - patch baba ) y calculará los parámetros de salida (Fig. 66).

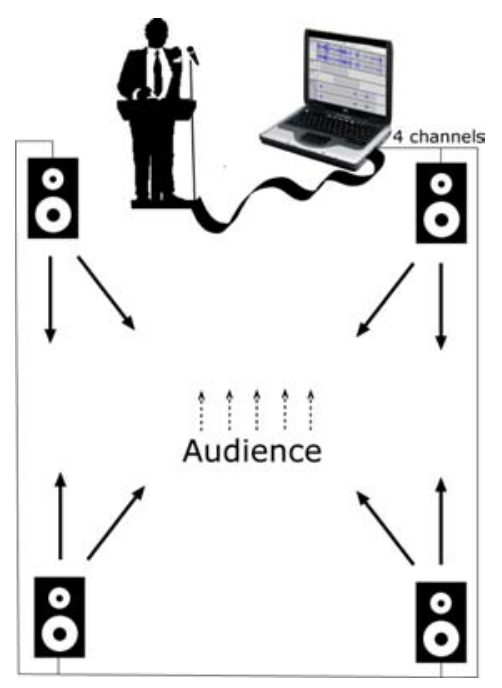

Fig. 66 Disposición espacial

Para la audición de las obras se propone la colocación de entre 4 y 9 altavoces. En función de la tarjeta de sonido y las condiciones de espacio y acústica se repartirán las diferentes salidas de audio (pista principal y complementarias). En el caso de colocar 5 monitores, 2 frontales y 3 traseros, la pista principal (right/left) saldrá por los 
delanteros (estéreo) y las pistas complementarias por los traseros. En el caso de contar con 4 altavoces las pistas complementarias se repartirán entre los dos traseros. Para una audición en estéreo se prepararon cuatro ejemplos de los poemas con las pistas mezcladas en estudio. Así será factible para la mayoría de formatos de reproducción.

Para una adecuada percepción de la obra, siempre y cuando no sea otro el objetivo, la luz será tenue, facilitando la atención sonora y evitando la distracción visual del entorno.

\subsubsection{ANALISIS DE LOS POEMAS}

La lectura detallada y en profundidad de cada poema, así como la discusión personal con sus autores ha ido dando forma a cada composición. Algunos pasajes centran su atención hacia objetos reales

o formas puramente tangibles. Otros hacen referencia a olores o sensaciones que escapan de una descripción musical. La casa Baba, durante nuestra visita presentaba rincones muy pintorescos (Fig. 67). Los grabados y relieves en las cornisas y las marquesinas tienen un alto valor artístico. La distribución de las salas y la disposición de las ventanas de la casa proporcionan una ventilación idónea para la alta temperatura y la humedad durante todo el año en Singapur. Las historias de sus inquilinos, familias adineradas, aristócratas e ilustrados venidos de Europa y América, los choques de estos avances con la tradición china y el apogeo que estas familias tuvieron en la sociedad de Singapur conforman una inmensidad de material para la creación lírica y musical. 

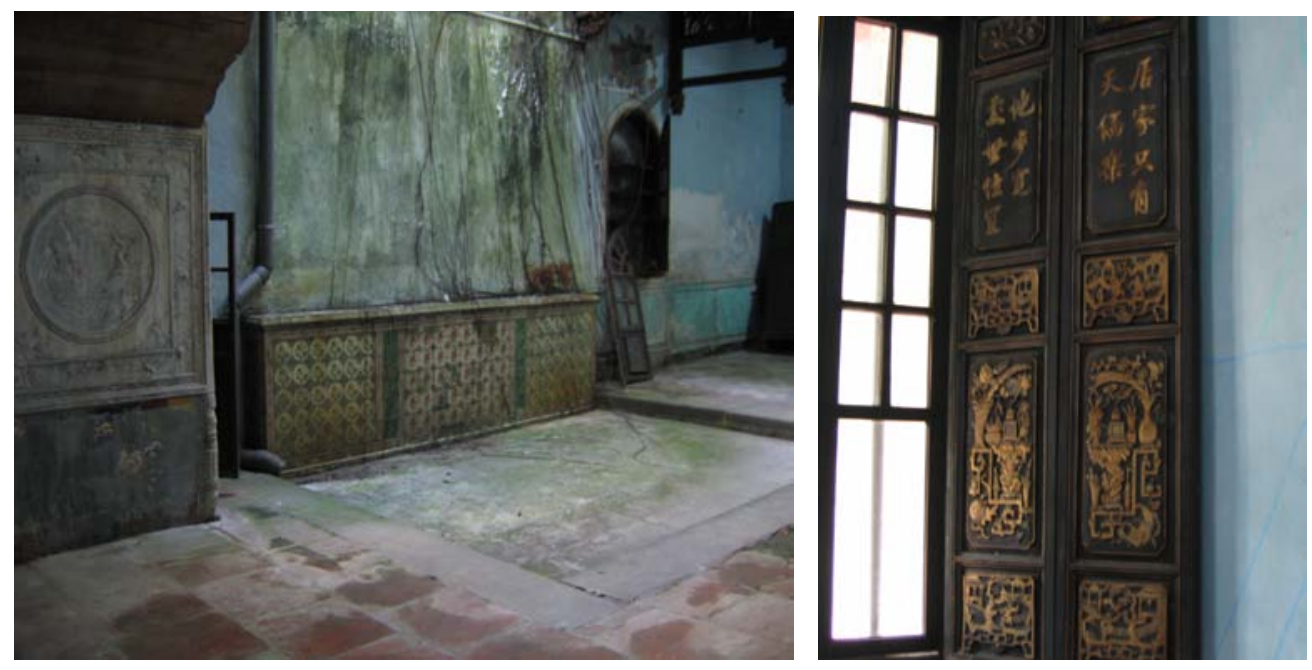

Fig. 67 Interior de la casa Baba

La inspiración musical para los poemas han sido los materiales (preferentemente armónicos) musicales chinos, malayos e indios. Las escalas pentáfonas y exátonas ${ }^{14}$ para las frases de alusión china, los ritmos irregulares de la percusión malaya y los timbres brillantes e incisivos de la cultura musical india.

Cada poeta trató de reflejar con más o menos grado de abstracción las sensaciones que se vivían en la casa Baba. Hay una línea continua por la que todos han pasado: la antigüedad de la casa, el revoloteo de los murciélagos en el segundo piso, los relieves y las inscripciones chinas.

A continuación veremos cada uno de los textos y una descripción musical (forma, recursos y timbres) de los poemas compuestos.

\footnotetext{
${ }^{14}$ Pentáfona es aquella escala que tiene 5 sonidos; hexátona, aquella que tiene 6 sonidos (Michels, 1982).
} 
1er POEMA: 'Neil Road house',

Dr A Yap.

It's probably true that I've played host

to so many, some of my guests

must have been imagined -

the batiked matriarch sobbing into

an embroidered hankie;

the brat whose prank was punished

with a smear of chilli;

the schoolgirls hiding

when the gentlemen called -

their lilting laughter funnelled

through peep holes,

feting the rooms,

today's three stories of gloom.

I remember the phonograph,

the first phone, its shrill tinkles,

the jolt of first electricity,

before it becomes a blur of passing bodies talking, walking,

heaving, leaving,

rearranged furniture,

coins dropped in corners

and other accidents,

bye bye to the nightsoil man,

tvs tittering till dawn,

dialogue, skipping images,

black, white, colour.

The rooms are cold at night,

my passages tickle.

I clear my throat,

and cough out bats;

flapping sounds, shrieks,

escape through the

gaps between my teeth. 


\section{Descripción Musical}

Más que una composición puramente acusmática este poema responde mejor al estilo Landscape o paisaje sonoro (ver apartado 5.1.2.3.2), el ruido generado en el interior del piano por diversos utensilios puede recrear el resquebrajar trozos de madera vieja, la manipulación de objetos metálicos, etc... El procesamiento del sonido del piano de cola nos ofrece diferentes puntos de vista del contenido musical en cada parte del poema. Se pueden diferenciar varias secciones. Una primera introducción realizada con elementos de ruido metálico y de maderas da paso al sonido del vinilo que nos servirá de hilo conductor a través del poema. Este nos introducirá en un espectro psicológicamente antiguo de percepción sonora. El tema inicial $A$, aparece a cargo del piano en un plano secundario. La estereofonía de los elementos de acompañamiento nos hacen centrar la atención en este tema musical. El vinilo y su adyacentes nos hacen pasar al tema $B$, el solo de bombo, una vez más acompañado por el piano que aparece ahora con una cualidad sonora distinta. A través de un decrescendo del piano aparecen los sonidos de maderas del comienzo que nos introducen en el tercer bloque, C: un canon de frecuencias agudas y muy puras generadas por un oscilador de frecuencias simple que se verá acompañado por un plato suspendido. El vinilo una vez más nos devuelve al tema percusivo y lejano del bombo que sirve como coda del poema. 
20 POEMA: 'Sayang Airwell', Heng Siok Tian

Airwell

in the centre of a baba home

shows me

a mosaic of blue.

Like a pre-hologram,

glimpsing an early sky:

I see amahs in samfoos

in their time and space

squatted here,

washing, working within the marbled squares,

for big master and mistress who slept above,

for little masters they would sayang and love.

Where was their half of the sky?

next to babas and nonyas twirling, whirling with a gramophone in an upstairs dance studio

now

the play den of fruit bats when owners upgraded,

layered with bat droppings, so decomposed they become earth.

To first lose the turquoise-blue of mosaic tiles, then the shapes of carved zodiac animals,

to leave them with the wings of bats,

to touch again these losses

as I linger on the airwell,

so sayang, sayang. 


\section{Descripción Musical}

El piano es el principal generador sonoro del poema. El rasgueo de una moneda del I-Ching en la región más grave de las cuerdas del piano sirve de introducción. Esta manipulación de los recursos sonoros en las cuerdas y la tabla armónica del piano se convierten en variaciones tímbricas. La congelación temporal de uno de estos elementos propicia el arranque y la aparición del tema A. El acompañamiento estará a cargo del ir y venir sobre las cuerdas de las bola chinas. Diferentes procesos de edición y retoque de sonido mediante VST Plugins (Virtual Sound Transform) (ver apartado 4.2.2.3) configuran los contrapuntos al tema central, estos se irán conmutando en más o menos cercanía en cuanto a los planos sonoros. Las variaciones se van incrementando hasta que aparece el tema $B$, el punteado con las yemas de los dedos en distintas regiones de cordaje del piano. Mientras este se desarrolla aparecen elementos del tema A. Una sencilla melodía modal basada en repertorio musical chino actúa de tema conclusivo del poema. Toda la estructura del poema trata de recorrer todo el abanico de recursos sonoros del piano, desde los sonidos más rudimentarios (rasgueo del entorchado en las cuerdas), la manipulación manual de la tabla armónica y de diversos elementos ajenos al piano en diferentes regiones de este, hasta la producción actual y más conocida del piano mediante el mecanismo de macillos. 
3er POEMA: 'Restoration', Yong

\section{Shu Hoong}

If only it is as easy as unclogging

peepholes in the floorboards

to peer into the past - instead I see

the visitor's hall one floor below,

vacant and awaiting the fall

of the makeover scalpel. Perhaps

it's only through precise incisions

that we uncover emblematic lesions

on Peranakan tiles, reveal the true

colour within the wall's epidermis

or dissect the meanings behind

Chinese blessings tattooed above door beams.

Perhaps it is through deep hypnosis

that we excavate the real source

of melancholy in someone else's tales,

memories that flutter like bat wings

roosting beneath fractured roof. 


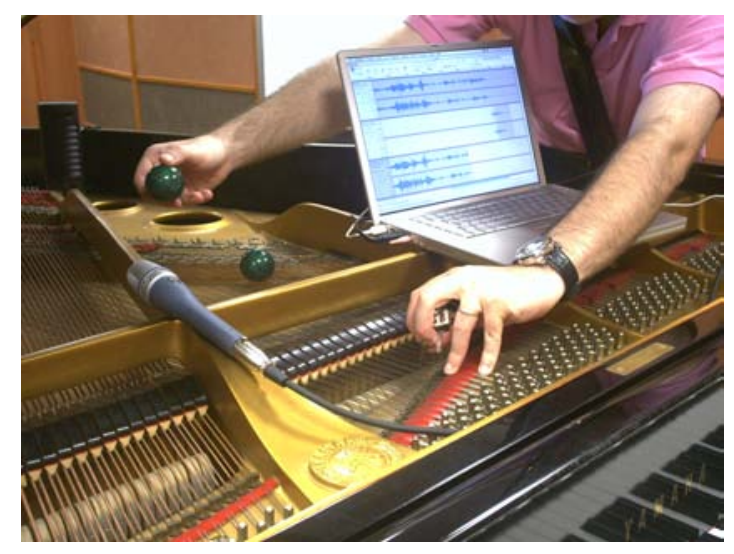

Fig. 68 Manipulando el interior de un piano

\section{Descripción Musical}

El sonido del vinilo y el goteo de agua grabado en la casa Baba, hace de tema introductor del poema. Al abrir la puerta de acceso al hall aparece el tema $A$, a cargo del piano. Este tendrá como acompañamiento el propio tema procesado a la vez que el rasgueo anticipado del tema B. A continuación oiremos un canon creado a partir de la manipulación de la región media (longitudinal) de distintas octavas del piano (Fig. 68), rasgueo manual. El sonido del vinilo actúa una vez más de hilo conductor. Una imitación breve de frecuencias agudas B (alusión al canon que aparecía en el primer poema) acompañadas por el material temático hace de introducción a la variación del tema $A$, unas veces en retroceso, otras en forma de 'salto de bola' (VST Plugin - mda bouncing bowl, mda Bandisto, mda DubDelay, etc...) (Audacity, 2010); todo ello, para crear una sensación de posición inexacta e hipnosis que el poema hace del paisaje de la casa. El propio sonido del vinilo sirve de conclusión difuminando el poema. 
4' POEMA: 'National Grain',

\section{Yeow Kai Chai}

That the bats also admired the house was clear:

From the way they flapped and squeaked

(wish you were) but also from generous

Droppings loosely here and there. Watch out.

Grey streaked across, dollops of Pollock. And

Don't start with the smell. Not today, honey.

Just like how a lepidopterist painstakingly

Pins a specimen onto this (rigged for posterity),

Every aspect of it was geared to please

The one and only towkay - friezes,

Rail balustrades, mythical creatures

And Chinese characters, all have found a perfect

Home... now retouched to the last wee comfort,
My repainter. Flip a panel on the mezzanine

And look below: Busily does everyone

Bluster and declaim, then pause and forward,

But lucky is the visitor who finds himself

Smacked upside the head by Mum

And, often, as flummoxed by the sudden

Swing of the electorate as everybody else

In this bollixed-up world where everything

Old is new again. (Just like this toilet basin.)

In things we trust. How will this wash

With the top? Caught red-handed, this marginalia

Has tended to detract from the key issue:

What really happened here and where were you? 


\section{Descripción Musical}

El comienzo de este poema es el más acusmático de todos. Aunque se pueden adivinar el choque de varias monedas, y la campana china SiJiPingAn, la mayor parte del poema está creado a partir del Shimianluo (especie de marimba colgante), Gong y campanillas chinas. El BianzHong (parecido al bombo) y el PienChing (especie de gong) conforman el contrasujeto al primer elemento del ShimianLuo tratadas en retroceso (VST Plugins mda RoundPan, Splitter, etc). La sección central se proyecta multi-dimensionalmente creando un paisaje lejano que hará de conmutador entre el trémolo del piano y el tratamiento de las monedas del I-Ching. Las campanas chinas acompañadas de campanillas colgantes y la superposición de distintos planos de manipulación de la madera exterior del piano harán de coda para concluir el poema (Fig. 69).

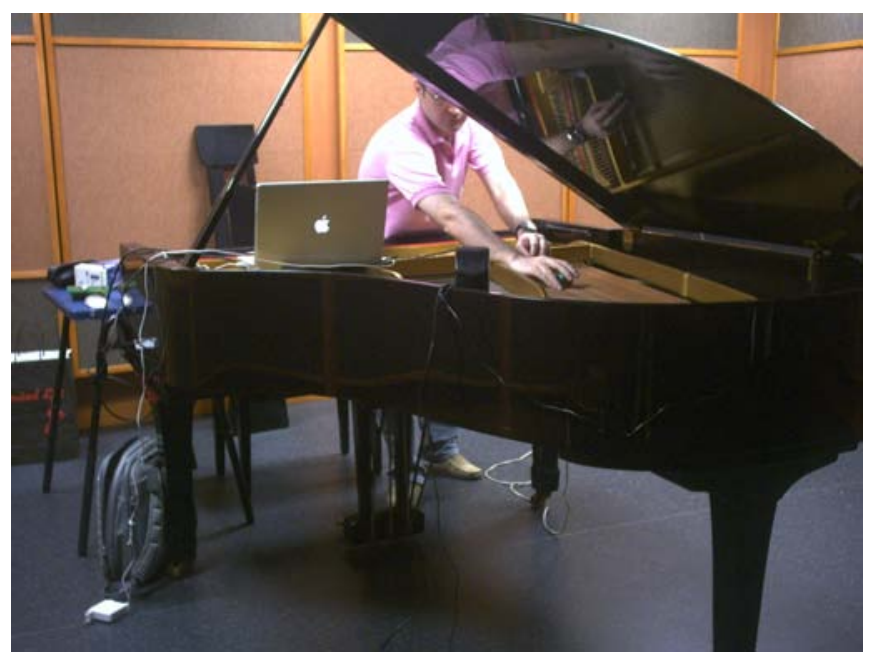

Fig. 69 El autor manipulando el cordaje de un piano en el Centre for Arts de Singapur

\subsection{CONSIDERACIONES}

La primera idea de integrar los aspectos de antigüedad y modernidad en este proyecto han sido fructíferos. El lenguaje electroacústico es 
tan versátil para su uso que, al igual que el lenguaje instrumental, representa, en un nivel de expresión emocional, una riqueza más amplia que el lenguaje hablado.

Las texturas que nos permiten elaborar las diferentes herramientas DSP (procesamiento digital del sonido) pueden acercarse a las impresiones que causan distintas formas sensoriales. De hecho, la aplicación de términos como crujiente, textura granulada, etc. en contextos musicales, la podemos remontar hasta la terminología culinaria.

El hecho de trabajar sobre poemas en inglés con tradición china me conectó una vez más con una dualidad: antiguo/moderno, y el procesamiento de voz aplicado, precisamente a una cultura con la mezcla fonética tan fuerte como Singapur. El problema de esta aplicación es que el primer instinto del oyente es reivindicar una audición inmediata de la obra electrónica. El concepto de material inamovible y cerrado que puede conmutarse para dar una naturaleza viva es lo que me interesó desde que conocí los cimientos filosóficos de la cultura oriental. El l-Ching y su teoría de los cambios y mutaciones en el ser humano me pareció otro rasgo importante a tener en cuenta en la elaboración de una aplicación electrónica. Desde el principio se huyó de hacer una obra en la que el factor aleatorio (o libre) mandase sobre el factor fijo. Más bien era el espíritu de la obra aquello que podría definirse libremente. El envase tenía ya una forma muy clara: los materiales sonoros de la casa Baba.

Otra premisa que funcionó de manera óptima, tanto en el trabajo artístico como en el procesamiento digital y la integración de materiales en estudio fueron los instrumentos típicos orientales. La audición y pruebas de cada uno de ellos me fue dando pistas de por 
dónde debía ir cada poema. Fue tan fuerte la personalidad de estos instrumentos que tuve que andar con ojo a la hora de procesarlos. Sus espectros armónicos, en la mayoría de los casos, se podían deteriorar en el proceso digital.

Gracias a la amabilidad de la Universidad Nacional de Singapur y al departamento del CFA (Centre for Arts) pude disponer de un aula insonorizada con un piano de cola Kawai C3 (Fig. 69). Con él pude generar gran cantidad de material sonoro utilizando diferentes objetos así como la integración de instrumental musical ajeno al piano. Inestimable fue la ayuda de Chrsitine Khor, directora general del CFA, Adrian D. Cheok, director del laboratorio Mixed Reality Lab de la NUS y Eng Tat Khoo, ingeniero técnico y gran compañero en Singapur.

En este ensayo, el tipo de gestualidad que tiene correspondencia con la factura sonora, es el acento y la manera de hablar del usuario. En este caso, existe una concordancia directa y se establece una coherencia entre las caracteristicas de la voz del lector y el resultado sonoro de la obra. 



\section{SONIDO AUMENTADO}

Sonido Aumentado es una aplicación mixta que integra el análisis sonoro complementado con la visualización de elementos de realidad aumentada. En este ensayo se explora el comportamiento del sonido y las implicaciones del gesto interpretativo. Utilizando el análisis espectral del sonido como entrada de datos, se gestiona la representación proyectada de una figura geométrica, siendo un grupo de instrumentistas quienes, de forma conjunta, controlan la visualización del objeto aumentado.

\section{MOTIVACION}

El campo de la realidad aumentada ha tenido hasta el momento poca investigación en lo referente al sonido. Es por ello que, desde mi punto de vista y como músico, supuso un gran reto; una oportunidad para investigar en el ámbito de esta nueva tecnología. Los parámetros de altura, intensidad, timbre y espacialización son los aspectos que determinan el lenguaje del sonido. Así pues, estos cuatro factores pueden servirnos como punto de partida en la indagación de 
realidades sonoras aumentadas. El ensayo que se muestra a continuación desarrolla algunos de estos parámetros aumentándolos en una proyección visual. El contacto físico del músico con su instrumento permite establecer otro parámetro, como es el de la sinestesia. Esta percepción gestual en la técnica interpretativa se transmite a la forma y características del objeto aumentado, creándose una interacción entre el músico y el ordenador a través del sonido emitido, que puede condicionar la interpretación del primero.

Este ensayo se ha realizado para un evento específico, Jazz \& Arts Meeting dentro del festival Jazz Panorama 2007, organizado por la Big Band Sedajazz y celebrado en el auditorio de la localidad de Torrent los días 18, 19 y 20 de julio. En este evento se proponen diferentes actividades, entre las que se incluyen: ponencias, experiencias, instalaciones, exposiciones, talleres, combos, videoconferencias, Jam sessions, clases de instrumentos, big band, conciertos y representaciones (performances).

\subsection{PLANTEAMIENTO}

El festival Jazz Panorama es un evento anual organizado por Sedajazz desde el año 1997. Inicialmente se ha celebrado en el Hort de Trénor de Torrent, pero desde hace unos años tiene lugar en el Auditori de Torrent. En este festival se organizan una serie de conciertos en vivo al que son invitados distintos artistas del mundo del Jazz; para esta convocatoria cabe destacar la participación de Latino Blanco Band, Eliane Elias, Pierrick Pedron Quartet, Kurt Elling y Sopra Le Nuvole.

Jazz \& Arts Meeting es un evento celebrado por primera vez en el año 2007, dentro del festival Jazz Panorama, para propiciar la interacción 
del Jazz con otras artes como el cine, teatro, pintura, escultura, poesía, electrónica, multimedia, etc., mediante diferentes experiencias de carácter formativo y con el fin de crear sinergias creativas. El evento se organiza mediante una serie de clases magistrales y prácticas, dirigidas tanto a músicos como a artistas de otras disciplinas. Con todo ello se pretende acortar distancias entre artistas de diferentes ámbitos, para seguir con la difusión del Jazz como lenguaje universal.

Para este evento, se propuso preparar un taller y realizar una representación en vivo de 15 minutos de duración con los alumnos asistentes al taller, que tendría lugar en el escenario del auditorio junto con las representaciones de otros talleres. Para ello se realizó una aplicación de realidad aumentada en la que se interaccionara con la visualización de los sonidos generados por los instrumentistas, y pudiera ser condicionada por los movimientos de uno de ellos, dentro de un entorno aumentado. En la fase del taller, los músicos adquieren conocimientos sobre la realidad aumentada, cómo funciona la aplicación y cómo interactuar con ella; también se explica el sistema a la audiencia antes de la representación. Hay que mencionar que durante la fase de taller, el feedback que se estableció con los músicos permitió modificar algunos parámetros de la aplicación para que se visualizase de una forma más didáctica y precisa.

Para la realización de este ensayo conté con la colaboración de la Doctora Cristina Portalés Ricart (Portalés Ricart, 2008), Ingeniera en Geodesia y Cartografía especializada en Realidad Aumentada, a la que debo agradecer su implicación tanto en la fase de laboratorio como en la preparación del taller y posterior coordinación y asistencia técnica durante la performance. También debo agradecer la participación del 
Laboratorio de Luz durante la fase de montaje, y al trombonista Toni Belenguer de Sedajazz por su implicación en la fase del ensayo y representación posterior.

\subsubsection{MARCO EN EL QUE SE INSCRIBE EL ENSAYO}

Siguiendo las descripciones que se han hecho en el mapa de conceptos (ver apartado 0.5) se puede presentar un marco general de este ensayo:

- Sensores: Micrófono, cámara Web y sensor inercial MT9 (XSens, 2007).

- Electrónica en Vivo: No se requiere.

- Tiempo real: Procesamiento de los datos que recoge el micrófono y el sensor inercial.

- Obra abierta/cerrada: Obra abierta.

- Partitura: No se requiere.

- Intérprete: Se requiere un grupo instrumental.

- Performance: No se requiere.

- Instrumentos acústicos: Se requiere un grupo instrumental.

- Improvisación: Se improvisa en el lenguaje musical de Jazz.

- Entorno o medio de reproducción: Concierto.

- Procesamiento digital imagen/sonido: Generación de un objeto 3d a partir de los datos del sensor y del sonido recogido por el micrófono.

- Software: Max MSP + Jitter (Cycling74, 2010). 


\subsubsection{MARCO TEÓRICO}

Este ensayo está basado en la tecnología de Realidad Aumentada. La realidad aumentada (RA, Augmented Reality) es una disciplina relativamente reciente. Las primeras definiciones que podemos encontrar restringen la RA a aquellos sistemas que utilizan displays tipo Head Mounted Displays (HMD, conocidos como cascos de realidad aumentada), apuntando además a un carácter exclusivamente visual. Definiciones posteriores extienden el concepto de RA, abriendo el campo a otros dispositivos y a contenidos multimedia no necesariamente visuales, por lo que surgen nuevas posibilidades. A continuación se apuntan algunas de estas definiciones:

- En (Janin et al., 1993) se utiliza el término de RA para definir un HMD que permite al usuario ver su entorno como una superposición de gráficos generados por ordenador.

- Según (Beaudouin-Lafon, 1994):

'La $R A$ reconoce que la gente está acostumbrada al mundo real, el cual no puede ser reproducido de forma fidedigna en un ordenador. Por lo que la RA lo que hace es construir en el mundo real aumentándolo con capacidades computacionales'.

A continuación hace una comparativa con la RV:

'En lugar de insertar al usuario en un mundo generado por ordenador, la $R A$ recubre el mundo real con el mundo virtual, o incrusta/fusiona ambos mundos'.

- De acuerdo con (Barfield, 1995) el concepto de RA

'se refiere a la ampliación del mundo real con imágenes sintéticas, por lo que no se requiere que la escena esté completamente generada 
por ordenador, sino que la imagen sintética se utiliza como complemento de la escena del mundo real'.

Sin embargo a continuación se añade:

'La RA no debe entenderse como exclusivamente visual, sino que debe incluir también información táctil/tangible y auditiva'.

- En (Bimber et al., 2005b) no se da una definición formal de lo que es RA, sino que se deja a disposición del lector quien, después de haber leído el libro, deberá reflexionar sobre la cuestión. Sin embargo, sí se hace una comparativa con los sistemas de RV, diciendo que, en contraposición a estos,

'en los sistemas de RA el entorno real no se suprime por completo, sino que juega un papel fundamental ya que, en lugar de someter a los usuarios en una inmersión dentro de un mundo puramente sintético, la RA intenta adherir suplementos sintéticos al mundo real'.

Subraya además, que existe un fuerte vínculo entre ambos mundos (real y virtual) establecido principalmente mediante una relación espacial.

Esta última reflexión se aproxima más al concepto de realidad aumentada actual, pues considera un terreno más amplio, sin restringir la tecnología de realidad aumentada a los sistemas que utilizan dispositivos HMD o son puramente visuales. También aporta un dato fundamental que no encontramos en las definiciones anteriores: la relación espacial que se establece entre el entorno real y el mundo virtual (o elementos virtuales) generados por ordenador. Este hecho implica directamente la necesidad de que exista algún tipo de sensor(es) que establezca(n) dicha relación. Considerando el entorno real como un espacio de tres dimensiones (3D), el problema 
queda resuelto mediante el cálculo de seis parámetros, que son tres traslaciones y tres rotaciones (ver apartado 2.1.2).

Según (Sherman y Craig, 2003), los sistemas de RA tienen constreñimientos de diseño que difieren de los sistemas de RV. Mientras que en la RV el objetivo es la visualización de suficientes polígonos para que el entorno creado sea creíble, en la RA el mundo ya existe, y sólo es necesario añadir una pequeña cantidad de información. Así pues, para la RA el reto consiste en producir sistemas independientes, portables, y que sean capaces de registrar y/o ubicar de forma precisa el entorno virtual en el entorno real. Además, los entornos visualizados en sistemas de RV normalmente permiten al usuario moverse de forma virtual por el espacio. Sin embargo, en RA el desplazamiento físico del usuario o de un robot (por ejemplo, en telepresencia) es generalmente el único método aceptado para viajar. En la siguiente figura (Fig. 70) se muestra un ejemplo de un entorno de RA mediante el empleo de las librerías BazAR.

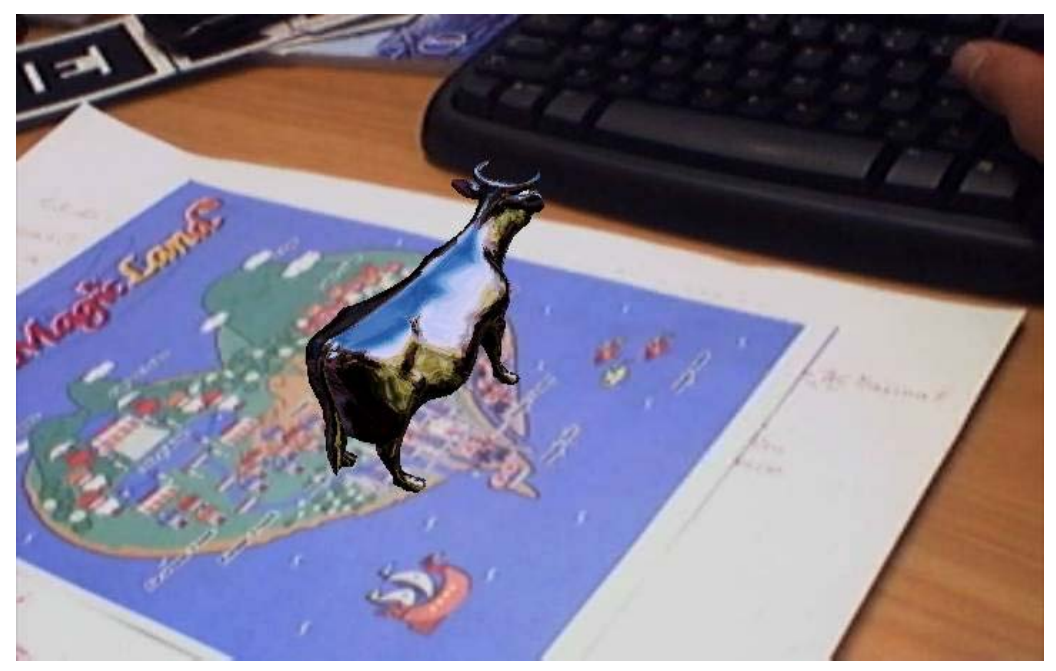

Fig. 70 Ejemplo de entorno de RA mediante las librerías BazAR, en (CVLAB Computer Vision Laboratory, 2007). 


\subsubsection{EL CONTÍNUO DE MILGRAM}

El concepto de realidad mezclada (RM, mixed reality) fue definido por primera vez en (Milgram y Kishino, 1994) a partir del continuo realidad-virtualidad, comúnmente conocido como continuo de Milgram (Fig. 71) que aparece referenciado por múltiples autores, como en (Milgram y Kishino, 1994; Milgram y Drascic, 1997; Billinghurst et al., 2001; Florins et al., 2005; Jacobs y Loscos, 2006; Lam et al., 2006). Según este continuo, dependiendo de la cantidad de entorno generado por ordenador, se puede establecer una clasificación que va desde el entorno completamente real al completamente virtual, pasando por los estados intermedios de realidad aumentada (RA) y virtualidad aumentada (VA). La tecnología de RM engloba a la RA y la VA. La diferencia entre estas dos últimas tecnologías radica en la cantidad de entorno sintético (o contenido generado por ordenador) frente a la cantidad de entorno real, aunque en muchos casos la línea que separa ambas tecnologías es difícil de trazar y algunas aplicaciones no se pueden catalogar claramente en una de estas categorías. Cabe señalar que Migram diferencia entre: Entorno Real - Realidad Aumentada - Virtualidad Aumentada Entorno Virtual. Sin embargo, en esta clasificación se entremezclan distintos conceptos ('entorno' frente a la tecnología de RA o VA). Es por ello que en la Fig. 72 se muestra una modificación (o ampliación) del continuo de Milgram, ya que contempla la diversidad de conceptos paralelos aportados por otros autores, comúnmente referenciados en la bibliografía consultada. 


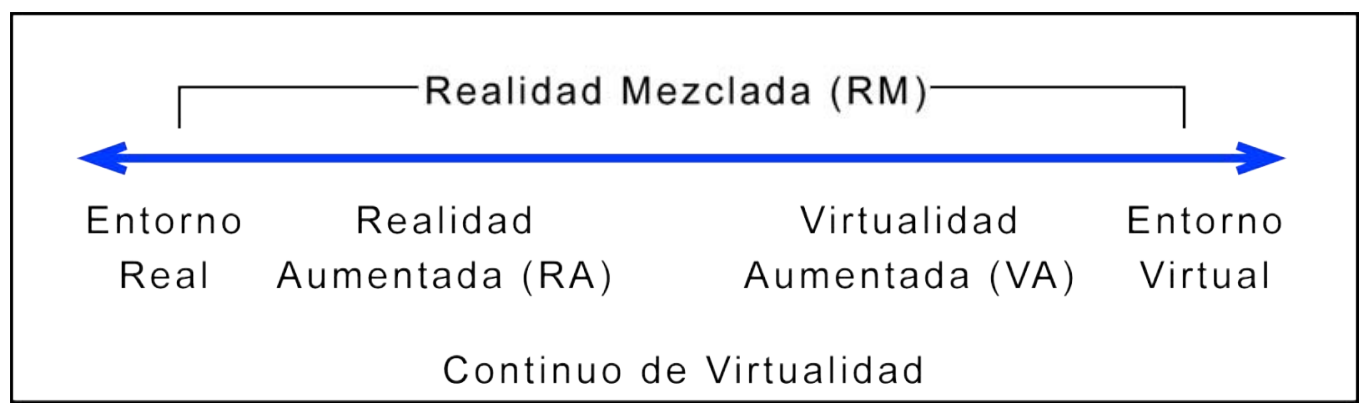

Fig. 71 Continuo de Milgram. A partir de (Milgram y Kishino, 1994).

\begin{tabular}{|c|c|c|c|}
\hline \multirow[t]{2}{*}{ Realidad } & \multicolumn{2}{|c|}{$\begin{array}{l}\text { Realidad Mezclada / } \\
\text { Realidad Híbrida }\end{array}$} & \multirow[t]{2}{*}{ Virtualidad } \\
\hline & $\begin{array}{c}\text { Realidad } \\
\text { Aumentada }\end{array}$ & $\begin{array}{l}\text { Virtualidad } \\
\text { Aumentada }\end{array}$ & \\
\hline \multirow{4}{*}{$\begin{array}{l}\text { Entorno Real / } \\
\text { Mundo Real }\end{array}$} & \multicolumn{2}{|c|}{ Entorno Mezclado / } & \\
\hline & \multicolumn{2}{|c|}{ Entorno Híbrido / } & Entorno Virtual / \\
\hline & \multicolumn{2}{|c|}{ Entorno Aumentado } & \\
\hline & $\begin{array}{l}\text { Entorno Real } \\
\text { Aumentado }\end{array}$ & $\begin{array}{c}\text { Entorno Virtual } \\
\text { Aumentado }\end{array}$ & Mundo Virtual \\
\hline Realidad Real & \multicolumn{2}{|c|}{ Realidad Videográfica } & $\begin{array}{l}\text { Realidad Virtual / } \\
\text { Realidad Sintética }\end{array}$ \\
\hline $\begin{array}{l}\text { o\% contenidos } \\
\text { generados por } \\
\text { ordenador }\end{array}$ & $\begin{array}{c}\text { ]o\%, 50\%[ } \\
\text { contenidos } \\
\text { generados por } \\
\text { ordenador }\end{array}$ & $\begin{array}{c}\text { ]50\%, 100\%[ } \\
\text { contenidos } \\
\text { generados por } \\
\text { ordenador }\end{array}$ & $\begin{array}{c}\text { 100\% contenidos } \\
\text { generados por } \\
\text { ordenador }\end{array}$ \\
\hline
\end{tabular}

Fig. 72 Continuo de Milgram ampliado con otros conceptos.

\subsubsection{CLASIFICACIÓN DE LOS SISTEMAS DE REALIDAD}

\section{AUMENTADA}

Según C. Portalés (Portalés, 2008), actualmente, no existe una única o clara clasificación de los sistemas de realidad aumentada, sin embargo existen algunos términos que establecen cierta catalogación, atendiendo a distintos criterios: 
- Según el entorno físico en el que se desarrolla la aplicación, podemos diferenciar entre sistemas dentro de recintos 0 cerrados (indoors) vs. sistemas al aire libre o abiertos (outdoors). La diferencia entre aplicaciones dentro de recintos y las aplicaciones al aire libre condiciona muchos aspectos de los sistemas de RA establecidos, principalmente el tipo de dispositivos de registro y displays utilizados. De hecho, en aplicaciones al aire libre, se suelen emplear receptores GPS y sensores inerciales para el registro, y PDAs o HMDs para los displays; mientras que en los recintos, los dispositivos de registro y displays son mucho más variados. Ejemplos de aplicaciones en espacios cerrados las encontramos en (Bimber et al., 2000; Broll et al., 2004); en espacios abiertos en (Piekarski y Thomas, 2003; Kameda et al., 2004; Avery et al., 2005).

- Según la extensión que abarquen, podemos distinguir entre sistemas locales (local) vs. ubicuos (ubiquitous). Los sistemas locales se desarrollan en un ámbito acotado, bien en espacios abiertos o dentro de recintos. Ejemplos de aplicaciones locales las podemos encontrar en (Schnädelbach et al., 2002; Park et al., 2006). Las aplicaciones ubicuas (u omnipresentes) son aquellas en las que la extensión del entorno aumentado es tan amplio, que el usuario tiene la sensación de que vaya donde vaya seguirá estando inmerso en la aplicación. En este tipo de RA se suelen utilizar diversas tecnologías de registro que se complementen, para permitir que el usuario pueda entrar en recintos o salir a espacios abiertos. Además, los sistemas suelen ser móviles, ya que el usuario debe desplazarse libremente. En (Kangas y Röning, 2002; Newman et al., 2003; Wagner et al., 
2004; Sandor y Klinker, 2005) se presentan técnicas de registro y aplicaciones en el ámbito de la RA ubicua.

- Según la movilidad de los dispositivos de registro y/o displays podemos distinguir entre sistemas móviles (mobile) vs. sistemas espaciales (spatial). En los sistemas móviles generalmente el usuario lleva consigo los dispositivos de registro, el display e, incluso, el ordenador o PDA que gestiona la aplicación. Estas aplicaciones son usuales, aunque no restrictivas, de espacios abiertos. Algunos ejemplos los encontramos en (Höllerer et al., 1999; Benford et al., 2006; Lee et al., 2006). Contrariamente, en aplicaciones espaciales, los dispositivos de registro y/o displays están fijos en el entorno, utilizándose en muchos casos sistemas de proyección sobre superficies tridimensionales. En (Bimber et al., 2005b) se hace un estudio exhaustivo sobre la RA espacial.

- Según el número de usuarios que simultáneamente pueden interactuar con el sistema, podemos distinguir entre sistemas individuales (individual) vs. colaborativos (collaborative). Así pues, el sistema es individual cuando existe la posibilidad de interacción de un solo usuario, y colaborativa si existe, como mínimo, la posibilidad de participación de dos usuarios de forma simultánea. Ejemplos de aplicaciones colaborativas las encontramos en (Szalavári et al., 1998; Broll et al., 2004; Cooper et al., 2004); de aplicaciones individuales en (Schnädelbach et al., 2002).

- Según el tipo de colaboración establecida (para sistemas colaborativos), podemos distinguir entre sistemas presenciales - cara a cara (face-to-face) vs. remotos (remote). En las 
aplicaciones colaborativas, se distingue si los usuarios colaboran cara a cara, estando físicamente presentes en el mismo entorno, o si la colaboración es remota, estableciéndose generalmente la comunicación a través de la red. Ejemplos de sistemas presenciales los podemos encontrar en (Rolland et al., 2002; Kaufmann y Schmalstieg, 2003); de sistemas remotos en (Billinghurst y Kato, 2002; Flintham et al., 2003).

- A parte de estos conceptos, en (Mackay, 1998) se describe otra clasificación de los sistemas de realidad aumentada introducida anteriormente en el año 1993, atendiendo principalmente a la localización de los dispositivos de registro. Según su autora, se pueden diferenciar varias formas de aumentar la realidad:

1. Aumentar al usuario: El usuario lleva consigo algún dispositivo, generalmente sujeto a la cabeza o en las manos, para obtener información sobre objetos físicos.

2. Aumentar el objeto físico: El objeto físico se transforma mediante la inclusión de entradas, salidas o dispositivos computacionales en él.

3. Aumentar el entorno, el usuario y el objeto: Ni el usuario ni el objeto son afectados directamente. En su lugar, dispositivos independientes recogen información del entorno, visualizando dicha información sobre objetos y capturando información sobre la interacción de los usuarios con los objetos.

Debemos matizar que esta clasificación aportada por Mackay no es de utilización extendida, y puede resultar ambigua si no se contextualiza exclusivamente en la localización de los dispositivos de registro y los 
displays, puesto que generalmente el objeto aumentado es aquel que está enriquecido con elementos generados por ordenador, independientemente de que lleve consigo o no diversos dispositivos.

\subsubsection{CAMPO DE APLICACIÓN}

La realidad aumentada se ha introducido en diversos campos destacando los siguientes:

- Arte: Podemos encontrar diversos ejemplos de piezas de realidad aumentada y realidad mezclada en el ámbito del arte, como por ejemplo en (Shaw, 1989; Hoberman et al., 1998; Koleva et al., 2001; Paul, 2003; Galantay et al., 2004; Wagner et al., 2004; Paulos y Jenkins, 2005; Torpus, 2005; Levin, 2006; Díaz, 2007). En muchos de estos trabajos se entremezclan habilidades artísticas y técnicas, surgiendo interesantes colaboraciones entre artistas, informáticos, tecnólogos, ingenieros, etc.

- Entretenimiento: Dentro del campo del entretenimiento existe una gran diversidad de sistemas de realidad aumentada. Podemos encontrar algunos ejemplos en (Bobick et al., 1999; Badiqué et al., 2002; Cheok et al., 2002; Andersen et al., 2004; Charles et al., 2004; Cooper et al., 2004; Matysczok et al., 2004; Romero et al., 2004; Avery et al., 2005; Barakonyi et al., 2005; Bimber et al., 2005a; Benford et al., 2006; Brandt, 2006; Lam et al., 2006; Park et al., 2006; Peitz et al., 2006; Rashid et al., 2006). No es de extrañar el creciente interés que despiertan estas aplicaciones en este campo; basta con tener en cuenta la gran industria del videojuego que existe en la actualidad con los sistemas de realidad virtual, y las grandes posibilidades que 
puede ofrecer la realidad aumentada como tecnología novedosa.

- Educación: Vinculadas al campo de la educación podemos encontrar también un creciente número de aplicaciones, como las presentadas en (Hall et al., 2002; Kaufmann, 2002; Kaufmann y Schmalstieg, 2003; Gillet et al., 2004; Kaufmann, 2004; Lu et al., 2004; Roussou, 2004; Klopfer et al., 2005; Garzotto y Forfori, 2006; Pan et al., 2006). En algunas ocasiones también se utiliza el término inglés de e-learning para referirse a sistemas de aprendizaje basados en tecnología multimedia.

- Edutainment: El término edutainment nace de la fusión de educación y entretenimiento (education + entertainment). Estos sistemas se basan en el aprendizaje mediante el juego, con el objetivo de ser más eficaces y atractivos. Algunos trabajos de RA dentro de este campo los podemos encontrar descritos en (Bobick et al., 1997; Bobick et al., 1999; Billinghurst et al., 2001; Cheok et al., 2006; De Souza e Silva y Delacruz, 2006; Garzotto y Forfori, 2006; MXR, 2006).

- Medicina: En el campo de la medicina es importante que los sistemas de realidad aumentada utilizados tengan un alto grado de precisión y fiabilidad en el registro, sobre todo si estos sistemas se van a emplear en operaciones que puedan resultar críticas para el paciente. A pesar de la poca madurez de la tecnología de realidad aumentada, como se ha explicado en la introducción de esta tesis, existen muy diversas actuaciones dentro del campo de la medicina, como por ejemplo las explicadas en (Nikou et al., 2000; Weidenbach et al., 2000; 
Rosenthal et al., 2002; Aschke et al., 2003; Balasingham et al., 2003; Fischer et al., 2004; Gelenbe et al., 2005; Konishi et al., 2005; Wacker et al., 2005; Mischkowski et al., 2006; Fischer et al., 2007).

- Psicología: En el campo de la psicología cabe destacar el trabajo desarrollado en la Universidad Politécnica de Valencia por (Juan et al., 2005; Juan et al., 2006a; Juan et al., 2006b; Juan et al., 2007; Pérez et al., 2007), que es pionero en el desarrollo de sistemas de RA para el tratamiento de distintos trastornos psicológicos.

- Ingeniería y arquitectura: Dentro del campo de la ingeniería y la arquitectura se pueden encontrar diversos ejemplos, como los descritos en (Ben-Joseph et al., 2001; Zlatanova, 2001; Bimber et al., 2003; Kaufmann y Schmalstieg, 2003; Broll et al., 2004; Gillet et al., 2004; King et al., 2005; Kealy y Scott-Young, 2006).

- Robótica y telerrobótica: Dentro del área de la robótica y telerrobótica podemos encontrar algunos sistemas de RA descritos en (Halme et al., 1999; Shaheen et al., 2001; Marchand y Chaumette, 2002; Aschke et al., 2003; Stilman et al., 2005; Nawab et al., 2007).

- Industria: En el campo de la industria podemos encontrar diversos ejemplos descritos en (Barfield et al., 1995; Ciulli et al., 1998; Behringer et al., 1999; Bass et al., 2001; Anastassova et al., 2005; Dangelmaier et al., 2005; Wang y Dunston, 2006).

- Militar: La industria militar es quizá uno de los campos que más ha impulsado diversas tecnologías relacionadas con la RA. Por 
ejemplo, tanto los vestidos computacionales como los dispositivos móviles para llevarlos en las manos tienen una procedencia de uso militar. De igual modo, el GPS se desarrolló para ser utilizado por el ejército de los Estados Unidos, y gran parte del software de simulación con tecnología de realidad virtual y aumentada se ha desarrollado para la industria militar. Podemos encontrar algunos ejemplos de aplicaciones en este campo en (Tappert et al., 2001; Hicks et al., 2002; Livingston et al., 2002; Hicks et al., 2003).

\subsubsection{SISTEMAS DE COORDENADAS TERRENO/OBJETO}

Como ya se ha apuntado anteriormente, el registro de los objetos virtuales dentro de un entorno de $\mathrm{RA}$ se hace en el espacio ${ }_{3} \mathrm{D}$; matemáticamente queda definido con 3 rotaciones y 3 traslaciones. Estos 6 parámetros se definen dentro del sistema de coordenadas terreno/objeto considerado. Un sistema de coordenadas es un conjunto de valores que permiten definir inequívocamente la posición de cualquier punto de un espacio euclídeo ${ }^{15}$. El sistema de coordenadas terreno u objeto permite definir la posición espacial de puntos pertenecientes a la superficie terrestre 0 a cualquier otra superficie. Éste es un sistema cartesiano tridimensional definido por las coordenadas $(X, Y, Z)$ y puede ser (Lerma García, 2002):

- Terrestre: Son sistemas de coordenadas fijos o anclados al terreno, y se puede distinguir entre:

- Sistema global (Fig. 73-a), cuando se toma en consideración la Tierra y por lo tanto el sistema de

\footnotetext{
${ }^{15}$ En matemática, el espacio euclídeo o euclidiano corresponde al plano euclidiano, al espacio tridimensional de la geometría euclidiana y a la generalización de ambos a más dimensiones.
} 
coordenadas viene dado de antemano (ej. sistema elipsoidal, sistema astronómico, etc.).

○ Sistema local (Fig. 73-b), cuando se toma en consideración una pequeña proporción terrestre, como por ejemplo una habitación, y el sistema de coordenadas se puede establecer arbitrariamente.

- Centrado en objetos (Fig. 73-c): Son sistemas de coordenadas situados en objetos, y por lo tanto no dependen del entorno en que esté situado dicho objeto. El objeto puede permanecer estático o estar en movimiento con respecto a la cámara, y se pueden dar distintos casos en aplicaciones de RA:

- El objeto y la cámara permanecen estáticos (su posición relativa será constante en el tiempo),

○ La cámara está fija y el objeto en movimiento,

- La cámara está en movimiento y el objeto fijo,

○ Tanto el objeto como la cámara están en movimiento.

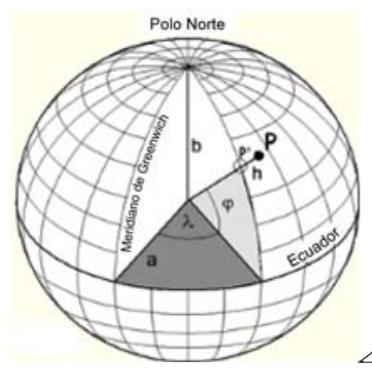

TERRESTRE GLOBAL

a

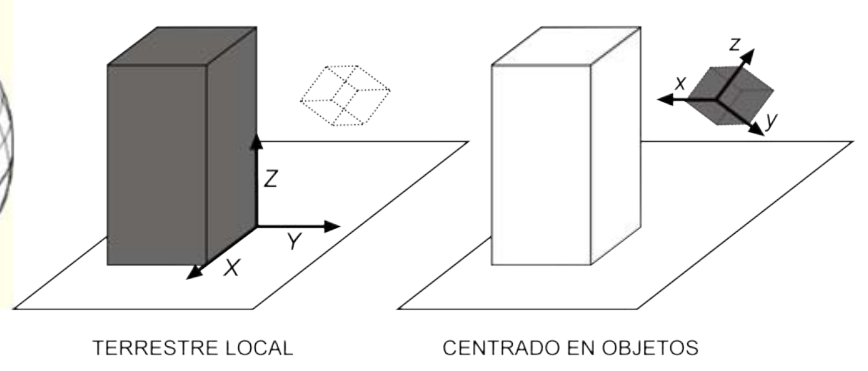

b

C

Fig. 73 Sistemas de coordenadas: a) Terrestre global: b) Terrestre local; c) Centrado en objetos, (Portalés, 2008) 
Los últimos tres casos citados se pueden considerar como uno sólo desde el punto de vista matemático, puesto que los tres implican que la posición relativa entre la cámara y el objeto no permanece constante, y por lo tanto es necesario el registro de la orientación externa en todo momento. De otro modo, en el caso en el que el objeto y la cámara permanecen estáticos, sólo será necesaria la previa calibración del sistema cámara-objeto.

En los sistemas centrados en objetos, la no dependencia del entorno físico puede suponer una gran ventaja, si lo comparamos con los sistemas terrestres que implican una transformación adicional, es decir, la orientación externa de la cámara y del objeto deben conocerse en el sistema terrestre para posteriormente poder obtener la orientación externa relativa cámara-objeto, necesaria para la construcción del entorno aumentado. El problema se reduce considerablemente cuando la cámara o el objeto están fijos, puesto que sólo será necesaria la obtención de la orientación externa en todo momento del objeto móvil, mientras que el otro bastará con calibrarlo de antemano. Es por ello que el registro en sistemas de referencia terrestres puede presentar limitaciones, puesto que implica que los objetos del entorno estén calibrados con respecto del sistema de referencia del sensor y que, después de la calibración, estos no se muevan (Neumann, 2001) - o de moverse, tanto el objeto como la cámara deberían llevar sensores, con el consiguiente encarecimiento del sistema, mayor complejidad de cálculo y disminución de precisiones (ya que los sensores deben estar calibrados/alineados entre sí).

Por otra parte, existen una serie de características propias de los sistemas terrestres globales que los hacen apropiados para muchas 
aplicaciones. La principal característica o ventaja es la posibilidad de abarcar grandes extensiones de terreno, por lo que son idóneos para aplicaciones abiertas. En este sentido, el registro en los sistemas de referencia terrestres locales o centrados en objetos suelen estar limitados al entorno de los objetos y/o al entorno visto por la cámara, siendo más utilizados en aplicaciones dentro de recintos.

A continuación se muestra una tabla comparativa entre los sistemas de registro terrestres y los centrados en objetos (Fig. 74):

\begin{tabular}{|c|c|}
\hline Sistemas de registro terrestres & $\begin{array}{c}\text { Sistemas de registro centrados en } \\
\text { objetos }\end{array}$ \\
\hline $\begin{array}{l}\text { Asumen que los objetos están } \\
\text { calibrados con respecto a la } \\
\text { infraestructura }\end{array}$ & $\begin{array}{l}\text { Permite que los objetos registrados se } \\
\text { muevan libremente en el entorno }\end{array}$ \\
\hline $\begin{array}{l}\text { El registro puede abarcar grandes } \\
\text { extensiones }\end{array}$ & $\begin{array}{l}\text { El registro es local al entorno de los } \\
\text { objetos }\end{array}$ \\
\hline $\begin{array}{c}\text { Pueden haber grandes infraestructuras } \\
\text { de registro que sean partes } \\
\text { permanentes del entorno }\end{array}$ & $\begin{array}{l}\text { Los objetos llevan consigo una } \\
\text { infraestructura de registro mínima, que } \\
\text { tiene pequeño impacto en el entorno }\end{array}$ \\
\hline $\begin{array}{c}\text { La resolución y precisión están en } \\
\text { unidades terrestres fijas relativas a los } \\
\text { componentes del sistema de registro } \\
\text { (ej. centímetros o pulgadas) }\end{array}$ & $\begin{array}{c}\text { La resolución y precisión son relativas a } \\
\text { la visión que la cámara tiene de los } \\
\text { objetos (los errores en unidades de píxel } \\
\text { varían en un rango de dimensiones } \\
\text { terrestres) }\end{array}$ \\
\hline $\begin{array}{l}\text { El registro de las oclusiones es } \\
\text { dificultoso }\end{array}$ & $\begin{array}{l}\text { El registro de las oclusiones se puede } \\
\text { llevar a cabo de manera semiautomática }\end{array}$ \\
\hline
\end{tabular}

Fig. 74 Comparación de dispositivos de registro, en (Neumann, 2001).

Además de las consideraciones generales de sistemas de referencia terrestres o centrados en objetos (dentro del entorno real), hay que señalar que el entorno virtual también tendrá su propio sistema de referencia, el cual deberá coincidir con el real o, de otro modo, deberá conocerse la matriz de transformación que los relaciona. 


\subsubsection{ORIENTACIÓN ESPACIAL}

Según el tipo de sensores y la metodología empleada para el cálculo de los parámetros de la orientación externa de la cámara, podemos distinguir varios tipos de sistemas:

- Métodos directos: Obtención de parámetros de la orientación externa directamente a través de los sensores, como un receptor GPS (registro de la posición espacial) o un INS (registro de las rotaciones).

- Métodos indirectos: Cálculo de la orientación externa, mediante técnicas y algoritmos matemáticos, a partir de los valores capturados por un sensor. Este apartado hace especialmente referencia a las cámaras (vision-based tracking), y a la necesidad de utilizar técnicas de visión por computador o de fotogrametría para el cálculo de la orientación externa a partir del análisis de la imagen.

- Métodos mixtos: Combinación de los anteriores. Como por ejemplo, un sistema combinado de INS y cámara que registra marcas fiduciales ${ }^{16}$.

Cada tipo de sensor registra unos datos distintos o de distinta manera, con lo que el cálculo posterior para obtener la orientación externa varía de unos a otros.

\subsubsection{DISPOSITIVOS DE REGISTRO / CONTROLADORES}

- Sensores mecánicos: Los sensores mecánicos pueden resultar un sistema económico y relativamente preciso para registrar la

\footnotetext{
${ }^{16}$ Marcas con diseños geométricos que son reconocibles por sistemas de medición.
} 
posición de la cabeza o de una parte del cuerpo (National Research Council Staff, 1994). Este tipo de sensores pueden medir incluso el movimiento del cuerpo por completo y no tienen latencias intrínsecas. La fuerza de reflexión se incorpora montando actuadores en las juntas de los enlaces. Se pueden distinguir dos tipos dependiendo de si los enlaces mecánicos los lleva enteramente el usuario sujetos a su cuerpo (body-based) o si están parcialmente anclados/enlazados al suelo (groundbased).

- Sensores magnéticos: Uno de los sensores de posicionamiento más populares son los de tipo magnético debido a su bajo coste, precisión modesta pero razonable y comodidad de manejo. Los sensores magnéticos no sufren de problemas de visibilidad, aunque son sensibles a campos magnéticos y materiales ferromagnéticos. Se suelen emplear varios sensores para registrar el movimiento del cuerpo entero.

- Sensores ópticos: Dentro de los sensores ópticos, hay distintas metodologías para el registro de la posición y/o orientación. Según (National Research Council Staff, 1994) la distancia se puede medir por triangulación (por ej. estéreo-visión), por tiempos (radar láser), o por interferometría. Se puede utilizar la luz pasiva del entorno (sistemas de estéreo-visión), la luz puede ser pulsada (radar láser), o se pueden poner sobre un cuerpo móvil una serie de marcas activas (diodos emisores de luz infrarroja - IREDs) o pasivas. Las cámaras o capturadoras pueden emplear series de CCDs (Charge Coupled Device) lineales o planos, PSDs (Position Sensing Detectors), o fotodiodos. 
- Sensores acústicos: Los sensores acústicos necesitan de al menos tres micrófonos para triangular la señal proveniente de un emisor sobre un cuerpo móvil. Para aplicaciones que requieran de precisiones y velocidades modestas, estos sensores son una alternativa económica a los sensores magnéticos, ya que los rangos son mayores y no se producen interferencias magnéticas. Sin embargo, se debe mantener una clara línea de visión entre el transmisor y el receptor, y la latencia es proporcional a la distancia más larga medida. Otro inconveniente se debe a las posibles interferencias acústicas causadas por diversos aparatos y a los ecos de las superficies duras, que pueden tener hasta un 90\% de reflectividad a las ondas ultrasónicas (National Research Council Staff, 1994).

- Sensores inerciales: La inercia se define como la propiedad de los cuerpos a mantener constante la velocidad lineal o rotacional, a menos que otras fuerzas actúen sobre éstos, de acuerdo a la primera ley de Newton. Por lo tanto, un sistema de referencia inercial es un sistema de coordenadas en el que se cumplen las leyes de Newton. Estos sistemas no se encuentran en rotación ni aceleración (Grewal et al., 2001). Los sensores inerciales (INS, Inertial Navigation Syste, o IMU, Inertial Motion Unit) se basan en fenómenos físicos para medir la aceleración y rotación relativas al sistema de referencia terrestre. Estos sensores son sistemas integrados que constan de giroscopios, acelerómetros y, en algunas ocasiones, de magnetómetros:

- Giroscopios: Un giroscopio mecánico es un sistema basado en el principio de conservación del momento angular que dice que un objeto rotado con una velocidad angular 
elevada, en ausencia de momentos externos, conserva su velocidad angular.

- Acelerómetros: Un acelerómetro mide la aceleración lineal del objeto al que está sujeto.

- Magnetómetros: Los magnetómetros miden la orientación de un objeto con respecto al campo magnético terrestre.

A partir de los datos registrados por el INS se obtienen de manera inmediata rotaciones $3 \mathrm{D}$. Para el cálculo de la posición, los datos registrados por éste deben ser doblemente integrados, asumiendo que sus condiciones iniciales de posición y velocidad son conocidas. Sin embargo, el resultado es sensible a la deriva y al sesgo del sensor, y los errores en la posición calculada se acumulan con el tiempo (Rolland et al., 2001).

Un ejemplo es el sensor inercial MT9 (Fig. 75) de Xsens (Xsens, 2007). El MTg es un dispositivo de pequeñas dimensiones que integra un giroscopio de referencia para la medida de rotaciones, utilizando sensores inerciales de tecnología MEMS (Micro-Electro-Mechanical Systems). El sensor inercial consta de tres tecnologías integradas: un acelerómetro, un giroscopio y un magnetómetro (consistente en una película fina magneto-resistiva). Su procesador interno, de bajo consumo, provee una orientación $3^{D}$ sin deriva (en forma de quaterniones, medidas angulares o matriz de rotación), junto con las aceleraciones triaxiales, las velocidades angulares (rate of turn) 3D, la orientación en el campo magnético 3D y la temperatura. 

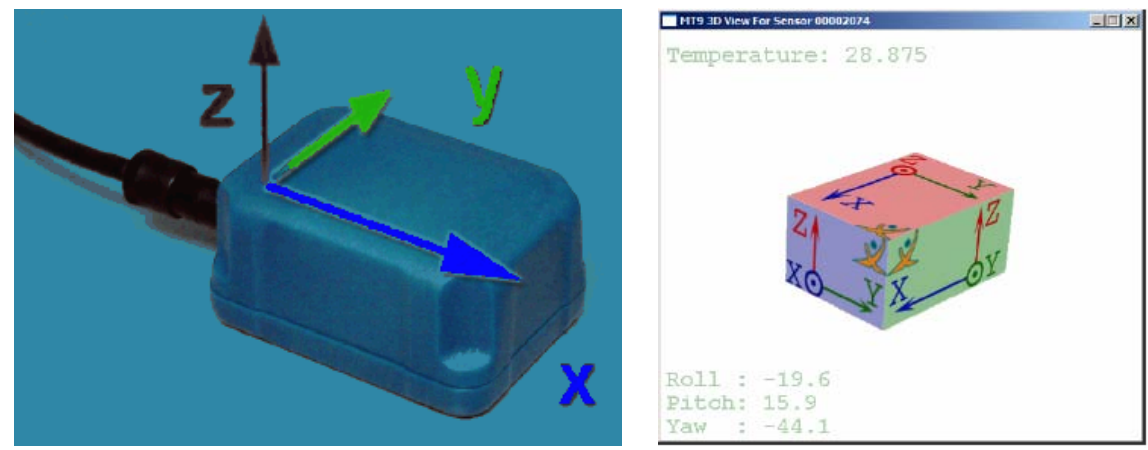

Fig. 75 Sensor inercial MT9 de Xsens y su representación virtual, en (XSens, 2007).

Como se ha explicado, mediante los sensores inerciales se obtienen únicamente las rotaciones; es por ello que muchos autores los utilizan en combinación con otros dispositivos de registro para el cálculo adicional de la posición espacial. En (Piekarski, 2006) desarrollan un sistema de RA en espacios abiertos (Fig. 76) en el que se utiliza la combinación de un GPS y un sensor inercial (el Inertia Cube 2 de Intersense) para calcular los seis parámetros de orientación externa del usuario. También se utilizan una serie de marcas para registrar movimientos de la mano del usuario mediante un sistema óptico. Otros autores que describen sistemas combinados de GPS y sensor inercial son (Azuma et al., 1999; Reitmayr y Schmalstieg, 2004; Avery et al., 2005; Demiris et al., 2005; Dow et al., 2005) (Fig. 75).
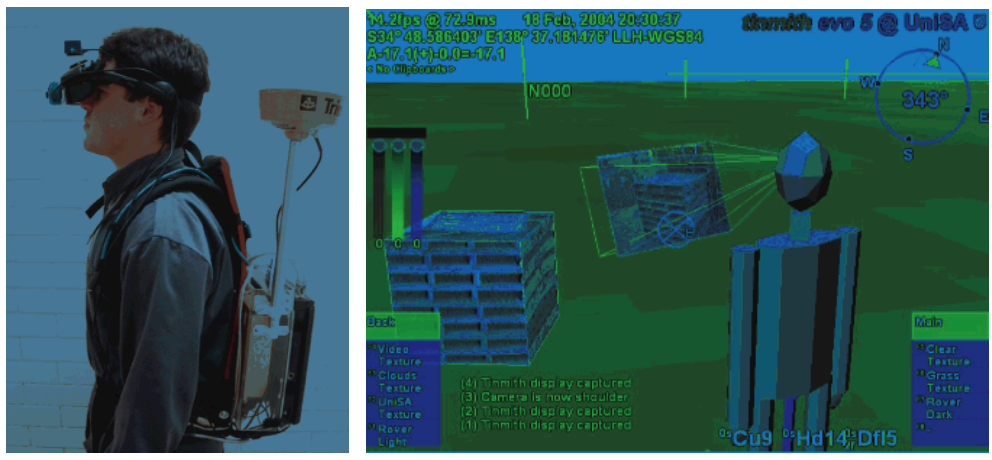

Fig. 76 Aplicación de RA en la que el usuario lleva GPS y un sensor inercial para el registro de su posición y orientación, y marcas para el reconocimiento de gestos de las mano, en (Piekarski, 2006). 


\section{- Sensores de radiofrecuencia:}

○ GPS: El sistema de posicionamiento global (GPS, Global Positioning System) constituye un sistema de radionavegación a escala global, basado en el registro de tiempos y frecuencias (Grewal et al., 2001; Rolland et al., 2001). Teóricamente, el sistema puede determinar la posición de un usuario dotado de un receptor GPS con la señal recibida por tres de los satélites, mediante el cómputo del tiempo que tarda el receptor en recibir las respectivas señales. En la práctica, sin embargo, la señal recibida por el reloj del GPS tiene un error (bias) adicional, por lo que hacen falta un mínimo de cuatro satélites para el cálculo conjunto de la posición y el error del reloj. Con el sistema SPS, el GPS ofrece precisiones en torno a los $100 \mathrm{~m}$; con el PPS las precisiones son diez veces mejores. Sin embargo, gracias al posicionamiento diferencial, mediante estaciones emisoras terrestres que mejoran la resolución del sistema, se consiguen precisiones centimétricas. Existen varios errores de posición que pueden aparecer limitando la precisión. Los errores principales incluyen errores de órbita de satélites, una mala geometría de los satélites, señales de trayecto múltiple, retardo atmosférico y la sincronización del receptor.

○ RFID: El sistema RFID (Radio Frequency IDentification, en español identificación por radiofrecuencia) es un sistema de almacenamiento y recuperación de datos remoto que usa dispositivos denominados etiquetas (tags). El 
propósito fundamental de esta tecnología es transmitir la identidad de un objeto mediante ondas de radio. Una etiqueta RFID es un dispositivo pequeño, similar a una pegatina, que puede ser adherida o incorporada a cualquier objeto. Contienen antenas para poder recibir y responder a peticiones por radiofrecuencia desde un emisor-receptor RFID. Las etiquetas pueden ser pasivas - activas; las primeras no necesitan alimentación eléctrica interna, mientras que las segundas sí lo requieren. Una de las ventajas del uso de radiofrecuencia es que no se requiere visión directa entre emisor y receptor (Wikipedia, 2008b). También se distingue la tecnología M-RFID (Mobile RFID), definida como los 'servicios que proporcionan información en objetos equipados con una etiqueta RFID a través de una red de telecomunicación' (Wikipedia, 2008a).

\subsubsection{DISPLAYS}

- Displays visuales: Los displays visuales o gráficos son dispositivos que permiten visualizar la imagen y están configurados por una serie de componentes ópticos, electrónicos y mecánicos para generar imágenes en algún lugar entre los ojos del usuario y el objeto físico que se aumenta (Bimber y Raskar, 2005). Dependiendo de la óptica que se utilice, la imagen se puede formar en un plano o en una superficie no-plana más compleja.

- Displays sonoros: El display que reproduce la señal digital sonora hacia el mundo analógico es el altavoz o auricular. Este display es un transductor, en concreto, un transductor 
electroacústico que sigue un doble procedimiento: eléctricomecánico-acústico (ver apartado 3.1.2.1). En la primera etapa convierte las ondas eléctricas en energía mecánica, y en la segunda convierte la energía mecánica en energía acústica. Es por tanto la puerta por donde sale el sonido al exterior desde los aparatos que posibilitaron su amplificación, su transmisión por medios telefónicos o radioeléctricos, o su tratamiento.

Según los estudios aportados en (Zhou et al., 2004), la adición de sonido $3^{D}$ puede ser un modo muy efectivo de complementar la experiencia del usuario en entornos de RA. Ayuda a la percepción de profundidad, realización de tareas y facilita la colaboración entre usuarios. Además, permite un entorno más realista y una sensación de inmersión mayor.

- Displays hápticos: En contraste con la naturaleza sensorial de la visión y audición, únicamente los sistemas hápticos permiten a la vez sentir y actuar sobre el entorno, por eso son controladores y displays simultáneamente, conociéndose con el nombre genérico de interfaces hápticas. Estos dispositivos se emplean para tareas que normalmente se realizan con las manos en el entorno real, tales como exploraciones y manipulaciones de objetos. Las interfaces hápticas más comunes utilizadas en entornos de realidad aumentada son aquellos guantes o exoesqueletos que pueden devolver fuerzas al usuario.

- Otros displays: La mayoría de los displays existentes en la actualidad son de tipo visual, sonoro o háptico. Hace una década se afirmaba que estos eran los únicos estímulos reproducibles en un ordenador. Sin embargo, existen algunos 
desarrollos en el campo olfativo y gustativo que tratan de reproducir sintéticamente olores y sabores (Barfield et al., 1995).

- Sistemas multimodales: Los sistemas multimodales son aquellos que integran distintos estímulos reproducidos de forma virtual. Con este tipo de sistemas se enriquecen de manera considerable los entornos aumentados, proporcionando un mayor grado de inmersión mental (o sensación de presencia) del usuario. Este hecho ha sido corroborado en (Ha et al., 2007), en el que se realizan varias pruebas para determinar el grado de inmersión de los usuarios dependiendo de los estímulos reproducidos (solamente visual, sonoro y háptico). El trabajo concluye que los sistemas que mayor grado de inmersión proporcionan son los integrados por 'visual + sonoro + háptico', seguido por 'visual + háptico' y 'visual + sonoro'.

\subsubsection{SOFTWARE: (MAX MSP /) JITTER}

Aunque existen muchos softwares diseñados para aplicaciones de RA (ARToolkit, BazAR, MXRToolkit, AMIRE, etc.) en este apartado nos centraremos en Max MSP Jitter, por ser el utilizado en el ensayo que nos ocupa.

Jitter es un conjunto de más de 130 objetos de vídeo, matrices y gráficos $3 \mathrm{D}$ para el programa Max MSP. Estos objetos extienden la funcionalidad del programa para generar, modificar y manipular datos matriciales - cualquier dato que se pueda expresar en forma de filas y columnas, como vídeos o imágenes estáticas, geometría 3D, texto, 
hojas de cálculo, sistemas de partículas, vóxeles ${ }^{17}$, o audio. Max MSP es un entorno de programación desarrollado en un principio para su uso en aplicaciones interactivas de música, pero ha ido ampliándose con nuevos objetos que hacen de él una herramienta multimedia muy estable.

La arquitectura de Jitter está optimizada para realizar tareas con video (pregrabado o en tiempo real), existiendo para ello una serie de operadores matemáticos, análisis, tratamiento del color, procesamiento del canal alfa, deformaciones espaciales, filtros de convolución y otros efectos. Además, la compatibilidad de Jitter con la arquitectura de QuickTime (OT) de Apple, le permite soportar todos los formatos admitidos por QT, así como la creación de ficheros, operaciones de edición, importar/exportar, efectos de QT, digitalización de vídeo, etc. Para aplicaciones en tiempo real, Jitter permite el control de cámaras de vídeo digital (DV), entrada y salida vía FireWire, y soporte para múltiples monitores.

El soporte integrado de gráficos $2 \mathrm{D} / 3 \mathrm{D}$ proporciona herramientas para utilizar gráficos OpenGL conjuntamente con video, incluyendo la capacidad de texturizar geometría 3D con entradas de vídeo en tiempo real, convertir entradas de audio y vídeo en datos geométricos, y renderizar modelos, NURBS, texto $2 \mathrm{D} / 3 \mathrm{D}$, y otras geometrías.

\footnotetext{
${ }^{17}$ El vóxel (del inglés volumetric pixel) es la unidad cúbica que compone un objeto tridimensional. Constituye la unidad mínima procesable de una matriz tridimensional y es, por tanto, el equivalente del píxel en un objeto 2D.
} 
Debido a las grandes posibilidades que ofrece este programa y a la gran cantidad de objetos que contiene, en los siguientes apartados se introducen únicamente los utilizados en este ensayo.

- Objetos 3d y cámaras virtuales: En este apartado se explican los objetos de control de la cámara virtual, los de los gráficos 3D y su posterior renderización en una ventana de OpenGL. Los objetos de control de la cámara virtual son pak camera para la posición 3D del centro de proyección y pak lookat para indicar la dirección del eje óptico de la cámara (hacia dónde apunta el eje óptico de la cámara). También podemos emplear pak up para establecer el ángulo de rotación a través de la dirección del eje óptico y lens_angle (a través de jit.gl.render) para el ángulo de apertura. En la Fig. 77 se muestra un ejemplo en el que primero se mueve la cámara (de la posición 0, 0, 2 a la posición 2, 2, 6) y a continuación se cambia la dirección del eje óptico (de o, o, o a $2,0,0)$.
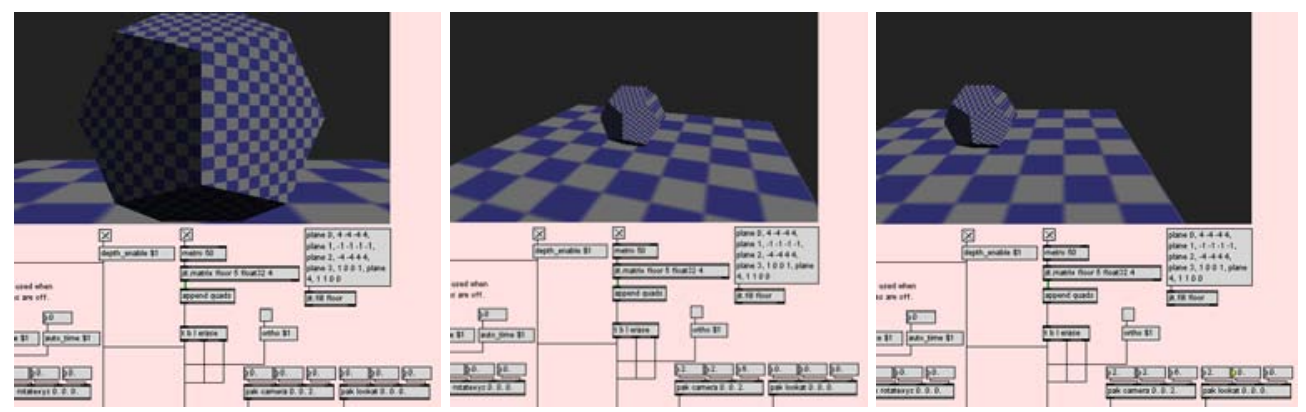

Fig. 77 Ejemplo de cambio de posición y dirección del eje óptico de la cámara virtual

Mediante el objeto jit.gl.render se pueden dibujar y manipular gráficos 2D/3D en una ventana $p$. window de OpenGL. El objeto jit.gl.model (Fig. 78) lee las descripciones de objetos $3 \mathrm{D}$ como colecciones de polígonos. Estas descripciones están guardadas 
en ficheros con formato obj. Así pues, los modelos 3D deben tener esta extensión para ser cargados en Jitter.

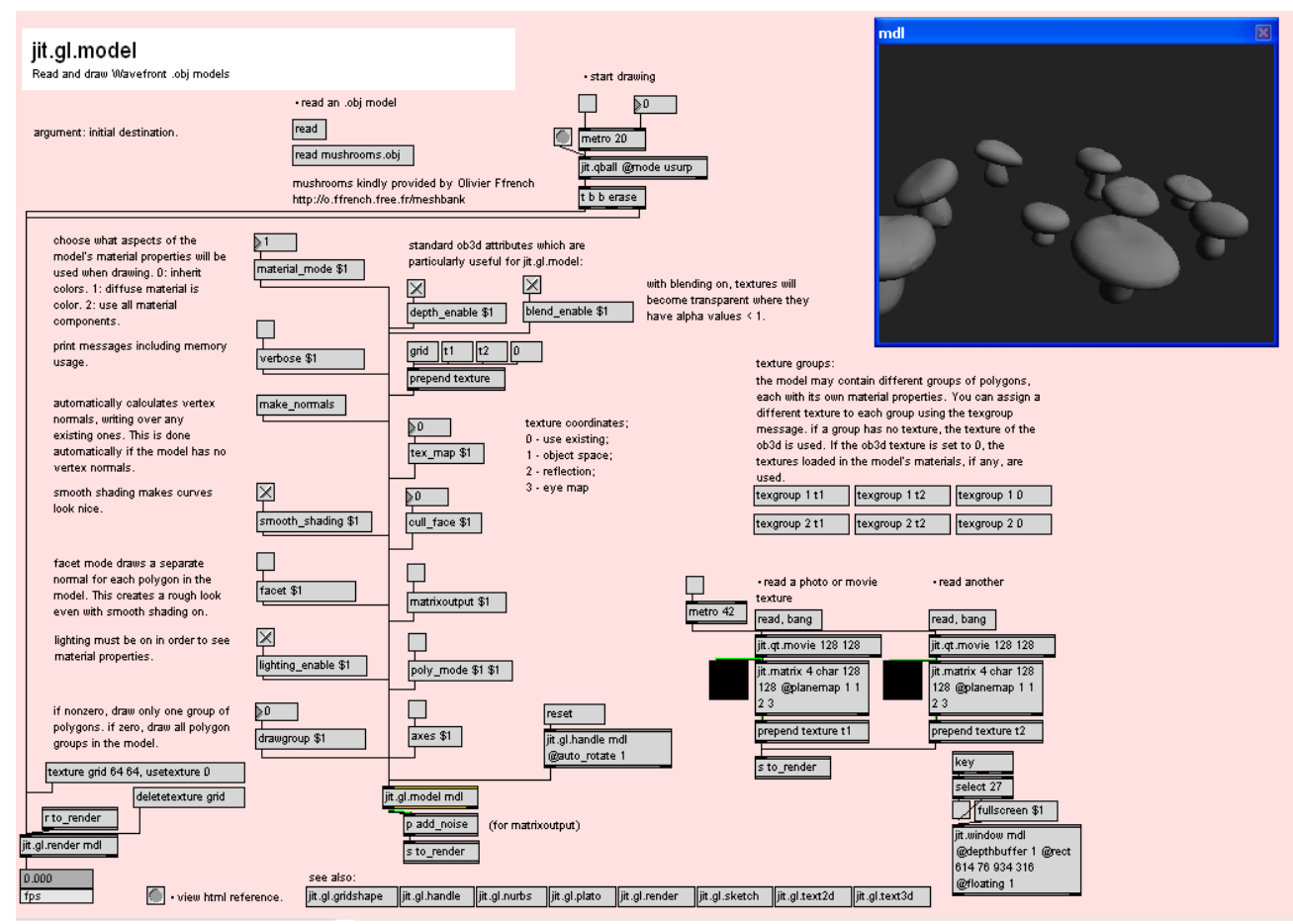

Fig. 78 Objeto jit.gl.model

Mediante jit.gl.model se pueden modificar diversos atributos de los modelos 3D: iluminación y sombreado, textura (imagen estática, vídeo pregrabado, vídeo en tiempo real, o color neutro), grupo de objetos renderizados, tipo de material, etc. En la siguiente figura podemos ver algunos ejemplos de visualizaciones para un mismo modelo (Fig. 79).

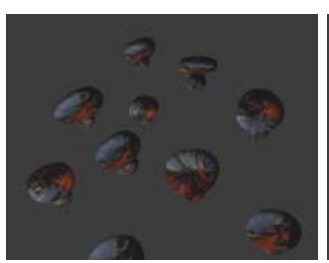

a

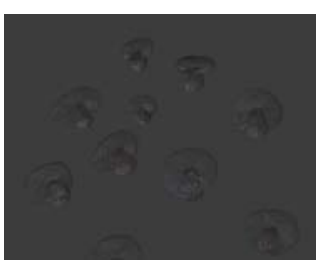

b

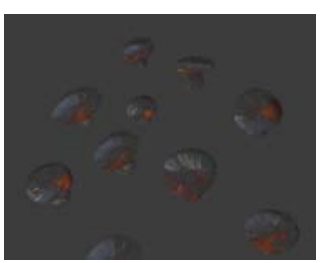

C

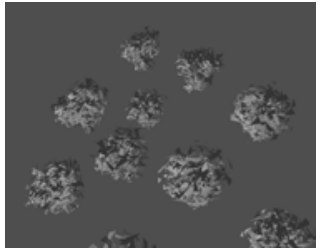

d

Fig. 79 Modelo obj modificado mediante jit.gl.model: a) Mapeado de vídeo; b) Modo de alambres; c) Transparencia (blend activado); d) Salida matricial 
Finalmente, mediante el objeto jit.window establecemos las propiedades (dimensiones, modo flotante, etc.) de la ventana OpenGL, y con el objeto jit.gl.render, designamos los gráficos $2 \mathrm{D} / 3 \mathrm{D}$ que se van a dibujar en dicha ventana.

- Integración de sensores: En este apartado se explican los objetos empleados en este ensayo para integrar distintos sensores en Jitter: cámara Web, micrófono y sensor inercial.

La entrada de la cámara web en Jitter se puede hacer mediante el objeto jit.qt.grab o el objeto jit.dx.grab. La ventaja del segundo en el caso de utilizar un PC, es que no requiere del programa QuickTime VDIG, ya que trabaja con DirectX. Estos objetos deben unirse con jit.gl.render para que la imagen capturada se dibuje en la ventana de OpenGL.

De otro modo, la entrada de la señal del micrófono se gestiona con el objeto adc (analog to digital converter), mediante el cual se registra, a un muestreo determinado, el voltaje recogido por el micro.

La conexión del sensor inercial MT9 de Xsens con el programa Jitter, se puede hacer mediante el objeto mtg programado por Laboratorio de Luz (Fig. 80). Este objeto devuelve las medidas en bruto del sensor (tiempo, aceleración, giros, campo magnético y temperatura) junto con los 9 parámetros de la matriz de rotación calculada. 


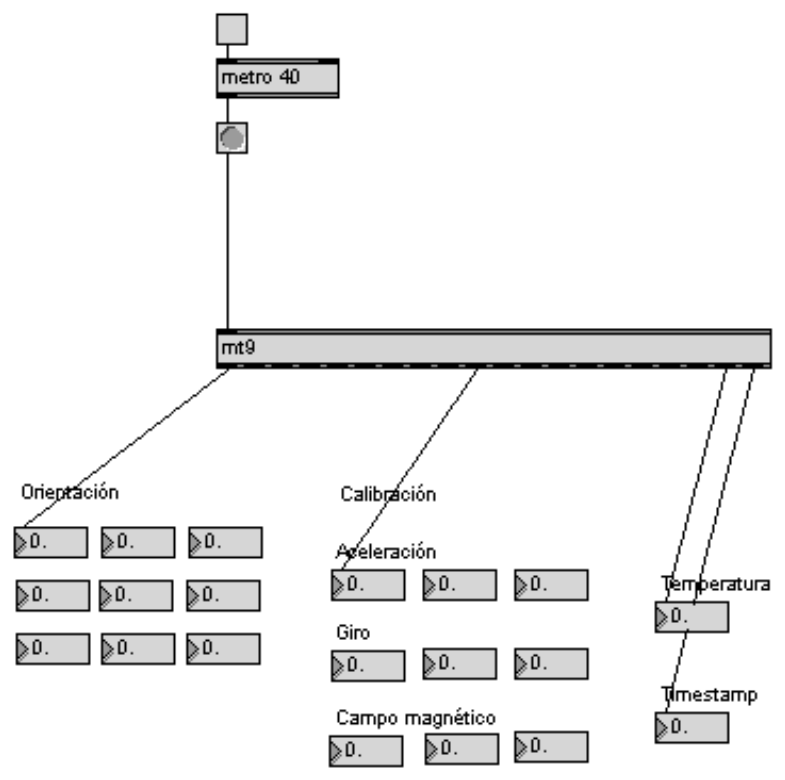

Fig. 80 Objeto mtg para Jitter

- Limitaciones: La principal limitación de este software es que no está expresamente elaborado para la realización de aplicaciones de realidad aumentada. Los procesos de cálculo que la tecnología RA implica (registro y combinación del entorno real y el virtual en tiempo real) hacen que se necesite de diversos objetos que realicen dichas tareas de forma conjunta. La utilización de imágenes de vídeo, gráficos $3 \mathrm{D}$ y, tal vez, registro de marcas fiduciales en las imágenes, hace necesaria la utilización de un hardware suficientemente potente.

\subsubsection{REFERENTES}

Diversos autores han tratado de darle forma al sonido mediante la generación de gráficos por ordenador. Por ejemplo, en (Paul, 2003) se describe la pieza del artista japonés Toshio Iwai, Piano - as image media (1995), en la que se utiliza una partitura virtual para activar las teclas de un piano, induciendo la proyección de imágenes generadas 
por ordenador sobre una pantalla (Fig. 81-a). La partitura la escriben los usuarios, mediante la asignación de puntos sobre una rejilla proyectada delante del piano. Tanto la melodía como las imágenes gráficas se generan de acuerdo a la distribución de los puntos en la rejilla.

Telesymphony (2001) de Golan Levin es una performance en la que los sonidos están generados por los teléfonos móviles de la audiencia (Paul, 2003). Esta pieza se presentó en un concierto que tuvo lugar en el festival de Ars Electronica de Linz, en el año 2001 (Fig. 81-b). A la entrada, se les pidió a los participantes que registraran sus números de teléfono móvil; a continuación se les asignó un asiento en la sala y se les enviaron una serie de nuevos tonos. Como cada uno de los asistentes tenía un asiento y tono asignado, la performance se podía dirigir perfectamente desde un equipo central mediante llamadas a los móviles. Al sonar el móvil de algún asistente, éste era iluminado por un foco de luz. El resultado se visualizaba en una serie de pantallas a los lados del escenario.

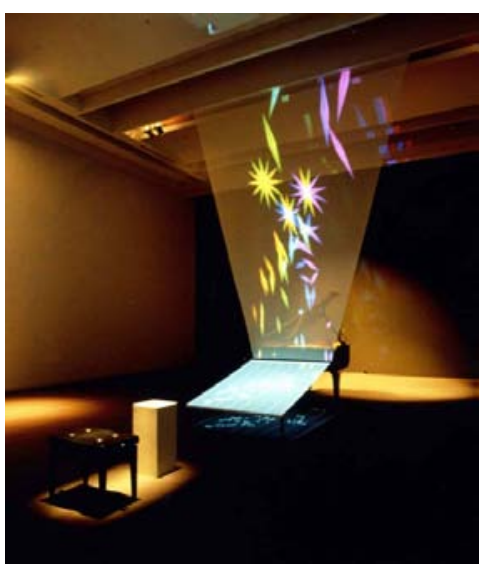

a

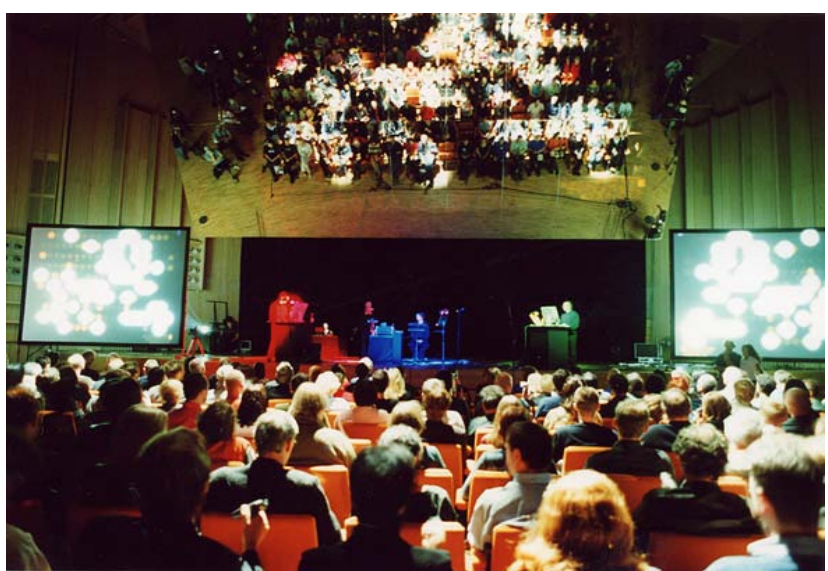

b

Fig. 81 a) Piano - as image media; b) Telesymphony, en (Paul, 2003) 
Messa di Voice (2003) es una performance audiovisual de realidad aumentada (Fig. 82), creada por Golan Levin en colaboración con Zachary Lieberman, en la que se utiliza el registro de los movimientos del cuerpo de dos actores en combinación con el análisis de los sonidos que emiten (habla, gritos, canciones, etc.), para generar unos elementos gráficos que se proyectan sobre una pantalla (Levin, 2006).

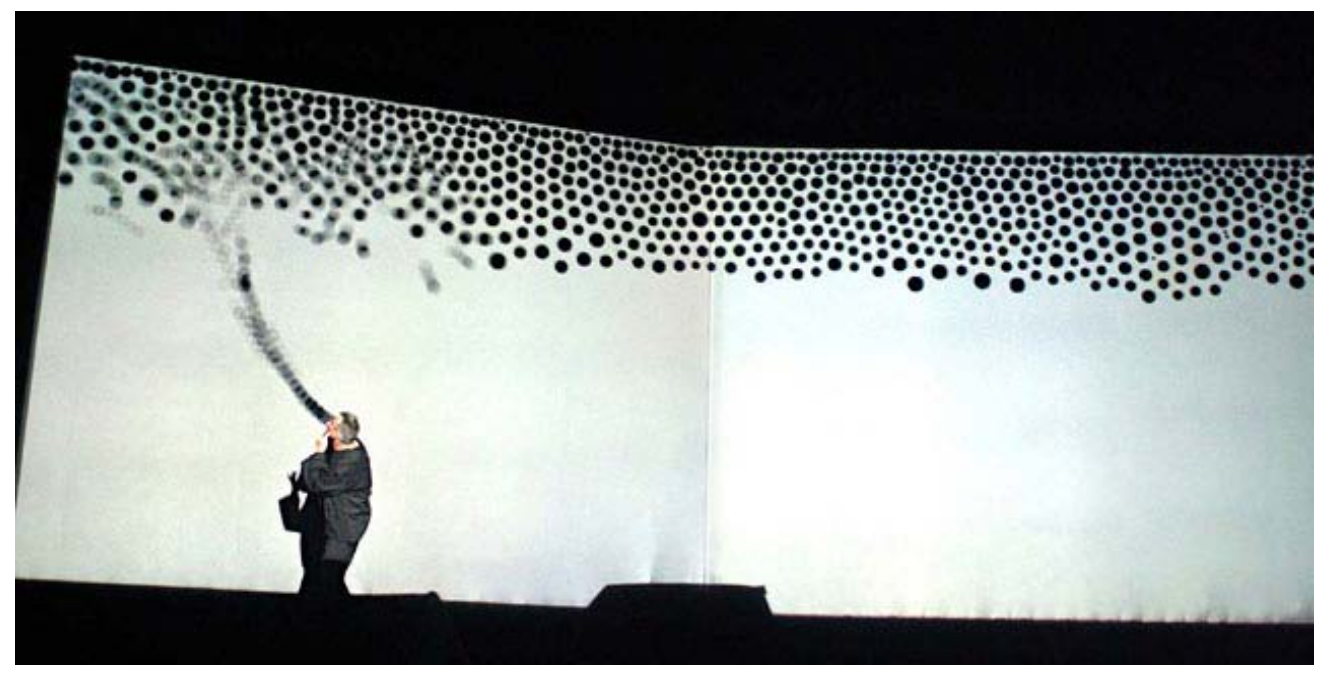

Fig. 82 Messa di Voice, en (Levin, 2006).

Otro referente de estos mismos autores es la pieza Hidden Worlds of Noise and Voice (2002), una instalación audiovisual interactiva de realidad aumentada, instalada durante dos años en la exposición de Ars Electronica Museum of the Future en Linz, Austria. El tema central es la relación mágica entre el habla y el medio etéreo que lo transporta. Los usuarios son capaces de ver una representación de sus voces, mediante figuraciones gráficas animadas que emergen de sus bocas al hablar, a través de un HMD. Cuando uno de los usuarios habla o canta, aparecen diversos gráficos de colores que emergen de su boca, representando dichos sonidos y adquiriendo una gran variedad de formas y comportamientos que están relacionados con las cualidades únicas de su voz (volumen, altura y timbre). Esta 
instalación permite la participación simultánea de seis usuarios, con un amplio rango de inmersión audiovisual y juego conversacional. Aquellos participantes que no estén equipados con los HMD, pueden ver una proyección en la mesa que representa la sombra de los gráficos generados (Fig. 83).

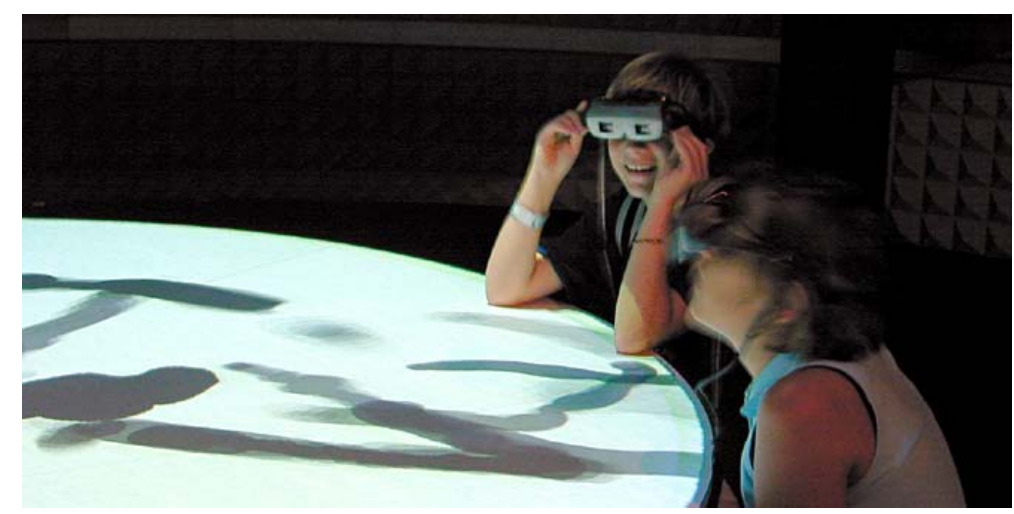

Fig. 83 Usuarios interactuando con The Hidden Worlds of Noise and Voice, en (Levin y Collaborators, 2008).

\subsection{DESCRIPCIÓN TÉCNICA}

\subsubsection{COMPONENTES DE LA APLICACIÓN}

\subsubsection{DISPOSITIVOS FÍSICOS}

Los elementos que conforman la aplicación de Sonido Aumentado son (Fig. 84):

- Un PC de mesa estándar con Sistema Operativo Windows XP.

- El software Max MSP (versión 4.5.5) con el módulo de Jitter (versión 1.5.1).

- Un sensor inercial. Se ha utilizado el MT9 de Xsens. 
- Una cámara Web. Se ha utilizado la cámara Live Cam! Voice de Creative, con un FOV de $85^{\circ}$ y una resolución de $640 \times 480$.

- Una pantalla que funciona a modo de espejo. Las dimensiones de la pantalla del Auditori de Torrent son de 15x11 metros, aproximadamente.

- Un proyector multimedia.

- Un micrófono de condensador AKG C2000.

- Instrumentistas: piano, vocalista, 2 trombones, flauta, batería, bajo eléctrico, tuba, guitarra eléctrica, saxo alto.

Parámetros como la luminosidad o las condiciones acústicas de la sala y de cada uno de los instrumentistas fueron condicionando los ajustes de la aplicación que se encargaba de gestionar cada uno de los dispositivos. Se fueron definiendo con la mayor exactitud posible las posiciones de la cámara y del micrófono así como las distancia de cada uno de los músicos y su instrumento, de modo que el análisis sonoro fuera lo más parecido entre los diversos timbres (Fig. 84). 


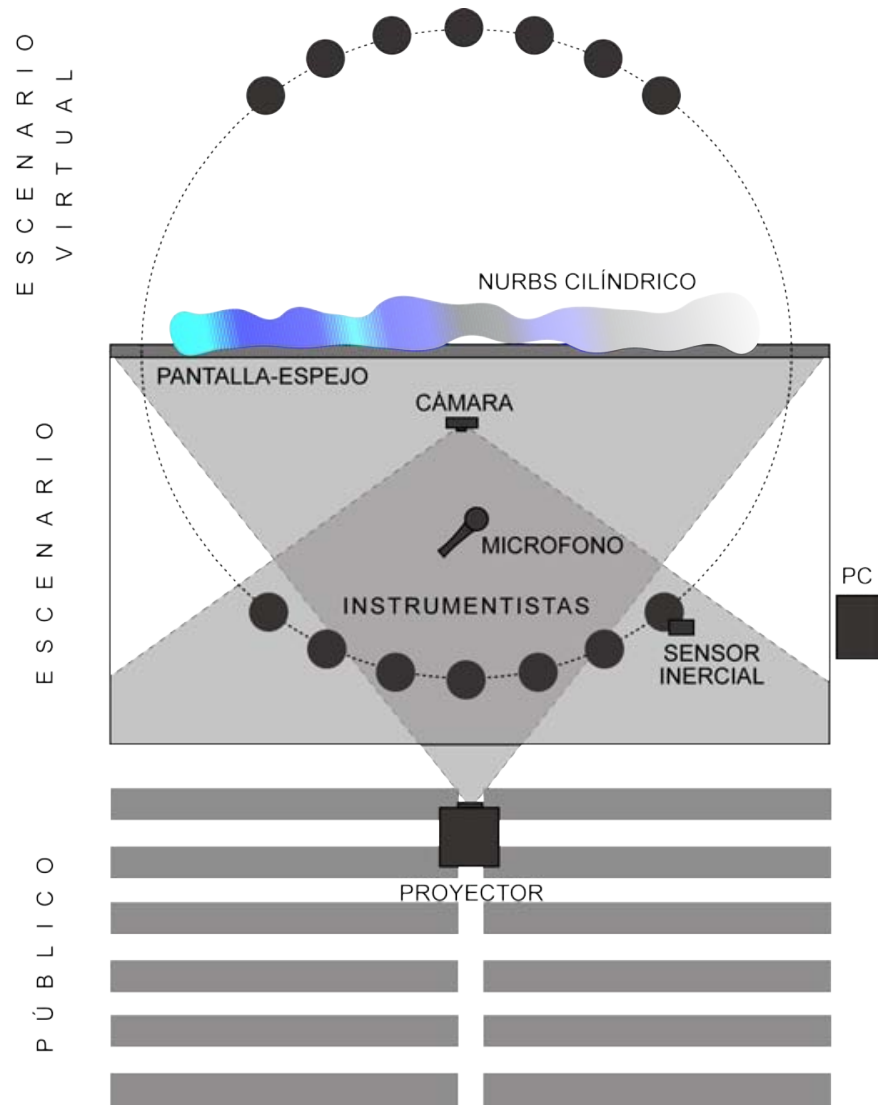

Fig. 84 Esquema de los componentes y distribución espacial de Sonido Aumentado.

La cámara permanece fija en el espacio y apunta hacia los instrumentistas, de tal forma que la pantalla siga la metáfora del espejo mágico (Portalés Ricart, 2008). El micrófono se sitúa entre la cámara y los instrumentistas. La distribución espacial de los instrumentistas (o músicos) en el escenario es tal que, junto con la representación de su imagen vista en la pantalla, forman un círculo en medio del cual se encuentra la representación visual (NURBS cilíndrico; ver apartado 2.2 .1 .2$)$ del sonido que emiten en conjunto. Los músicos dan la espalda al público, con la finalidad de visualizar en todo momento el elemento virtual. El público puede ver el rostro de los músicos a partir de la imagen representada en la pantalla a modo de espejo. 


\subsubsection{ELEMENTOS VISUALES}

Para la visualización del sonido se ha utilizado un elemento virtual que consiste en un NURBS (Non Uniform Rational B-Splines) cilíndrico moldeable a partir del objeto js jitaudioznurbs.js (ver apartado 2.2.2), cuya forma, color, luminosidad y texturizado varía de acuerdo a diversas características sonoras. De este modo, el elemento virtual variará dependiendo del timbre de cada instrumento, las notas que emita (altura) y la intensidad (amplitud). También se han establecido otros parámetros que varían de forma aleatoria o siguiendo un ritmo temporal (ver apartado 2.2.2), así como un cambio en la orientación a partir de las rotaciones del sensor inercial. EI NURBS (Fig. 85) tiene la posición y un ángulo fijos; solamente varían dos de sus rotaciones, las cuales se registran a partir del sensor inercial, que lo puede llevar consigo uno de los instrumentistas, un bailarín o un usuario cualquiera.

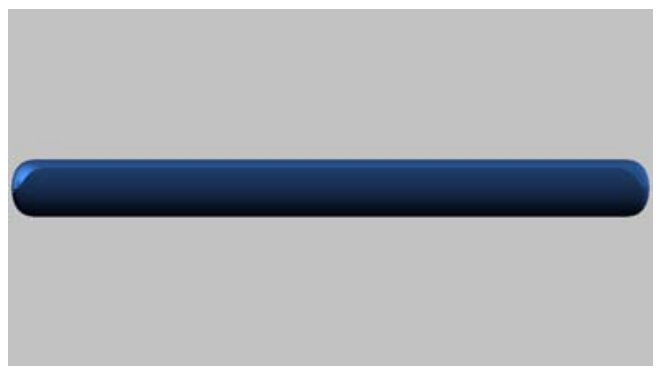

a

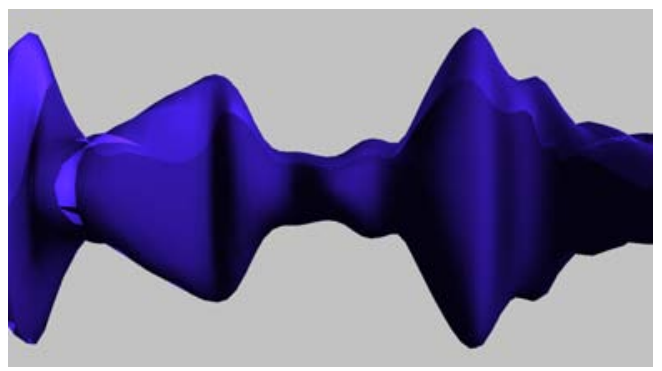

C

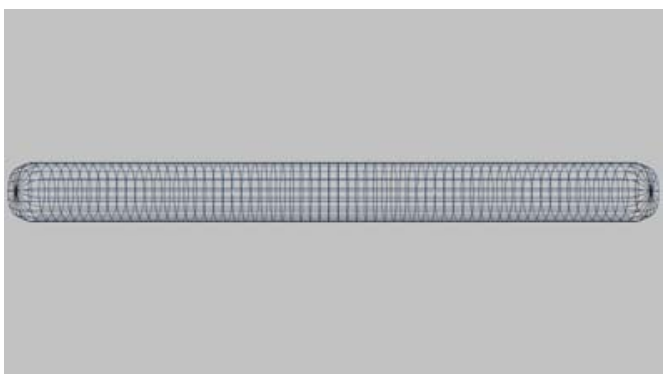

b

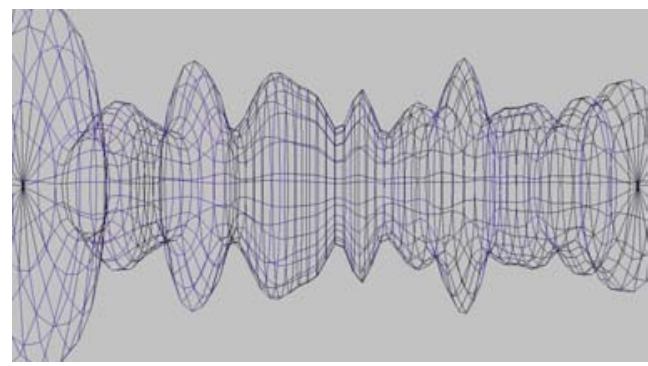

d

Fig. ${ }_{5}$ NURBS cilíndrico a partir de js jitaudioznurbs.js, donde: a) Con textura;

b) Representación alámbrica; c) Con textura y deformaciones a partir de un audio; d) Representación alámbrica y deformaciones a partir de un audio 


\subsubsection{DESARROLLO, PROCESO}

Para la elaboración de Sonido Aumentado se ha utilizado el programa Max MSP Jitter (Puckete y Zicarelli, 1990), en el que se ha desarrollado una aplicación propia de realidad aumentada mediante la combinación de varios objetos. La interacción persona-ordenador se realiza a dos niveles: sonoro y háptico. En el primer caso, la interfaz es un micrófono que recoge los sonidos emitidos por los músicos; en el segundo caso, la interfaz es un sensor inercial que lo puede llevar uno de los instrumentistas $u$ otra persona que desee participar en la visualización del NURBS. A continuación mostramos el patch principal de programación y los sub-patches, explicando cada uno de ellos con detalle.

El patch principal (Fig. 86) está basado en jit.gl.nurbs-audiorender.pat que se distribuye con el módulo de Jitter. El objeto principal es el js jitaudioznurbs.js, que define la forma del NURBS cilíndrico, cuya superficie se deforma de acuerdo al audio mediante programación javascript. La entrada del micrófono se activa mediante el comando startwindow o mediante el objeto IO (Input/Output). La ventana de OpenGL queda definida con el objeto jit.window. Las dimensiones de la superficie cilíndrica varía de 1 a 4 cada 100 segundos (mediante el objeto line), mostrándose en el primer caso con formas angulosas, que se van suavizando a medida que aumentamos el valor numérico. También se han establecido unos tiempos para definir la forma en que se dibuja la superficie (mediante el objeto metro), con lo que una parte del cilindro cambia de texturizado a alámbrico cada 40 segundos, y la otra parte lo hace cada 70 segundos, coincidiendo en el mismo durante ciertos intervalos de tiempo. Todos los elementos que definen al cilindro se envían al objeto jit.gl.nurbs. 


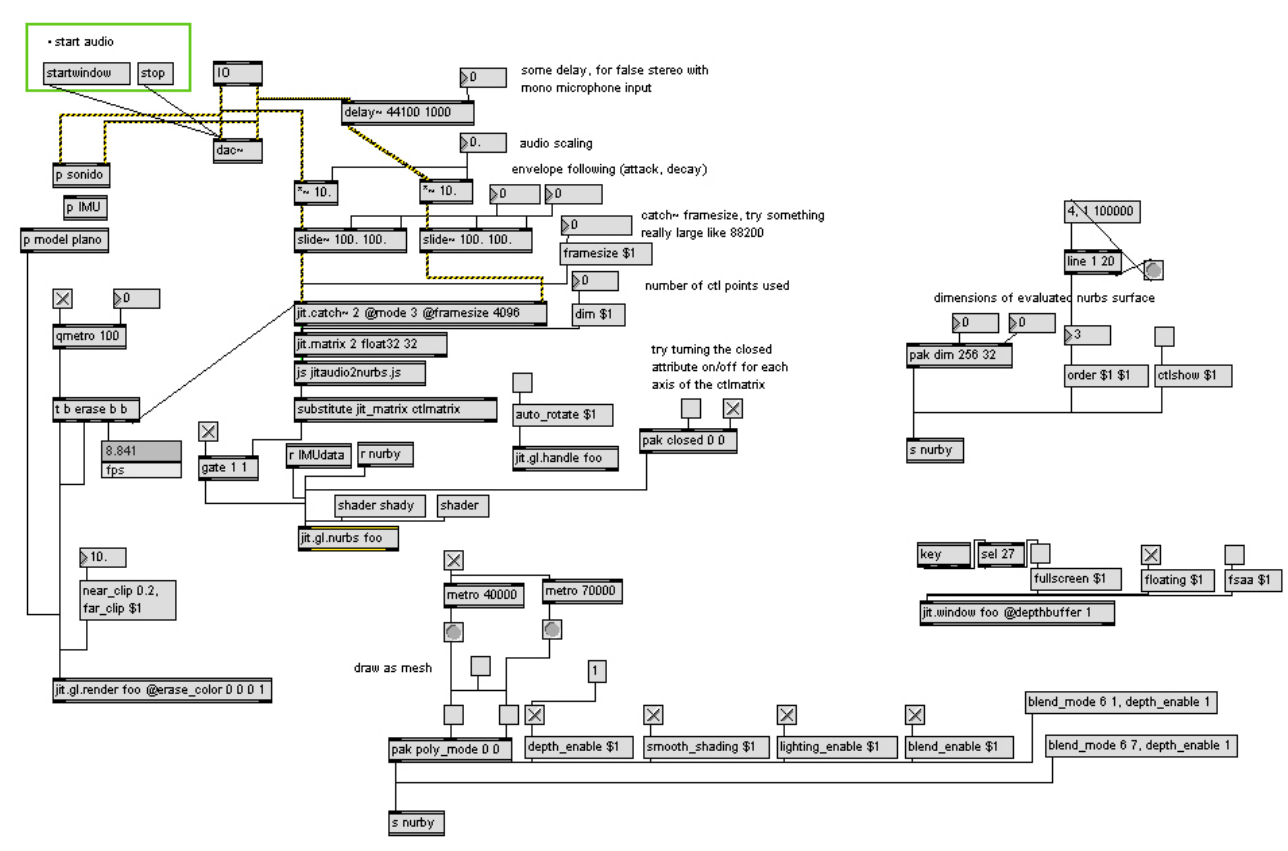

Fig. 86 Patch principal de Sonido Aumentado

p sonido (Fig. 87): en este sub-patch se hace un análisis del sonido que recoge el micrófono mediante el objeto fiddle , obteniendo la altura y amplitud del sonido. Debido a que estos valores cambian muy rápidamente, se calcula la media de los últimos 10020 valores, mediante zl group y mean. A continuación estos valores se escalan mediante división por 100 y son asignados al valor del rojo y a la luminosidad del cilindro virtual. La ganancia de la entrada del micro está ajustada de tal forma que los valores de la amplitud registrada varían entre 70 y $90(\mathrm{~dB})$, por lo que los valores del rojo serán bastante altos (entre 0.7 y 0.9 ), potenciándose así los colores cálidos en el cilindro. El valor de luminosidad tiene establecido un rango, de tal forma que puede variar entre 0.3 y 1, ya que valores más próximos al o hacen que el cilindro se visualice como una mancha negra, y valores por encima del 1 lo emblanquece demasiado. Los valores del verde y del azul son determinados aleatoriamente por el sub-patch $p$ mood_machine. 


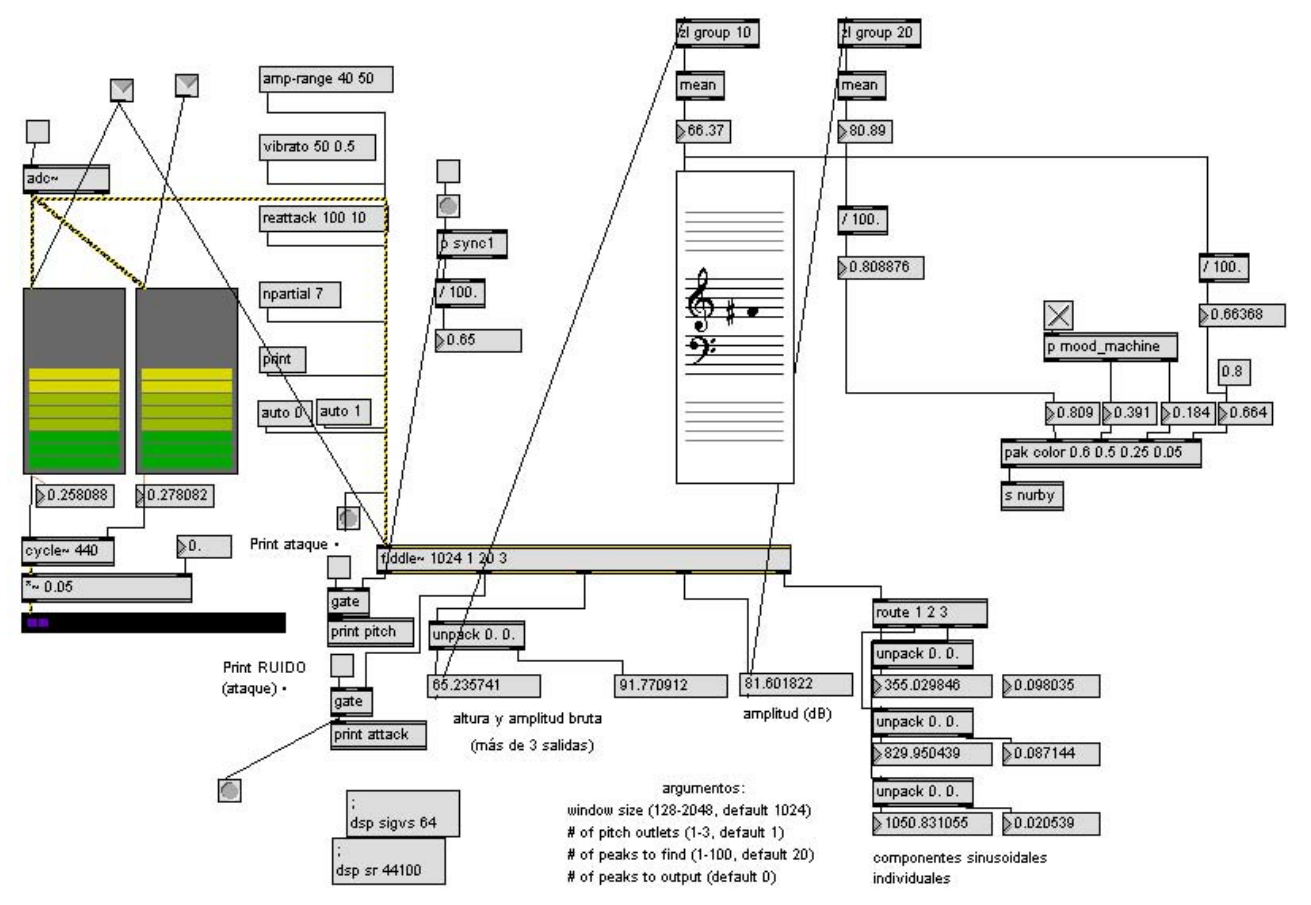

Fig. 87 Sub-patch p sonido

p model plano (

Fig. 88): Carga un plano en formato obj sobre el que se mapea la imagen capturada en tiempo real por la cámara mediante el objeto prepend texture. Este plano se envía a la ventana de OpenGL (con el nombre de foo, en este caso) mediante el objeto jit.gl.model. La posición del plano dentro de la ventana de OpenGL queda establecida con el objeto pak position, la orientación mediante pak rotatexyz, y la escala mediante pak scale. 

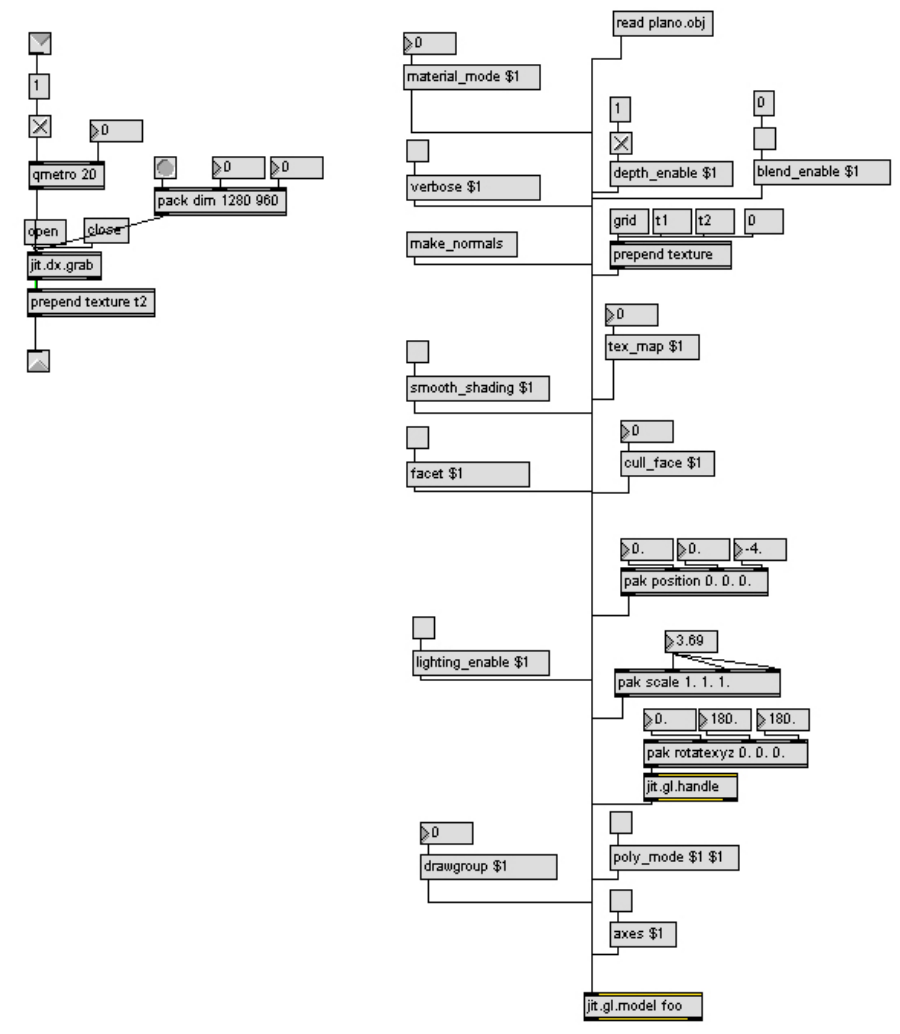

Fig. 88 Sub-patch $p$ model plano

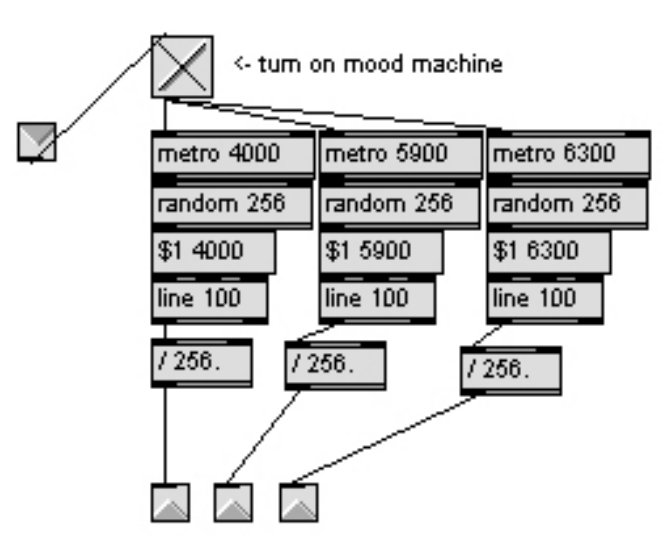

Fig. 89 Sub-patch p mood_machine p mood_machine (Fig. 89):

En este patch se eligen valores entre o y 256 de forma aleatoria mediante el objeto random. Estos valores se envían a continuación al sub-patch $p$ sonido, para asignarlos a los parámetros del verde y del azul del cilindro virtual, dentro de la gama RGB. 


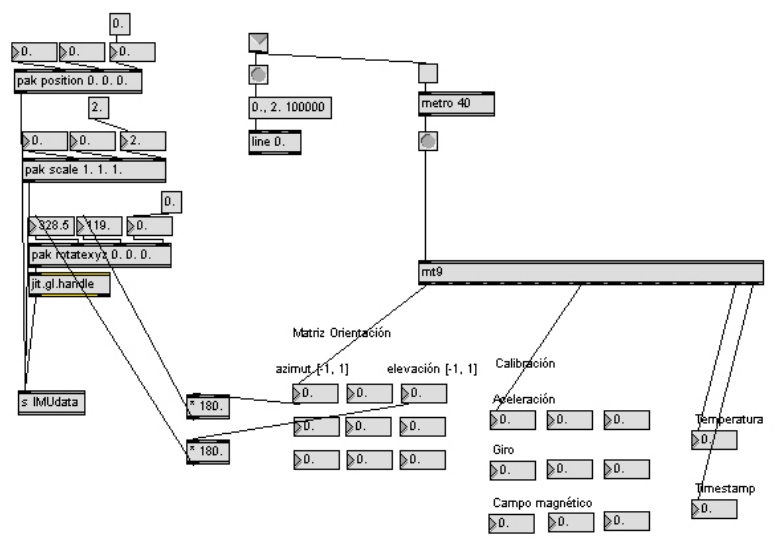

Fig. go Sub-patch p IMU p IMU (Fig. 90): Recoge los valores registrados por el sensor inercial mediante el objeto mtg y asigna dos de sus rotaciones a las rotaciones en $X$ e $Y$ del cilindro virtual, mediante el objeto pak rotatexyz. La posición y escalado del cilindro también se determinan en este patch mediante los objetos pak position y pak scale, respectivamente.

\subsubsection{CONSIDERACIONES / RESTRICCIONES TÉCNICAS}

Es importante mencionar que algunas partes de este ensayo son en cierta manera improvisadas, ya que las características del recinto y las necesidades de los músicos condicionaron algunos aspectos del mismo. En cuanto al escenario, sus dimensiones eran excesivas para el número de músicos que formaron el combo integrado por los asistentes al taller. En este caso la iluminación jugó un papel muy importante, tanto para la iluminación de los instrumentistas como para permitir que el publico tuviera una buena percepción de la pantalla y el objeto virtual. La utilización de dispositivos que necesariamente van conectados al ordenador a través de cables (sensor inercial y cámara Web), obligó a que la agrupación tuviese que situarse cerca del PC, por lo que los músicos no pudieron ubicarse 
completamente en el centro del escenario. Finalmente, las condiciones lumínicas de la sala en modo 'concierto' (parámetros preestablecidos para un teatro standard) condicionaron algunos parámetros de la aplicación, viéndose la imagen capturada por la cámara un tanto oscura durante la representación en vivo, por lo que el efecto de la pantalla a modo de espejo era poco luminoso.

\subsection{PERFORMANCE}

\subsubsection{TALLER}

El taller se realizó en el escenario del auditorio durante un par de horas a media mañana y otro par de horas por la tarde, al cual asistieron un total de nueve músicos: un batería, una flauta, una guitarra eléctrica, un piano de cola, un saxo alto, dos trombones, una tuba y una cantante. Tras montar la pieza en el escenario, se explicó brevemente el funcionamiento de la aplicación creada con Max MSP Jitter y el modo en que se producía la interacción con el objeto (NURBS) generado. A continuación los músicos fueron probando uno a uno su instrumento, para ver el resultado de su interpretación, tras lo que se ajustaron algunos de los parámetros de la aplicación mediante un feedback directo con ellos. Finalmente, los músicos que participaban en el taller realizaron un ensayo en conjunto de diversas piezas musicales, visualizando en todo momento el objeto virtual fruto de su interpretación. En las siguientes imágenes se muestran algunos momentos durante el transcurso del taller (Fig. 91). 

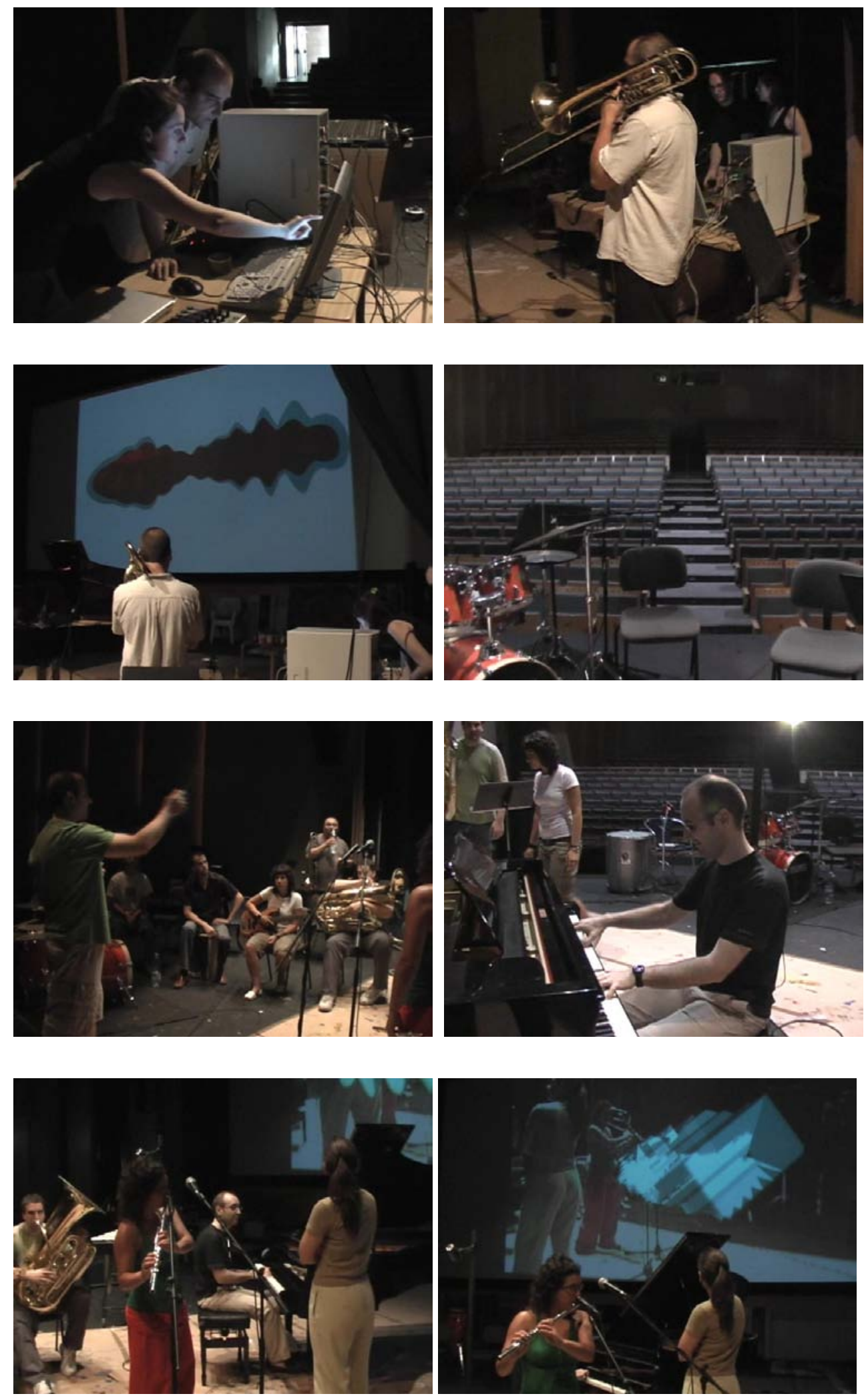

Fig. 91 Imágenes tomadas durante el taller de Sonido Aumentado 


\subsubsection{REPRESENTACIÓN EN VIVO}

La representación en vivo tuvo lugar a las 20:00 en el Auditori de Torrent (Valencia) con la asistencia de diverso público. En primer lugar se explicó a la audiencia en que consiste la realidad aumentada y el funcionamiento de la pieza Sonido Aumentado. Para que entendieran la relación directa entre sonido emitido por los instrumentistas y la visualización gráfica en la pantalla, cada uno de los músicos hizo un solo con su instrumento, mostrando la variación entre notas graves y agudas, dinámicas, articulaciones, y recursos tímbricos. Para que la explicación resultase más clara, en esta fase se mostró el NURBS sobre un fondo grisáceo y se restringieron algunos parámetros, como las rotaciones. En las siguientes figuras podemos ver algunos ejemplos de la forma que adquiere el NURBS cilíndrico dependiendo del instrumento y la nota emitida (de acuerdo al índice acústico francobelga). Sin embargo, no resulta fácil establecer una relación directa entre las distintas notas musicales, especialmente porque los sonidos son emitidos en directo, produciéndose ruidos residuales en la señal recogida y el timbre de cada instrumento es diferente a los demás (Fig. 92).

\section{BATERÍA}

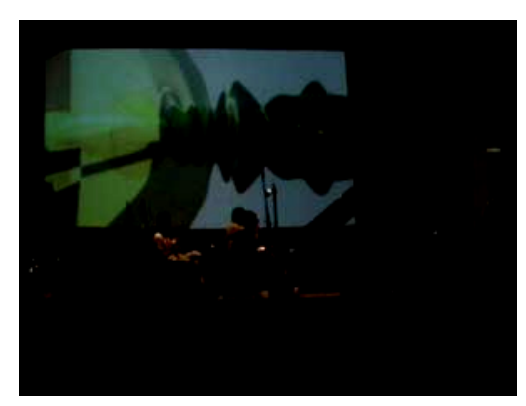

caja clara

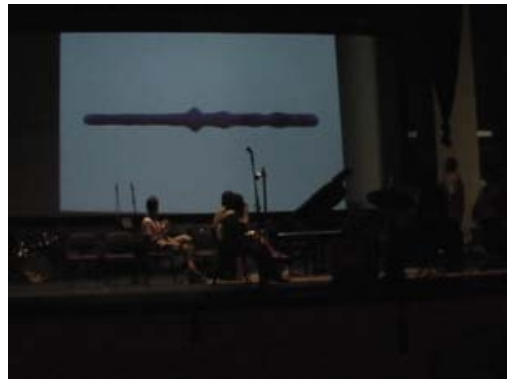

plato hit hat

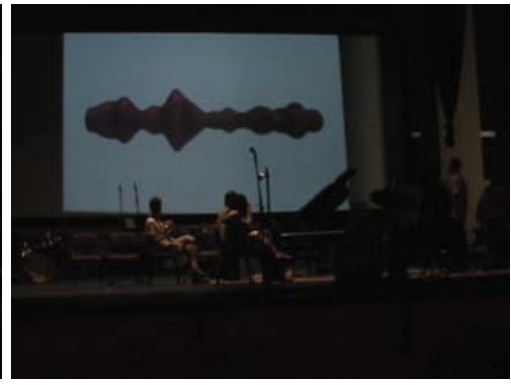

plato suspendido 


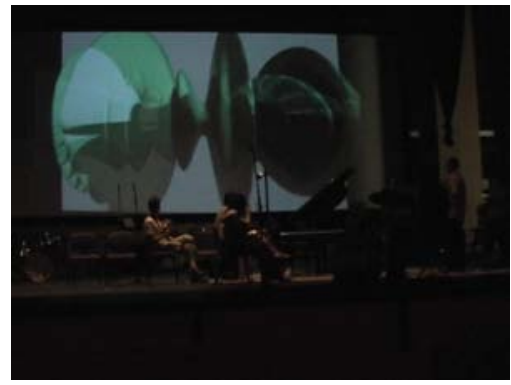

redoble tom tom

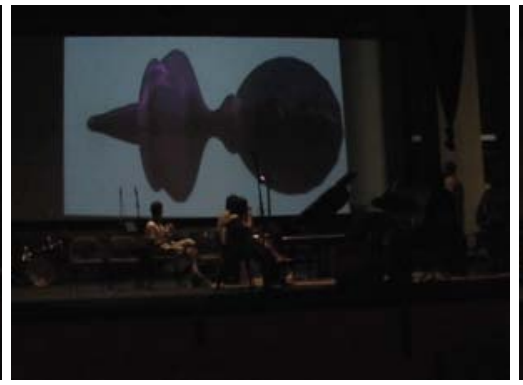

tom tom grave

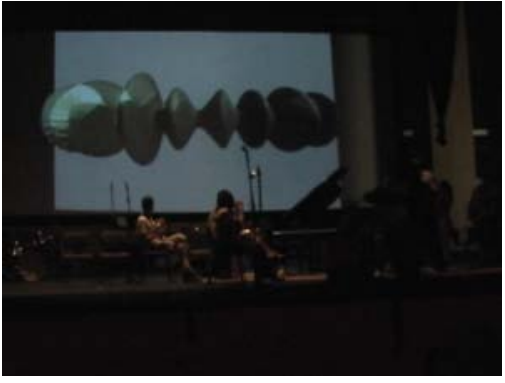

tom tom medio

\section{FLAUTA}

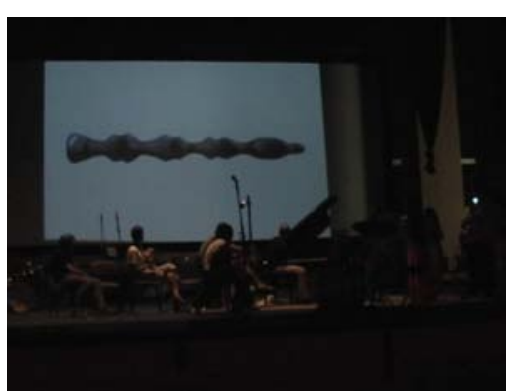

do 3

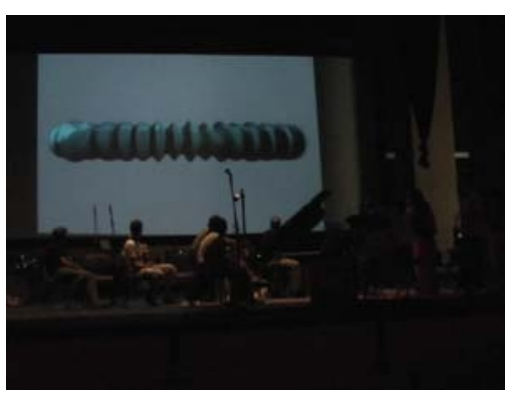

re 4

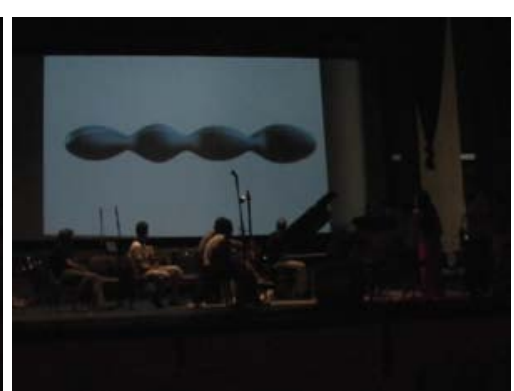

fa 4

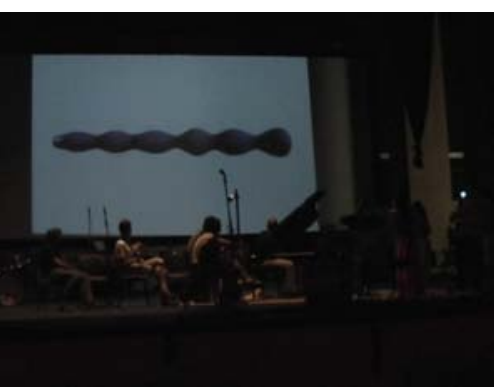

sib 3

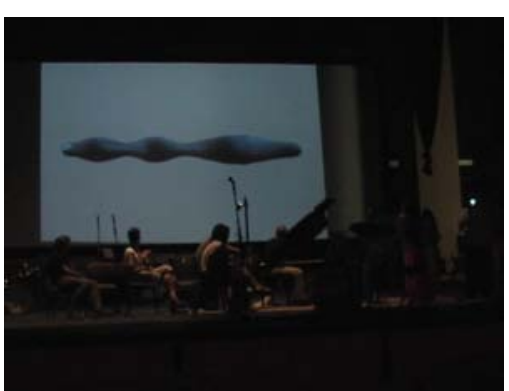

fa 5

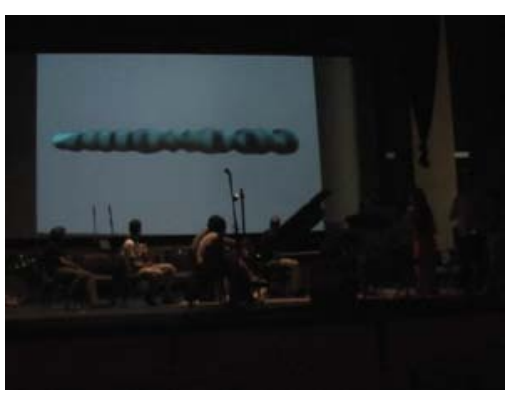

$\operatorname{sib} 4$

\section{GUITARRA ELÉCTRICA}

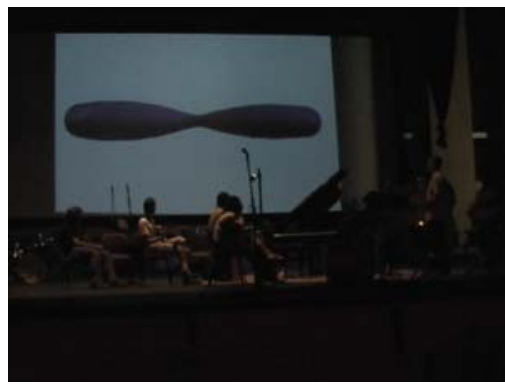

fa 2

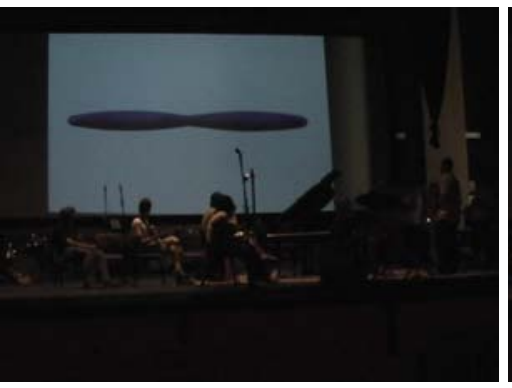

fa 4

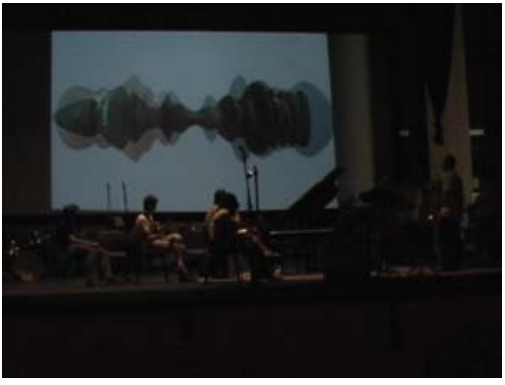

si mayor séptima 


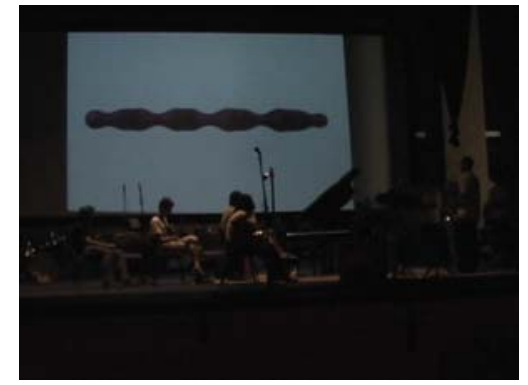

re 1

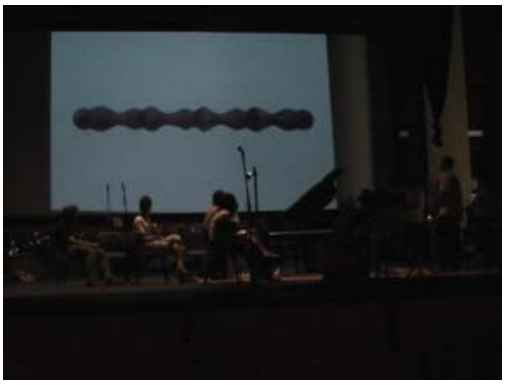

re 2

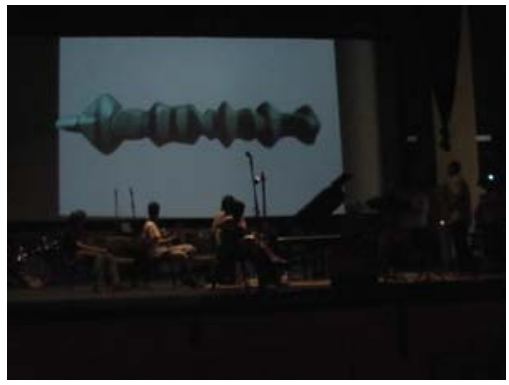

mib mayor sustained

\section{SAXO ALTO}

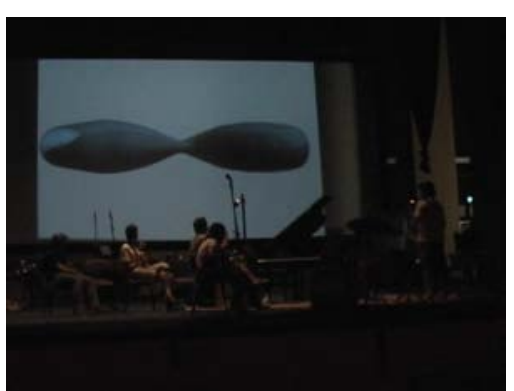

fa 3

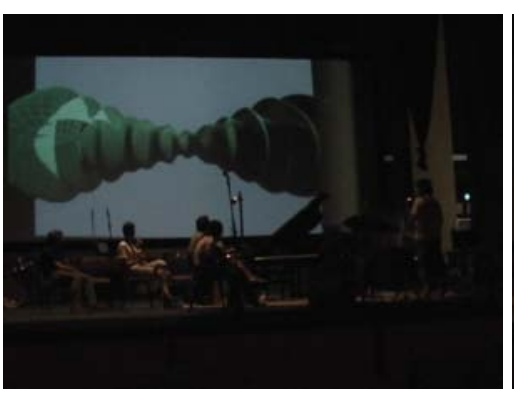

sib 1

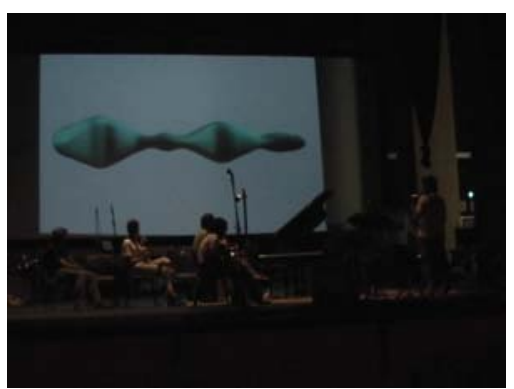

fa 4

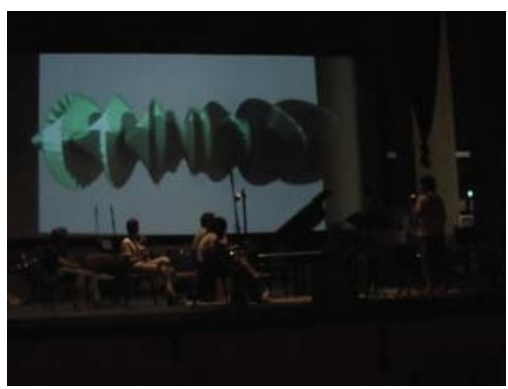

lab 2

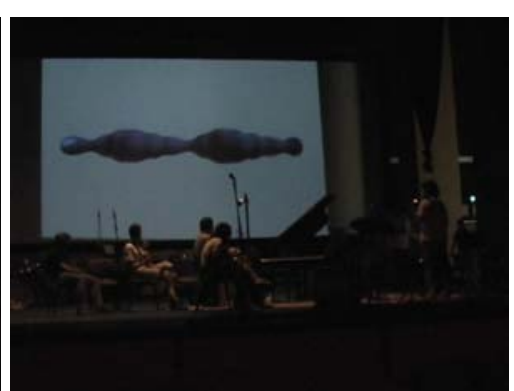

do 4

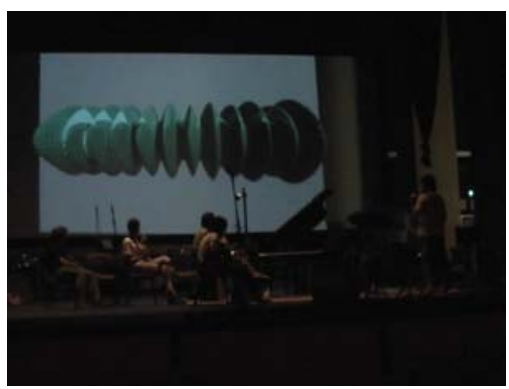

$\operatorname{lab}_{3}$

TROMBÓN

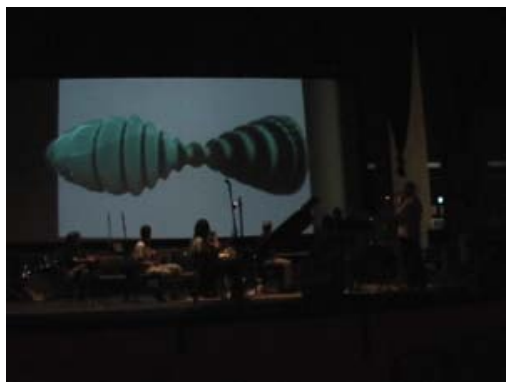

do 4

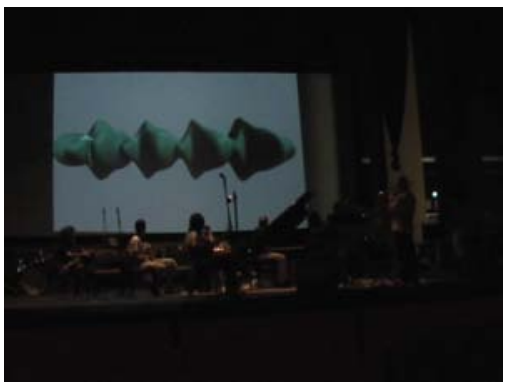

re 3

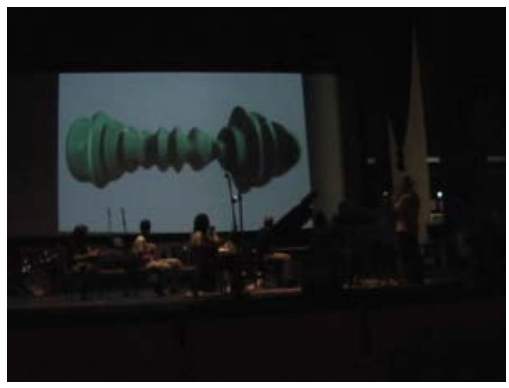

mi 2 


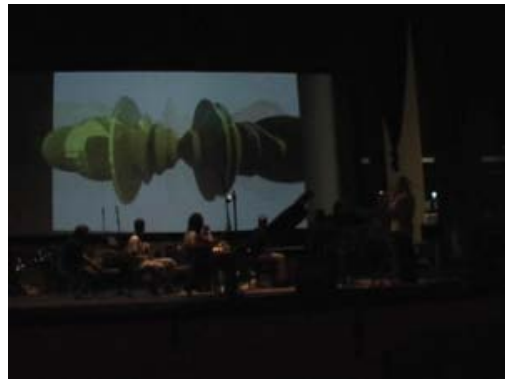

lab 1

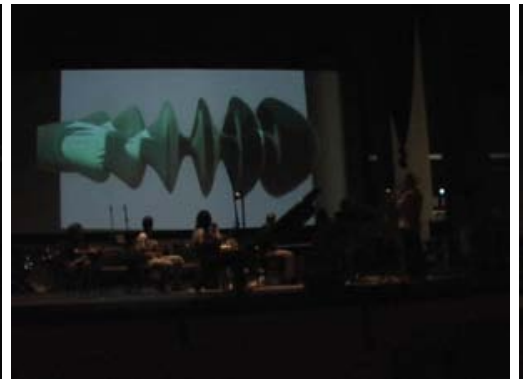

lab 2

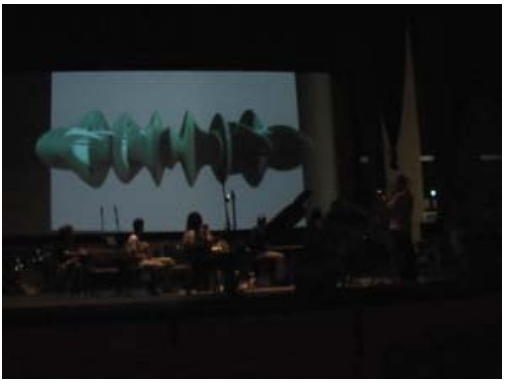

lab 3

\section{TUBA}

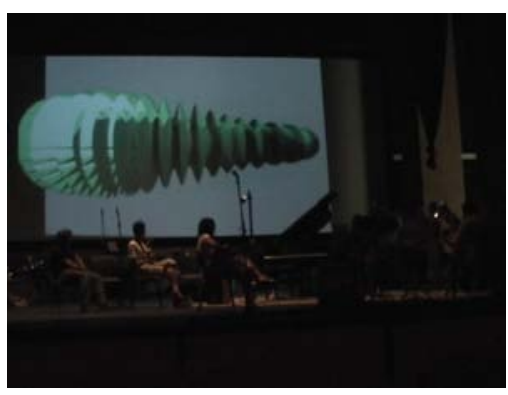

fa 2

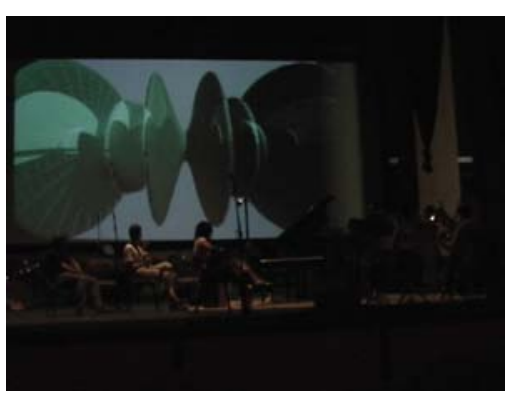

do 2

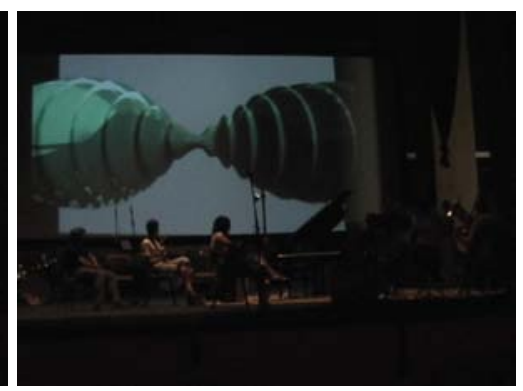

fa 2 (forte)

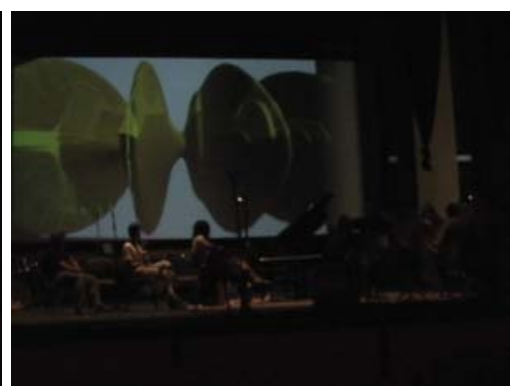

sol 1

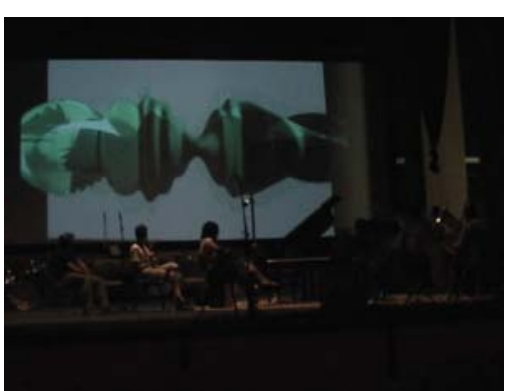

fab 2

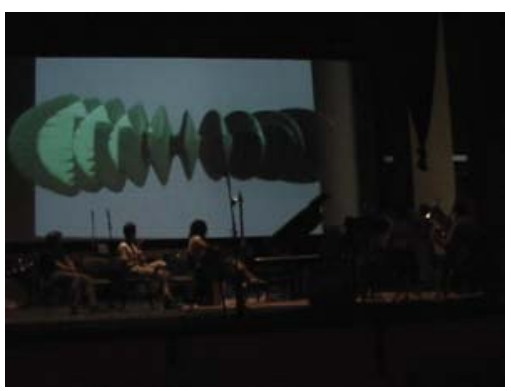

sib 1

VOZ

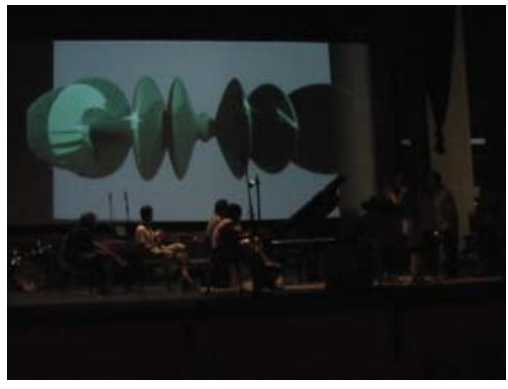

re 3

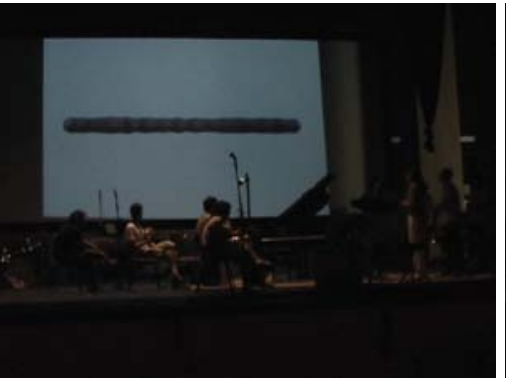

mi 3

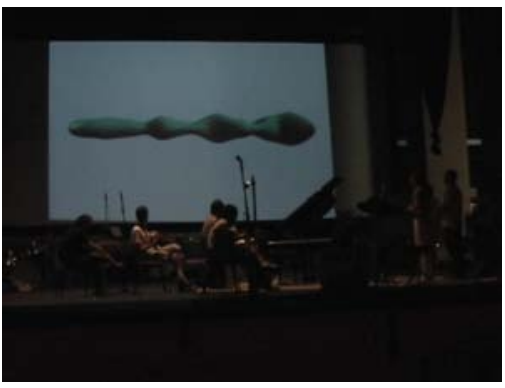

fab 3 


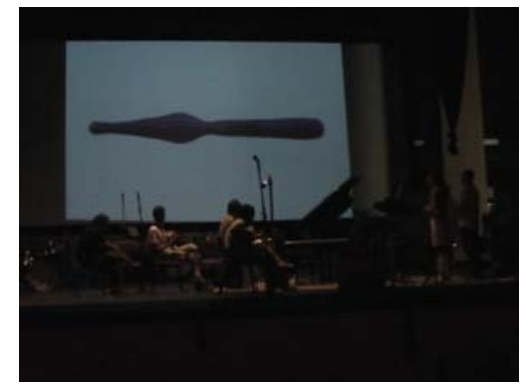

sol 3

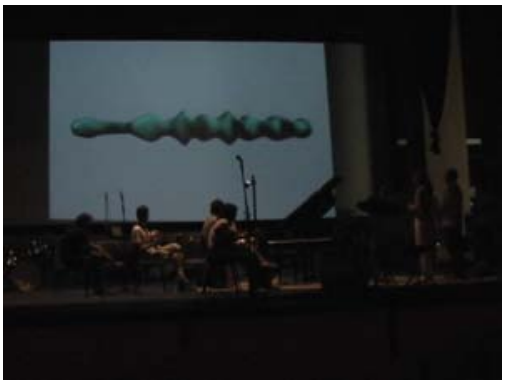

la 3

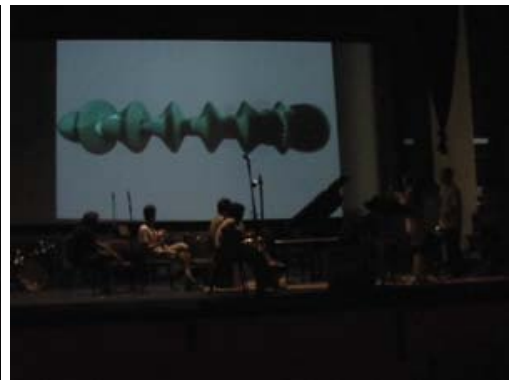

si 3

Fig. 92 Visualizaciones del sonido de acuerdo al instrumento utilizado y a la nota emitida

Una vez terminada la explicación, se procedió a la representación de diversas piezas de Jazz, en una Jam session. Respecto a las rotaciones de la visualización del sonido, finalmente se decidió que las controlara un voluntario del público, mujer en este caso, la cual subió al escenario y se le apuntaron algunas indicaciones para el correcto manejo del sensor, permaneciendo al lado de los músicos durante toda la representación. Las piezas representadas fueron dos temas que se habían ensayado en el taller de la mañana; la primera de ellas fue una improvisación sobre la escala frigia (o escala española); la segunda fue una improvisación a partir de un ritmo de blues. En la siguiente figura podemos ver una serie de imágenes del evento (Fig. 93).
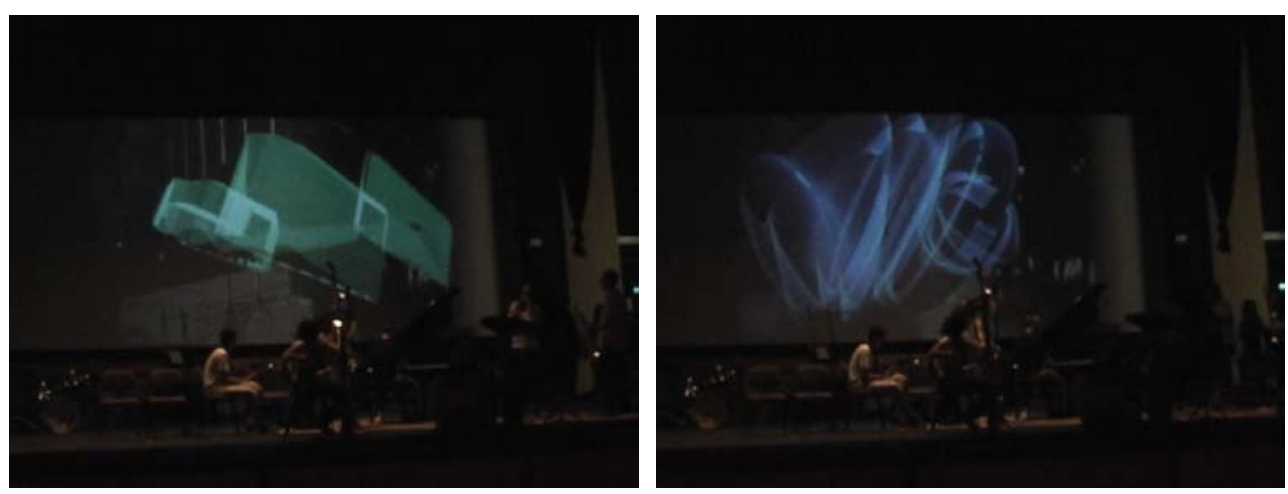

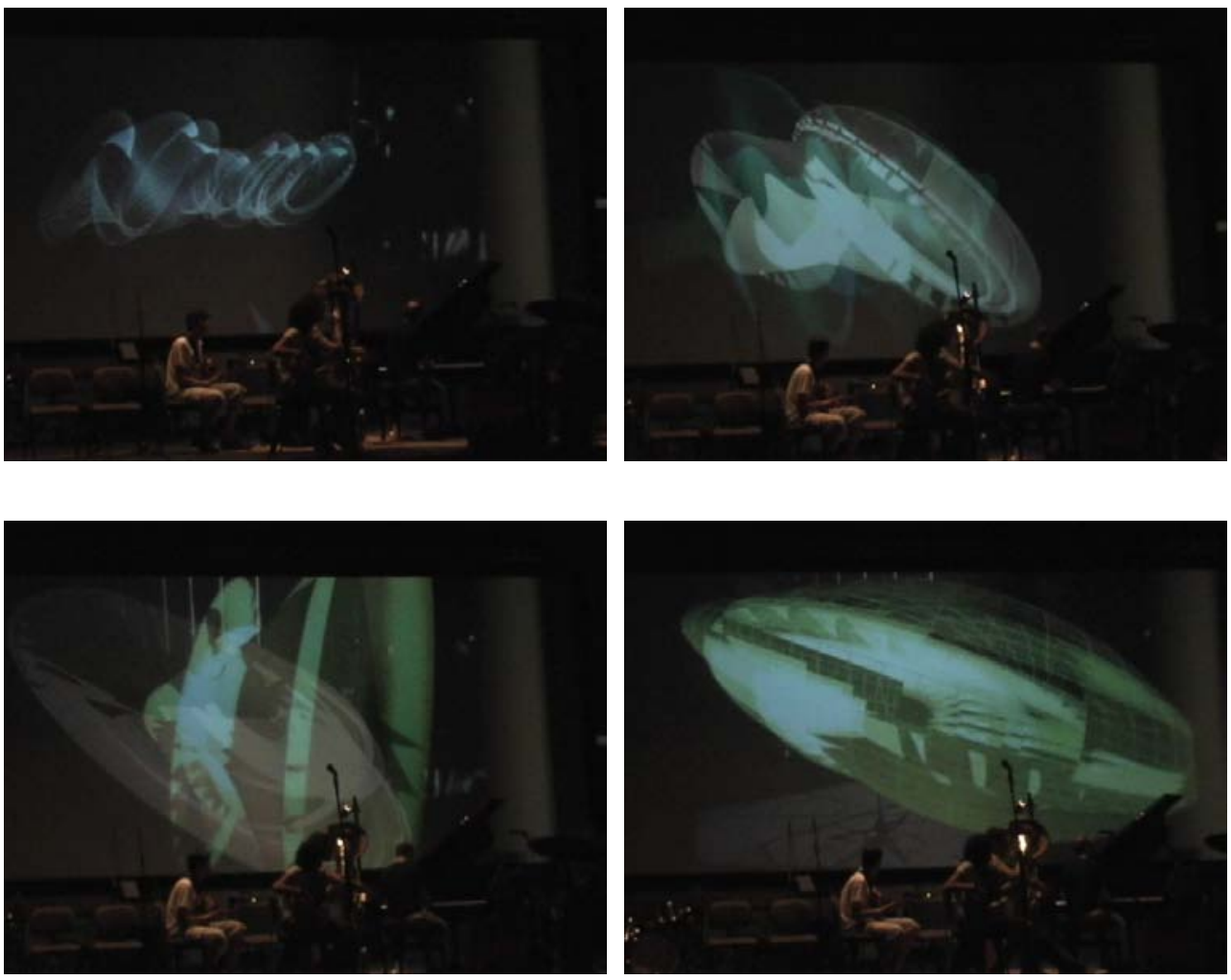

Fig. 93 Imágenes tomadas durante la Jam session

En la representación se ha observado la dificultad que experimentan los músicos a situarse en el escenario dando la espalda al público, puesto que están acostumbrados a dirigirse siempre hacia ellos para poder proyectar el sonido de su instrumento hacia la audiencia. Es por ello que algunos prefirieron sentarse de medio lado, para poder ver simultáneamente al público y a la pantalla.

\subsection{CONSIDERACIONES}

El resultado visual del evento fue muy celebrado por la audiencia y los participantes en el taller. Las correspondencias de color, volumen y formas del objeto aumentado sirvieron como parámetro conductor en las improvisaciones de los instrumentistas. Se estableció un patrón de comportamiento en cuestiones musicales propias como volumen, 
ritmo métrico y armónico, recursos técnicos y desarrollos temáticos estableciendo un nuevo formato interpretativo.

La manera de improvisar en el músico especializado en el lenguaje del Jazz se vio complementada por el elemento visual y este diálogo entre sonido y referencia visual abrió un camino nuevo en las posibilidades de expresión artística, gestualidad e interpretación, que condicionaron la elección de los propios patrones rítmicos y melódicos de la improvisación jazzística. 



\section{TANGRAM}

TanGram, es una obra para cuarteto de percusión con 4 tam-tams y 4 sensores remotos Wii de Nintendo (Nintendo, 2010). Este sensor funciona como dispositivo inalámbrico en una composición con electrónica en vivo. Al mismo tiempo que se exploran las posibilidades de este entorno, se propone en este capítulo una nueva y concreta notación musical que, integrada en una partitura despliega los símbolos e indicaciones relativos a los eventos y procesos gestuales de los intérpretes.

\section{MOTIVACION}

Este ensayo se centra en la exploración de la comunicación e interacción entre instrumentos acústicos, dispositivos y expresiones digitales, dando como resultado una obra mixta con su consecuente y única expresión notacional, la partitura, en la que se trata de concretar las posibilidades de integración entre el uso multi-tímbrico y resonador del tam-tam (Mellers, 1992) con la expresión gestual del movimiento de este dispositivo inalámbrico tan accesible. Mediante la 
utilización de librerías libres y un entorno de programación dirigido a objetos, como el Max MSP (Puckete y Zicarelli, 1990) se plantea un entorno de expresión creativa que permite al músico la exploración de los recursos sonoros de su instrumento, de la interacción con otros usuarios, así como del aprovechamiento de la gestualidad intrínseca en el desarrollo interpretativo.

\subsection{PLANTEAMIENTO}

Desde mi participación más directa en las posibilidades de expresión electrónica dentro de la interpretación para concierto siempre me llamó la atención la incomodidad que en muchos casos suponen los dispositivos electrónicos y su integración en el espacio interpretativo, ya sea porque el músico deba llevarlos encima, utilizando el sensor más antiguo, el micrófono, como cualquier otro dispositivo que recoja los parámetros que tengan que ver con el intérprete y/o con el instrumento.

Una de las mayores dificultades a las que se enfrenta el músico que hace electroacústica es el control que debe tener sobre los aparatos y dispositivos electrónicos. Equipamiento de altavoces, mesas de mezclas, microfonía, tarjetas de audio, ordenador, componentes periféricos, etc. Normalmente la instalación de este entorno de concierto se hace en ubicaciones que a menudo no tienen los requisitos técnicos necesarios para garantizar una comodidad en el despliegue de medios. Si a esto le sumamos el dispositivo que actúa como sensor para recoger los parámetros que interesan al compositor es muy posible todo este entramado de aparatos presente algún problema en la interacción con dicho sensor. Por ello, a veces el intérprete no tiene plena autonomía interpretativa, o sus recursos 
gestuales se ven limitados por el enjambre de aparatos y cables. Por ello, cada vez se hace más necesaria la indagación de dispositivos que no interfieran en la parte de interpretación instrumental así como de elemento que garanticen un disfrute, un uso intuitivo y cómodo de los recursos para la electrónica en vivo.

A partir de conocer el lanzamiento a finales del año 2006 de la consola de entretenimiento de Nintendo y el control remoto Wii pensé en la comodidad de acceso y uso para aplicaciones que requieran el registro de datos que tengan que ver con el parámetro visual de la interpretación musical: la gestualidad del intérprete.

Antes de decidirme por utilizar el mando Wii, barajé varias opciones de dispositivos que actuaran como sensores y registran la gestualidad que me interesaba. La placa Arduino (Cuartielles y Banzi, 2006), mostrada en Fig. 94, por ejemplo, es un prototipo de placa electrónica básica libre, a partir de la cual se pueden crear diversos dispositivos, implementando sensores que recojan datos concretos como aceleración, luminosidad, presión, etc. Este tipo de placas requieren de una cierta compatibilidad con estos sensores, en relación a voltajes, resistencias, etc. y esto restringe el ámbito de la exploración. Además, la posibilidad más inmediata de conexión de este tipo de placa con el ordenador es mediante cable de red o USB. Para integrar un sensor en el cuerpo del músico permitiéndole a su vez una libertad de movimientos, necesitamos reducir la utilización de cables, más aún si tratamos de explorar cualquier indicio de performance o movimiento escénico. Esto se puede lograr por ejemplo, mediante el dispositivo adicional Xbee, aunque su utilización requiere de ciertos conocimientos de electrónica y programación en lenguaje $\mathrm{C} / \mathrm{C}++$. En cualquier caso no se descarta su empleo en futuras investigaciones. 
Una vez interpretados los datos del sensor integrado en estas placas, se requiere de un conversor a flujo de datos concreto. En el caso de la plataforma Max MSP (Puckete y Zicarelli, 1990), uno de los entornos más comunes y fiables de programación para la electrónica en vivo, y de los objetos que están diseñados para este entorno, habría que convertir estos datos, mediante código $\operatorname{OSC}^{18}$ (Open Source Code) o utilizando un objeto concreto que transforme estos datos al entorno de programación escogido.

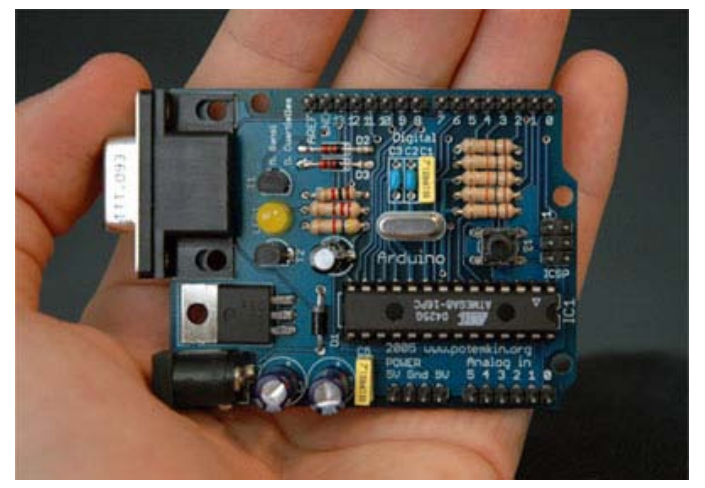

Fig. 94 Placa Arduino, en (Cuartielles y Banzi, 2006)

Para resolver todas estas cuestiones de accesibilidad en el caso del mando Wii, se planteó la posibilidad de utilizar la vía de transmisión inalámbrica Bluetooth, ya que la decodificación que realiza el objeto aka.wiiremote, de las librerías 'aka' (Akamatsu, 2009), reduce todos los pasos e inconvenientes, desde el movimiento libre del instrumentista, hasta el fácil uso de un proceso para el control en vivo. Otro factor determinante para el empleo del mando Wii es que dispone de 12 botones independientes. Esto permitirá prescindir de otro dispositivo que actúe como disparador (pedal) o la colaboración de otro usuario que dispare la lista de eventos, dando plena autonomía al intérprete.

\footnotetext{
${ }^{18}$ Código fuente abierto: es el término con el que se conoce al software distribuido y desarrollado libremente.
} 
TanGram fue un encargo de 'Kontakte, grupo de percusión' (Kontakte, 2009) (Fig. 95). Se planteó la posibilidad de experimentar con el material del que dispone este cuarteto de percusión más los recursos de la electrónica en vivo. La preparación de la obra se realizó en el auditorio del Conservatorio de Música 'San Rafael' de Buñol (Valencia) durante el verano de 2009. Durante estos días hubo un constante diálogo entre autor e intérpretes de manera que se fueron puliendo todos los perfiles de la obra. El estreno de la obra se llevó a cabo en el marco de la VI Convención Nacional de Percusión, celebrado durante el mes de Septiembre de 2009 en Badajoz.

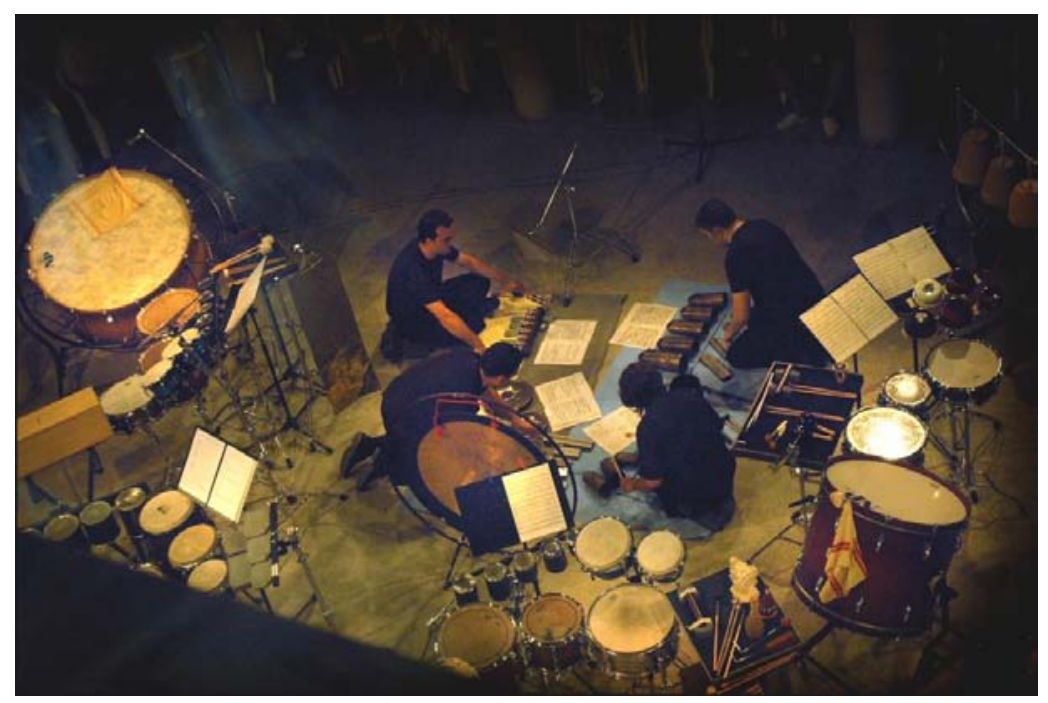

Fig. 95 Captura de concierto, Kontakte, grupo de percussió, en (Kontakte, 2009)

\subsubsection{MARCO EN EL OUE SE INSCRIBE EL ENSAYO}

Siguiendo las descripciones que se han hecho en el mapa de conceptos (ver Apartado 0.5) se puede presentar un marco general de este ensayo:

- Sensores: 4 Micrófonos y 4 Mandos Wii de Nintendo (Nintendo, 2010) 
- Electrónica en Vivo: Se requiere.

- Tiempo real: Procesamiento de los datos que recoge el micrófono y el movimiento del mando Wii.

- Obra abierta/cerrada: Obra abierta ya que el sonido que se genera depende de la interpretación.

- Partitura: Se requiere.

- Intérprete: Se requiere un cuarteto de percusión.

- Performance: Existe componente escénico con un cierto margen de improvisación.

- Instrumentos acústicos: Se requieren 4 tam-tams.

- Improvisación: En la obra hay un pasaje en el que el percusionista 3 realiza una breve improvisación con el tam-tam y el movimiento de la Wii.

- Entorno o medio de reproducción: Concierto.

- Procesamiento digital imagen/sonido: Sonido.

- Software: Max MSP (Cycling74, 2010).

\subsubsection{REFERENTES}

Una obra de esta naturaleza es susceptible de asociarse, desde un prisma puramente musical, a la performance experimental o a la improvisación escénico-musical, sin embargo la intención de esta composición ha sido conformar una obra de expresión artística musical utilizando recursos técnicos y herramientas en pleno desarrollo sin descuidar tanto la metodología de experimentación 
como el protocolo artístico de las obras creadas para formaciones camerísticas instrumentales.

A continuación se hará, a diferencia de los demás temas, una diferenciación entre las diferentes facetas de referencia que presenta este ensayo: dispositivos de registro, instrumentos utilizado, notación y plateamientos en una partitura, y performance en una obra de esta naturaleza.

\subsubsection{DISPOSITIVOS}

El sensor más antiguo, accesible y común en el mundo de la música es el transductor electroacústico: el micrófono. Según para qué usos se requiera y en función de parámetros como su direccionalidad o sensibilidad, son más indicados de válvulas, dinámicos, de condensador, etc...

Para (Kientzy, 1990) y especialmente en su interpretación del programa dedicado a la música rumana y como miembro del trío promoZICA trio junto a Cornelia Petroiu y Reina Portuondo, la solución pasa por la colocación de un sistema de micro inalámbrico situado en la manga del traje, permitiéndole un rápido acercamiento a la embocadura del saxo y por tanto a la captación de todos los efectos tímbricos que puede generar con la boca y la lengüeta del instrumento.

Por otro lado, en sus obras para saxo y electrónica Trombonsis y DSPBop, (Climent, 2001) utiliza en su primera versión de la obra, aparte de un micro de contacto un despliegue de dispositivos que le permiten controlar todo el discurso electrónico, más otros aparatos para el control de determinados procesos en vivo (Fig. 96). 


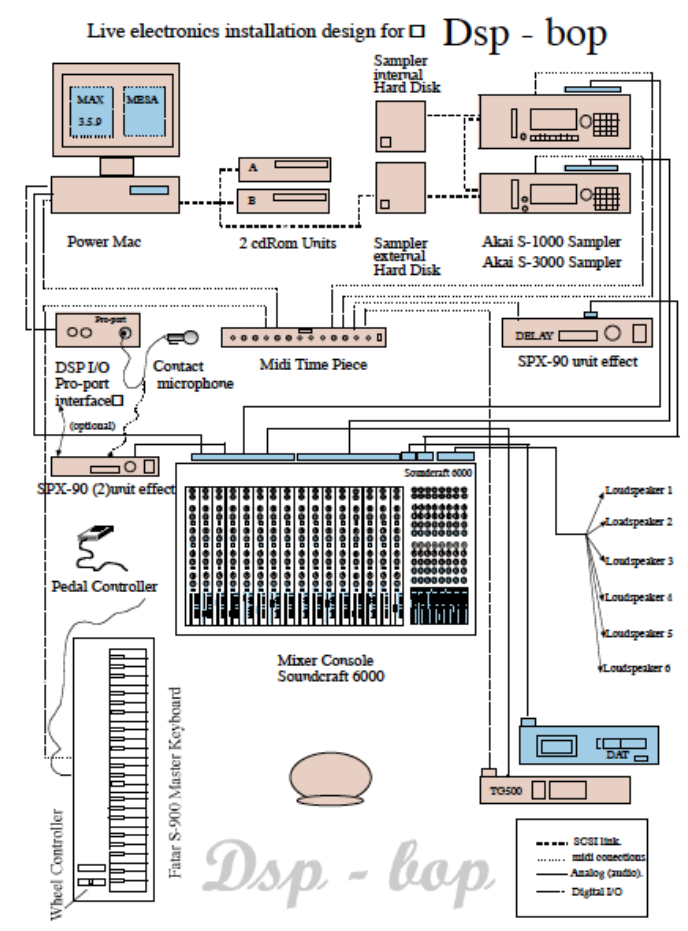

Fig. 96 Despliegue de dispositivos para DSP-bop, en (Climent, 2001)

El compositor Valenciano Gregorio Jiménez (1960), en su obra Los misterios de Mitra (2008) para flautas y electrónica utiliza ambos dispositivos, un pedal midi y un micro de condensador Senheisser con pre-amplificador K6 con cápsulas ME66. Esta obra mezcla procesos de transformación sonora en vivo y muestras grabadas en estudio (Fig. 97).

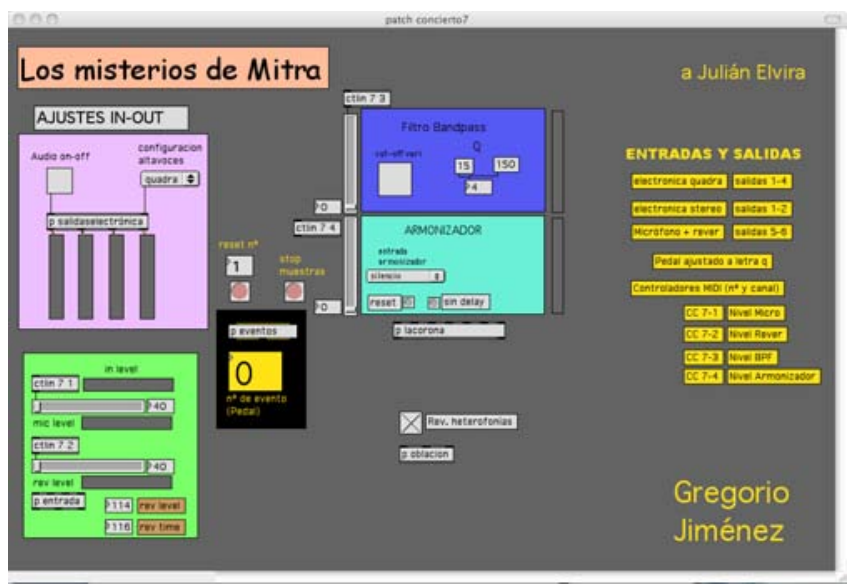

Fig. 97 Captura del Patch Los Misterios de Mitra de G. Jiménez 
El mismo Jiménez desarrolla en algunas obras propias secciones dedicadas a la improvisación controlada mediante dispositivos sensores, en concreto el dispositivo 'I-CubeX' (Infosuionsystems, 2010), que integra varios sensores conectados con el ordenador mediante protocolo MIDI, Bluetooth o USB: sensores de presión, de proximidad, de luz, flexión, etc (Fig. 98). En su obra 'Fragmentos' (2008) para violín, cello, piano, 3 percusionistas y electrónica dispone dichos sensores sobre un pié de atril. En la obra desarrolla un discurso recíproco entre los materiales acústicos, la escritura camerística y el lenguaje electroacústico improvisado.

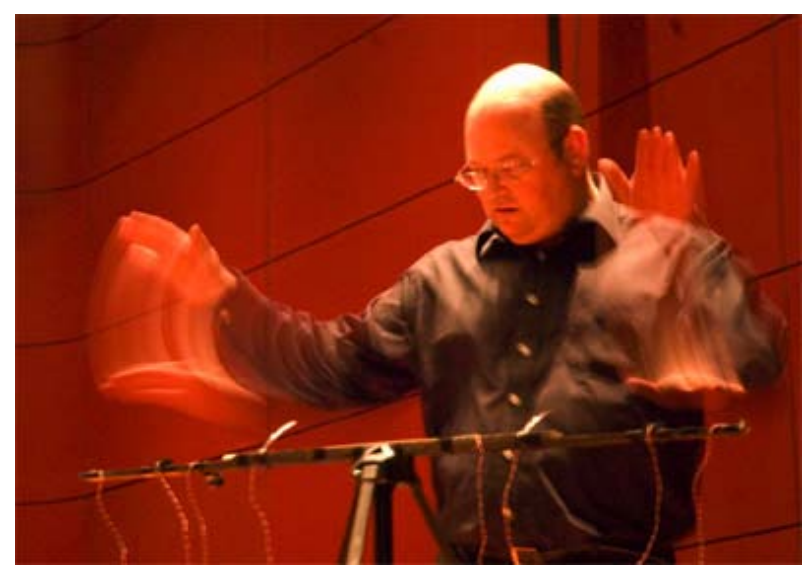

Fig. 98 Captura durante el estreno de Fragments de G. Jiménez

A modo de instrumento virtual y como expansor de las propiedades del instrumento, la obra Agravidade Liberta (Climent, 2003) para Marimba, 6 baquetas preparadas y electrónica en vivo, se utilizó el sensor Memsic 2125 y el sensor de presión Flexiforce sobre la placa BASIC Stamp (Parallax Inc., 1987). Todo el sonido de la marimba se recoge por el micro y se procesa (transmitido por cable Ethernet) en el entorno Max MSP, donde dicho sonido sufre variaciones de timbre, densidad, altura, etc (Fig. 99). 


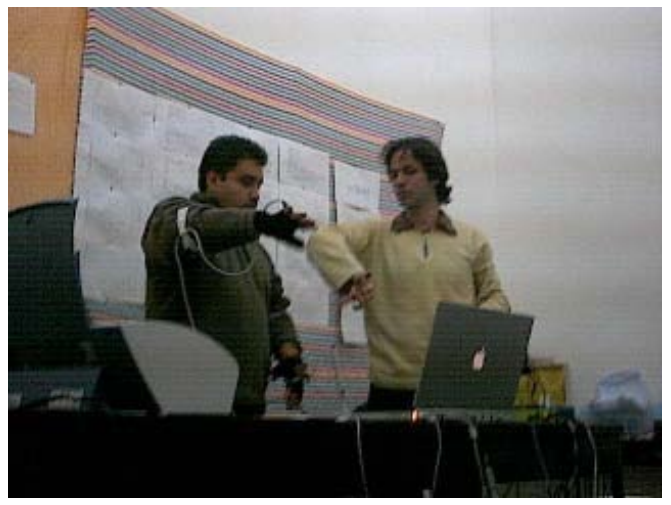

Fig. 99 Ricardo Climent probando la inclinación de los guantes, Méjico, 2003

El dispositivo se integró en unos guantes, de modo que quedaban asegurados contra el dorso de la mano del intérprete (Fig. 100). El movimiento de sus brazos constituye un parámetro adicional para el control sonoro de los procesos en vivo o de los parámetros de material grabado y editado previamente en el estudio.
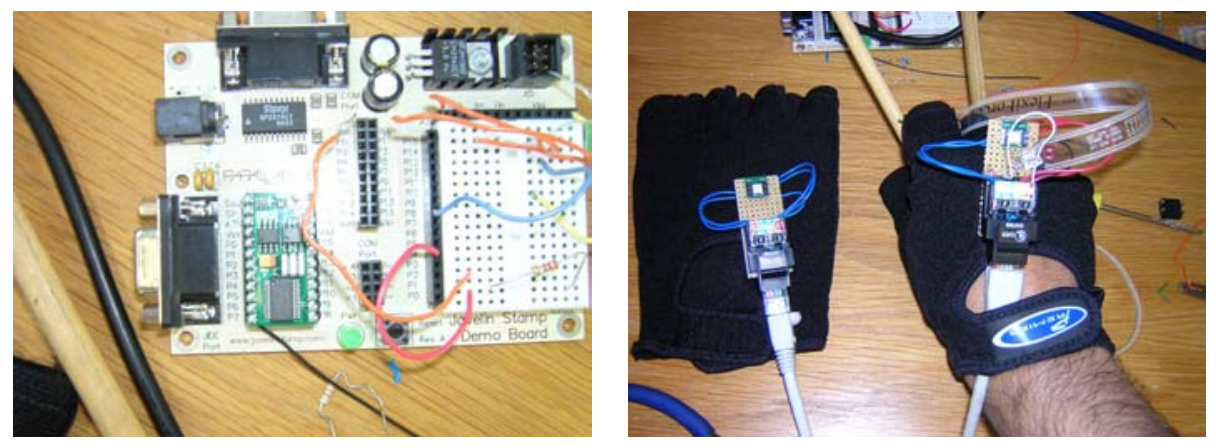

Fig. 100 Placa BASIC STAMP y Sensores para baquetas para Agravidade Liberta, en (Climent, 2003)

En cuanto a sensores inalámbricos que tienen que ver con el movimiento del intérprete, Ricardo Climent en su obra 'Voyages extraordinaires: Le Gyrosbone' (2005) para trombón preparado y electrónica en vivo (Fig. 101), utiliza la plataforma de sensores 'La kroonde Gamma_' (Coduys et al., 1999), un sistema inalámbrico de alta precisión, que integra multitud de sensores, diseñado para aplicaciones en tiempo real (Fig. 102). 

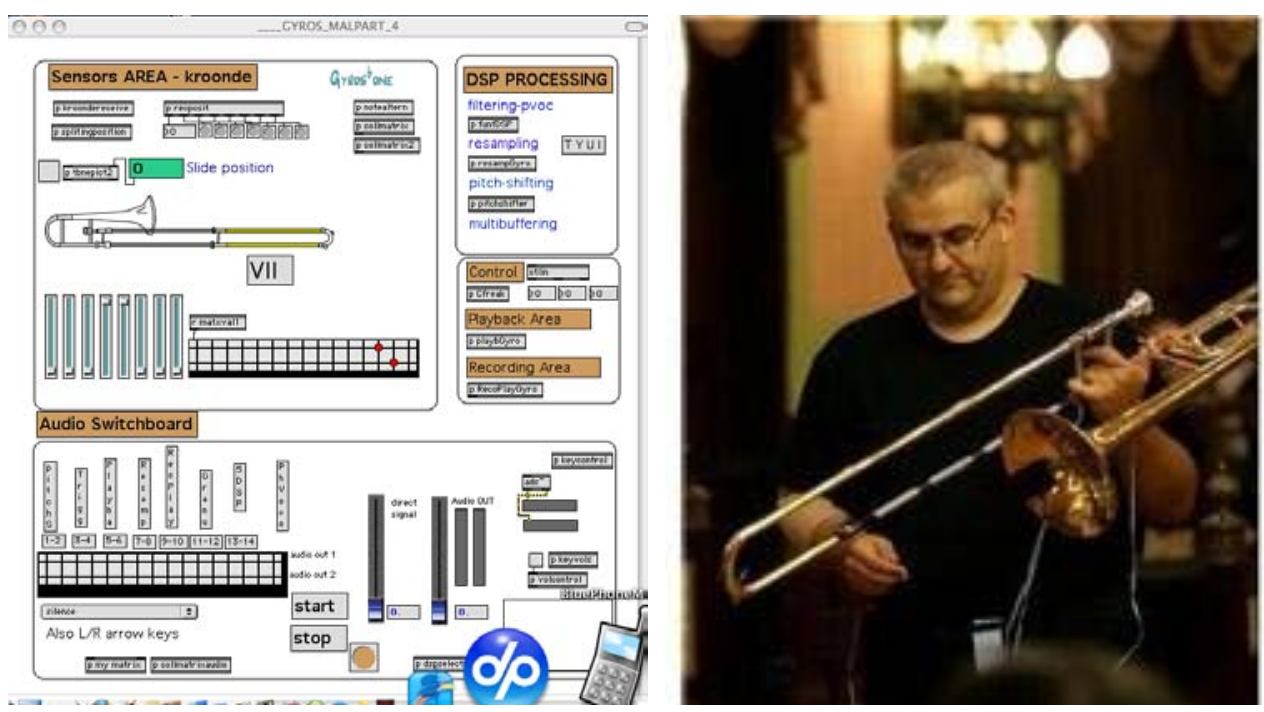

Fig. 101 Captura del Patch Le Gyrosbone y Carlos Gil durante el estreno de 'Le Gyrosbone'

En concreto, el autor coloca sensores fotosensibles, flexómetros, inclinómetros y acelerómetros en las válvulas y la campana del trombón de manera que recogen la mayor parte posible de parámetros que tienen que ver con la gestualidad y el comportamiento del instrumento.

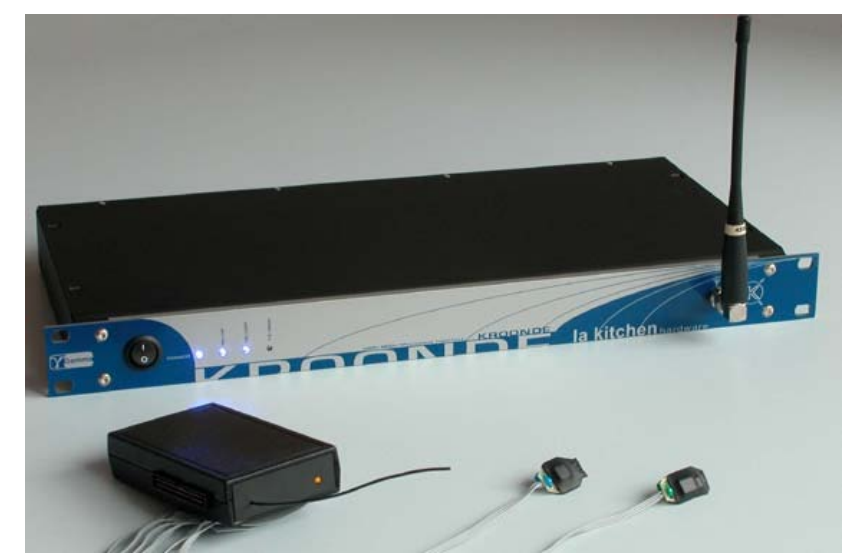

Fig. 102 Sistema La Kroonde, en (Coduys et al., 1999)

\subsubsection{INSTRUMENTAL}

El compositor alemán Karlheinz Stockhausen exploró de manera única la tímbrica del tam-tam en su obra Microphonie en 1964. Con la ayuda 
de su colaborador Jaap Spek, descubrió el abanico de efectos que se podían extraer del tam-tam con la ayuda de diferentes utensilios con los que golpear y frotar el instrumento más el uso de microfonía y filtros eléctricos. Esta obra le ayudaría a extender su concepto de microforma y macroforma. A partir de pequeñas células sonoras se podía configurar el total del discurso sonoro o macroestructura formal de la obra. Mikrophonie (Fig. 103) fue la primera obra junto con Mixtur (1964), para orquesta, cuatro generadores y moduladores de anillo ${ }^{19}$, en que, para Stockhausen desapareció la división entre música instrumental y electroacústica (López, 1989, 45-48).

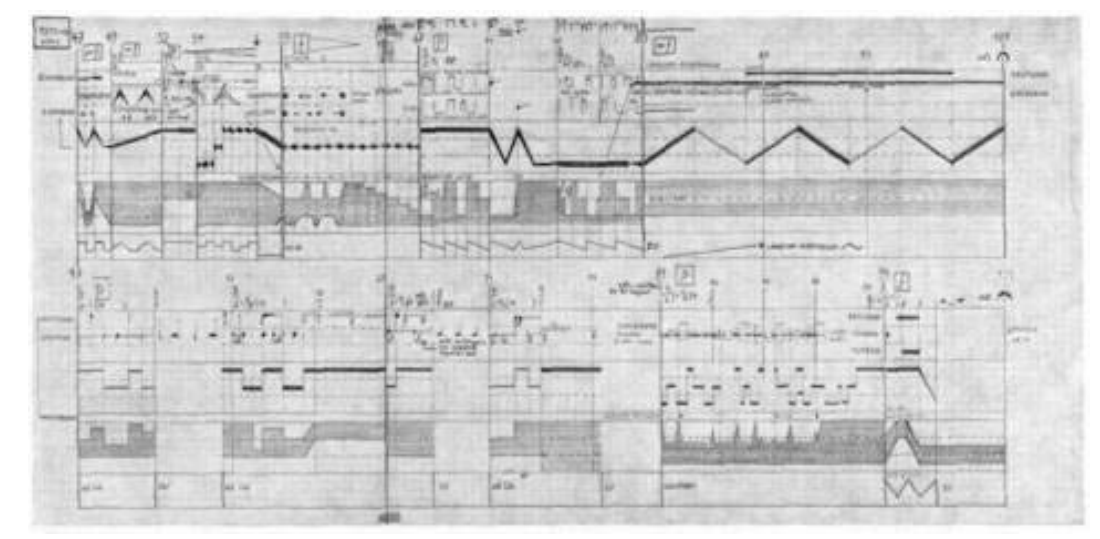

Fig. 103 Fragmento de Mikrophonie (1964) en (http://brainiacconspiracy.typepad.com/my_weblog/2007/12/stockhausen.html)

\subsubsection{NOTACIÓN}

La representación gráfica de los eventos sonoros en la historia de la música electroacústica ha sido siempre un complejo paradigma. Actualmente cada compositor confecciona el guión o partitura de aquellas obras que utilizan instrumental acústico en función de las necesidades de la obra y del instrumental que requieran, bien por

19 Modulación en anillo: proceso electrónico, que consiste en la multiplicación de dos señales, donde una es típicamente una onda sinusoidal $u$ otra forma de onda simple. 
necesidades de coordinación interpretativa o por mera exploración gráfica. En (Berenguer, 1974, 39) podemos ver algunos de los pictogramas que representan el movimiento sinusoidal de la parte electrónica en su obra Estratos sonoros (1972) para orquesta y electrónica (Fig. 104).

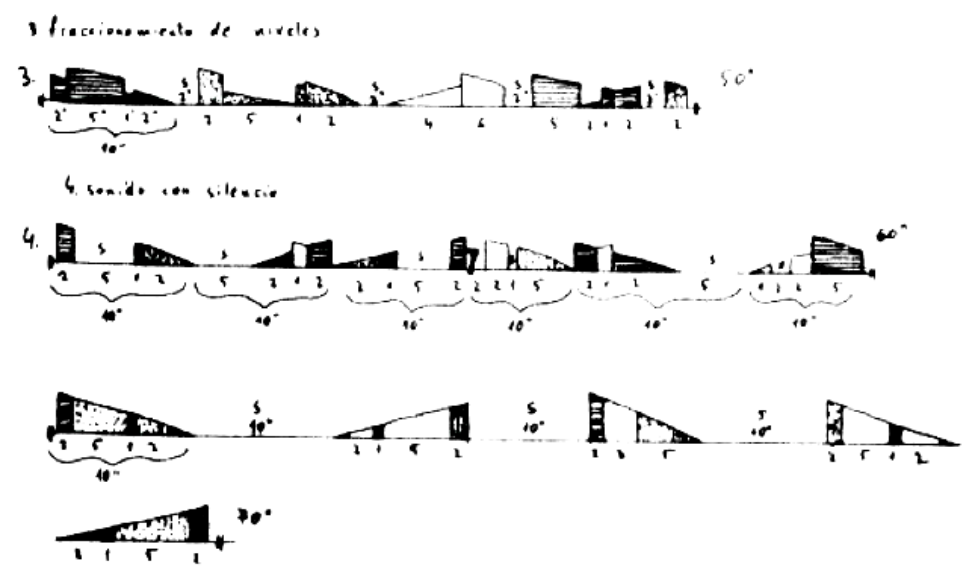

Fig. 104 Indicaciones de tiempo y cinta magnética, en (Berenguer, 1974)

Esta representación tiene su base de diseño espacial en la notación para la música de rítmica no métrica. En (Morgan, 1992, 419-435) podemos observar como el compositor polaco Krysztof Penderecki (1933) utilizaba ya en la década de los 6o, franjas densas para representar el movimiento y altura de los clusters $^{20}$ en su obra para orquesta de cuerda, Treno (1960).

Avanzando sobre esta idea y las posibilidades de representación gráfica, Edgar Varèse (1883-1965) en su trabajo para la obra Poème Électronique (1957-58) en colaboración con el arquitecto Le Corbusier (1887-1965) y el compositor lannis Xenakis (1922-2001) para el Pabellón Philips en 1958 (Fig. 105) - primera obra concebida como entorno espacial que integrara video, luz y música en un espacio

\footnotetext{
${ }^{20}$ Cluster: Literalmente racimo. En música se refiere a un acorde compuesto por tonos y/o semitonos consecutivos.
} 
determinado - (Stephenson, 2006), afirma que cuando se fueron desarrollando los primeros instrumentos electrónicos, los empezó a utilizar más allá de la pura organización sonora. Su intención fue de liberarse de la arbitrariedad, aludiendo al sistema temperado; la posibilidad de obtener cualquier número de ciclos, o si se desea, la subdivisión de la octava y consecuentemente la formación de cualquier escala; insospechados rangos en registros graves y agudos; armónicos desconocidos obtenidos a partir del uso de subarmónicos ${ }^{21}$; la posibilidad de obtener cualquier timbre diferencial, combinación de sonido y nuevos niveles dinámicos, desconocidos desde el prisma orquestal; un sentido de proyección del sonido en el espacio mediante la emisión de cualquier parte o partes de la sala; ritmos cruzados e independientes los unos con los otros; tratados simultáneamente o basados en el contrapunto tradicional, puesto que el ordenador puede generar cualquier número de notas, cualquier subdivisión de ellas u omitir cualquier fracción - todo ello en una unidad de medida de tiempo que es imposible de lograr por medios humanos (Varèse, 1967).

${ }^{21}$ Subarmónico: Frecuencias que están por debajo de la frecuencia fundamental de un oscilador en una proporción de 1/x. 


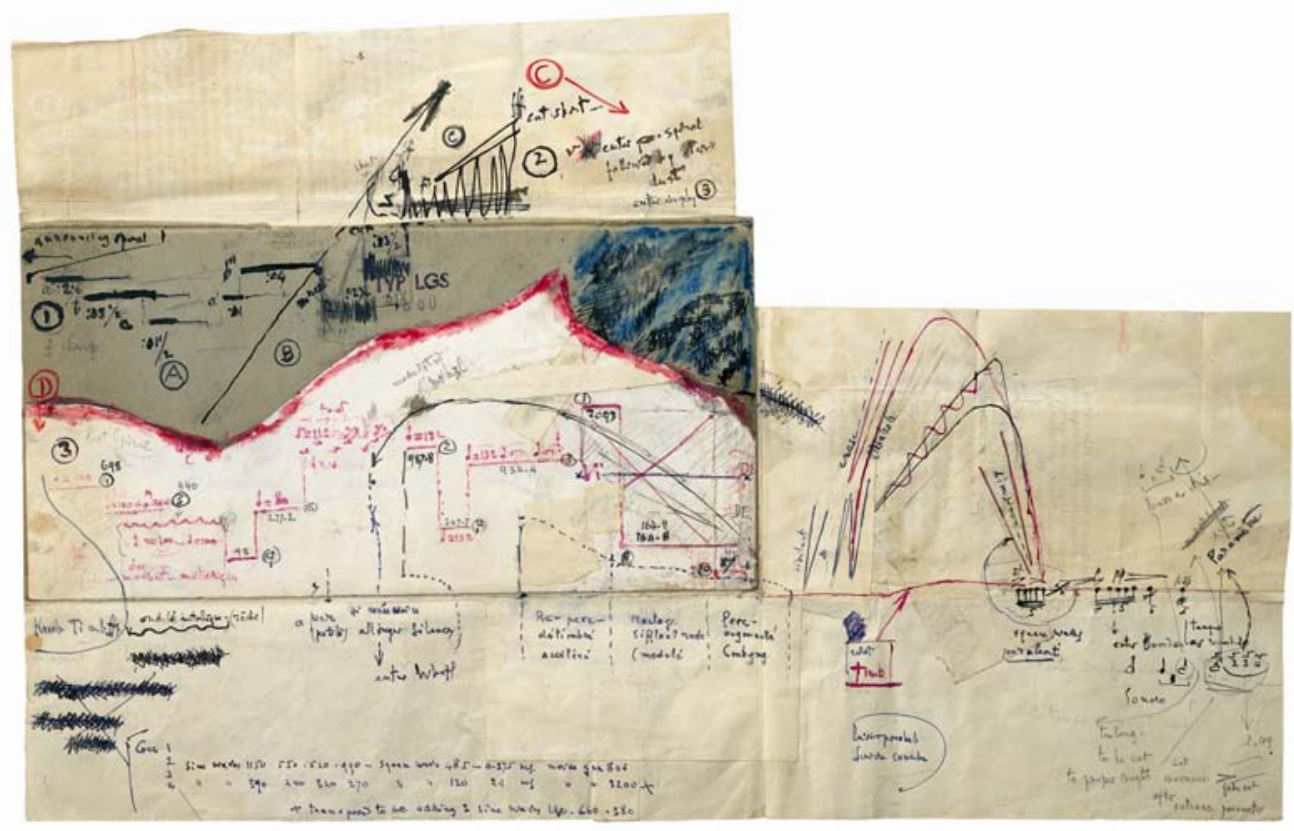

Fig. 105 Fragmento de Poème Électronique de E. Varèse, en (Varèse, 1957-58)

Por otro lado el compositor anglosajón Jonty Harrison (UK, 1952), en su obra Unsound Objects (1995) realizó una serie de dibujos en los que trataba de plasmar el gesto que realiza su obra para cinta (Fig. 106). La dirección simbólica del trazo, el grosor o el color dan una idea bidimensional de la trayectoria de las muestras y el comportamiento sonoro (Harrison, 1995).
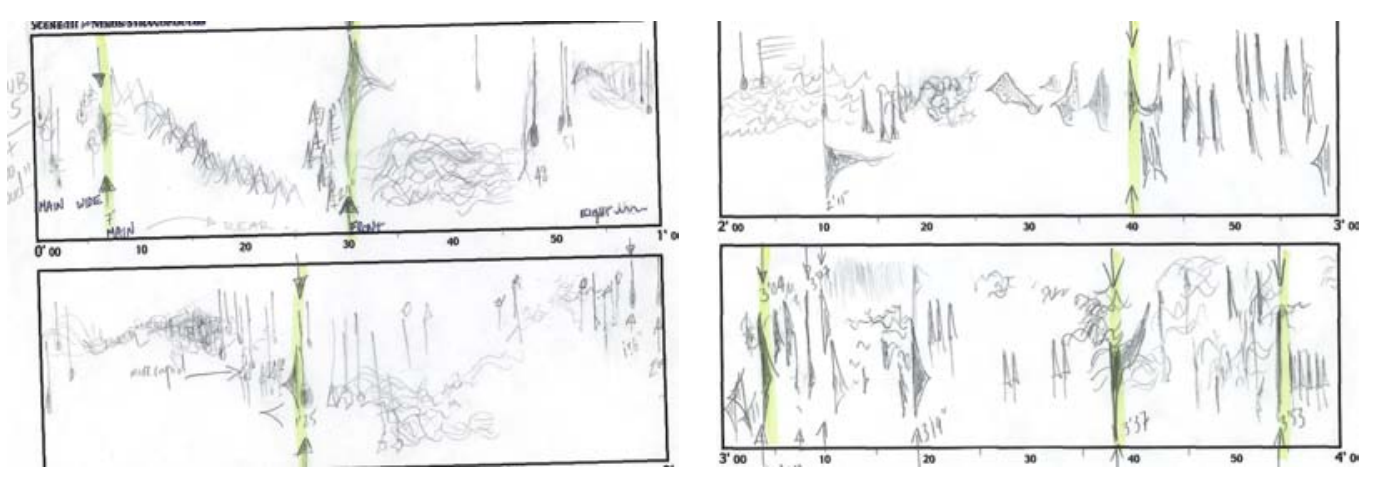

Fig. 106 Fragmento de Unsound Objects, Harrison (1995) en (Berezan, 2009)

Así mismo se puede apreciar la exploración por parte del compositor neocelandés Dennis Smalley (1946) en su obra Valley Flow (1991-92) y 
Vortex (1982) para multi-cinta, en las ilustraciones siguientes, (Fig. 107), que a modo de partitura simbólica definen los gestos sonoros en su obra (Smalley, 1982).
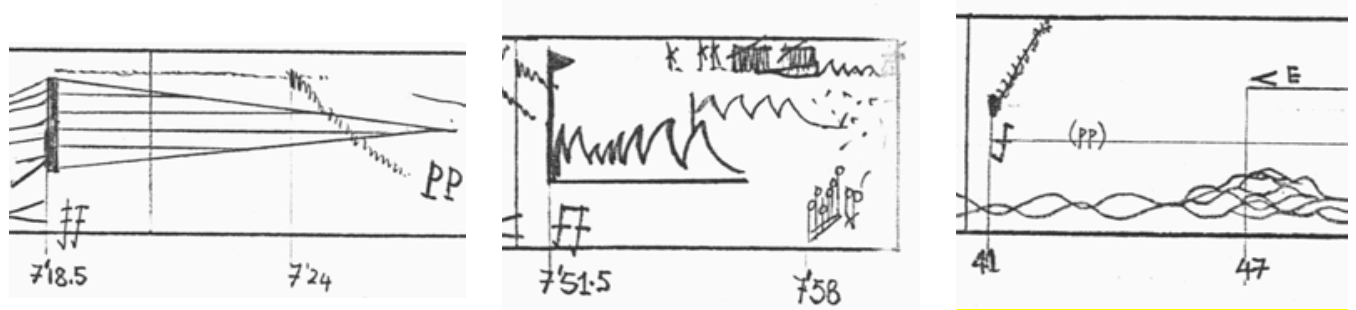

Fig. 107 Fragmento de Vortex (1982) en (Samlley, 1982)

Otro punto de partida para la configuración de un entorno notacional adaptado a una obra para instrumentos y electrónica, fue la obra de Ricardo Climent, Acute (2007), para cuarteto de percusión y 'objetos encontrados' Esta obra replantea la idea de objetos encontrados (ampliamente empleado en los entornos de composición e improvisación), de modo que el compositor entregó a los instrumentistas 44 pequeñas muestras sonoras, grabadas y procesadas en estudio, para que los percusionistas encontraran su análogo sonoro utilizando y manipulando objetos cotidianos como un molinillo de café, un globo, un bidón metálico, etc. Esta obra no utiliza electrónica en vivo, sino cinta grabada, en paralelo con el sonido de los objetos. La partitura contempla leyendas referentes a la esencia de los parámetros que el autor elige: el espectro sonoro, el gesto en el ataque con los utensilios, velocidad, movimiento, etc... (Fig. 108). Todo ello de manera aproximada, ya que cada intérprete puede elegir intuitivamente sus objetos (Climent, 2008). 
TABLE II.

CLASSIFICATION OF SOUND SPECTRUM NOTATION IN ACUTE

\begin{tabular}{|c|c|c|c|}
\hline S O U N D & S P E C T R U M & & \\
\hline DISCRETE & CONTINUOUS & \multirow{5}{*}{$\begin{array}{c}\text { ENDINC } \\
\theta \\
\theta \\
\theta= \\
\theta=\end{array}$} & \multirow{2}{*}{$\begin{array}{l}\text { TYPES } \\
\text { Abrupte }\end{array}$} \\
\hline Pitched & & & \\
\hline $\begin{array}{l}\text { Complox } \\
\text { Pitch (bell type) }\end{array}$ & SI ABLE & & Sharp \\
\hline $\begin{array}{l}\text { Non Pitched } \\
\text { (noise type) }\end{array}$ & & & Marked \\
\hline e.g. of hybrid spectrum & $\begin{array}{l}\text { time durat } \\
\text { acealerando/rit }\end{array}$ & & $\begin{array}{l}\text { Flat } \\
\text { Resonating }\end{array}$ \\
\hline
\end{tabular}

Fig. 108 Fragmento de la leyenda de Acute, en (Climent, 2008)

La partitura conforma una re-ubicación en la investigación y la tipología/morfología de la exploración instrumental de la percusión, así como en la música de objetos concretos comenzada por Pierre Schaeffer en su tratado de los Objetos Musicales (Schaeffer, 1966), continuada por Dennis Smalley en (Smalley, 1997), y reunida por (Thoresen, 2007) (ver Tema 5).

En la partitura de 'Le Gyrosbone', descrita en el apartado anterior (3.1.2.1) de Ricardo Climent, podemos ver la integración entre las indicaciones propias del comportamiento electrónico asociado a los sensores y la notación tradicional de una obra para instrumento solo (Fig. 109).

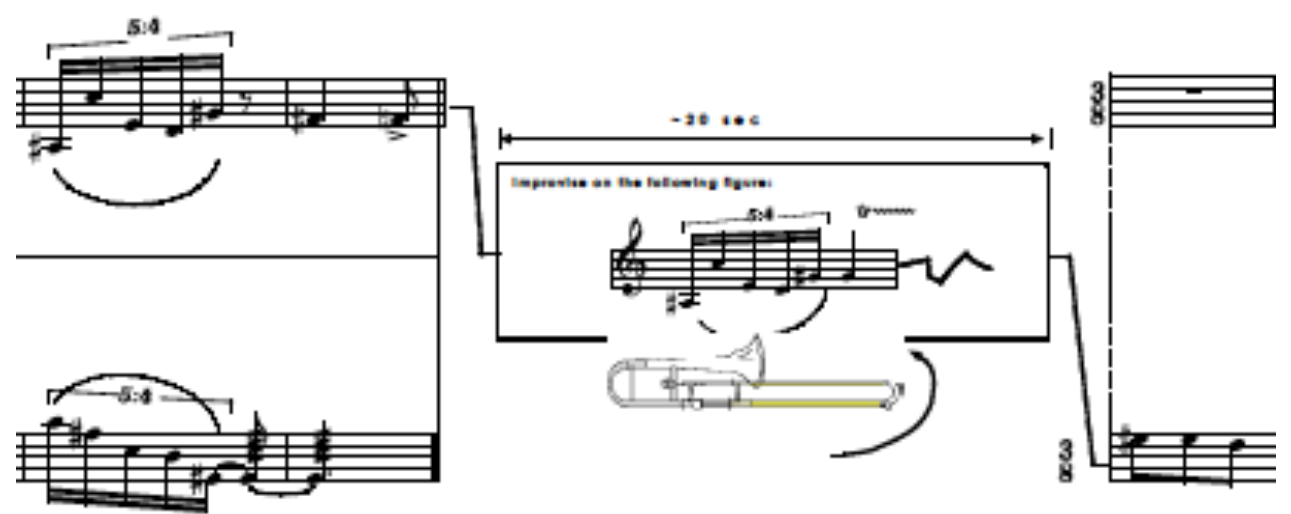

Fig. 109 Fragmento de Le Gyrosbone (2005), R. Climent 


\subsubsection{PERFORMANCE}

La obra que nos ocupa tiene un componente colateral de performance, dada la visualidad de la pseudo-coreografía que se establece para el control de la inclinación en los mandos Wii y por el cambio de baquetas que constantemente están realizando los instrumentistas. El referente principal cuando hablamos de performace relacionada con la música en el siglo XX es John Cage (1912-1992). Si bien su obra es ingente en el plano de la performace, la referencia principal para la génesis de TanGram ha sido su obra Water Walk (1960). Me llamó la atención que pese a estar continuamente cambiando de actividad, el collage sonoro que va formando durante la obra es más interesante que la propia performance. Cada fuente sonora produce un material que en todos los casos está perfectamente implementado al resto de sonoridades. Se plantea una disociación entre el objeto de la acción y el fin de la obra de arte, entendida en este caso como obra sonora.

En lo referente al origen de los planteamientos de Cage en el sentido de la percepción y ubicación del individuo así como la disociación en el proceso musical-performático hacia la obra de arte, se puede plantear la cuestión: ¿Dónde estamos cuando escuchamos música? La presencia no tiene por qué ser algo que demos por supuesto. El hombre, como señala (Sloterdijk, 2001, 56-70), es más bien 'el metafísico animal de la ausencia'. En el momento actual se da una gran contradicción. No existen ritos de ausencia validados -como la práctica de subirse a una columna y permanecer ascéticamente allí y, al mismo tiempo, existe mucha mayor ausencia de uno mismo en la vida cotidiana. No es extraño, por tanto, que la disociación sea, en su 
diferentes manifestaciones, y especialmente en la obra de arte sonoro, una patología en auge.

En una entrevista con Daniel Charles, Cage afirma: 'Lo que es importante es insertar al individuo en el flujo de todo lo que sucede. Para hacer esto, el muro del ego debe de ser demolido; gustos, memoria y emociones deben ser debilitados. Se puede tener una emoción, simplemente no debemos pensar que es tan importante. Tómala de una manera en que luego la puedas dejar caer. No la reelabores!' (Rocha Iturbide, 1991).

\subsection{DESCRIPCIÓN TÉCNICA}

A continuación se analizarán los parámetros de construcción de la obra, las necesidades que ha presentado una composición de esta naturaleza y las necesidades de integración que han presentado los factores experimentales y los parámetros de creación musical.

\subsubsection{COMPONENTES DE LA OBRA}

\subsubsection{METODOLOGÍA NOTACIONAL}

Los intérpretes necesitan de instrucciones precisas sobre la posición de ataque en la superficie del tam-tam. Para ello, se eligió un trigrama (pauta de tres líneas) simbolizando los tres posibles puntos donde golpear o frotar: el borde superior, el centro y el borde inferior del instrumento. Se añadieron indicaciones adicionales para ilustrar la portería o sujeción del tam-tam.

Dado que el mando Wii nos proporciona dos parámetros. Inclinación en el eje de la $x$ (vertical) y en el eje $y$ (horizontal), se establecieron dos 
símbolos de los cuales se desprenden trazos curvos que dibujan el movimiento que tiene que realizar el intérprete. En la siguiente figura (Fig. 110), la inclinación vertical que tiene que gesticular el percusionista 1 con el mando Wii está sincronizado con la figuración rítmica que realizan los demás intérpretes.

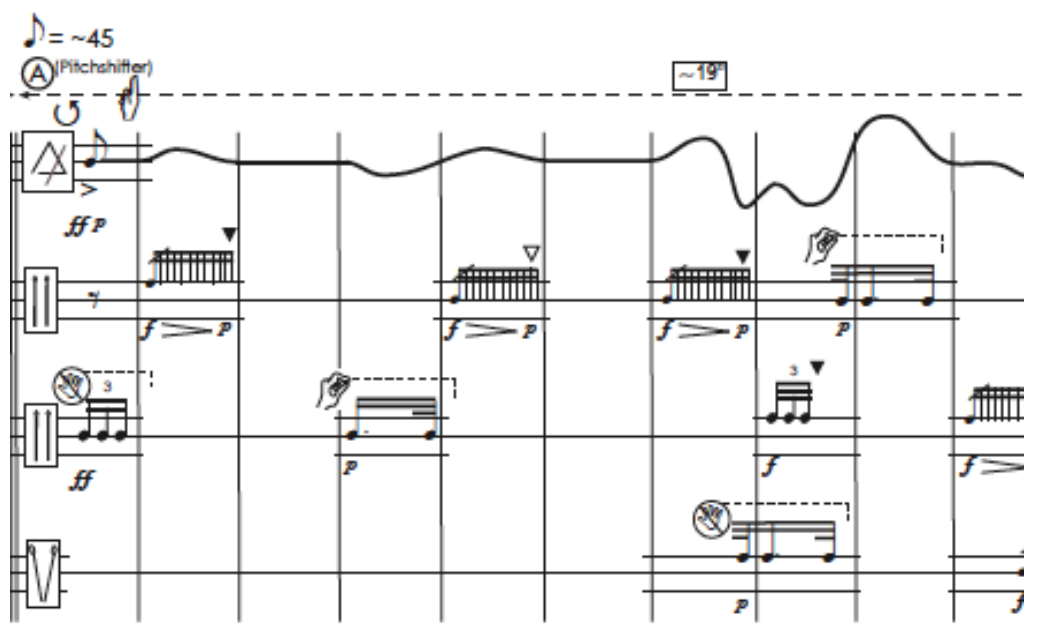

Fig. 110 Fragmento de TanGram

Para controlar el apagado de la resonancia del instrumento, se definieron 3 tipos de ejecución, abrupta o suavemente, así como dejarlo resonar (Fig. 111). La manera técnica en que ejecuten estas indicaciones en una opción libre para el intérprete.

\section{Sound endings}

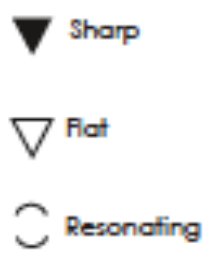

Fig. 111 Símbolos de apagado

También se contemplan dos indicaciones distintas para la opción del efecto de amortiguado de la resonancia (Fig. 112) con la mano que no 
sujeta la baqueta, agarrando firmemente el borde del tam-tam o tapando con la palma de la mano el centro del tam-tam.

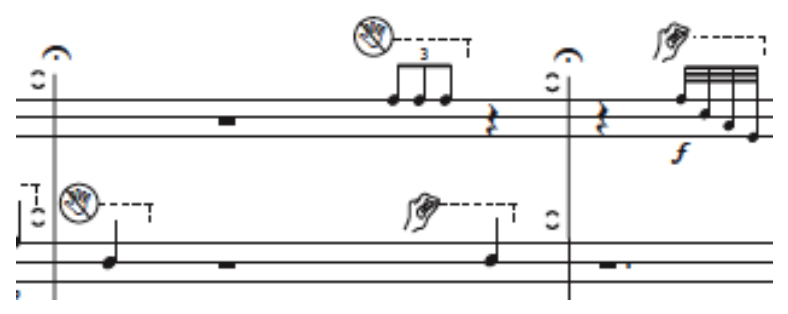

Fig. 112 Amortiguado de la resonancia

La dinámica usada va desde el fortissimo (fff) al pianissimo (ppp), así como el uso de pausas abruptas en el discurso de la obra. De todos modos, la acústica de la sala repercute en la intensidad de ataque así como de la respuesta de los procesos electrónicos. Los intérpretes tienen que valorar sobre la marcha la elección de ciertos parámetros.

La notación referente a la rítmica musical se ha mantenido bajo el criterio de notación métrica tradicional, incluyendo en ocasiones simbología semi-aleatoria o escritura abierta (Fig. 113).

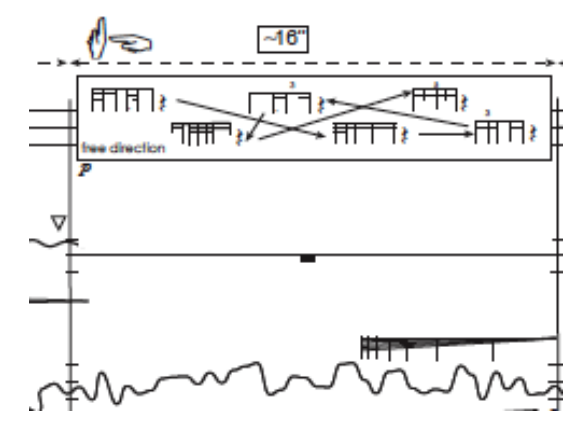

Fig. 113 Escritura abierta

\subsubsection{NATURALEZA RÍTMICA}

Como obra de percusión, la articulación y estructura está enteramente generada por la organización motívica de células rítmicas. Sólo algunos usos de arco o técnicas de frotado actúan como excepción 
espacial en el total de la obra. En cambio no se ha pretendido la exclusividad de planteamientos rítmicos como término musical y técnica compositiva, sino como disposición espacial de recursos y células rítmicas, aludiendo a la metodología de Tarkowskij (Deltcheva y Vlasov, 1997), quien se preocupó por la escenografía rítmica (esculpir en el tiempo) y no por la edición temporal. En términos de la obra que nos ocupa, se refiere a la espacialidad de las escenas sonoras y sus tipologías específicas. A su vez, cada proceso electroacústico requiere un tempo específico para adaptar dicho tempo a cada respuesta electrónica.

El tempo métrico de la obra está definido por unidades de tiempo aproximado expresado en segundos. No existen indicaciones de compás (Fig. 114). Independientemente, se optó por el complemento de indicaciones de metrónomo aludiendo a la figuración que resulta más simbólica en el contexto de cada sección. Así pues, el intérprete integra cada metrónomo dentro de una franja flexible de tiempo, ya que a menudo se utilizan diferencias significativas de duración de notas. A su vez, las condiciones acústicas del recinto plantean en cada caso la adaptación del tempo interpretativo y pueden hacer variar determinadas indicaciones métricas.

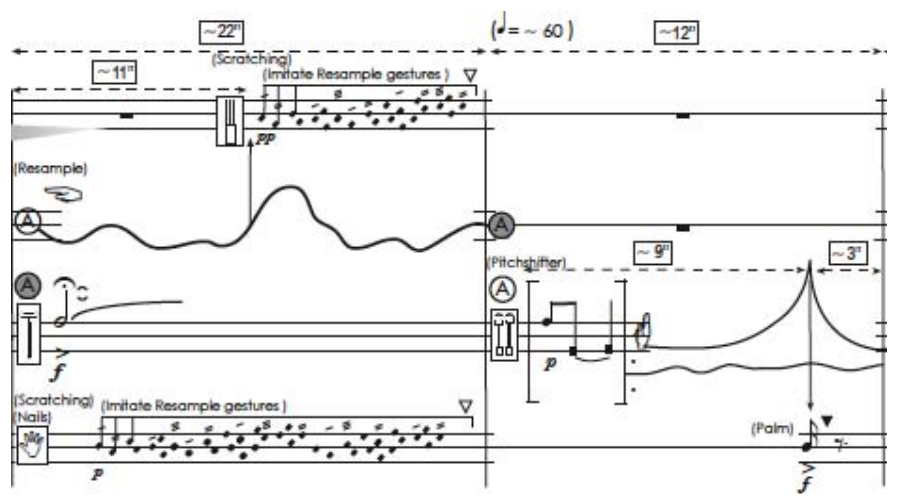

Fig. 114 Divisiones temporales 
La partitura está configurada como un conjunto indivisible para su realización en concierto. Ya que la obra es totalmente colaborativa e interactiva en el plano interpretativo, ya sea entre instrumentos como entre procesos electrónicos e instrumentos, no se planteó la posibilidad de producir particellas ${ }^{22}$ individuales para la interpretación. La simbología de cada instrumentista está coordinada con los demás, de modo que necesita visualizar las otras partes para concertar todos los elementos.

Cuando un intérprete permanece inactivo durante una franja de tiempo se redujo el trigrama a una sola línea, de este modo se eliminan indicaciones innecesarias reduciendo la confusión de elementos gráficos.

\subsubsection{ANÁLISIS FORMAL DE LA OBRA}

La partitura, incluida la parte computacional (procesos en tiempo real) desarrolla una iteración de probabilidades basada en el juego chino TanGram y en sus piezas geométricas. Conceptos como espectro armónico, brillo espectral, pulso, multi-direccionalidad y armonicidad actúan como capas complementarias con el sonido original del tamtam.

Siete piezas configuran este sencillo juego. Así pues, siete procesos digitales, siete secciones y siete motivos rítmicos configuran la partitura (impulso simple, ritmos binarios, ternarios, ... hasta figuración de septillos). Se ha procurado encontrar el equilibrio en la expresión musical y en la correspondencia o divergencia entre el

\footnotetext{
${ }^{22}$ Particella: En italiano 'parte'. Partitura individual extraída de un guión (orquestal y/o coral) general.
} 
sonido original del instrumento y la mimética respuesta del discurso electrónico.

La utilización métrica de la obra parte del impulso simple, más o menos extendido en el tiempo (mediante el amortiguado de la resonancia), hasta la variación temporal de este elemento, mediante el frotado o el redoble. Este impulso irá desarrollándose hacia células rítmicas de 2, 3 hasta 7 figuras de distinta duración dependiendo del fraseo y la naturaleza de cada sección. Cada una de las 7 secciones que forman la obra contiene uno o más procesos electrónicos. En el apartado 3.2.2.2 podemos ver una descripción detallada de cada uno de ellos.

- En la primera sección (compases 1 - 8) se explora la poliritmia entre el sonido del tam-tam y su consecuente respuesta electrónica. En este caso se han utilizado un modificador de altura (pitchshifter), un delay ${ }^{23}$ controlado y un modificador de tempo (resampleador) en dos canales. En esta sección ya se plantea un diálogo entre los instrumentistas y la electrónica. Una pausa de 3 segundos aproximadamente actúa de coma sintáctica para la segunda sección.

- En esta segunda (cc. 9 - 28) parte un objeto realiza un proceso de síntesis granular (a partir de la grabación sobre un buffer ${ }^{24}$ ) respaldando un redoble irregular del primer percusionista a la vez que los demás realizan colaborativamente un contrapunto rítmico obstinado. Después de una pausa de 2 segundos, aparece por primera vez el sonido con altura determinada. El

\footnotetext{
${ }^{23}$ Delay: Término anglosajón que significa retardo.

${ }^{24}$ Buffer: es un espacio de memoria en el que se almacenan temporalmente datos.
} 
objeto fiddle ${ }^{25}$ (Puckette, 1997) conectado a un generador de señal simple interpreta el frotado por parte del instrumentista 2 , y ejecuta un impulso electrónico prolongado (con envolvente de altura definida) que sirve como origen para el rebote del percusionista 3. En la segunda sección, el frotado con la baqueta de triángulo provoca al seguidor de altura (fiddle ) y la inclinación del brazo modifica la altura, todo ello coordinado con las células rítmicas del resto de intérpretes.

- La tercera sección (cc. 29 - 39) comienza con un ataque triple sincronizado en los 4 percusionistas. A partir de aquí aparecen elementos métricos extraídos de la $2^{\text {a }}$ sección de manera aislada y simbólica. Este juego de eco y respuestas se verá desarrollado en esta sección, ampliado por un armonizador sobre la célula ternaria del comienzo (percusionista 2). El percusionista 1 introduce elementos semi-aleatorios que irán tomando forma en la siguiente sección.

- Esta 4 sección (cc. 40 - 48) comienza con el golpe en forte del martillo de campana (percusionista 3), los percusionistas 1 y 4 actúan como un granulador humano con el empleo del rasgado utilizando las baquetas de rastrillo y las uñas sobre la superficie del tam-tam.

- La quinta sección (cc. 49- 50) comienza una vez más como la tercera, esta vez con un ataque sincronizado cuádruple. A continuación se establece un espacio de 30 segundos aproximados en los que un intérprete ad limitum, improvisa con el efecto electrónico del delay controlado por la inclinación del

${ }^{25}$ Fiddle : Objeto diseñado por Miller Puckette que realiza un seguimiento de altura a partir de una señal compuesta. 
brazo. Al término de esta parte de improvisación empieza la 6a sección, aquí se vuelven a introducir células rítmicas simples de hasta 4 impulsos que irán formando un collage motívico itinerante.

- La 6a sección (cc. 51 - 55) continúa con la idea de la sección anterior excepto que los percusionistas 2 y 3 emplean el arco como elemento de tempo continuo y extendido en el espacio temporal.

- La última sección (cc. 56 - 67) se enmarca en una recapitulación a modo de conclusiones sonoras dibujando los elementos más significativos de la obra: la expresión rítmica simple y su desarrollo en el tiempo (gestos rítmicos, motivos, figuraciones, polirritmias, etc.) en el plano del material sin altura definida, y su versión con altura definida como resultado de la exploración y del diálogo con los medios electrónicos.

\subsubsection{ELEMENTOS ACÚSTICOS}

En el repertorio de música occidental, el tam-tam es el correspondiente al instrumento chino tradicional, el Gong. Se suele entender que los tam-tams son generalmente más pequeños y la parte de ataque central no tienen ningún relieve (Mellers, 1992). Están fabricados en bronce y sus diámetros varían en función de modelos, marcas, etc.

El grupo de percusión 'Kontakte' dispuso de 4 tam-tams con diferentes diámetros: 31, 25, 21 y 17 pulgadas. No es absolutamente necesario disponer de estos diámetros para la ejecución de la obra, pero sí es imprescindible formar una familia de 4 instrumentos de tamaños significativamente diferentes y contar con el orden de 
tamaño indicado en la partitura para cada percusionista. En el capítulo o vimos como el tamaño de los instrumentos condiciona la puesta en escena de la obra y los parámetros de transformación sonora tienen que ser ajustados dadas las condiciones acústicas que estos generan.

El uso de baquetas concretas es una parte esencial para esta obra y para las cualidades sonoras del ataque sobre la superficie del tam-tam. Se han definido 12 tipos distintos de baquetas para golpear sobre la superficie del instrumento (Fig. 115), 2 posibilidades de ataque con la mano, 2 utensilios adicionales: cinta adhesiva y una cortina de piedras pequeñas sujeta a la portería, y el uso de un arco para frotar contra el borde del tam-tam. Los tipos de baquetas empleadas son: de marimba, martillo de campanas, con cabeza de goma tipo 'Missom', con cabeza de nylon tipo jazz, con cabeza de madera tipo concierto, con cabeza grande de goma y flexible tipo 'superball', escobillas, baqueta tradicional de tam-tam, tipo 'Rute', con doble cabezal (madera y algodón), de platillos tipo rastrillo y baqueta metálica (de triángulo). 


\section{Symbology}

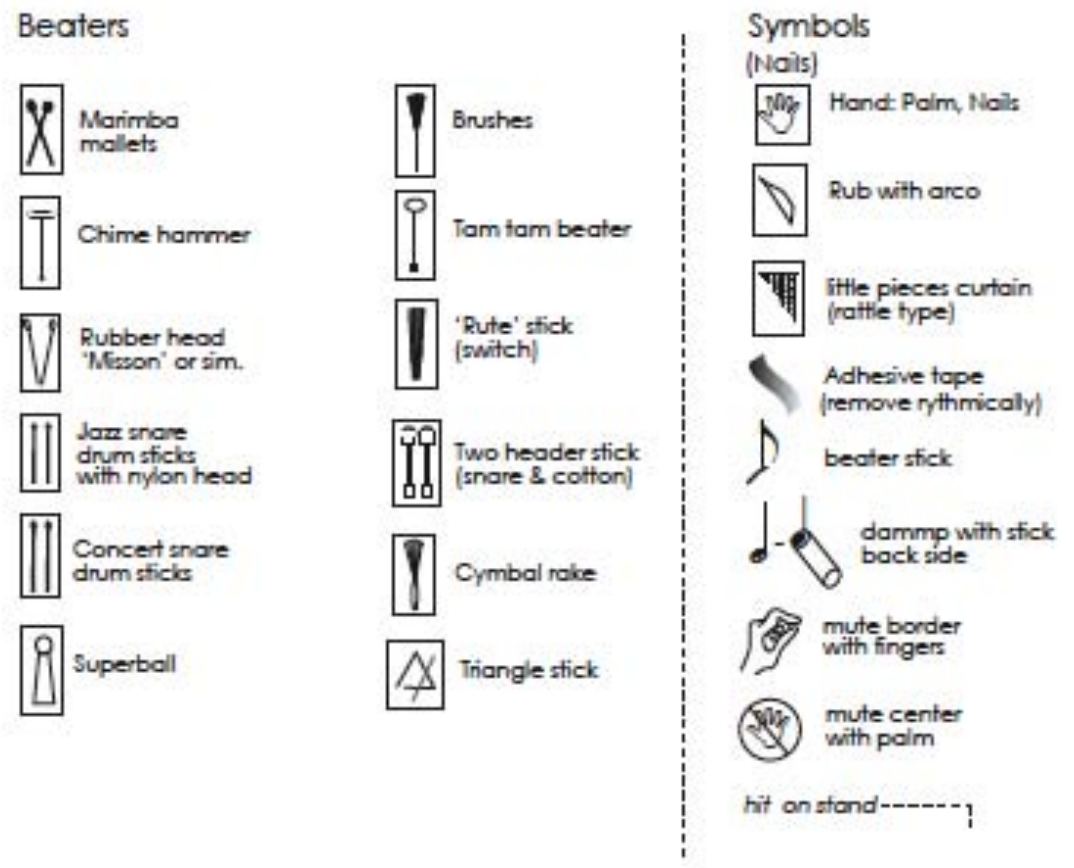

Fig. 115 Simbología de baquetas y utensilios

En ocasiones se utiliza el mango de algunas baquetas, por tanto existe también un símbolo específico en la partitura para indicar este uso.

\subsubsection{DEL GESTO A LA NOTACIÓN SONORA}

Aunque algunos compositores electroacústicos han desarrollado algunas conclusiones sobre análisis gestual del sonido para el análisis de la electrónica en vivo, mi intención es reorientar estos hallazgos en la confección de la partitura, ofreciendo la libertad adecuada al intérprete para controlar y variar las respuestas de los demás intérpretes. Se procuró describir de manera precisa como, después de resolver el puzzle del comportamiento de la inclinación en el eje de x o de y con el mando Wii, el grupo de percusión 'Kontakte' (Kontakte, 2009), los intérpretes que encargaron esta obra electroacústica, tuvieron que hacer extensivo el uso colaborativo y las diferentes 
experiencias en concierto, llamando a su propia memoria y creatividad. Después de activado cualquier proceso, ellos integraban la escucha y el movimiento para conformar la coordinación necesaria entre ritmos, baquetas, gestos y diálogos recíprocos.

La gestualidad de la obra, inclinaciones, rotaciones y figuras en el aire por parte de los intérpretes está inspirada en las técnicas y gestos del Tai Chi. Especialmente en los cinco animales que representan diferentes energías con supuestas propiedades terapéuticas: tigre, ciervo, mono, oso y grulla. Como la gran mayoría de planteamientos filosóficos orientales, el Tai Chi es una integración corporal de los elementos opuestos del yin y del yang, la flexibilidad y la dureza (ZinLai, 2001). Esta dualidad se corresponde en TanGram, en la interacción entre el instrumento acústico y los recursos electrónicos. El procesado del flujo de datos desde el sensor Wii y los procesos electrónicos diseñados para esta obra, requiere de una gestualidad suave, tal y como requiere la práctica de este arte marcial. El movimiento de los intérpretes cambiando de baquetas, utilizando distintas técnicas de apagado y amortiguado del sonido más la inclinación de sus brazos interactuando con la Wii conforman un collage gestual que está totalmente integrado y desarrollado en el discurso sonoro (Fig. 116). 


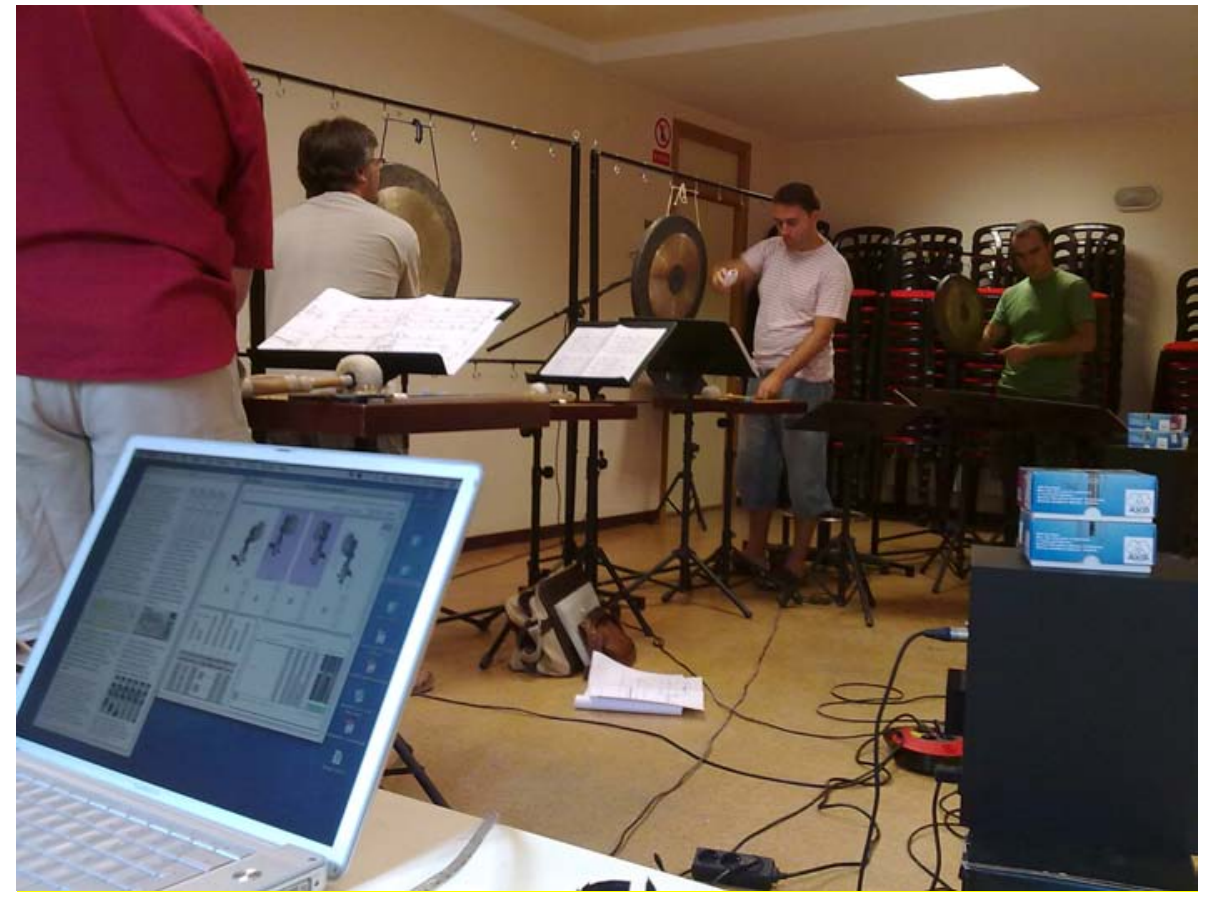

Fig. 116 Kontakte ensayando TanGram

La gestualidad del intérprete, en todo caso, está supeditada a las necesidades técnicas de los procesos digitales y a los requisitos técnicos en la ejecución motriz de los percusionistas. Por tanto y a veces, el objetivo de dibujar ciertos perfiles que sean reconocibles a estas figuras o elementos no resultan totalmente precisos.

\subsubsection{AUTONOMÍA INTERPRETATIVA}

Normalmente, en obras electroacústicas con electrónica en vivo, se requiere de un técnico, que a menudo es el propio compositor, para controlar la parte electrónica, lista de eventos, ganancia, balance, etc... Ya que los intérpretes que hicieron el encargo de TanGram querían disponer de autonomía en la puesta en concierto de la obra, la aplicación (Patch) en Max MSP se diseñó de manera que estuviera totalmente controlada por los instrumentistas mediante el control remoto del mando Wii. Los botones ' $A$ ' de cada Wii disparan cada proceso almacenado en el objeto 'coll'. Una matriz orienta los datos 
de cada Wii a un proceso específico. A su vez, 4 micrófonos se activan o desactivan en función de una matriz similar. Con los botones 'arriba' y 'abajo' pueden controlar también la ganancia total del resultado electrónico en caso de que consideren modificarlo en el transcurso de la obra.

Antes del comienzo de la obra, los intérpretes sólo activan el patch, encienden sus mandos Wii y lo sincronizan con el dispositivo Bluetooth del ordenador presionando las letras $q$, w, e y $r$ para el activado de la señal y las letras $a, s, d$ y $f$ para desactivar la comunicación del mando Wii.

En cualquier caso, y como veremos en el capítulo 3.2.4, el patch cuenta con una opción de manejo desde el teclado del ordenador por parte de un asistente técnico ajeno al grupo.

\subsubsection{MONTAJE DE LA OBRA}

El montaje de la obra ha sido un punto decisivo en la evolución y consecución de TanGram. Dada la naturaleza intuitiva del intérprete para manejar el dispositivo que actúa como sensor, el desarrollo de los ensayos y la configuración final de la partitura, que ha ido cambiando en función de las necesidades que cada una de las situaciones ha ido requiriendo, se ha dispuesto el proceso de montaje como parte decisiva en la creación de la obra.

Los ensayos se realizaron en el Conservatorio de Buñol (Valencia) durante el verano de 2009 en el aula de Percusión. En ella se dispusieron 4 tam-tams de diámetros diferentes y se probaron distintas posiciones de cada uno de los intérpretes de modo que hubieran contacto visual entre ellos para sincronizar las entradas y 
eventos conjuntos descritos en la partitura. La colocación que se decidió como idónea es la siguiente (Fig. 117):

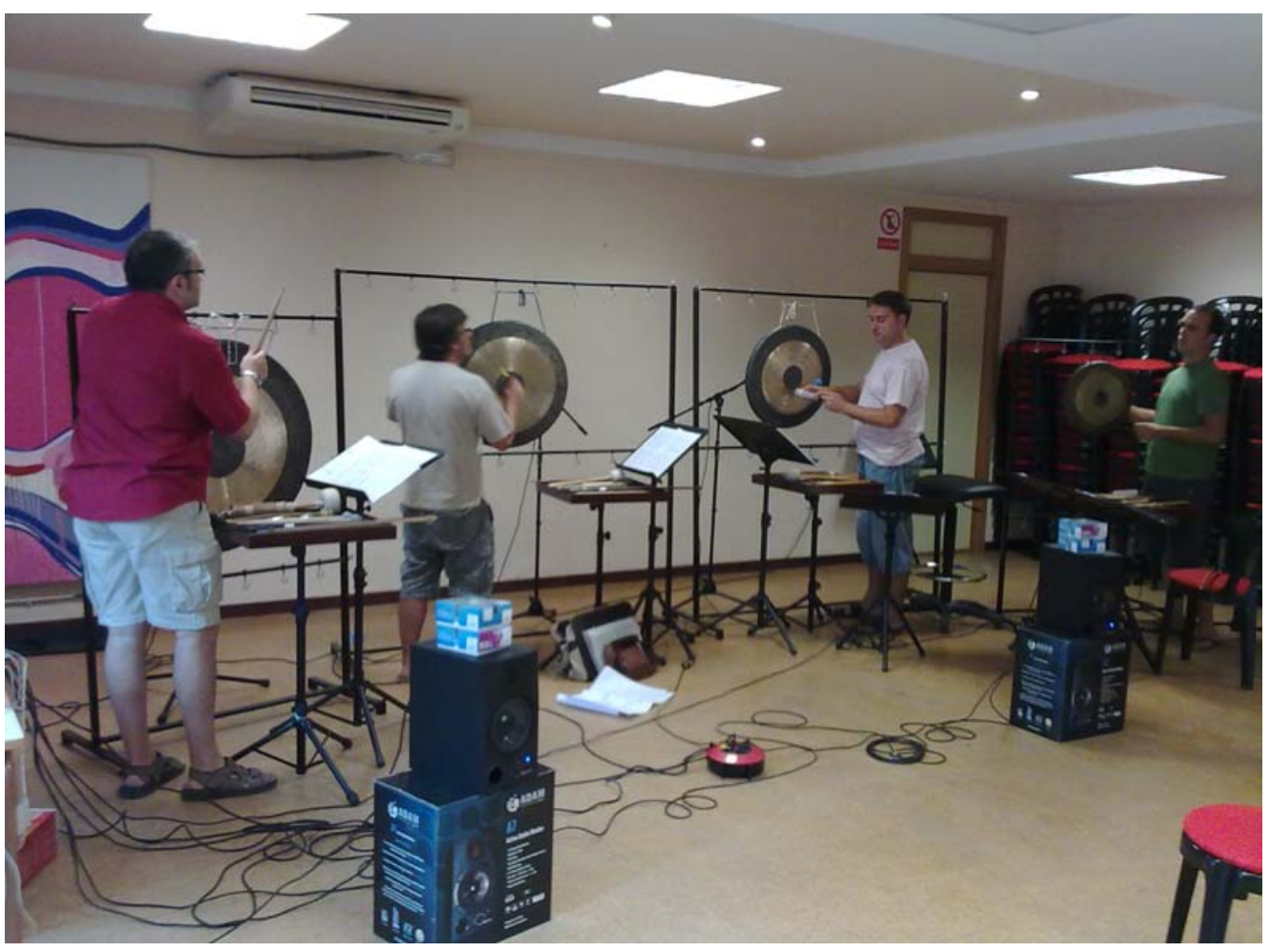

Fig. 117 Ensayo de TanGram

En esta posición, los percusionistas $2^{\circ}$ y $3^{\circ}$ adquieren el rol de referentes para los percusionistas $1^{\circ}$ y $4^{\circ}$, quienes están además en contacto visual entre sí. En un principio se planteó la posibilidad de orientar a los instrumentistas zurdos en una u otra posición, pero este parámetro no constituye una necesidad importante para un percusionista profesional dado que además, tienen que manejar ambas manos y antebrazos para la realización de la obra: golpeos, rasgados, rebotes, redobles, amortiguado del sonido, usos y cambios de baquetas y manejo y rotaciones del mando Wii, etc (Fig. 118). 

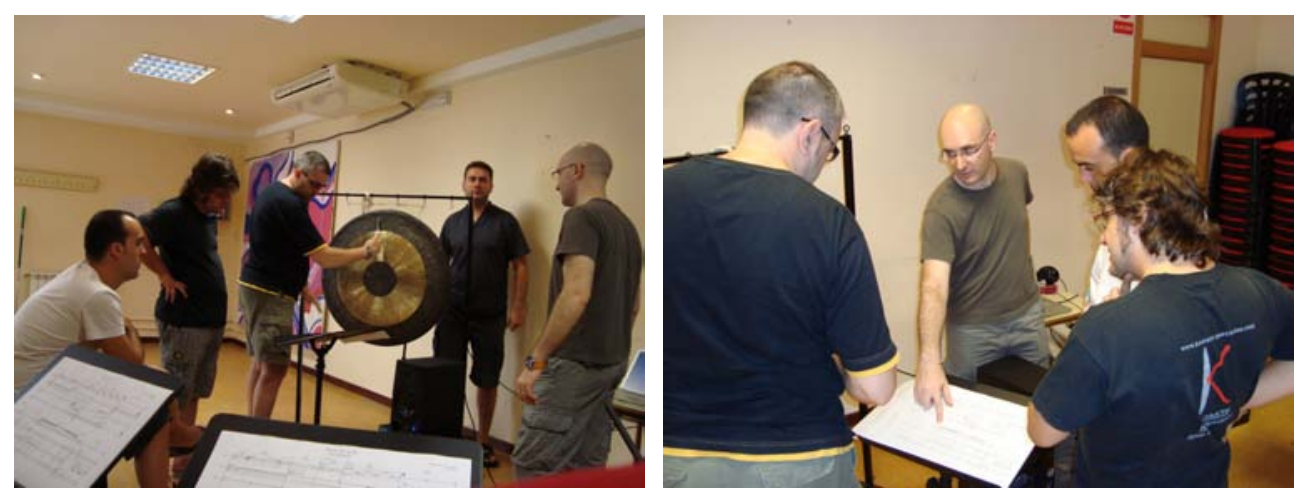

Fig. 118 Primera lectura de TanGram

Otro factor decisivo en el montaje de la obra fueron los parámetros de sonorización del espacio. Las condiciones que presenta una sala de conciertos o auditorio, como en el que se desarrolló el estreno, son imposibles de simular en una sala de ensayo. Esto condiciona en gran medida la planificación técnica de la parte electrónica. Por un lado, la microfonía tiene que ajustarse al instrumento y a su comportamiento dado el espacio escénico; por otro lado la amplificación que se realiza del material resultante (sonido directo y procesado) tiene que tener el máximo de equilibrio posible para el feedback que se establece en la interpretación de los instrumentistas con su propio sonido.

Para las condiciones acústicas de la sala de ensayos del conservatorio de Buñol se utilizaron:

- Microfonía: para la captación de los tam-tams de los que disponíamos en la sala y en función de la respuesta de dichos instrumentos a las dimensiones de la sala se utilizaron 4 micros 
AKG C430. Estos son micros cardioides ${ }^{26}$ de campo cercano, cápsula pequeña, e ideal para percusiones 'overhead' (pesadas).

- Amplificación: se utilizaron un par de Altvoces autoamplificados Adam A7.

- Una tarjeta de Audio multicanal MOTU Traveller 828 Mkll.

- Un Macintosh PowerBook $\mathrm{G}_{4}$ con un procesador de $1.67 \mathrm{GHz}$ y 2 GB de memoria RAM.

\subsubsection{DESARROLLO, PROCESOS DE ELECTRÓNICA EN VIVO}

\subsubsection{DISPOSITIVOS FÍSICOS}

El sistema en el que se diseñó la aplicación fue un PowerBook $\mathrm{G}_{4}$ de Macintosh, con el sistema operativo Tiger 10.4.11, con un procesador de $1.67 \mathrm{GHz}$ PowerPC con 2 GB DDR SDRAM. Versión de Bluetooth 1.9.5f4 y versión del software Max MSP 4.6.3, ya que los requisitos mínimos para el enlace con el objeto aka.wiiremote es un Mac OS X 10.4.8 o superior, Max MSP 4.6.2 o superior y Bluetooth 1.6.3 o superior.

A continuación se hará una descripción de los instrumentos que se han utilizado como vehículo de transmisión de datos entre intérprete y ordenador.

${ }^{26}$ Los micrófonos cardioides son micrófonos unidireccionales con un diagrama polar con forma de corazón (de ahí el nombre), lo que se traduce en una mayor sensibilidad hacia los sonidos que le llegan por su parte frontal $y$, por el contrario, un mínimo de sensibilidad a los que le llegan por su parte posterior, donde se va produciendo una atenuación gradual. 


\subsection{MANDO REMOTO WII}

En la imagen siguiente (Fig. 119) podemos ver los componentes incluidos en el mando Wii: el sensor de Infrarrojos, circuitos, inductores, memorias, Bluetooth, etc...

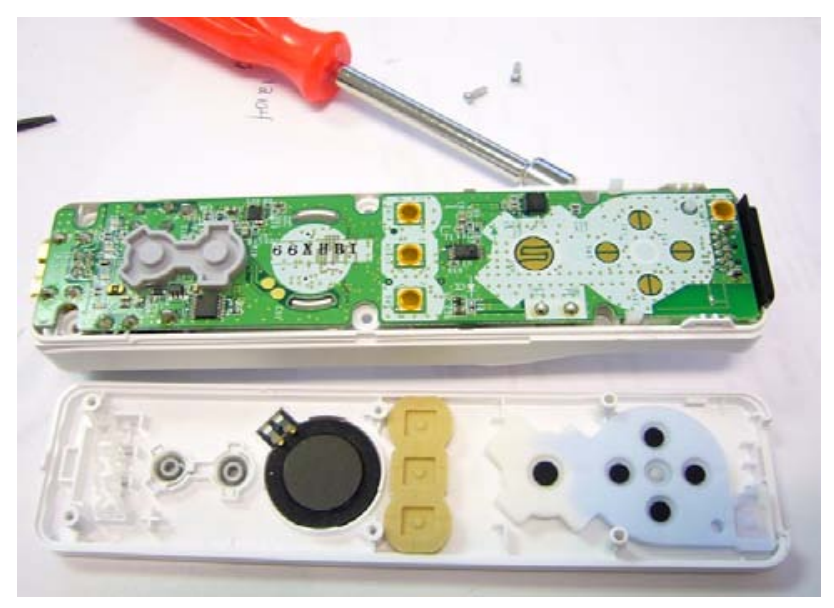

Fig. 119 Interior del mando Wii, en (Seidle, 2006)

El disco de color negro grande corresponde al altavoz. Los leds son los indicadores de determinadas funciones como el estado de la pila, conexión, etc.

El acelerómetro (Fig. 120) que lleva integrado es el modelo ADXL 330, un tipo de sensor desarrollado con triple eje. Este sensor mide la aceleración con un límite mínimo a escala completa de $\pm 3 \mathrm{~g}^{27}$. Puede medir la aceleración de la gravedad estática en aplicaciones de inclinación, así como la aceleración dinámica resultante por movimientos de choque o vibración (Devices, 2009).

\footnotetext{
${ }^{27}$ Las fuerzas $\mathrm{G}$ no son una medida de fuerza sino una medida intuitiva de aceleración. Está basada en la aceleración que produciría la gravedad terrestre en un objeto cualquiera en condiciones ideales (sin atmósfera $u$ otro rozamiento). Una aceleración de $1 G$ es generalmente considerado como igual a la gravedad estándar, que es de 9.80665 metros por segundo cuadrado (m/s2) (BIPM, 2010).
} 


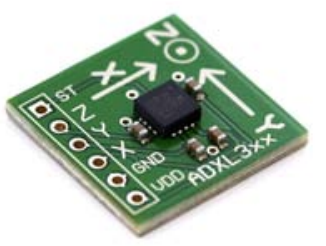

Fig. 120 Acelerómetro ADXL 330, en (Seidle, 2006)

En la siguiente imagen (Fig. 121) podemos ver el comportamiento de los rangos numéricos que tienen los ejes del mando Wii. Los valores indican la posición en los círculos concéntricos cuando la frontal del mando (lado con botones) se coloca en la posición dada. Por ejemplo: la orientación de la figura con los valores (x: 0.000, y: 0.065, z: 0.981) corresponde a la posición del borde apuntando hacia abajo y los botones delanteros apuntando hacia la cara de estos valores. El giro hacia la derecha en una dirección dada produce valores positivos, los giros hacia la izquierda resultan en valores negativos.

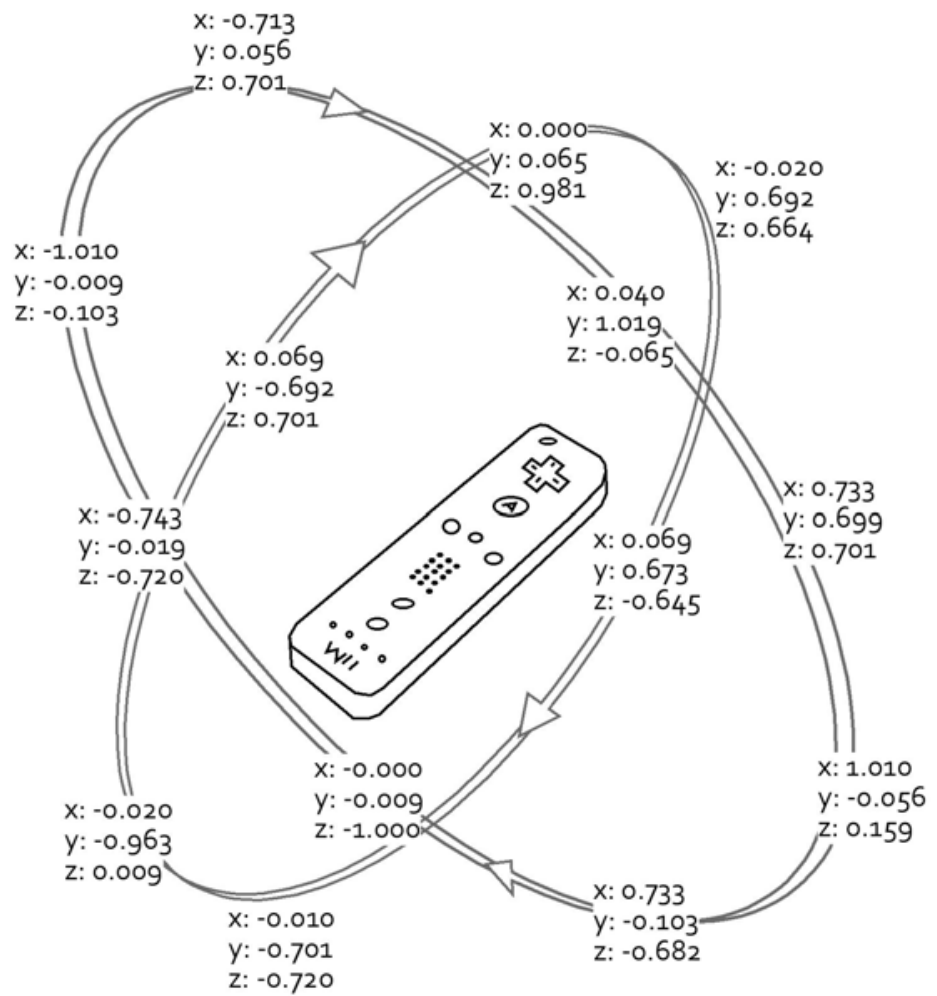

Fig. 121 Ejemplo de valores de aceleración en los 3 ejes, a partir de (Xiig19o, 2008) 
A continuación podemos ver los inductores $33 \mathrm{uH}, 10 \mathrm{uH}$ y $4.7 \mathrm{uH}$ (Fig. 122), las pequeñas partes redondeadas $(330,100,4 R 7)$. Su función es la reducción de tensión continua (DC) mediante un convertidor de potencia (Buck, reductor o Boost, elevador). La placa cuadrada central corresponde al BCM 2042, es un dispositivo Bluetooth de bajo coste. Sus características son: una memoria $8051 \operatorname{CORE}^{28}$ y RAM/ROM interpretando el perfil y almacenamiento de un dispositivo de interacción humana (HID). En la foto derecha podemos ver el chip ST 4128 BWP, que corresponde a una memoria EEPROM ${ }^{29}$ de $128 \mathrm{kbit}$ (Fig. 122 y Fig. 123) donde una sección de 6 kilobytes puede ser libremente leída y escrita por el sistema (Seidle, 2006).

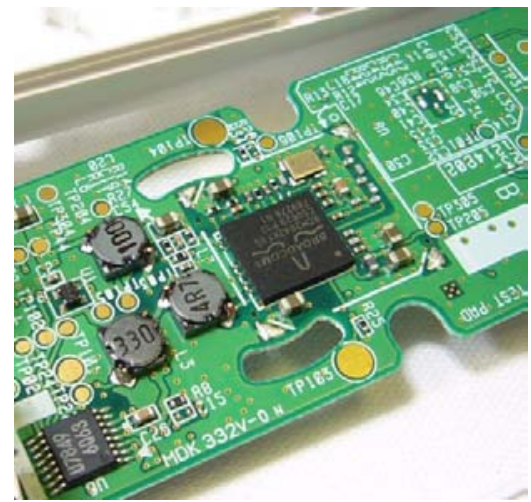

Fig. 122 Inductores y Blvetooth BCM 4042, en (Seidle, 2006)

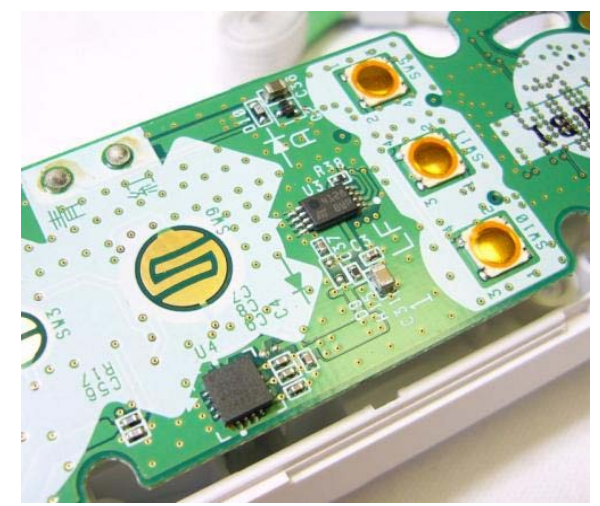

Fig. 123 Acelerómetro y EEPROM, en (Seidle, 2006)

\subsection{GESTIÓN DE DATOS VIA BLUETOOTH}

Ya que la aplicación fue diseñada como una secuencia orgánica de eventos (procesos DSP) exclusivamente en vivo y determina una distribución colaborativa de los intérpretes (Fig. 124), se diseñó una

\footnotetext{
${ }^{28}$ Core: Traducido como Núcleo, significa el lugar donde se encuentra la CPU.

${ }^{29}$ EEPPROM: Es un tipo de memoria ROM que puede ser programado, borrado y reprogramado eléctricamente.
} 
aplicación (patch) en Max MSP (Puckete y Zicarelli, 1990) como herramienta e interface de partida en la consecución de procesos.

La transmisión de datos vía Bluetooth se testeó con varias aplicaciones. La más estable con el sistema, que a la vez enviaba un flujo, más o menos estable de datos, es el software OSCulator (Troillard, 2006-2008). Este software transmite datos entre aplicaciones por código abierto: OSC (Open Source Code). Ya que el destino final de los datos es el entorno Max MSP, se requería la implementación en el patch de los objetos udpsend y udpreceive o de la librería de OSC desarrollada por el Center for New Music and Technology de la universidad de California (CNMAT, 1987) - para versiones anteriores a la 4.6 - para la conversión de datos a valores concretos, pero los parámetros de datos (inclinaciones y botones) tenían que configurarse por separado y definirse en Max MSP. Dependiendo de la versión del programa y del modelo de tarjeta Bluetooth pueden aparecer problemas de conexión. Otra dificultad consiste en la activación previa de OSCulator para parear los mandos, antes de lanzar el patch principal.

Finalmente, para transferir los datos del mando Wii al Max MSP se utilizó una librería específica: aka.wiiremote (Akamatsu, 2009). Este objeto está diseñado especialmente para este entorno y permite un flujo totalmente estable de datos vía Bluetooth. Cada percusionista activa o desactiva su propia lista de eventos pulsando el botón con la letra 'A' del mando Wii previa activación de los 4 mandos (Fig. 124). 


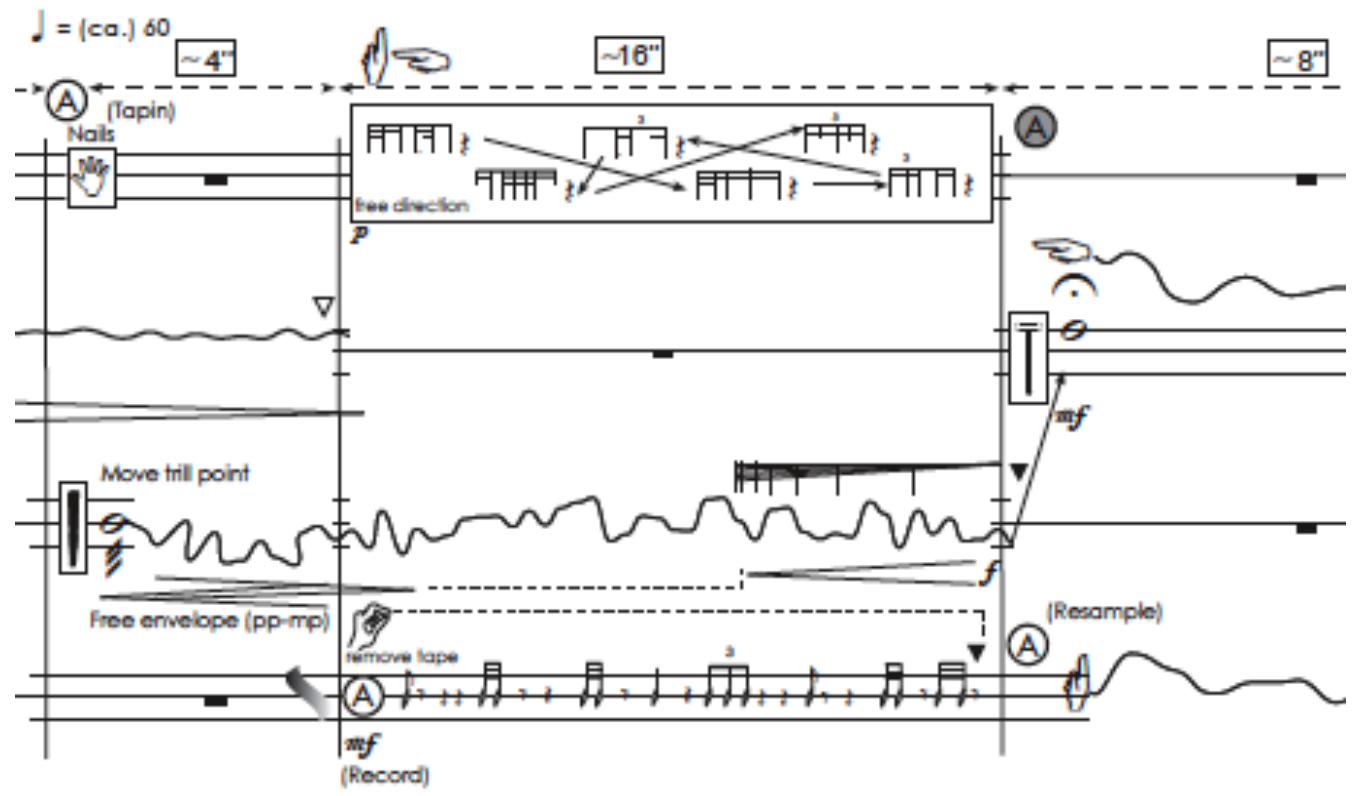

Fig. 124 Activación de eventos en la partitura de TanGram

La librería de objetos aka (Akamatsu, 2009) está diseñada para interpretar los datos de los sensores del mando Wii. La transmisión de datos se efectúa vía Bluetooth y el pareado (conexión) con el ordenador tiene una respuesta estable. El objeto acepta más de un mando al mismo tiempo. Para la obra TanGram se testearon 4 mandos simultáneamente sin recibir errores ni interferencias en los movimientos de cada uno. Cada mando Wii envía datos por una dirección concreta que queda fijada al ordenador al conectar el objeto en el programa Max MSP. A veces el reconocimiento de las direcciones de los mandos Wii por parte del ordenador y dependiendo del controlador Bluetooth, puede presentar algunos conflictos, en este caso y tal y como indican las instrucciones de la librería sólo se necesita eliminar el dispositivo conflictivo del menú de Bluetooth del sistema, y volverlo a conectar desde el propio objeto aka.wiiremote (Fig. 125). 


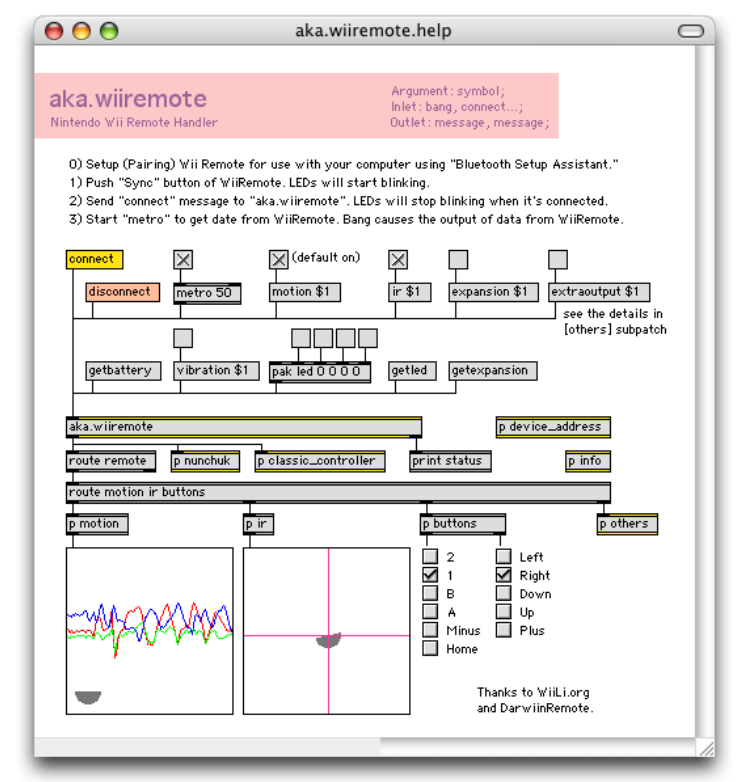

Fig. 125 Objeto aka.wiiremote, en (Akamatsu, 2009)

Ya que se necesitaba un escalado concreto de este rango para cada proceso electrónico, se utilizó el objeto de Max scale para configurar el rango que requerían cada uno de los 7 procesos electrónicos. Para enviar la señal de activación de los botones que servirían como disparadores desde el objeto aka. wiremote al patch principal y a los 7 procesos DSP (uso de las flechas arriba y abajo y botón 'A') se usó el objeto send (Fig. 126). 

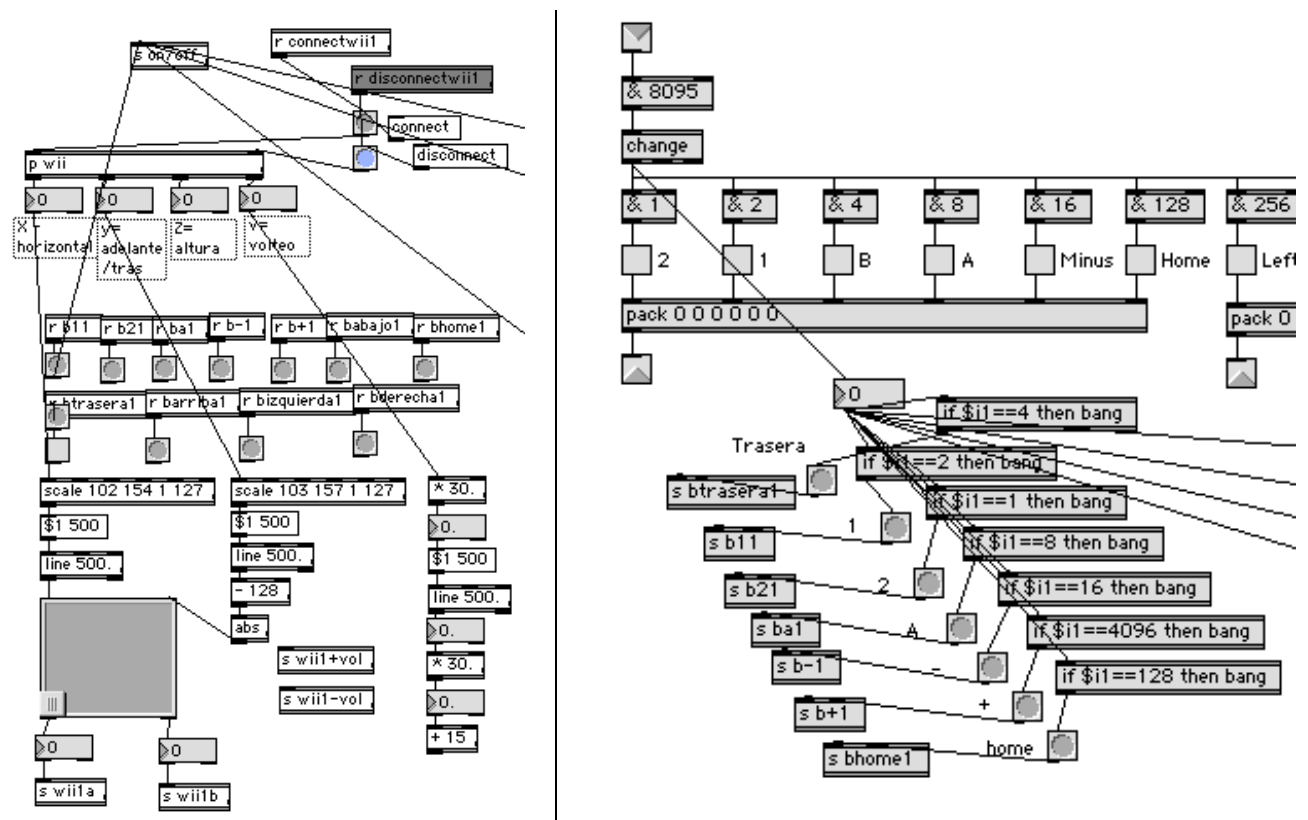

Fig. 126 Escalado y Envío de los valores y botones desde el objeto aka.wiiremote

\subsubsection{Discurso en tiempo real sobre DSP}

El concepto de Proceso en Vivo se ha explorado y discutido extensamente en entornos de improvisación y composición. Sin embargo, la integración de dispositivos hápticos en intérpretes de percusión, como extensión de sus extremidades, abre un abanico de posibilidades en la metodología e investigación en lo que se refiere al campo de la música electroacústica, y permite una consecuente exploración en el concepto de performance. Para explicar la integración entre el dispositivo inalámbrico y el uso tradicional de baquetas en los instrumentos de percusión, podemos comenzar por la incursión en la partitura (Fig. 127), que está diseñada para precisar ambos usos. 


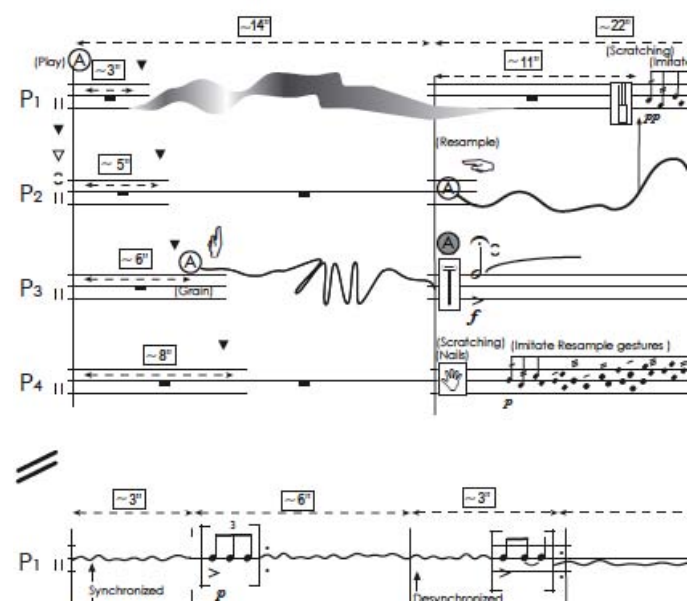

Fig. 127 Fragmento de la partitura

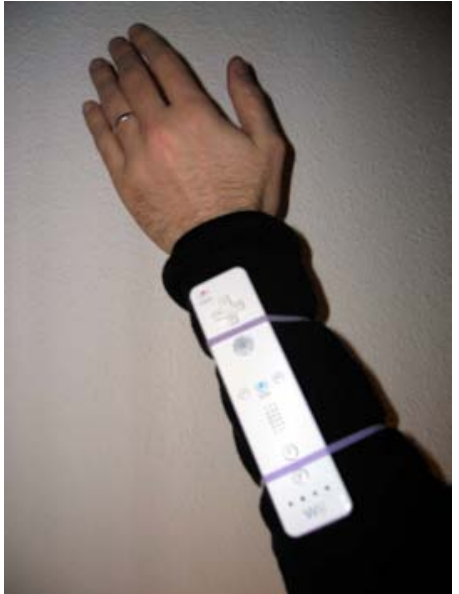

Fig. 128 Mando Wii

Cada percusionista tiene asido al antebrazo (Fig. 128) un mando Wii para registrar los parámetros que se irán trazando a lo largo de la obra. Tal y como se ha descrito en el apartado 3.2.2.1, el mando Wii tiene 1 acelerómetro con 3 ejes que pueden ser usados casi indistintamente, o al menos en lo que se refiere a la inclinación que necesitan nuestros intérpretes. Así pues, la mayoría de procesos leerán al menos dos parámetros, inclinación en el eje horizontal e inclinación en el eje vertical (Fig. 129).

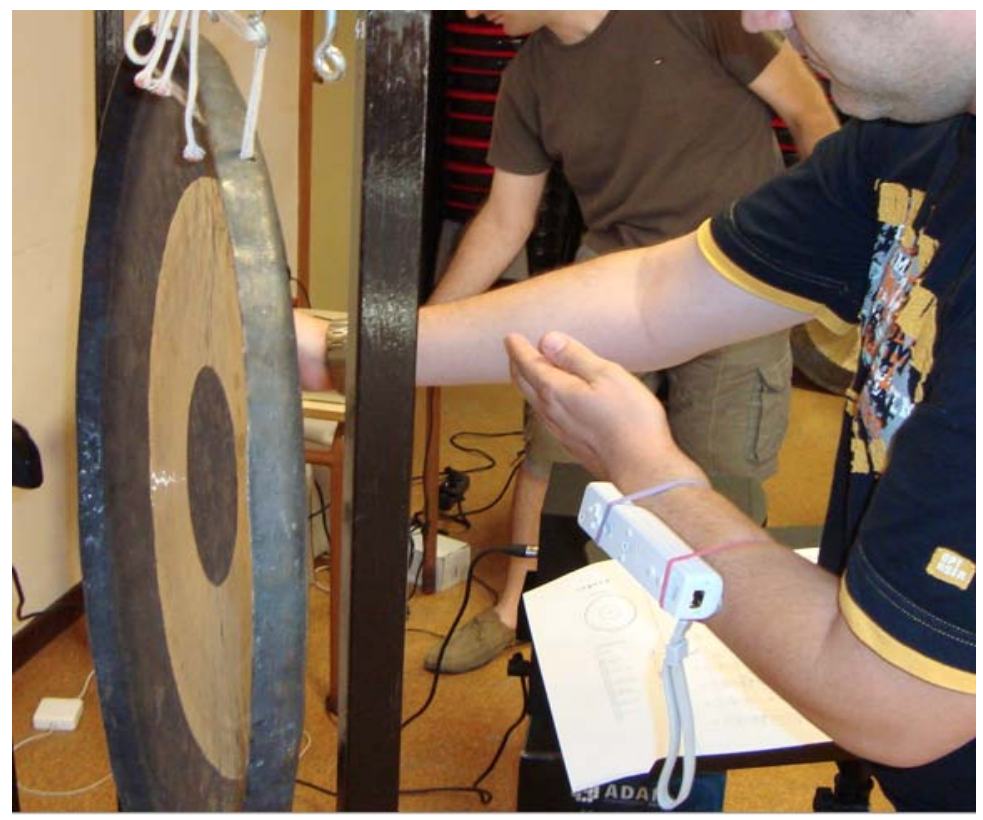

Fig. 129 Prueba del mando Wii durante un ensayo de TanGram 
En el patch principal que se ha diseñado para la situación de ensayo podemos ver 2 ventanas (Fig. 130). En la ventana 'Processes' aparecen los procesos electrónicos que se utilizan: Síntesis granular, Síntesis por modulación de frecuencia, resampleador, secuenciador múltiple en cascada, modificador de altura, armonizador y delay variable. En la ventana 'Control' están los sub-patches que procesan la toma de audio, la lista de eventos, el itinerario de las señales y datos, el controlador midi para el caso en el que se cuente con un técnico o ayudante y los objetos que procesan la señal de los mandos Wii.

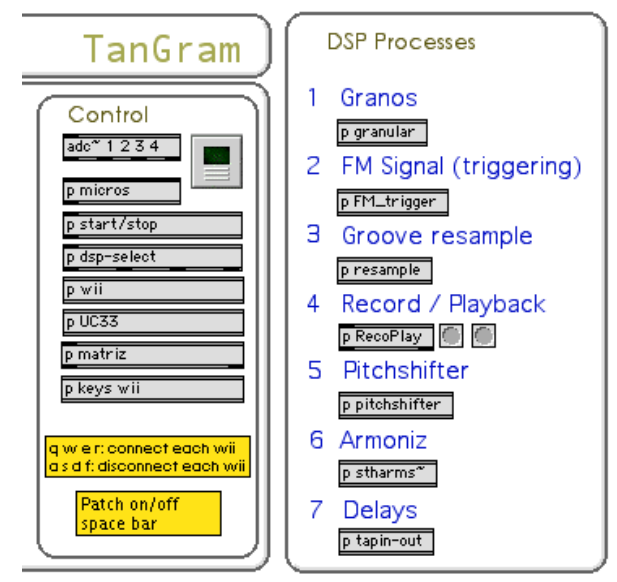

Fig. 130 Procesos DSP

A continuación se detallarán las particularidades de cada proceso de sonido digital (DSP) y su comportamiento en la obra.

DSP 1 - Síntesis granular (Fig. 131): Este proceso está basado en el objeto poly de la librería de Max MSP. Funciona mediante la lectura de un buffer que previamente se ha grabado durante el transcurso de la obra y permite el control polifónico de los parámetros de dicha memoria obteniendo una descomposición en granos. El objeto contempla 4 factores diferentes (más otros parámetros adicionales, que en este caso se han dejado fijos): tiempo entre grano y grano, tramo de sonido que se utiliza para el proceso, duración del tramo 
(ambos en milisegundos), panning ${ }^{30}$ (en este caso, stereo), y transposición. Se han escogido los parámetros de localización, duración y transposición del tramo para granular. Puesto que la obra está concebida para una difusión stereo, el panning se ha mantenido fijo en su total amplitud.

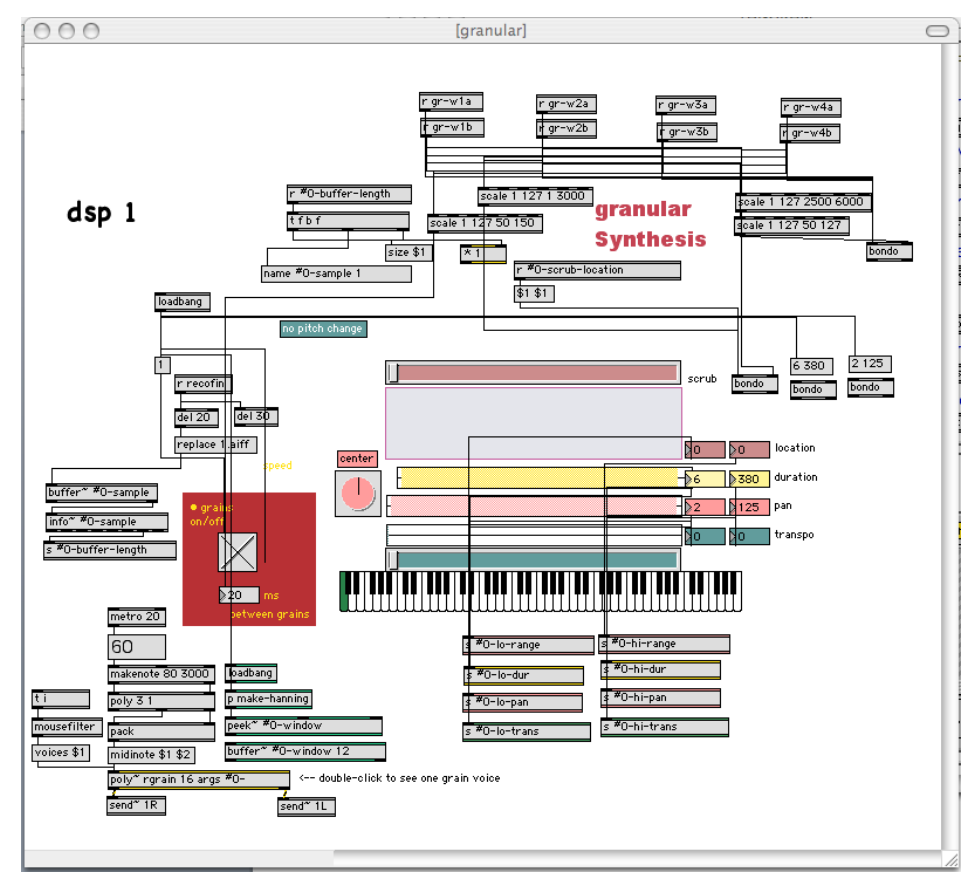

Fig. 131 Síntesis granular

DSP 2 - FM_trigger ${ }^{31}$ : Con la ayuda del objeto fiddle (Puckette, 1997), se puede extraer en altura definida el complejo sonido del tam-tam. Así pues, este análisis de altura (acogido a una análisis espectral) nos sirve para excitar una señal simple por modificación de frecuencia (FM), que actúa como eco electrónico del instrumento (Fig. 132). Se ha establecido un espacio temporal aleatorio (comprendido entre 3 y 9 segundos) en el que se permite la aparición de dicha señal electrónica. El índice de modulación y la amplitud se han fijado de manera

\footnotetext{
${ }^{30}$ Panning: término anglosajón que se refiere a la espacialización del sonido.

${ }^{31}$ Trigger: literalmente 'disparador'.
} 
invariable después de hacer varias pruebas de respuesta de este proceso con los parámetros tímbricos del tam-tam y de la baqueta oportuna. Los parámetros de frecuencia y armonicidad dependen del análisis de altura que efectúa el objeto fiddle .

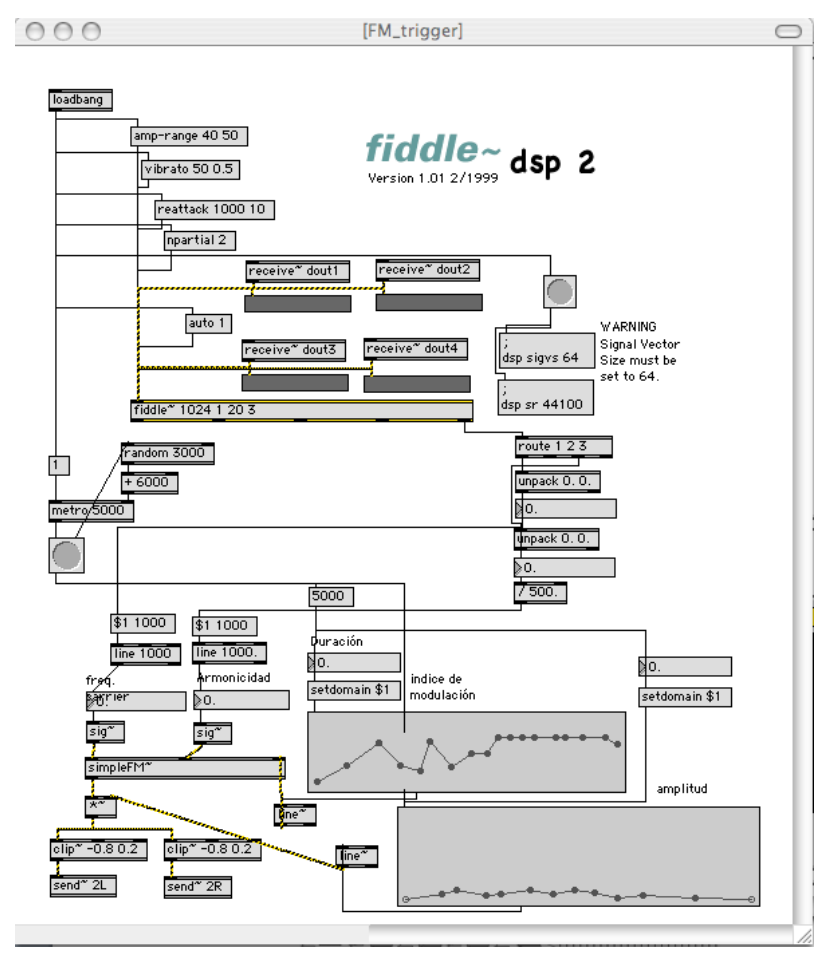

Fig. 132 FM_trigger

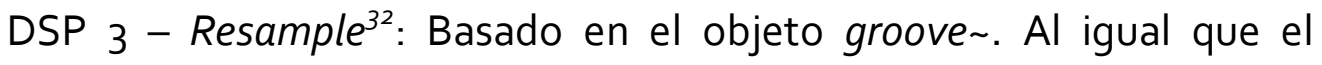
objeto de síntesis granular (DSP 1), este proceso funciona mediante la lectura de un buffer que previamente se ha grabado. La posibilidad que nos permite el objeto groove es la de alterar la velocidad de las muestras grabadas de modo que creamos bucles variables. Los parámetros que controlamos con la inclinación de los mandos Wii en este objeto son: el punto de inicio y fin de nuestro bucle, así como de la velocidad de reproducción. El objeto está duplicado puesto que

\footnotetext{
${ }^{32}$ Resample: Re-muestreado, alteración de las características temporales de un archivo de sonido.
} 
disponemos de dos parámetros definidos por el mando Wii, la inclinación del el eje vertical y el horizontal (Fig. 133).

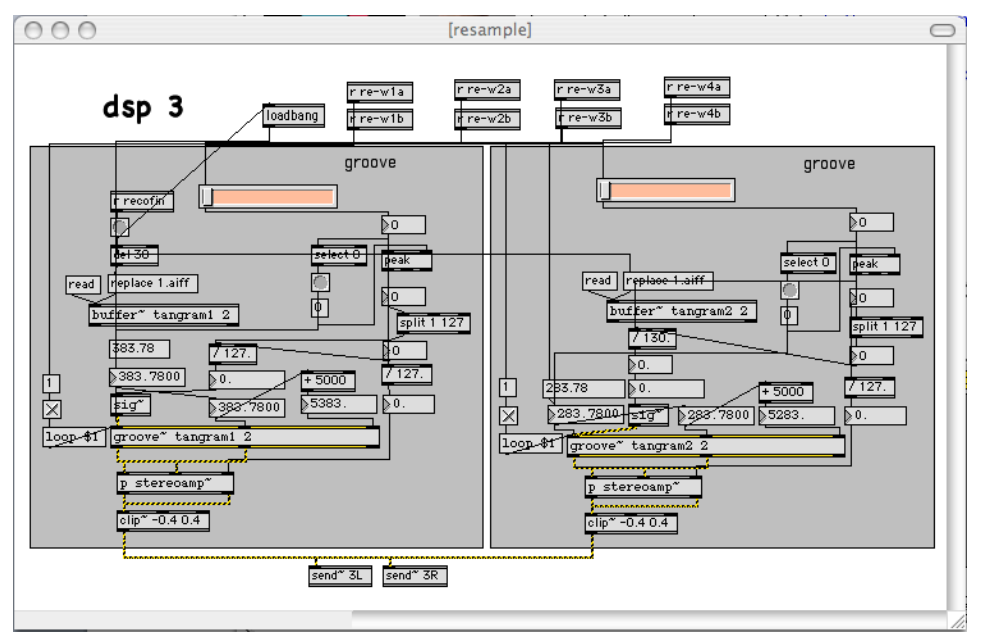

Fig. 133 proceso Resample

$\mathrm{DSP}_{4}$ - RecoPlay: Se trata de una reproducción semi-aleatoria en cascada de la muestra que ha sido almacenada previamente en la memoria de un buffer (Fig. 134). La memoria tiene una duración establecida de 6 segundos en este caso. Cada impulso disparado puede generar que la muestra se estire hasta durar 82 segundos. Este proceso tiene implicaciones en el cambio de altura ya que el mecanismo funciona a partir del objeto play , un reproductor sencillo que permite establecer punto de inicio y final, así como la mencionada velocidad de lectura que utilizamos en este caso. Este objeto presenta un problema ya que la reproducción de la muestra almacenada puede comenzar o terminar con un ruido residual propio del encendido o apagado del proceso. Por tanto se añadió un objeto que hace de apagador progresivo o intensificador de ganancia (fade in/out) eliminando así la aparición de 'clicks' residuales. 


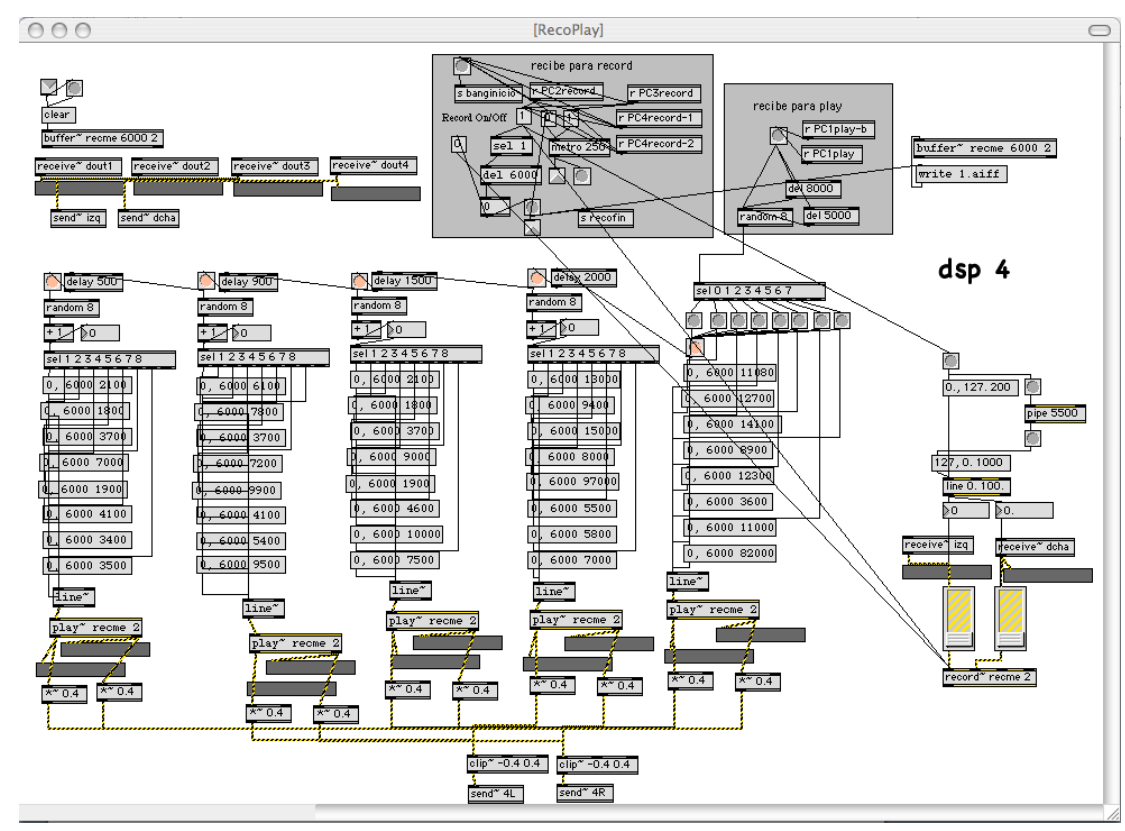

Fig. 134 Proceso RecoPlay

DSP - 5: Pitchshifter (Fig. 135): Este objeto es un modificador de altura en tiempo real basado en un análisis armónico, llamado comúnmente FFT (Fast Fourier Transform, o transformada de Fourier). Este teorema plantea que cualquier forma de onda, a condición de que sea periódica (se repita siempre igual) se puede descomponer en una serie más o menos larga (quizás infinita) de ondas puras (sinusoidales) llamadas armónicos. Estos armónicos son tales que su combinación o mezcla dan lugar de nuevo al sonido original, y sus frecuencias son múltiplos enteros de la del sonido fundamental. Igualmente necesita de un buffer para la modificación de los parámetros, pero esta vez el proceso se realiza en tiempo real. 


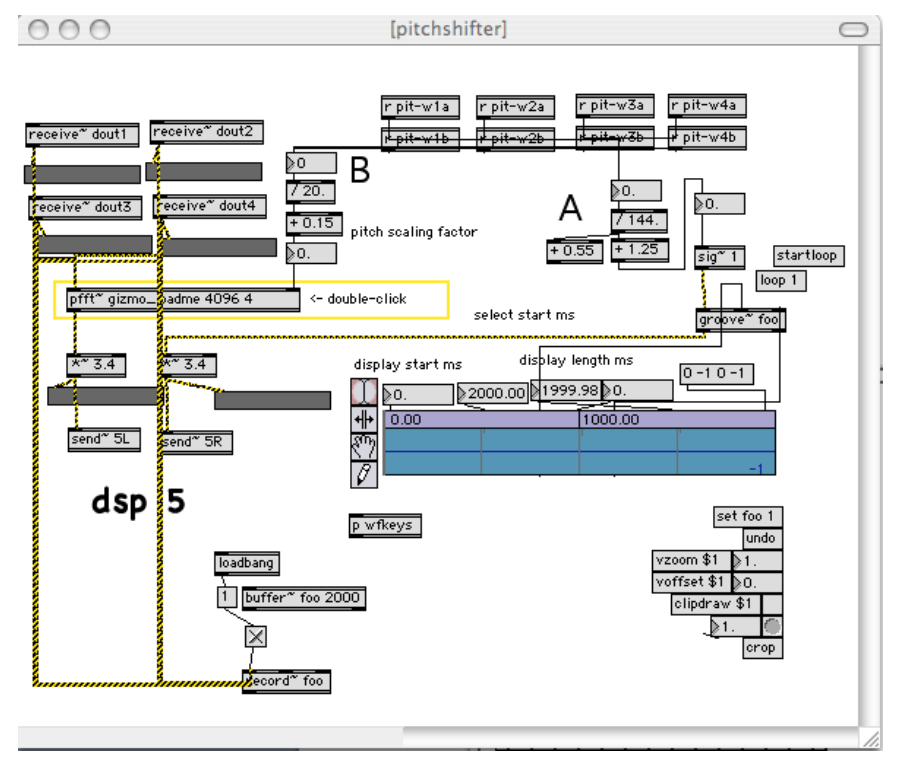

Fig. 135 Pitchshifter

DSP - 6: Armonizador (Fig. 136): La librería de objetos 'Jimmies' (Settel, 1994-98) contiene un armonizador que me permitía controlar la transposición del resultado final. Este objeto externo presenta las posibilidades de control de retardos (delay), amplitud de difusión y ganancia, pero estos parámetros se definieron de manera fija (delay y amplitud de difusión=0) después de la exploración de la respuesta al sonido del tam-tam. Al igual que el efecto resample (DSP 3), se establecieron dos vías del mismo proceso por separado, para los dos ejes de inclinación, $x$ e $y$.

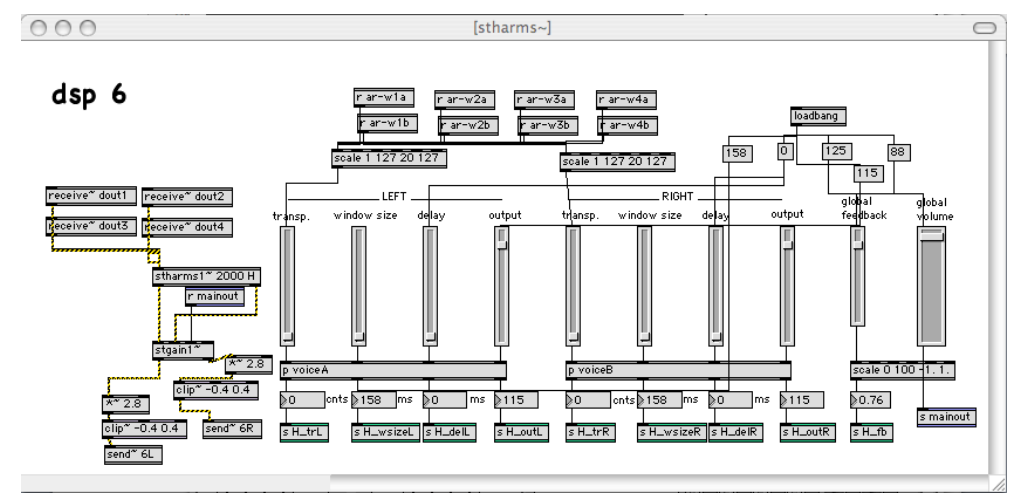

Fig. 136 Proceso armonizador 
DSP - 7: Delay (Fig. 137): Este objeto nos permite retrasar la señal en vivo y retroalimentarla de modo que se pueden obtener múltiples ecos. No necesitamos objetos externos o adicionales, simplemente utilizamos el objeto tapin y tapout , ambos integrados en las librerías de Max MSP. Del mismo modo, se puede controlar la duración de la estela de ecos que tenemos.

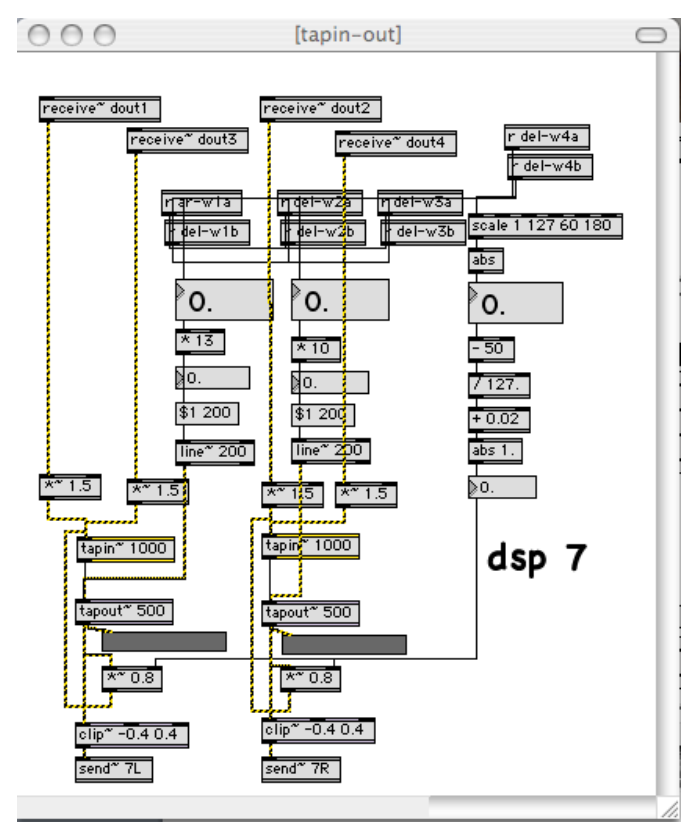

Fig. 137 Proceso de delay

En todos los procesos se ha realizado un escalado de los valores que proceden de las inclinaciones de los mandos Wii para adaptarlos a las necesidades de cada objeto.

Para el correcto funcionamiento del patch ha sido necesaria una metódica planificación del recorrido de las señales, tanto el sonido a través de los 4 micros de los tam-tam, los datos de inclinación de los 4 mandos Wii, y todo redirigido a los 7 procesos DSP. Como se ha mencionado en el apartado 3.1, el patch funciona de modo secuencial, de manera que existen listas de eventos para cada intérprete. Dado que cada proceso tiene dos parámetros modificados por la inclinación 
de los mandos, un mismo efecto no puede estar leyendo dos o más mandos al mismo tiempo, pero sí se han utilizado los efectos de manera simultánea. Para ello el entorno de Max MSP dispone de los objetos route, para señales de datos y matrix para señales de línea, que permiten ordenar y secuenciar todas estas señales (Fig. 138).

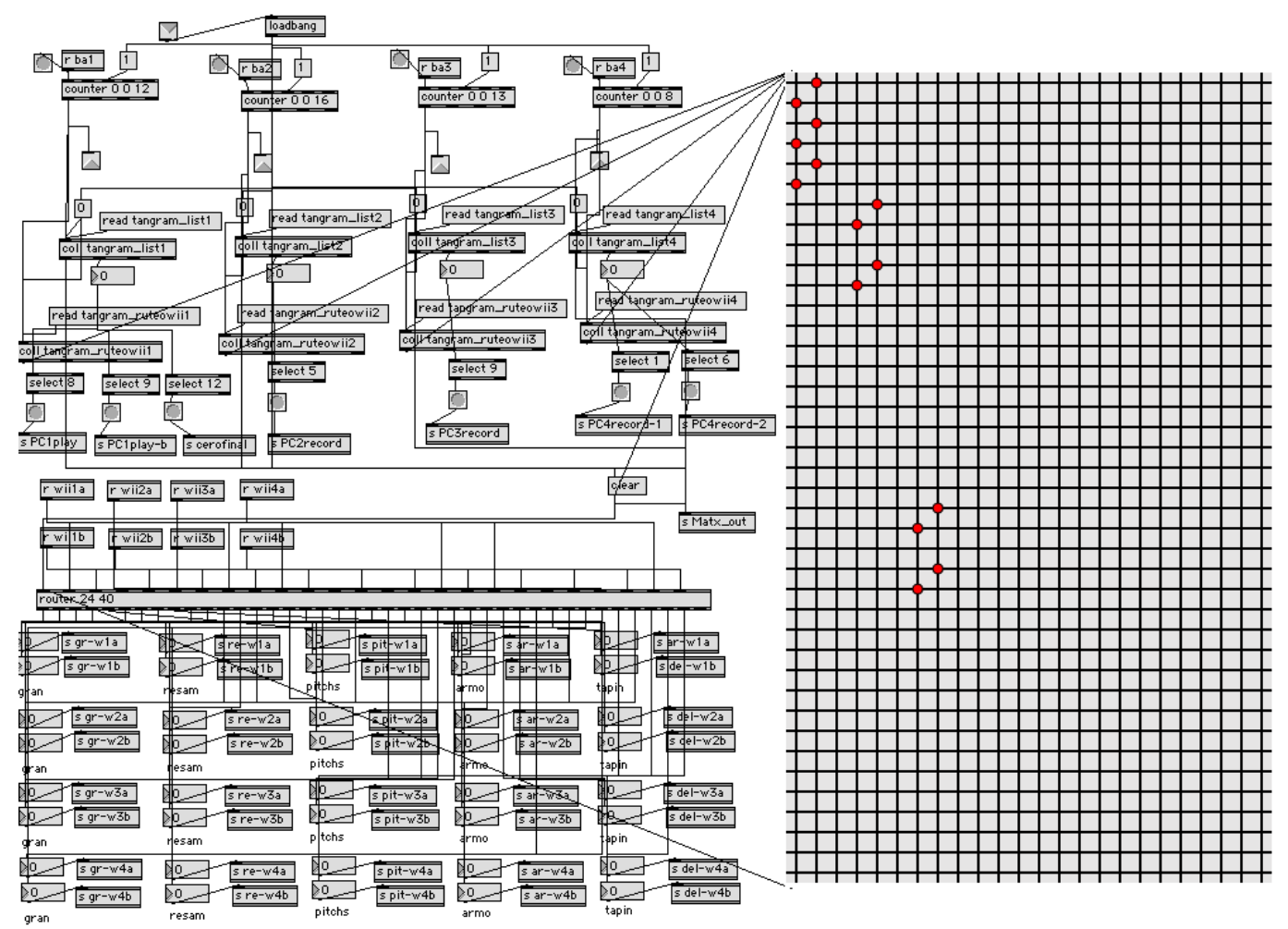

Fig. 138 Matriz de datos en Max MSP

\subsubsection{PATCH DE CONCIERTO}

En la siguiente imagen (Fig. 139) podemos ver la apariencia que presenta el Patch principal diseñado específicamente para la situación de Concierto: 


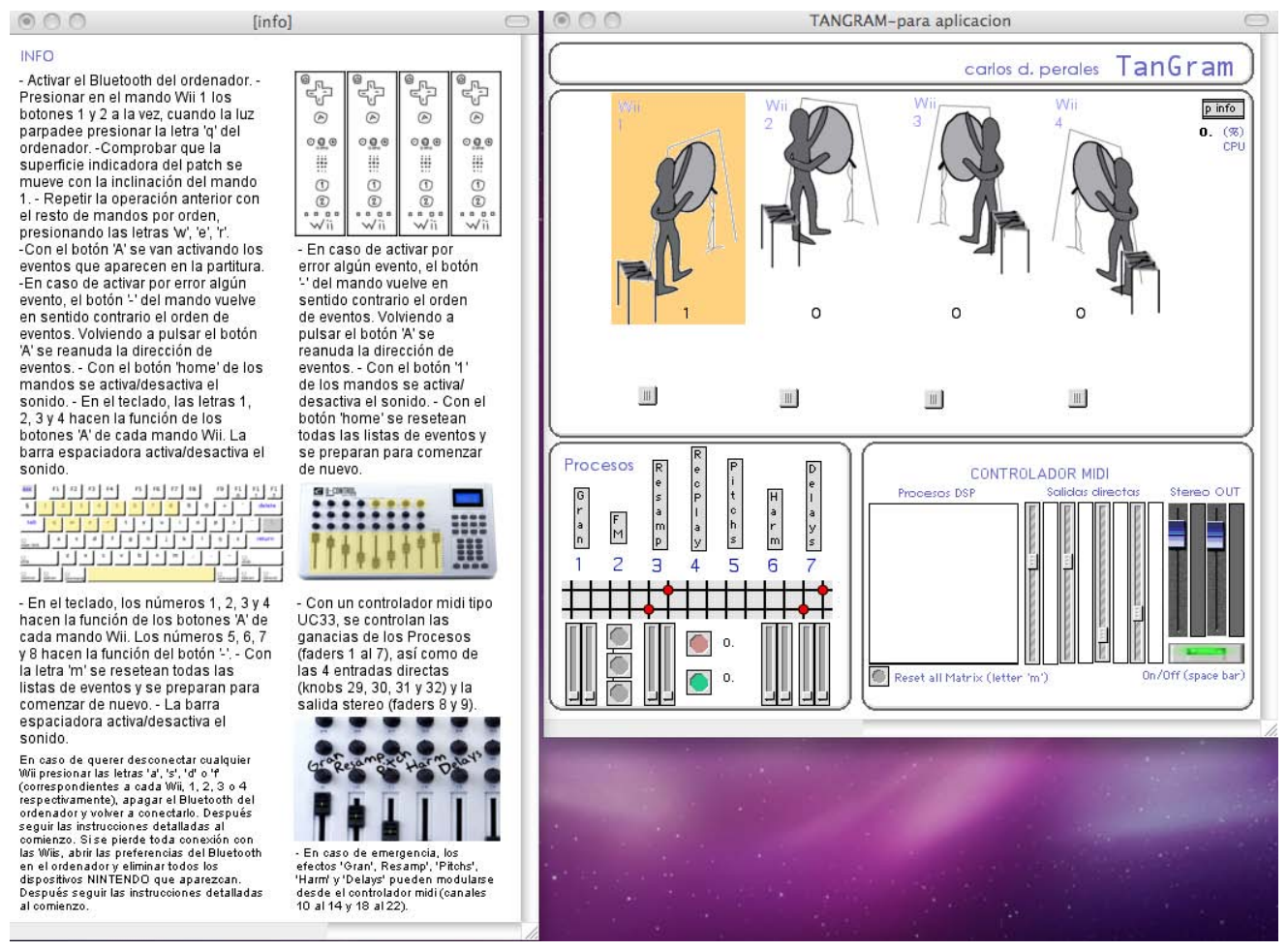

Fig. 139 Captura del Patch principal TanGram

Podemos ver al abrir el programa que aparecen dos ventanas. La que se sitúa a la izquierda es una explicación del manejo del Patch a modo de ayuda e indicaciones de manejo sobre los recursos programados para el asistente técnico que se recomienda en la interpretación de la obra. También se han ilustrado los comandos que se pueden ejecutar desde el teclado del ordenador (activar/desactivar procesos y micros) para casos de mal funcionamiento en directo. Además aparece una captura de los faders (potenciómetros) que están vinculados al patch desde el controlador MIDI externo.

A la derecha aparece la Interface propia del Patch en la cual podemos ver unos indicadores de la disposición de los intérpretes, que se irán iluminando en función del mando Wii o micro activo en cada momento de la obra. Debajo hay un pequeño rectángulo que dibuja la posición que tienen en todo momento los mandos Wii. También se han diseñado unos indicadores de actividad de procesos, así como el 
movimiento que se realiza desde los faders del controlador MIDI en cuestiones de ganancia de entrada o salida.

Todos los sub-patchs están ocultos en la ventana principal para facilitar el uso de la aplicación. En caso de necesidad, el patch se puede editar y al extender la ventana principal aparecen los objetos que realizan cada proceso, en ventanas nuevas.

\subsubsection{RECURSOS ADICIONALES EN CONCIERTO}

La señal de entrada que el Patch toma de los micros (objeto adc , conversor analógico a digital) es redirigida, además de hacia los procesos digitales, hacia la salida directa, de modo que se puede controlar una amplificación del sonido bruto de los tam-tams (Fig. 140). Para graduar estos valores (señal procesada y señal bruta) se previó el uso de un controlador midi tipo UC33 de M-Audio o similar en el diseño del Patch.

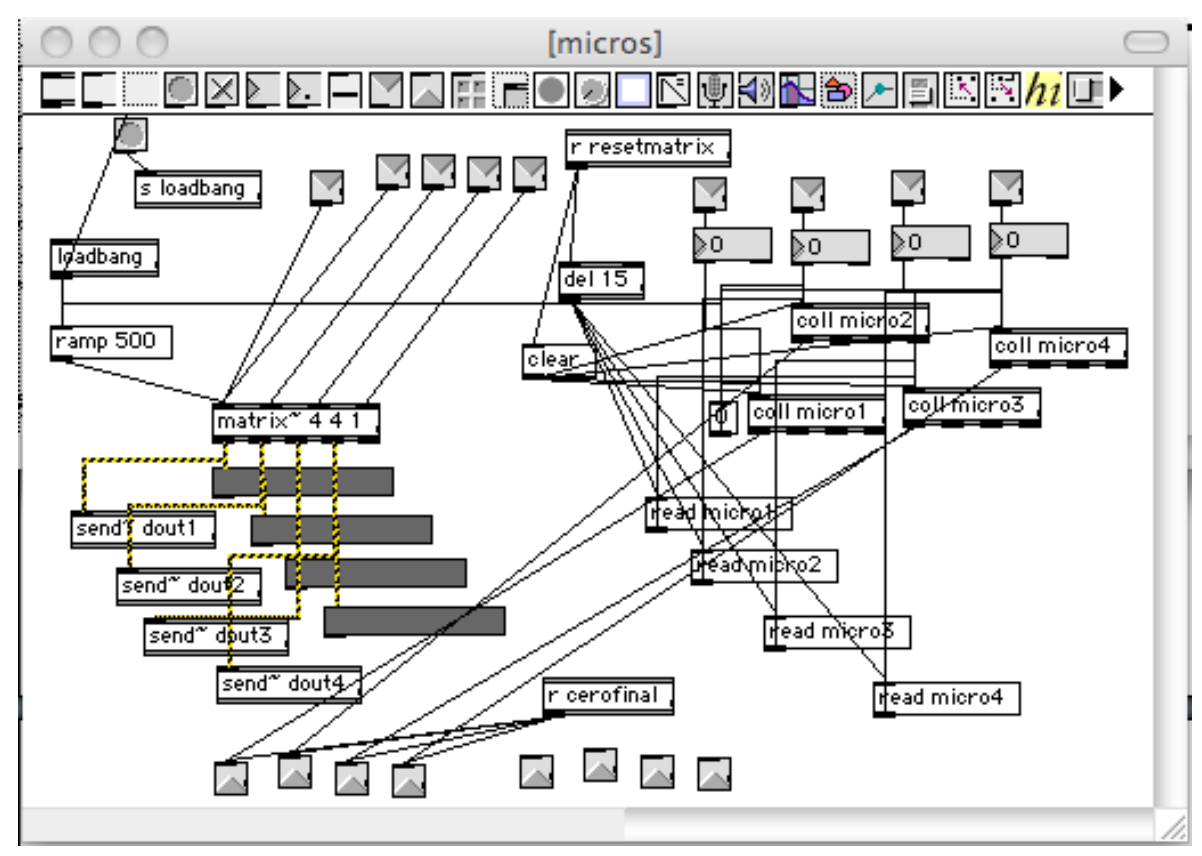

Fig. 140 Sub-patch encargado de la gestión de la entrada y salida de micros. 
También se previó la situación en la que el Bluetooth del ordenador o alguno de los mandos Wii pudiera generar datos erróneos, fallar la propia conexión con el ordenador o con alguno de los procesos en mitad del concierto. No es de extrañar que la cercanía de otros dispositivos o aparatos electrónicos puede interferir en conexiones inalámbricas de este tipo. Pensando en este factor y para garantizar una continuidad en la marcha de la obra se diseñó un sub-patch alternativo en el cual, cada uno de los valores que son gestionados por los mandos Wii pudiera manejarse mediante el empleo de un controlador MIDI (Fig. 141) por la persona que hace de asistente técnico en este tipo de obras.

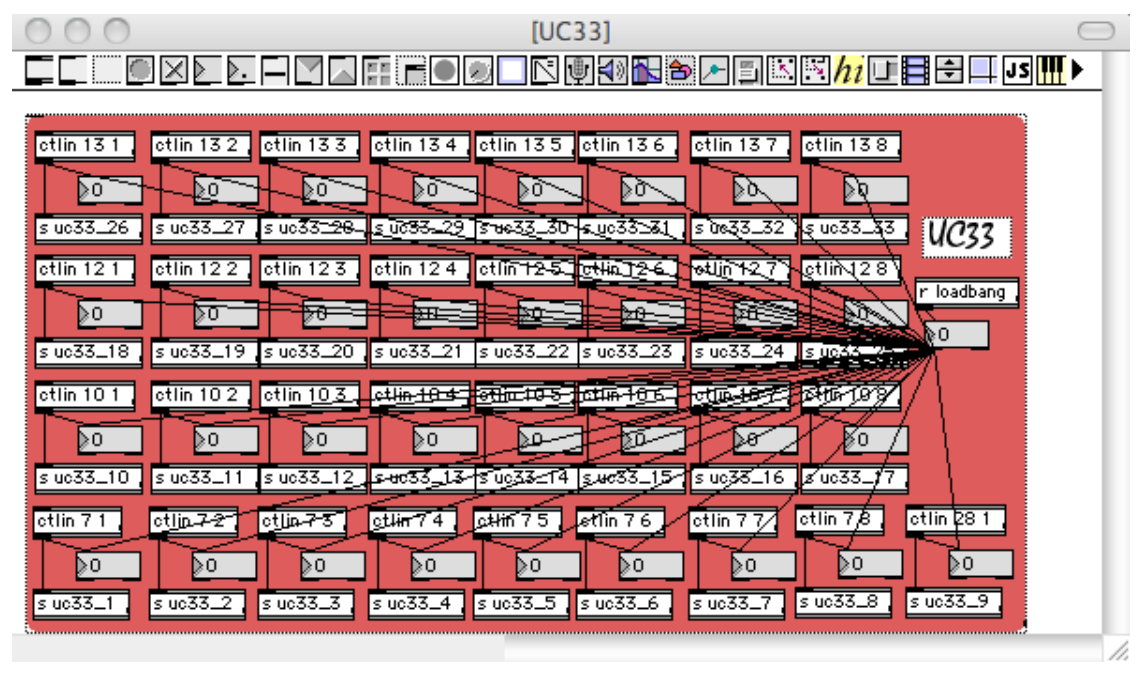

Fig. 141 Sub-patch para controlar los datos vía MIDI

\subsection{PERFORMANCE}

La obra se estrenó en el VII Congreso Internacional celebrado en Badajoz en Septiembre de 2009. La sede del Congreso fue el Auditorio Manuel Rojas de Badajoz.

El escenario en un concierto para este Cuarteto de Percusión, queda dividido en varios espacios dedicados a cada obra, ya que el programa 
del concierto contenía obras que requieren instrumental de percusión variada. En este caso se establecieron dos niveles de altura para distribuir cada una de las 5 obras ejecutadas en el concierto. TanGram se dispuso en el centro del escenario, para resaltar la 'teatralidad gestual' que tiene la obra.

Los tam-tams de los que dispusieron para el concierto fueron de los siguientes diámetros: 80, 65, 55 y 45 cms (Fig. 142).

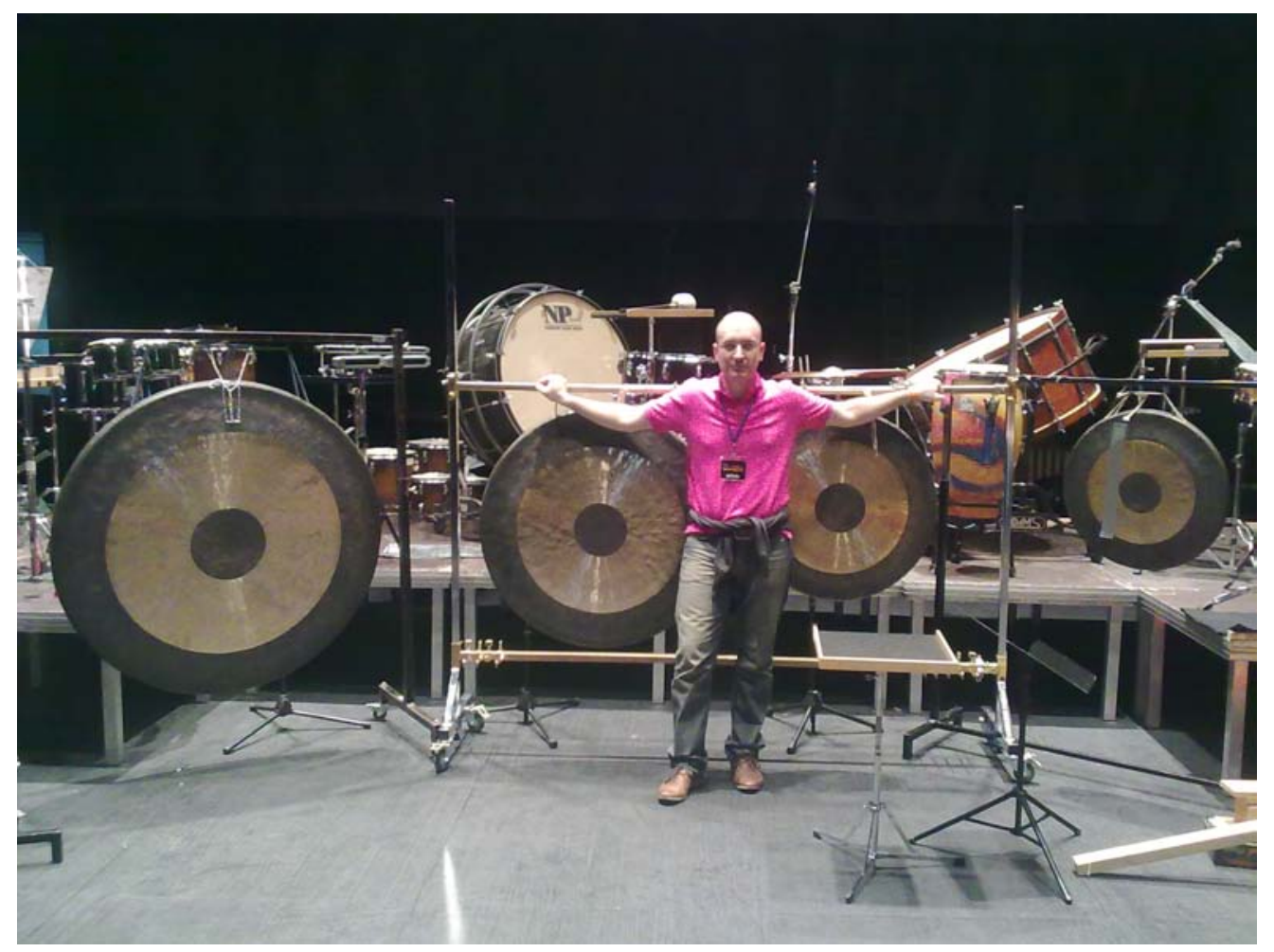

Fig. 142 Espacio escénico para TanGram, Badajoz 2009

Los micros que aportó la empresa de sonido fueron: AKG C1000, micros de condensador cardioide semejantes al modelo utilizado en los ensayos y montajes previos de la obra. El sistema de amplificación y sonorización corrió a cargo de la empresa contratada para asistir a los requerimientos de los grupos instrumentales.

Para la realización y vigilancia de los procesos en vivo y la coordinación con los mandos Wii y el Patch de Max MSP, se colocó 
una mesa adyacente a la boca del escenario en la cual dispuse el ordenador, la tarjeta de audio y el controlador MIDI UC33 de M-Audio (Fig. 143) para manejar los valores de ganancia (entrada y salida de los micros): hacia los procesos del Patch y de salida hacia el sistema de amplificación en la sala.

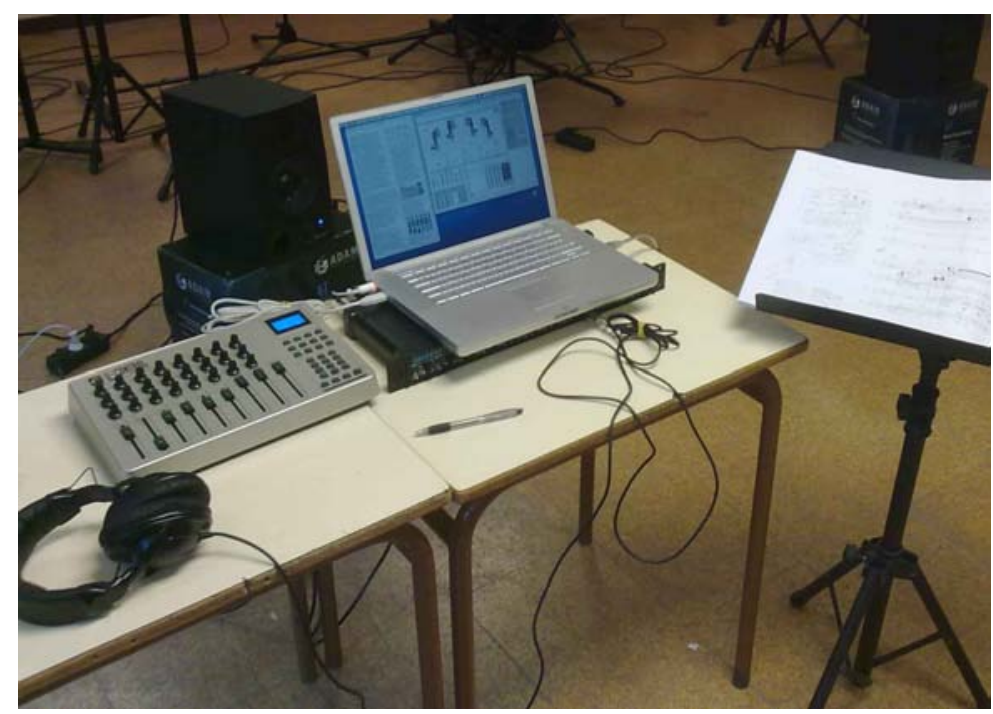

Fig. 143 Mesa de control: controlador MIDI UC33, PowerBook G4, Tarjeta de Audio MOTU Traveller 828 Mkll.

En mitad de la representación se produjo un fallo de conexión momentáneo en uno de los mandos Wii. Este incidente se pudo salvar de manera eficaz, sin afectar a la marcha de la obra, gracias al subpatch alternativo que se ha descrito en el capítulo anterior (3.2.3).

\subsection{CONSIDERACIONES}

Este ensayo trata de explorar la implementación de aspectos de comportamiento gestual en una obra mixta para percusión y electrónica en vivo (Fig. 144). Con la introducción de la autonomía que garantiza el control remoto Wii a través del entorno de Max MSP, se propone un nuevo camino para la expresión creativa, apoyada en las 
ideas y metodologías de Tarkowskij en sus películas y montajes (Dempsey, 1981, 12-17) y su exposición de la idea de su 'Mirror'. Además, la partitura utiliza una tipología específica que precisa el movimiento y la gestualidad generada o transformada mediante las técnicas de DSP. Una explicación de la metodología propuesta en la lectura e interpretación de la partitura conlleva a la valoración de algunos ejemplos de notación en conceptos como gestos de movimiento, variaciones de longitud, etc, que pertenecen al vocabulario musical y electroacústico.

El tam-tam es un resonador muy común. Obviamente no se pretendió hacer una obra entera basada en este parámetro, ya que la electroacústica nos proporciona la opción de utilizarlo como una exploración del sonido. Así mismo, en TanGram no se planteó la construcción un mundo paralelo de objetos concretos en el instrumento, sino la exploración de recursos tradicionales con toda clase de baquetas de percusión, más la incursión de dos fuentes concretas, el uso de cinta adhesiva sobre la superficie del tam-tam y una cortina de piedras pequeñas colocada en el bastidor o portería del instrumento.

Aunque el referente escénico fue la obra Water Walk de John Cage y TanGram tiene como punto de referencia el constante cambio de baquetas y posiciones de sordina en el tam-tam, no hubo un deseo tácito de crear una obra cuya esencia fuera el disfrute visual, al menos tanto como el auditivo.

Por tanto y al igual que argüía Marcel Duchamp (Cabanne, 1987) cuando afirmaba que en ocasiones el significado de la obra de arte la crea el espectador y no el artista, TanGram explora el diálogo entre el gesto actoral del intérprete y las sensaciones sonoras de la electrónica 
en vivo para que en cada caso, el espectador disfrute aquel aspecto que estime más interesante.

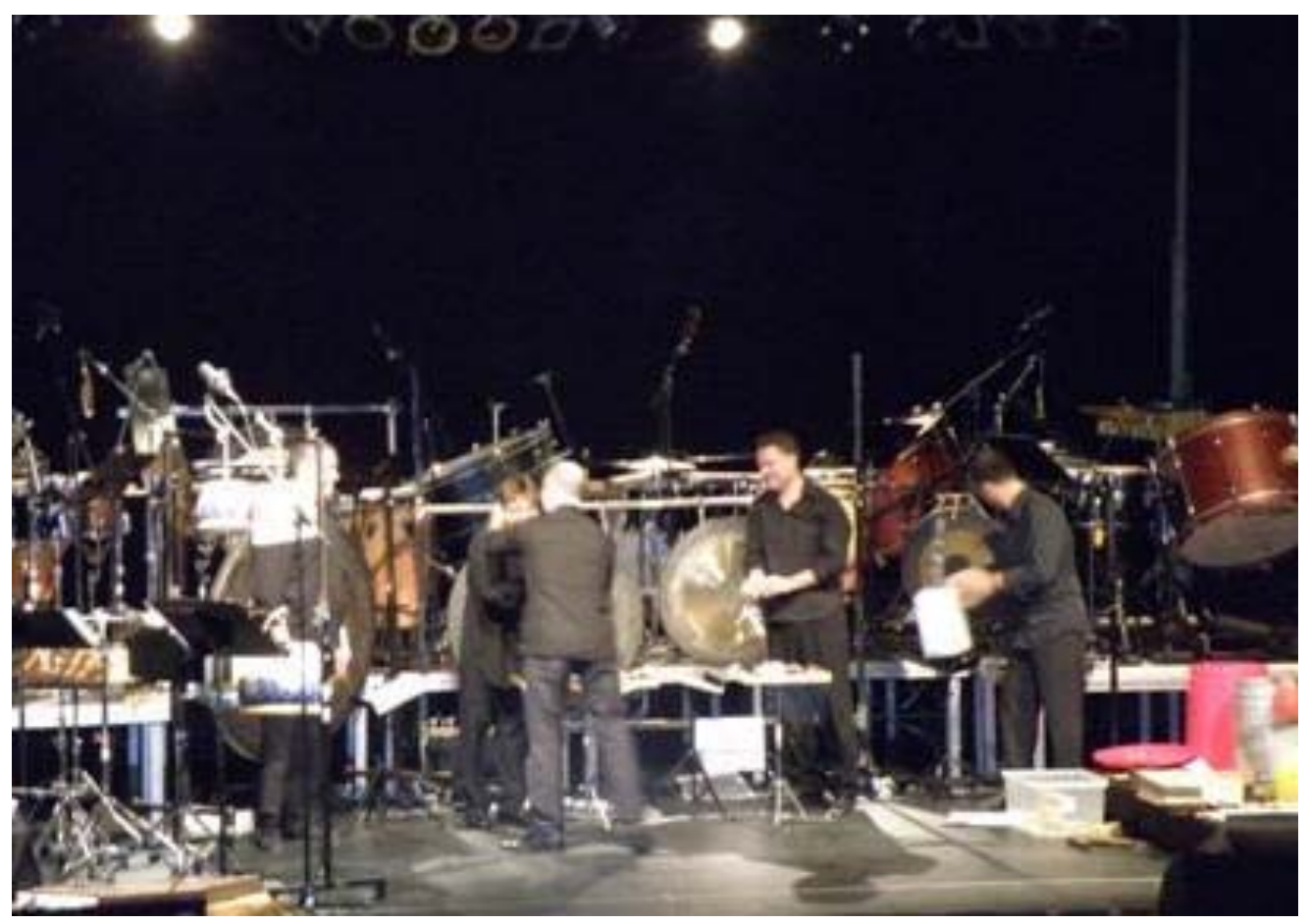

Fig. 144 Saluda en el estreno de TanGram, 2009 



\section{ELECTROACÚSTICA Y VIDEO- PERFORMANZA}

En el siguiente ensayo se aborda la composición del diseño sonoro para la video-performanza Porque la perdí, cuya parte visual ha sido creada y dirigida por Maica Ontiñano. En este caso el diseño y la exploración sonora tienen un desarrollo integral paralelo a la creación y evolución de la parte creativa: danza, performance y video. No existía un material sonoro ni una parte ambiente previa. Toda la composición sonora forma parte desde el principio del génesis de la obra y como un componente más, la expresión sonora juega en este caso un papel de primer orden en el trazado de ejecución y edición final del video. La captura de sonidos, ambientes, instrumentos y planificación formal de la parte musical formó parte de manera paralela a la del proyecto global desde el inicio del proyecto; de hecho, fue recolectada y editada en las mismas localizaciones y durante los mismo días del rodaje. 


\section{MOTIVACION}

Como ya se ha señalado en capítulos anteriores la naturaleza abstracta del lenguaje electroacústico y concreto hace especialmente sensible el empleo de esta naturaleza sonora a expresiones de tipo visual, plástico y más aún en el plano figurativo. La danza, recreada en un formato visual como es el video, adquiere una dimensión extendida en cuestiones como espacialización, perspectiva, temporalización y forma. En este sentido es donde el empleo del lenguaje electroacústico y sus posibilidades de adaptación a la expresión artística adquieren sentido. Los parámetros de manipulación visual tienen en muchos casos, una correspondencia directa con los procesos de transformación y edición del sonido (ver Tema 5).

El concepto de 'Performanza' responde a la voluntad de unir Video, Performance y Danza en una misma pieza. La performance y la danza, desde un punto de vista convencional, se han contemplado como disciplinas distintas, procedentes del mundo de las artes plásticas y de la danza respectivamente. Pero lo cierto es que desde los años 60 ha habido colaboraciones entre artistas, bailarines y artistas sonoros que han ido configurando una serie de prácticas con características similares, a pesar de que la procedencia disciplinaria de sus autores fuera distinta (Baigorri, 2004).

En este proyecto se introduce un concepto tomado de los objetivos que propone la autora del video: 'Improvisación Site-Specific', esto es: el uso de la improvisación in situ en la naturaleza como proceso de creación. El trabajo se realiza en el lugar específico desde el principio, a través de la improvisación para que la acción esté totalmente involucrada con el espacio y condicione directamente la naturaleza del sonido. 
El rodaje del video tuvo lugar en Gavín, municipio de Huesca, y se rodó durante los días 23 de Agosto al 2 de Septiembre de 2007. La puesta en escena de la parte danzable corrió a cargo de los bailarines valencianos Pep Garrigues y Rocío Pérez. El equipo técnico lo llevó a cabo la productora 'cinema-nu' (Catalá, 2010) dirigida por Julia Catalá y el asesoramiento artístico de Álvaro de los Ángeles.

\subsection{PLANTEAMIENTO}

Porque la perdí nació con la intención de rescatar el testimonio y el entorno social y cultural de un pequeño pueblo del pirineo aragonés. En palabras de su autora:

"Porque la perdi' nos habla de la memoria de un lugar, centrándose en su entorno natural, a través del vídeo, la danza y la performance in situ. Una serie de testimonios de varios ancianos del pueblo de Gavín (Pirineo Oscense) nos comentan aspectos de su vida de antaño, en relación con la naturaleza y el paisaje: el trabajo en los campos, el bosque, el agua, los caminos, etc., y cómo aquella relación se ha perdido. A partir de estos testimonios, bailarines y cámara improvisan e interactúan con el lugar, en busca de esa memoria perdida, con la intención de encontrarla, y darle una nueva dimensión al lugar. ${ }^{133}$

El video tiene una duración total de 21 minutos, está rodado en HDV / formato 16:9, en castellano y con subtítulos en inglés. Tiene dos partes diferenciadas. La primera parte consta de los testimonios de los lugareños; en esta parte no existe diseño musical, sólo la captura

33 Comentario facilitado por la autora (Agosto de 2010). Pendiente de publicación. 
directa de los testimonios. La segunda parte contiene 4 escenas: La primera escena fue rodada en 'la era' (una extensión de trigo) donde los dos bailarines interactúan con el entorno y el paisaje; La segunda, en un campo de frutales donde los bailarines interpretan una improvisación utilizando unos palos de madera típicos de la zona; La tercera corre a cargo de la bailarina, quién desarrolla una secuencia inspirada en uno de los testimonios introducidos por los vecinos de Gavín; La cuarta, rodada en el espesor de un sendero oscuro, 'el Cerrao', donde se desarrolla una improvisación de carácter psicológico e intimista por parte del bailarín. Cada parte tiene una definición sonora distinta, ya que la planificación y resultado final de cada escena (tanto en el plano de la performance y el baile, como en el montaje de vídeo) pretendian un objetivo y un significado diferente de partida (ver apartado 4.2$)$,

La obra contó con el soporte del Gobierno de Aragón e Ibercaja a través de la Beca en Artes visuales en 2007. Fue proyectada en la Sala de exposiciones Torre Nueva, 35 (Zaragoza); a través de 'Proyectaragón' III Muestra Audiovisual Aragonesa; y Sesión VIII: Voces femeninas III, Salón de Actos CAI. Paseo Independencia, 10, (Zaragoza).

\subsubsection{PLANTEAMIENTO CONCEPTUAL}

A continuación se describirán los trayectos conceptuales por los que ha caminado este ensayo. Se ha considerado oportuno incluir una reflexión acerca de las definiciones, géneros e intenciones expresivas que definen esta creación visual, así como el marco en el que se inscriben las consecuentes metodologías de creación sonora. 
Uno de los conceptos que condicionarán la creación y el desarrollo de la creación musical es el citado anteriormente como 'Improvisación Site-specific. Este planeamiento de creación espontánea plantea unas condiciones de planificación absolutamente restrictivas y dependientes del momento creativo en sí. Es por esto que la generación de material sonoro, grabación, y por ende, procesos de edición y secuenciación, dependieron también de este aspecto.

Durante la grabación del video se fueron presentando distintas situaciones, fuentes sonoras, objetos y enclaves que determinaron, tanto el resultado visual como el material y procesos sonoros (Fig. 145).

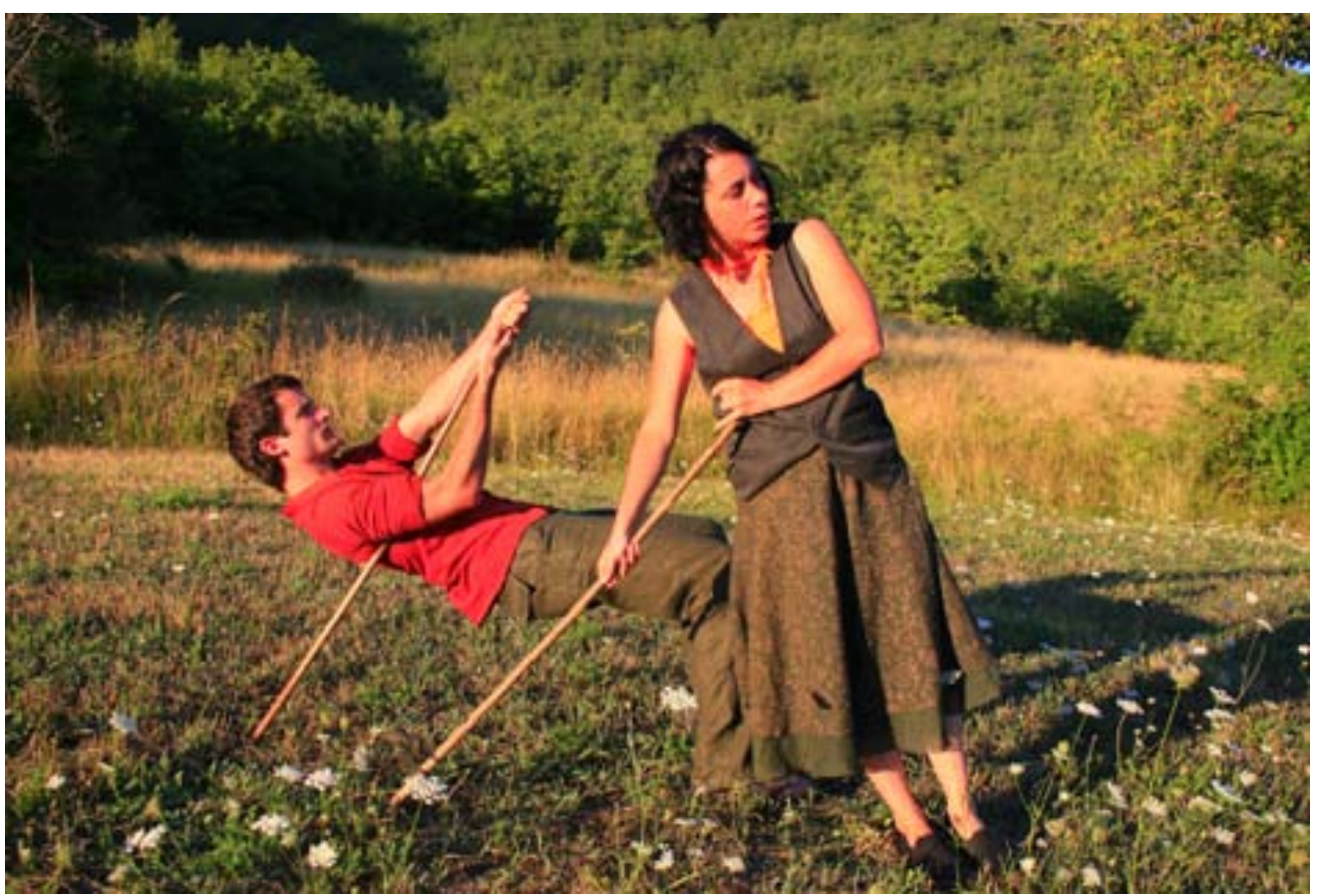

Fig. 145 Captura de Porque la perdí

Es por tanto interesante recalcar que este ensayo recoge una metodología de creación y desarrollo muy específica en tanto en cuanto que la parte técnica dedicada a la imagen, y la parte técnica 
dedicada al audio, construyeron un diálogo recíproco constante en cuestiones de integración conceptual, expresiva y temporal.

Dada la naturaleza específica de este video y los matices concretos que se desprenden de ella, es conveniente detenerse a analizar los términos que definen su origen visual.

\subsubsection{MARCO EN EL QUE SE INSCRIBE EL ENSAYO}

Siguiendo las descripciones que se han hecho en el mapa de conceptos (ver Apartado 0.5) se puede presentar un marco general de este ensayo:

- Sensores: No se requiere.

- Electrónica en Vivo: No se requiere.

- Tiempo real: No se requiere.

- Obra abierta/cerrada: Obra cerrada.

- Partitura: No se requiere, aunque para la composición de las partes instrumentales existe una partitura.

- Intérprete: Se requiere un violoncellista y un cantante.

- Performance: Se requieren dos bailarines.

- Instrumentos acústicos: Se requiere un violoncello y un cantante.

- Improvisación: Los bailarines realizan una improvisación Sitespecific (apartado 4.1.3.3).

- Entorno o medio de reproducción: Reproducción en soporte digital de video. 
- Procesamiento digital imagen/sonido: Se procesan tanto la imagen como el sonido.

- Software: Para el procesamiento de sonido se ha utilizado Max MSP (Cycling74, 2010) y Logic (Apple, 2010b).

\subsubsection{MARCO TEÓRICO}

\subsubsection{VIDEO-DANZA}

Desde sus comienzos en los años 6o, el vídeo ha cruzado sus caminos con múltiples prácticas, aunque las posturas más ortodoxas seguían manteniéndolas clasificadas. Como comenta Laura Baigorri:

'Coexisten, sin poderse sustraer a un particular hibridismo, el vídeo documental, el de ficción, el videoarte, el vídeo musical y la video-danza.' (Baigorri, 2004)

Sin embargo, a finales de los años 80 , es cuando empieza a haber una mayor conciencia de que estas prácticas pueden trabajar unidas, y como apunta también Baigorri, los críticos, instituciones y artistas coinciden en que este lastre clasificatorio no hace más que dificultar la aceptación y difusión del vídeo en el mundo del arte y expresan su voluntad - casi unánime - de abandonar esta multiplicidad de denominaciones a favor de una concepción totalizadora del arte. A partir de los 9o, pues, para un sector mayoritario, tanto de artífices como de teóricos del medio, el vídeo deja de existir como tal para dar paso al 'Arte' (Baigorri, 2004).

En este sentido y como podemos ver en (Rosenberg, 2006), se denomina video-danza a una obra audiovisual cuyo contenido es el/los cuerpo(s) en movimiento, o danza. Cuerpo, movimiento, tiempo e 
imagen, video. Un diálogo que se centra en las significaciones del cuerpo en imagen, en un espacio-tiempo. La video-danza, que bien podría ser body-art o videoarte, es emprendida generalmente por creadores que provienen de las artes visuales, las audiovisuales, o desde el arte de la danza. Lo importante es que existe un resultado donde estos dos lenguajes se hacen uno y cuyo producto final es audiovisual. $Y$, ¿en qué se diferencia entonces el videoarte del videodanza?. Según (Hernández, 2010) en la manera de abordar la obra, de acercarse a ésta y comprenderla, en la intención que lleva al realizador a apropiarse del concepto danza.

Utilizar un cuerpo danzante como protagonista con todas las características que lo distinguen: energía, tensiones, tonos, pulsos, formas, secuencias de movimiento y transiciones, entre otras, supone una fijación, una reflexión de un cuerpo vivo, o de un cuerpo - o imagen - en movimiento, y en este contexto el lenguaje sonoro de la electroacústica y en especial la metodología espectromorfológica responde a cada uno de los parámetros descritos (ver Tema 5). De este modo, la especificidad de este formato de video basado en la danza, sea cual sea el punto de vista con el que se afronta esta práctica o arte, adquiere una serie de matices perceptuales (texturas tímbricas, atmósferas, ambientes sonoros, células motívicas, micro estructuras, desarrollos temáticos...) que se generan y obtienen gracias al tratamiento sonoro electroacústico.

Así pues, abordar esta reflexión del cuerpo en movimiento, y capturarla en una secuencia de imágenes que nos condicionan, por ejemplo la ilusión de una temporalidad, podría ser una clave que nos sitúe frente a este tipo de obras, frente a artistas que han encontrado una herramienta para plasmar esta situación paradójica, de cuerpos 
virtuales, desmaterializados, conceptualizados y sus oportunas correspondencias sonoras.

Por otro lado, entre el cuerpo y soportes como cine, video e Internet, se dan distintas relaciones, ritmos y metodologías relacionadas al formato en particular y a su correspondencia imagen-sonido. Son los medios por los que el realizador-artista se conecta con el espectador y conecta con éste con su mirada o su discurso, los que determinan la naturaleza sonora del proyecto. Una figuración más directa y basada en la naturaleza plástica del objeto visual la que hace necesaria una paleta sonora específica (instrumentos acústicos, grabados sin retoques de procesos digitales complejos), en cambio la desmaterialización o conceptualización de la imagen nos permite una recreación y tratamiento más abstracto de los componentes del sonido.

\subsubsection{PERFORMANCE}

Veamos algunas definiciones y características acerca de lo que se considera la performance asociada a la danza:

Laura Baigorri (Baigorri, 2004) comenta:

'Tanto la performance como el happening están fuertemente condicionados por la personalidad de cada artista y resulta difícil clasificar todas sus variables : se pueden realizar una sola vez o repetirse indefinidamente, se puede improvisar o seguir un 'guión', se puede actuar en grupo o en solitario, en museos y galerías o al aire libre y en la calle.'

Para Nikos Stangos (Stangos, 1986) por ejemplo, el happening comprende un tipo de sensibilidad artística, que tiene que ver con el 
collage-entorno, compuesta por el sonido, la duración del tiempo, las sensaciones gustativas e incluso, los olores.

También continúa diciendo acerca de la relación con el teatro y la performance:

'Esencialmente, eran acontecimientos abstractos que apenas guardan relación con una representación teatral convencional y cuyo objetivo consistía en crear un contexto emocional; cuando se había producido la catarsis, se acababa la obra de arte.'

En cuanto a la danza, José Antonio Sánchez nos dice que los caminos de la danza han sido muy diversos: algunos han recuperado la técnica, otros la emoción, la teatralidad e incluso el histrionismo. Pero lo que en todos estos años - desde los 60 - no ha desaparecido es la idea de que la danza puede ser algo más que una composición armoniosa de movimientos destinada a ilustrar la música, agradar a la vista o sorprender con sus retos a las limitaciones físicas del común de los mortales (Sánchez, 1999).

\subsubsection{IMPROVISACIÓN SITE-SPECIFIC}

\subsection{INTRODUCCIÓN}

La improvisación Site-specific (Lugar-específico) asociada a la performance emergió a partir de los planteamientos artísticos radicales a mediados de la década de los 60 y principio de los 70. Quizás representa la mayor, revolucionaria y ambiciosa reinterpretación del teatro y la performance del siglo XX (MacAuley, 2000).

Las performances Site-specific tienen connotaciones que abarcan muchos aspectos de la creación escénica. Los tres puntos más 
importantes y decisivos para este ensayo son: (1) La interacción con la audiencia, (2) el debate interno sobre Whethersite-specific (cualquier sitio específico) es Site-exclusive (lugar exclusivo) o Site-generic (lugar genérico), y (3) teoría práctica sobre la elección de lugares .

La primera gran sección de este apartado reflexiona sobre la relación entre el Site-specific y el público. Las cuestiones y debates que han surgido acerca de la novedad y la participación íntima entre los performers y su público ha tenido una influencia considerable sobre las obras Site-specific como un todo. Este tipo de performance entiende a la audiencia como un elemento vital en la producción global y no meramente como personas que pagan y que están aisladas al proceso creativo. Muchas representaciones dependen íntimamente de la energía y fascinación mutua que existe entre el actor (artista) y el público. Como podemos ver (Schechner, 1988a; Kantor, 1993; Wilkie, 2002; Kwon, 2004), a menudo el público es parte de la propia representación.

Estos aspectos íntimos hacia una filosofía básica y unos principios profesionales en el Site-specific reaccionan frente una percepción distante, fría y elitista del teatro tradicional y ayuda a mantener la performance teatral fuera de una industria asociada a una sociedad elitista. Esta reflexión plantea preguntas importantes, tal y como se exponen en (Essays, 2010): ¿Puede la propia identidad del público verse alterada por una performance?, y: ¿pueden aparecer varias identidades espontáneas en representaciones de este tipo? Las respuestas a estas preguntas han sido planteamientos importantes en la esfera del Site-specific. 
Antes de analizar estas tres líneas principales haremos una panorámica sobre la historia y orígenes de las performances Sitespecific y los artistas que han contribuido a su desarrollado.

\subsection{HISTORIA DE LA PERFORMANCE SITE-SPECIFIC}

Las obras Site-specific son una forma de arte que fue creada para existir en un determinado espacio y condicionada en su forma por el ambiente y el espacio de ese lugar.

En el origen del movimiento artístico Site-specific hubo un intento de sacar el arte de lo que se percibía como las atmósferas viciadas y pretenciosas de las galerías y los edificios de teatro, para su incorporación a una mayor variedad de lugares al aire libre o interior. Una definición acerca de funcionamiento del Site-specific se encuentra el del Diccionario de Videoarte (Schechner, 1988b):

'Locations and environments may have some kind of drama or meaning for ordinary people but this has no significance for the bourgeoisie until interpreted by the heightened sensibilities of the director'.

'Las ubicaciones y ambientes pueden tener algún tipo de connotación o significado para la gente común, pero no para la burguesía hasta que no sean interpretadas por la sensibilidad de un director.

En otras palabras, el propósito del Site-specific y su razón de ser es dar a conocer al público los méritos artísticos de los edificios y espacios comunes que siempre han sido de interés para los hombres ordinarios, pero que pasan desapercibidos por los artistas e instituciones elitistas ancladas al pasado. 
En este sentido y como comenta Katrina McPherson, una de las grandes ventajas de grabar la video-danza en un Site-specific, es que la coreografía interactúa con el entorno, haciendo que el espacio no sea un simple decorado (McPherson, 2006).

\subsection{PERFORMANCE SITE-SPECIFIC: PÚBLICO}

- Interacción General con el Público

Quizás, la contribución principal de la Performance Site-specific como un arte o forma híbrida frente a la obra Site-specific como un todo, ha sido la transformación radical de la construcción del concepto del público, y cómo éste experimenta y condiciona la performance en vivo.

Este uso del público por los actores del Site-specific ha conseguido por primera vez, y según Fiona Wilkie (Wilkie, 2002):

'...el sentido de una identidad de audiencia colectiva, un público consciente que se construye apropiadamente a sí mismo como un cuerpo interpretativo a través de un marco acumulativo de marcos contemporáneos de experiencias.'

- Audiencia y Comunidad

La Performance Site-specific ha conseguido para el arte Site-specific en general recuperar la importancia de la comunidad en la que una particular performance o exhibición de arte toma lugar. Una compañía de performance Site-specific particular como 'The Olimpias' (Olimpias, 2010), basa su trabajo sobre cuestiones de posesión, en línea con el tema de la discapacidad. En Petra Kuppers (Kuppers, 2007), directora de la compañía, vemos que este tipo de performance pretende observar a la comunidad local y sus modos de habitar su entorno. La 
compañía trabaja con la comunidad para elaborar nuevas lecturas del lugar, reinterpretar el espacio, manteniendo viva su historia y su presencia.

Vemos por tanto que la identidad de la comunidad y los parámetros que definen su entorno son cuestiones básicas en la construcción de una performance Site-specific.

- Cuestiones con el Público

No obstante, algunos autores como Jan Cohen-Cruzh (Cohen-Cruz, 1998) sostienen que tomar un teatro o edificio local con una ubicación concreta como para la performance Site-specific, no favorece necesariamente la creación de un entorno más íntimo o el sentido de la identidad o identidades múltiples. El mismo Cohen-Cruz comenta:

'El espacio está siempre controlado por alguien y existe en alguna parte, por lo que está, inevitablemente, marcado por una clase particular o raza, y no es igualmente accesible a todos. Uno debe preguntarse si el acceso a un público más amplio realmente establece una diferencia entre la performance Site-specificy y el edificio de teatro.'

Esta cita se plantea como nota de advertencia para los artistas del Site-specific ya que automáticamente asumen que, por el simple hecho de crear cualquier tipo de lugar, conseguirán inmediatamente un sentido más profundo o más trascendental de participación de público y diversidad de la que se encuentra en un teatro tradicional.

\subsection{SITE-SPECIFIC FRENTE A SITE-GENERIC}

El debate entre los conceptos Site-specific y Site-generic ha sido germen para multitud de interpretaciones, que han planteado 
preguntas sobre la 'pureza' de la performance Site-specific. Por encima de todo, se puede plantear la pregunta: ¿es posible, para los teóricos e intérpretes del Site-specific, encontrar u obtener un modelo 'puro' de funcionamiento contra las formas híbridas con las que este modelo se puede comparar? Es decir: ¿se puede configurar la construcción de un paradigma ideal de Site-specific y luego mostrar cómo las variaciones de este paradigma son beneficiosas para sus modos propios? En este sentido, Miwon Kwon sugiere (Kwon, 2004):

'Para hacer una pieza verdaderamente Site-specific se entenderá que ésta se sienta totalmente inscrita en ese lugar, tanto en su contenido como en su forma, de lo contrario, y si cambia, se convierte en el concepto de 'sitio como vehículo'.'

Miwon Kwon, plantea por tanto, que una definición de este modelo puro puede presentar variaciones, y pueden ser saludables en cuanto al enriquecimiento natural de dicho modelo; el trabajo de los teóricos sería definir estas variaciones y atribuir a cada una de ellas las áreas independientes de actuación.

\subsection{TIPOS DE UBICACIONES}

Los debates internos dentro de la literatura del Site-specific en cuanto a la selección del tipo de ubicaciones para sus representaciones han tenido una considerable influencia sobre las decisiones acerca de la planificación general.

Como podemos ver en (Schechner, 1988a), los lugares teatrales son mapas de la cultura allá donde estén; más aún, en (Hetherington, 1998) vemos que ciertos espacios actúan como sitios para la representación de la propia identidad. 
La manipulación artística del espacio es vital para el desarrollo del Site-specific, y la única opción en este propósito ha sido la exploración de alternativas de espacios y ubicaciones en los que llevar a cabo este tipo de teatro.

Acerca de espacios públicos, Cohen-Cruz (Cohen-Cruz, 1998) argumenta que estos espacios permiten a los artistas e intérpretes utilizar el espacio que normalmente es considerado como 'públicamente inhabitable' para atraer a los transeúntes, haciendo accesible y atrayente la representación. Los espacios se encuentran en lugares tales como galerías, museos, iglesias, enclaves abiertos, paisajes, etc, utilizados frecuentemente para otras cuestiones.

Uno de los artistas contemporáneos que trabaja en la naturaleza Sitespecific es el escultor Andy Goldsworthy (UK, 1956). En referencia a su obra comenta Smith:

'Estos trabajos se han hecho después de una prolongada estancia en el lugar donde se ha logrado encontrar un sentimiento íntimo y un punto de partida que empieza alli' (Smith, 1997).

Smith defiende que cuando los artistas deciden trabajar en un lugar específico, ya sea colaborando con la naturaleza o construyendo algo, lo que hacen es improvisar (Smith, 1997).

La improvisación es definida por Hazel Smith como 'una coincidencia entre producción, y transmisión. Es la capacidad de usar los cuerpos, espacio y todos los medios humanos para generar una expresión física coherente de una idea, una situación, etc, y hacerlo de forma espontánea, en respuesta al estímulo del entorno' (Smith, 1997).

También apunta el mismo autor que la improvisación y la composición no son opuestos, sino que están separados por un proceso de creación 
gradual y por tanto, todas estas reflexiones nos van a ayudar en la configuración final de un proyecto práctico.

De esta reflexión nace la propuesta de creación simultánea del sonido y la composición musical a partir de la libre creación, la performance in situ de los bailarines para este proyecto.

\subsubsection{REFERENTES}

La compañía catalana La Fura dels Baus (Baus, 2010) en su obra Degustación de Titus Andronicus adaptación de la tragedia de Shakespeare, plantea unos elementos característicos: un espacio único compartido por el público y los artistas, una escenografía que se presenta a través de diferentes elementos de soporte virtual y un lenguaje a camino entre el texto y el cine. El espectador se mueve por toda la sala en un espacio custodiado por cuatro grandes pantallas de vídeo que rodean la acción (Fig. 146). La música ha sido compuesta por Robert Medzo.

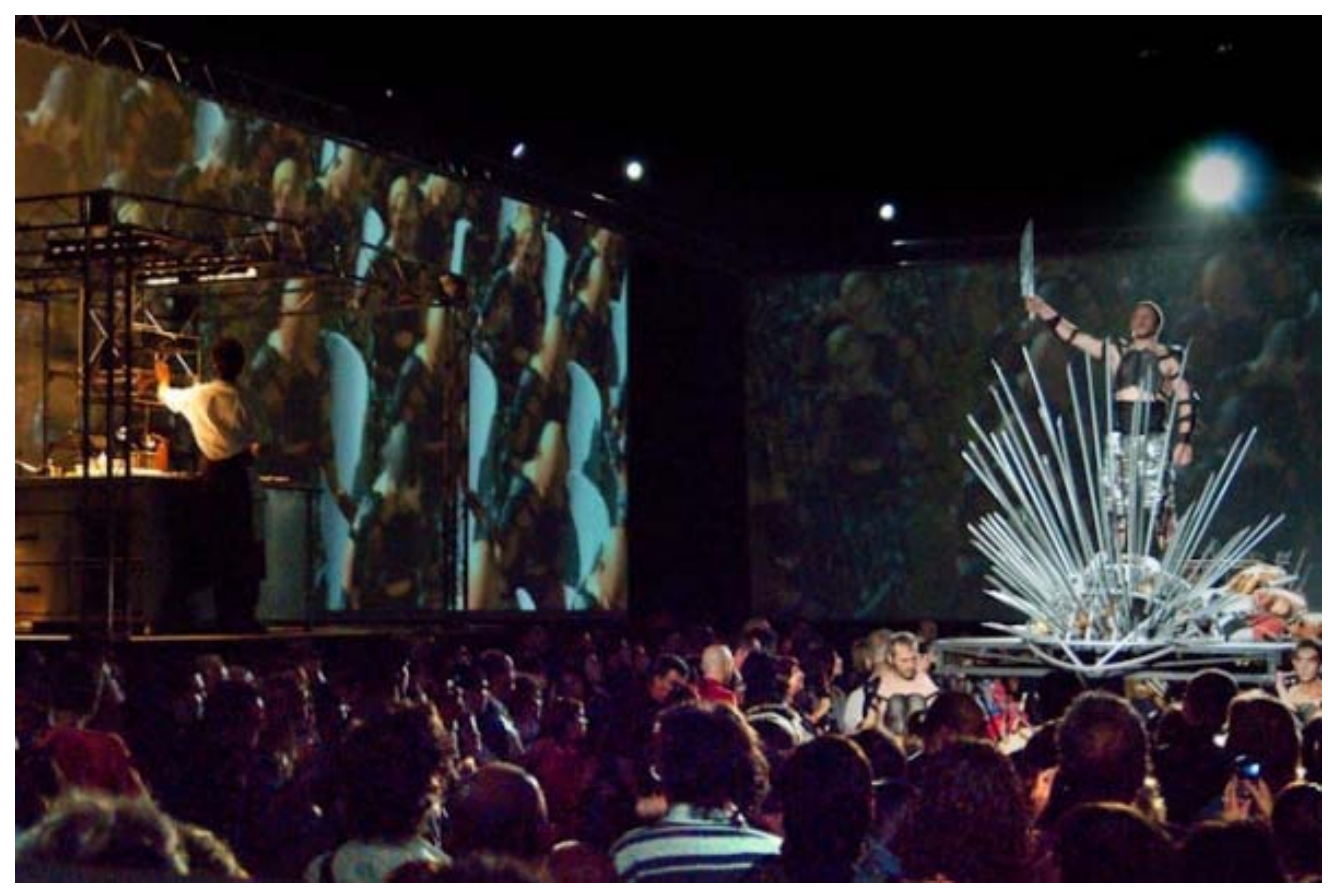

Fig. 146 Captura de Degustación de Titus Andronicus, en (Baus, 2010) 
El montaje de video-danza titulado One flat thing, reproduced (Fig. 147) del coreógrafo William Forsythe (New York, 1949), con diseño sonoro de Tom Willems (Países Bajos, 1955) y dirección de Thierry de Mey (Bruselas, 1956) desarrolla un discurso sonoro basado en texturas sostenidas en el tiempo mediante el empleo de herramientas de síntesis granular (ver Tema 5), síntesis $\operatorname{cruzada}^{34}$ e impulsos cortos generados a partir de osciladores modulares. Estos tres elementos están fusionados a los sonidos ambientales, en los cuales resaltan los pasos de manera contundente y los golpes propios de la coreografía. La integración de ambos elementos se presenta de manera fortuita, no existe una planificación en cuanto a la correspondencia entre sonidos de síntesis y grabaciones directas.

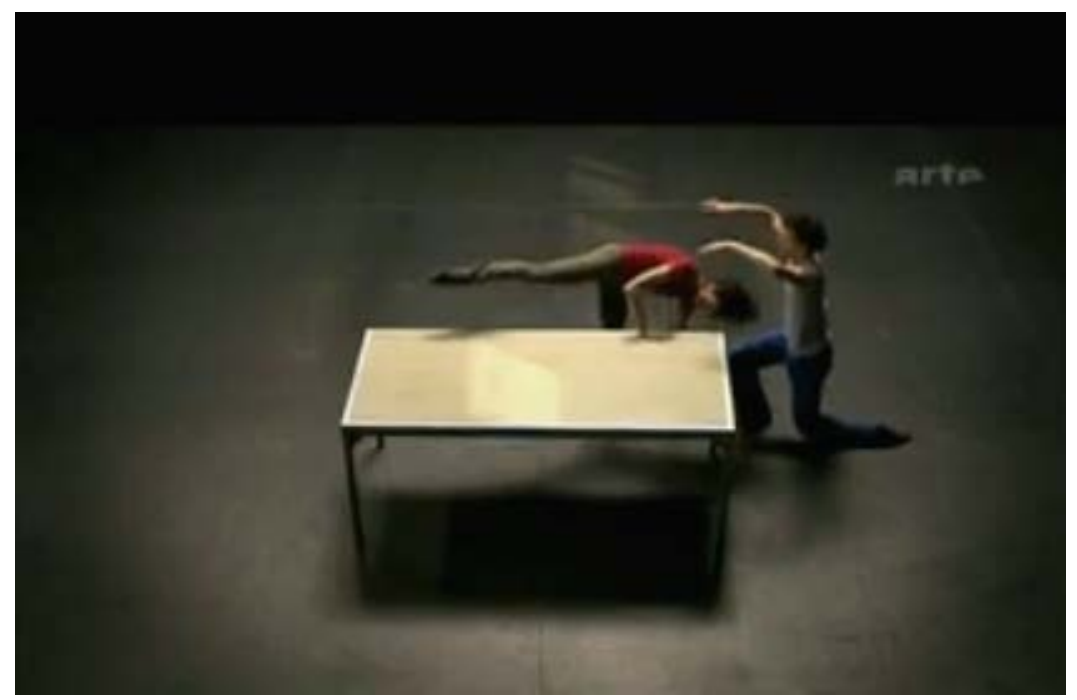

Fig. 147 Captura de One flat thing, reproduced, en (Forsythe, 2010)

La obra está rodada como en una película de acción, alternando planos fijos, travellings, marcos congelados y ángulos poco comunes. El lenguaje coreográfico de Fortsythe es casi gramatical. Las frases

\footnotetext{
${ }^{34}$ Producción sonora mediante la que cualquier parámetro de un sonido (por ejemplo, la amplitud o la frecuencia) se aplica sobre un parámetro (no necesariamente el mismo) de otro sonido.
} 
que compone son, a veces, disparatadas, pero hace un discurso coherente con los tiempos contemporáneos, tan actual que se adelanta al presente. Puede ser difícil ver sus obras, pero son piezas fruto de la experimentación. Lo que se experimenta son las sensaciones, no la coreografía; son piezas pensadas, analizadas y creadas para el medio que utiliza en ese momento (Lewinsky, 2010).

Otra aplicación de materiales sonoros abstractos y medios electroacústicos a la video-danza la podemos ver en Hodoku (2008), creada y dirigida por la argentina Nadia Patrian. La primera parte del video, en el que aparecen una bailarina sobre fondo negro con grandes contrastes de luz, utiliza unos impulsos sostenidos en el tiempo mediante el empleo de osciladores y moduladores de frecuencia. En las siguientes partes, este material sonoro evoluciona en bucles y patrones rítmicos de estética new-age que no aportan nada a la psicología del personaje principal y la intención original de la obra.

'Esta historia se centra en una mujer cuya memoria y piel evocan por última vez los avances y retrocesos de una relación. La incomunicación toma fuerza, la falta de contacto acentúa el lado oscuro interior de ambos. Exponiendo sus sentimientos opuestos llegan al desenlace, doloroso para ella, lógico para él. El recuerdo y la aceptación de esta crisis encienden una nueva luz en ella.' (Patrian, 2008).

La propia autora comenta que para la realización de Hodoku (Fig. 148) fue muy importante el lenguaje y simbología de elementos como el agua y la tierra para integrar la creación e interpretación de los bailarines. También la importancia del espacio negro como un espacio/tiempo nulos, el pasado se filtra en el presente de ELLA hasta 
que ELLA opta por el fluir en el presente y liberar ese pasado cargado de dolor.

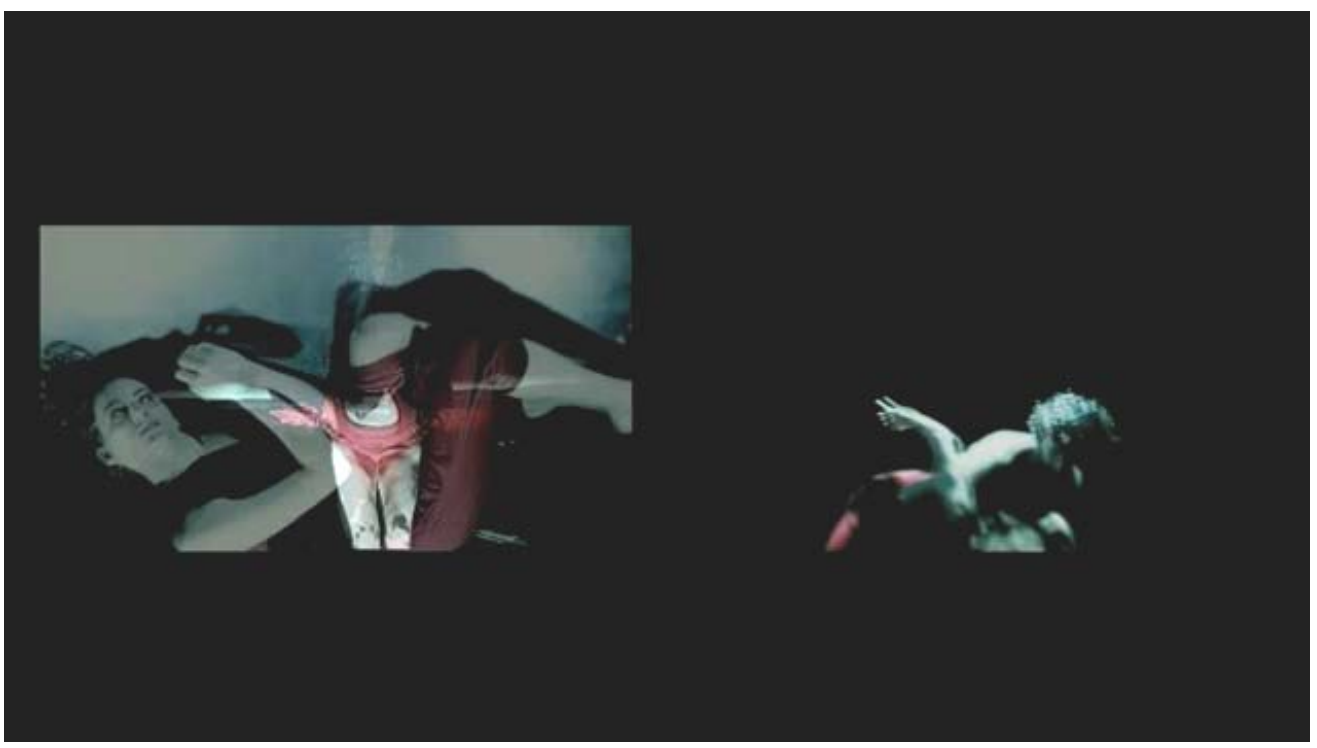

Fig. 148 Captura de Hodoku, en (Patrian, 2008)

Durante la exploración de referentes en el género de la video-danza se ha comprobado que en multitud de ocasiones la planificación y expresión sonora pasan desapercibidas en el planteamiento global del video. No existe una lógica y coherente correspondencia entre imagen-sonido. Se crea en estos casos, un desequilibrio en la rigurosidad de las facturas de video y audio.

En cuanto a video-danzas que utilicen instrumentos acústicos y poco tratamiento digital podemos mencionar al checo Jirí Kylián y su obra Sleepless (Fig.149). En ella el compositor alemán Dirk Haubrich, decide establecer un discurso sonoro basado en una adaptación de los pasajes lentos del Adagio y Rondó KV 617 en Do menor de Mozart 
para instrumentos de uso no frecuente como la Armónica de cristal ${ }^{35}$ (Fig. 150) En la primera parte del video, 'Paso a dos', aparecen pequeñas células aisladas que son ejecutadas también por instrumentos de la familia de la percusión: bombo, crótalos, gongs afinados y marimba.
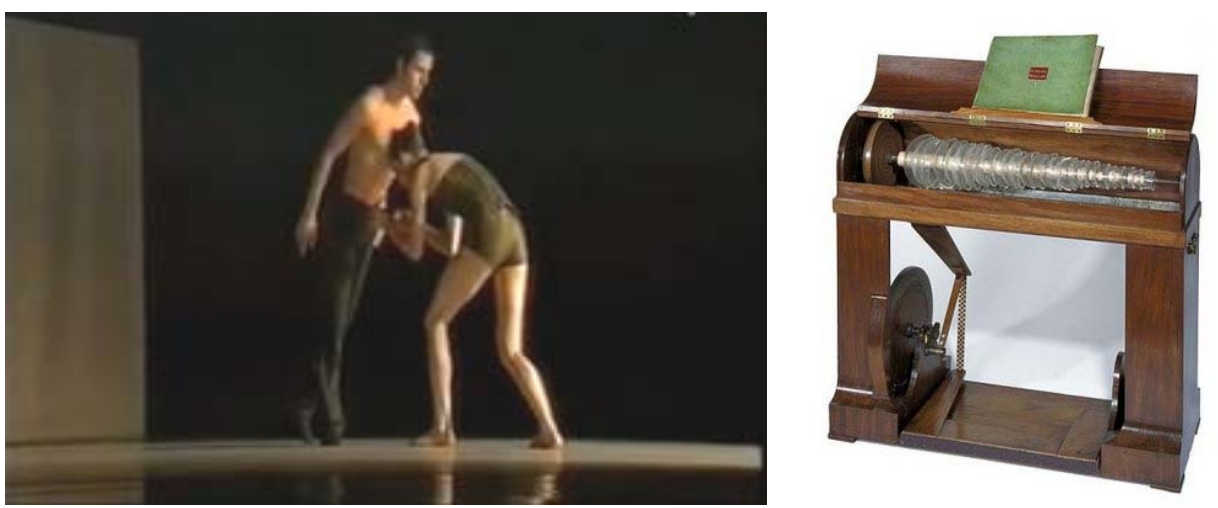

Fig.149 Captura de Sleepness

Fig. 150 Armónica de Cristal

En el plano del Site-Specific fué significativo el video de Thierry de Mey: Ma Mère l'Oye (Mi madre la Oca) (Fig. 151), creada en 2004 con el comisionado de ARTE. La video-daza está inspirada y basada en el ballet del mismo nombre del compositor Maurice Ravel que escribió en 1908, basado en los cuentos fantásticos de Charles Perrault. En esta obra se presentan varias viñetas a modo de collage filmadas en los bosques a las afueras de Bruselas.

\footnotetext{
${ }^{35}$ La armónica de cristal es un instrumento idiófono mejorado por Benjamin Franklin en 1762, después de ver en Cambridge, Inglaterra, un concierto de copas de vino llenas de agua tocadas por Edmund Delaval. Consiste en una serie de platos o boles de cristal de diferentes tamaños superpuestos y alineados horizontalmente, atravesados por un eje conectado por correa a un pedal que los hace girar mientras se toca, a la manera de una vieja máquina de coser. Actualmente tiene un registro de cuatro octavas.
} 

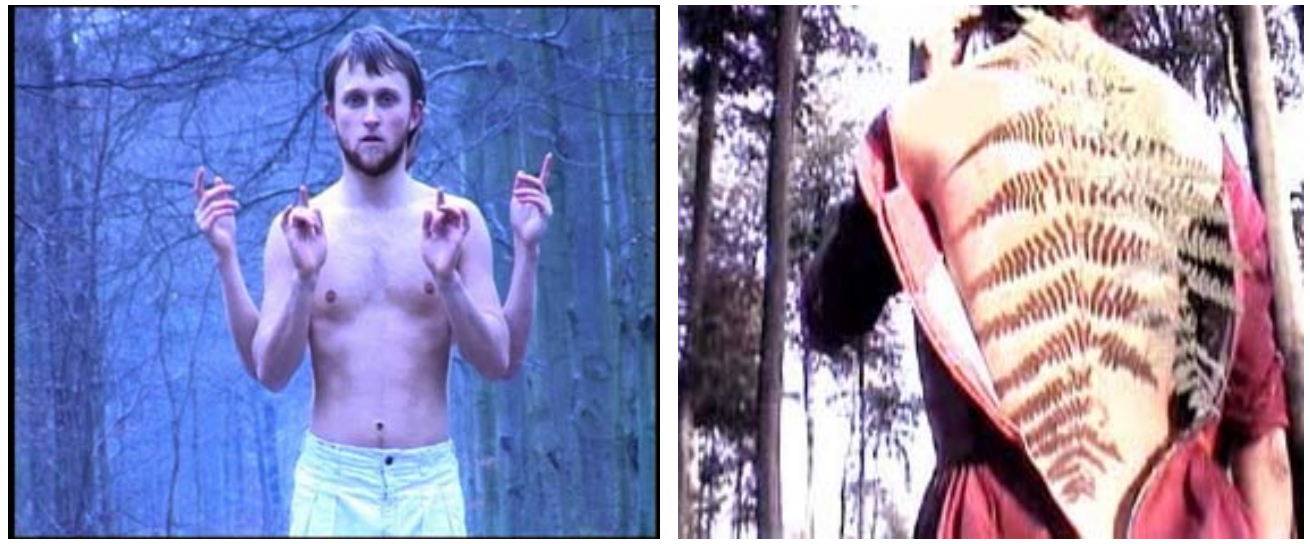

Fig. 151 Capturas de Ma Mère l'Oye, en (Mey, 2008)

En este caso los bailarines adquieren un rol determinado en función de la historia, el personaje, el entorno o la música que está sonando, y recrean unas secuencias danzadas a modo de semi-improvisación. Al mismo tiempo existe un tratamiento del sonido ambiental, ruidos de pisadas, y respiraciones, a cargo de los técnicos de sonido Frédéric de Molder y Boris van der Avoort, que como podemos ver en (Schmidt, 1976) confieren, al resultado final y en cualquier contexto audio-visual, una percepción más realista de la acción visible.

Este realce de ruidos ambientales y sonidos generados por la propia acción de la danza y los personajes, ha sido un parámetro muy influyente y determinante en la planificación del proyecto que nos ocupa en este ensayo. La identidad del lugar y las condiciones del paisaje partieron como argumentos prioritarios en el tratamiento conceptual del proyecto.

Otro referente del mismo autor es Rosas danst Rosas con música del propio Thierry De Mey y Peter Vermeersch (Mey, 1997); filmado en la antigua Escuela Técnica del arquitecto Henry Van de Velde (18631957) en Lovaina (Bélgica) (Fig. 152). La versión de la película es mucho más corta que el propio espectáculo. En su película de Thierry 
De Mey opta por una versión inter-cut (mediante superposición de fragmentos cortados bruscamente) en la que, además del elenco de cuatro bailarines, también cuenta con históricos artistas del mundo de la danza. En el montaje se aprovechan al máximo las cualidades geométricas y espaciales del edificio de Van de Veldes. Por cierto, el edificio fue totalmente renovado justo después de la película que se hizo, por lo que se convirtió sin estar planeado en un documento histórico de los testimonios de la arquitectura original.

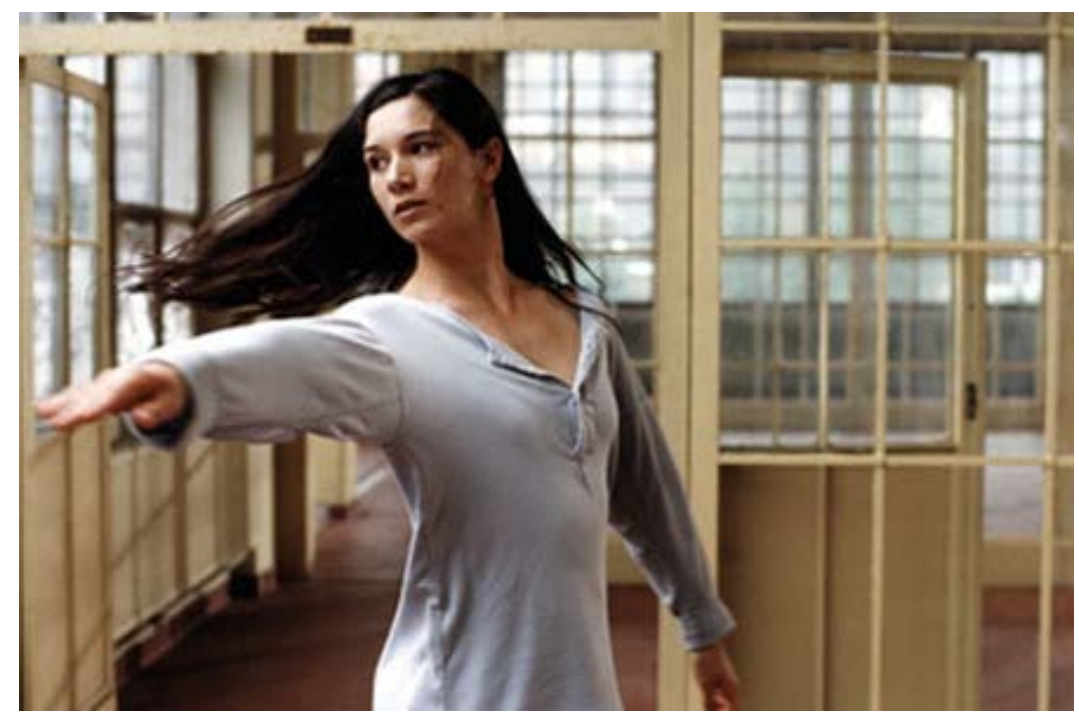

Fig. 152 Captura de Rosas danst Rosas, en (Mey, 1997)

La lectura visual a través de la danza que hace Thierry de Mey en Fase $^{36}$ (2002) (Fig. 153) de la música minimalista de Steve Reich (Nueva York, 1936) Violin Phase, Piano Phase, Clapping Music y Come Out confirma las cuestiones de coherencia entre el objeto sonoro y el gesto de la imagen que se han descrito en (ver Apartado 5.1.2.3) y se

\footnotetext{
${ }^{36}$ Reich en sus inicios desarrolló varias técnicas de composición musical, que incluyen el uso de loops (bucles) en cinta - tal como en sus primeras obras It's Gonna Rain (1965) y Come Out (1966) - , efectos de fase repetidos Phase Patterns (1972), Violin Phase y Piano Phase (1967) - y nuevos conceptos musicales —en Pendulum Music (1968), la retroalimentación con micrófonos y en Four Organs (1970), el alargamiento -.
} 
propone como objetivo en este ensayo. Las cuatro partes de la performance fueron filmadas en cuatro lugares diferentes: Piano Phase en the Rosas Performance Space en Vorst, Come Out en el nuevo edificio Coca-Cola en Anderlecht, Violin Phase en Tervuren forest y Clapping en el Felix Pakhuis en Antwerp (Bélgica) (Mey, 2002).

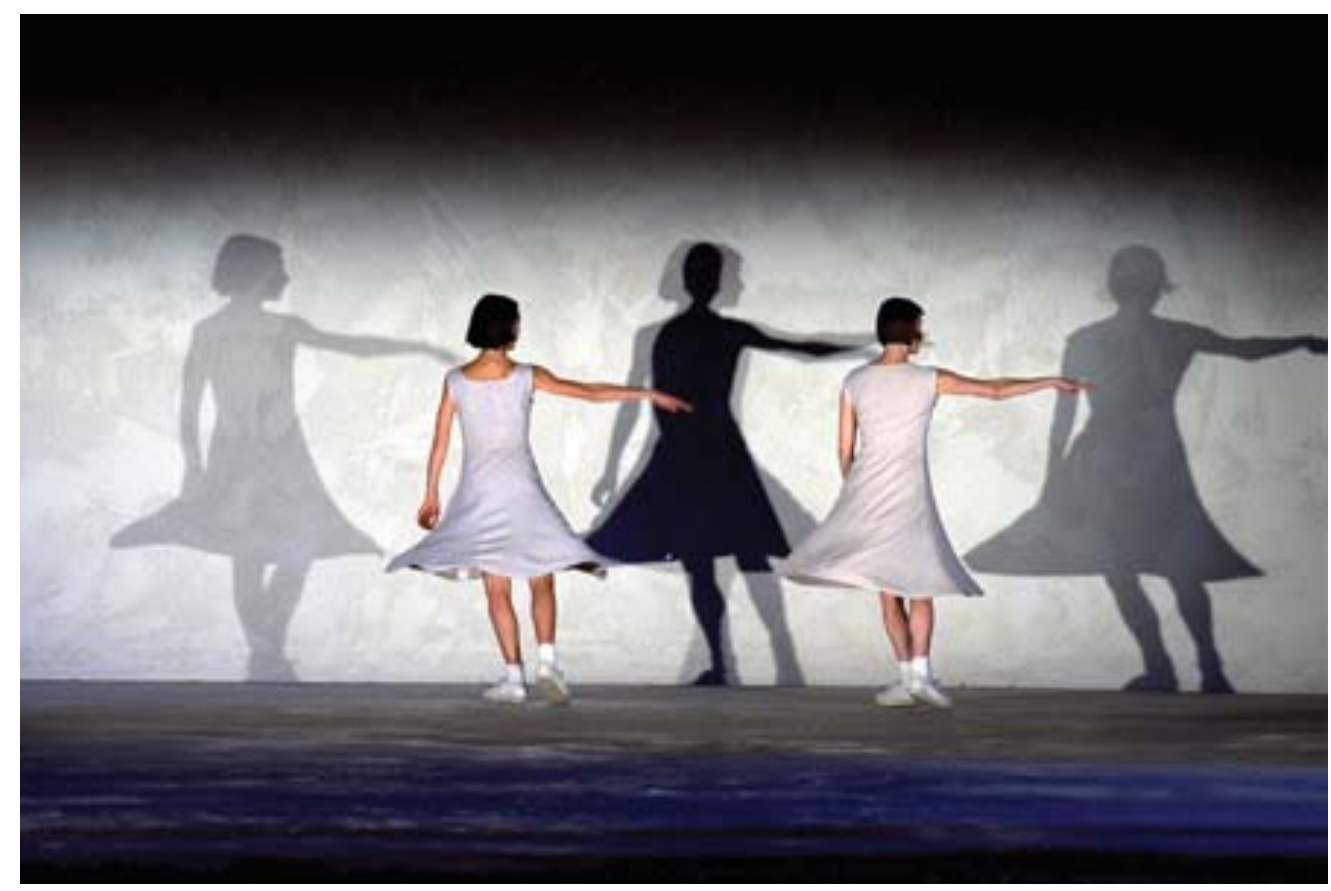

Fig. 153 Captura de Fase, en (Mey, 2002)

David Eugene, Josh Martin y Hardi Barnewold Edwards, a partir de la obra del ecléctico compositor italiano Fausto Romitelli (1963-2004) Professor Bad Trip/lctus, (Professor bad trip_lesson1, Professor bad trip_lesson 3) y fragmentos de Seascape, Green, Yellow and blue y Trash TV trance, donde combina sonidos acústicos y electrónicos con influencias evidentes de ruido de cintas, música de Penderecki, y Rock; con el diseño sonoro de Charo Calvo y Benjamin Dandoy dan vida sonora a la producción de Wim Vandekeybus (Bélgica, 1963) Here After (2007), una adaptación cinematográfica de la performance Puur, presentada en el Festival de Avignon 2005 en el hermoso enclave Cantera de Boulbon (Vandekeybus, 2010a). 
Flotando entre la ficción y la danza se mezclan fragmentos desechados de la película rodada en formato Super8 con imágenes de las secuencias de baile en formato $16 \mathrm{~mm}$ (Fig. 154). Los intérpretes bailan sobre los sonidos cortados del compositor italiano Fausto Romitelli y la música lírica de David Eugene Edwards (Edwards, 2010); las imágenes fueron filmadas en una fase posterior en los escenarios naturales de Oye-Plage (Francia) y en su propio estudio (Vandekeybus, 2010b).
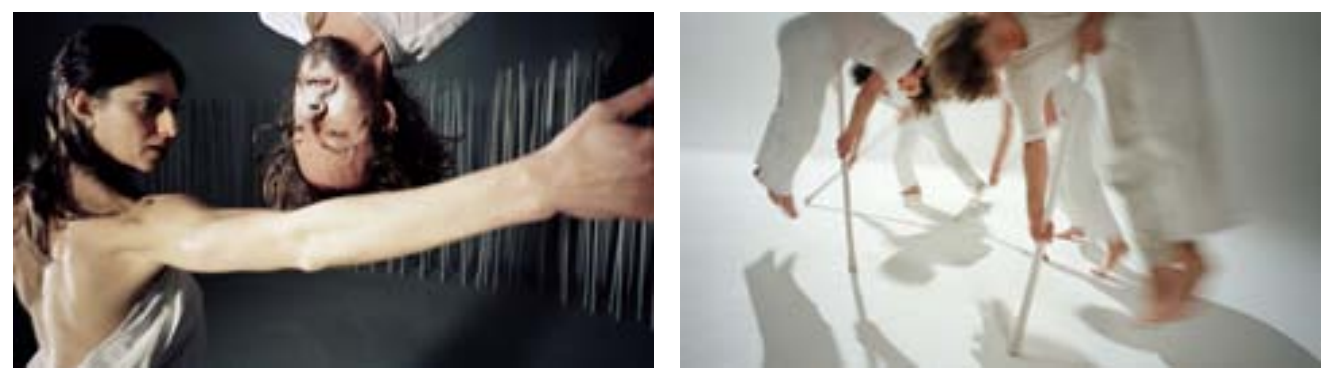

Fig. 154 Capturas de Here After, en (Vandekeybus, 2010a)

El video cuenta la historia de una comunidad aislada en la que un tirano loco comete un infanticidio. En las escenas podemos ver cómo los personajes reviven sus recuerdos en el más allá, como si sus emociones y traumas fueron capturadas en la memoria de sus cuerpos. La película muestra el efecto del terror y la destrucción en una comunidad, así como cuestiones existenciales fundamentales: la vida/muerte, culpabilidad/penitencia, la identidad/memoria, lamento/negación y poder/libertad.

La coreógrafa y directora británica Rosemary Lee junto a Peter Anderson y música en vivo de Larry Mindel concibieron Mirror Mirror On The Wall (1986), una pieza teatral de danza que involucra a un variado elenco de bailarines locales mayores de 10 años en hasta 75 localizaciones diferentes (Fig. 155). 

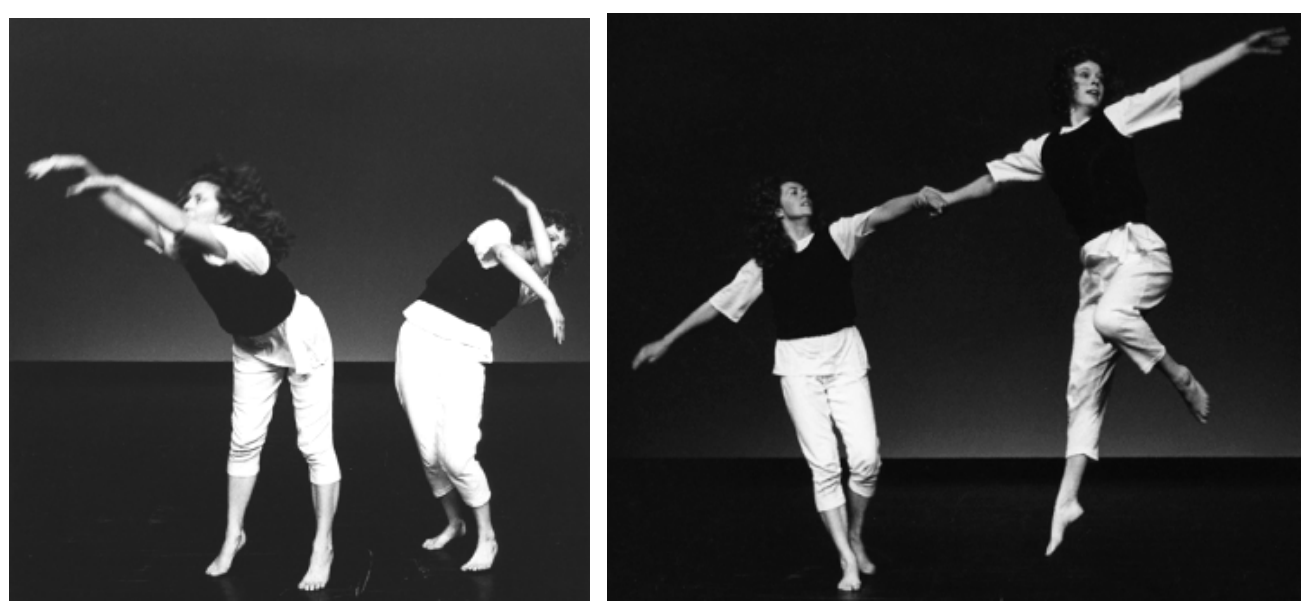

Fig. 155 Capturas de Mirror Mirror in the Wall, en (Lee, 1986)

De la misma autora podemos ver en Remote Dancing (2004-2008) con música de Graeme Miler, una instalación interactiva donde se establece un diálogo entre realidad y mundo virtual aplicado a la danza: el espectador y el bailarín que aparece en la pantalla.

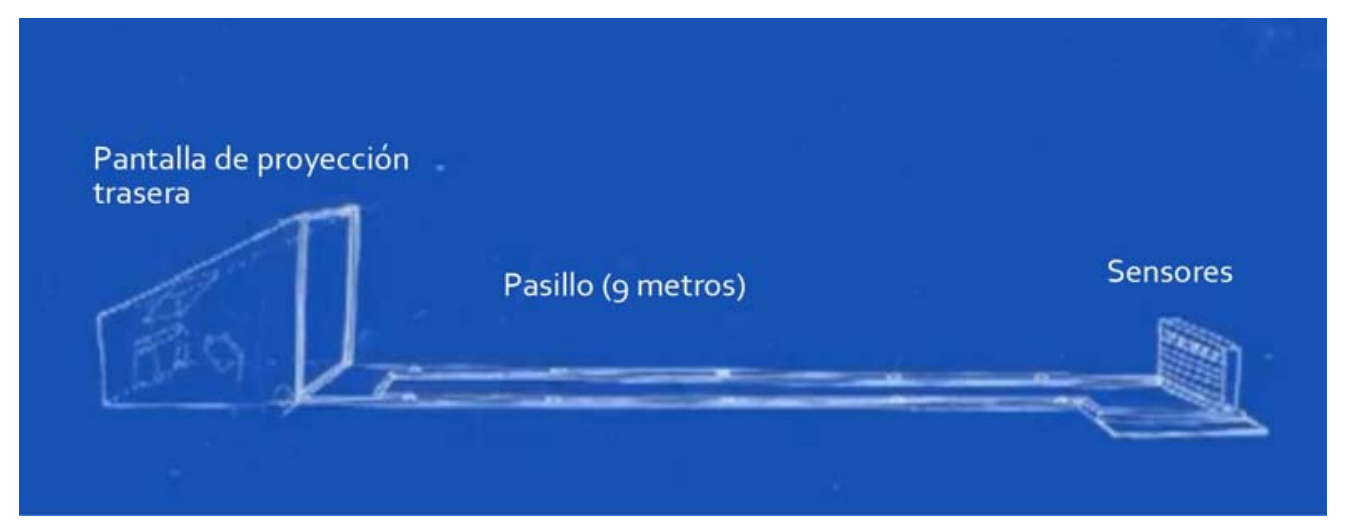

Fig. 156 Esquema de Remote Dancing, en (Lee, 2010a)

Como podemos ver en la Fig. 156, el espectador entra en un pasillo para encontrarse con un compañero de baile virtual, que le espera bailando en el fondo desde el principio (Fig. 157). A medida que comienza la exploración de las respuestas y cambios sutiles que experimenta la imagen con su propio movimiento, el espectador aprende que puede manipular el vídeo hacia delante o hacia atrás y más rápido o más lento. Cuanto más tiempo permanece dentro, 
aparecen más secciones de baile y se van revelando nuevos contextos. Se pueden llegar a reunir hasta seis compañeros de baile virtuales de todas las edades en la escena visual (Fig. 158).
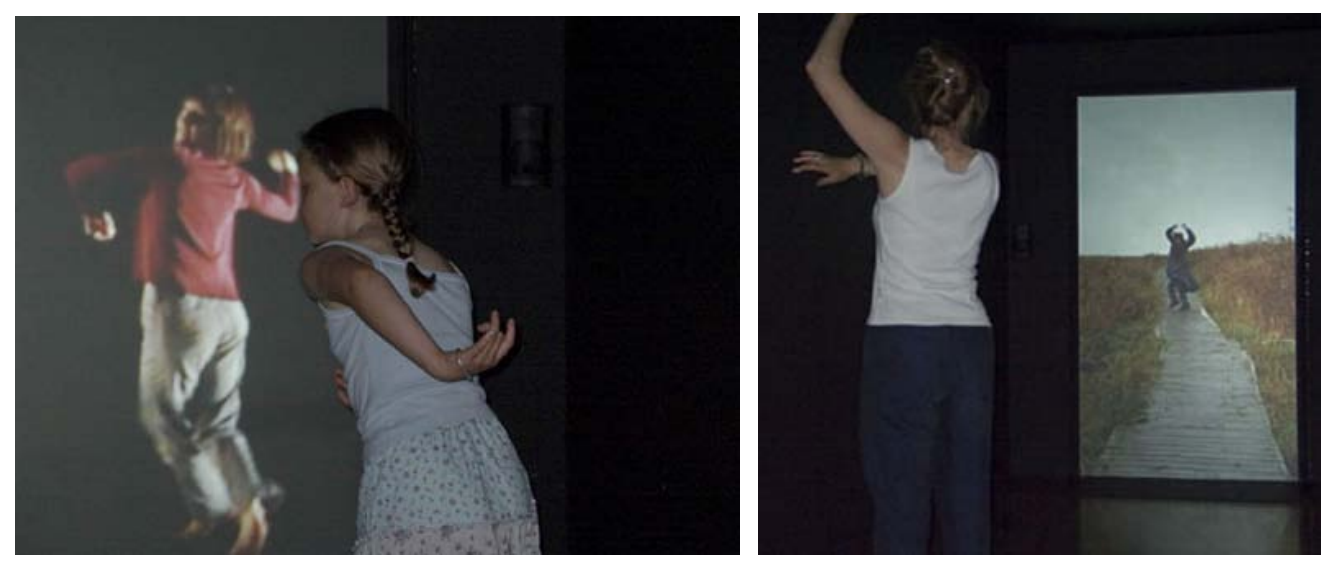

Fig. 157 Capturas de Remote Dancing, en (Lee, 2010a)

Rosemary Lee se propone continuamente investigar sobre nuevos contextos y medios de comunicación e interacción. En Remote Dancing trabaja junto a Nic Sandiland, explorando maneras de involucrar íntimamente al público como elemento participante y coreográfico. El sonido para la instalación está diseñado por el polifacético artista y compositor anglosajón Graeme Miller. Para las distintas viñetas que aparecen en la pantalla utiliza varios ambientes sonoros mediante diferentes instrumentos sampleados: piano, guitarra, voz, marimba, campanas, cuerda, y sonidos ambientales además de procesos digitales como el empleo del delay y distintos tipos de reverberación.

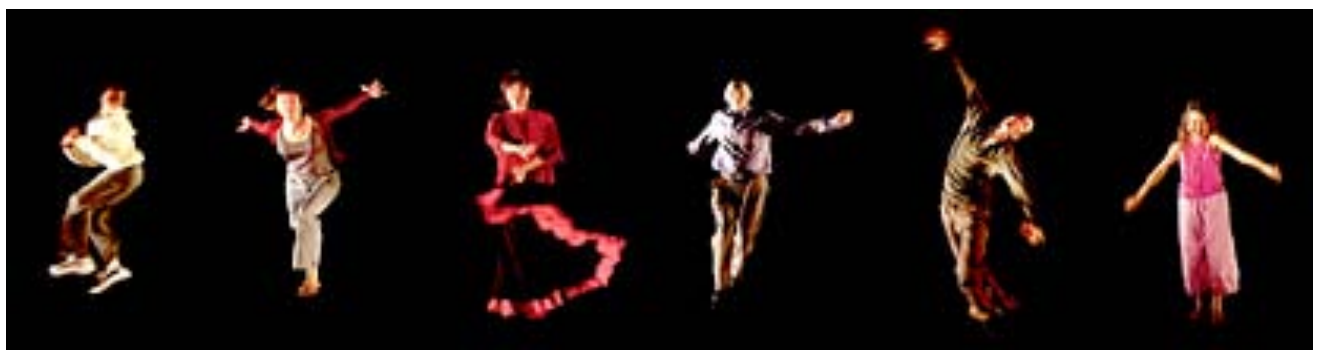

Fig. 158 Seis bailarines virtuales en Remote Dancing, en (Lee, 2010a) 
La misma autora británica diseñó las coreografías para la instalación con sonido y danza de Nic Sandiland Stereo Dances (2004-2008) con músicas de: Khosid Wedding Dances' titulado Muzsikas (grupo de música de celebración y folklore judío) (KhosidWeddingDances, 2010), Speres 1st Movement del pianista de Jazz Keith Jarrett, La Valse d'Amelie de Yann Tiersen, y Yodel 1 de Penguin Café Orchestra.
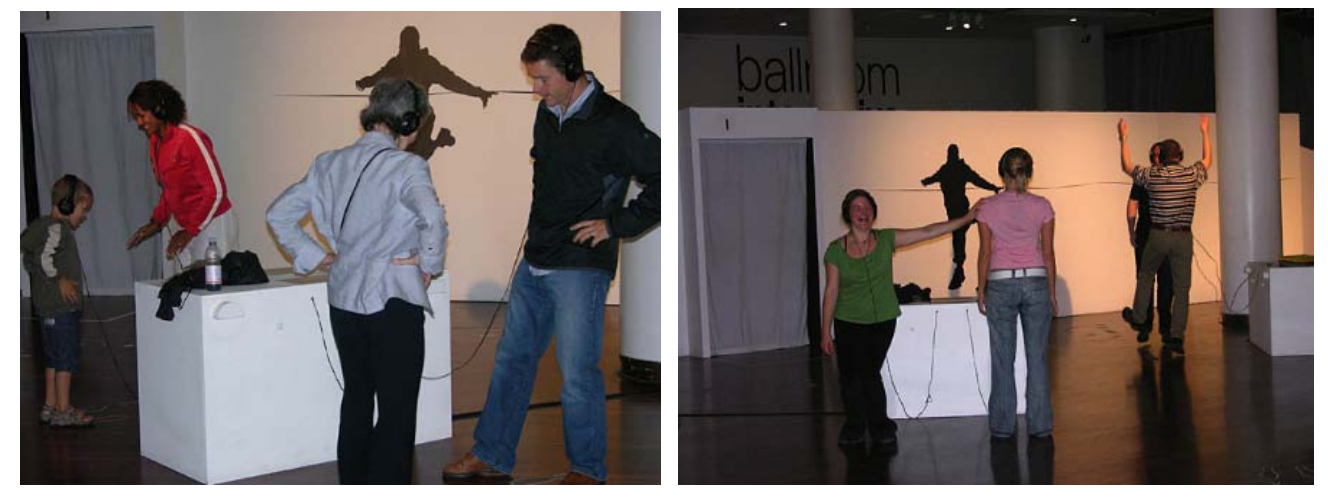

Fig. 159 Instalación Stereo Dances, en (Lee, 2010b)

Stereo Dances es una instalación sonora de danza. En ella, cada participante puede crear un dúo privado con un compañero, mientras oyen las instrucciones del baile y la música a través de unos auriculares individuales. Hay preestablecidos cuatro bailes para probar: la versión Folk, la meditativa, la versión original y una versión inesperada (Fig. 159).

En la misma idea de la interacción entre elementos reales y virtuales Lightwalking (2007), de la misma directora, consiste en la performance dentro de una instalación audio-visual llamada Volume (2006), un conjunto de postes lumínicos controlados mediante un sistema interactivo que responde al movimiento humano, creando una serie de experiencias audio-visuales (Lee, 2007); esta instalación interactiva ofrece un espacio concreto y especial para una performance con danza. Instalado en el Jardín John Madajski durante el invierno de 
2006 en el Victoria and Albert Museum de Londres (Fig. 160). La obra constituye una colaboración entre Playstation ${ }^{\circledR}$ y el colectivo United Visual Artists (UVA, 2010), con el diseño del grafitero Robert Del Naja, el grupo musical Massive Attack y Neil Davidge (Wikipedia, 2010j) y estudio de diseño onepointsix (onepointsix, 2010).
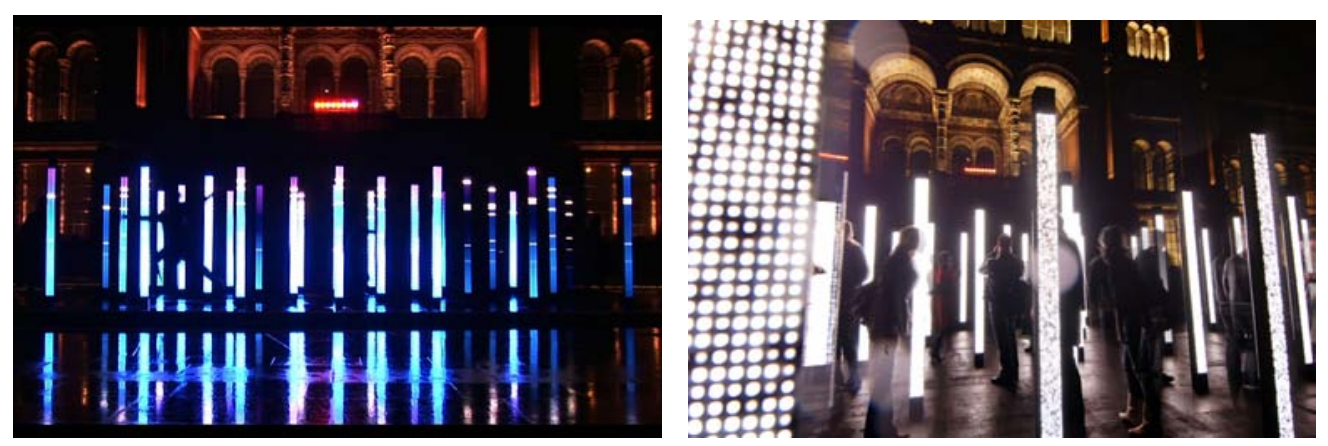

Fig. 160 Instalación Volume para Lightwalking, en (UVA, 2010)

El sonido de la instalación está formado por elementos melódicos y rítmicos en un estilo minimalista, lounge y tri-hop ${ }^{37}$, con sonidos ambientales propios de la naturaleza: pájaros, aire, insectos, agua, etc.

\subsection{DESCRIPCIÓN TÉCNICA}

Como se ha descrito en los capítulos anteriores, Porque la perdí nació con la intención de capturar la esencia de un pequeño pueblo del

37 Trip hop, también conocido como el sonido de Bristol (Bristol Sound) o Bristol acid rap, es un término creado por la revista inglesa Mixmag, para describir el trabajo de DJ Shadow, que daba al oyente la impresión de estar en un viaje. Se caracteriza por el uso de breakbeats (patrones rítmicos diferentes del 4/4, en contraposición con el ritmo constante del house), pero a una velocidad lenta (entre 60 y $120 \mathrm{bpm}$ ) en comparación con otros tipos de música que emplean este recurso; siendo una combinación de hip hop, house, reggae, soul, jazz, música electrónica y downtempo (los ritmos más lentos de la escena, como el dub, el chillout, el lounge o el propio trip hop) (Wikipedia, 2010r). 
pirineo aragonés a través de los testimonios y las experiencias de varios ancianos, en una obra clasificada por su creadora como 'videoperformanza'. Este planteamiento conceptual y estilístico plantea una metodología muy acotada en lo referente al diseño sonoro y a la composición musical.

El factor principal que determinó la parte danzada y su significado lo definió el testimonio de los ancianos que aparece en el comienzo del vídeo (hasta el instante $7^{\prime}{ }^{\prime \prime} 5^{\prime \prime}$ ). En esta parte se cuentan vivencias de la guerra civil española, el modo de vida de sus vecinos en la posguerra, su relación con la naturaleza y el clima de la zona, hábitos de vida y comportamiento social. Los testimonios que fueron apareciendo propiciaron situaciones y conceptos inmediatos y espontáneos que más tarde serían utilizados por los bailarines:

- $1^{\mathrm{a}}$ escena: 'La Era' ( $\left.7^{\prime} 15^{\prime \prime}-9^{\prime} 05^{\prime \prime}\right)$. En esta escena los bailarines recrean la recogida y avienta del trigo. La reflexión hombrenaturaleza.

- $2^{\text {a }}$ escena: 'Frutales' ( 9 ' $\left.05^{\prime \prime}-12^{\prime} 10^{\prime \prime}\right)$ : Aparecen unos largos palos de madera que sirven de apoyo a los ancianos para manejarse por los caminos. Alrededor de este elemento se reflexiona sobre el paisaje y la mirada hacia el interior del pueblo.

- $3^{\mathrm{a}}$ escena: 'El Camino' (12' 10" - 16' 02"). Reflexión acerca de la figura de la mujer en su historia más reciente. La bailarina recrea una anécdota que cuenta uno de los ancianos: las mujeres tenían que recorrer varios kilómetros, casi a oscuras y por sendas de campo cerrado, con una cesta en la cabeza para llevar a los maridos la comida a tiempo. 
- $4^{\mathrm{a}}$ escena: 'El Cerrao' (16' 02" - 21'): El bailarín se embulle en la densidad de un paraje natural. Se explora la carga psicológica y emotiva de la naturaleza en su estado más salvaje.

Después de oír los testimonios de los ancianos y trazar los conceptos que definirían la parte artística con la autora del video, el orden de actuación que definió la naturaleza de las etapas creativas del sonido fue el siguiente:

- Las ubicaciones en las que se rodaron las escenas condicionaron directamente el planteamiento sonoro original: grabación de muestras, ruidos, fondos y planificación de ambientes.

- Después, las coreografías improvisadas y las performances de los bailarines en cada ubicación fueron perfilando la naturaleza del montaje visual y sonoro: en este punto mi labor como compositor fue la de reflexionar acerca de los materiales sonoros recolectados, y la observación de las performances y el comportamiento del baile.

- En una última fase, el montaje de video, la edición de las imágenes y la exacta duración final del proyecto definieron los detalles que condicionarían el resultado sonoro final: en esta etapa, y después de recibir el proyecto visual quasi-acabado, se configuró todo el diseño sonoro: la composición musical y la edición de materiales electroacústicos a partir de la muestras recolectadas en campo (ruidos, fondos, ambientes, realces específicos, etc.).

Después de concluir todas estas etapas y terminar el proyecto sonoro final se hicieron varios visionados generales con la autora del video, los 
montadores y los bailarines para perfilar pequeños detalles que podían beneficiar al resultado final, tanto en el plano del montaje visual como en el sonoro.

\subsubsection{GRABACIÓN Y EDICIÓN DE MUESTRAS}

El equipo que se utilizó para la grabación tanto de los testimonios de los ancianos como para la recolecta de muestras sonoras en campo fue:

- 1 PowerBook $\mathrm{G}_{4}$ de Macintosh, con el sistema operativo Tiger 10.4.11, con un procesador de $1.67 \mathrm{GHz}$ PowerPC con 2 GB DDR SDRAM.

- 1 Tarjeta de Audio externa Firewire MOTU Traveller.

- 2 micros Sennheisser con Preamplificador K6, con cápsulas ME66.

- Auriculares de estudio Cerrados ${ }^{38}$ Audio-technica ATH-M4ofs.

- Un par de pies de micro y cableado.

Uno de los elementos sonoros principales que se definieron desde el principio y que planteó la mayor parte del trabajo fue el sonido ambiental de los paisajes (viento, agua, animales, insectos, ...) y los ruidos que generaban los bailarines en los distintos enclaves (pisadas, saltos, giros, respiraciones, choque de palos, etc.). Cada ubicación y

\footnotetext{
${ }^{38}$ A diferencia de los Supraaurales, que están apoyados sobre el pabellón auditivo, los Circumaurales Cerrados rodean completamente la oreja y permiten el aislamiento auditivo más o menos completo del sujeto que escucha y, asimismo, impiden que el sonido reproducido salga al exterior, por eso sus aplicaciones suelen estar más dedicadas al campo profesional, como monitorización de estudio o mezcla (Wikipedia, 2010c).
} 
escena presentaba unas necesidades especiales. A continuación se analizarán cada una de las situaciones que se dieron en la captura de ruidos y ambientes.

\subsubsection{ELEMENTOS AMBIENTALES}

Desde el principio del rodaje se decidió que toda la parte de audio, ya tuviera diseño sonoro electrónico, música instrumental o ruido ambiente, sería producida en el estudio con bibliotecas de sonidos recolectados durante la estancia en Gavín. Es por esto que el rodaje de video y el proyecto de sonido ocurrieron de manera paralela, cumpliendo las necesidades específicas de cada uno de ellos. Los elementos que conformaron la galería principal para el montaje de sonido ambiental fueron: Aire, Pasos, y Respiraciones.

Aire - Este elemento fue uno de los grandes retos del proyecto. Las distintas localizaciones y los ruidos ambientales (Fig. 161) requieren de una estrategia bien definida para conseguir unas texturas de aire o viento idóneas. Se localizaron enclaves diferentes para captar distintos tipos de aires de manera controlada (frecuencias más agudas, más graves, más violentos, más suaves, con más o menos sonido de aves, insectos, etc.).
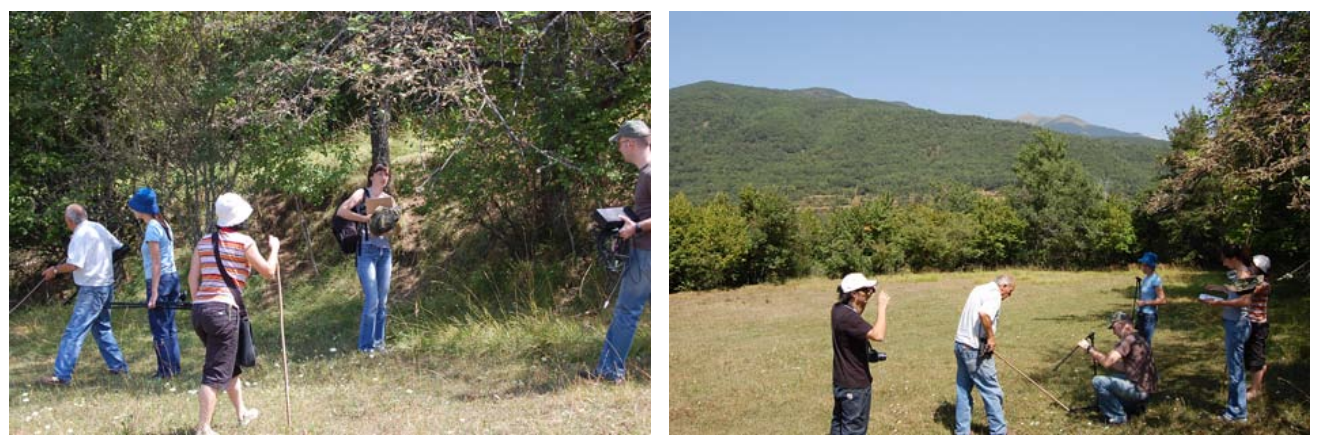

Fig. 161 Sesión de grabación 
Pasos - Como performance semi-improvisada, en la que los bailarines intercambiaban comentarios e instrucciones, para la coordinación de los pases de baile, sobre la marcha, se hacía imposible grabar el sonido ambiente al natural. Otros elementos como, público eventual en los rodajes, o aviones sobrevolando la escena, supusieron que todo este material sonoro se grabara en condiciones distintas al momento de la performance. Para ello se tomaron notas de los movimientos que realizaban los bailarines y se reprodujeron en un espacio más controlado con el mismo tipo de suelo y el mismo tipo de calzado, para su uso posterior en el montaje en el estudio (Fig. 162).
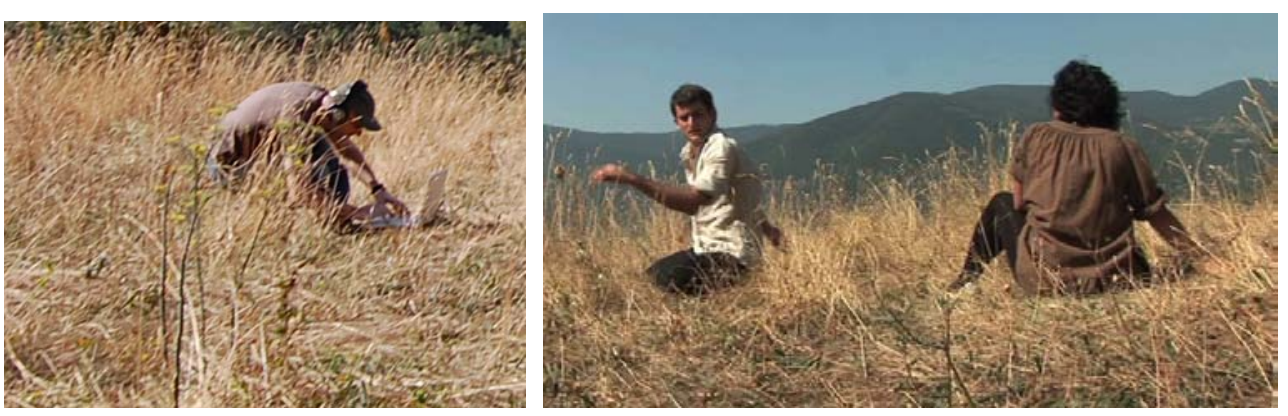

Fig. 162 Grabación en 'la era'

Respiraciones - En las cuatro partes de la performance bailada existía en el planteamiento original de la autora del video, una intención clara de resaltar el sonido de las respiraciones de los bailarines. Como en el apartado anterior, y por cuestiones de limpieza y concreción en las muestras de sonido, se grabaron varios clips cortos conformando una biblioteca con diferentes matices y categorías para las respiraciones de los dos bailarines (Fig. 163). 


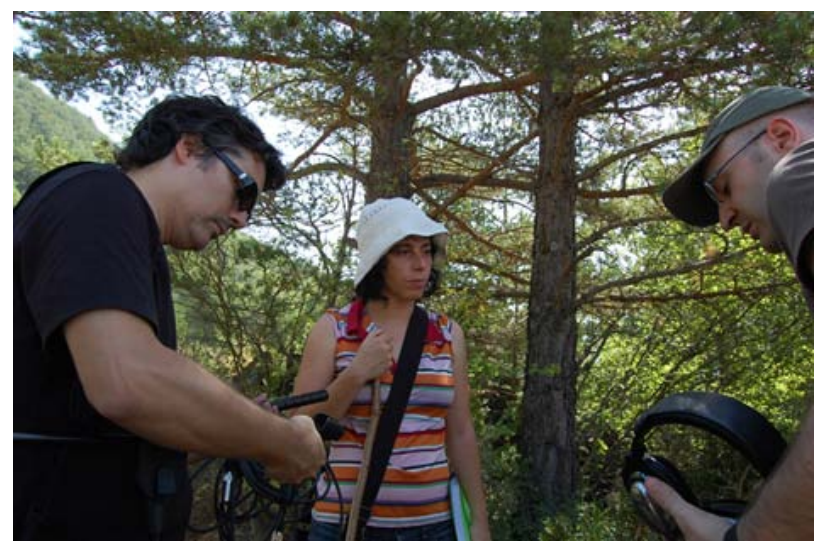

Fig. 163 Grabación de sonidos de respiraciones

\subsubsection{OBJETOS TÍPICOS}

Palos - En la segunda escena, 'Los frutales', la coreografía se basa en el uso de unos palos típicos de la zona (Fig. 164). Igualmente se grabó una galería específica basada en golpes de palos, choques, arrastres y ruidos provocados por estos en la performance.
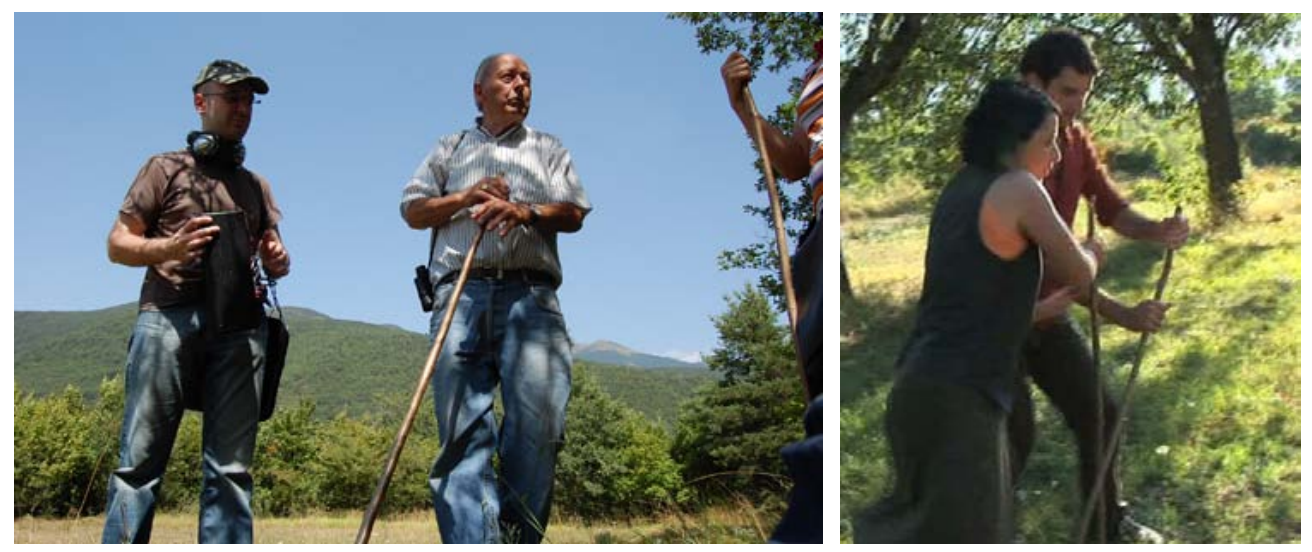

Fig. 164 Grabación de sonidos de palos

Cencerros - Uno de los elementos que sirvieron para la posterior edición y composición de la parte electroacústica fueron una familia de cencerros que tenían unos vecinos del pueblo en su casa de campo (Fig. 165). 

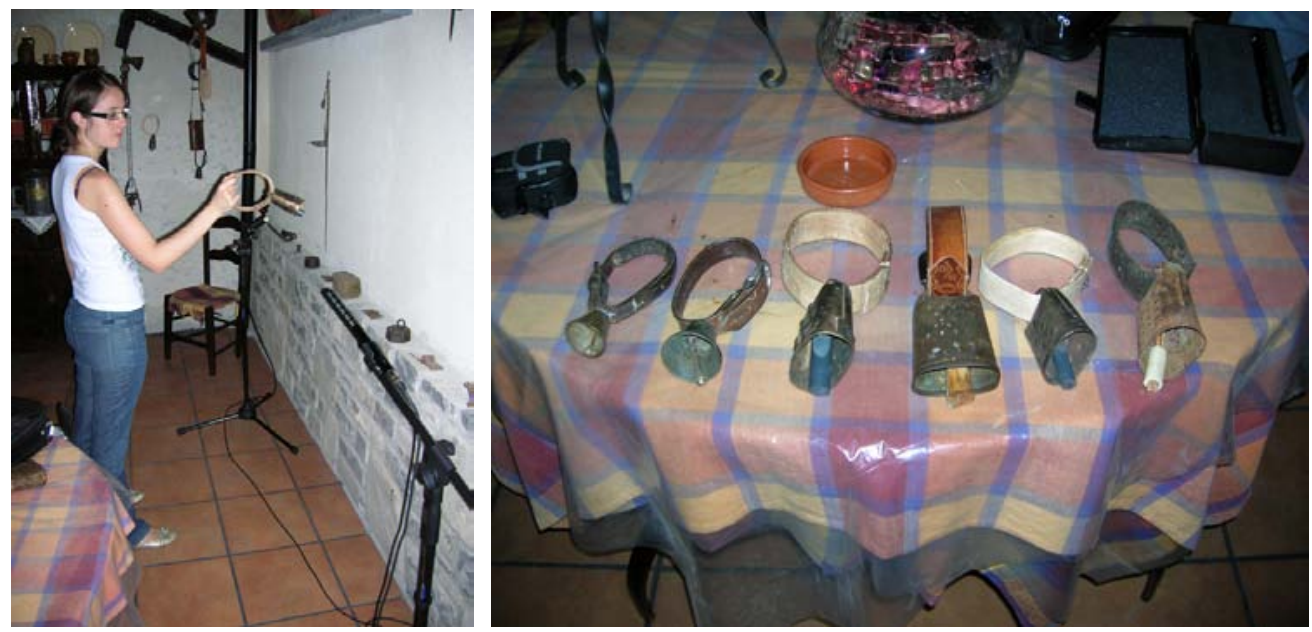

Fig. 165 Grabación de cencerros

\subsubsection{PARTE INSTRUMENTAL}

Después de consensuar la cantidad y tipología de instrumentos y timbres acústicos que necesitaba la autora del video en su visión del video, se eligieron dos identidades sonoras fundamentales. Estos dos instrumentos acústicos que componen el diseño sonoro específico para la parte musical son: Voz blanca (niño) y Violoncello. La voz blanca confiere a la imagen una dimensión extendida a las respiraciones de los bailarines y el violoncello colorea las imágenes y el ambiente rural y añejo de los paisajes del pirineo aragonés.

Violoncello - Se compusieron dos fragmentos de temática diferente, uno más lírico utilizando el empleo de arco típico y otro más rítmico utilizando el recurso del pizzicato y el llamado col legno (término italiano que indica el golpeo con la madera del arco sobre las cuerdas) (Fig. 166 Fragmento para Violoncello). Este instrumento aparece en la $2^{a}$ y $3^{a}$ escena. 


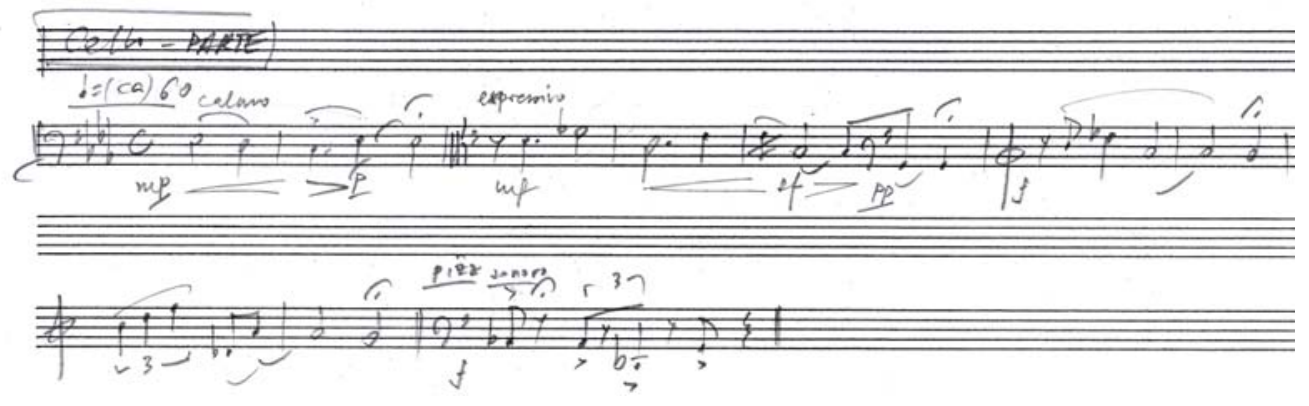

Fig. 166 Fragmento para Violoncello

Voz - Dos pequeñas células motívicas forman la frases melódicas que aparece en las escenas $1^{a}, 3^{a}$ y $4^{a}$. Los giros interválicos están inspirados en la obra Rothko Chapel del compositor norteamericano Morton Feldman (Fig. 167 Fragmento para voz blanca).

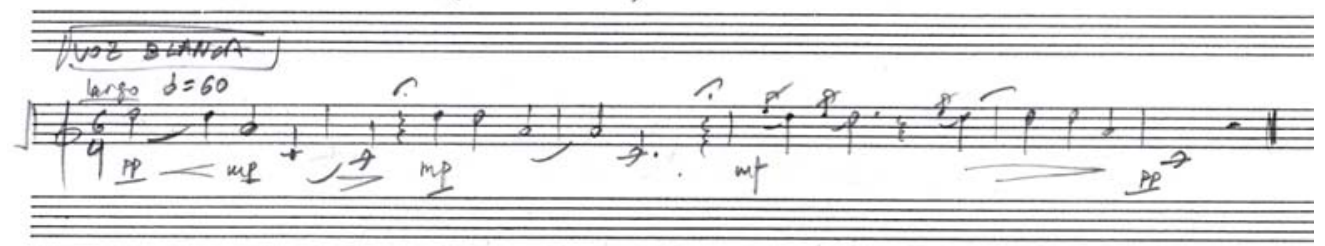

Fig. 167 Fragmento para voz blanca

\subsubsection{PARTE ELECTRÓNICA}

Los tres fragmentos construidos en lenguaje puramente electroacústico aparecen en las escenas $2^{a}$ y $3^{a}$, y $4^{a}$ respectivamente. Ambos son texturas sostenidas y alargadas en el tiempo (con resultados e intenciones distintas) que se han procesado mediante síntesis granular (ver Apartado 3.2.2.2).

- El primero sostiene en su totalidad el discurso sonoro de la $2^{a}$ escena, en la que el video muestra una escena que recrea una de las anécdotas contadas en la parte de los testimonios acerca de la figura de la mujer. La idea del sonido partió de los elementos que se cuentan en dicha anécdota: la mujer recorre 
durante horas un sendero llevando en la cabeza una cesta con la comida, platos, vasos y cubiertos. A partir de esta idea se utilizaron sonidos grabados de utensilios de labranza, adornos metálicos y elementos de cocina (Fig. 168), y se procesaron en Max MSP mediante el patch Granular 2.5 de N. Sakonda (ver Apartado 3.2.2.2), obteniendo patrones cíclicos y ritmos erráticos a partir de micro estructuras tímbricas de timbre metálico.
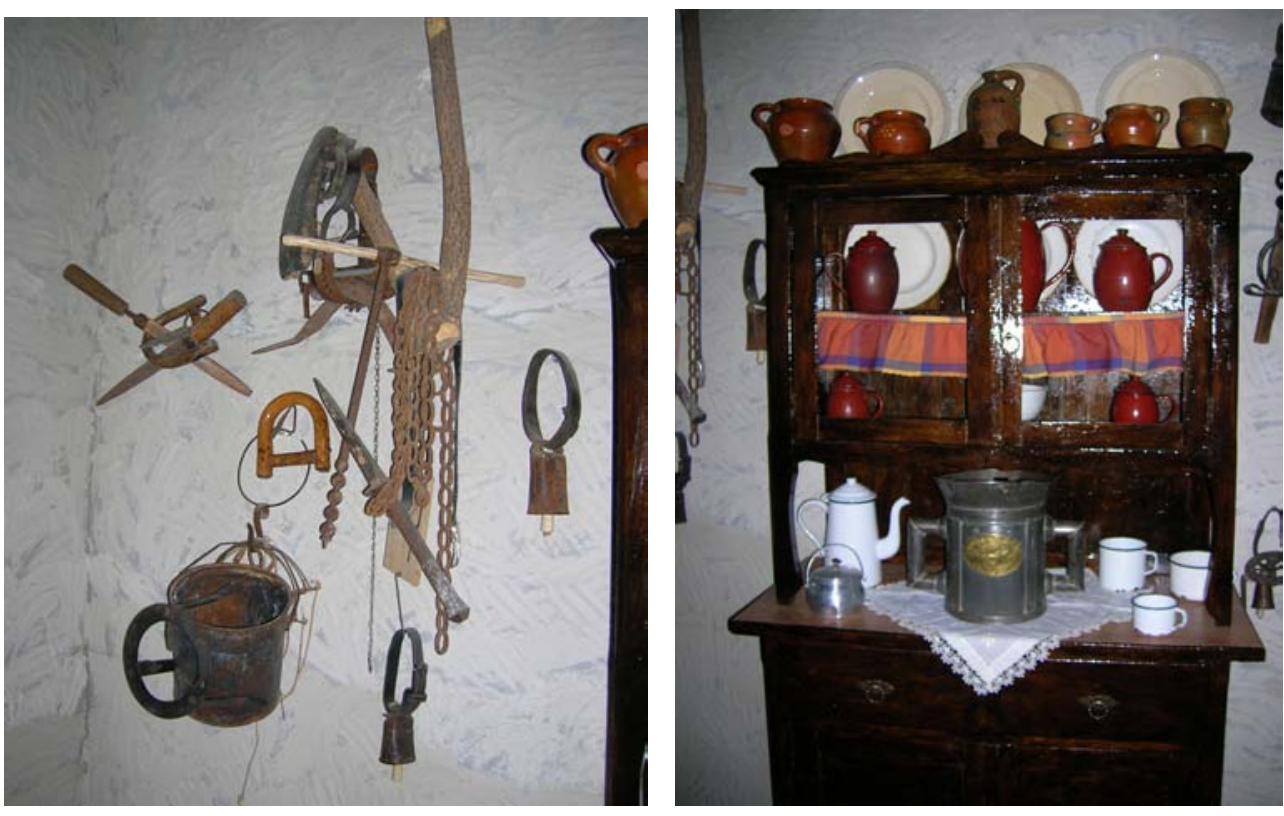

Fig. 168 Utensilios de labranza y cocina típicos de Gavín

Este resultado sonoro se acompaña con dos elementos ambientales intencionadamente resaltados: respiraciones cíclicas de la bailarina que aparece en escena, y ruidos de pisadas y pasos en un camino irregular con ramas secas, gravilla y pequeñas piedras (Fig. 169). Estos tres elementos conforman un obstinato rítmico y textural que confiere a la imagen un sentido dramático coherente, tal y como se proponía el significado de esta escena a partir de la anécdota contada por los ancianos. 

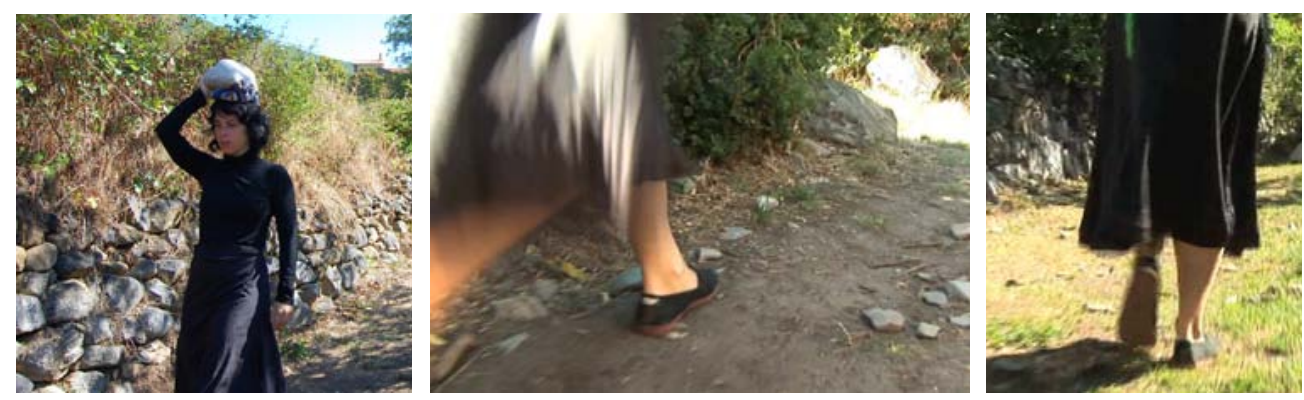

Fig. 169 Capturas de 'El Camino'

El enlace de esta $2^{\text {a }}$ escena con la siguiente, 'Frutales', se produce gradualmente haciendo desaparecer el material descrito anteriormente con los nuevos elementos que acompañarán toda la $3^{a}$ escena.

- El segundo fragmento electroacústico se introduce mediante una textura creada a partir de muestras de sonido grabadas en entornos naturales de Gavín. Al igual que el primer fragmento el material se procesó mediante el empleo de síntesis granular. En este caso los sonidos procesados van solapados con ruido ambiente natural, de modo que la electroacústica se establece de manera natural y como un fondo sonoro, y no manifiesta ningún carácter dramático concreto. De este modo el material sonoro interpretado por el violoncello y el diseño de ruidos (respiraciones, pisadas y palos) mantienen un papel protagonista.

- El último fragmento, compuesto íntegramente mediante lenguaje electroacústico, se corresponde a la escena rodada en 'El Cerrao'. En este caso las muestras que han sido procesadas para conseguir el timbre y la textura que acompañan estas imágenes, con un importante componente de carga dramática, se extrajeron de muestras grabadas de los cencerros que se han 
descrito en el capítulo 4.2.2. Se exploraron sonidos sostenidos en el tiempo con alturas definidas y sutiles oscilaciones. Esta escena también tiene sonidos ambientales realzados, y en este caso especialmente, ya que las imágenes que aparecen en el video tienen un componente plástico importante: agua, barro, hojas y contrastes fuertes de luz (Fig. 170).
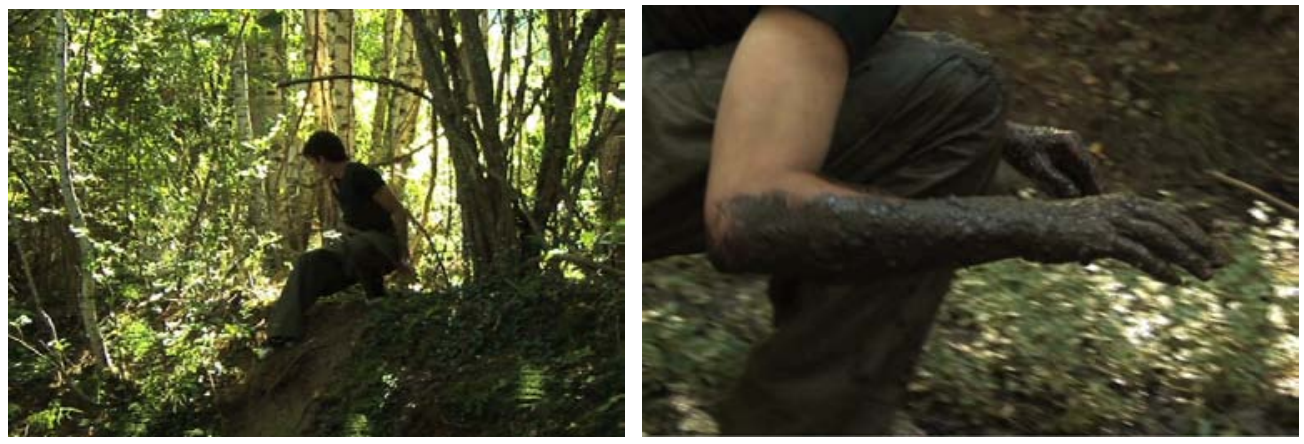

Fig. 170 Capturas de 'El Cerrao'

\subsubsection{SECUENCIACIÓN}

Todo el proyecto se secuenció y editó en el programa Logic (Apple, 2010b) (ver Apartado 5.2.4). Para los efectos de espacialización, densidad y sensación dimensional de las muestras instrumentales y electrónicas se utilizaron varios plug-ins $\mathrm{AU}^{39}$ : Space designer de Apple (Apple, 2010c) y L3UltraMaximizer de la librería Waves (Waves, 2010) (Fig. 171).

\footnotetext{
39 Unidades de Audio (AU, Audio Units). Son complementos proporcionados por Core Audio (interfaz de programación de aplicaciones desarrollada por Apple Inc) para Mac OS X, que funcionan como herramientas específicas con una interfaz gráfica, pensadas para generar, procesar, recibir, o manipular los flujos de audio en casi en tiempo real con una latencia mínima (Wikipedia, 2010b).
} 

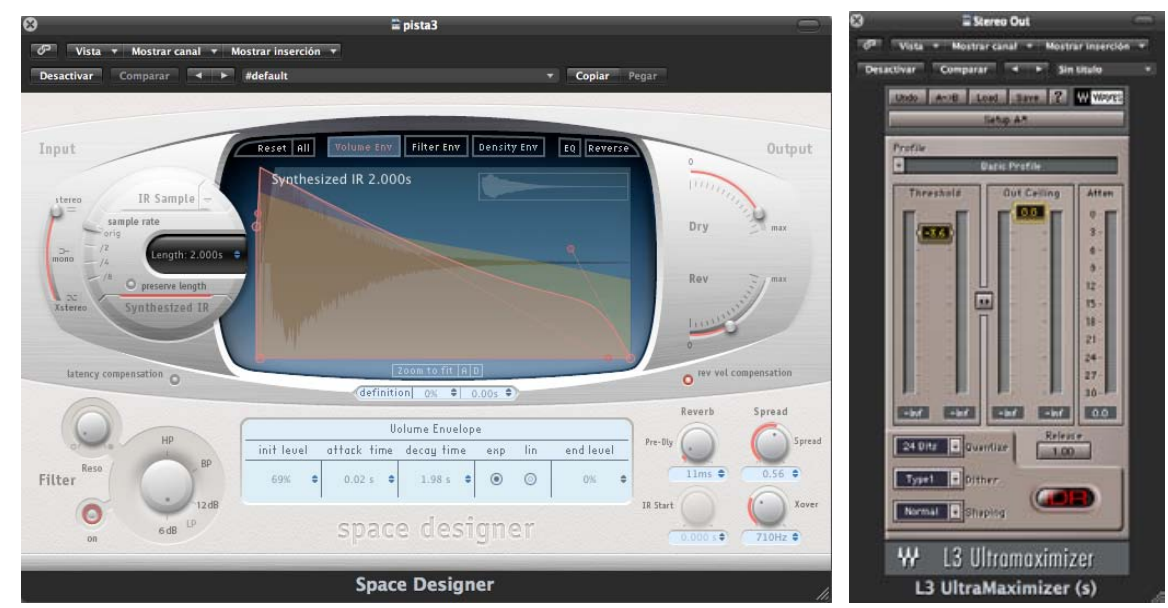

Fig. 171 Modulos AU utilizados, Space designer, en (Apple, 2010C) y L3UltraMaximizer, en (Waves, 2010)

Además de estos módulos de edición y procesado de señal, se utilizaron los mismos procesos de ecualización y compresión que se describen en el ensayo 'Espectromorfología y el gesto visual'.

A continuación podemos ver un diagrama temporal con los elementos sonoros que se han utilizado en las diferentes partes del video (Fig. 172).

$21^{\prime}$

\begin{tabular}{|l|l|l|l|l|}
\hline Video & \\
\hline Diseño sonoro-ambiente & \\
\hline Voz & \\
\hline Violoncello \\
\hline Electroacústica
\end{tabular}

Fig. 172 Materiales sonoros en Porque la perdí 


\subsection{CONSIDERACIONES}

El proceso creativo y la metodología que se han descrito en este ensayo han propiciado una experiencia de creación artística musical muy concreta. El hecho de asistir al rodaje de la performance y la danza, formar parte de la creación espontánea in situ, capturar las muestras de sonido en el lugar exacto y bajo condiciones controladas, y disponer de los elementos acústicos ambientales utilizados en el montaje del video permite elaborar un contenido sonoro mucho más fiel y coherente a la planificación e intenciones originales de la creadora del video.

A partir de esta sincronía metodológica, la gestualidad sonora que se obtiene a partir de estos planteamientos, garantiza un discurso sonoro muy concreto y cuyo germen se encuentra en la propia factura de la obra. 


\section{ESPECTROMORFOLOGÍA Y EL GESTO VISUAL}

El siguiente ensayo describe un proyecto de colaboración con la artista valenciana Mamen Marcos y el mejicano Carlos Barragán para el cual se me encargó producir y realizar una Banda Sonora Original para el video-documental 'Manos que dan forma' sobre artistas y artesanos valencianos y mejicanos. Para esta ocasión se planteó la posibilidad de utilizar lenguajes propios de la música electroacústica y se trazaron objetivos concretos en la exploración de la expresión sonora sobre el comportamiento del sonido y su descripción espectromorfológica para concretar los significados de las texturas y de los recursos que se utilizarán durante la creación de materiales electroacústicos.

\section{MOTIVACION}

El lenguaje electroacústico en el campo del video-documental no tiene un amplio recorrido, dado que principalmente su origen es totalmente abstracto (Larson, 1985). Aunque bien es cierto que toda textura sonora tiene una asociación visual o plástica, no es el objetivo del 
compositor electroacústico jugar con este orden de asociación. Al contrario, los parámetros formales en la construcción de composiciones electroacústicas o acusmáticas se corresponden frecuentemente a herencias constructivas de lenguajes musicales anteriores al siglo XX. La archiconocida forma sonata (de estructura temática A-B-A') ha sido el referente por excelencia en el análisis de obras artísticas de muy diverso pelaje.

En los últimos años existe una tendencia en los creadores sonoros (compositores que trabajan con el lenguaje electroacústico o la estética acusmática) de ampliar el objeto de su expresión artística al campo visual, utilizando herramientas que en origen y forma están diseñadas a partir de utilidades propias del sonido. La aplicación más común tanto para creación, edición y manipulación en vivo es Jitter, y forma parte del paquete Max MSP (Puckette y Zicarelli, 1990) que sirve como plataforma de programación para compositores, creadores y artistas sonoros.

Para establecer una correspondencia entre imagen y gesto sonoro habrá que sentar antes unos patrones de coherencia conceptual en referencia al comportamiento del sonido y de las figuras que puedan generar en nuestra imaginación. Para ello tendremos que hablar de espectromorfología o comportamiento del sonido desde la perspectiva de sus componentes tímbricos y acústicos (Smalley, 1997). A veces existe una inercia de ensayo-error y un patrón de comportamiento basado en la intuición durante el proceso creativo del compositor electroacústico y en la mayoría de los casos no se plantea una hoja de ruta en la intención del resultado psicológico de la obra. 
Para la realización de este trabajo fue imprescindible contar con un planteamiento de partida riguroso y metódico en conceptos como percepción psicológica del sonido y descripción del comportamiento sonoro en un contexto electroacústico.

La realización del video-documental 'Manos que dan forma' tuvo dos fases. La primera sobre una duración de 1 hora y 40 minutos. La segunda una versión más corta para pases televisivos y presentación a certámenes y concursos de 53 minutos. En los siguientes apartados de detallará la realización de dicho material y las necesidades que han ido presentando cada una de sus partes.

\subsection{PLANTEAMIENTO}

'Manos que dan forma' es un video-documental que se rodó y editó durante los años 2008 al 2009, a caballo entre Méjico y España y con soporte económico del Ministerio de Cultura, Ministerio de Educación y Ciencia, la Universidad Politécnica de Valencia a través del vicerrectorado de Cultura y el vicerrectorado de Investigación, Desarrollo e Innovación. El objetivo de este proyecto fue la grabación de testimonios de artesanos que estaban en contacto con la materia plástica a través de las manos. Se recogieron testimonios de hasta 50 artistas relacionados con la creación y artesanía tradicional o experimental. Materiales tan diferentes como la médula, el barro, el hierro, acero, piedra, hilos, cuero, etc., planteaban un reto muy interesante en lo referente a la correspondencia entre imagen-textura visual y asociación psicológica de materiales sonoros y gestos propios del lenguaje electroacústico y acusmático, o de objetos concretos. 
En este sentido se ha realizado un análisis del comportamiento acústico y las correspondencias gestuales y visuales según la espectromorfología heredera del compositor e investigador Dennis Smalley (Smalley, 1997).

El video cuenta con 3 intermedios independientes al hilo conductor: una panorámica de las fiestas tradicionales valencianas, otra panorámica mejicana y un episodio sobre la expresión vocal del performer y poeta visual Bartolomé Ferrando (Valencia, 1951). En estos episodios no hay diseño sonoro, sólo contienen las pistas de sonido ambiente grabadas durante el rodaje en campo.

Para la realización de gran parte del material acústico conté con la colaboración de Ximo Lambíes, percusionista y profesor del Conservatori Municipal Ciutat de Moncada (Valencia) con el que pude probar y explorar las posibilidades acústicas de la familia de la percusión y en especial la búsqueda de elementos y texturas concretas a partir de instrumentos étnicos y de pequeña percusión.

\subsubsection{MARCO EN EL QUE SE INSCRIBE EL ENSAYO}

Siguiendo las descripciones que se han hecho en el mapa de conceptos (ver Apartado 0.5) se puede presentar un marco general de este ensayo:

- Sensores: No se requiere.

- Electrónica en Vivo: No se requiere.

- Tiempo real: No se requiere.

- Obra abierta/cerrada: Obra cerrada. 
- Intérprete: No se requiere en el resultado final, aunque para la grabación de muestras se utilizó un percusionista y un pianista.

- Performance: No se requiere.

- Instrumentos acústicos: No se requiere, aunque para la grabación de muestras se utilizaron un piano e instrumentos de étnicos y de percusión.

- Improvisación: No se requiere.

- Entorno o medio de reproducción: Reproducción en soporte digital de video.

- Procesamiento digital imagen/sonido: Sonido y edición de imagen.

- Software: Para el procesamiento de sonido se ha utilizado Logic (Apple, 2010b), Max MSP (Cycling74, 2010), Csound (Csound, 2010a), Absynth (NI, 2010).

\subsubsection{MARCO TEÓRICO}

A continuación desarrollaremos los tres grandes pilares sobre los que se sostiene este ensayo: la Espectromorfología como Metodología aplicada a la definición y creación del comportamiento sonoro (Apartado 5.1.2.1); los Modos de Audición (Apartado 5.1.2.2) y los Comportamientos de la Percepción (Apartado 5.1.2.3) en el lenguaje electroacústico.

\subsubsection{METODOLOGÍA ESPECTROMORFOLÓGICA}

El primer hilo conductor de este ensayo ha sido la investigación sobre el lenguaje espectromorfológico y la categorización de términos 
asociados al comportamiento sonoro de las muestras grabadas, editadas y remezcladas en estudio para la creación de la música para el video 'Manos que dan forma'. El concepto de Espectromorfología (Smalley, 1997), proporciona al oyente del lenguaje electroacústico un abanico de términos y un vocabulario accesible para describir, comprender y ordenar los diferentes eventos sonoros, estructuras y espacios de este lenguaje. Como podemos ver en (Landy, 2007; Patton, 2007; Thoresen, 2007), esta definición permite crear criterios de coherencia sonora entre la materia visual y los componentes acústicos.

La contribución de la espectromorfología al campo del análisis musical es el de superar el desafío que impone la música electroacústica: crear conceptos sin la mediación del registro escrito, teniendo como punto de salida y de llegada, la escucha.

La propuesta de Smalley debe ser contextualizada dentro de una genealogía conceptual que no le es ajena. De esta forma, se podría observar en la espectromorfología, una manera de profundizar y complementar los conceptos que Pierre Schaeffer denomina 'Tema y Versión' (Schaeffer, 1966), o su par complementario acuñado por Michel Chion: 'Hacer y Entender' (Chion, 1983).

Es fundamental la asociación de estos conceptos. Por un lado, creo importante encontrar los vínculos de un desarrollo teórico-conceptual que comenzó con Schaeffer y continúa con Chion y Smalley, entre otros. Por otro lado, la complementariedad de estos puntos de vista ayuda a desenvolver un dispositivo analítico, que sirve de subsidios tanto para las narrativas teóricas cuanto para la creación de nuevas sintaxis composicionales. 
La propuesta de Smalley posibilita aprender a escuchar la energía interna del sonido, entendiendo que aprender a escuchar implica el comportamiento del sonido en el tiempo y dentro de su estructura como elemento discursivo (Chion, 1983).

Pensando la definición de espectromorfología como la interacción entre el espectro sonoro (espectro-) y la manera como él cambia y evoluciona en el tiempo (-morfología) (Smalley, 1997), no es posible aislar este concepto de una tradición teórica que se inicia con Schaeffer. El concepto de factura de Pierre Schaeffer es definido como la forma en que la energía se comunica y se mantiene en la duración (Schaeffer, 1966). También en la definición de criterio de forma encontramos la siguiente definición que se acerca mucho a la propuesta de Smalley:

'El proceso energético: es el mantenimiento, donde aparece la forma en que el sonido se perpetúa en la duración. Si es efímero, se trata de un impulso; si se prolonga de manera continua, se trata de un sonido sustentado; si se prolonga por repetición de impulsiones, se trata de un tercer tipo de ocupación de duración...' (Schaeffer, 1966).

Creo que es importante pensar que en estas propuestas se abre un campo desde lo analítico que, sin dejar de lado toda una tradición conceptual, posibilita reflexionar, interpretar y fundamentalmente crear conceptos, sustentados en y desde la percepción.

Desde el corpus de la espectromorfología es posible por tanto pensar también en una sintaxis composicional, porque aunque la espectromorfología no es una teoría de composición, puede influir en los métodos de composición desde que el compositor tenga un 
dominio de los conceptos como para describir y diagnosticar el fenómeno sonoro (Smalley, 1986).

En la edificación teórica desarrollada por Denis Smalley a lo largo de 20 años, se encuentran herramientas analíticas que permiten potenciar la capacidad de entender el binomio percepción-recepción del fenómeno sonoro, tanto en el contexto de escucha de la música electroacústica como en cualquier otro. Estableciendo un puente que va de la morfo-tipología de Schaeffer a la espectromorfología de Smalley, es posible continuar desarrollando nuevas ideas en un camino fundado en las bases de la percepción y la escucha.

Ampliar la discusión para una mejor apreciación de la experiencia de la escucha musical y profundizar el conocimiento basado en la percepción las características espectro-morfológicas del sonido (timbre, masa, grano, ataque, tético, continuación, terminación, movimiento textural, comportamiento espectral, perfil espectral, nota/ruido, etc) es imprescindible para desarrollar una escucha alfabetizada en lenguajes perceptivos y receptivos (Caesar, 2006). De esa forma se podrá iniciar un nuevo camino para entender el concepto de 'micro-escucha' propuesto por Silvio Ferraz, que establece un proceso de escucha que procura trascender del objeto hacia la sensación: no oir el sonido, sino aquello que no está en el sonido, que está en el oír, aquello que está en la escucha, que está en el operar cortes, (para explorar) nuevos territorios (Ferraz, 2005). De esta forma, el conocimiento partirá de las bases de la percepción para legitimar la música desde un saber musical, descubrir lo que antes estaba velado y escuchar de manera diferente lo que ya se escuchaba.

Los términos tradicionales que han servido para describir la música occidental resultan frecuentemente inadecuados para este contexto 
desde que este lenguaje prescinde de una representación basada en figuras de altura y duración (Aguilar, 2006).

Esta propuesta de análisis de términos y conceptos a veces pasa desapercibida por creadores y compositores que, inconscientemente hacen un uso intuitivo del comportamiento que se deriva del sonido.

Por este cambio en la práctica musical convencional, la espectromorfología puede ser abordada desde un ángulo alternativo que considera el vocabulario como el informante de la elección y creación del material sonoro. Desde esta perspectiva, el vocabulario ya no funciona de forma descriptiva, sino que precede a la composición, la dirección de la trayectoria de la composición se marca desde la planificación inicial de una pieza. Esta nueva aplicación es un intento de sistematización y un esfuerzo para subsanar la elección, aparentemente infinita, de posibilidades a las que nos enfrentamos al comenzar un nuevo trabajo (Kendall, 2009).

A partir de este análisis se propone una herramienta para facilitar la planificación y realización de proyectos de esta índole. La composición del vocabulario tiene margen suficiente para llegar a convertirse en una herramienta pedagógica. El uso de conjuntos de palabras y combinaciones como puntos de partida para la creación de materiales coherentes en el comportamiento sonoro es un ejemplo de cómo esta metodología puede ser empleada en un marco educativo. La clasificación de los sonidos como metadatos queda definida como una manera espectromorfológica de trabajar. Este vocabulario, por tanto, propone desarrollar este enfoque, que iniciaron Ricard y Herrera (Ricard y Herrera, 2004), utilizando la tipo-morfología de Pierre Schaeffer, para el etiquetado y almacenado de un sonido. No ha habido una investigación más allá de este planteamiento. El uso de 
etiquetas espectromorfológicas permitirá, dentro de un sistema de pensado para el sonido, desarrollar una serie de enfoques para el compositor de música electroacústica y facilitará la creación de nuevos materiales y nuevos sonidos para el montaje de estrategias.

A continuación se describirán la pautas y principios por las que se ha regido el ordenamiento lingüístico y la categorización de términos. Se analizarán los criterios que han permitido esta ordenación conceptual y se establecerán las correspondencias de significado con las imágenes del video-documental.

\subsection{ESTRUCTURACIÓN DE TÉRMINOS}

Desde el desarrollo de la espectromorfología como un instrumento descriptivo, basado en la percepción auditiva (Smalley, 1997), sus aplicaciones hasta ahora solamente han permanecido en contextos de análisis (Thoresen, 2007), representación visual y funciones de notación (Patton, 2007). En este ensayo se plantea una aplicación alternativa de la espectromorfología, usando su vocabulario descriptivo para informar sobre los aspectos del proceso de composición en música electroacústica, pensada en este caso para complementar una imagen plástica. La investigación se ha centrado principalmente en la creación de material abstracto de sonido en este proyecto visual y su catalogación con etiquetas espectromorfológicas.

\subsection{METODOLOGÍA}

Las estrategias compositivas utilizadas en este ensayo se plantean como parámetros de ayuda en lugar de soluciones técnicas o procesos algorítmicos, presentan puntos de partida para el desarrollo de materiales, eventos y estructuras. En cuanto a la confrontación de sonidos y su ensamblaje, formas visuales y simbología se empleará la 
subjetividad para ilustrar criterios coincidentes con los términos lingüísticos. Algunos diagramas están acompañados de capturas de imágenes tomadas del análisis espectral, donde 'tiempo' corresponde al eje horizontal y frecuencia al vertical. En estas visualizaciones, la forma corresponde a la amplitud y timbre, mientras que la posición relativa corresponderá con posición espectral.

\subsection{FUNCIONES ESTRUCTURALES}

En el primer diagrama (Fig. 173), se introducen tres estrategias composicionales tomadas del vocabulario estructural de funciones de Smalley.

\begin{tabular}{|c|c|c|}
\hline INICIOS & CONTINUACIÓN & CONCLUSIÓN \\
\hline Partida & Transcurso & Llegada \\
Surgencia & Transición & Desaparición \\
Anacrúsico & Prolongación & Terminar \\
Ataque & Mantenimiento & Soltar \\
Acéfalo & Estacionamiento & Resolución \\
Tético & & Deslizar \\
\hline
\end{tabular}

Fig. 173 Procesos estructurales, en (Smalley, 1997)

\subsection{ELECCIÓN DEL MATERIAL SONORO EN FUNCIÓN DE LA TERMINOLOGÍA}

Tomando la emergencia y el comportamiento del sonido en el tiempo, se estableció una criterio de elección: en función de estar más o menos presentes en el tiempo, y la progresiva aparición/desaparición de estos. Se establecieron dos categorías (Fig. 174). 


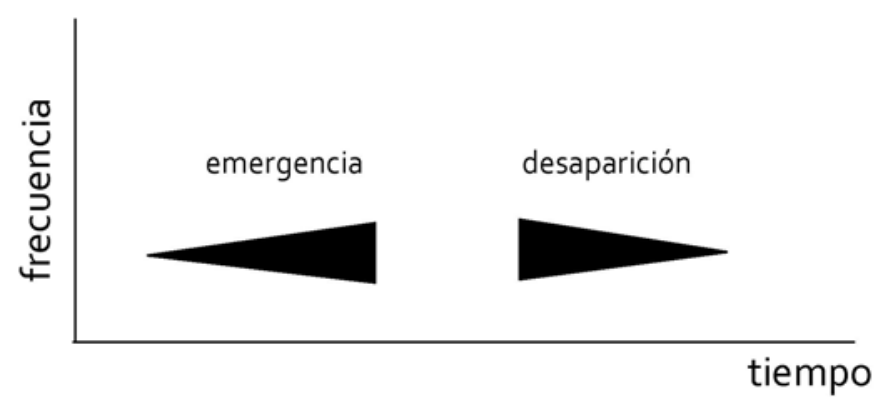

Fig. 174 Equivalencia visual de un objeto emergente y otro que desaparece, en (Blackburn, 2009)

\subsection{ELECCIÓN DEL MATERIAL SONORO EN FUNCIÓN DEL TRAZADO}

Como podemos ver en (Blackburn, 2009), la terminología puede también influir en el dibujo y la manipulación de un sonido simple. Eligiendo el ataque, el desarrollo y el receso, se puede dictar el trazado del sonido a través de la acentuación del comienzo más estricto, la extensión del desarrollo y el transcurso hasta el total receso de la tensión sonora.

\subsection{ELECCIÓN DEL MATERIAL SONORO A PARTIR DE}

\section{LA ESTRUCTURA}

Un tercer uso de este vocabulario está basado y condicionado por la creación de estructuras. Ataque, desarrollo y receso puede ser aplicado también a tres sonidos diferentes que forman una unidad y que dan lugar a una nueva figura llamada en este caso 'unidad sonora' (Fig. 175). 


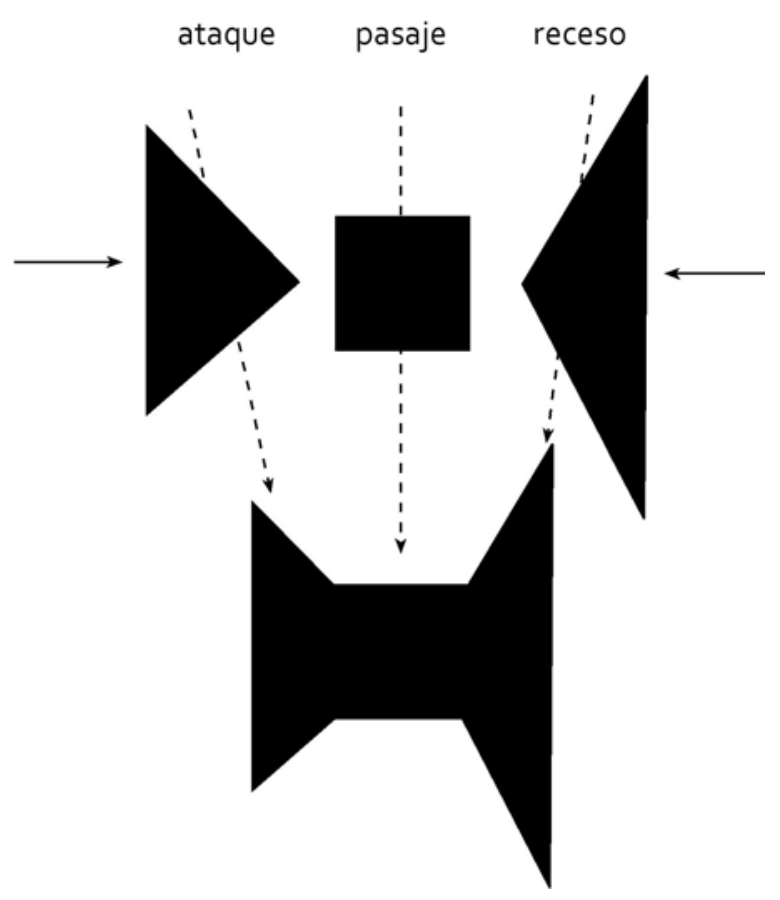

Fig. 175 Construcción de una Unidad sonora, en (Blackburn, 2009)

Esta unidad sonora puede verse ensanchada y ampliada dando lugar a frases más largas llamadas 'Cadenas Morfológicas' (Smalley, 1986). En este proceso de expansión algunos sonidos permiten funciones dobles. La siguiente figura muestra como el receso (c) actúa como una conclusión para la primera unidad sonora (1), y un ataque junto con un desarrollo puede generar una segunda unidad de ataque nueva (2). La conclusión de la segunda unidad (e)a su vez proporcionaría potencialmente un desarrollo y un receso para la tercera unidad, y así sucesivamente (Fig. 176). 


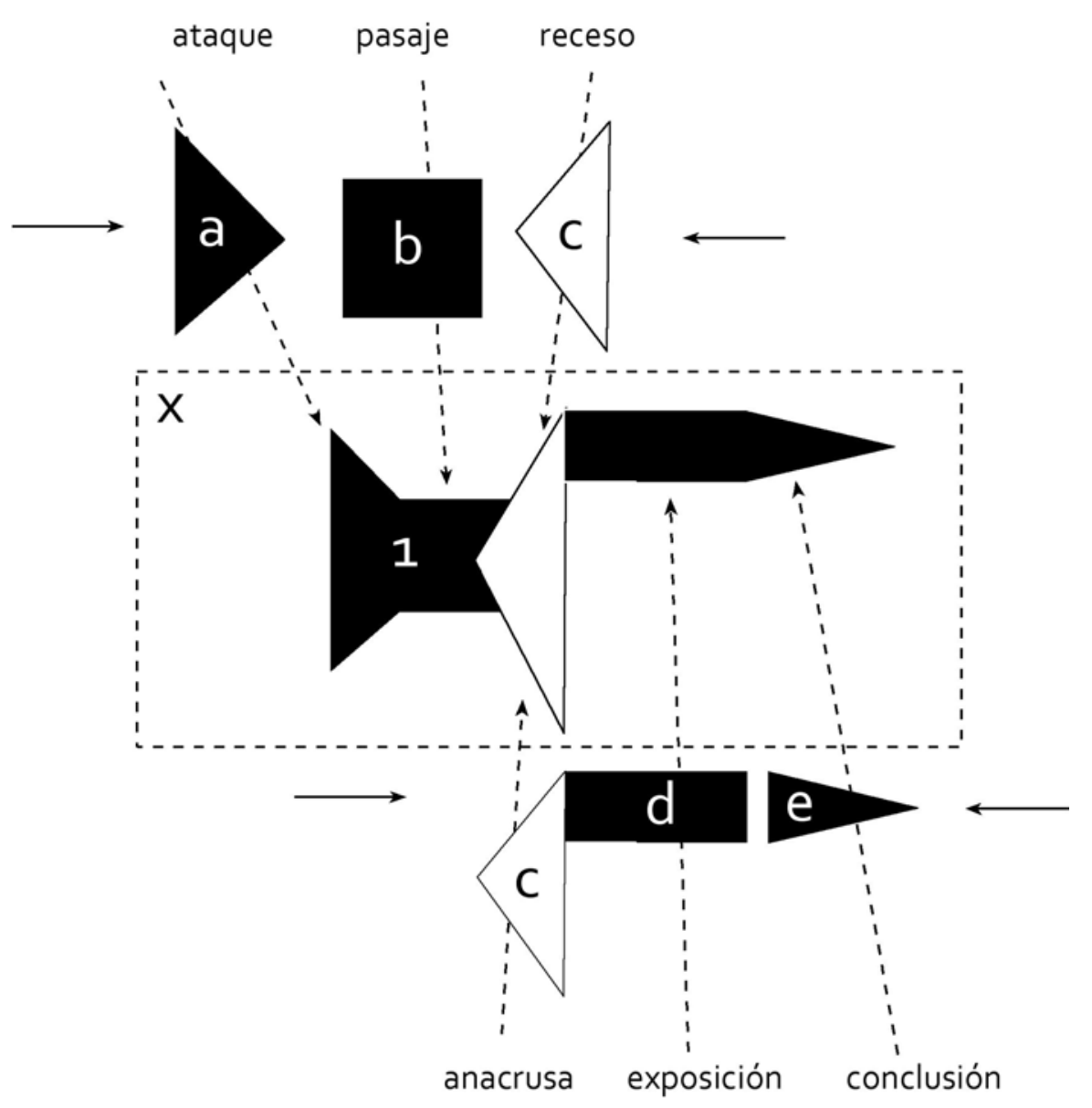

Fig. 176 Cadena Morfológica creada a partir de dos Unidades Sonoras y funcionalidades duales del sonido 'c', en (Blackburn, 2009)

\subsection{COMPONIENDO MOVIMIENTOS}

Otro conjunto de palabras propias de la espectromorfología han sido implementadas usando estrategias similares a las descritas anteriormente. Los movimientos y procesos de crecimiento descritos en las siguiente figura (Fig. 177), proporcionan una idea de la construcción del sonido y sus variaciones. 
UNIDIRECCIONAL $<\begin{aligned} & \text { ascendente } \\ & \text { plano } \\ & \text { descendente }\end{aligned}$

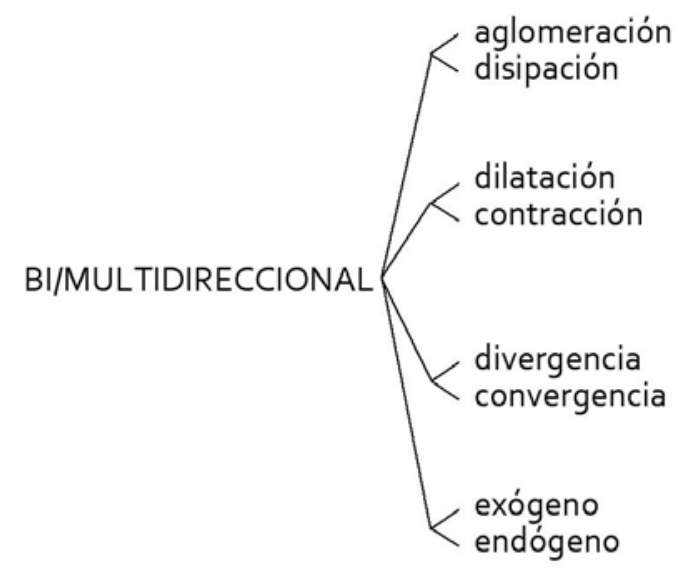

CICLICO/CÉNTRICO $\begin{aligned} & \text { rotación } \\ & \text { espiral } \\ & \text { giro } \\ & \text { vórtice } \\ & \text { pericentral } \\ & \text { movimiento centrífugo }\end{aligned}$

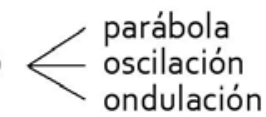

endógeno

Fig. 177 Movimiento y Procesos de evolución, en (Smalley, 1997)

Por ejemplo, los términos 'descendente', 'plano' y 'ascendente' están extraídos de sonidos individuales, mientras que el concepto de movimiento bi/multi-direccional nos proporciona información sobre distintos movimientos conjuntos (Fig.178). La diferencia entre estos dos ejemplos es significativa para la categorización de términos cuando tratamos de etiquetar grandes bases de datos de sonidos. Los términos que nos suministran información acerca de su estructura y comportamiento nos facilitarán el acceso y comprensión en el proceso compositivo (Harchanko, 2003). Si bien es cierto, estas etiquetas no son suficientes cuando se trata de conjuntos extensos y asociaciones tímbricas compuestas.
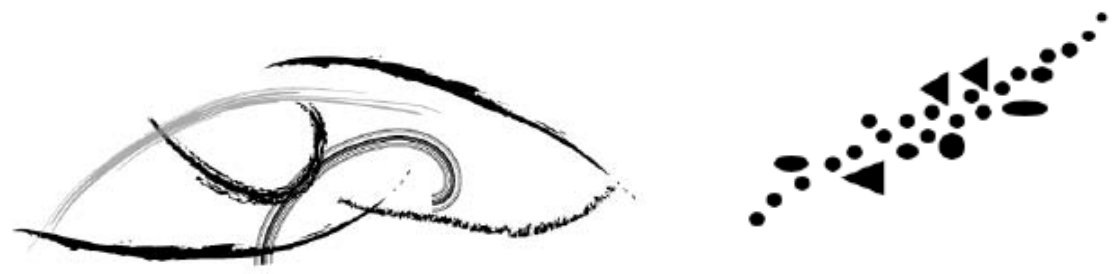

Fig.178 Mov. compuesto: Multi-direccional

Fig. 179 Textura compuesta: Masa 
Las palabras que dependen de materiales compuestos, y estos dependen a su vez de varios sonidos que conviven durante un tiempo determinado. Estas palabras a menudo derivan en el término 'texturas'; Por ejemplo, la palabra que sugiere que muchos sonidos se mueven en una dirección determinada. También se entiende una 'textura' como el conjunto de pequeñas unidades, que pueden ser una colección de diferentes sonidos o múltiplos de uno mismo. Textura en movimientos tipo turbulencia, convolución y streaming son ejemplos de palabras compuestas y comportamientos mixtos (Davis Tom y Karamanlis, 2005). A la inversa, la creación de movimientos y texturas a partir de palabras compuestas es mucho más difícil en la relación término-sonido. Puesto que los objetos sonoros compuestos dependen del trazado y del dibujo de varios parámetros (dependientes del tiempo, de alturas, de timbre y del espacio) se hace necesaria una intuición terminológica que escapa a categorías cerradas (Parra i Esteve, 2005).

\subsection{DISEÑANDO COMPORTAMIENTOS}

El diagrama de comportamiento plantea un vocabulario útil para establecer y comprender la relación, construcción y posición del material sonoro entre varios materiales sonoros. Perceptualmente, el ritmo es un subproducto de la posición horizontal y por tanto, el tiempo en una obra puede ser controlado y redirigido utilizando las muestras en función de estos términos espectromorfológicos (Fig. 180). 


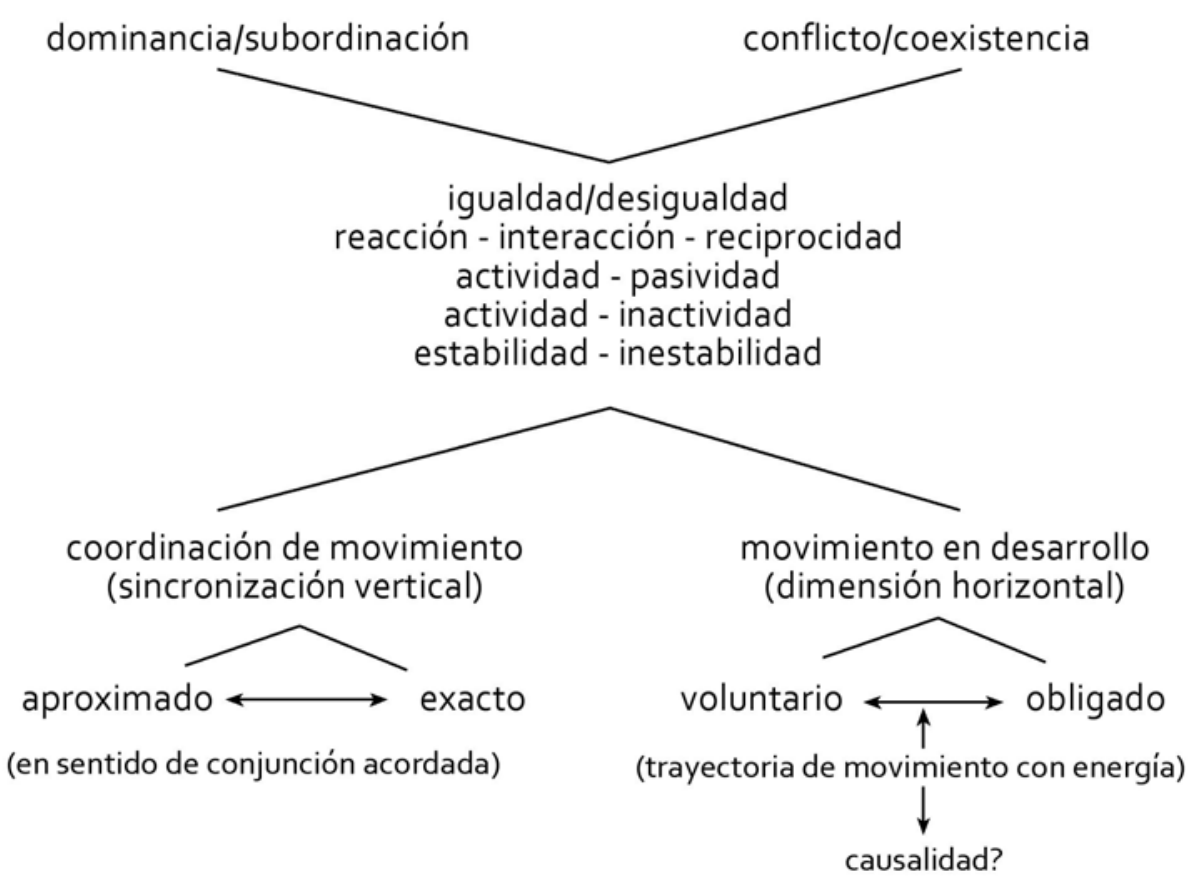

Fig. 180 Comportamientos (Smalley, 1997)

Por ejemplo, el comportamiento apresurado y rápido se referencia incondicionalmente por la comparación que se le hace con un evento colindante, anterior o posterior. Este contacto: sonido con sonido, es responsable desde una perspectiva de causalidad (Fig.181 y 182). Smalley describe con el ejemplo del apresurado-continuo-voluntario que: los pasajes comprimidos de movimiento rápido, y sus variaciones en el espaciamiento secuencial 'demuestran cómo un contexto o evento, condiciona al siguiente' (Smalley, 1997).
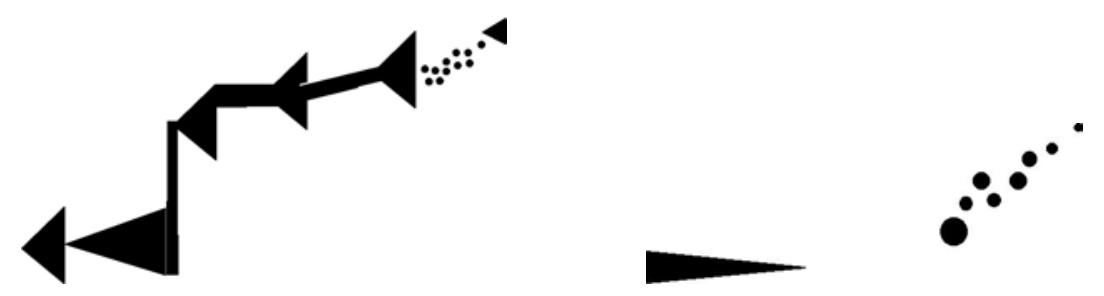

Fig.181 Comportamiento apresurado Fig. 182 Comportamiento voluntario 


\subsection{PRECISIÓN TERMINOLÓGICA}

Las estrategias descritas anteriormente presentan una selección de términos que se consideran útiles y apropiados para la composición de materiales, eventos y estructuras. Esta selección no es definitiva, así pues se han establecido conclusiones sólo a partir de mi propia práctica en esta investigación. Ha sido posible aislar e identificar vocablos funcionales sobre otros términos menos útiles. Palabras más ilustrativas como, espiral, nube, caudal y otras con una asociación física, volar, deriva, ataque, aparecen mejor situadas para facilitarnos la creación de material nuevo. Esta identificación es paralela en nuestra respuesta cuando oímos música electroacústica. A menudo se produce en la escucha una referencia tangible en nuestra visión mental cuando percibimos un sonido más físico, más plástico (Mowitt, 1987).

\subsection{TERMINOLOGÍA ADICIONAL}

Los conjuntos de palabras en la metodología espectromorfológica no están cerrados a nuevas incorporaciones. Durante mi investigación, la adición de nuevas palabras ha ayudado a la creación de eventos sonoros que a menudo requieren un alto grado un detalle. Un ejemplo de esta práctica sucedió cuando se presentaban artistas que trabajan con materiales preferentemente étnicos. En estos casos, la asociación con instrumentos fabricados a partir de materiales similares, despierta en el oyente una correspondencia directa y establece una dualidad expresiva que a veces trasciende el discurso temporal de la imagen, permitiendo al realizador del video ensanchar la percepción de la idea del artesano y entrar en detalles psicológicos propios del mensaje artístico (Fig. 183). 

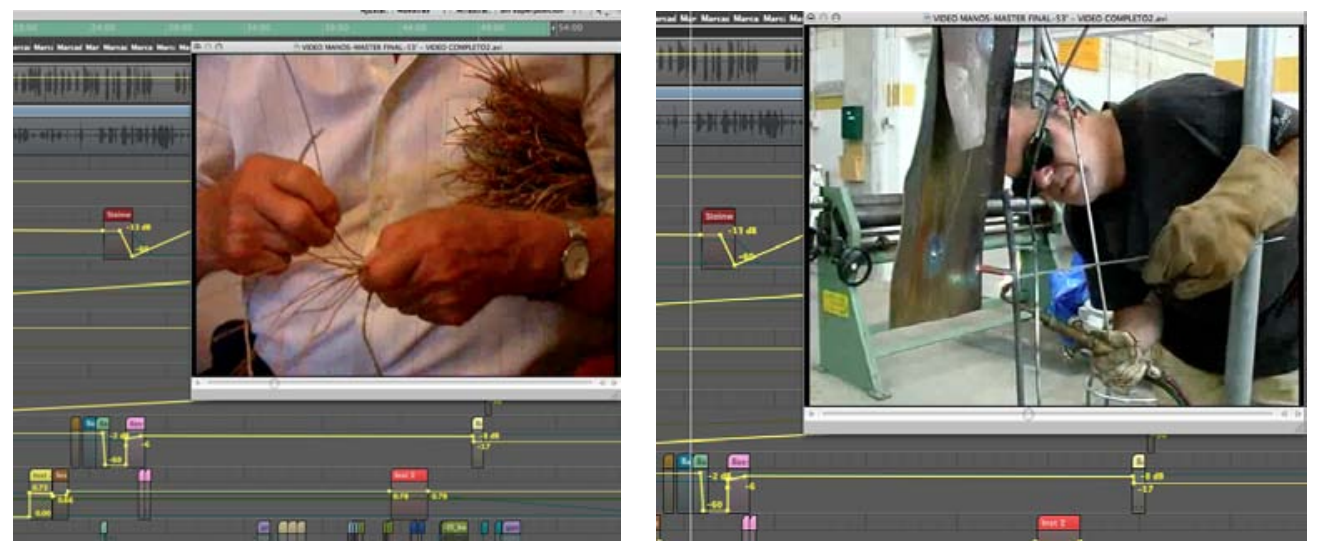

Fig. 183 Captura de la edición del video

\subsection{META-DATOS}

Los meta-datos asociados al sonido (cualidades específicas y etiquetas de categorías) encapsulan la información relacionada con los parámetros del dispositivo de grabación en el momento de la captura, y etiquetan automáticamente al archivo con la duración, la profundidad de bits por segundo y el sampleado. Se pueden añadir etiquetas descriptivas referentes directamente al archivo, permitiendo una búsqueda rápida y precisa cuando deseemos encontrar archivos con ciertos criterios. Spotmeta (SpotMeta, 2010) y Punakea (Punakea, 2010), son dos ejemplos de software que facilitan estos procesos a través de la descripción manual de datos (Fig.184 y 185).

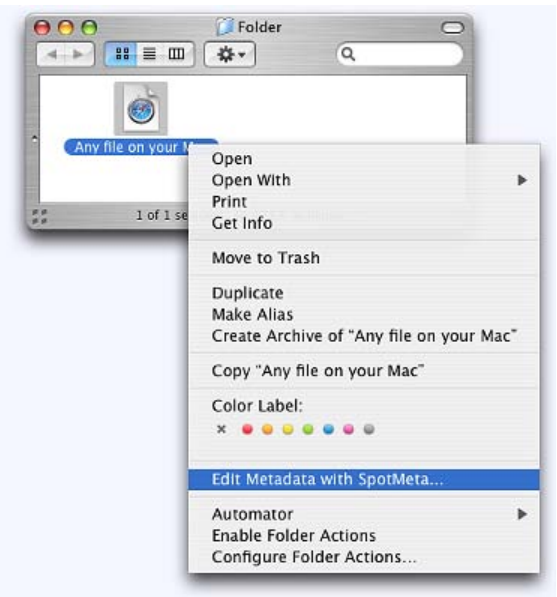

Fig. 184 Captura de SpotMeta

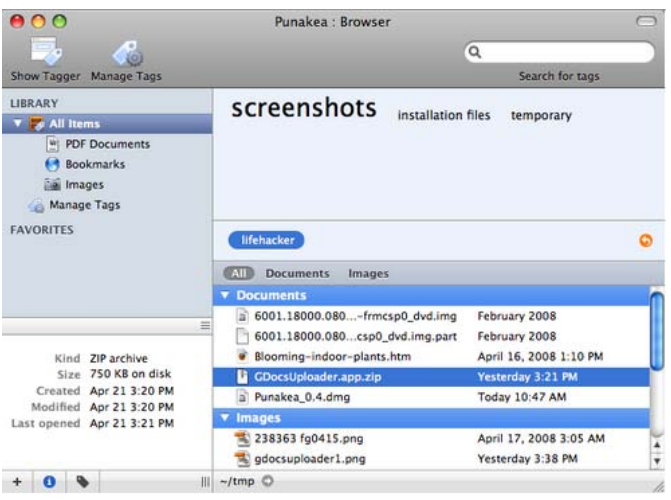

Fig. 185 Captura de Punakea 
Las etiquetas y meta-datos son algo muy habitual en los medios de comunicación. Por ejemplo, en producciones de cine, las librerías de sonido de dimensiones sustancialmente grandes son escaneadas para localizar archivos específicos que concuerden con eventos visuales. Un rápido y eficiente acceso sólo se consigue a través de un etiquetado específico referenciado al material original.

- Meta-datos espectromorfológicos:

El etiquetado del material sonoro con la terminología de descripción espectromorfológica puede funcionar con variedad de metodologías para la composición de música electroacústica. Por ejemplo, la localización de sonidos con frecuencias agudas (etiquetados con información espectral) proporciona un punto de arranque en la elaboración de un espacio espectral concreto (Blackburn, 2009). La localización de objetos tipo ataque-continuidad-receso proporciona al compositor un abanico de posibilidades automatizadas que permiten más agilidad en el proceso creativo. Incluso se podrían plantear espacios de especulación e improvisación espectromorfológica donde el etiquetado y definición de banco de datos y eventos sonoros posibilitara un manejo intuitivo y directo. En esta línea, el grupo de improvisación electroacústico formado por Manuella Balckburn (UK, 1984) y Diana Simpson (UK, 1982), Splice Girls, ha implementado sistemas de búsqueda avanzada en sus sesiones de improvisación (ConcreteMoniker, 2010).

Por otro lado, el compositor Ricardo Climent (Valencia, 1965) tiene abierta una línea de investigación orientada al diseño de aplicaciones y sistemas para la localización avanzada de archivos, usando el software Max MSP asociado a la tecnología Spotlight de Mac OS X (Apple, 2010a). 


\subsubsection{MODOS DE AUDICIÓN}

Investigaciones recientes en música electroacústica sugieren que no escuchamos en una forma fija, uniforme $u$ objetiva, sino que percibimos la música de maneras diversas y adoptamos distintas aproximaciones en nuestra audición. Más aún, es bastante frecuente que adoptemos estrategias auditivas diferentes durante el transcurso de una misma pieza (Cádiz, 2008).

Los aspectos más sobresalientes de las estructuras y superficies musicales (espectromorfología) llevan a los oyentes a adoptar estrategias diversas en la audición y por tanto la identificación que hagan con el componente visual. Por ejemplo, una rápida secuencia monofónica de eventos sonoros autónomos no se escucha de la misma manera que una densa textura granular que evoluciona en el tiempo. Similarmente, es poco probable que escuchemos de la misma manera una pieza con una clara narrativa musical y otra con una superficie musical altamente abstracta.

A continuación se hará una descripción de los modos de audición más relevantes para el planteamiento de este ensayo.

\subsection{MODOS SCHAEFFERIANOS DE AUDICIÓN}

Pierre Schaffer identifica cuatro modos de audición (Smalley, 1992). Los primeros dos modos se relacionan con la audición ordinaria y los modos tres y cuatro guardan relación con la audición musical. Estos modos son:

- Écouter. El oyente se ocupa de la proveniencia de los sonidos y el mensaje que conllevan. La atención se enfoca en la ocurrencia o en los eventos conectados al sonido. Por ejemplo, si escuchamos el sonido de un automóvil atravesando una calle, 
no nos interesa el sonido en sí mismo, sino lo que significa; probablemente el vehículo va muy rápido y nos podría atropellar. Este modo trata al sonido como un signo de su fuente.

- Ouir. No hay intención de escuchar, pero un sonido nos llega y no podemos evitarlo. Un ejemplo de esto puede ser una explosión o un llanto súbito. Este es el nivel más crudo y elemental de percepción auditiva.

- Entendre. Corresponde a un proceso selectivo donde algunos sonidos son preferidos respecto a otros. De acuerdo a su etimología, significa mostrar una intención de escuchar.

- Comprendre. Un paso más allá del modo tercero. Implica la intención de aprehender un significado o unos valores, tratando al sonido como un signo que se refiere a este significado como una función de un lenguaje o de algún código (audición semántica).

\subsection{AUDICIÓN DE FONDO}

Barry Truax propone el término audición de fondo (background listening) para diferenciar un nivel distinto de audición que ocurre cuando existen sonidos que permanecen en el fondo de nuestra atención (Truax, 2001). Esto sucede cuando un auditor no escucha un sonido en particular que sin embargo está presente, debido a que ese sonido no tiene alguna significación inmediata o relevante. Sin embargo, el oyente es consciente de él y si se le pregunta si ha escuchado el sonido en cuestión probablemente responderá de forma afirmativa. Los sonidos que son escuchados en el fondo ocurren frecuentemente y por lo tanto son esperados y predecibles. Se les 
presta atención solamente si es necesario; de lo contrario, no son ni siquiera notados.

\subsection{AUDICIÓN REDUCIDA}

En la teoría de Schaeffer (Schaeffer, 1966), la audición reducida (Écoute Réduite) corresponde a la actitud con la que el auditor escucha sonidos por su propio valor, como un objeto sonoro puro, carente de una fuente sonora y sin un significado atribuible a ésta. En la audición reducida, el foco es el objeto sonoro en sí mismo (no a lo que se refiere) y con los valores que conlleva (y no los que sugiere).

El nombre audición reducida se refiere a la noción de una reducción fenomenológica, porque consiste en descartar de la percepción auditiva todo lo que no le es propio, de manera que se llegue a escuchar solamente el sonido puro, en toda su materialidad, sustancia y dimensión. La audición reducida y el objeto sonoro se correlacionan directamente y se definen mutuamente como la actividad y el objeto de la percepción.

Dado que en la audición ordinaria el sonido siempre es tratado como un vehículo, entonces la audición reducida se convierte en un proceso anti-natural, que va en contra de todo condicionamiento. El acto de remover las referencias auditivas habituales es un acto voluntario y artificial.

\subsection{MODOS AUDITIVOS SEGÚN SMALLEY}

Denis Smalley extiende los modos Schaefferianos al combinarlos con los conceptos de autocentricidad y alocentricidad de Schachtel (Capítulo 5.1.2.3.3). Como resultado, propone los siguientes modos (Smalley, 1992): 
- Indicativo. Corresponde al primer modo de Schaeffer y considera al sonido como un mensaje y centrado en el objeto. En este caso, el sonido actúa como una señal o un signo de algo que no es sonoro por naturaleza, algo necesario, por ejemplo, para la supervivencia.

- Reflexivo. Este modo está centrado en el sujeto, es claramente autocéntrico y se basa en respuestas emocionales al objeto percibido. El objeto y la emoción no son separables en este caso.

- Interactivo. Corresponde a los modos tres y cuatro de Schaeffer y es claramente alocéntrico. Involucra una relación activa de parte del sujeto para explorar continuamente las cualidades y estructuras del objeto. Esta modo abarca la audición estructural, actitudes estéticas hacia los sonidos y la música y el concepto de audición reducida de Schaeffer (Capítulo 5.1.2.2.3). Los modos indicativos y reflexivos son los dominantes. En cambio, el embarcarse en una relación interactiva requiere de esfuerzo y voluntad. A pesar de esto, en mi opinión, una relación de este tipo es la necesaria para apreciar realmente la música y constituye un requisito básico para el análisis.

\subsection{MODOS AUDITIVOS SEGÚN DELALANDE}

La teoría analítica de François Delalande, basada en el análisis de comportamientos auditivos, obtiene conclusiones estructurales del estudio de diversos testimonios auditivos (Delalande, 1998). En ellas argumenta que la mejor forma de representar los distintos aspectos de una obra musical se consigue al basar el análisis en una amplia 
muestra de experiencias auditivas, con el objetivo de extraer los elementos estructurales y narrativos comunes a ellas. Este tipo de análisis es llamado por Delalande análisis de conductas auditivas.

Delalande propone tres diferentes conductas auditivas: taxonómica, enfática y figurativa.

- La audición taxonómica se manifiesta a través de la tendencia a distinguir grandes unidades morfológicas tales como secciones y hacer una lista mental de ellas. También se manifiesta en la habilidad para notar cómo estas unidades se relacionan e interconectan entre ellas.

- La conducta enfática presta atención a las sensaciones, las cuales son comúnmente descritas como el producto psicológico del sonido. Esto está claramente relacionado con el modo reflexivo de Smalley (Smalley, 1992).

- En la audición figurativa el oyente tiende a pensar que los sonidos evocan algo que se mueve y que está vivo y presta su atención a la superficie musical, a los detalles sobresalientes.

\subsubsection{COMPORTAMIENTO DE LA PERCEPCIÓN}

\section{ELECTROACÚSTICA}

Para establecer una coherencia entre elementos visuales y objetos sonoros, se ha propuesto una metodología basada en los parámetros que condicionan la percepción de la electroacústica para la correspondencia entre espacios visuales (países, regiones, paisajes, monumentos, edificios, almacenes, talleres, etc.) y naturaleza sonora de las muestras utilizadas (elementos grabados con o sin procesos electrónicos). 
Antes de establecer patrones de actuación específicos se han analizado distintas teorías y propuestas vinculadas a la percepción del sonido y sus correspondientes procesos de cognición mental. A continuación se describen los planteamientos empleados en este ensayo.

\subsection{PERSPECTIVA AMBIENTAL}

Luke Windsor, profesor de la Universidad de Leeds especializado en percepción y análisis de la música electroacústica, propone que los sonidos sean entendidos con relación a los ambientes dinámicos, en los cuales éstos se encuadran, ya sean sonidos creados naturalmente $o$ mediante alguna mediación cultural (Windsor, 1996). En consecuencia, y según podemos ver en (Cádiz, 2008) las dificultades teóricas y analíticas que posee la música electroacústica, requerirían soluciones basadas en una conciencia dual del auditor sobre los aspectos naturales y culturales del sonido.

En otras palabras, esto sugiere que la música electroacústica posee una naturaleza dual. Por una parte, los sonidos son percibidos, y por la otra, significan. Son percibidos porque proveen información que permite a un organismo reaccionar adecuadamente a su ambiente de una manera directa. $Y$ también significan porque son interpretados como elementos culturales con un contenido explícito.

Esta idea puede ser directamente relacionada con los modos tercero y cuarto de los modos de audición de Schaeffer (Schaeffer, 1966). El tercer modo (Entendre) implica seleccionar algunos sonidos sobre otros y el modo cuarto (Comprendre) implica asignar un significado a esa experiencia. 
En este propósito de delimitar las connotaciones psicológicas en la percepción del sonido, aparece el contexto de la 'acústica ecológica', en el que los sonidos no son concebidos como entidades abstractas relacionadas una con la otra, como por ejemplo tonos de colores o timbres, ni tampoco como signos referentes a conceptos $\mathrm{U}$ objetos. Por el contrario, se considera que los sonidos proporcionan un contacto directo entre los oyentes y los eventos visuales (y ambientales) significativos (Windsor, 2000).

Estas ideas están basadas en el trabajo de James J. Gibson, creador del enfoque ecológico para la percepción visual, quien afirma que la percepción no requiere de la mediación de representaciones mentales del mundo externo. Este argumento es contrario al punto de vista dominante de la percepción y cognición musical, en el cual el procesamiento, el almacenamiento y la manipulación de la información en la mente son lo principal (Gibson, 1986).

De acuerdo con (Windsor, 2000), el enfoque ecológico asume que el ambiente está altamente estructurado y que los organismos son sensibles a dicha estructura. Sin embargo, esto no significa que la memoria, el lenguaje y otros sistemas simbólicos no tengan un rol importante en nuestra experiencia del mundo, sino que la percepción, por un lado; y los sistemas simbólicos que facilitan la mediación, el almacenamiento y la comunicación de las percepciones, por el otro, son cosas distintas.

Esta perspectiva 'ecológica' se basa en la percepción de eventos. Este tipo de percepción trata de identificar las propiedades invariantes de eventos que especifican las características permanentes y cambiantes del ambiente que son importantes para un organismo. Este enfoque es distinto de la psicoacústica tradicional en el sentido de que ésta 
última se ocupa de identificar cambios en alturas, estructuras espectrales o duraciones, mientras que la primera trata de identificar las transformaciones en las estructuras acústicas que informan al auditor de cambios importantes en el medio ambiente (entorno visual).

Cabe destacar que este punto de vista no implica que los sonidos no puedan ser percibidos con ciertas cualidades, tales como los objetos sonoros de Schaffer o que ellos no puedan significar. Lo que sí implica es que los sonidos no necesitan de tal mediación para informarnos acerca del entorno visual y que las fuentes sonoras pueden ser difíciles de ignorar, debido principalmente a la naturaleza no musical de los sonidos electroacústicos.

En conclusión, esta visión es fundamentalmente opuesta al concepto acusmático de Schaeffer en el sentido de que la música electroacústica, más que proveer un método de lidiar con fuentes sonoras, es más bien una fuente informativa de estímulos acústicos estructurados. La percepción de música electroacústica puede ser radicalmente distinta a la percepción de eventos reales, pero esto no es sólo audición acusmática o reducida. El oyente que está vinculado visualmente a un ambiente rico en estimulación y estructura percibirá eventos no sólo a través de la información presente en un fragmento sonoro sino del ambiente como un todo, sea éste acústico o no.

\subsection{PAISAJE SONORO}

El término 'paisaje sonoro' es frecuentemente utilizado en el lenguaje electroacústico para designar diversos modos de hacer o entender dicho lenguaje, pero plantea diferencias de concepto importantes entre compositores y artistas sonoros. 
Este ensayo se presta a explorar texturas y ambientes relacionados directamente con los elementos espaciales o ambientales del video. Si bien es cierto, cada viñeta (fragmento individual de un artesano) conforma un paisaje sonoro absolutamente característico e intransferible a otra viñeta y más aun, permite planificar los niveles de detalle que se deseen, es por esto que no se pueden establecer grupos o epígrafes genéricos ni definir patrones globales para varias viñetas.

En (Wishart, 1986) podemos ver que un paisaje sonoro se define como la fuente imaginaria de los sonidos percibidos. Por ejemplo, el paisaje sonoro de los sonidos escuchados en una sala de conciertos está constituido por músicos tocando instrumentos. El paisaje sonoro de la misma música tocada a través de altavoces también corresponde a músicos tocando instrumentos. ¿Cuál es el paisaje sonoro de una pieza de música electroacústica? La respuesta a esta pregunta no es fácil y depende de cada pieza en particular. El planteamiento de un concierto de electroacústica para un público no acostumbrado a este lenguaje produce una cierta desorientación. Esta desorientación se debe a la incapacidad de definir una fuente sonora imaginable, un paisaje sonoro, para los sonidos percibidos.

Smalley menciona que el extenso rango de fuentes sonoras que han sido incorporados a la música electroacústica ha provocado una revolución en el contenido sonoro, ante lo cual se observa una variada gama de respuestas auditivas (Smalley, 1992). Wishart (Wishart, 1986) propone que nuestra percepción de un paisaje sonoro puede ser descompuesta en tres partes:

- naturaleza del espacio acústico percibido: elementos visuales (formas, volúmenes, colores, luminosidad...) 
- la disposición de los objetos sonoros en tal espacio: espacialización concreta, trayectorias, movimientos cíclicos ...

- identificación de objetos sonoros individuales: detalles o panorámicas, efectos visuales, ilusiones ópticas...

\subsection{AUTOCENTRICIDAD Y ALOCENTRICIDAD}

El psicoanalista Ernest Schachtel (1903-1975) establece una diferencia entre actividades perceptuales centradas en el sujeto y centradas en el objeto (Schachtel, 1984). Podemos ver, a partir de (Smalley, 1992), que para hacer la diferenciación, propone dos modos perceptuales.

- El modo Autocéntrico es el basado en el sujeto y en respuestas básicas y sentimientos de satisfacción o insatisfacción. Este enfoque está relacionado con las reacciones subjetivas a los estímulos. Esta idea de percepción es primitiva, basada en necesidades y se asocia con las primeras relaciones del niño con el mundo. Cabe destacar aquí la similitud con la percepción ecológica propuesta por Windsor.

- Por el contrario, el modo Alocéntrico es el centrado en el objeto en el sentido de que no involucra las necesidades del individuo. La satisfacción o insatisfacción no son relevantes en este caso. Este modo implica un proceso activo y selectivo de focalización en un objeto para posteriormente discernir sus propiedades. Las actitudes musicales autocéntricas se relacionan con respuestas emocionales al sonido. En cambio, las actitudes alocéntricas involucran la aprehensión de las estructuras musicales y la apreciación de sonidos fuera de un contexto musical. Este modo constituye un encuentro directo con el sonido y está directamente relacionado con el modo 
cuarto de Schaeffer (Schaeffer, 1966) y con el modo interactivo de Smalley (Smalley, 1992).

La autocentricidad y alocentricidad pueden existir en forma paralela y también varían de acuerdo con cada oyente. Hay algunos que en la presencia de un sonido inmediatamente utilizarán un enfoque autocéntrico mientras otros seguirán una estrategia alocéntrica. Esta idea complementa la naturaleza sonora dual que propone Windsor, en el sentido de que los sonidos son percibidos (en el sentido autocéntrico) pero también significan (de una manera alocéntrica). También esta idea puede vincularse directamente con las conductas auditivas de Delalande (Capítulo 5.1.2.2.5).

\subsection{SUSTITUCIÓN}

Denis Smalley (Smalley, 1992) introduce el término sustitución (surrogacy) como una forma de describir el nivel o el grado en los cuales los oyentes relacionan perceptualmente los sonidos con fuentes físicas y gestuales reales o imaginarias en un contexto acusmático. A medida que el nivel de sustitución se hace más fuerte, los auditores pueden asignar causas imaginarias a distintos sonidos y a su evolución espectromorfológica, o etiquetar el sonido como abstracto. Smalley denomina a estos varios niveles como órdenes de sustitución (Smalley, 1986).

\subsection{DISCURSO NARRATIVO}

Cada proceso creativo desarrolla su propia narrativa, incluso de forma distinta a los propósitos del compositor (Giomi y Ligabue, 1998). En su trabajo, Giomi y Ligabue proponen un análisis narrativo de música electroacústica utilizando un proceso analítico basado en aspectos perceptuales y una metodología estética-cognitiva, desarrollada por 
los propios autores. Este análisis pretende operar en forma análoga al análisis de una obra literaria, donde existen protagonistas y antagonistas, y una trayectoria narrativa claramente establecida.

Para la construcción estructural de los elementos sonoros en este ensayo se ha considerado este tipo de análisis; permite el examen de los objetos narrativos desde distintos puntos de vista, empezando por unidades pequeñas como los objetos o eventos sonoros para seguir con cadenas sintagmáticas, estrategias compositivas y la segmentación de la estructura formal de la pieza. Esta división estructural se basa en criterios tales como material, comportamiento rítmico-dinámico, coherencia, morfología tímbrica, densidad, movimiento y tensión. Este análisis también considera estrategias de comienzo y final, el uso de la analepsia (repetición narrativa) y la prolepsia (anticipación narrativa), asociaciones semánticas tanto musicales como metafóricas y asociaciones psicológicas extra musicales.

\subsubsection{REFERENTES}

El empleo del lenguaje electroacústico en contextos gráficos o visuales está siendo en los últimos años un referente principal en la creación artística musical (Schumacher, 2009). Es significativo que convocatorias y festivales tan importantes como Synthèse (Bourges, Francia) (Synthése, 2010), Primavera Electroacústica en la Habana (Cuba) (LNME, 2010), Fylkingen (Finlandia) (Fylkingen, 2010), Musica Viva (Portugal) (Music, 2010), y congresos internacionales como EMS (EMS, 2010), CEMVA (CEMVA, 2010), etc..., dedican una gran parte de sus programas y conciertos a la electroacústica con video. Sin embargo en otros contextos, como la video-danza (ver Tema 4), o el 
video-documental, no se ha visto una trayectoria clara en el empleo de esta estética musical.

Como punto de arranque en la concepción sonora de este ensayo se han considerado lenguajes y estéticas basadas en video creados y diseñados para música electroacústica. Un ejemplo de esto es el trabajo de la compositora María Eugenia Luc (Argentina, 1959) quien ha desarrollado un catálogo de obras creadas a partir de expresiones artísticas sobre soporte de video grabado. En su obra Gaia (Rekalde, 2010a) para el artista visual Josu Rekalde (Bizkaia 1959), desarrolla un discurso con movimientos rápidos e impredecibles que describen a modo de metáfora visual que el planeta donde vivimos resulta de un cúmulo de materias físicas y sensibles que lo convierten en un organismo complejo. La teoría de la tierra como Gaia (Lavelock, 1979) (Fig. 186), propuesta por James Lovelock (Reino Unido, 1919), metaforizada en imágenes por Josu Rekalde sobre un directo de música de María Eugenia Luc. Esta formación no es exclusivamente electroacústica, sino que utiliza una formación camerística con 1 Flauta, 1 Saxofón, Percusión y Piano.

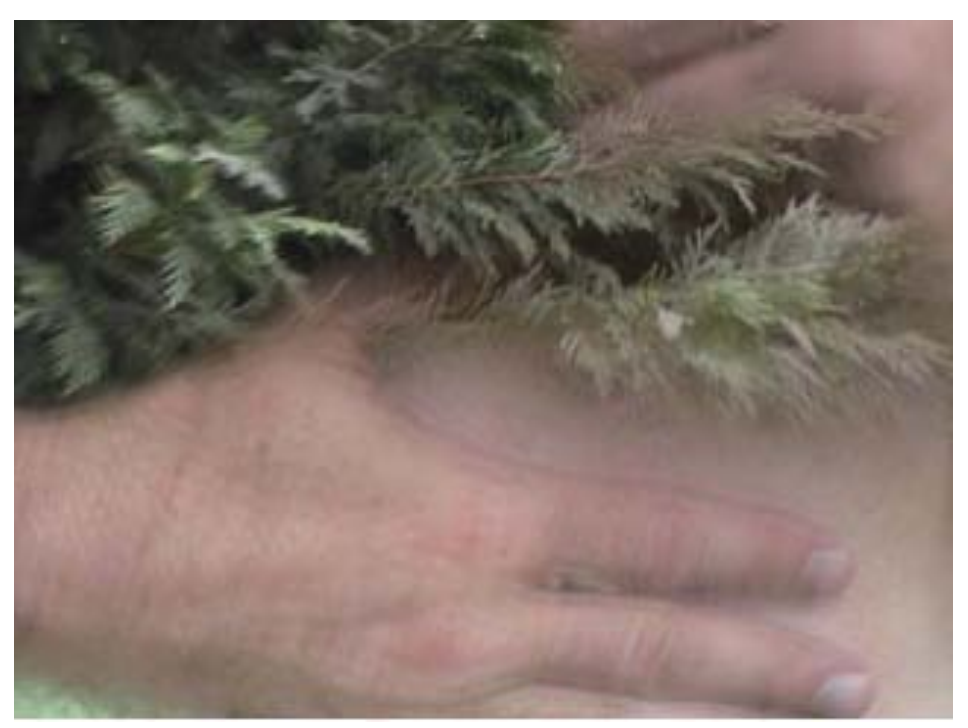

Fig. 186 Captura de Gaia, en (Rekalde, 2010a) 
Gaia es una investigación que parte de las experiencias artísticas de Josu Rekalde, en torno a la conciencia social y los conflictos humanos, expandiéndolas hacia las leyes para la vida. En esta exploración se para a admirar el planeta de donde parten. A través de imágenes ambiguas de la biosfera inmediata metaforiza la creación de la existencia mediante una sutil intervención en la velocidad y dirección de las imágenes, proponiendo un tejido de cambios que desafían las evidencias. De este modo acomoda las formas, superficies, y manipulaciones de su hábitat a los movimientos erráticos de la música de María Eugenia Luc.

En una línea similar se presenta Vuelos Migratorios (Rekalde, 2010b), (Fig. 187) donde, partiendo de una instalación y rescatando secuencias de trabajos anteriores Josu Rekalde los polariza para hablar de la migración y como la huida transforma el uno en el otro. Una denuncia de los conflictos humanos de los otros, contrapuesta sutilmente al confort de la cultura del bienestar.

Desde un inicio, con textos suspirados y escritos en blanco sobre negro, tanto en castellano como árabe, de un poema sobre la autoexclusión se plantea la dualidad sociocultural del mundo árabe y occidental. Para ello Maria Eugenia Luc planteó de igual modo una dualidad sonora utilizando dos instrumentos totalmente opuestos en lo que a organología y acústica se refiere: el Violín y el Saxofón. Un tercer elemento es el material electroacústico que desarrolla un discurso paralelo y complementario a los giros y diseños de los instrumentos. En este caso, la electroacústica adquiere un papel de cohesión o divergencia respecto a la imagen que ayuda al espectador a entender el planteamiento estético del autor. 


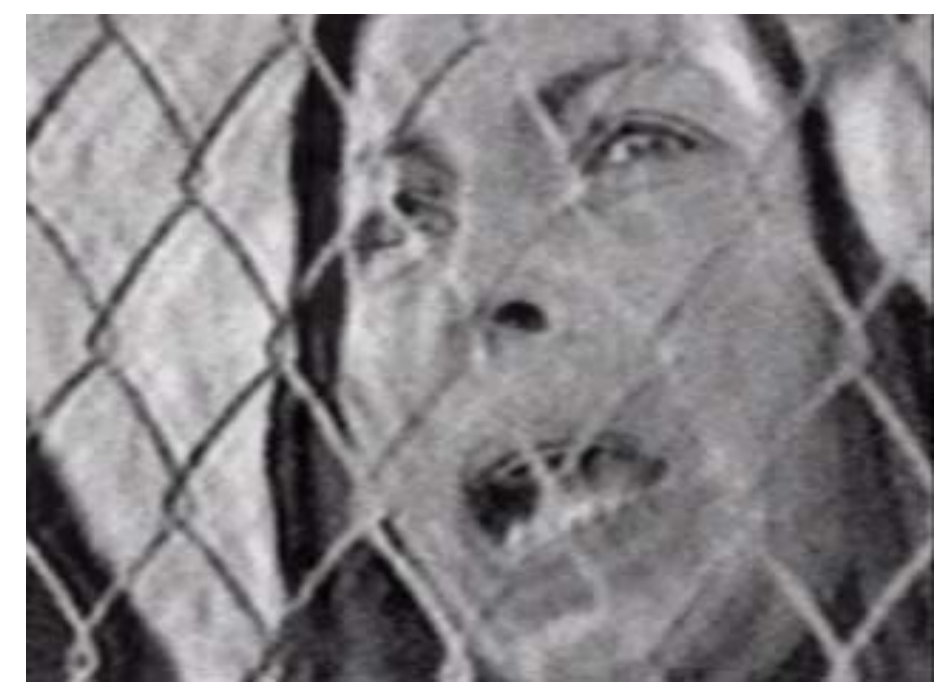

Fig. 187 Captura de Vuelos migratorios, en (Rekalde, 2010b)

Desde otra perspectiva más abstracta y menos definida en el mensaje social se encuentran las creaciones electroacústicas y visuales del canadiense Thierry Gauthier (Québec, 1970) cuya visión del lenguaje electroacústico tiene más consonancia directa con el gesto visual abstracto. En su obra Portrait d'une femme (Gauthier, 2010) (Fig. 188), desarrolla un discurso de objetos y texturas concretas que se podrían encuadrar en una estética propia del Landscape (Barret, 1999). En este caso, las atmósferas y superficies sonoras conforman un sostenimiento del tiempo sobre el cual se producen cambios y matices sonoros muy sutiles. En ocasiones el video marca la línea narrativa del video $y$ en otras es el material sonoro el que desencadena giros inesperados en la secuencia visual.

'Retrato de una mujer' es un videomusical abstracto sobre detalles e imágenes macroscópicas de la mujer. La profusión de imágenes heterogéneas de la mujer junto a la relación sonidovídeo revela la complejidad de su personalidad. 


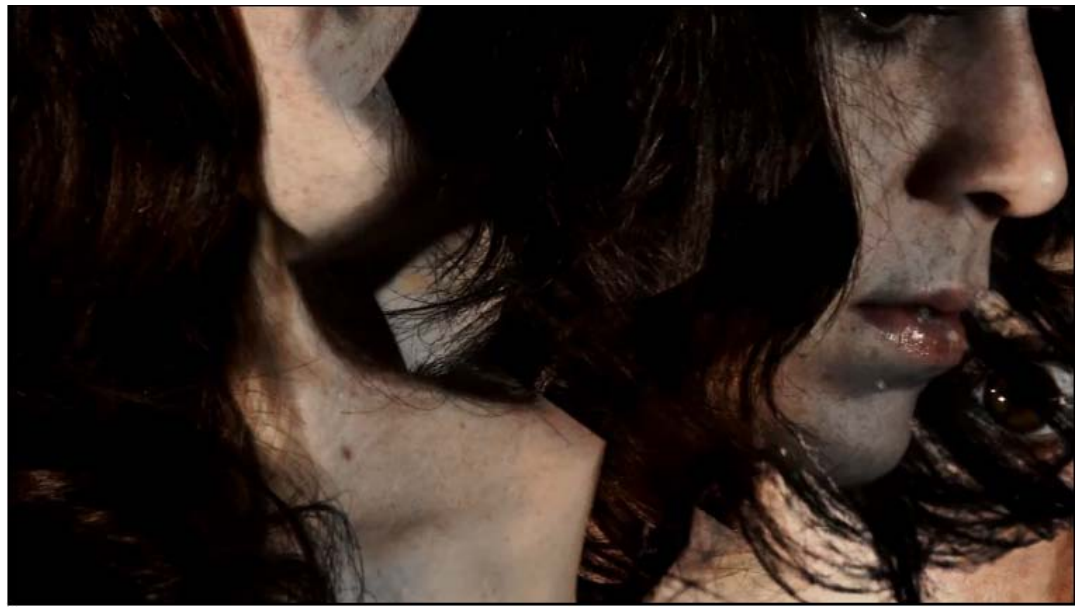

Fig. 188 Captura de Portrait d'une femme, en (Gauthier, 2010)

Otro ejemplo de la concepción atmosférica y concreta del lenguaje audiovisual con electroacústica se recoge en Nord/Sud, del mismo autor (Fig. 189). En este caso Thierry Gauthier desarrolla una dualidad sonora evidente. Construye el discurso musical a través de dos elementos contrastantes y diferenciados, por un lado el empleo de impulsos electrónicos graves sostenidos en el tiempo mediante filtros y efectos de reverberación y por otro lado el empleo de sonidos concretos de origen paisajístico, aire, Iluvia, ambientes urbanos, silbidos, etc. A menudo el cambio de imagen se produce sincronizado con estos impulsos electrónicos a modo de 'pase de diapositivas'.
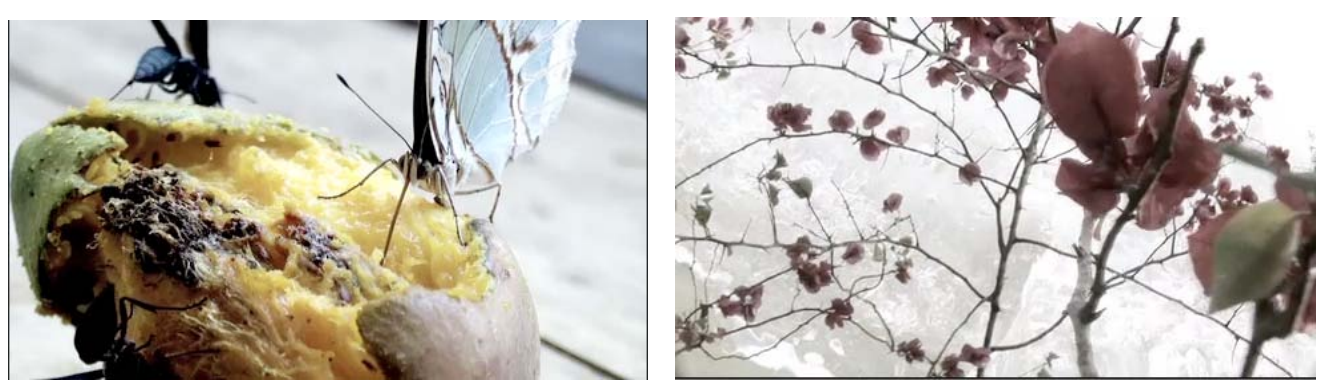

Fig. 189 Capturas de Nord/Sud, en (Gauthier, 2010) 
En palabras del autor:

'Nord/Sud es una composición de audiovisual figurativo que representa la naturaleza y el instinto de supervivencia con ansiedad, tensión y nostalgia. El trabajo envuelve desde lo microscópico a lo macroscópico y continúa los enlaces en la cadena alimenticia. Las imágenes fueron tomadas durante un invierno en Costa Rica, Méjico y Québec. La música está construida a partir de grabaciones de campo, piano preparado, platos frotados con arco y síntesis.'

El compositor y artista visual Stefano Scarani (Italia, 1966), tiene un catálogo de obras audiovisuales que integran el lenguaje electroacústico con el video arte. En su obra Perg (Scarani, 2010), (Fig. 190) realiza un material concreto basado en breves muestras de Marimba procesadas y editadas, consiguiendo texturas microscópicas que se van generando por acumulación y superposición. Todo esto acompaña a la imagen que de igual modo tiene una construcción basada en una direccionalidad acumulativa. El video tiene dos partes unidas mediante un intermedio. La segunda parte desarrolla texturas granuladas más densas que las de la primera parte, aunque la naturaleza de todo el material sonoro está basado en la Marimba. Esto confiere una coherencia y consistencia al discurso audio-visual. 


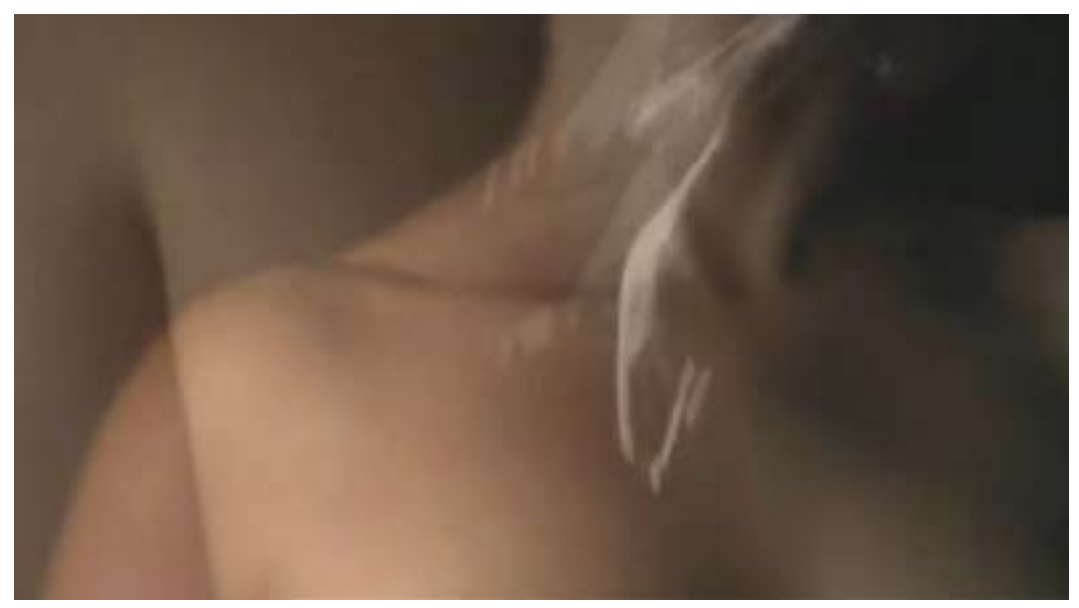

Fig. 190 Captura de Perg, en (Scarani, 2010)

El grupo artístico 'Tangatamanu' (Tangatamanu, 2010), integrado por los compositores y artistas plásticos y visuales Alberto Morelli (Italia, 1959), Julia Chiner (Valencia, 1970), Franco Parravichini (Italia, 1956), Cristina Morelli (Italia, 1962), y Danio Catanuto (Italia, 1977), han realizado multitud de proyectos de vídeo para los cuales han contado con Stefano Scarani como compositor electroacústico. En la mayoría de los casos existe un tratamiento digital de instrumentos acústicos pregrabados como el piano, violín, flauta, percusión, etc., para la realización de la parte sonora.

En el plano de la multidisciplinariedad artística podemos encontrar el proyecto 6ox6o (Fig. 191), un punto de encuentro para compositores, bailarines, y video-artistas que plantean un proyecto común de 60 minutos a partir de aportaciones de diferentes compositores con fragmentos de 1 minuto. Esta plataforma fue creada y diseñada por Robert Voisey (USA, 1969), creador también de Vox Novus (VoxNovus, 2010), una iniciativa para la promoción de jóvenes compositores e intérpretes. De acuerdo con lo que dice la página de la casa productora del disco (Vox Novus), el material está hecho para escucharse de tres maneras: en primera instancia, como está dispuesto, es decir, en el 
orden de los tracks; la segunda de forma aleatoria; y por último, escuchar cada pieza por separado y de forma repetida, para descubrir los métodos compositivos de cada autor.

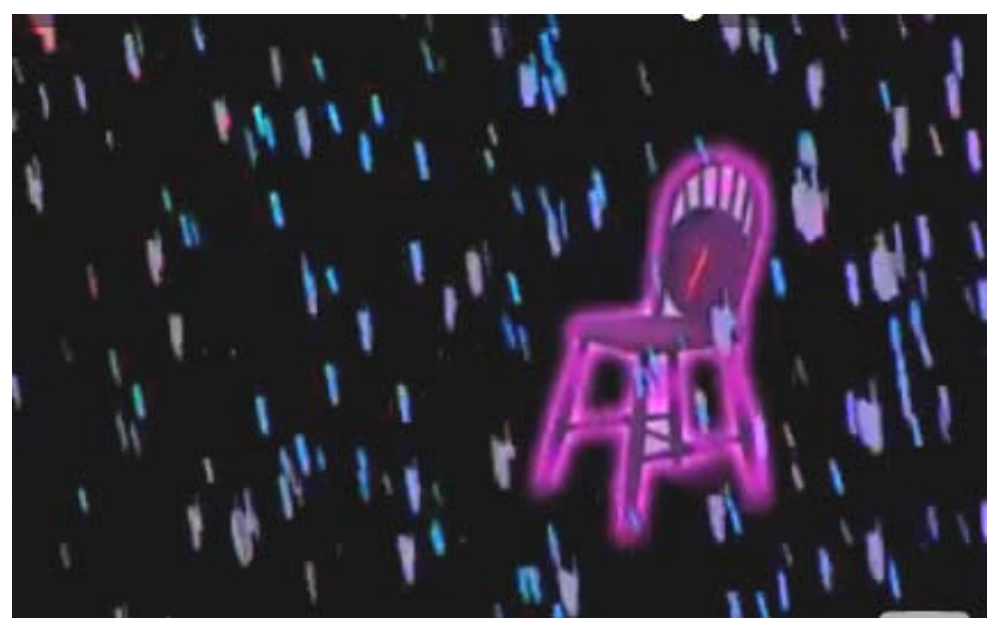

Fig. $19160 \times 60$ A Circle of Sound, White Fungus Productions, en (60x60, 2008)

La idea de incluir fragmentos de 60 segundos de diferentes compositores en un solo álbum, surgió con el polifacético pianista y performer Guy Livingston (Tennessee, 1967), frecuente colaborador en proyectos de muy distinta naturaleza con artistas y creadores audio-visuales. Naturalmente el número de piezas incluidas en el disco también sería de 60 (para promediar una hora en total); y para que el asunto fuera aun más ecléctico e innovador, pidió a 60 compositores diferentes, de 60 ciudades distintas alrededor del mundo, componer una pieza de dicha duración para este proyecto en particular.

En la siguiente imagen vemos una captura de un video inspirado en John Cage de la video-artista holandesa Nelleke Koop, con música de Andrea Nicoli, en el que Guy Livingston realiza una performance gestual sobre un piano cerrado (Fig. 192). 


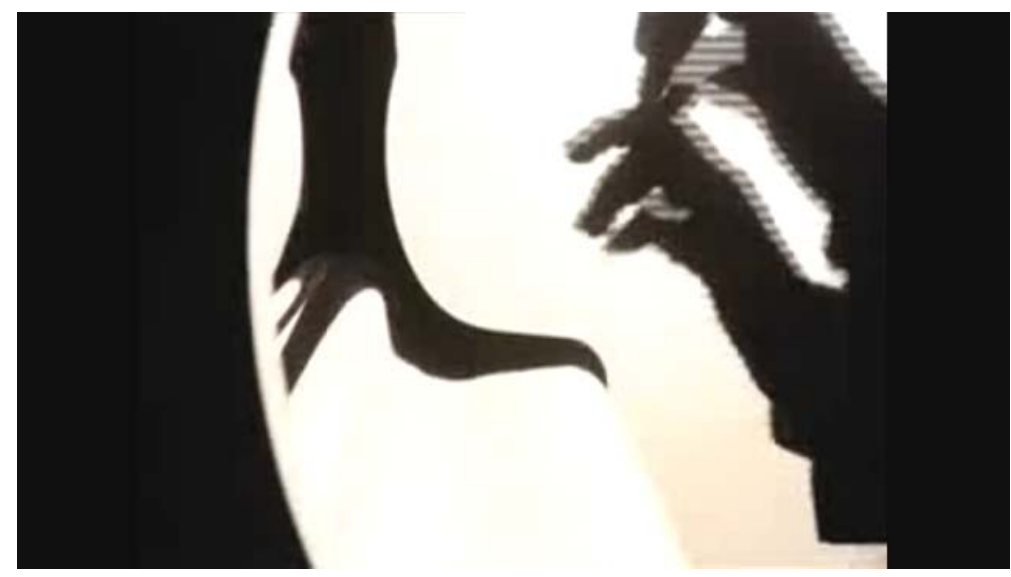

Fig. 192 Captura de 'no entry (no exit)', en (Koop et al., 2010)

Maggi Payne (Texas, 1945), co-directora (desde 1992) del Center for Contemporary Music at Mills College, Oakland, Canadá, e involucrada también en varios proyectos con la plataforma $60 \times 60$, desarrolla parte de su labor creativa como compositora y flautista en proyectos con video con el video artista Ed Tannenbaum (New York, 1953).

En su obra Ahh-Ahh (ver 2.1) (Fig. 193), compuesta en 1987, la música forma parte de una performance llamada Queve the Lizards (A la cola de los lagartos), donde se planteó el trabajo con sonidos de agua, serpientes, y silbidos explotando las posibilidades de espacialización del sonido. Más tarde este material evolucionó hacia componentes más abstractos: ruido blanco, respiraciones humanas con altura definida y sin ella, sonidos de flauta resonantes, caja con distintos procesos de modulación. El material de video está construido sobre una live-performance (representación en vivo) donde utiliza un procesador de video digital y un Instrumento de video computacional llamado Fairlight CVI (Computer Video Instrument) (Audiovisualizers, 2010). Todos los procesos de la danza están procesados en tiempo real. En representaciones en vivo se ejecutan muestras pre-grabadas junto al material del directo. 


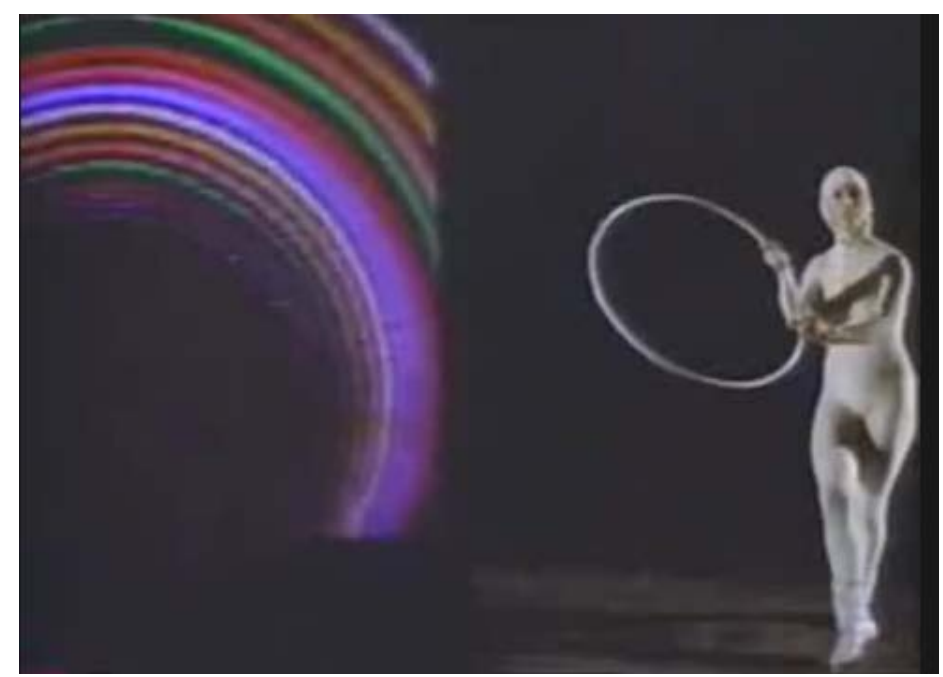

Fig. 193 Captura del procesamiento de señal de video, en (Tannenbaum, 2010)

Otra obra de referencia de la misma compositora es Flights of fancy para el video de Tannanbaum Viscous Meanderings (1985) (SIGGRAPGH, 2010) (Fig. 194). El sonido diseñado para esta obra consiste en la utilización de células rítmicas cortas y repetitivas con material sonoro basado en sintetizadores modulares y ruido blanco. La estética de la obra es de corte pop y minimalista y heredera de los planteamientos musicales del compositor estadounidense Philip Glass (Baltimore, 1937). La correspondencia con la imagen está construida a partir del parámetro de la acumulación. Los distintos instrumentos y timbres aparecen, se superponen y evolucionan cuando la imagen realiza cambios significativos de cantidad y densidad. En este caso, en el video, grabado en tiempo real, la audiencia ve al bailarín y al cámara en el escenario. La señal resultante de la cámara se convierte en un buffer de resolución $(256 \times 240)$ controlada con un ordenador especial que él mismo construyó. 


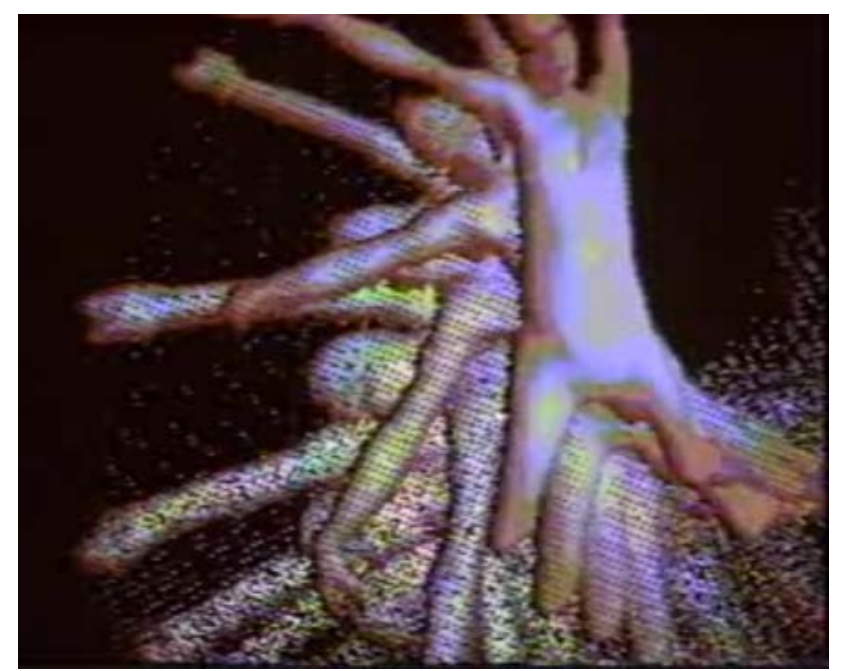

Fig. 194 Captura del video Viscous Meanderings, en (Tannenbaum et al., 1985)

\subsection{DESCRIPCIÓN TÉCNICA}

\subsubsection{FUENTES INSTRUMENTALES}

Para la realización de este proyecto se tuvieron que definir varias categorías en la definición global de muestras. Por un lado se grabaron diferentes giros y células melódicas compuestas previamente en los siguientes instrumentos acústicos (Fig. 195):

- Clarinete en si b

- Piano

- Guitarra acústica

- Santoor persa

- Crótalos

- Instrumentos étnicos y de pequeña percusión: toba o tambor de agua, kabasa, shekere, spring drum o tambor de primavera, lira, timbales, wookblocks, mokugyo, congas, platos suspendidos (tipo crash, tipo ride, tipo chinos), claves, log drum, sonajas, cortina de metal y crótalos. 


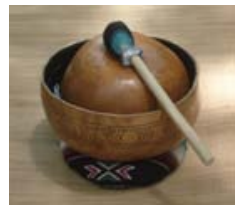

toba

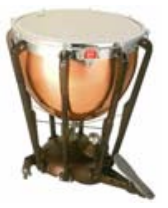

timbal

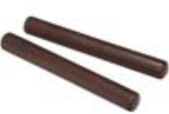

claves

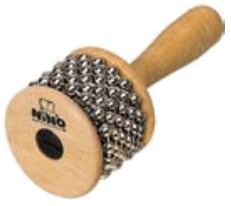

kabasa

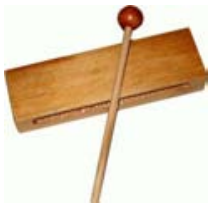

woodblock

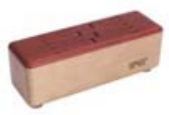

logdrum

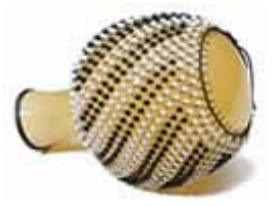

shekere

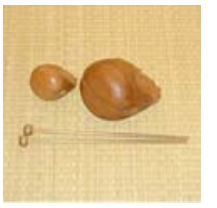

mokugyo

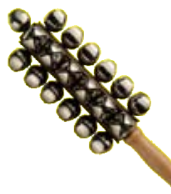

sonajas

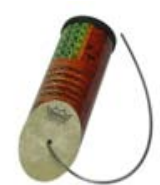

spring drum

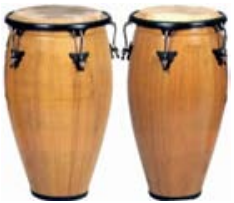

congas

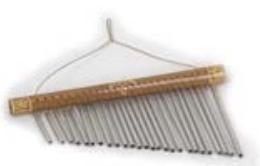

cortina de metal

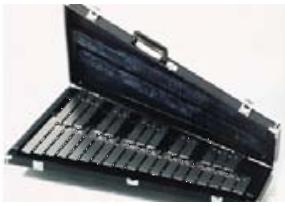

lira

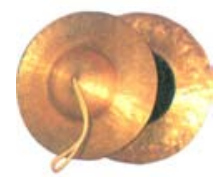

platos

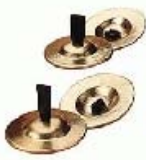

crótalos

Fig. 195 Instrumentos de percusión grabados

Como se puede apreciar en la figura anterior se eligieron instrumentos de todas las familias y materiales que tiene la percusión: madera, metal y parches (sintético y piel). El parámetro de afinación concreta no supuso un hándicap decisivo en la elaboración de muestras o fragmentos musicales ya que la propia electrónica (procesos de síntesis) permite transformar instrumentos de afinación no definida en definida y viceversa.

Por otro lado se creó una base de datos con los mismos instrumentos tratados mediante diferentes procesos de transformación digital (DSP, digital sound processing) atendiendo a los criterios espectromorofológicos descritos anteriormente (Apartado 5.2.2). Por último se incorporaron muestras ajenas al material acústico, es decir, archivos creados a partir de síntesis concreta que tienen una naturaleza más abstracta (Apartado 5.2.3). 


\subsubsection{NATURALEZA PLÁSTICA: INSTRUMENTOS}

\section{ACÚSTICOS}

Después de realizar una visualización y puesta en común del material con los creadores y la productora de video, se establecieron 2 líneas principales en la adición de sonido y música. Se valoraron por un lado las condiciones tímbricas y asociativas de cada instrumento de la paleta orquestal dependiendo de cada episodio del video y se estableció la necesidad de la aplicación del lenguaje electroacústico para la obtención de atmósferas, texturas y ambientes que proporcionaran el color sonoro adecuado a las necesidades de los creadores del video. En este sentido podemos establecer dos grandes categorías en la definición de objetos sonoros utilizados en este ensayo:

\subsection{PLASTICIDAD SONORA}

En este caso, los instrumentos que son directamente reconocibles por el oyente adquieren matices de colorido y de complementación sonora con la imagen. La guitarra o el piano utilizados en frases breves y concisas (sin matices estilísticos declarados) definen un pasaje o fragmento visual en el aspecto más colorista y neutral, sin implicaciones psicológicas complejas añadidas (Fig. 196). La materia constructiva de estos pasajes se corresponde con una estética musical consonante que no es definible como propia de periodos clásicos o románticos de la historia musical occidental. En la mayor parte del video se ha evitado definir patrones asociables a la literatura tonal de los siglos XVII al XX. De otro modo se hubieran ocasionado confrontaciones e incoherencias estilísticas innecesarias con el lenguaje abstracto y contemporáneo de la parte electroacústica. 


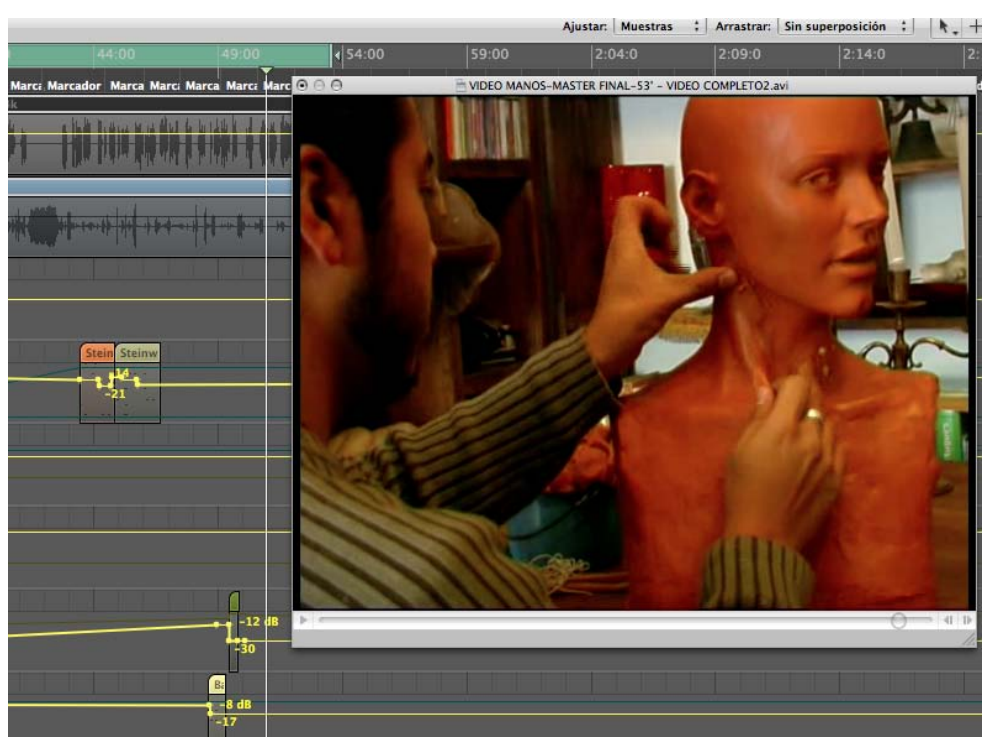

Fig. 196 Captura de la edición de sonido

\subsection{CORRESPONDENCIA SUBJETIVA O META-}

\section{SONORA}

La intención del autor del video fue la de crear ciertas ocasiones en las que el oyente percibiera la psicología de algunos artistas y su opinión más trascendente sobre la creación y manipulación de la materia, la posición del artista frente a la expresión artística y el contexto subjetivo que se desprende de ella. Para ello se procesaron las muestras instrumentales de modo que se establecían naturalezas sonoras de componente más abstracto. Mediante diferentes procesos de síntesis digital se fueron obteniendo timbres y texturas cuya naturaleza aunque en origen era la puramente acústica, al ser transformadas pasaron a un plano menos explícito y más abstracto en cuestiones de significante (Fig. 197). 


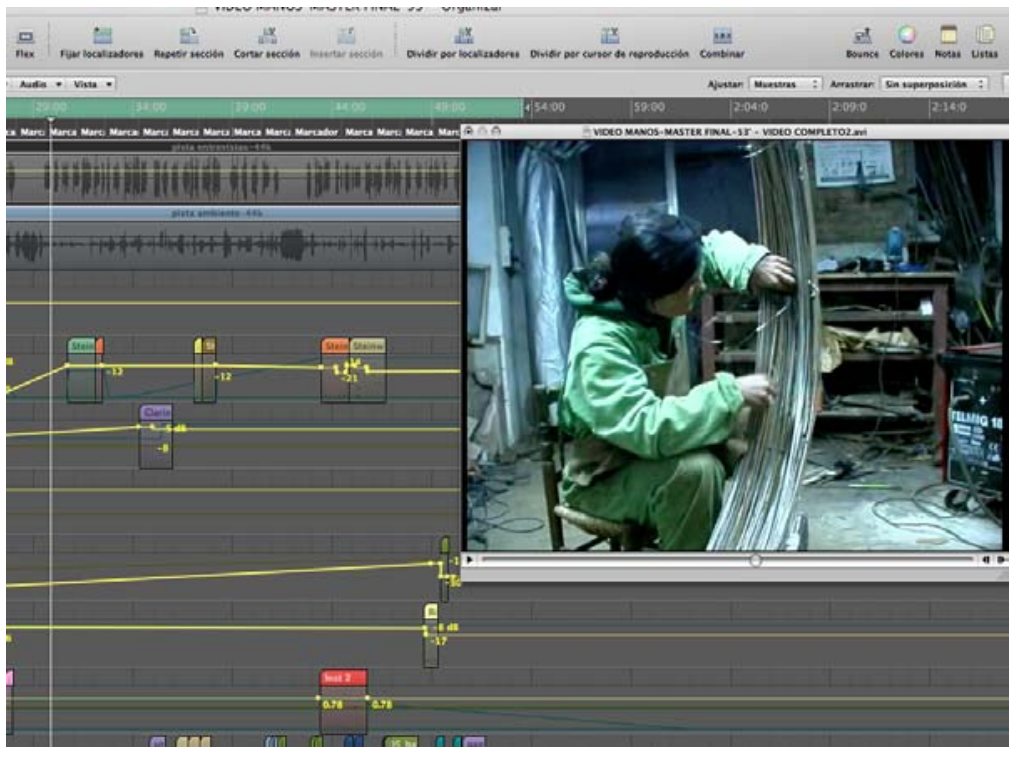

Fig. 197 Captura de la edición de sonido

Ambas categorías fueron tratadas con la misma metodología que se ha descrito en el anteriormente (ver Tema o). De este modo se producían situaciones en las que una misma muestra, y de un mismo instrumento, podía capitularse de un modo o de otro dependiendo la cantidad y cualidad de procesos digitales por las que hubiera pasado. Esto conforma un abanico muy rico y ordenado a la hora del trabajo de edición y maquetación sobre un material tan concreto. Así mismo, esta metodología proporciona una coherencia que de otro modo podría presentar incoherencias en la correspondencia imagen (artista, objetos, psicología) - sonido (textura, comportamiento, asociación).

\subsubsection{PROCESAMIENTO DIGITAL}

Los procesos de edición y manipulación por los que pasaron las muestras dependen de las prestaciones y tipología que nos ofrecen los distintos paquetes de software que existen en el mercado. Naturalmente hay un mercado tan ingente de aplicaciones para el procesamiento de señales de audio que el compositor o artista sonoro 
termina por reducir a sus propias necesidades y gustos. Para este ensayo he contado con las siguientes herramientas:

- Max MSP 5 (Puckette y Zicarelli, 1990), esta plataforma de programación dirigida a objetos, permite una planificación en detalle de cualquier proceso de sonido que pueda estar comercializada por cualquier otro fabricante. Las ventajas que presenta son: la gran difusión y exploración a las que se ven sometidas sus aplicaciones por infinidad de compositores, programadores, desarrolladores y artistas. De este modo podemos acceder a multitud de patchs (aplicación) de naturaleza libre o derechos de autoría. En inconveniente que presenta es la dificultad que exige al neófito cuando descubre que está diseñado como una plataforma de programación y aunque el manejo de los objetos es bastante intuitivo requiere conocer y dominar ciertos protocolos de comunicación y comportamiento que necesitan de un exhaustivo estudio previo antes de utilizarlo en procesos complejos. Dentro de esta plataforma se han utilizado los siguientes recursos y procesos:

- Procesos de granulación, basados en el patch de Nobuyasu Sakonda (Sakonda, 2010) (Fig. 198). Este proceso nos permite desarrollar sonidos y texturas sostenidos o extendidos en el tiempo a partir de la manipulación y tratamiento minúsculo (hasta 5 milisegundos) de las partes (granos) conforman de cualquier archivo de sonido. Nos permite recrear situaciones temporales paradójicas, extraer propiedades acústicas y tímbricas de una muestra sonora que de otro modo pasarían desapercibidas. 


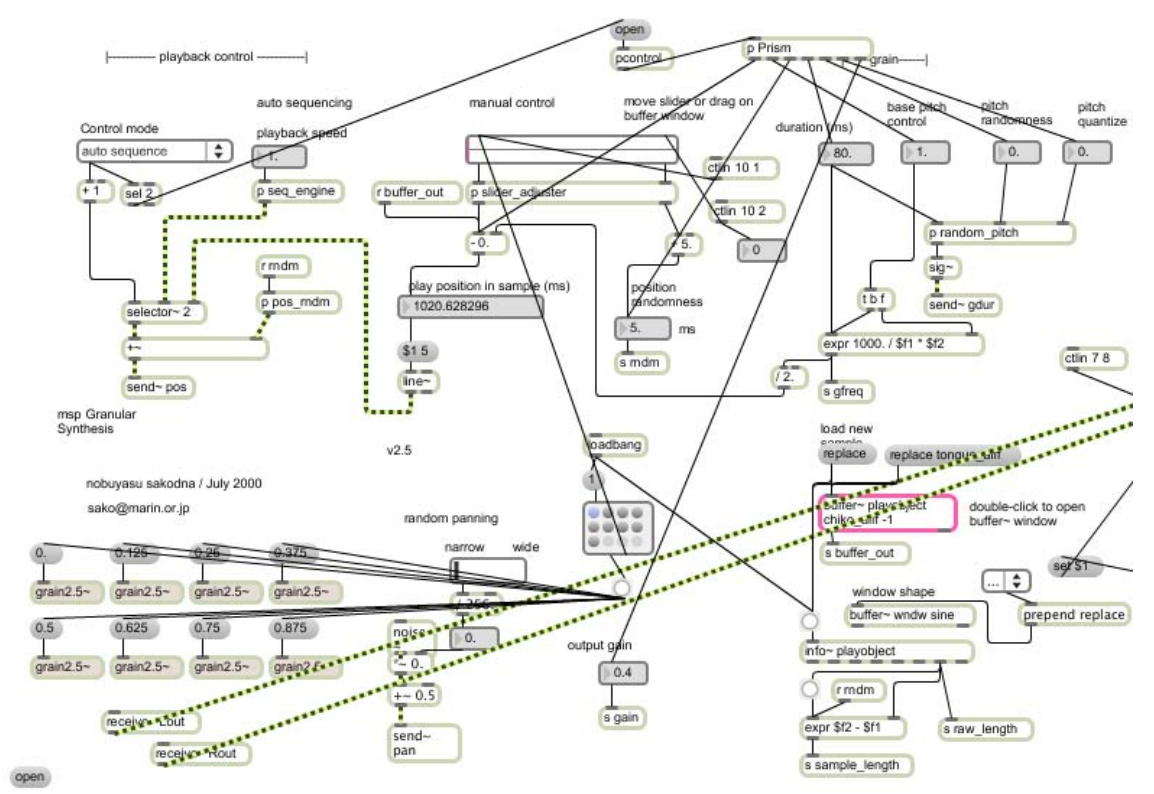

Fig. 198 Captura de Granular 2.5 de Nobuyasu Sakonda, en (Sakonda, 2010)

- Procesos de descomposición temporal, creación de bucles y repeticiones desarrollados con la ayuda del objeto grooveduck (Fig. 199).

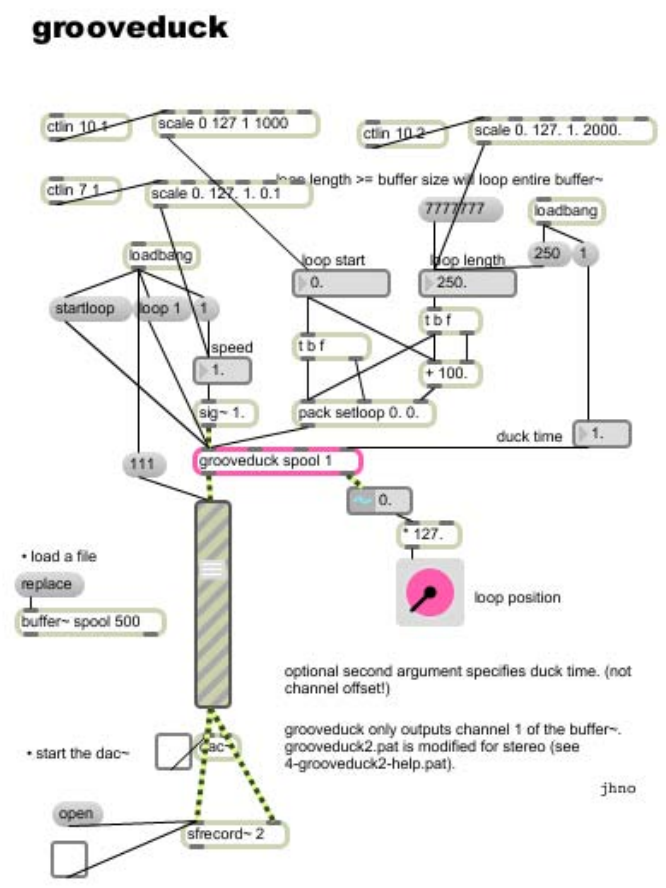

Fig. 199 Captura del objeto grooveduck 
- Transformaciones tímbricas desarrolladas con la ayuda también de un objeto de la librería propia de Max MSP llamado vocoder, que permite analizar y resintetizar sonidos para obtener un timbre tipo vocal. Este proceso está basado en el análisis por la transformada de Fourier (FFT) (Berenguer, 1974).

Alguno de estos procesos han sido descritos anteriormente en el ensayo TanGram. Dada la flexibilidad de la plataforma Max MSP también tienen un uso accesible para situaciones de live electronics (electrónica en vivo) y procesos en tiempo real. En este caso han servido como herramientas en la creación, edición y exploración de muestras de sonido.

- Csound 5 (Csound, 2010a) (Fig. 200), es un paquete de software orientado al igual que Max MSP, a crear, editar, analizar y componer música y sonido. También es llamado así el propio lenguaje de programación que se usa para controlar el software (Csound, 2010a). Funciona correctamente en máquinas pequeñas y lentas, aunque si se ejecuta en equipos más potentes, es posible utilizarlo en tiempo real, crear interfaces gráficas de usuario, y conectarlo a otros programas vía drivers o red. En el propio entorno de Csound existen aplicaciones, programadas por desarrolladores, que ofrecen un grado de detalle en el procesamiento de señales diferente a Max MSP (Puckette y Zicarelli, 1990). A continuación haré una breve descripción de los procesos utilizados en esta plataforma: 


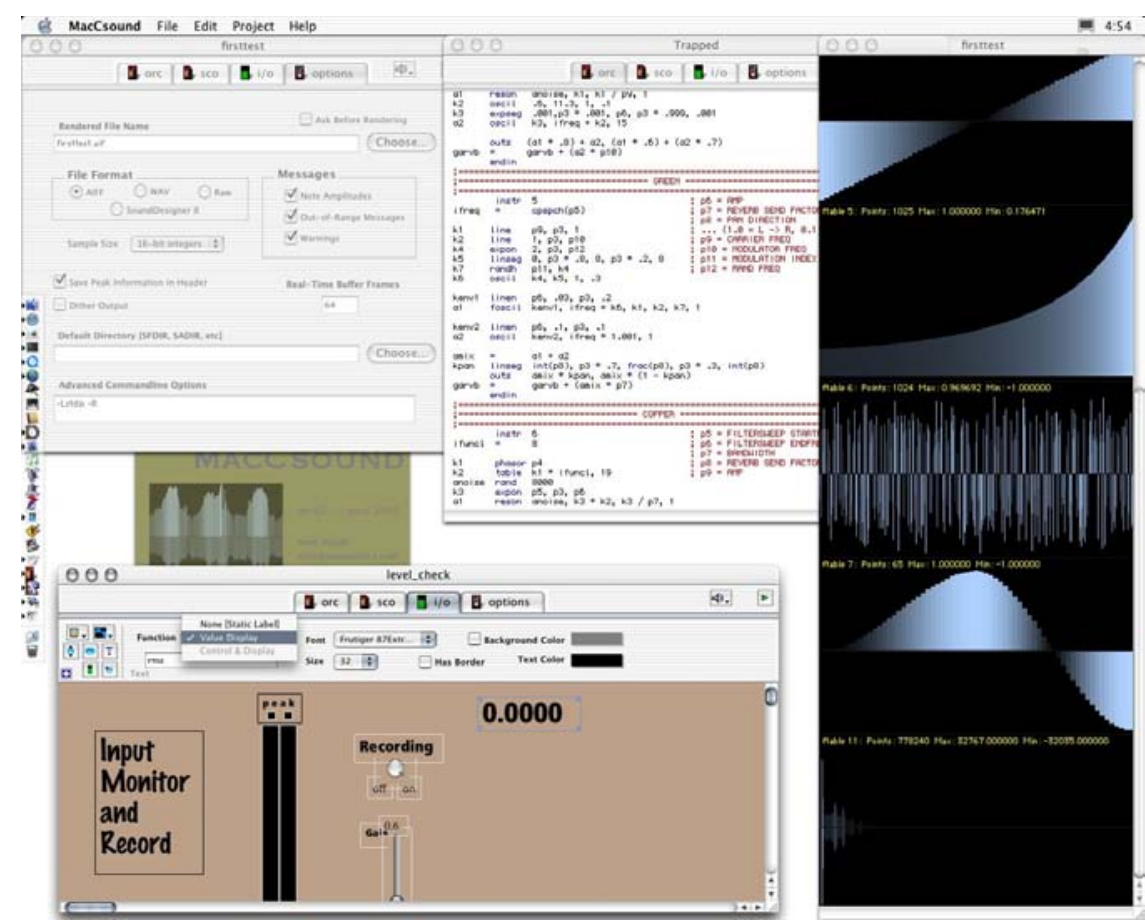

Fig. 200 Captura del programa Csound 5, en (Csound, 2010a)

- Creación de texturas suspendidas en el tiempo. Consiste en la mezcla de transformaciones sobre reverberaciones naturales y artificiales y procesos sobre vocoder (síntesis sobre tímbrica vocal) con expansión temporal.

- Experimentación a partir el código abierto de Alan Lee (Boulanger, 2000) sobre síntesis granular. Manipulación de la altura y amplitud de muestras previamente montadas en estudio. A continuación podemos ver parte de este código en el cual son manipulables multitud de parámetros: desde la ratio de sampleado, hasta la longitud de los granos, pasando por el margen de movimiento que pueden tener estos granos en una escala reducida de frecuencia (Fig. 201). 


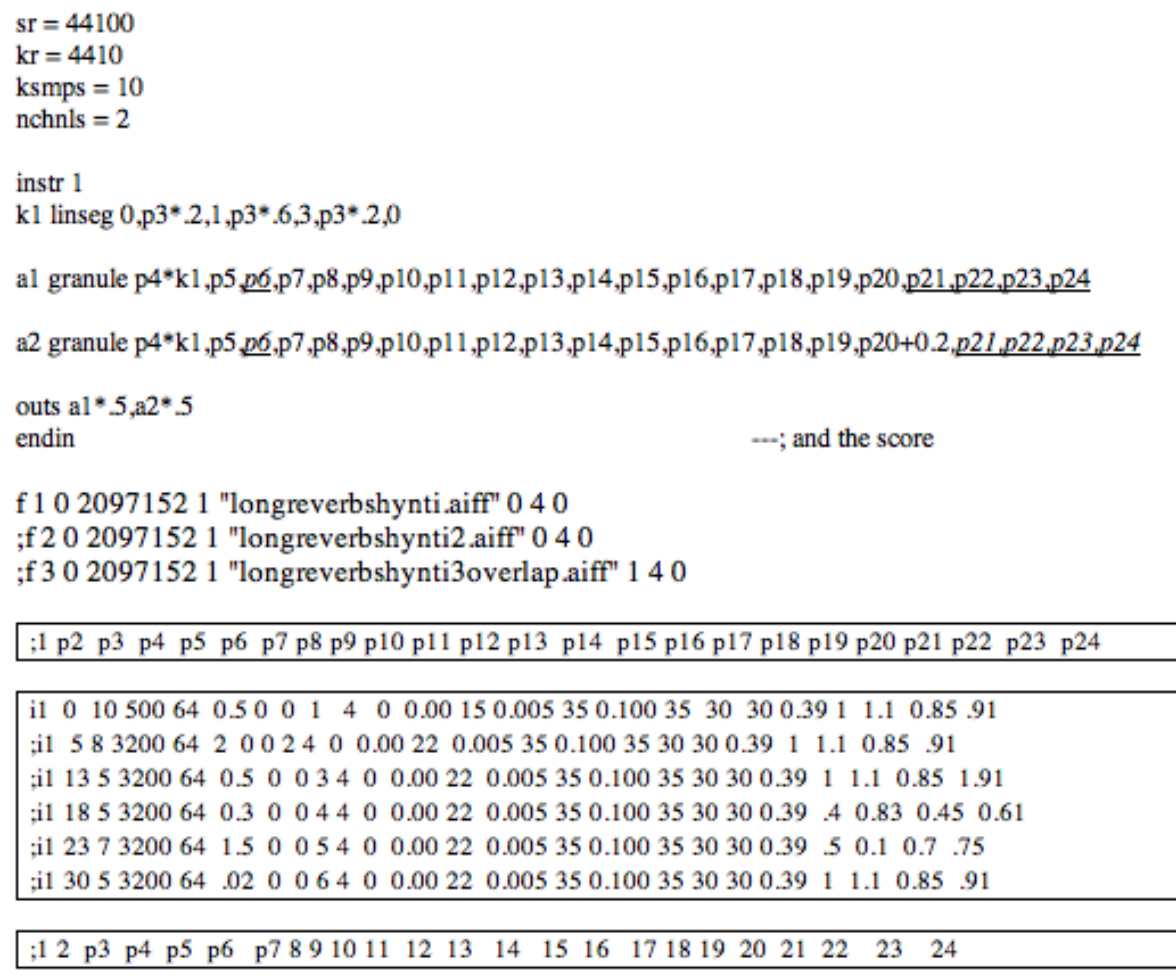

Fig. 201 Captura del código basado en Alan Lee, en (Boulanger, 2000)

- Generación de ritmos erráticos de sonidos tipo crujido o chasquido, con panorámica random. Para ello, cloné los experimentos y la manipulación anterior sobre las alturas creando más densidad e impredictibilidad.

\subsubsection{SÍNTESIS Y DISEÑO SONORO}

En la actualidad existen infinidad de plataformas y entornos de edición que ofrecen librerías de sonidos generados a partir de sintetizadores modulares. Para la creación y diseño de las partes abstractas de este proyecto se han utilizado las generadas por los módulos Reaktor (Fig.202) y Absynth (Fig. 203), pertenecientes al paquete de instrumentos de Kontakt 6, del fabricante Native Instruments ( $\mathrm{NI}$, 2010). Esta función sería perfectamente diseñable y programable en Max MSP o Csound indistintamente, sin embargo los siguientes 
paquetes de efectos e instrumentos ya tienen unas prestaciones preestablecidas y una interfaz gráfica muy intuitiva que facilitan el uso del compositor sin necesidad de pasar por toda la programación de código.

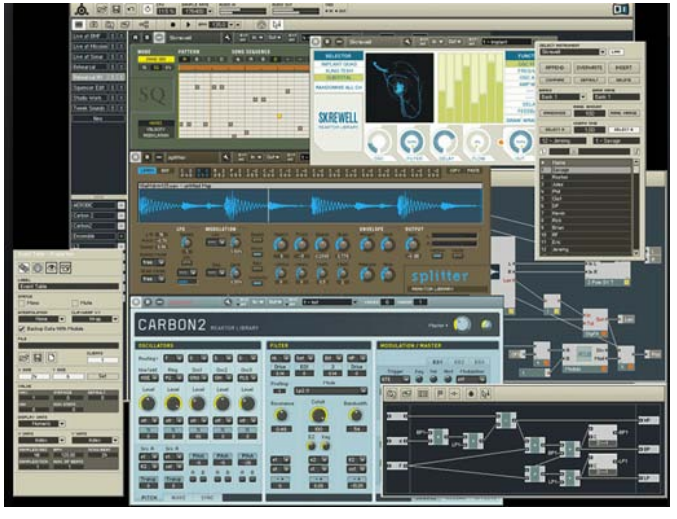

Fig.202 Captura de Reaktor

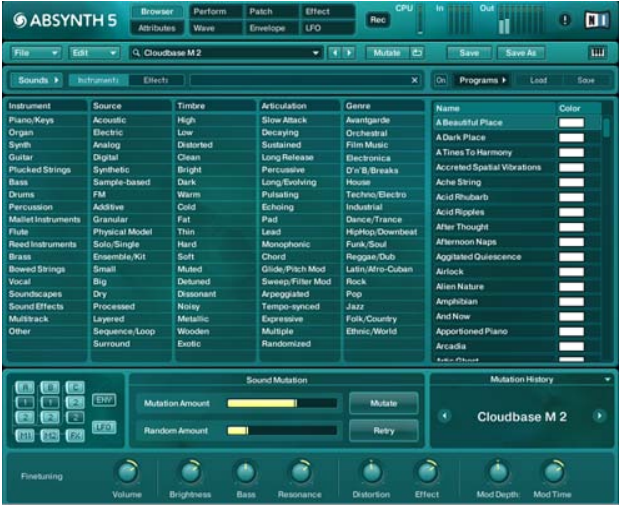

Fig. 203 Carptura de Absynth

Por otro lado, también se han explorado las posibilidades de los sintetizadores integrados en el secuenciador de Apple, Logic (Apple, 2010b): Sculpture (Fig. 204), Ultrabeat (Fig.205) y EXS24 (Fig. 206). Cada uno presenta unas características concretas, aunque la base de todos se sostiene sobre la síntesis y la opción de definir más o menos parámetros a partir de varios osciladores de frecuencia.

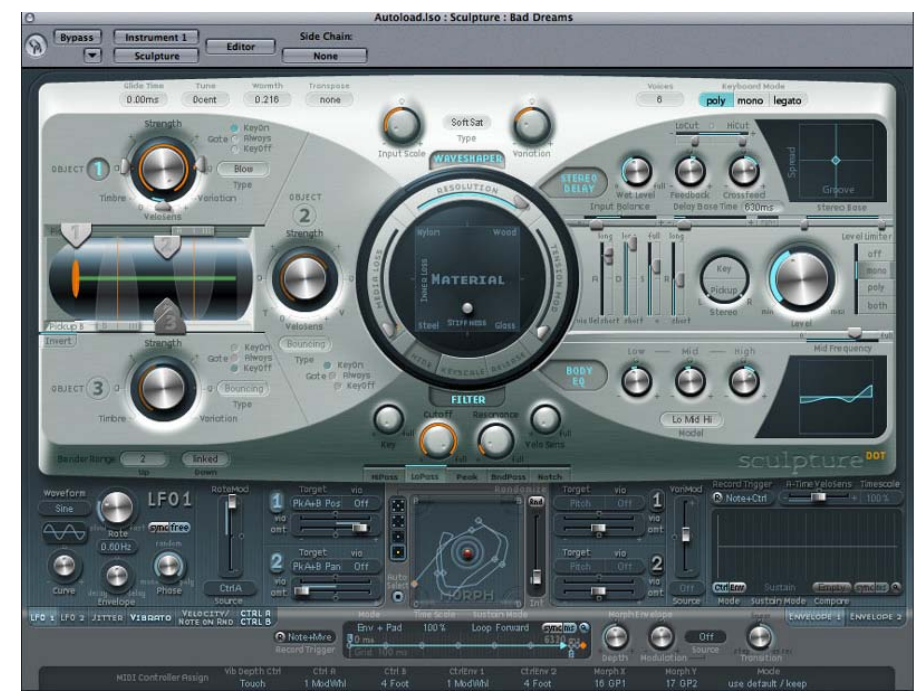

Fig. 204 Captura de Sculpture 
En el caso de Ultrabeat, nos permite cargar muestras pregrabadas y dispararlas con una determinada velocidad o frecuencia de tiempo, modificar algunos parámetros de altura, timbre o panorámica, así como aplicar diferentes filtros y efectos.

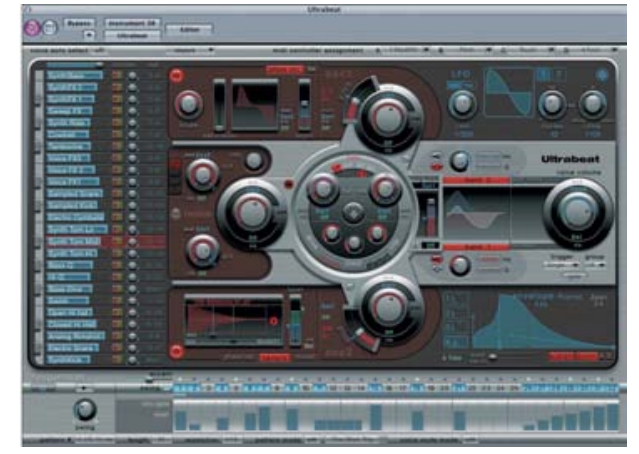

Fig.205 Captura de Ultrabeat

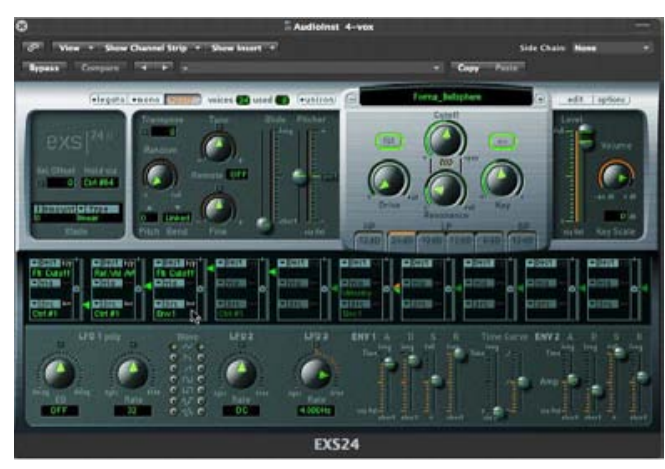

Fig. 206 Captura de ESX24

\subsubsection{SECUENCIACIÓN}

La herramienta fundamental para la secuenciación de todas las muestras y sonidos creados y recolectados después de un amplio trabajo de campo (grabaciones en vivo con los instrumentistas, sampleado de muestras y extracción de resultados a partir de plataformas de edición y softwares de creación musical) es el secuenciador. En este caso se optó por la utilización de Logic (Apple, 2010b), en un ordenador MacBook Pro con un procesador de 2.66 GHz Intel Core 2 Duo con 4 GB 1067 MHZ DDR3 de Apple. La interfaz gráfica y las prestaciones técnicas lo presentan como uno de los programas más potentes, estables y conocidos del mercado (Fig. 207). 


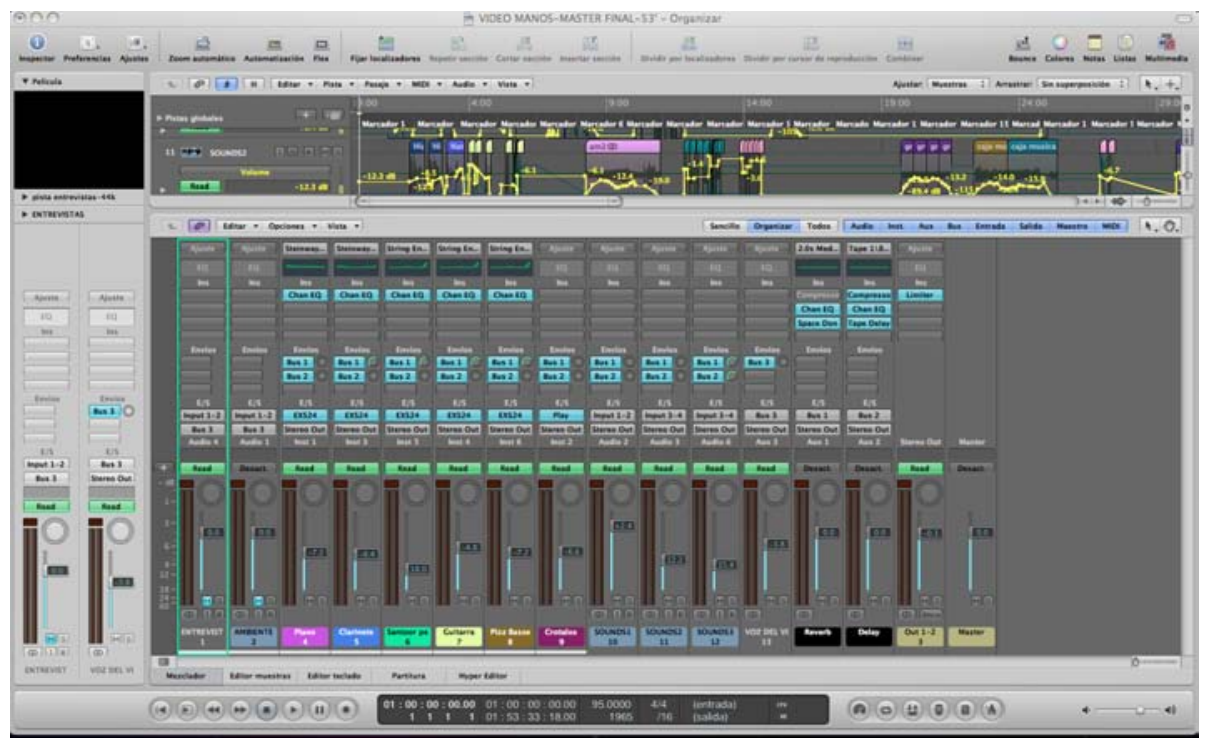

Fig. 207 Captura de la sesión en Logic

Entre las ventajas que ofrece este programa en un trabajo de secuenciación de este tipo, donde se hace necesaria la integración de materiales directos, grabados, acústicos y electroacústicos, está las de poder cargar una serie de prestaciones adicionales que nos permitan manipular parámetros como Ecualización, Compresión, y efectos de tipo espacial como Reverberación, Eco, etc... (con o sin retraso temporal) que nos garantizan una integración tímbrica absoluta del resultado final.

En este proceso de secuenciación se hizo necesario contar con las pistas de ambiente que los autores del video habían rodado. Existía por tanto una labor previa por parte del montador del video en la que ya estaba definido el ruido ambiente, los comentarios de los artistas y los cortes que el autor había decidido respetar. Si bien es cierto que se me ofreció la posibilidad de alterar este orden preestablecido, mi intención desde un principio fue la de mantener en la medida de lo posible este primer estadio de edición sonora. De este modo la parte musical (acústica y electroacústica) se adaptó en todo momento al primer boceto del productor. 


\subsection{CONSIDERACIONES}

Los creadores del video-documental planificaron una primera versión con una duración total de 1 hora y 40 minutos. Y sobre esta versión se trabajó desde el principio. Es importante recalcar que es de máxima importancia contar con una versión de tiempo lo más ajustada posible para trabajar en la composición y edición de sonido sobre la imagen ya que el diseño de la forma temporal es decisivo para obtener un discurso musical coherente al planteamiento del proyecto. De otro modo la labor del compositor tiene que cambiar y rehacerse a cada momento cuando la duración se ve sustancialmente modificada (Chion, 1994).

Después de proponer el material final para su difusión en festivales de video-arte y retransmisiones por televisión, se valoró la posibilidad de reducir la duración hasta conformar una nueva versión de 53 minutos. Este hándicap es de vital importancia en la creación de la música ya que los tempos y espacios de percepción del sonido cambian sustancialmente dependiendo del material visual del que disponemos. Es por esto que a partir del primer formato se tuvo que rehacer toda la secuenciación temporal para la versión más corta.

La solución de los creadores y productores del video para reducir el formato del video fue reducir cada entrevista individual en 10 segundos aproximadamente. Esto planteó la necesidad de rehacer la disposición y cantidad de material sonoro creado para cada artista y cada transición. En primera instancia se trataron de respetar los materiales creados para los diferentes artistas que iban apareciendo en el video, pero fue inviable dado que se establecía una aceleración innecesaria e incoherente a la propia naturaleza de los sonidos y de la lógica visual. Para solucionar este problema se hizo necesaria una 
planificación temporal totalmente nueva y diferente. Los materiales de dimensiones temporales reducidos pudieron en la mayoría de casos, permanecer con su correspondiente secuencia y artista, ya que estaban pensados y creados a partir de ellos mismos, sin embargo las texturas más extensas y atmósferas de unión entre varios artistas se tuvieron que rehacer y reubicar para mantener el ritmo y tempo psicológico del sonido planteado al comienzo de este proyecto.

Las correspondencias gestuales entre la imagen y sonido que se proponen en la hipótesis de esta tesis se han conseguido a partir de la catalogación y examen exhaustivo que se desprende del estudio espectromorfológico descrito en este ensayo. Así pues, una metodología tan concreta como esta, proporciona una coherencia interna entre la imagen y sus particularidades con el gesto sonoro, su comportamiento y sus características. 


\section{CONCLUSIONES}

En un contexto de composición musical raramente se emplean análisis de resultados o se extraen conclusiones sobre una obra. En el mejor de los casos, estas perduran en el tiempo y se programan con asiduidad en plataformas de difusión como festivales, conciertos, convenciones o por el contrario pasan del estreno a un discreto contenido bibliográfico por el que algún investigador revoloteará en algún momento.

En una investigación con una gran carga práctica, como es esta tesis, se pueden extraer conclusiones a partir de la lectura transversal de los capítulos expuestos, discutiendo algunos aspectos que se consideran más relevantes y significativos. También se considera útil adjuntar una visión personal, tanto de las facilidades como de las dificultades que ofrece el lenguaje musical electroacústico.

La electroacústica como manera de entender el arte musical, vive su auge en estos días; ofrece un abanico de posibilidades en lo referente 
a la expresión interpretativa y a las diferentes artes con componente escénico, que lo convierte en una pieza clave en la investigación de nuevas fronteras artísticas. En esta tesis se ha mostrado como un lenguaje a priori nacido en el seno de la más pura abstracción, ha ido flexibilizando sus cotas para transversalizarse hacia formatos que no tienen nada que ver con sus planteamientos originales. Tanto sus posibilidades expresivas como los recursos y dispositivos que están diseñados para su uso y manipulación, permiten la extensión de sus virtudes hacia otras parcelas del arte aparentemente desvinculadas del sonido.

En los últimos años y gracias al desarrollo de aplicaciones y programas que permiten un uso intuitivo y accesible a la creación y manipulación del sonido y su procesamiento digital, existe un creciente interés por parte de la comunidad investigadora en estudiar las posibilidades expresivas en entornos de interpretación musical, por lo que surge la necesidad de estudiar los aspectos relacionados con el componente humano. Al margen de las conclusiones que se han derivado de cada uno de los ensayos (temas 1 al 5) realizados en esta tesis, se pueden derivar algunas conclusiones referentes al intérprete:

- La utilización de sensores inalámbricos como el accesible mando Wii de Nintendo o el sensor inercial MT9 permiten desplegar toda una serie de posibilidades gestuales en un marco de interpretación musical. El instrumentista amplia sus posibilidades de interacción con el sonido y con los demás intérpretes;

- Además se pueden establecer patrones de improvisación concretos que pueden estar basados en la visualización de un objeto; 
- La automatización de procesos de almacenaje y selección de archivos de sonidos grabados, vinculados a categorías semánticas, permite diseñar aplicaciones abiertas que funcionen como intérpretes virtuales semi-controlados;

Con respecto a representaciones visuales o a la correspondencia del gesto sonoro con la imagen podemos extraer una serie de conclusiones:

- La utilización de recursos y procesos pensados para el análisis del sonido pueden invertirse para generar herramientas de visualización. Los displays gráficos basados en proyecciones facilitan una visualización compartida, posibilitando la participación colaborativa en el uso de un único dispositivo (con la consecuente reducción de costes) al tiempo que permiten una escalabilidad de los datos mostrados;

- La abstracción de ideas y conceptos visuales se pueden sintetizar mediante las posibilidades de transformación que ofrecen las aplicaciones de edición de sonido, de este modo se pueden integrar o diferenciar dos mundos perfectamente solubles, la plasticidad de los instrumentos acústicos tradicionales con los timbres y texturas sonoras de la música electroacústica;

- Tanto el gesto visual como la imagen, pueden ver su naturaleza conceptual transformada, extendida y ampliada mediante el empleo y la aplicación de gestos sonoros concretos.

Se puede afirmar que la electroacústica es una nueva categoría expresiva que puede verse enriquecida y favorecida gracias a la fusión y a la síntesis con otras disciplinas artísticas. El formato de 
electroacústica con video se ha establecido en algunas plataformas de creación como un vehículo de investigación expresiva paralelo a la creación sólo con sonido.

A continuación se hará una comparativa entre los diferentes programas utilizados en la composición, edición y transformación de sonido (Fig. 208).

\begin{tabular}{|c|c|c|}
\hline SOFTWARE & VENTAJAS & DESVENTAJAS \\
\hline $\begin{array}{c}\text { Max MSP + Jitter } 4.6 \text { y } 5 \\
\text { (Ensayos } 1 \text { al 5) }\end{array}$ & $\begin{array}{l}\text { Nivel de programación: } \\
\text { No necesario } \\
\text { Amplio desarrollo de } \\
\text { objetos libres } \\
\text { Integración de periféricos } \\
\text { Alta estabilidad } \\
\text { Electrónica en vivo } \\
\text { Datos multimedia: } \\
\text { OpenGL, VRML (y otros } \\
\text { formatos 3D), sonido, } \\
\text { imagen, video. } \\
\text { Windows y Mac }\end{array}$ & $\begin{array}{c}\text { No es software libre. } \\
\text { No es software específico } \\
\text { para edición y } \\
\text { manipulación de video ni } \\
\text { entornos de Realidad } \\
\text { Aumentada. }\end{array}$ \\
\hline $\begin{array}{c}\text { Logic } 9 \\
\text { (Ensayos } 4 \text { y } 5 \text { ) }\end{array}$ & $\begin{array}{c}\text { Entorno profesional } \\
\text { Amplia versatilidad } \\
\text { Interface intuitiva } \\
\text { Integración de } \\
\text { instrumentos y módulos } \\
\text { VST y AU }\end{array}$ & $\begin{array}{c}\text { No es software libre } \\
\text { Exclusivo de Macintosh } \\
\text { Alto consumo de recursos } \\
\text { Complejo }\end{array}$ \\
\hline $\begin{array}{c}\text { Audacity 1.2.6a } \\
\text { (Ensayo 1) }\end{array}$ & $\begin{array}{c}\text { Software libre } \\
\text { Interface sencilla } \\
\text { Desarrollo e integración } \\
\text { de Plug-ins y bibliotecas } \\
\text { gratuitas }\end{array}$ & $\begin{array}{c}\text { Bajo desarrollo de } \\
\text { aplicaciones y } \\
\text { prestaciones } \\
\text { Sólo recomendado en } \\
\text { Windows Vista, } 7 \text { y Mac } \\
\text { OS X } 10.6\end{array}$ \\
\hline $\begin{array}{l}\text { Csound } 5 \\
\text { (Ensayo 5) }\end{array}$ & $\begin{array}{l}\text { Software libre } \\
\text { Lenguaje de }\end{array}$ & $\begin{array}{l}\text { Alto nivel de } \\
\text { programación }\end{array}$ \\
\hline
\end{tabular}




\begin{tabular}{|c|c|c|}
\hline & $\begin{array}{c}\text { programación propio } \\
\text { Bajo consumo de recursos } \\
\text { en computadoras lentas } \\
\text { Linux, Windows y Mac }\end{array}$ & $\begin{array}{c}\text { Interface confusa } \\
\text { Integración compleja de } \\
\text { periféricos y dispositivos } \\
\text { Tiempo real en } \\
\text { computadoras potentes }\end{array}$ \\
\hline $\begin{array}{l}\text { Reaktor } 5 \\
\text { (Ensayo 5) }\end{array}$ & $\begin{array}{c}\text { Entorno modulary } \\
\text { gráfico } \\
\text { Amplio abanico de } \\
\text { presets e instrumentos } \\
\text { Emulación de } \\
\text { Sintetizadores } \\
\text { Ingeniería inversa } \\
\text { Windows y Mac }\end{array}$ & $\begin{array}{l}\text { No es software libre } \\
\text { Complejo manejo y } \\
\text { manipulación de } \\
\text { aplicaciones y } \\
\text { prestaciones } \\
\text { Ejecutable en modo } \\
\text { AudioUnit o Standalone }\end{array}$ \\
\hline $\begin{array}{l}\text { Absynth } 5 \\
\text { (Ensayo 5) }\end{array}$ & $\begin{array}{l}\text { Interface gráfica fácil e } \\
\text { intuitiva } \\
\text { Gran versatilidad en } \\
\text { síntesis modular } \\
\text { Windows y Mac }\end{array}$ & $\begin{array}{c}\text { No es software libre } \\
\text { Ejecutable en modo } \\
\text { AudioUnit o Standalone }\end{array}$ \\
\hline $\begin{array}{c}\text { Peak Pro } 5 \\
(\text { Ensayo 1, } 3 \text { y 4) }\end{array}$ & $\begin{array}{c}\text { Interface sencilla } \\
\text { Desarrollo e integración } \\
\text { de Plug-ins y bibliotecas }\end{array}$ & $\begin{array}{c}\text { No es software libre } \\
\text { Exclusivo de Macintosh } \\
\text { Inestabilidad }\end{array}$ \\
\hline
\end{tabular}

Fig. 208 Comparación entre los distintos programas utilizados en esta tesis. Ventajas e inconvenientes encontrados

Uno de los puntos clave en la utilización de los diferentes tipos de software es el tema del coste. En la actualidad existe un creciente interés por el desarrollo de plataformas de distribución libre, sin embargo las posibilidades y prestaciones que ofrecen los programas de pago suelen ser sustancialmente superiores a aquellos. Además, el desarrollo de drivers y periféricos por parte de terceros es decisivo cuando se refiere al uso de dispositivos complementarios. 
En cualquier caso, las oscilaciones de coste, condiciones y prestaciones son muy frecuentes en el mercado de software, no son una referencia a largo plazo.

En la siguiente imagen (Fig. 209) podemos ver una comparativa con los diferentes métodos de registro (sensores) que se han utilizado en esta tesis.

\begin{tabular}{|c|c|c|}
\hline SENSORES & VENTAJAS & DESVENTAJAS \\
\hline $\begin{array}{c}\text { Micrófono } \\
\text { (Ensayos } 1 \text { al 5) }\end{array}$ & $\begin{array}{c}\text { Gran accesibilidad } \\
\text { Integración en la gran } \\
\text { mayoría de plataformas } \\
\text { de sonido }\end{array}$ & $\begin{array}{c}\text { Ingente gama de modelos } \\
\text { y prestaciones en el } \\
\text { mercado }\end{array}$ \\
\hline $\begin{array}{l}\text { MTg Xsens } \\
\text { (Ensayo 2) }\end{array}$ & $\begin{array}{c}\text { Registra } 9 \text { parámetros } \\
\text { distintos ( } 3 \text { magnitudes } \\
\text { en } 3 \mathrm{D} \text { ) } \\
\text { Precisión media } \\
\text { Conexión estable }\end{array}$ & $\begin{array}{c}\text { No es inalámbrico } \\
\text { Necesita conexión a red } \\
\text { eléctrica } \\
\text { Coste elevado } \\
\text { Hubo que diseñar un } \\
\text { objeto específico para } \\
\text { conectar con Max MSP }\end{array}$ \\
\hline $\begin{array}{c}\text { Wii Nintendo } \\
\text { (Ensayo 3) }\end{array}$ & $\begin{array}{c}\text { Gran accesibilidad } \\
\text { Bajo coste } \\
\text { Conectividad via } \\
\text { Bluetooth } \\
\text { Estabilidad con } 4 \text { Mandos } \\
\text { a través de } A k a \\
\text { (Akamatsu, 2009) y Max } \\
\text { MSP } 4.6\end{array}$ & $\begin{array}{c}\text { Inestabilidad en Max MSP } \\
5 \\
\text { Precisión baja }\end{array}$ \\
\hline
\end{tabular}

Fig. 209 Comparación entre los distintos métodos de registro utilizados en esta tesis. Ventajas e inconvenientes encontrados

\section{Líneas futuras}

A partir de la experiencia adquirida después de la realización de los ensayos descritos en esta tesis y mi actividad como compositor e 
intérprete, sería importante realizar nuevas investigaciones e incursiones en situaciones artísticas similares.

- Desarrollar aplicaciones en el ámbito de la realidad aumentada aprovechando la versatilidad de este entorno y las posibilidades de expresión sonora asociados al gesto y el espacio físico.

- Integración de sistemas de registro con una alta precisión y estabilidad en el procesamiento de datos y su correspondencia con parámetros escénicos, tanto en interpretaciones con instrumentos, cantantes, actores, performers, bailarines, etc.

- Explorar otros dispositivos y metodologías no abarcadas en esta tesis. Uno de los aspectos que está en creciente desarrollo es la integración eventual del público al objeto artístico en las representaciones, mediante el empleo de pequeños dispositivos móviles, tales como PDAs o teléfonos móviles.

- Incursión en el mundo del Arte sonoro (descrito en la introducción de esta tesis), y la instalación vinculada al sonido.

- Exploración profunda de la dialéctica del lenguaje electroacústico para establecer concordancias entre la percepción cognitiva del gesto sonoro, el visual y el espacial. 



\begin{abstract}
ANEXO I
Este anexo contiene una descripción de las obras para electroacústica, con o sin instrumentos, compuestas durante el periodo de la elaboración de esta tesis. Como se apuntaba en la Introducción, este trabajo paralelo a la realización de los ensayos, completa mi formación y experiencia como compositor e investigador en lenguajes y planteamientos estéticos relacionados con la composición musical asistida por medios electrónicos.

\section{Obras para Cinta}

El término 'cinta' se refiere en este caso a las obras que están pensadas para su reproducción por altavoces. Aunque es evidente que ya no se utilizan las cintas magnéticas (tape) que utilizara Schaeffer en sus primeras obras concretas, el término se sigue utilizando al referirse a composiciones electroacústicas en soportes grabados. Todas las obras están preparadas para difundirse en dos formatos: stereo (2 canales) u octofónico (8 canales), dependiendo de las características de cada representación o soporte de reproducción.
\end{abstract}


- Synapse (2007) $-7^{\prime} 15^{\prime \prime}$

Existen enfermedades cerebrales que están ligadas a un funcionamiento anormal de ciertas sinápsis neuronales. Algunas patologías, como la arteriosclerosis cerebral, más conocida como Alzheimer, se han hecho un injusto hueco en nuestra sociedad. Pero hay atrofias cerebrales que tienen un origen aun más perverso. El mercado de poder está estableciendo a día de hoy pautas de control dirigidas especialmente a aquellos sectores más vulnerables. Los grandes lobbies se plantean qué clase de medidas pueden atrofiar aún más nuestra percepción de la realidad. Existe entonces un objetivo consensuado para redirigir nuestra cognición. Es cuando esta patología diseñada nos plantea como enfermos moldeables. No se trata pues de que no oigamos o no queramos oír, es más bien que nos roban los instrumentos de audición. Nuestra vida se convierte entonces en un carrusel de falsas imágenes, de recuerdos desmembrados, de impresiones manidas, de crispación continua... La destrucción neuronal involuntaria de las sinapsis colinérgicas en el plano social no es fruto de una estulticia voluntaria sino de una estulticia promovida. Esta sinapsis sonora está dedicada a todos aquellos que quieren luchar contra sí mismos.

Esta obra fue estrenada en el festival Zeppelin, organizado por Sonoscop y Orquesta del Caos, que fue celebrado en Barcelona en Mayo de 2008.

- La midi d'un marteau (2008) - 4' 20"

La retórica simbolista de Mallarmé y la lírica impresión de Debussy han atraído a ciertos compositores y amantes de la entropía a lo largo de los últimos años. El arte, después de haberse visto sacudido por 
gran variedad de estéticas y estilos parece querer pararse a veces en la ensoñación más absurda de sus creadores. Largas y edulcoradas metáforas acerca de la permeabilización de los conceptos y los gestos reflexivos acaban por minar mi paciencia como consumidor del arte sonoro. Esta obra parte de dos conocidas obras francesas que serán de-construidas y destiladas hasta sus connotaciones más grotescas y carnales. Frente a la pasividad de la idea, la activación de la ironía y la burla sonora debe servir también como revulsivo más eficaz en el avance socio-cultural.

- Mystic nits (2008) - 4' 41"

En plena modernidad tecnológica me sorprende ver aún el método manual de retirar con paciencia las liendres del pelo de los niños. A veces mi subconsciente me lleva por derroteros grotescos y quiere hacer asociaciones un tanto rocambolescas. En esta obra veo a un amanuense luchando contra las liendres, pero esta vez, las liendres no son otras que las ideas antiguas de la adoración a los mitos. A la vez que aquellas son difíciles de eliminar, estas tampoco lo ponen nada fácil. La modernidad no puede quedarse en el vano adelanto de las tecnologías y por ello este amanuense sonoro quiere eliminar todo rastro antiguo: prejuicios, miedos, ataduras religiosas, dobles y hasta triples morales.

Esta obra resultó premiada como finalista en el 'VI Concurso Internacional de Composición Miniaturas Electroacústicas' organizado por la Junta de Andalucía y Confluencias, celebrado en Huelva en 2008 (Fig. 210). 


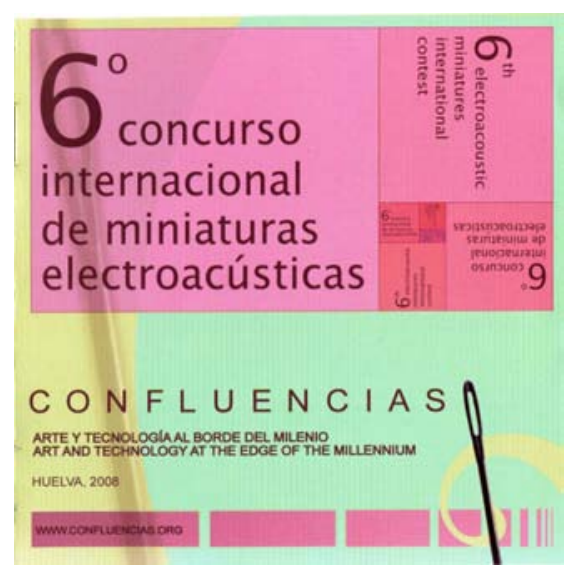

Fig. 210 Portada del CD del VI Concurso Internacional de Composición Miniaturas Electroacústicas, Huelva, 2008

- Creaky motion (2008) - 2' 48'

Esta miniatura electroacústica está creada con motivo del cincuentenario de la composición de la primera obra acusmática: Etude aux Chemins de Fer de P. Schaeffer.. Al igual que aquella, la obra se centra en los recursos sonoros del mundo del tren. Los engranajes, las tuercas, los pitos y crujidos de las vías actúan como instrumentos abstractos que se focalizan o se diluyen en el espacio. El esquema formal de la obra se genera en diferentes viñetas que se irán difundiendo en diferentes panorámicas.

Esta obra está recogida en el CD Musica Concreta, 6o Aniversario 2' 49", AMEE (Asociación de Música Electroacústica de España) (Fig. 211), que fue presentado en concierto el día 25 de octubre de 2008 dentro del marco del XV Festival Internacional Punto de Encuentro celebrado en Valencia. 


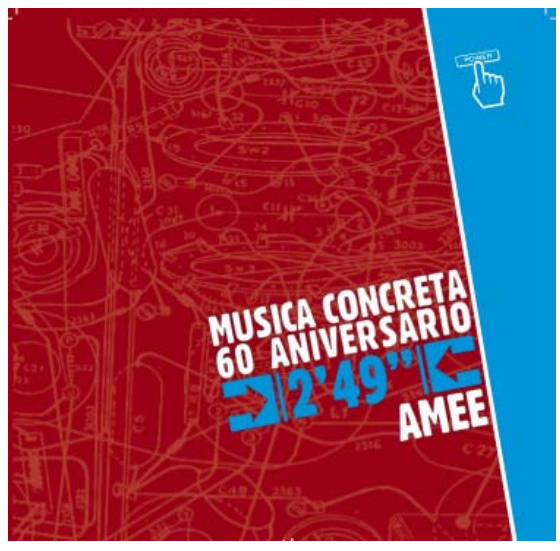

Fig. 211 Portada del CD 60 Aniversario 2' 49"AMEE, Valencia, 2008

- Hydra (2009) $-7^{\prime} 05^{\prime \prime}$

Aubrey de Grey, ingeniero informático especializado en análisis de datos genético sostiene que la senescencia (degeneración molecular), es un parámetro que según las últimas investigaciones podría corregirse. Afirma que tenemos un $50 \%$ de probabilidades de lograr el objetivo de vivir hasta 1000 años en 25030 años de investigación. Se corregiría en este caso la información genética que tienen las células para envejecer y deteriorarse. En base a esta conjetura me llamó la atención que hay organismos, como la Hydra, que no poseen este defecto congénito. La Hydra es un animal de agua dulce que, generalmente posee unos pocos milímetros de longitud y que despierta gran interés para la comunidad científica, ya que tienen esta habilidad regenerativa. Parecen ser únicas en el mundo animal ya que no padecen la senescencia. En base a esta habilidad de autoreparación y autoregeneración la obra se divide en 3 secciones. Cada una de ellas tiene un comportamiento parecido, ya que las muestras utilizadas desarrollan microevoluciones sobre sí mismas, degenerándose y transformándose en materiales análogos. 
Esta obra fue estrenada en el Festival Synthèse celebrado durante el mes de Mayo de 2009, organizado por el IMEB (Institut International de Musique Electroacoustique) en Bourges (Francia).

\section{- Electronic birds (2009) - 5'14"}

La nanotecnología alcanza hoy cotas inimaginables en disciplinas tan dispares como la medicina o la industria armamentística. A partir de incontables ejemplos encontrados en la biología se sabe que miles de millones de años de retroalimentación evolucionada puede producir máquinas biológicas sofisticadas y estocásticamente optimizadas. A partir de la idea de crear macroestructuras complejas a partir de nanomateriales que originaran vida artificial nació Electronic birds. La obra nace a partir de tres miniaturas electroacústicas: Iron bird, Radio bird y Cuco, tres pájaros electrónicos que dan nombre a esta serie. Inspirados en los dibujos de Rick Kaplan y Jess Lee. Haciendo uso del lenguaje espectromorfológico desarrollado por Dennis Smalley me interesaba la exploración de diferentes comportamientos y desarrollos sonoros. Experimentando con estos parámetros surgió una creación multidireccional, recíproca y de movimientos cíclicos y evolutivos que desarrollan estos fantásticos pájaros de naturaleza electrónica.

Esta obra está recogida en el CD AMEE Vol. I, un triple CD que vió la luz en el marco del XVI Festival Internacional de Música Electroacústica Punto de Encuentro celebrado en Valencia durante el mes de Octubre de 2009 (Fig. 212). 


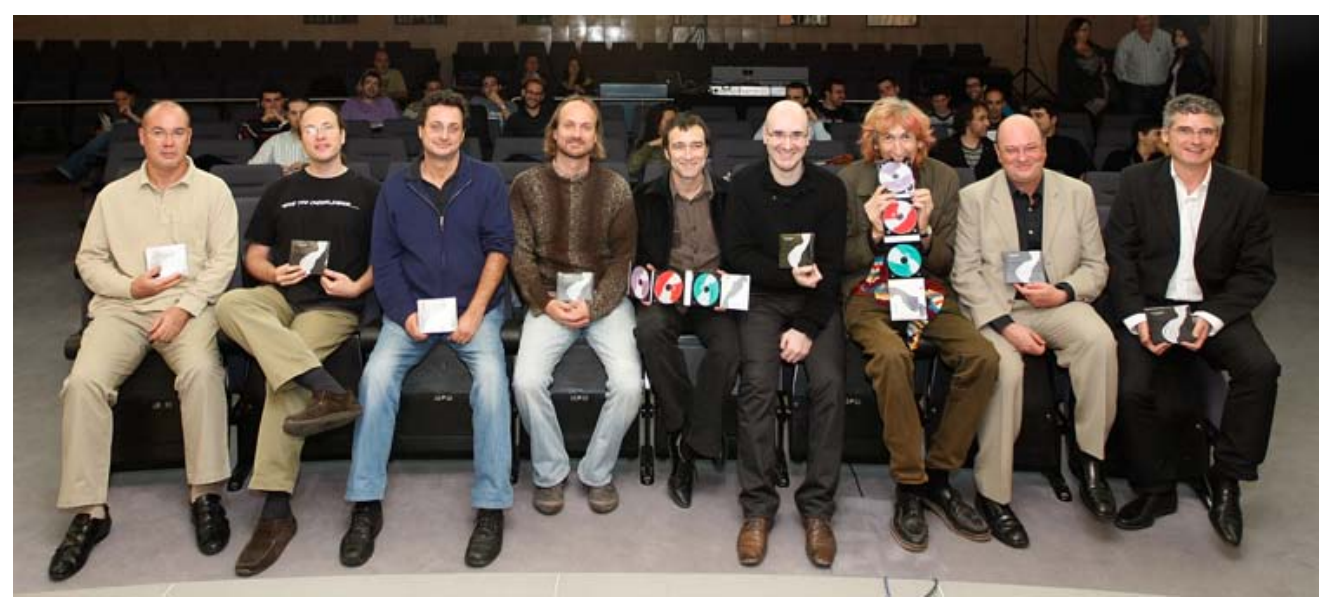

Fig. 212 Presentación del triple CD AMEE Vol. I, Valencia, 2009; de izquierda a derecha Enrique Mateu, Manuel Bonino, Daniel Roca, Jacco van den Hoek, David Alarcón, El autor, Miguel Molina, Gregorio Jiménez y Josep Lluís Galiana.

- Plastic bourée (2010) - 8' 18"

En un mundo moderno, los hábitos antiguos pasan a un olvido libre y voluntario. A veces obviamos que nuestros patrones de aprendizaje son casi idénticos desde hace unos cuantos millones de años. En esta línea, Plastic Bourrée parte de un concepto aberrante. La esencia de la métrica binaria y el pulso sincopado de esta danza medieval es reventada y subvertida más allá de la trascendencia estética que nos concede hoy el arte digital sonoro. La modernidad del lenguaje espectromorfológico nos permite reparar en los detalles, filigranas, ciclos y estructuras que construyen este pastiche sobre una danza antigua. Obra realizada en Valencia. Estreno absoluto.

Esta obra fue seleccionada en el Concurso 'Laboratorio del Espacio' dentro de las XVII Jornadas de informática y electrónica musical (JIEM) organizadas por el LIEM (Laboratorio de Electrónica e Informática Musical) y el CDMC (Centro para la Difusión de la Música Contemporánea), celebrado en el Museo Nacional Centro de Arte Reina Sofía en Madrid durante el mes de Junio de 2010. 


\section{Obras para instrumentos con electrónica}

- Clavichord_IO (2007)-8'13"

\section{Para clavicordio y electrónica}

A raíz de la construcción que llevé hace unos cuantos años de una réplica de un clavicordio del s. XVII, se me ocurrió ampliar las posibilidades acústicas de este instrumento. Un abuelo del pianoforte podría expandir sus recursos expresivos más allá de la estética y la moda de la música pretemperada. La electrónica en vivo y los procesos digitales del timbre del instrumento permiten crear una esfera de recursos sonoros nuevos. La obra está pensada para este modelo de clavicordio ligado, es decir, hay sonidos que comparten cuerda. Así pues se puede jugar con el recurso percusivo cuando ambos sonidos ligados atacan al mismo tiempo. Además, la elevación de la cuerda, propia del ataque de las tangentes, permite lo que en alemán se conoce como Behebung, que no es otra cosa que el vibrato en los instrumentos de cuerda pulsada. La gradación dinámica del sonido produce en estos instrumentos, unas ligeras desafinaciones que, en la época de apogeo eran empleadas por compositores como Couperin o Frescobaldi. Es precisamente desde los preludios non mesuree del francés desde donde parte la concepción de la obra. La libertad de interpretación se indica en células melódicas específicas. La sincronía precisa que a priori puede querer el intérprete electrónico es sólo el primer peldaño en la creación contemporánea. El mismo Boulez sufrió las limitaciones humanas en cuestiones de interpretación para algunas de sus obra. La electrónica suple esta deficiencia genética. Sin embargo la idea del arte como tal no puede verse observada desde el prisma digital porque el factor de incertidumbre y espontaneidad que el humano aporta, es el eslabón que nos hace únicos. 
En esta obra se mezclan muestras grabadas con procesos de transformación digital en tiempo real. La obra fue estrenada el 28 de Mayo de 2008 en el festival 'Primavera Electroacústica' en Valencia en el Club Diario Levante con la asistencia técnica de Gregorio Jiménez en la parte electrónica (Fig. 213).
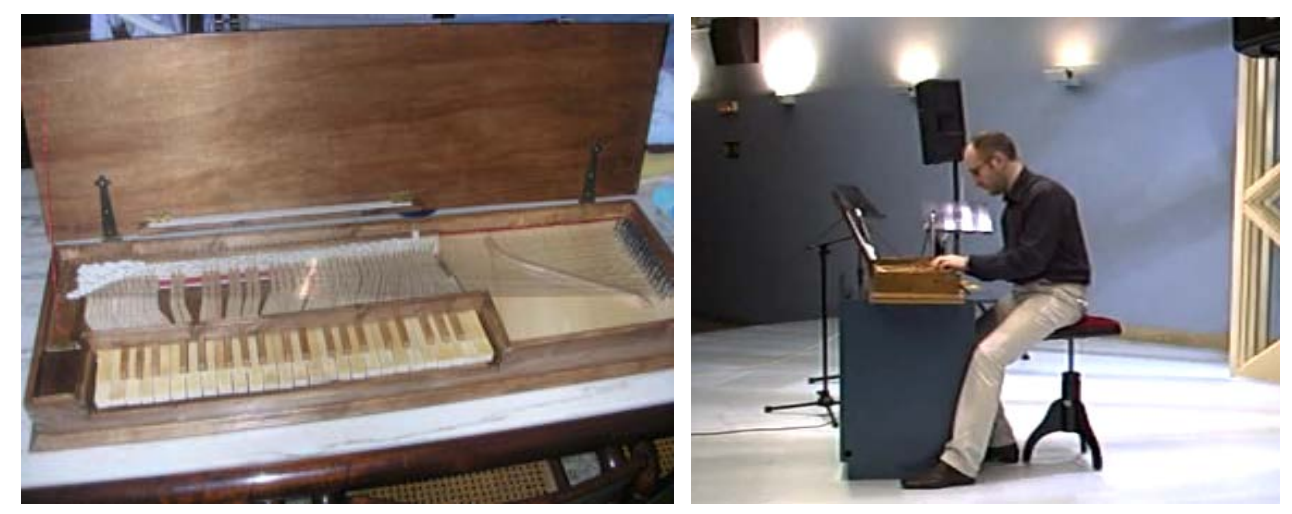

Fig. 213 Reproducción del Clavicordio modelo NM264785a Anónimo, Collection Musikseet de Estocolmo, y El autor durante el estreno de Clavichord_IO en el Club Diario Levante (Valencia)

- $\operatorname{Jev}(2009)-10^{\prime}$

\section{Para 2 marimbas y cinta}

El antropólogo Marvin Harris planteó una serie de postulados que explican el origen del machismo basado en sus estudios Etnológicos y el riesgo de superpoblación y desabastecimiento que supone una ratio de 10 mujeres por 1 hombre en las tribus del Amazonas. La supremacía del hombre se ha ido convirtiendo en un triste parámetro cultural y social que a lo largo de nuestro siglo se ha visto casi erradicado. En favor de esta igualdad tan discutida los parámetros de sutilezas y juegos de encanto de la mujer a veces desaparecen y quedan anestesiados por el deseo de acercarse al un prototipo asexuado y socialmente no comprometedor.

A veces la única manera de disfrutar de las cosas es fijarse en los pequeños detalles. Si cogemos 4 encajes distintos y lo miramos desde 
lejos veremos que son prácticamente iguales, pero si los cambiamos de orden el conjunto adquiere matices distintos. Jeu trata de configurar un tapiz hecho con 4 encajes, hilados con hilo muy fino. Cada uno de ellos corresponde a una esencia femenina, la esencia de las perlas y los brillos que adquieren con la luz, el rumor del movimiento y la estela que deja en el aire, las flores o aderezos a la belleza natural, y los gestos, minúsculos detalles que conciertan o desconciertan a quienes quieren disfrutarlos.

Esta obra utiliza muestras grabadas que se desarrollan al mismo tiempo que la parte de marimbas. La electrónica extiende la parca tímbrica de este instrumento gracias a la expresión electrónica. Con ella se exploran e indagan a modo de metáfora la psicología gestual de la mujer, su juego de encantos, y los elementos que la distinguen.

La obra se estrenó en la IV Academia Internacional NEXEduet celebrada en Diciembre de 2009 en el Conservatorio de Cullera (Valencia) como parte del concierto en el que se estrenaban las obras que resultaron finalistas del II Concurso de composición organizado por el dúo de percusión NEXEduet, formado por los percusionistas Sisco Aparisi y Jordi Francés. El estreno contó con la asistencia técnica de Vicent Gómez en la parte electrónica (Fig. 214).
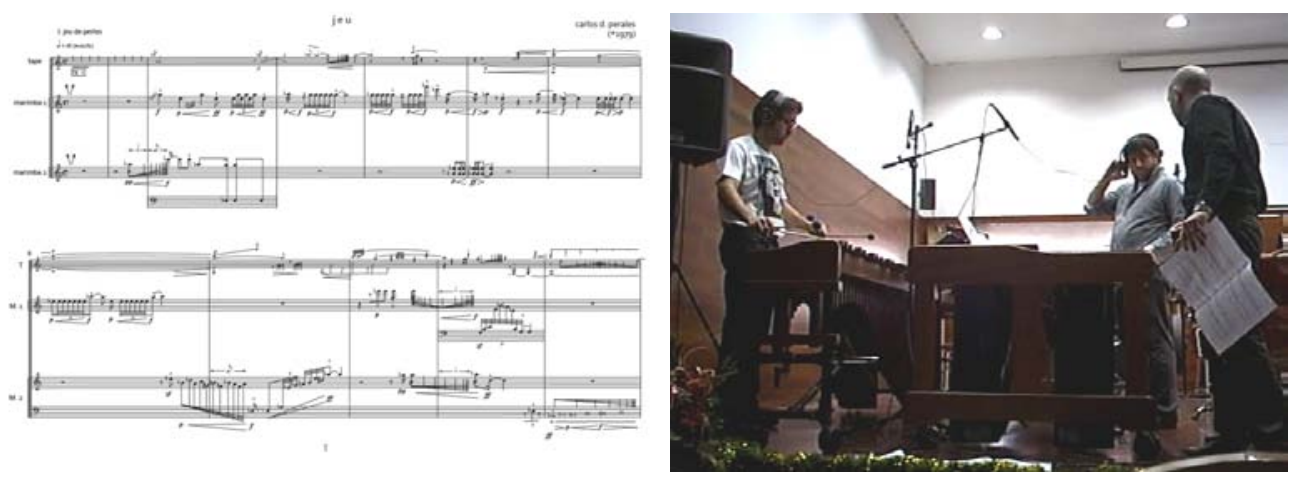

Fig. 214 Paritura de Jeu, yS. Aparisi, J. Francés y El autor durante el estreno de Jeu, 2009 
- Theatrique (2009) - 9'

\section{Para saxo barítono y electrónica en vivo}

El lenguaje teatral es uno de los medios de expresión más antiguos en el arte. Ethos frente a Pathos se refieren a la dualidad expresiva de la emoción estática o dinámica respectivamente. En el teatro griego el Ethos formó parte del canon en gran parte de la historia clásica. El Pathos es el uso de los sentimientos humanos para afectar el juicio, y puede adquirir distintas lecturas, como sufrimiento humano, emoción íntima, o conceptos éticos referidos a lo percibido por la persona, biológica o culturalmente. En Theatrique se trata la conexión de estos elementos y se exploran los modos de la persuasión dialéctica y la retórica.

La expresión del gesto sonoro tiene una dimensión que va más allá de la propia psicología musical. La visualización durante la creación del sonido ha acompañado a este contexto artístico desde su origen y condiciona la propia expresión sonora. La electrónica en vivo cataliza las propiedades del evento acústico que se produce, nos permite modificarlas, deconstruirlas y al mismo tiempo, nos predispone en la percepción de este discurso. Theatrique está dedicada a Xelo Giner, con la cual se establecieron unas pautas de complicidad esenciales en la creación y exploración del planeta sonoro que desarrollamos en estos días.

La obra se estrenó en Octubre de 2009 durante el XVI Festival Punto de Encuentro organizado por la AMEE (Asociación de Música Electroacústica de España) y corrió a cargo de Xelo Giner y contó con la asistencia técnica del propio autor en la parte de electrónica en vivo (Fig. 215). 

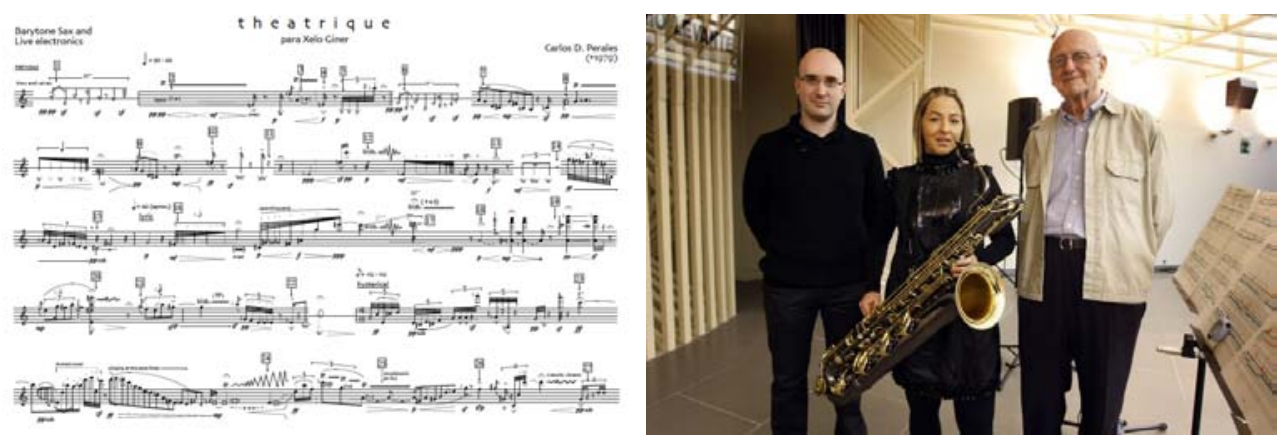

Fig. 215 Partitura de Theatrique y foto del estreno, de izquierda a derecha, El autor, Xelo Giner y Andrés Lewin Richter, 2009

- Dans (2010)-8' 20"

\section{Para cuarteto de percusión y cinta}

En la danza ritual hay una gran parte de la tragedia humana, danzas de guerra, ritos de iniciación, báquicas, macabras, trances de muerte, etc, han constituido uno de los vehículos más poderosos en la dialéctica cultural de los pueblos. Dans es el término utilizado en Sudáfrica para designar a la danza. En las regiones más desfavorecidas de la tierra han perdurado bailes y cortejos de una riqueza rítmica y expresiva que trascienden la gestualidad corporal. En Dans se abordan estos rituales danzables explorando sus comportamientos rítmicos y la configuración estética que representan.

La obra está dedicada a Kontakte, grupo de percusión. Este cuarteto de percusionistas fue el responsable del encargo de TanGram para 4 tamtams y 4 mandos Wii (ver tema 3). Existe una fantástica relación profesional y personal con cada uno de los miembros, Ximo Lambíes, Miguel Ángel Orero, Francisco Vidagany y Sergio Izquierdo; esta complicidad se hace absolutamente necesaria en la investigación artística, ya que se establece un diálogo entre intérprete y compositor que propicia un enriquecimiento mutuo, generando situaciones artísticas para la innovación de los lenguajes musicales. 
La obra se estrenó en el Ciclo de Percusión 'Baketes', organizado por el Auditorio 'El Molí' de Benetússer (Valencia), celebrado durante el mes de Mayo de 2010 (Fig. 216).
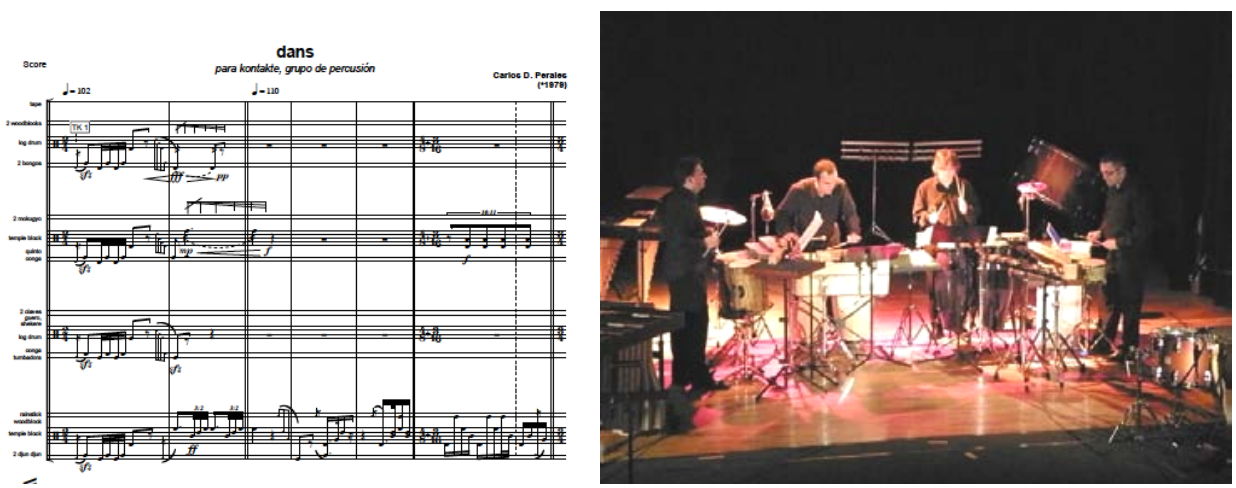

Fig. 216 Partitura de Dans y Kontakte, grupo de percusión durante el estreno de la obra, 2010

- Soleá (2010)-7' 30"

\section{Para flauta, clarinete, violín, cello, piano y electrónica}

En poesía, Soleá se refiere a una combinación métrica propia de la lírica popular andaluza, compuesta por tres versos de arte menor octosílabos que suele versar sobre el tema de la soledad y el desengaño. En el flamenco, es habitualmente bailado por una bailaora solista que realiza movimientos típicamente femeninos; llama la atención con el movimiento de sus brazos, ondulaciones de caderas y quiebros de cintura, su desplante y su seriedad acompañados de zapateados. La Soleá tiene un tempo lento y pesado. Describe una parte importante del mundo y el sentir del pueblo andaluz, su gestualidad y su expresividad.

\footnotetext{
Vestida con mantos negros

piensa que el mundo es chiquito

y el corazón es inmenso.
}

Vestida con mantos negros. 
Piensa que el suspiro tierno

y el grito, desaparecen

en la corriente del viento.

Vestida con mantos negros.

Se dejó el balcón abierto

y el alba por el balcón

desembocó todo el cielo.

¡Ay yayayayay,

que vestida con mantos negros!

Federico García Lorca, (García-Lorca, 2004) 
ANEXO II 



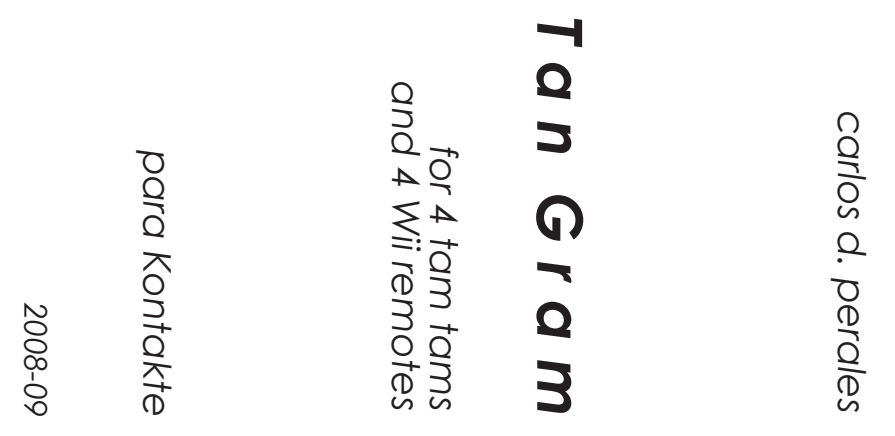




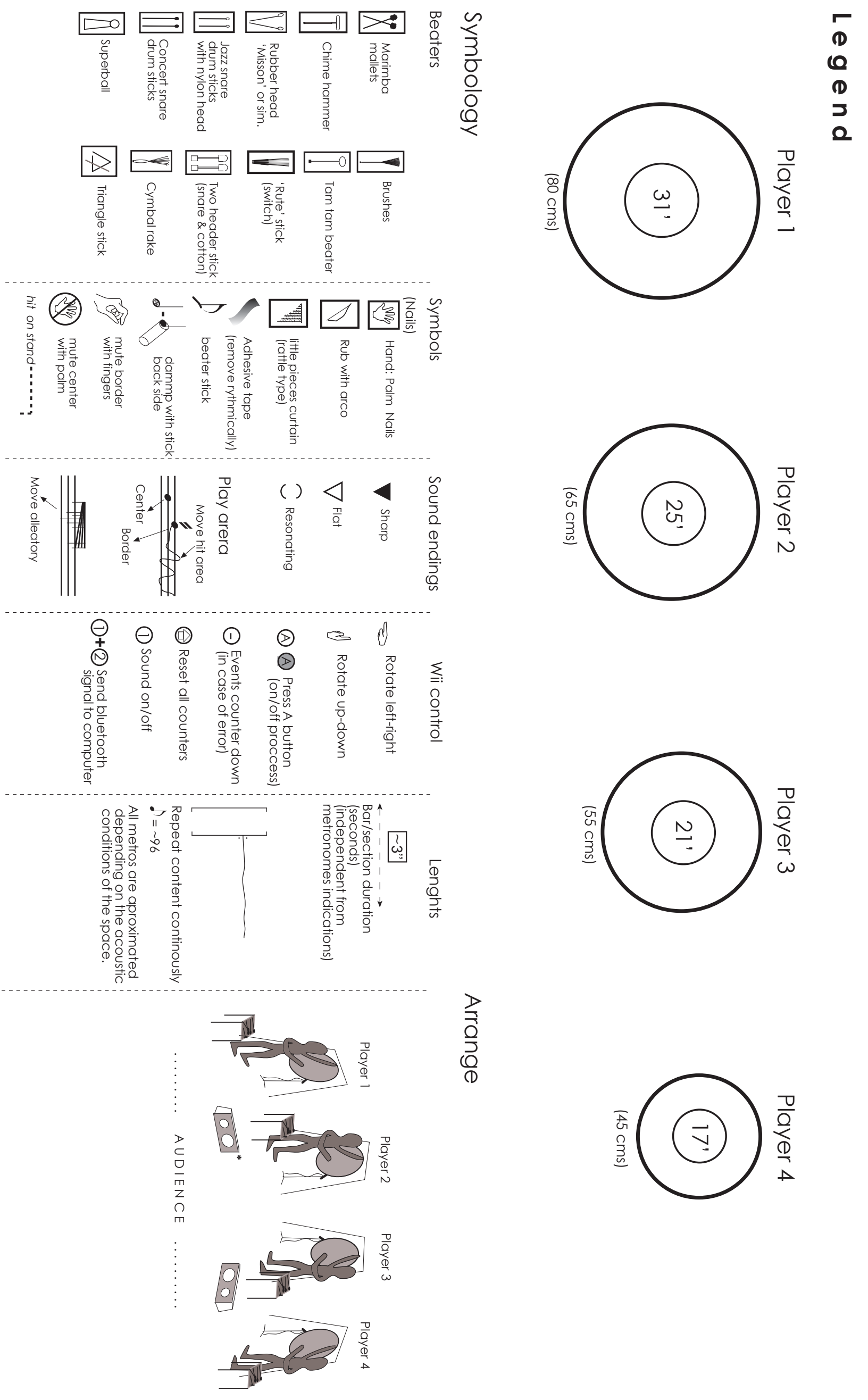




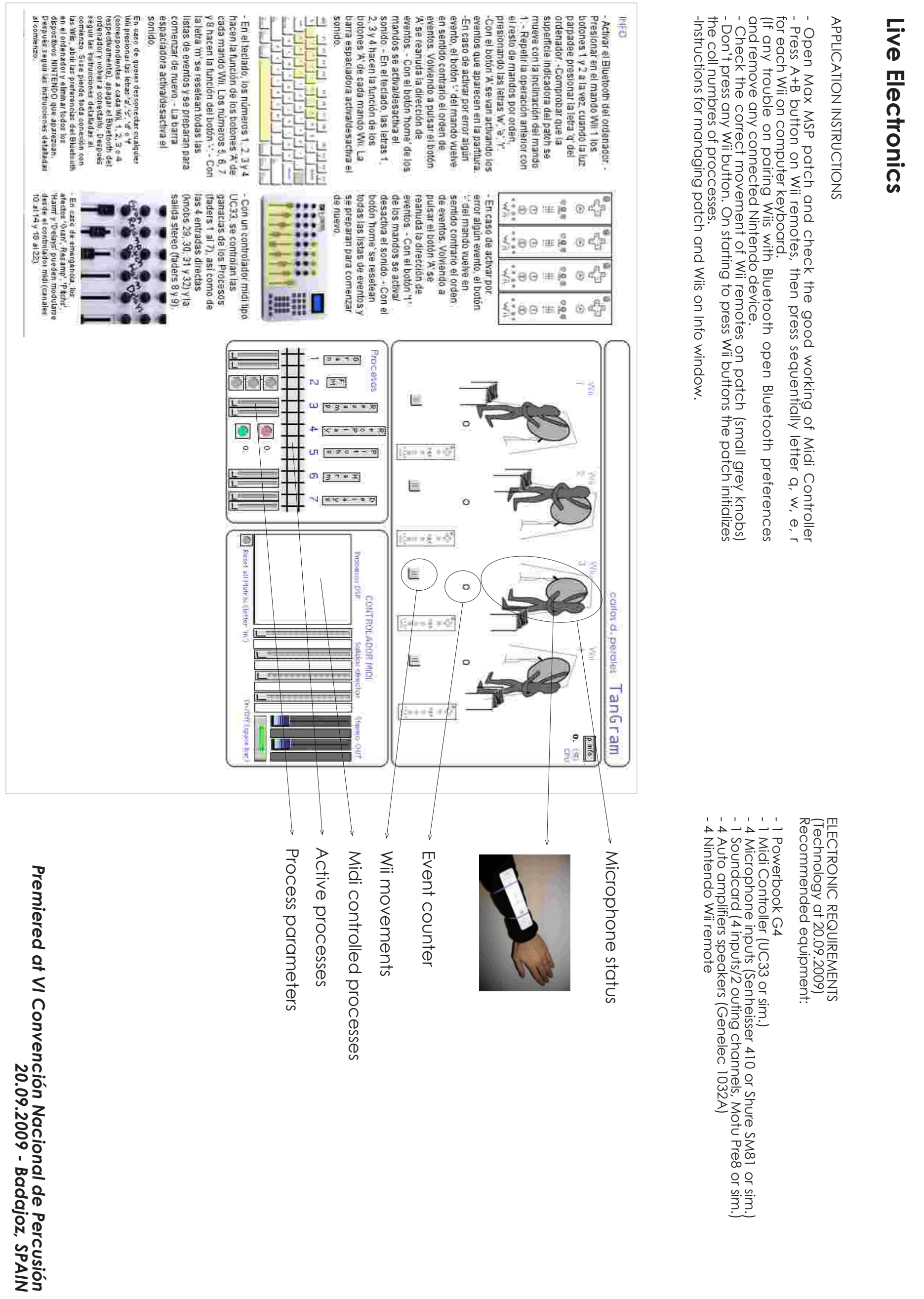




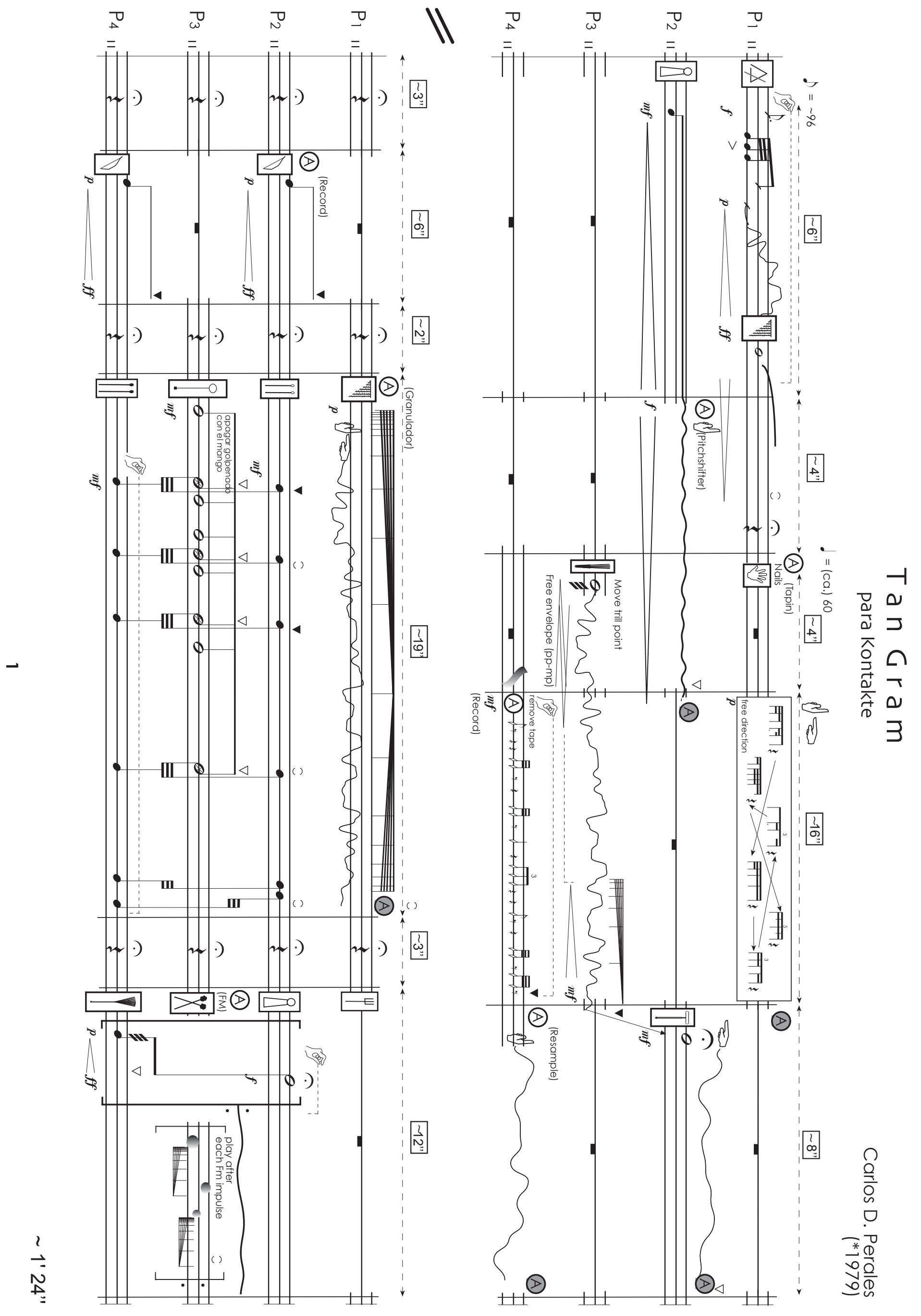




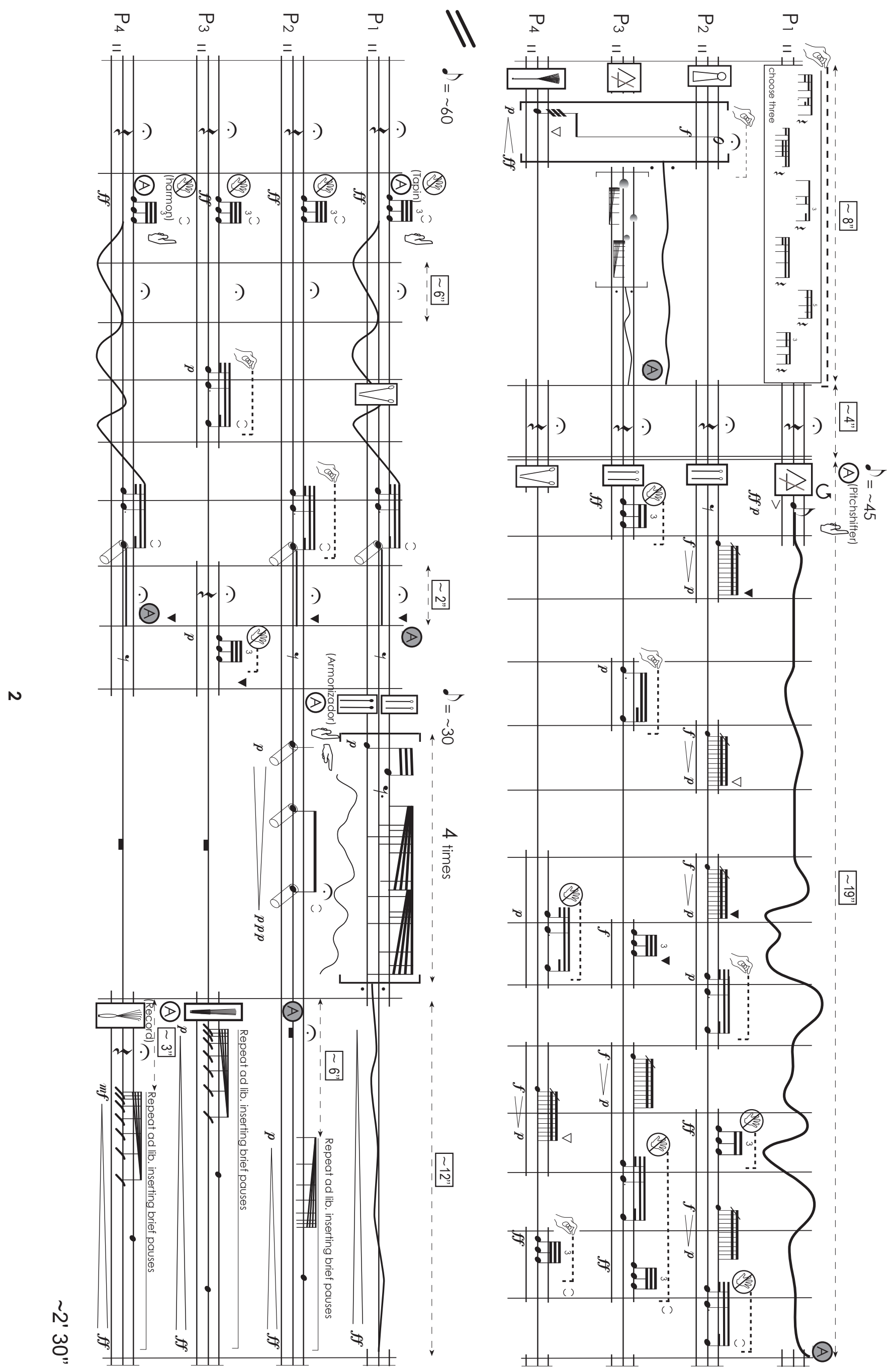




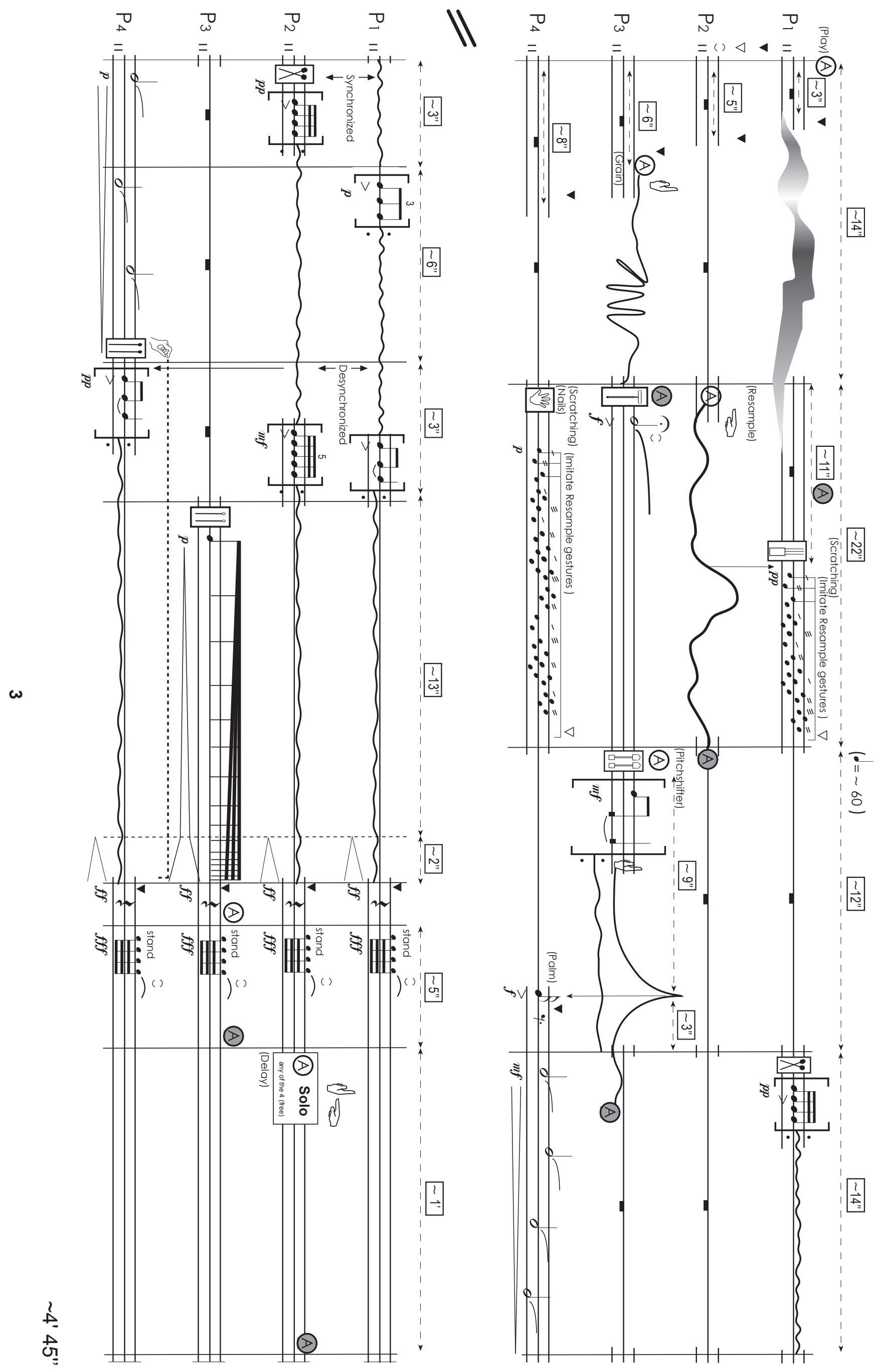




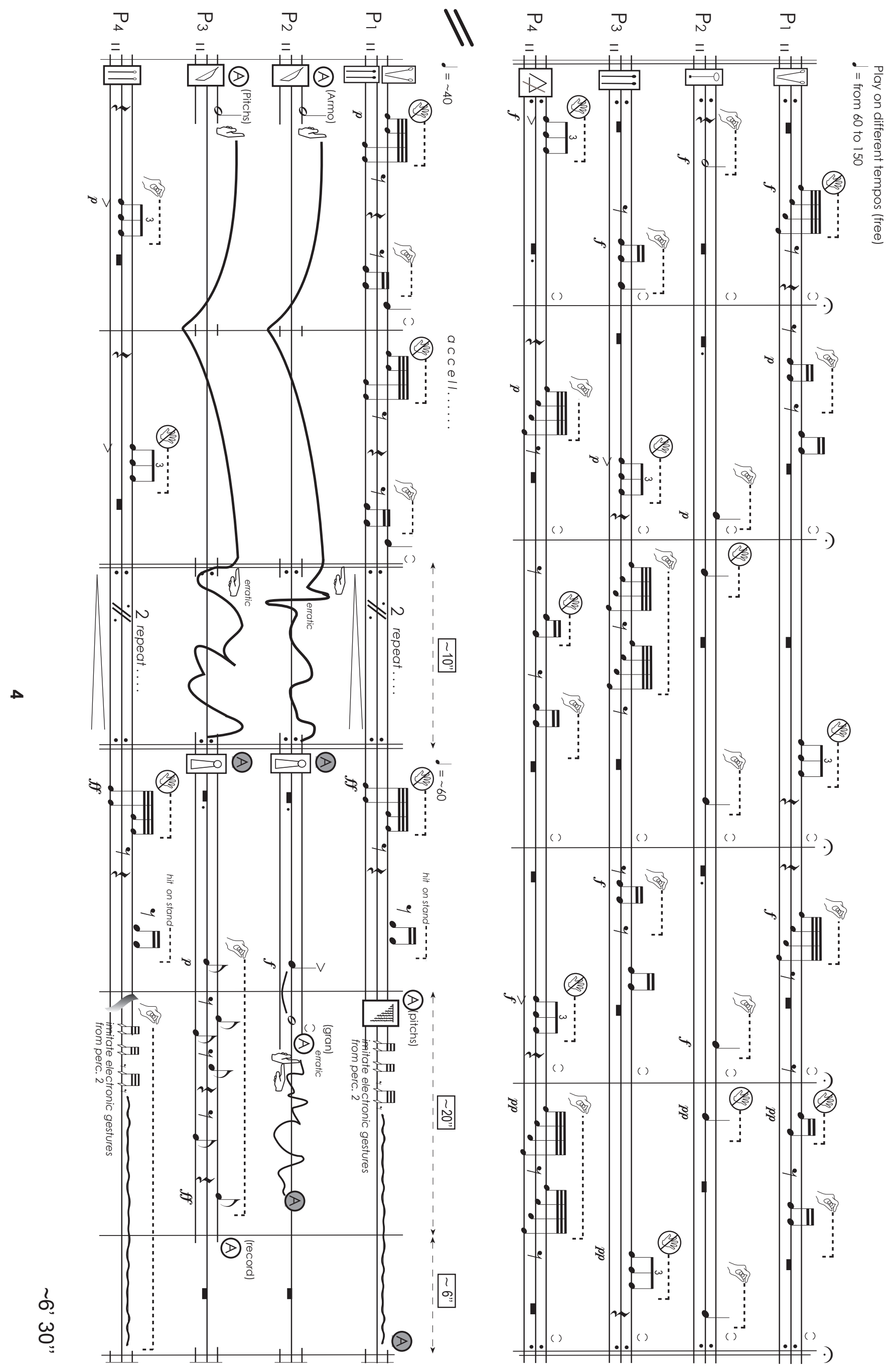




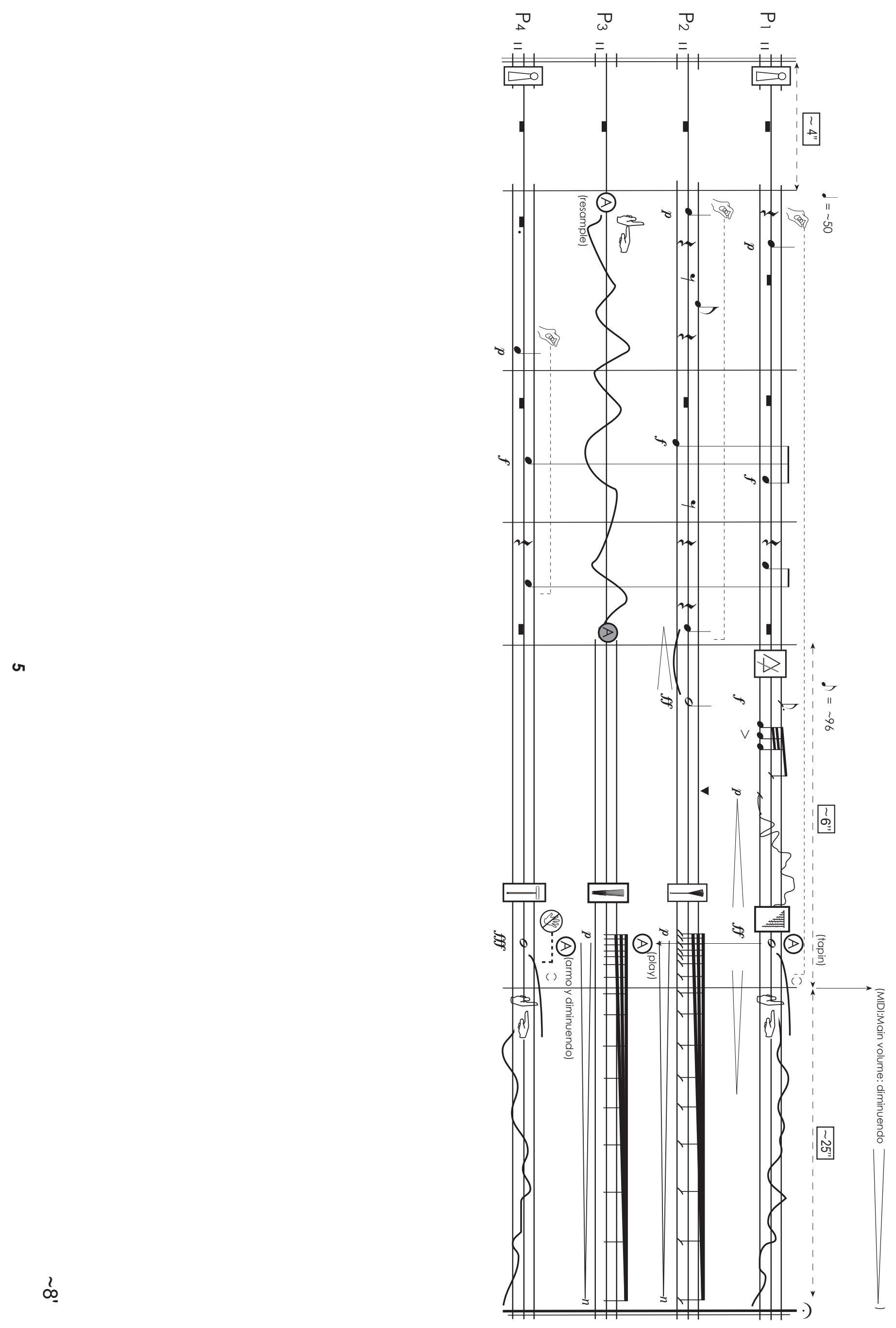


ANEXO III

\section{Publicaciones}

Portalés, C. and Perales, C.D., 2009. Sound and Movement Visualization in the AR-Jazz Scenario. Proceedings of the 8th International Conference on Entertainment Computing (ICEC). Paris, France, pp. 167-172. (Aslo in: Lecture Notes in Computer Science; Vol. 5709).

Perales, C.D., Portalés, C. and Sanmartín, F., 2009. Sonic Gestures Applied to a Percussive Dialogue in TanGram using Wii Remotes. Proceedings of the 8th International Conference on Entertainment Computing (ICEC). Paris, France, pp. 216-221. (Aslo in: Lecture Notes in Computer Science; Vol. 5709).

Perales, C. D., 2009. Haffter e Ibert (Música para el Quijote). Actas del Congreso 'Reflexiones en torno a la música y la imagen desde la Musicología española', (editora y coordinadora Matilde Olarte). Salamanca, Plaza Universitaria Ediciones, 2009. [ISBN 978-84-8675902-5] (1.007 pp). 
Portalés Ricart, C., C. D. Perales Cejudo and A. Cheok, 2007. Exploring Social, Cultural and Pedagogical Issues in AR-Gaming Through The Live LEGO House. International Conference on Advances in Computer Entertainment Technology (ACE'07), Salzburg (Austria), 203 , pp. $238-239$. 


\title{
Sound \& Movement Visualization in the AR-Jazz Scenario
}

\author{
Cristina Portalés, Carlos D. Perales \\ Universidad Politécnica de Valencia, Camino de Vera, s/n. 46022 Valencia. SPAIN \\ criporri@upvnet.upv.es, $\underline{\text { carpece@ @doctor.upv.es }}$
}

\begin{abstract}
This paper describes AR-Jazz, an augmented reality application designed to visualize sound and movements in live jazz performances. The augmented scenario is achieved within the program Max MSP Jitter, with an integrated inertial sensor and a microphone. As a display, a cinema screen is used. The application was first shown at the SedaJazz Festival 2007 in Valencia (Spain). In first place, a workshop was made in order the musicians to become familiar with the application. Secondly, a live performance was shown. The experience is described in this paper.
\end{abstract}

Keywords: augmented reality, jam session, sound visualization, inertial sensor.

\section{Introduction}

Augmented Reality (AR) is an emerging technology that has a great potential in several fields of knowledge, such as art [1], entertainment [2], education [3], psychology [4] and architecture [5]. This technology progresses towards collaborative and highly interactive systems, with the integration of hybrid devices that perform the 3D real-time registration. Multimodal systems are increasing, with the consideration of visual, sonic and/or haptic stimuli [6], thus enlarging the concept of AR towards more than mere visual systems.

In this paper the AR-Jazz application is described, an interactive AR system designed for live jazz performances. This paper explores the sound and movement as input data to manage the projected representation of a geometrical figure, with a group of musicians who jointly control the display of the augmented object.

This work was performed for a specific event, the Jazz \& Arts Meeting inside the Panorama Jazz Festival 2007, organized by the Big Band Sedajazz and held in the auditorium of Torrent (Valencia). Jazz \& Arts Meeting is an event for the interaction between Jazz and other arts such as cinema, theatre, painting, sculpture, poetry, electronics, media arts, etc., through different formative experiences and to develop creative synergies. The event is organized through a series of lectures and practices, promoting the participation of musicians and artists from other disciplines. It aims to bridge the gap between artists from different fields, to further the spread of jazz as a universal language. For this event, we prepared a workshop that was held in the morning and afternoon, and make a live performance in the evening with the students attending the workshop. 


\section{AR-Jazz in Detail}

The parameters of height, intensity, timbre and spatialization are aspects that determine the sonic language. Thus, these four factors can serve as a starting point in investigating sonic augmented reality. AR-Jazz develops some of these parameters augmented in a visual projection. Physical contact of musicians with their own instruments introduces another parameter, the synaesthesia. This gesture perception in the interpretive technique is transmitted to the shape and characteristics of the projected object, creating an interaction between the musician and the computer through the sound, which may affect the interpretation of the first.

\subsection{Physical components}

The elements that integrate the AR-Jazz augmented environment are (Fig. 1): A standard personal computer; The Max/MSP (v. 4.5.5) software within Jitter (v. 1.5.1); The MT9 inertial sensor of Xsens; A web cam (we used the Live Cam! Voice camera of Creative, within a FOV of $85^{\circ}$ and a video resolution of $640 \times 480$ pixels); A cinema screen that acts as a mirror. The Auditori de Torrent screen size is of about $15 \times 11 \mathrm{~m}$; A powerful multimedia projector; A microphone; Several musical instruments.

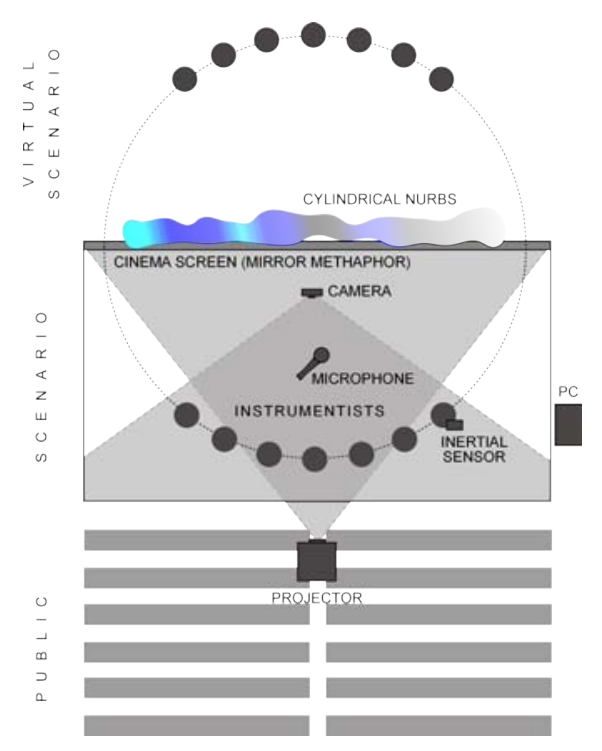

Fig. 1. Spatial arrangement of elements in the AR-Jazz application.

The camera remains fixed during the performance and pointing to the musicians, so that the visual display (the cinema screen) follows the metaphor of a magic mirror (see section 2.3). The microphone is located between the camera and musicians. The spatial distribution of musicians on stage is such that, together with their own 
projected image, form a circle in the middle of which is the visual representation of live sound (a kind of cylindrical NURBS). The musicians give the back to the public, in such a way that they do not loose visual contact with the in real time generated virtual object. The public can see the face of the musicians from the projected image on the screen (as it were a mirror).

\subsection{Virtual elements}

The produced sound is visually represented by a virtual element that consists of a modifiable cylindrical NURBS (Non Uniform Rational B-Splines), made from the Jitter object js jitaudio2nurbs.js. Its shape, colour, brightness and texturing varies according several characteristics of sound. Thus, the virtual element will vary depending on the timbre of each instrument, the emitted notes (height) and intensity (amplitude). Moreover, other parameters that vary randomly or at a temporary rate are introduced, as well as a change in the object orientation according to the registered rotations of the inertial sensor. The 3D position and one rotation of the object are fixed; only vary two of its rotations, which are recorded from the inertial sensor that can be carried by one of the instruments, by a dancer or by another user.

\subsection{Magic mirror metaphor}

In AR-Jazz the 'magic mirror metaphor' is introduced, as opposed to the 'magic lens metaphor', widely used in augmented reality systems. Based on the distinction between the lens and mirror, we can say that depending on the type of display used and the spatial arrangement of the camera, the augmented reality can be viewed through a window into a fictional world or as a reflection of that. The magic lens metaphor is most evident in the handheld devices, such as PDAs or mobile phones with integrated cameras, which is approximated to a lens through which we discover a new reality (the augmented environment). In AR-Jazz, the new reality is shown as an altered reflection of the real environment, reversing the spatial arrangement of the camera that shows the user as a fundamental part of the augmented environment, also increasing the sense of presence $[7,8]$.

\subsection{Computational processes}

Jazz-AR was designed within the program Max/MSP Jitter. The human-computer interaction takes place at two levels: sonic and haptic. In the first case, the interface is a microphone that captures the sounds emitted by the musicians; in the latter case, the interface is an inertial sensor that is carried by one person (a musician, a dancer or other user). The program is composed of a principal patch and a set of sub-patches; these are described in the following lines.

The main patch is based on jit.gl.nurbs-audiorender.pat, which is free distributed within Jitter. The main object is js jitaudio2nurbs.js, which defines the shape of a cylindrical NURBS that changes its shape according to the microphone audio input. 
Some random values have been defined in order to change the appearence of the NURBS (blending, smooth shading, wired, surface dimensions, etc.). All the elements that define the cylinder are sent to the object jit.gl.nurbs.

In the $p$ sonido sub-patch (Fig. 2), an analysis of the registered sound is analysed by the fiddle object, obtaining the sound height and amplitude. Because these values change very quickly, the mean value of the last 20 records is considered. Then, these values are scaled and assigned to the red colour and luminosity parameters of the virtual cylinder. The values of green and blue are selected randomly.

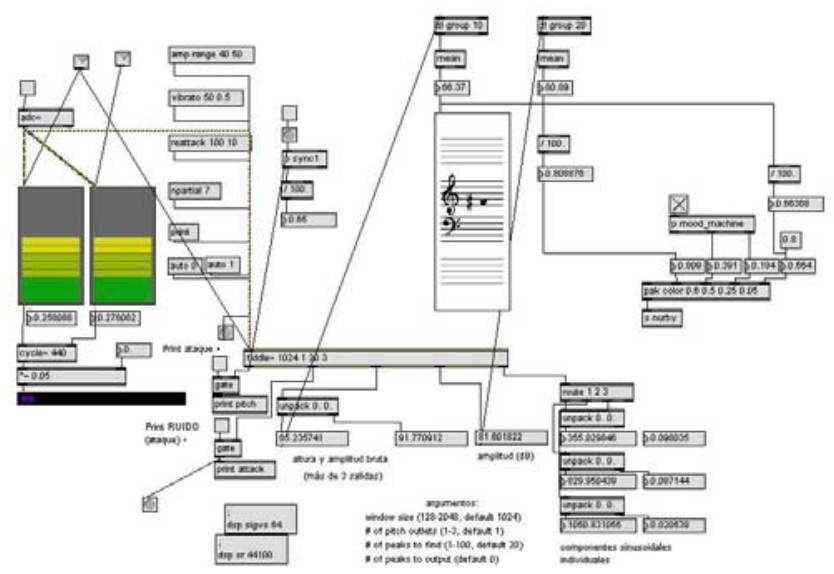

Fig. 2. Visualization of the $p$ sonido sub-patch.

The $p$ model plano sub-patch loads a plane in obj format where the image captured in real time by the camera is mapped.

The $p I M U$ sub-patch picks up the values registered by the inertial sensor and assigns the $\mathrm{X}$ and $\mathrm{Y}$ rotations to the virtual cylinder. This sub-patch consists of an interface between the MT9 inertial sensor and the Max/MSP Jitter software. It has been developed by Laboratorio de Luz [9] and can be freely downloaded at [10].

\section{User Interaction}

\subsection{Workshop}

The workshop was held on the stage of the auditorium for two hours in the morning and another couple of hours in the afternoon. It was attended by a total of nine musicians: a drummer, a flute, an electric guitar, a piano, an alto saxophone, two trombones, a tuba and a singer. After mounting the piece on stage, it was explained to the musicians. Then they played their instrument one by one, to see the AR-Jazz feedback to their individual interpretation. Finally several pieces of music were interpreted together in a jam session. In Fig. 3 some images are depicted. 

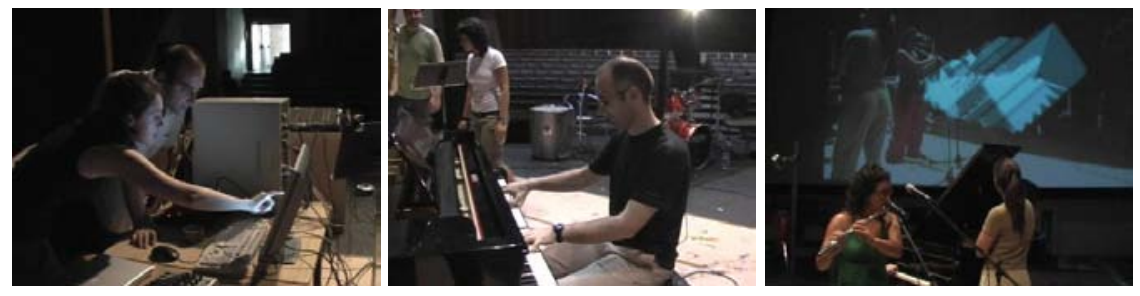

Fig. 3. Images at the workshop.

\subsection{Live Performance}

The live performance took place at 20:00 in the Torrent auditorium with the assistance of public. First, the AR-Jazz application was explained to the audience. To understand the direct relationship between the emitted sound by the instruments and the displayed graphics on the screen, each of the musicians made an improvisation with their own instrument. To make the explanation clear, at this stage the NURBS was shown on a grey background, and its rotations were fixed. In Fig. 4 some examples are depicted.

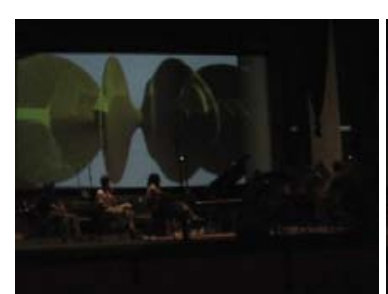

a

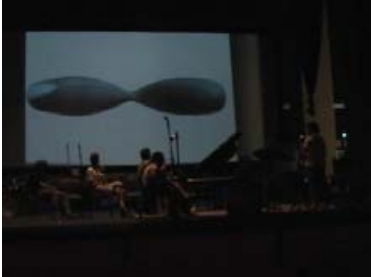

b

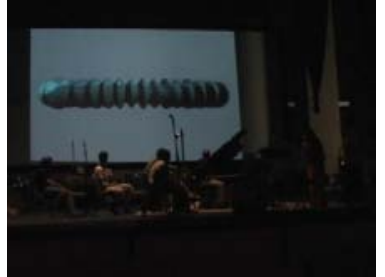

c

Fig. 4. Musicians playing one by one in AR-Jazz, where: a) Tuba; b) Saxo alto; c) Flute.

Afterwards, some pieces were interpreted in a Jam session (Fig. 5). The inertial sensor was carried by one person of the audience. The represented pieces were two items that had been tested in the workshop, the first was an improvisation on the Spanish scale, whereas the second was an improvisation based on a blues rhythm.
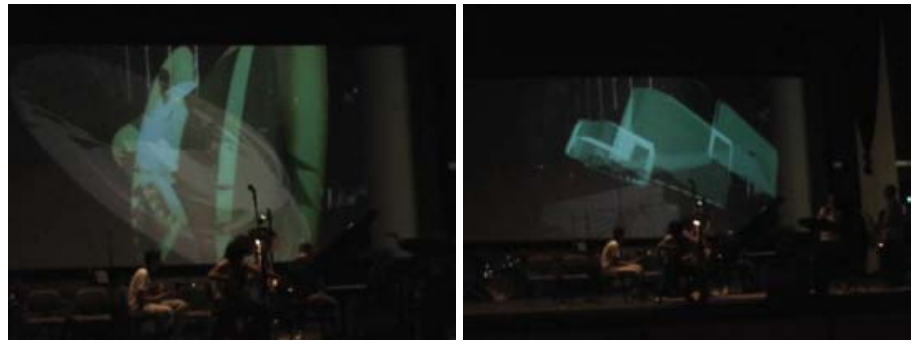

Fig. 5. Jam session in AR-Jazz environment. 


\section{Conclusions}

AR can be used in many different fields; in our case we show a successful integration of this technology within the artistic discipline of jazz by means of AR-Jazz, an application designed to visualize music and movements during live performances. The use of the magic mirror metaphor allows a new distribution of musicians on the stage: although they give their back to the public, the audience is able to see their faces as a projection on a cinema screen. Interaction is achieved by means of a microphone and a miniature inertial sensor, thus integrating visual, sonic and haptic stimuli, some real and some virtually generated. Our experience shows that the use of multimodal systems does greatly enrich AR applications, increasing user and audience engagement.

Acknowledgements. This research wouldn't be possible without the collaboration of Laboratorio de Luz.

\section{References}

1. Galantay, R., Torpus, J., Engeli, M.: "living-room" Interactive, Space-Oriented Augmented Reality. In: Proceedings of the 12th annual ACM international conference on Multimedia. New York, NY, USA: ACM, (2004)

2. $\quad$ Cheok, A.D., Goh, K.H., Wei, L., Farbiz, F., Fong, S.W., Teo, S.L., Li, Y., Yang, X.: Human Pacman: a mobile, wide-area entertainment system based on physical, social, and ubiquitous computing. Personal and Ubiquitous Computing, 8(2): p. 71--81, (2004)

3. Kaufmann, H., Schmalstieg, D.: Mathematics and geometry education with collaborative augmented reality. Computers \& Graphics, 27(3): p. 339--345, (2003)

4. Juan, M.C., Alcañiz, M., Monserrat, C., Botella, C., Baños, R.M., Guerrero, B.: Using augmented reality to treat phobias. IEEE Computer Graphics and Applications, 25(6): p. 31--37, (2005)

5. Ben-Joseph, E., Ishii, H., Underkoffler, J., Piper, B., Yeung, L.: Urban Simulation and the Luminous Planning Table: Bridging the Gap between the Digital and the Tangible. Journal of Planning Education and Research, 21(2): p. 196-203, (2001)

6. Ha, T., Chang, Y., Woo, W.: Usability Test of Immersion for Augmented Reality Based Product Design, in Technologies for E-Learning and Digital Entertainment, K.-c.H.e. al., Editor, Springer Berlin / Heidelberg. p. 152--161, (2007)

7. Giner Martínez, F., Portalés Ricart, C.: The Augmented User: A Wearable Augmented Reality Interface. In: International Conference on Virtual Systems and Multimedia, Ghent (Belgium): Hal Thwaites, (2005)

8. Portalés Ricart, C., Entornos de realidad aumentada en el campo del arte, in Departamento de Pintura, Universidad Politécnica de Valencia: Valencia. p. 508, (2008)

9. Laboratorio de Luz, http://www.laboluz.org/base_e.htm.

10. Portalés, C., http://personales.upv.es/criporri/multimedia_cristina_portales.php. 


\title{
Sonic Gestures Applied to a Percussive Dialogue in TanGram Using Wii Remotes
}

\author{
Carlos D. Perales, Cristina Portalés, Francisco Sanmartín \\ Universidad Politécnica de Valencia, Camino de Vera, s/n. 46022 Valencia. SPAIN, \\ carpece@doctor.upv.es, criporri@upvnet.upv.es, frasanpi@pin.upv.es
}

\begin{abstract}
TanGram, is an original music score composed by Carlos D. Perales for Percussion Quartet and Nintendo Wii Remotes used as a wireless interface for Live Electronics. This paper examines how this composition explores exiting research in interaction and communication between instruments and digital sound processing discourse to produce a unique music mixed-media score, to explore the sonic possibilities of a multi-timbrical instrument with the integration of the visual gestures of an accessible device using processes of real-time gestural mimesis.
\end{abstract}

Keywords: Music; Electroacoustic; Live Electronics; Percussion.

\section{Real Time Discourse Based on Digital Sound Processes}

\subsection{Designing Behaviour}

The concept of real time processes has been extensively explored and discussed in composition and improvisation environments [1]. However the integration of wearable devices on percussion performers as an extension of them, especially in percussion pieces, opened a scope for another twist, as methodologies and research from the field of Acousmatic Music and performance explorations were introduced. To explain the integration between the wireless interface and the traditional use of mallets in percussion instruments, we start with the music score, which is designed to precise both uses.

Each percussionist has attached to his arm the Wii remote control in order to achieve a new parameter in movements and gestures (Fig. 1). Because the application runs as an organic sequence of events (DSP processes) and determines a collaborative distribution for the performers, a standalone Max MSP patch [2] was designed as a start point in the managing of processes. In order to connect the Wii dates with Max MSP a specific library object, named aka.wiiremote [3] have been used. This object allows a stable data transfer via Bluetooth. Each percussionist activate/deactivate their own events list using the 'A' button on Wii remote control. 

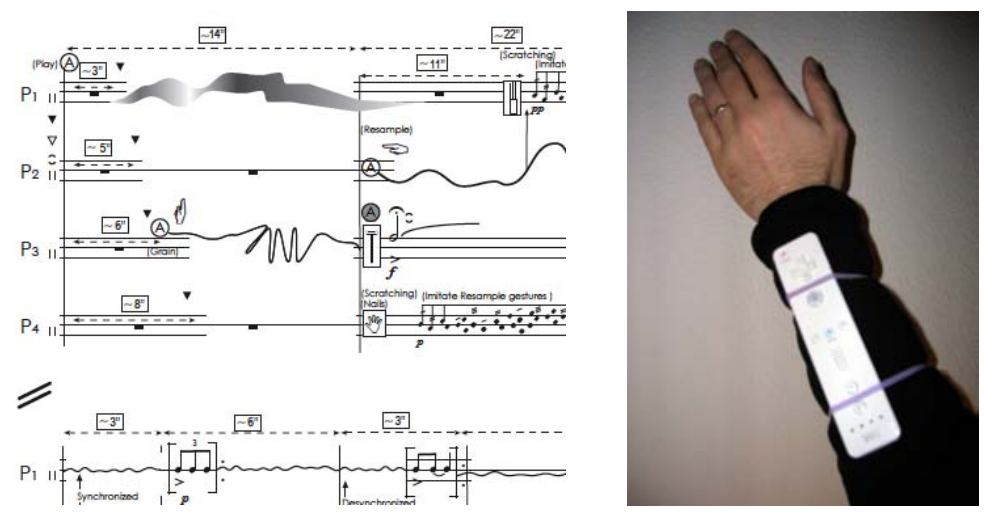

Fig. 1. Score excerpt - Wii remote.

\subsection{From Gestures to Notated Sound}

Although some electroacoustic composers have developed some conclusions of gestural analysis of sound for the analysis of live electronics performances, my intention was to reorient this findings towards writing a musical score that bring the freedom to the performer to control and vary the responses to the other performers. I wanted to describe in an precise way, how after solving the tilt behaviour puzzle of acceleration in the $x$ or $y$ axes, 'Kontakte Percussion Group' [4], the performers who commissioned this electro-acoustic score, had therefore to make extensive use of their collaboration and the different performances experiences by calling on their sonic memory and creativity. After activate any process, they had to listen and interiorize their own movements for the necessary coordination between rhythms, mallets, gestures and feedback dialogue.

During this process of integration, which involved microphone experimentation and digital techniques, a sound engineer, who also produced the CD recording of the piece in winter 2009 , assisted the performers.

\section{Tam-Tam Morphology; a Further Step}

\subsection{Score Re-contextualization}

This score is a re-contextualization of existing research in typology and morphology of percussion exploration and concrete sonic objects started by Pierre Schaeffer [5], continued among others by Dennis Smalley [6], and reunited by Lasse Thoresen [7]. Karlheinz Stockhausen made a specific multi-timbrical exploration of the tam-tam in his piece Microphonie. 
Anyway I didn't want to build a parallel world of concrete objects on the instruments but a traditional use of tam-tam with all kind of percussion beaters and two concrete sources as adhesive tape and stones curtain (Fig. 2).

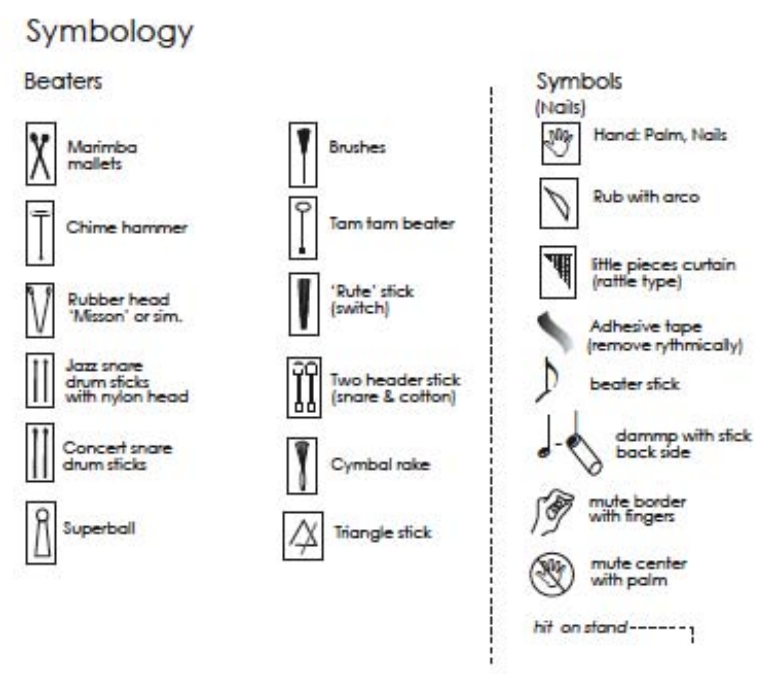

Fig. 2. Beater symbology.

The tam-tam is a very common resonator. Obviously I didn't want to make a whole piece based on this parameter, because the electroacoustic give us the chance to explore it as an extension of it sound.

\subsection{Performer Independence}

Normally in electroacoustic pieces with live electronics a technician is required to control the live events and common aspects as gain, balance, etc. As the performers wanted to be independents on playing the score, the patch designed is almost entirely controlled from the Wii buttons. The up and down buttons control the stereo gain. The 'A' button triggers each process saved from a coll. A matrix orient the incoming dates from each Wii to a specific DSP process (Fig. 3). Also the four microphones are activates or deactivated depending on other similar matrix reading from a coll list of events. 


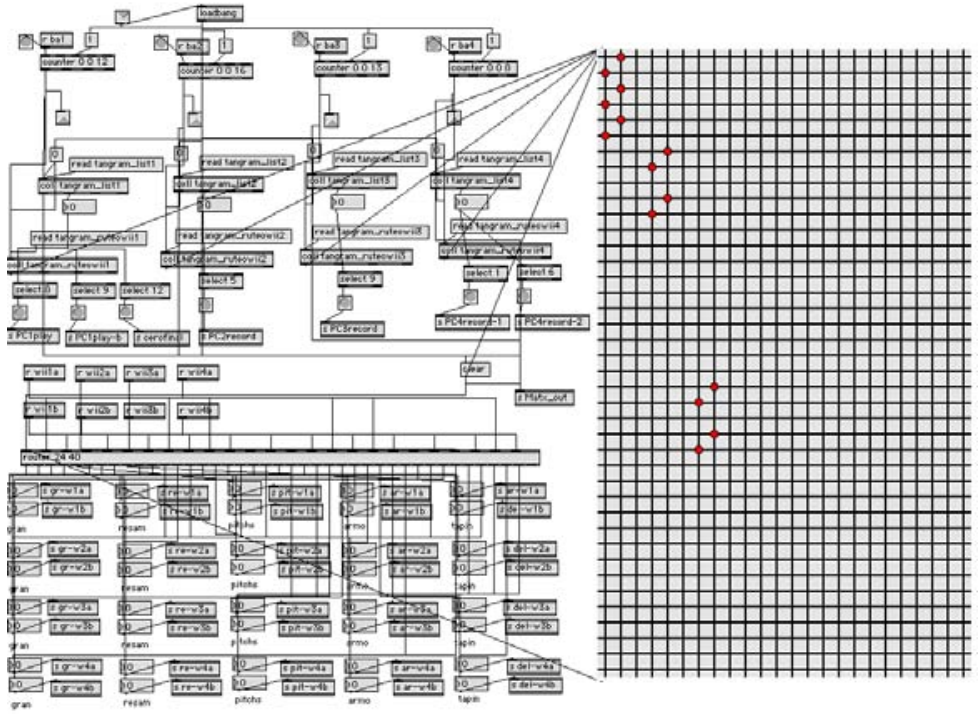

Fig. 3. Max MSP Matrix.

\subsection{Digital Behaviour}

The musical score, including the computer part (real time processes) is a path iteration of probabilities based on Chinese TanGram game and its geometric pieces. Concepts of sound spectrum, spectral brightness, pulse, multi directionality and harmonicity act as parallel layer with the tam-tam live sound.

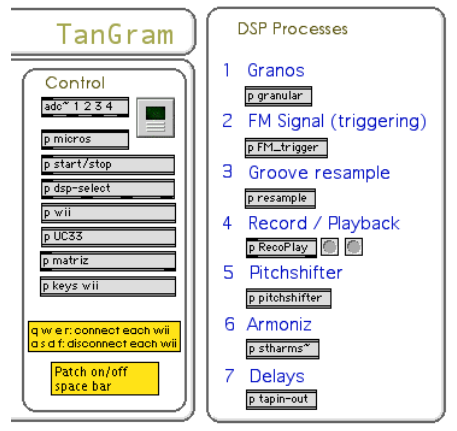

Fig. 4. DSP Processes.

Seven pieces configures this easy Chinese game. Therefore, seven digital processes, seven sections and seven rhythmic motives where established for the score (Fig. 4), aiming to find beauty and musical expression in the matches and divergences 
between the original sound of the tam-tams and the mimetic response of the electronic discourse.

\subsection{Notated Methodology}

Performers need clear instructions to play around the Tam surface. A 'trigram' was established meaning the three points to hit or rub on it surface. Additional symbols were attached on score to illustrate the stand support. In order to control the damping of the tam-tam resonation, I define whether performers have to stop the resonation sharply, flatly or leave it sounding (Fig. 5). The way that they damp is a free option. In Fig. 6, the tilt of performer 1 is synchronized between the other performers.

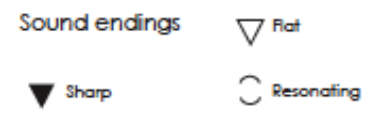

Fig. 5. Damping marks

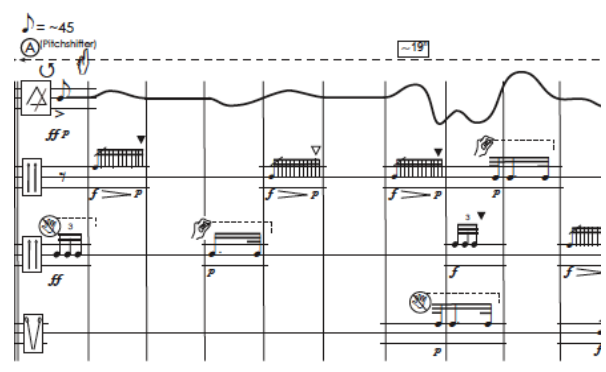

Fig. 6. Score excerpt.

Also damping with the left hand in two ways modifies each beater attack: by holding the edge or covering the centre area with the hand's palm. Dynamics are fortissimo (fff) to pianissimo (ppp) and some dramatic pauses are used.

\subsection{Rhythmic Nature}

As a percussion piece the articulation and structure is entirely driven by rhythm. Only some uses of bowing and rubber techniques act as an exception of the whole piece. However, it is not just understood as rhythm in musical terms but as pace, informed by Tarkowskij's methodology [8], which is not focused on the temporal editing, but on the rhythm of the scenes (sculpting in time); in TanGram terms, it refers to the pace of different sonic scenes with a characteristic typology. By the way each electroacoustic process requires a specific tempo, so the rhythm is adapted to each response. 


\section{Conclusions}

This paper has discussed the implementation aspects of gestural behaviour in a mixed-media piece for percussion and lives electronics called TanGram. With the introduction of the autonomy given by the Wii remote control via Max MSP patch, in this context, the author proposes a new route for creative expression, informed by Tarkowskij's ideas and methodologies in film and scene montage [9], when exposing the Ideal to its Mirror. Similarly, the score utilizes vocabulary and specific typology to precisely notate gestures and movement, generated and transformed employing computer and recording techniques. An explanation of the existing methodology to read and interpret the score leads to some detailed examples about how to notate in time concepts such as movement gestures, length variations and others, which belong to the electroacoustic vocabulary.

Acknowledgment. 'Kontakte Grup the Percussió' commissioned TanGram. The score and research behind it was realized between 2008 and 2009.

\section{References}

1. Percussion in the New-Old World. Wilfrid Mellers. The Musical Times, Vol. 133, No. 1795 (Sep., 1992), pp. 445-447

2. Max MSP software by Miller Puckette and David Zicarelli. http://www.cycling74.com

3. Aka Universal Objects for Max MSP 4.6: http://www iamas.ac.jp/ aka/max/

4. Kontakte Grup de Percussió. http://www.kontakte-percusion.com Last visited 20-January2009

5. Typology and Morphology of Sonic Objects. Pierre Schaeffer . Traite des objets musicaux. Essay Interdisciplines. Nouvelle edition, Seuil. 1966

6. Dennis Smalley, Spectromorphology: Explaining sound-shapes. Organised Sound: Vol. 2, no. 2. Cambridge University Press: 107, 126. 1997

7. Spectromorphological analysis of sound objects: an adaptation of Pierre Schaeffer's typomorphology. Lasse Thoresen. Organised Sound archive. Volume 12 , Issue 2 (August 2007). Pages 129, 141. 2007

8. Andrej Tarkowskij's films. Lost Harmony: Tarkovsky's "The Mirror" and "The Stalker" Michael Dempsey. Film Quarterly, Vol. 35, No. 1 (Autumn, 1981), pp. 12-17. Published by: University of California Press

9. Back to the House II: On the Chronotopic and Ideological Reinterpretation of Lem's Solaris in Tarkovsky's Film. Roumiana Deltcheva and Eduard Vlasov. Russian Review, Vol. 56, n.4 (Oct., 1997), pp. 532-549. Published by: Blackwell Publishing on behalf of The Editors and Board of Trustees of the Russian Review 


\title{
ERNESTO HALFFTER FRENTE A JACQUES IBERT: \\ DOS COMPOSITORES PARA EL CINE DEL QUIJOTE
}

\author{
Carlos David PERALES CEJUDO \\ Dpto. DECADHA, Universidad Politécnica de Valencia, \\ Camino de Vera s/n, 46022 Valencia \\ carpece@doctor.upv.es \\ carlosd.perales@gmail.com
}

\section{Resumen}

En este artículo se analizan dos bandas sonoras diferentes creadas para las adaptaciones cinematográficas de la novela de Cervantes "Don Quijote de la Mancha”: Ernesto Halffter para Rafael Gil, 1948, y Jacques Ibert para Georg Wilhem Pabst, 1933. Se ha llevado a cabo un análisis musical desde varios puntos de vista: formalmente, instrumentalmente, armónicamente, análisis de tempos, duraciones, etc. Todo desde una perspectiva técnica y compositiva donde se ofrece un análisis comparativo del trabajo realizado por dos compositores que, siendo básicamente sinfónicos, tuvieron la posibilidad de trabajar para la industria del cine. Finalmente se presentan una serie de conclusiones donde, un autor en más medida que el otro, se van a ver sujetos a la lectura personal que cada director hará en su película de la figura del Quijote.

\section{INTRODUCCIÓN}

Alrededor de la figura del Quijote se han realizado infinidad de análisis, sin embargo no son tantos los que han desarrollado un estudio de las bandas sonoras que acompañan a las adaptaciones cinematográficas. Es por esto por lo que en este trabajo se pretende analizar dos bandas sonoras totalmente distintas, aunque de dos compositores estilísticamente próximos. Se trata, así pues de una comparativa puramente musical y analítica de las bandas sonoras compuestas para las películas de Rafael Gil,1948 y Georg Wilhem Pabst, 1933 sobre "Don Quijote de la Mancha”.

La estética musical de Ernesto Halffter y Jacques Ibert puede analizarse desde una perspectiva similar. Como autores coetáneos pasearon por la industria del cine con brevedad y hoy podemos contemplar la histórica coincidencia cinematográfica de la novela de Don Quijote de la Mancha. En esta, la manera de abordar la composición musical para los personajes y las circunstancias en las que estos se desenvuelven, va a depender en gran parte del planteamiento que van a 
tener los directores de ambas películas. La lectura de la novela de Miguel de Cervantes se hace a veces tan personal que se crean diversos y opuestos Quijotes allá por dónde se recuerdan.

Antes de entrar en el análisis de las bandas sonoras y para situar las obras se darán unos breve apuntes sobre la vida y el contexto social de los autores.

\section{ERNESTO HALFFTER EN ESPAÑA}

El madrileño Ernesto Alberto Halffter Escriche (1905-1989), fue el tercero de los seis hijos del matrimonio compuesto por la catalana Rosario Escriche Erradón y Ernesto Halffter Hein- el primer Halffter procedente de Könisberg (Alemania), afincado en España-, joyero de profesión. Su madre le inició, al parecer, en sus primeras lecciones musicales, siendo su tío materno, Ernesto Escriche, concertista de piano.

Tras su primera aportación al mundo musical con su obra "Crepúsculos” (1922) para piano, Ernesto se descubre por su singular título de "Sinfonietta" (1925) obra para orquesta, a la que se le concede el Premio Nacional de Música. Ingenio y maestría brillan en tal recreación que advierte triunfos para este joven compositor, que con tan sólo 20 años consigue adscribirse a la cumbre artística nacional. En 1924, Ernesto Halffter culmina una etapa decisiva en su vida a través de su conocimiento directo con el maestro Ravel en París, con el cual trabajó intensamente durante casi un año. Su matrimonio con la pianista portuguesa Alicia Cámara Santos (1928) le vincula de forma especial con el país vecino, en el que permaneció durante largas temporadas ("Rapsodia Portuguesa" para piano y orquesta (1940) y las "Canciones Portuguesas" (1943). La actividad compositiva es compaginada con la labor docente, desde el año 1934, en que es nombrado Catedrático numerario de Conjunto Vocal e Instrumental y Director del Conservatorio de Música de Sevilla, cargo que desempeña durante tan sólo dos años, apartándole tal función directiva de su quehacer creador. Posteriormente, en 1942, es nombrado Profesor Adjunto al Instituto Español de Lisboa. Sus cualidades como compositor le llevan a crear admirables partituras para cine como la que nos ocupa "Don Quijote de la Mancha", o "Bambu", "La Señorita de Fátima, Historias de la Radio... A partir de 1957, comienza a trabajar arduamente en la conclusión de la cantata "Atlántida", obra póstuma que Falla deja inacabada a su fallecimiento en 1946.

El reconocimiento oficial se produce especialmente a partir de 1963, año en que se le impone la Gran Cruz de Alfonso X el Sabio. En 1969, nace su "Concierto para Guitarra y Orquesta”, estrenado por Narciso Yepes y bajo la dirección de Igor Markevitch. La década de los años setenta es fecunda y pródiga también en relación a los méritos y recompensas obtenidas por el artista. Destaquemos pues su ingreso en la Real Academia de Bellas Artes de San Fernando en Madrid (1973). Lúcidamente y con absoluta consciencia llega nuestro compositor al final de su trayecto (1989, año en que fallece). En 
1988 ofrecerá su último fruto musical: "Homenaje a tres compositores españoles” (a Federico Mompou, Joaquín Turina y Rodolfo Halffter, su hermano mayor).

Alrededor de estos años y con el fin de la guerra civil se abre un periodo de raquitismo cultural que abarca todo el decenio de los cuarenta. Frente al esplendor del primer tercio del siglo XX, el panorama cultural de posguerra es desolador. Las causas son múltiples. Al masivo exilio exterior de los protagonistas más representativos de la edad de plata se unió el exilio interior forzado o voluntario. En los años centrales del siglo XX, y sobre todo a partir de 1945, los nuevos rumbos de la política internacional impusieron cambios importantes para el régimen franquista, y en consecuencia en el plano cultural, bajo la dirección del ministro Ibáñez Martín. El cambio fue hacia el nacional-catolicismo. La nueva doctrina lo invadió todo, desde la Universidad Central hasta la enseñanza primaria. En boca del propio obispo Herrera Oria: "Désenos la Universidad y todo lo demás se nos dará por añadidura". Dirigismo educativo y cultural que también se extendió al campo de la creación y la investigación. Todavía en plena guerra civil, en 1938, el gobierno de Burgos suprimía la Junta para Ampliación de Estudios. Un año más tarde, por Ley del 24 de noviembre de 1939, se creaba el Consejo Superior de Investigaciones Científicas.

El control desde el gobierno central llegaba a todos los sectores de la nación. El campo de acción que ofrecía el cine, era uno de los mejores instrumentos para la consecución de los planes de la dictadura franquista. Los guiones de las películas eran analizados por la censura que se encargaba de "adaptar" a su gusto la creación de los artistas. En la película de Rafael Gil, que en principio pretendía ser una de las más fieles adaptaciones del Quijote, terminó sucumbiendo de una forma u otra a las premisas ultracatólicas del régimen. El propio Rafael Gil diría: "Pabst no creo que haya llegado siquiera a leer Don Quijote"1. El marcado sentido católico de don Quijote desdice mucho de la idea original de Cervantes sobre su caballero andante.

\section{JACQUES IBERT EN FRANCIA}

Jacques Ibert (1890-1962), estudió en el Conservatorio de París siguiendo el curso de composición con Paul Vidal y ganando varios premios en la entidad en 1914. Su carrera fue interrumpida por el servicio militar hasta 1919. Entonces fue desmovilizado y obtuvo el Prix de Rome con su cantata "Le Poete et la Fee”. Durante su estancia en Roma no sólo escribió numerosas obras importantes, tales como "Ballade de la Geole de Reading" y la famosa suite sinfónica "Escales". Además viajó extensamente por Italia, España y Túnez, ganando una experiencia que afectaría a su trabajo. Más tarde, en 1937, estuvo de vuelta en Roma como director de la Academie de France, un cargo que mantuvo hasta 1960. Con excepción del

1 RAMÍREZ MORALES, Dulce-Néstor "Don Quijote de la Mancha” en el cine universal, Ciudad Real, Instituto de estudios manchegos, 1958 , pág. 6. 
oratorio, Ibert realizó contribuciones importantes a todos los géneros creativos. Su producción total es difícil de definir en términos estilísticos debido a que los elementos son extremadamente diversos. Deseaba estar libre de las influencias y nunca se interesó por modas pasajeras. Comenzó su carrera estudiando arte dramático antes de dirigirse a la música en particular. Como sucedió con Debussy, la música de Ibert está relacionada con otras artes y la expresión musical era parte de una respuesta imaginativa total a todos los aspectos de la experiencia. Ibert fue uno de los compositores franceses más "completos". Las siete óperas que escribió (dos en colaboración con Honegger) poseen un carácter liviano. Una de sus partituras más importantes y satisfactorias es precisamente el ballet "Le Chevalier Errant" basado en Don Quijote y que expresa en términos generales el conflicto interno humano moviéndose entre la esperanza y la desesperación. Eligió formas clásicas como base pero las flexibilizó e incluso fantaseó con ellas siempre con un profundo sentido del balance y sin llegar a ser excéntrico como otros colegas. Un estilo ecléctico que era exacto y elegante supo expresar ideas imaginativas en un ropaje orquestal perfecto. La brillantez y la fantasía se pueden observar en obras como "Feerique", "Ouverture de Fete" o "Bacchanale", mientras que la "Symphonie Marine" es una obra puramente romántica. Entre sus otras obras instrumentales el "Concierto para Flauta" es reconocido como una obra maestra en el género, dentro de la música de cámara de Ibert sobresale por su brillantez y profundidad aquel "Cuarteto para Cuerdas" completado bajo las terribles circunstancias de la Segunda Guerra Mundial. El "Trío para violín, cello y arpa” también pertenece a esos años y fue escrito para la hija del compositor, una talentosa arpista. Muere el 5 de febrero de 1962 en París

Alrededor de nuestro periodo de estudio, Europa se va a encontrar en un momento de continuos cambios políticos y sociales. A la remodelación primera del mapa europeo de la segunda guerra mundial, se le sucederá las continuas revueltas. Una de las más importantes fue en Francia a cargo del sector minero. La política de alianzas, las deudas contraídas en la guerra y los continuos cambios en la economía transantlántica condicionarán la actividad social y cultural del primer tercio europeo.

\section{JACQUES IBERT PARA GEORG WILHEM PABST, “DON QUICHOTTE” - 1933}

La música compuesta para la película de Georg Wilhem Pabst (1933) por J. Ibert constituye un planteamiento muy particular en cuanto a la musicalización de la novela Cervantina.

Desde el principio de la gestación de la película se tenía muy claro el protagonismo de la música para el film. Así pues, deberíamos remitirnos al estreno de la ópera de Jules Massenet, en 1910 para delimitar el origen de la película de Pabst, ya que constituye el primer contacto del bajo de ópera Fiodor Chaliapin, quien ha pasado a la historia como pionero entre los cantantes de ópera, especialmente en cuanto al repertorio romántico ruso. Y que como apunta F. Herranz (2005) “a parte de afinar, intentó actuar convincentemente en los escenarios”. La propia ópera Massenet según afirma Vselod Bagno fuera 
especialmente escrita para Chaliapin, "Era Don Quijote, el Caballero de la Triste Figura. Si, justamente de la Triste Figura, y tan honesto, tan santo, que resultó ridículo y cómico para toda esta canalla, esta herrumbre, indigna hasta de su coraza (...)

Oh Don Quijote de la Mancha, te quiero entrañablemente"2.

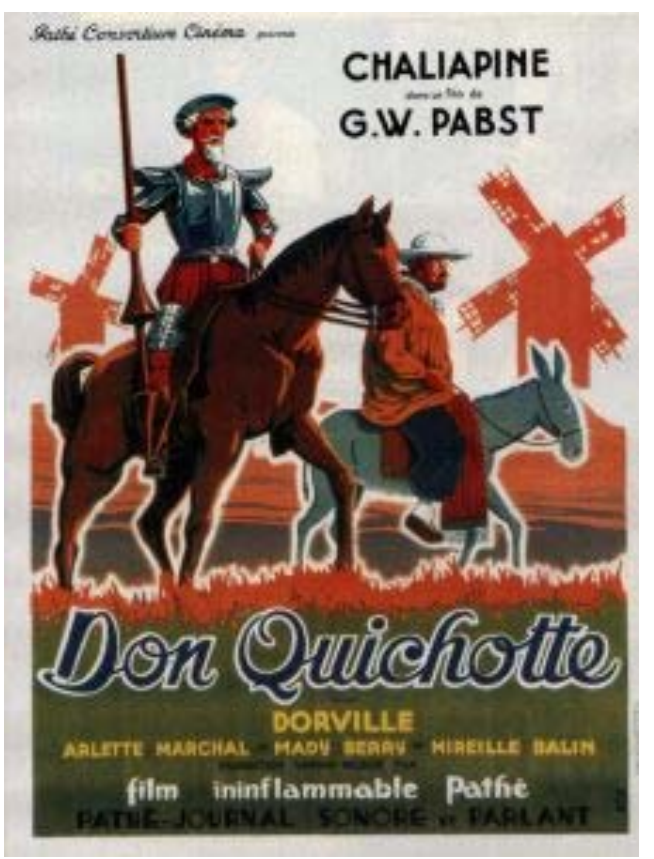

Es así como Chaliapin propone a principio de los años 30 llevar al cine la adaptación cinematográfica, protagonizada por él y a manos de un gran director. Se propone el trabajo a grandes directores como Eisenstein, Chaplin, Jean de Limur, Bernard Deschamps, Víctor Tourjansky, pero por diferentes cuestiones ninguno llega a realizar la película. Al final, con recortes de presupuesto y la imposición del lucimiento del cantante contó con la aprobación de Pabst. ${ }^{3}$

La propia génesis y el planteamiento que nace con la película impiden la lógica o al menos, la establecida lógica de la subordinación de la música a la imagen. En nuestro caso podemos hablar en estos términos ya que, las canciones que se compondrán para la figura de don Quijote y el propio

Sancho actuarán en detrimento de la propia acción de la película. En la mayor parte de la película se podría hablar de una estética de ópera filmada en lugar de una música compuesta y pensada sobre y para la acción.

Está formada por cinco canciones : "Chansons de Don Quichotte et Chanson de Sancho” sobre texto de Paul Morand y Alexandre Arnoux. Cuatro de ellas interpretadas por Don Quijote y una por Sancho, de las cuales la primera se debe a Aleksander Sergeevich Dargomyskij y las cuatro restantes a J. Ibert. El encargo de las canciones al compositor francés tiene diversas anécdotas añadidas. En una primera versión se afirma que Maurice Ravel compuso las tres canciones que le encargó Chaliapin, pero las retiraría de la película "por desacuerdos con la empresa productora del film"4. En otra ocasión demoraría la composición hasta ver terminada la película. Y otras fuentes indican que se convocó un concurso para componer las canciones que aparecerían en la película. Y una cuarta hipótesis apunta a que el propio Ravel fue el que cedió el encargo a su discípulo Ibert. Al margen de todas las especulaciones con el resto de música que aparece en la película no se tiene ninguna evidencia de que corriese a cargo de Ibert. La mínima música “de acción” que sigue después de los créditos, como son la que pone fondo a las sobras chinescas (realizadas por Lotte Reiniger), que surgen de la primera página del libro, así como alguna señal a cargo de la trompetería en forma de fanfarria al más puro estilo impresionista, es presumiblemente atribuible a Ibert. Si bien, no se tiene otra constancia más allá de la documentación de la película.

\footnotetext{
2 BAGNO, Vsevolod, El "Quijote” vivido por los rusos, Madrid, Diputación de Ciudad Real/CSIC, 1994, pág. 110

${ }^{3}$ FERNÁNDEZ CUENCA, Carlos, G. W. Pabst, Madrid, Filmoteca Nacional de España, 1967, pág. 51.

4 FERNÁNDEZ CUENCA, Carlos, 1998 [1948], pág. 45.
} 
Como la propia ilógica consecución de la música, desde un punto de vista cinematográfico, son destacables las alteraciones más o menos elaboradas sobre el entorno y los pasajes de la novela. En la primera parte, escena 18, el director rompe toda coherencia colocando a don Quijote, que canta una lánguida serenata a Dulcinea, frente al mar (en la Mancha!). Así pues, la cómica canción de Sancho (con gran influencia del Vodevil y el Cabaret francés de principio de siglo) puede resultar un tanto forzada en cuanto al tempo cinematográfico. El carácter sintético de la película si que se corresponde con los tipos de canciones que se emplean en ella.

A continuación veremos por orden de aparición las diferentes músicas que Pabst e Ibert recrearon para la película. La versión utilizada para este análisis es la versión francesa.

Aquí podemos ver las duraciones de la música en la película:

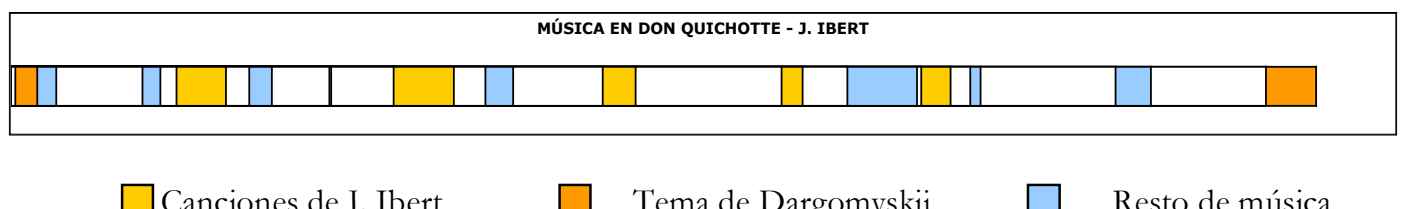

Canciones de J. Ibert $\quad \square \quad$ Tema de Dargomyskij $\quad \square \quad$ Resto de música

- La primera música que se puede oír es la que acompaña a los créditos iniciales. Es una melodía de Dargomyskij llamada "Sierra Morena". En modo menor y a modo de marcha fúnebre (con ritmo base de habanera) adelanta el presagio trágico del final de la novela. El ritmo básico comienza en Si m, de llevado por la sección de metales, en una consecución armónica básica: I-V-I, pero con un intento vago de simular las armonías españolas. Utiliza la cadencia española y la mezcla con giros modales propios para el empleo de cualquier ambiente exótico. El tema de Dargomyskij es presentado por la sección de cuerda de la orquesta y tras un puente correrá a cargo del oboe. Esto mutará en una breve fanfarria de corte impresionista a la que sigue un pasaje cómico donde el fagot contrasta con el oboe romántico anterior. El ambiente deja de ser trágico para convertirse en cómico y grotesco. Esto terminará diluyéndose para dar paso a la voz del hidalgo.

- $\quad$ Más adelante, y sin una justificación en pantalla se oye a lo lejos una guitarra (y no un laúd, como correspondería para la época) con la peculiaridad de que podría tratarse de un punteo de repertorio clásico español contradiciendo una puesta en escena bastante rural.

- Sigue el anuncio de la representación del Amadís de Gaula a cargo de una nueva fanfarria para trompeta (que solo utiliza un acorde de La M) y tamboril, Algo grotesca y breve, que se podrá oír en segundo plano a lo largo de la escena. En el 
carro que lleva a la compañía de teatro se puede ver un joven mozo que porta un laúd, además de un trompa natural (trompas de señal que solo disponen de sonidos naturales) y el tamboril.

1. Comienza la primera canción propiamente dicha para el lucimiento del bajo Chaliapin: "Chanson du Quichotte” sobre texto del poeta renacentista Ronsard. La influencia se puede muy bien encontrar en la obra de Bizet, Beriloz y Massenet. Sobre un ritmo de polonesa ( , original del s. XVIII en 3/4 y a menudo de carácter melancólico) se intenta

reflejar un valor de gallardía y coraje al personaje. En todos los casos, las canciones de Ibert recrean de manera algo prefabricada y plastificada la españolidad del personaje. Esto es algo que tan bien aprendieron los compositores franceses cuando tratan de abordar temáticas españolas.

- Posteriormente podemos oír la música de fiesta que acompaña a la representación teatral de Amadís. Una pequeña orquesta con instrumentación típica del teatro callejero, clarinete, fagot, trompeta, tamboril, etc. Desarrolla una cómica y grotesca ambientación para el desarrollo de la obra. Sobre ritmos sincopados y obstinatos estos instrumentos recrean unos giros melódicos bastante ridículos (basados también en la cadencia andaluza: la m, sol M, fa M mi M) acorde con la ambientación y los personajes que intervienen en la escena.

Podemos advertir dos brevísimas intervenciones de la trompeta a modo de señal.

2. La segunda canción, propiamente compuesta para la figura de don Quijote, es la "Chanson à Dulcinée" sobre texto de A. Arnoux.. El caballero canta frente al corral de la taberna, en el que duerme Dulcinea junto con su amante y los actores de la compañía. En compás de 3 tiempos y con forma de "recitativo accompagnato" con arpa (seguramente con la intención de aludir a la lira que acompaña tradicionalmente en la tradición de la ópera barroca a los personajes enamorados) con un breve interludio de 2 oboes y guitarra que hace de nexo entre dos estrofas iguales; todo en forma de estribillo y dos coplas. Esta serenata está diseñada con un estilo a medio camino entre la españolidad (grupetos ornamentales de 5 y 7 sonidos) y el francesismo (empleo de escalas tomadas de los tonos antiguos) inherente al

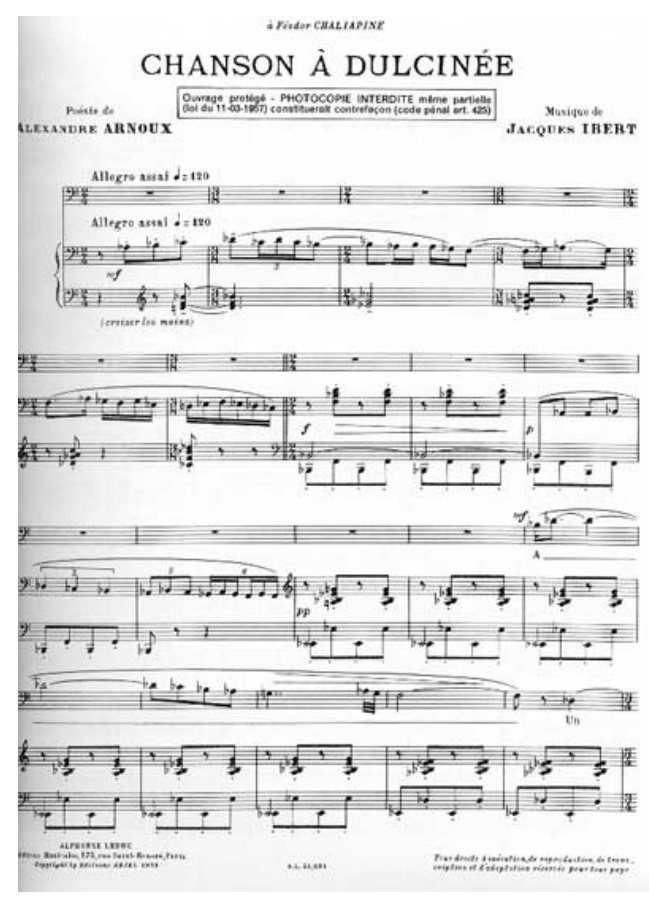
compositor. 
- Seguidamente y con motivo de la lucha contra las ovejas podemos oír un pasaje de gran calidad instrumental, donde interviene el tutti de la orquesta, que ambientará un momento épico junto con algunos efectos cómicos y joviales. El compositor comienza por tanto con la visión terrorífica de los ejércitos de carneros y ovejas y lo lleva a una recreación de disfrute jovial y alegre por parte de don Quijote. Es así como el director y el compositor ven la psicología del guerrero de la triste figura, sentimientos complementarios: por un lado el arrojo del guerrero y por otro el disfrute de verse caballero luchando por una causa noble. Al final resulta vencedor acompañado de una señal victoriosa a cargo de la trompetería.

3. La tercera canción es sin duda alguna la más desigual y heterogénea de toda la música de la película: "Chanson de Depart" sobre texto de Alexandre Arnoux. Comienza a la española con un punteo de guitarra típico de una seguidilla. Todo acompañado por una agrupación bastante pintoresca: el fagot, el clarinete bajo, el oboe, trompetas con sordina, etc. A continuación podemos oír y ver algo totalmente contradictorio. Don Quijote canta frente al mar de la Mancha (!), y lo hace a su amada con un cante jondo típico del albaicín granadino (con una técnica vocal operística excelente y con alguna nota cambiada de la necesaria escala andaluza). Pero esto no queda así y muta, al final de la sección recitada, en un aria escueta, típica de la ópera romántica (en concreto muy similar con fragmentos de la ópera de J. Massenet "Don

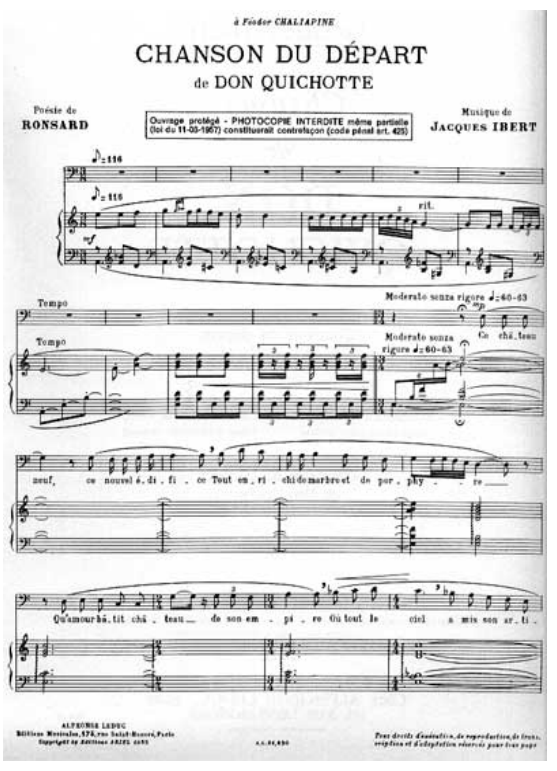
Quichotte").

4. La cuarta canción que aparece en la película corre a cargo de Sancho Panza: “Chanson de Sancho”. En la versión inglesa correrá a cargo de George Robey, quien aventaja al que nos ocupa aquí; el actor francés Dorville, no está demasiado acertado musicalmente con la partitura. El número musical está constituido al más puro estilo de música ligera. Con un sentido muy cómico que nos puede recordar a la opereta tradicional de Künnecke, Offenbach, etc. La instrumentación está bien cuidada en cuanto al empleo de los instrumentos típicos de una banda de pueblo. La trompeta irá casi en todo momento acompañando a la voz de Sancho, mientras una

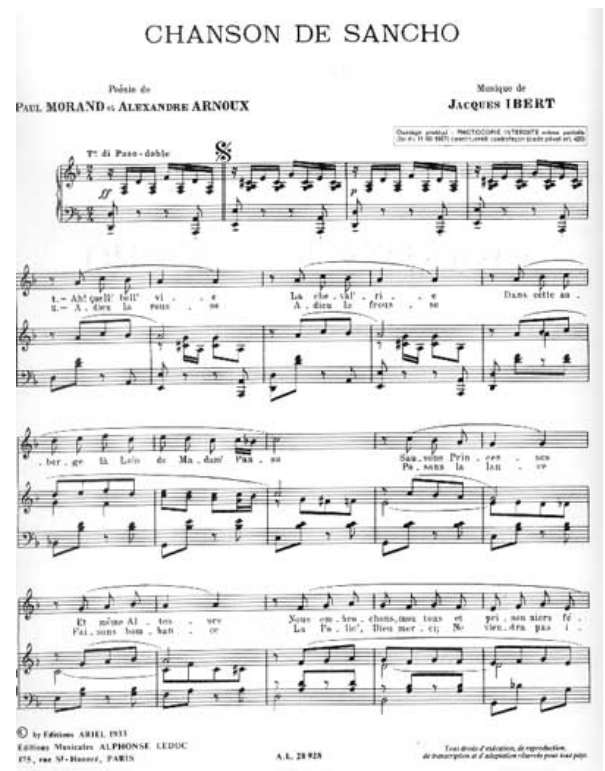


tuba y unos bugles irán haciendo de relleno rítmico y armónico de esta pieza.

- Una breve intervención de la trompeta anunciará la llegada de la misiva del Duque invitándolos a su castillo. Una vez allí el sonido del clavicémbalo al ritmo de danza renacentista ambientará la estancia en el castillo. Repentinamente y algo brusco cambia la estética de la ambientación musical, tornándola en un interludio cortesano y lírico a cargo del oboe y la cuerda de la orquesta. Casi de seguido acompañará a la escena una danza pastoril y a cargo de un tutti instrumental sobre ritmo de gavota ( )tamboril nos inspirará la simpatía entre los cortesanos la presencia grotesca de ambos

personajes.

5. La quinta canción es la más cercana al aria operística típica francesa. La influencia de Poulenc y Offenbach es más que notable. El empleo de cadencias típicas del impresionismo, la melodía en modos antiguos como el Mixolidio y la instrumentación camerística y preciosista de este estilo conforman la "Chason du Duc".

- La fanfarria que precede y anuncia el combate entre don Quijote y el caballero del Grifón muestra una vez más el toque impresionista del compositor francés.

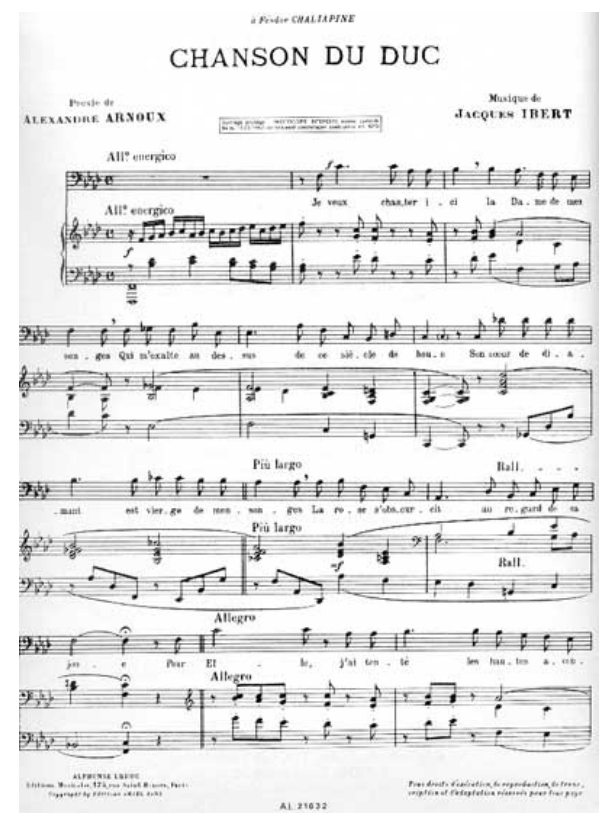
A lo largo de la película la ausencia de música (excepto la que aquí nos ocupa) no ha tenido un factor tan expresivo como hasta ahora. La retirada altiva de don Quijote ante la farsa de los duques se ve reforzada por el silencio del público del castillo.

- La lucha de los molinos está acompañada musicalmente por un furioso y terrible tutti atonal que puede recordarnos a alguna danza tribal de Stravinsky, con arpegios y escalas de la sección de madera junto a los poliritmos de la percusión. A todo esto se une el tema de Dargomyskij "Sierra Morena" a cargo de las trompetas, mientras don Quijote lucha desigualmente contra los molinos. Acabada esta secuencia y terminada la intervención del tutti orquesta, solo se puede oír el viento como señal de vencimiento. Esto se vuelve más amargo y dramático ante las risas abundantes con las que los aldeanos reciben al caballero enjaulado, de vuelta a casa. 
6. La última canción que nos ocupa es extradiegética. Con la voz en “off” y a cargo de don Quijote, hecho ya leyenda, el director consigue una gran emoción. Él ha muerto mientras veía como sus libros y sus ideas se queman en el fuego. El tema de Dargomyskij vuelve a aparecer esta vez con voz de Chaliapin. La canción remite al último acto de la ópera de Massenet, en la que el caballero moribundo regala a Sancho la "Isla de los Sueños" prometida. Vuelve a aparecer aquí el ritmo de habanera.

No hay en esta muerte claudicación de don Quijote a favor de Alonso Quijano. Este, fallece consumido junto a sus ideales lo que le otorga a la narración una estructura circular según la cual el personaje nace y muere con sus lecturas. ${ }^{5}$

De un total de 82 minutos de película, 31 suponen la totalidad de la música, y solo 15 minutos corresponden a las canciones para bajo compuestas para F. Chaliapin. Después de analizar estilo, instrumentación, ritmos, etc. Podemos concluir apuntando la variedad de aspectos que conforman la música para el filme. Todas las contrariedades entre analistas y entendidos sobre la película de Pabst, pueden trasladarse a la propia música. La lírica en las canciones de Chaliapin, contrastan con el intento de españolizar algunos momentos rurales y aristocráticos. En esta recreación Cervantina, el director partió de la premisa de las canciones para don Quijote y tuvo que andar con cautela entre la estética de acción propia del lenguaje cinematográfico y la filmación estática de las canciones del personaje. Al igual que la propia película y la lectura tan personal y poética que hace Pabst, Ibert confecciona un heterogéneo material sonoro al servicio de esta particular visión. La contradicción musical es solo el comienzo en el análisis de esta película.

\section{ERNESTO HALFFTER PARA “DON QUIJOTE DE LA MANCHA” - RAFAEL GIL, 1948}

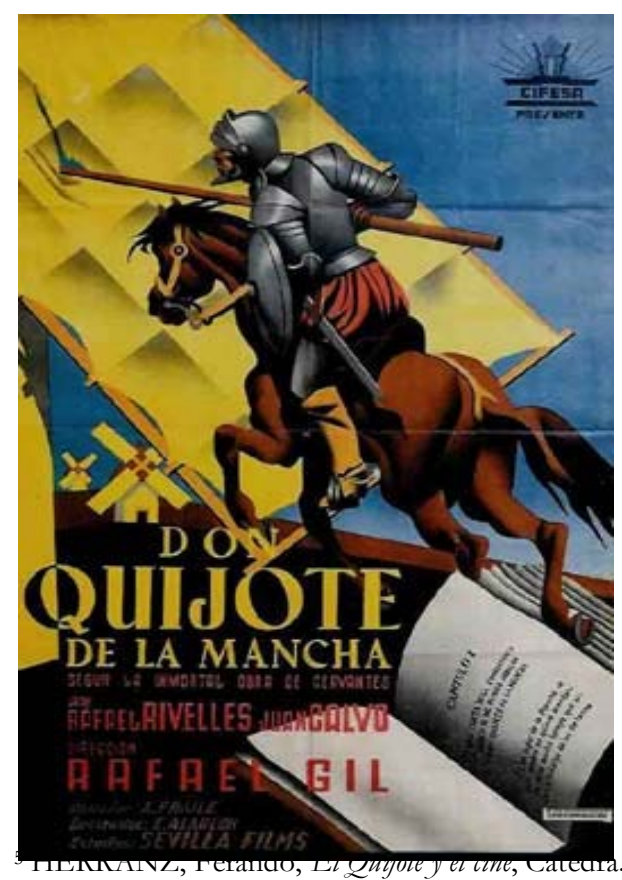

Esta superproducción de Cifesa pretendía ser una de las más veraces de las adaptaciones cinematográficas del Quijote cervantino. Al elenco de estrellas nacionales (Rafael Rivelles, Juan Calvo, Alfredo fraile, Sara Montiel, etc.) se le sumó la maestría y el polifacético talento artístico del compositor Ernesto Halffter. En palabras de Perez Perucha, constituía "un film de altos vuelos"6. La exaltación ${ }^{7}$ del patrimonio nacional y de las posibilidades que la película ofrecía a sus creadores era el objetivo único de esta apuesta cinematográfica, conocido el declive en las producciones de comedias que había visto años atrás ("El caudal de nuestra gloriosa historia, la riqueza incomparable de

${ }^{6}$ COMPANY, Juan Miguel, "Dos cuentos para dos”, en Julio Perez Perucha (ed.), Antología del cine español 1906-1995, Madrid, Cátedra, 1997, pág. 218.

7 “Noticiario Cifesa”,núm. 14, marzo de 1936 
nuestra literatura, clásica y contemporánea, el valioso tesoro folclórico de nuestras canciones populares y la singular e inagotable cantera de nuestras costumbres y modos de vida... hemos de seguir llevando nuestra producción”). Sin embargo, esta propia exaltación patriótica está muy lejana del verdadero espíritu del Quijote, que no es otro que el componente melodramático y de exaltación de conflictos amorosos, que fue en la década de los 40 la base del éxito y aún hoy, el principal valor de la novela.

No se han encontrados datos que nos aporten luz acerca de las circunstancias en las que el maestro Halffter aceptara el encargo de la música para la película de Rafael Gil. Lo cierto es que se apostó desde un principio por la maestría tanto por los decorados en los estudios Sevilla Films de Madrid, como el asesoramiento de la Real Academia Española como la partitura a cargo de Ernesto Halffter.

El material musical de la película es de una amplitud, en principio, y en términos cinematográficos, increíblemente enorme. Halffter utiliza una técnica compositiva muy cercana al material sonoro típico del repertorio romántico orquestal. La instrumentación no apuesta, seguramente por el fiel planteamiento del director, por timbres y realizaciones llamativas. La música está sonando casi la totalidad de la película. Hay que remarcar el dominio absoluto del compositor, logrando una coherencia total entre escenas donde la música pasa desapercibida y los enlaza con momentos de tensión e importancia notables.

A continuación se muestra un diagrama con las duraciones de la música en la película. Analizaremos por orden de aparición las intervenciones musicales que Halffter y Rafael Gil confeccionaron para la película:

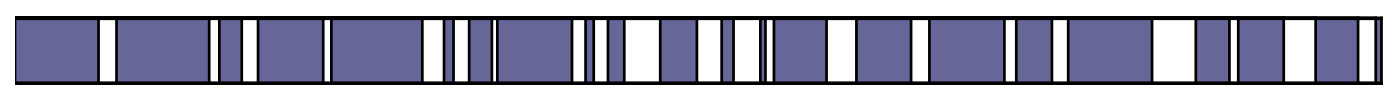

Podemos advertir la enormidad de la música compuesta para la película. De un total de 133 minutos, 98 (color azul) suponen la duración de la banda sonora.

La música comienza con los créditos y la sintonía de Cifesa. Seguidamente podemos oír un fragmento de aire sublime y a modo de himno religioso, cantando el texto "Gloria" a cargo de voces femeninas (primera subliminalidad religiosa). Todo esto es el primer símbolo que el espectador percibe de la obra, exaltación como objetivo primero de la adaptación. 
Seguidamente podemos advertir como el maestro va a ir enlazando los diferentes efectos del propio desarrollo escénico. Durante las escenas pintorescas en las que don Quijote lee las obras de caballería.

Utilizará más adelante, y de nuevo como motivo de exaltación máxima, el coro de voces femeninas, haciendo una alusión celestial y divina a todas los pensamientos de don Quijote.

Coral a modo del estilo Bachiano, a cargo de la sección de cuerda de la orquesta para la vela de armas y el diálogo de don Quijote con el posadero. La lucha con los posaderos (con gran manejo del tutti orquestal con efectos coloristas en la sección de madera y metal) y la condescendencia de dueño de la posada ante el altercado es igualmente enlazada con maestría por Halffter (utilizando una vez más los motivos épicos de la figura altiva de don Quijote).

El estilo compositivo, muy cercano en el renacer del estilo que reivindicó Pedrell y que tan bien conoció a través de su maestro Falla, trata de conjugarse con los efectos de excentricidad del planteamiento en la interpretación de Rivelles. Así pues, los madrigales, las tonadas, las seguidillas y tonadillas del s. XVIII, se adaptan al gusto del compositor para recrear en ciertos momentos aquellos ambientes cervantinos. Sin embargo, como se ha apuntado antes, los efectos tímbricos e instrumentales contemporáneos, aprendidos de la escuela francesa con la que Halffter tenía cierta cercanía, acompañan gran parte de la película.

El combate contra los molinos, es un ejemplo ala vez que contiene momentos propios de la ópera romántica, puede enmarcarse cercana a cualquier escena épica y bélica de las obras de Borodin, o Mussorgsky.

En la escena en la que topa con una diligencia de damas nobles y clérigos, Halffter, con especial habilidad enlaza efectos épicos, románticos, cómicos o excéntricos, utilizando la paleta orquestal con total dominio. Material armónico impresionista, neorenacentista, clásico o barroco aparecen a gusto del compositor en la situación en la que considera transmitir una idea loca de don Quijote o una lucha especialmente real y trágica.

Blanca $\mathrm{M}^{\mathrm{a}}$ Seoane, poniéndole voz a Dorotea, compone e interpreta una bella canción pastoril en un curioso modo "Lidio" (con el $4^{\circ}$ grado alterado), alternando con hábil interés la declamación tradicional del repertorio folclórico español con sus recursos armónicos, dando un color exótico a la vez que llano y pastoril.

Es curioso observar la ambientación trágica, ridícula y patética que acompaña a la llegada de don Quijote enjaulado, de vuelta a casa. La vergüenza es destacada y enfatizada especialmente aquí. 
Una fanfarria anunciará la aparición de los duques, a cargo de la sección de trompas. Otra señal de trompa anunciará la llegada del demonio, que aparecerá durante la cena en el castillo de los duques. Es curioso observar como en el ambiente noble y altivo del palacio de los duques, Halffter utilizará un lenguaje barroco y clásico en lugar de una ambientación renacentista (sin empleo de clavicémbalo, laúd, etc.) típica de estas escenas y utilizada por Ibert.

La llegada de Trifaldín supone otra escena con música diegética, con tambores y flautas de pico. Un preludio muy madrigalista a cargo la cuerda acompaña al discurso de la dueña dolorida o sirvienta barbuda de Malambruno.

La aventura a lomos de Clavileño supone un genial pasaje orquestal, de colorido impresionista que se ve rematado con el desenlace del encantamiento. El momento de tensión a cargo de la marimba y el pedal agudo de los violines remarca la tensión dramática.

Un acierto supone el empleo del cromatismo en el pasaje a cargo de la cuerda, en el que Sancho se desilusiona y rechaza el gobierno de la Ínsula. Aunque la interpretación de Juan Calvo es brillante, la atmósfera de desaliento que Halffter logra transmitir es un acierto compositivo.

La última y definitiva vuelta de don Quijote a casa, está ambientada sobre el tema de inicio, en estilo renacentista, lírico y poético haciendo uso de la pequeña orquesta de cuerda con flauta. Ya no es momento para recrear comicidad, o desánimo. Solo el preludio de un final predecible e inevitable.

Ante la recaída de la salud de don Quijote aparecen los apuntes siniestros de los trombones y las trompas en modo menor, a contratiempo, como un fondo obstinato. Mientras el caballero recuerda sus aventuras y reconoce su locura, el coro de voces femeninas aparece dándole un sentido exaltado y religioso a la reflexión. Un espacio de escena en la que el silencio se hace penetrantemente trágico es el momento en el que se despide de Sancho, de su familia y muere.

Por último, los créditos nos darán una vez más el sentido circular de la película. Como bien apuntan los rótulos en pantalla: "y esto no fue el fin, sino el principio", don Quijote sigue como leyenda, con el himno claramente religioso que acompaña al sentido que el compositor da a la figura de don Quijote.

Es interesante apuntar los momentos en los que no hay música:

- $\quad$ Escena en la $1^{a}$ posada. 
- $\quad$ Selección y quema de libros.

- Don Quijote y Sancho se unen como caballero y escudero.

- Descansan de la pelea con la diligencia y Sancho cura la herida a don Quijote.

- $\quad$ Se marchan de la $2^{\mathrm{a}}$ posada.

- Roban el yelmo barbero y el del burro.

- Sancho vuelve al pueblo para llevar la carta a Dulcinea.

- Historia de Cardenio y Dorotea.

- $\quad$ Reencuentro entre las parejas de Dorotea y Cardenio.

- $\quad$ Trifulca con el barbero en la $3^{a}$ posada.

- Le comunican a don Quijote la existencia de su propio libro.

- Hablan don Quijote y el bachiller pactando un duelo.

- Discurso del demonio en el castillo del Duque.

- Discurso de Trifaldín.

- Disputas del gobierno de Barataria.

- Abandonan la Ínsula y el castillo del Duque.

- Sansón Carrasco comunica al gobernador de Barcelona sus intenciones.

- Vuelta a casa.

- Enfermo, reconoce sus locuras en la cama a sus cercanos. Especialmente a Sancho. Muere.

Pueden parecer muchas escenas sin música, pero sólo suponen un $26 \%$ del total de la película. Se puede ver como, en general, son escenas que o bien, no son especialmente significativas o que resultan de gran interés en el relato. En el segundo caso el director (seguramente y dada la relativa inexperiencia de Halffter) decidiría contrastar con el silencio, escenas tan significativas como la quema de libros o la muerte del propio don Quijote.

\section{CONCLUSIONES}

De este análisis se pueden derivar diferentes aspectos. Unos hacen coincidir a ambos autores, y otros los oponen directamente. Como se apuntaba al comienzo, el planteamiento o la adaptación de los directores de ambas películas va a condicionar el resultado de la adaptación y por consiguiente el estilo que el compositor cree oportuno recrear. Podemos ver puntos de unión entre Ibert y Halffter. 
- El principal y más obvio es la cercanía en estilo estético de ambos. Ibert, heredero de la escuela francesa y promotor de los más eclécticos avances de los “ismos" del siglo XX vienen a coincidir con la escuela en la que Halffter aprende. A través de Falla, Ernesto Halffter desarrolla aspectos que lo hacen similar a los planteamientos impresionistas y expresionistas franceses.

- Otro punto coincidente es la oposición radical entre las ideas musicales para la heroicidad, comicidad o tragedia del personaje de don Quijote. Ambos tienen muy claro el preciso contraste que el argumento del Quijote requiere.

- Los dos autores intentan, más o menos acertadamente recrear los ambientes rurales o palaciegos de la época de Cervantes (instrumentación, armonía, estilo).

Como puntos opuestos entre ambos, podemos apuntar los siguientes factores:

- Hay una diferencia sutil, pero no menos importante entre las estéticas musicales en la búsqueda del ambiente español. Ibert, lo hace a la francesa, y como es obvio Halffter lo hace a la española. Esto, en términos musicológicos y de coherencia de estilo supone una ventaja para el músico español. Si bien, es cierto que el planteamiento de ambas películas es tan opuesto que habría que conocer que música hubieran hecho cada uno, en sus respectivos opuestos.

- El estilo de Ibert es algo más excéntrico que el estilo de Halffter. El compositor francés utiliza los medios orquestales al servicio de lo pintoresco, de lo excéntrico, de lo ridículo. Halffter está mucho más atento al discurso novelesco de la acción. No plantea una visión frívola de la figura de don Quijote, la llena de humanidad y de heroicismo humano. Así pues, la concepción patética y trágica pertenece a Ibert frente a la exaltación humana y divina del personaje de Halffter.

\section{BIBLIOGRAFÍA}

ACKER, Y. y SUÁREZ-PAJARES, J. Emesto Halffter (1905-1946), Música en dos tiempos, Madrid, Residencia de Estudiantes, 1997

BAGNO, V., El "Quijote” vivido por los rusos, Madrid, Diputación de Ciudad Real/CSIC, 1994.

CIFESA, Noticiario, núm. 14, marzo de 1936. 
COMPANY, J. M., El trazo de la letra en la imagen, Cátedra, 1987.

COOK, N., De Madonna al canto gregoriano, Música Alianza Editorial, 2001.

GALLEGO GARCÍA, M. M., Quijote y la música, Revista mensual de publicación en Internet: Filomúsica.

GROUT, J. y PALISTA, V., Historia de la música occidental II, Alianza Música, 1984.

HEREDERO, C. F., suplemento El Cultural, El Mundo, 6-12 de enero de 2005.; Don Quijote en el cine, IVAC "La Filmoteca", núm. 557, 15 al 18 de Noviembre, 2005.

HERRANZ, F., El Quijote y el cine, Cátedra. 2005.

IBERT, J., Partitura: ed. Alphonse Leduc, París (Francia).

MARCO, T., Pensamiento Musical y siglo XX, Fundación Autor, 2002.

MICHELS, U., Atlas de música, Alianza Música, 1982.

NOMMICK, I. El Quijote en la ópera, CVC, 2005.

PÉREZ, M., Diccionario de la música y los músicos, Istmo, 1985.

PÉREZ PERUCHA, J., Antología del cine español 1906-1995, Madrid, Cátedra, 1997.

PISTON, W., Armonía, Labor, 1991.

PRIETO MARUGÁN, J., Don Quijote de la Mancha y la música, Consejería de Educación y Cultura, Valladolid,1999.

RAMÍREZ MORALES, D. N., Don Quijote de la Mancha en el cine universal, Ciudad Real, Instituto de estudios manchegos, 1958 . 
SIEMENS HERNÁNDEZ, L., El quijote en la música vocal, Instituto Cervantes, 2005. 



\section{Exploring Social, Cultural and Pedagogical Issues in AR-Gaming through the Live LEGO House

\author{
Cristina Portalés \\ Laboratorio de Luz \\ Universidad Politécnica de Valencia \\ Camino de Vera s/n, 46022 \\ +34963877007 \\ criporri@doctor.upv.es
}

\author{
Carlos D. Perales \\ Dto. Pintura \\ Universidad Politécnica de Valencia \\ Camino de Vera s/n, 46022 \\ +34 963877007 \\ carpece@doctor.upv.es
}

\author{
Adrian D. Cheok \\ Mixed Reality Lab \\ National University of Singapore \\ 7 Engineering Drive 1, BLK E3A \\ +65167514 \\ adriancheok@mixedrealitylab.org
}

\begin{abstract}
Live LEGO House (LLH) is an interactive Augmented Reality (AR) environment to explore coexistence and multicultural factors through gaming. The system consists basically of a physical/real house built with the LEGO blocks, which is enriched with different non-physical/virtual multimedia files (sounds, videos and 3D animations), insisting in social, cultural and pedagogical issues that the AR technology can bring for children. Tactile, visual and auditory stimuli are present at the game.
\end{abstract}

\section{Categories and Subject Descriptors}

H.5.1 [Information Interfaces and Presentation (HCI)]: Multimedia Information Systems - Artificial, augmented, and virtual realities.

\section{General Terms}

Design, Experimentation, Human Factors, Languages.

\section{Keywords}

Augmented Reality, Interaction, Collaborative, Gaming.

\section{INTRODUCTION}

AR-gaming has increased in the last years $[1 ; 3 ; 6]$, demonstrating its great potential for the entertainment. Other works exploit the potential of physical and social interactions that AR can offer [4]. Following these works, in LLH more than a game is proposed, as it pays special attention in social, cultural and pedagogical issues for children, demonstrating the great potential that the AR technology can bring in these areas.

Copyright is held by the author/owner(s).

ACE'07, June 13-15, 2007, Salzburg, Austria. ACM 978-1-59593-640-0/07/0006.
LLH has been specially developed, but not restricted, for children between 3-7 years old. To keep children's attention at these ages, a large variety of funny sounds, graphics and videos are introduced. The thematic of all these media is 'multicultural', so children can indirectly learn about other cultures. Furthermore, in order to reinforce good environmental and social concepts, some restrictions regarding to water and sound are introduced, in such a way that positive coexistence between players is fomented.

The game can be divided in the following steps:

1. Build your own house within the LEGO blocks.

2. Tell the program where the objects are (calibration procedure).

3. Explore the AR environment within your partner.

\section{GAME DESIGN}

According to [5], important issues of game design in AR include:

\subsection{Technical Characteristics}

The whole system of the LLH consists on (Figure 1):

- A computer work station, with the MXRToolKit libraries;

- Display system: a computer screen;

- Tracking system: a web cam and MXRToolKit square markers;

- Tangible part: The LEGO blocks that form the house/furniture and the dolls;

- Two speakers where sounds are reproduced.

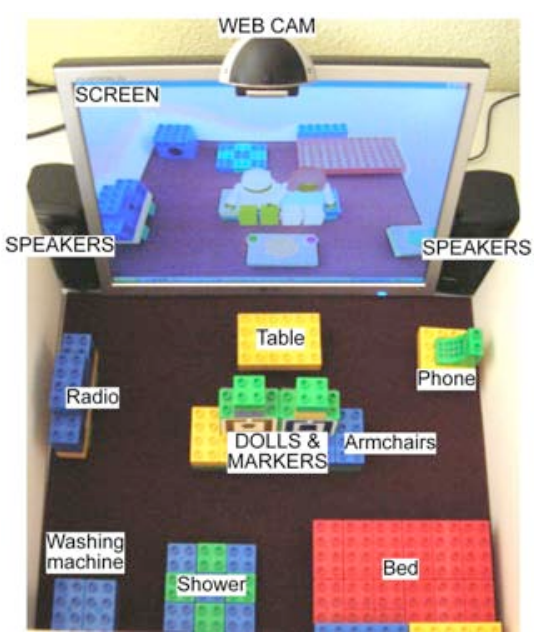

Figure 1. Schema of the LLH system. 


\subsection{Interactivity}

Human-computer interaction is achieved through markers attached to real dolls. The development of amicable interfaces is a key goal to achieve, so that even users not familiar with computers can enjoy the advantages that they offer them. Users can build the house as they wish, so furniture are somehow nonstatic objects. That means that whenever the application is started or furniture is moved, the user should 'tell the program' where the real objects are placed. This step is called 'calibration procedure', and is easily achieved via the keyboard. Interaction is triggered by two ways: by dolls' proximity to the elements of the house or by dolls' tilting (roll and pitch). Produced actions and rendered multimedia files depend upon previous or common interactions.

\subsection{Social, Cultural and Pedagogical Issues}

Social and/or cultural issues can be established in direct communication between players, if they belong to different social or cultural environments. Also, social, cultural and/or pedagogical factors are implicit in the LLH via the multimedia files, which include sounds, videos and 3D-objects.

\subsection{Collaboration}

In LLH game, children collaboration is achieved face-to-face. Children will have to agree in some aspects, as the sequence of their actions conditions the multimedia files that are rendered, and actions of a doll condition other doll. These dependencies are made in order to foment positive collaboration. Negative coexistence is avoided via some kind of restrictions and/or prohibitions regarding to sound and water. For example:

- If both dolls are watching TV, a program that delights both will be displayed. If children want to change TV channel, they will have to agree (one doll should get up from the armchair).

- If one of the dolls is sleeping, the sound is not allowed, that means that the other doll cannot listen to the radio or make a telephone call.

- If one doll has too many showers in a single day, no more water is left, and the other doll cannot have a shower or put the washing machine.

- If a doll sits in front of the table to have lunch, it only will be able to eat or drink, but not both at the same time. To properly have lunch, both dolls need to do the action at the same time.

\subsection{Game Scenarios}

Game takes place in the mixture of real and virtual environments, in the real house and in the house shown at the screen (Figure 2). Commonly, AR is thought to be mainly visual. But it has to be noticed that, although video-based approaches are the primary interest in AR environments, also sounds or other kind of media can be incorporated in order to enrich the experience. According to the virtual stimulus, the LLH scenario integrates the three possibilities, which are tactile, visual and auditory, as olfactory and gustatory do not have their virtual equivalent. According to [2], this represents the most advanced multi-modal AR. That means, children can touch, see and hear in the LLH game.

\section{CONCLUSION}

In this paper, the LLH interactive AR game has been shown. While children explore the house, several multicultural sounds, videos and $3 \mathrm{D}$ models are rendered, thus incising in the great potential that AR-systems can bring for the social, cultural and pedagogical issues for children. LEGO blocks are very popular between children (and adults), so they will find the physic part of the game very familiar and easy to play with. LLH still keeps the bases of the LEGO, allowing children to collaborate and use their imagination and creativity while playing, but adds some kind of multimedia files that enrich the game experience and foment other kind of mutual collaboration and interaction.

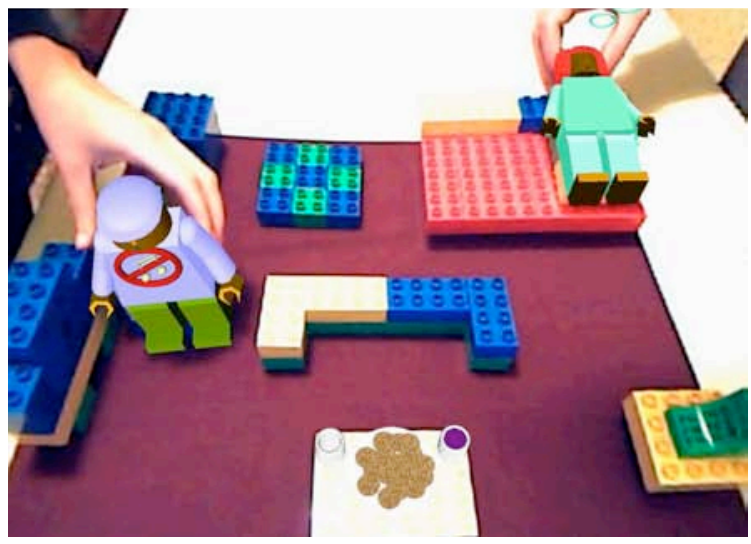

Figure 2: Mutual coexistence at the LLH scenario; One doll is sleeping, so the other cannot make sound (radio off).

\section{REFERENCES}

[1] Andersen, T. L., Kristensen, S., Nielsen, B. W. and Grønbæk, K. Designing an Augmented Reality Board Game with Children: The BattleBoard 3D Experience. In Proceeding of the 2004 conference on Interaction design and children: building a community. ACM Press, New York, NY, 2004, 137-138.

[2] Barfield, W., Rosenberg, C. and Lotens, W. A. Augmentedreality displays. Virtual environments and advanced interface design. Oxford University Press, Inc., New York, NY, 1995, 542-575.

[3] Brederode, B., Markopoulos, P., Gielen, M., Vermeeren, A. and de Ridder, H. pOwerball: The design of a novel mixedreality game for children with mixed abilities. In Proceeding of the 2005 conference on Interaction design and children (IDC '05). ACM Press, New York, NY, 2005, 32-39.

[4] Cheok, A. D., Teh, K. S., Nguyen, T. H. D., Qui, T. C. T., Lee, S. P., Liu, W., Li, C. C., Díaz, D. and Boj, C. Social and physical interactive paradigms for mixed-reality entertainment. Computers in Entertainment (CIE), Volume 4, Issue 2. ACM Press, New York, NY, 2006.

[5] Liarokapis, F. An exploration from virtual to augmented reality gaming. Simulation \& Gaming, Vol. 37, No. 4. SAGE Publications, 2006, 507-533.

[6] Metaxas, G., Metin, B., Schneider, J., Shapiro, G., Zhou, W. and Markopoulos, P. SCORPIODROME: An Exploration in Mixed Reality. Social Gaming for Children. In Proceedings of the 2005 ACM SIGCHI International Conference on Advances in computer entertainment technology (ACE'05). ACM Press, New York, NY, 2005, 229-232. 


\section{BIBLIOGRAFÍA}

60x60, 2008. White Fungus, New Zealand. http://www.youtube.com/watch?v=QzmozlHGIc\&feature=player embedded [Visitado: 28 de Julio, 2010] 120years, 2010. 120 Years of Electronic Music. http://120years.net/machines/melochord/index.html [Visitado: 7 de Agosto, 2010]

(Ed) Nattiez, J. J., 1995. The Boulez-Cage correspondence. Cambridge University Press. 188 páginas.

(ed) Simpson, J. and (ed) Weiner, E., 2009. Oxford English Dictionary. USA, Oxford University Press.: 22000.

Aguilar, A., 2006. Refleciones sobre el análisis de música electroacústica. ANPPOM - XVI Congresso da Associação Nacional de Pesquisa e Pós-graduação em Música. Brasilia, Universidad de los Andes: 4.

Akamatsu, M., 2009. Aka Objects. http://www.iamas.ac.jp/ aka/max/ [Visitado: 15 Enero 2009].

AnalogArtEnsemble, 2010.

Trautonium. http://www.analogartsensemble.net/labels/Paul\%20Hindemith html [Visitado: 8 de Agosto, 2010]

Anastassova, M., Burkhardt, J.-M., Megard, C. and Ehanno, P., 2005. Results from a user-centred critical incidents study for guiding future implementation of augmented reality in automotive maintenance. International Journal of Industrial Ergonomics, 35(1):

$67-77$. 
Andersen, T. L., Kristensen, S., Nielsen, B. W. and Grønbæk, K., 2004. Designing an Augmented Reality Board Game with Children: The BattleBoard 3D Experience. Proceeding of the 2004 conference on Interaction design and children: building a community IDC '04, ACM Press, New York, NY, USA: 137 - 138

Apple, 2010a. http://www.apple.com/es/macosx/ [Visitado: 13 de Julio de 2010]

Apple, 2010b. Logic Studio. http://www.apple.com/es/logicstudio/ [Visitado: 15 de Julio, 2010

Apple, 2010c. Plug-ins. http://www.apple.com/logicstudio/plug-ins/ [Visitado: 2 de Agosto, 2010]

Appleton, J. H. and Perera, R. C., 1975. The Development and Pactice of Electronic Music. Englewoods Cliffs: Prentice-Hall, Inc. 288 páginas.

Ariza, J., 2003. Las imágenes del sonido, Universidad de Castilla-La Mancha, Cuenca, 264 páginas.

Arq-lab-vox, 2010. Arq history. http://arqlab.vox.com/library/posts/tags/arq-historyl [Visitado: 7 de Agosto, 2010]

Arroyo Almaraz, I., 2003. Creación de imágenes mentales según la naturaleza y las formas de los estímulos. Universidad Complutense, Madrid. 547 páginas.

Aschke, M., Wirtz, C. R., Raczkowsky, J., Worn, H. and Kunze, S., 2003. Stereoscopic augmented reality for operating microscopes. International Congress Series, 1256: 408-413.

Audacity, 2010. Audacity. http://audicity-2010.net/?a=Audacity [Visitado: 8 de Agosto, 2010]

Audiovisualizers, 2010. FairLight Computer Video Instrument. http://audiovisualizers.com/toolshak/vidsynth/fair_cvi/fair_cvi.h tm [Visitado: 28 de Julio, 2010]

Avery, B., Thomas, B. H., Velikovsky, J. and Piekarski, W., 2005. Outdoor augmented reality gaming on five dollars a day. Proceedings of the Sixth Australasian conference on User interface - Volume 40, Australian Computer Society, Inc. Darlinghurst, Australia, Australia: 79 - 88.

Azuma, R., Weon Lee, J., Jiang, B., Park, J., You, S. and Neumann, U., 1999. Tracking in unprepared environments for augmented reality systems. Computers \& Graphics, 23(6): 787-793.

Badiqué, E., Cavazza, M., Klinker, G., Mair, G., Sweeney, T., Thalmann, D. and Thalmann, N. M., 2002. Entertainment Applications of Virtual Environments. capítulo 55 in Handbook of Virtual Environments: Design, Implementation, and 
Applications. (Ed. K. M. Stanney). Lawrence Erlbaum Associates páginas: $1143-1166$.

Baigorri, L., 2004. Video; primera etapa. El video en el contexto social y artístico de los años 60-70., Madrid. 256 páginas.

Balasingham, I., Samset, E., Hansen, A. and Aurdal, L., 2003. An interactive augmented reality $3 \mathrm{D}$ visualization system for destroying liver tumor using cryoablation. International Congress Series, 1256: 690-695.

Barakonyi, I., Weilguny, M., Psik, T. and Schmalstieg, D., 2005. MonkeyBridge: autonomous agents in augmented reality games. Proceedings of the 2005 ACM SIGCHI International Conference on Advances in computer entertainment technology, ACM Press New York, NY, USA: $172-175$.

Barfield, W., 1995. Virtual Environments and Advanced Interface Design. Oxford University Press, Cary, NC, USA. páginas.

Barfield, W., Rosenberg, C. and Lotens, W. A., 1995. AugmentedReality Displays. capítulo 14 in Virtual Environments and Advanced Interface Design. (Eds. W. Barfield and T. A. Furness). Oxford University Press, USA páginas: 557 - 590.

Barret, N., 1999. Little Animals: Compositional Structuring Processes. Computer Music Journal: Cambridge, MA, 23: 11-18.

Bass, L., Siewiorek, D., Baver, M., Casciola, R., Kasabach, C., Martin, R., Siegel, J., Smailagic, A. and Stivoric, J., 2001. Constructing Wearable Computers for Maintenance Applications. capítulo 22 in Fundamentals of wearable computers and augmented reality. (Eds. W. Barfield and T. Caudell). Lawrence Erlbaum Associates, Mahwah, New Jersey. páginas: 663-694.

Baus, L. F. d., 2010. La Fura dels Baus. http://www.lafura.com/web/index.html [Visitado: 30 de Julio, 2010]

Beaudouin-Lafon, M., 1994. Beyond the Workstation: Mediaspaces and Augmented Reality in People and Computers. (Eds. G. Cockton, S. W. Draper and G. R. S. Weir). Cambridge University Press, Glasgow. IX.

Behringer, R., Chen, S., Sundareswaran, V., Kenneth, W. and Vassiliou, M., 1999. A distributed device diagnostics system utilizing augmented reality and $3 \mathrm{D}$ audio. Computers \& Graphics, 23(6): 821-825.

Ben-Joseph, E., Ishii, H., Underkoffler, J., Piper, B. and Yeung, L., 2001. Urban Simulation and the Luminous Planning Table: Bridging the Gap between the Digital and the Tangible. Journal of Planning Education and Research, 21(2): 196-203. 
Benford, S., Crabtree, A., Flintham, M., Drozd, A., Anastasi, R., Paxton, M., Tandavanitj, N., Adams, M. and Row-Farr, J., 2006. Can You See Me Now? ACM Transactions on Computer-Human Interaction (TOCHI), ACM Press New York, NY, USA, 13 (1): $100-133$.

Berenguer, J., 1974. Introducción a la Música electroacústica. Fernando Torres, Valencia. 116 páginas.

Berenguer, J., 1996. Actas de la Académie Internationale de Musique Électroacoustique, Barrière, $\mathrm{F}$.

Bennet, G., /Bourges. [Visitado: 3 de Agosto, 2010]

Berezan, D., 2009. Acousmatic music as archetypal music. http://www.davidberezan.com/homepage/archetypes.html

[Visitado: 2 enero 2009].

Bermúdez Acosta, J., 1980. Nueva Generación de Instrumentos Musicales Electrónicos. Marcombo Boixareu Editores, Barcelona. 261 páginas.

Bias, 2010. Peak. http://www.bias-inc.com/ [Visitado: 8 de Agosto, 2010]

Billinghurst, M. and Kato, H., 2002. Collaborative Augmented Reality. Communications of the ACM, 45: 64-70.

Billinghurst, M., Kato, H. and Poupyrev, I., 2001. The MagicBook Moving Seamlessly between Reality and Virtuality. Computers and Graphics: 2 - 4.

Bimber, O., Coriand, F., Kleppe, A., Bruns, E., Zollmann, S. and Langlotz, T., 2005a. Superimposing Pictorial Artwork with Projected Imagery. IEEE MultiMedia, 12(1): 16 - 26.

Bimber, O., Emmerling, A. and Klemmer, T., 2005b. Embedded Entertainment with Smart Projectors. Computer, 38(1): 48 - 55.

Bimber, O., Encarnação, L. M. and Schmalstieg, D., 2003. The virtual showcase as a new platform for augmented reality digital storytelling. Proceedings of the workshop on Virtual environments 2003, ACM Press. New York, NY, USA, 39: 87 95.

Bimber, O., Encarnao, L. M. and Schmalstieg, D., 2000. Augmented Reality with Back-Projection Systems using Transflective Surfaces. Computer Graphics Forum, 19(3).

Bimber, O. and Raskar, R., 2005. Spatial Augmented Reality: Merging Real and Virtual Worlds. páginas.

BIPM, 2010. Resolution of the 3rd meeting of the CGPM (1901). http://www.bipm.org/en/CGPM/db/3/2/ [Visitado: 26 de Julio, 2010] 
Blackburn, M., 2009. Composing from spectromorphological vocabulary: proposed application, pedagogy and metadata. EMS og. E. og. Buenos Aires: 7.

Bobick, A., Davis, J. and Intille, S., 1997. The KidsRoom: An Example Application Using a Deep Perceptual Interface. Workshop on Perceptual User Interfaces: 1 - 4 .

Bobick, A. F., Intille, S. S., Davis, J. W., Baird, F., Pinhanez, C. S., Campbell, L. W., Ivanov, Y. A., Schütte, A. and Wilson, A., 1999. The KidsRoom: A Perceptually-Based Interactive and Immersive Story Environment. Presence: Teleoperators and Virtual Environments, 8(4): 367-391.

Boulanger, R., 2000. The Csound Book: Perspectives in Software Synthesis, Sound Design, Signal Processing, and Programming. The MIT Press. páginas.

Boulez, P., 2001. Puntos de Referencia. Gedisa, Barcelona. 495 páginas.

Brandt, E., 2006. Designing exploratory design games: a framework for participation in Participatory Design? Proceedings of the ninth conference on Participatory design: Expanding boundaries in design, ACM Press New York, NY, USA, 1: 57 - 66.

Britannica, 2010. http://www.britannica.com/bps/image/7164/4105/Aeolian-harp [Visitado: 8 de Agosto, 2010]

Broll, W., Lindt, I., Ohlenburg, J., Wittkämper, M., Yuan, C., Novotny, T., Schiecky, A. F. g., Mottramy, C. and Strothmann, A., 2004. ARTHUR: A Collaborative Augmented Environment for Architectural Design and Urban Planning. Journal of Virtual Reality and Broadcasting, 1(1): 1 - 10.

Burns, K., 2010. History of Electronic and Computer Music incuding Automatic Instruments and Composition Machines. http://www.djmaquiavelo.com/History.html [Visitado: 7 de Agosto, 2010]

Cabanne, P., 1987. Dialogues With Marcel Duchamp. 133 páginas.

Cádiz, R. F., 2008. Estrategias auditivas, perceptuales y analíticas en la música electroacústica Centro de Investigación en Tecnologías de Audio, Instituto de Música, Pontificia Universidad Católica de Chile: 16 .

Caesar, R., 2006. Revista Polemica Imagem,(número 15).

Cage, J., 1999. Escritos al oído. Colegio oficial de aparejadores y arquitectos técnicos de la región de Murcia. 209 páginas.

Cage, J., 2002. Pourl les oiseaux: Entretiens avec Daniel Charles. L'Herne, Paris. 295 páginas. 
Castanet, P. A., 1988. L'espace spiralé dans la musique contemporaine in (L'Espace: Msique/Philosophie, textos reunidos y presentados por Jean-Marc Chourel et Makis Solomos). Ed. L'Harmattan, Paris.

Catalá, J., 2010. cinema-nu. http://www.cinema-nu.com/ [Visitado: 20 de Julio, 2010]

CEMVA, 2010. http://call4scores.blogspot.com/2008/08/cemva-20082nd-electroacoustic-contest.html [Visitado: 17 de Julio, 2010

Chapel Hinojosa, R., 1995. ACERCA DE LOS INSTRUMENTOS ELECTRÓNICOS, LA MÚSICA ELECTROACÚSTICA $Y$ LAS COMPUTADORAS. Teoría y Crítica de Arte.

Charles, F., Cavazza, M., Mead, S. J., Martin, O., Nandi, A. and Marichal, X., 2004. Compelling Experiences in Mixed Reality Interactive Storytelling. Advanced Computer Entertainment $\left(\mathrm{ACE}^{\prime} \mathrm{04}\right): 32-41$.

Cheok, A. D., Teh, K. S., Nguyen, T. H. D., Qui, T. C. T., Lee, S. P., Wei, L., Li, C. C., Diaz, D. and Boj, C., 2006. Social and physical interactive paradigms for mixed-reality entertainment. ACM Computers in Entertainment, 4(2).

Cheok, A. D., Weihua, W., Yang, X., Prince, S., Wan, F. S., Billinghurst, M. and Kato, H., 2002. Interactive Theatre Experience in Emboided + Wearable Mixed Reality Space. ISMAR.

Chion, M., 1994. Audiovisión. Columbia University Press. 239 páginas.

Chion, M., 1983. Guide des objects sonores, Pierre Schaeffer et la recherche musicale. Éditions Buchet/Chastel, Paris. 188 páginas.

Chion, M., 1994. The Three Listening modes, The Real and the Redered and Television, VIdeo Art, Music Video, Audio-Vision on Screen, New York. páginas.

CIIC, China Internet Information Center 2010. Los instrumentos musicales tradicionales de China. http://spanish.china.org.cn/spanish/173463.htm [Visitado: 9 de Agosto, 2010]

Cipriani, A., 2008. Acousmonium in Rome. http://www.artselectric.org/stories/080825_cipriani.html [Visitado: 5 de Agosto, 2010]

Ciulli, N., Giordano, S. and Sparano, D., 1998. A cooperative environment based on augmented reality: from telepresence to performance issues. Computer Networks and ISDN Systems, 30(16-18): 1447-1455.

Climent, R., 2001. Porfolio of compositions. The Queen's University of Belfast, 160 páginas. 
Climent, R., 2006. Reinventando la interdisciplinariedad a través de las nuevas tecnologías. 10 Congreso Internacional de Musica y Tecnologías Contemporaneas. Sevilla: 3.

Climent, R., 2008. Applications of Typomorphology in Acute; Scoring the Ideal and its Mirror. Sound Music Conference 2008. Berlin: 3 .

Clozier, C., 1997. Composition-difusion/interprétation en musique électroacoustique. Actes III de l'Académie de Bourges.

CNMAT, U. o. C., 1987. Max MSP external, Berkeley. http://cnmat.berkeley.edu/ [Visitado: 4 Abril 2009].

Coduys, T., Di Giugno, G., Pihet, V., Nguyen, T. and Latour, C., 1999. La Kitchen, The Kroonde Gamma_. http://www.la-kitchen.frl [Visitado: 3 Agosto 2008].

Cohen-Cruz, J., 1998. Radical Street Performance, Routledge, London. 312 páginas.

ConcreteMoniker, 2010.

http://www.concretemoniker.co.uk/artists/the-splice-girls/ [Visitado: 07.2010]

Cooper, N., Keatley, A., Dahlquist, M., Mann, S., Slay, H., Zucco, J., Smith, R. and Thomas, B. H., 2004. Augmented Reality Chinese Checkers: 117 - 126.

Csound, 2010a. http://www.csounds.com/ [Visitado: 16.06.2010]

Csound, 2010b. http://es.wikipedia.org/wiki/Csound [Visitado: 14 de Agosto, 2010]

Cuartielles, D. and Banzi, M., 2006. Arduino. http://www.arduino.cc/es/ [Visitado: 12 Junio 2008].

CVLAB - Computer Vision Laboratory, 2007. bazAR Documentation, Ecole Polytechnique Fédérale Lausanne. http://cvlab.epfl.ch/software/bazar/html/index.html [Visitado: 29 September 2007].

Cycling74, 2010. Max MSP. http://cycling74.com/ [Visitado: 7 de Agosto, 2010]

Dangelmaier, W., Fischer, M., Gausemeier, J., Grafe, M., Matysczok, C. and Mueck, B., 2005. Virtual and augmented reality support for discrete manufacturing system simulation. Computers in Industry, 56(4): 371-383.

Davidson, J. W., 1991. The perception of Expressive Movement in Music Performance. Cornell University, London. 382 páginas.

Davis, M. F., 2003. History of Spatial Coding. Journal of the Audio Engineering Society, 51(No 6): 554-569.

Davis Tom and Karamanlis, O., 2005. Gestural Control of Sonic Swarms: Composing with Grouped Sound Objects. EMS og. E. og. Buenos Aires: 4 . 
De Souza e Silva, A. and Delacruz, G. C., 2006. Hybrid Reality Games Reframed: Potential Uses in Educational Contexts. Games and Culture, 1(3): 231 - 251.

Delalande, F., 1998. Music analysis and reception behaviors: Sommeil by Pierre Henry. Journal of New Music Research, 27: 13-66.

Deltcheva, R. and Vlasov, E., 1997. Back to the House II: On the Chronotopic and Ideological Reinterpretation of Lem's Solaris in Tarkovsky's Film. Russian Review, 56(4): 532-549.

Demiris, A. M., Vlahakis, V., Makri, A., Papaioannou, M. and loannidis, N., 2005. intGuide: A platform for context-aware services featuring augmented-reality, based on the outcome of European Research Projects. Signal Processing: Image Communication, 20(9-10): 927-946.

Dempsey, M., 1981. Lost Harmony - Tarkovsky's The Mirror and The Stalker in Film Quarterly. (Ed. P. JStor. University of Pennsylvania). University of California Press 35, No. 1 páginas: 12-17.

Deutsch, H. A., 1976. An Introduction to the History, Theory, and Practice of Electronic Music. Alfred Publishing Company, Inc., Nueva York. 321 páginas.

Devices, A., 2009. ADXL335, Norwood, MA - U.S.A. http://www.sparkfun.com/datasheets/Components/SMD/adx/3 35.pdf [Visitado: 25 de Julio, 2010]

Dhomont, F., 1996. Acousmatic Updates. Journal of Electroacoustic Music, 9(Enero).

Díaz de la Fuente, A., 2005. Estructura y significado en la música serial y aleatoria. Tesis doctoral. Universidad Nacional de Educación a Distancia, 403 páginas.

Díaz, D. J., 2007. De la plaza al chat: análisis de las transformaciones del espacio público desde la práctica artística neomedial. Tesis doctoral. Universidad Politécnica de Valencia, Valencia. 459 páginas.

DiscreteSynthesizers, 2006. The Novachord Restoration Project. http://www.discretesynthesizers.com/nova/intro.htm [Visitado: 8 de Agosto, 2010]

Dodge, C. and Jerse, T., 1997. Computer Music. Synthesis, composition, and performance. Schirmer. 480 páginas.

Doherty, D., 1998. Sound Diffusion of Stereo Music over a Multi Loudspeaker Sound System: from first principles onwards to a successful experiment. Journal of Electroacoustic Music, 11: 9 11.

Dow, S., Lee, J., Oezbek, C., Maclntyre, B., Bolter, J. D. and Gandy, M., 2005. Exploring spatial narratives and mixed reality experiences 
in Oakland cementery. Advanced Computer Entertainment (ACE'05), Valencia: 51 - 60.

Drake, C. and Palmer, C., 1991. Recovering structure from expressions in music performance. Proceedings of Cognitive Science, Chicago.

EARS, 2010.

Acusmático.

http://www.ears.dmu.ac.uk/spip.php?page=rubriqueLang\&lang =es\&id rubrique $=18$ [Visitado: 4 de Agosto, 2010]

EbrisaOnline, 2010. David Edward Hughes. http://www.ebrisa.com/portalc/ShowArticle.do\%3Bjsessionid= 81F377888FC807FDD127101578425C28?articleld=92094

[Visitado: 8 de Agosto, 2010]

Edwards, D. E., 2010. http://www.wovenhand.com/ [Visitado: 31 de Julio, 2010]

Electrotap, 2008. Software and hardware for innovative music, media, and art. http://www.electrotap.com/taptools/ [Visitado: 8 Febrero 2008].

Ellis, A. K. and Fouts, J. T., 2001. Interdisciplinary Curriculum: The Research Base. Music Educators Journal. MENC: The National Association for Music Education, 87(5): pp. 22-26+68.

ElMusiquiatra, 2010. La Historia de los Sintetizadores antes de 1900. http://www.elmusiquiatra.com.ar/viewtopic.php?f=8\&t=24597 \&view=unread [Visitado: 8 de Agosto, 2010]

ElTamiz, 2008. Inventos Ingeniosos.

http://eltamiz.com/2008/01/31/inventos-ingeniosos-elfonografo/ [Visitado: 8 de Agosto, 2010]

EMF, 2006.

The

Acousmonium.

http://emfinstitute.emf.org/exhibits/acousmonium.html

[Visitado: 5 de Agosto, 2010]

EMS, 2010. http://www.ems-network.org/ [Visitado: 17 de Julio, 2010]

Endnote, 2010. http://www.endnote.com/ [Visitado: 12 de Agosto, 2010]

Essays, F., 2010. http://www.ukessays.com/essays/theatre/sitespecific-performance.php [Visitado: 30 de Julio, 2010]

Ferraz, S., 2005. O Livro das Sonoridades, Sau Paulo. 131 páginas.

Fischer, J., Bartz, D. and Straßer, W., 2004. Occlusion Handling for Medical Augmented Reality using a Volumetric Phantom Model. (VRST'04).

Fischer, J., Eichler, M., Bartz, D. and Straer, W., 2007. A hybrid tracking method for surgical augmented reality. Computers \& Graphics, 31(1): 39-52.

Flintham, M., Anastasi, R., Benford, S., Hemmings, T., Crabtree, A., Greenhalgh, C., Rodden, T., Tandavanitj, N., Adams, M. and 
Row-Farr, J., 2003. Where On-Line Meets On-The-Streets: Experiences With Mobile Mixed Reality Games. CHI, 5: 569-576.

Florins, M., Trevisan, D. G. and Vanderdonckt, J., 2005. The continuity property in mixed reality and multiplatform systems: a comparative study in Computer-Aided Design of User Interfaces IV. (Ed. R. Jacob). Kluwer Academic Publishers, Netherlands. 26 páginas: $323-334$.

Forsythe, W., 2010. The Forsythe Company. http://www.theforsythecompany.com/publikationen.html?\&L= 1 [Visitado: 20 de Julio, 2010]

Fylkingen, 2010. http://www.fylkingen.se/ [Visitado: 17 de Julio, 2010] Galantay, R., Torpus, J. and Engeli, M., 2004. "living-room" Interactive, Space-Oriented Augmented Reality. ACM Multimedia (MM'o4): 64-71.

García de la Torre, A., 2006. Música y nuevas tecnologías, VitoriaGasteiz. http://www.arteleku.net/mrbe/?p=133

García-Lorca, F., 2004. Poema de la Soleá. Obras I. Poesía 1. Edición de Miguel García-Posada. Biblioteca Literaria. Akal ediciones. 240 páginas.

Garzotto, F. and Forfori, M., 2006. Hyperstories and Social Interaction in $2 D$ and $3 D$ Edutainment Spaces for Children. $\mathrm{HT}^{\prime} 06$ : 57-67.

Gauthier, $\quad$ T., $2010 . \quad$ Portrait d'une femme. http://www.thierrygauthier.com/en/audiovisual.php [Visitado: 17 de Julio, 2010

Gelenbe, E., Hussain, K. and Kaptan, V., 2005. Simulating autonomous agents in augmented reality. Journal of Systems and Software, 74(3): 255-268.

Gibson, J. J., 1986. The Ecological Approach to Visual Perception. Psychology Press; New edition. 332 páginas.

Gillet, A., Sanner, M., Stoffler, D., Goodsell, D. and Olson, A., 2004. Augmented Reality with Tangible Auto-Fabricated Models for Molecular Biology Applications. IEEE Visualization: 235-241.

Gillies, D., 1996. Artificial Intelligence and Scientific Method. Oxford University Press. $176+$ xiv páginas.

Giomi, F. and Ligabue, M., 1998. Understanding electroacoustic music: analysis of narrative strategies in six early compositions. Organised Sound, 3: 45-49.

Gómez Gutiérrez, E., 2009. Introducción a la Síntesis de Sonidos). Escola Superior de Musica de Catalunya, Barcelona. Curso 2009-2010.

Grewal, M. S., Weill, L. R. and Andrews, A. P., 2001. Global Positioning Systems, Inertial Navigation, and Integration. John Wiley \& Sons. 391 páginas. 
Griffiths, P., 1978. Modern Music a Concise History from Debussy to Boulez. Thames and Hudson, Nueva York. 216 páginas.

Grigg, L., Johnston, R. and Milsom, N., 2003. Emerging Issues for Crossdisciplinary Research. Conceptual and Empirical Dimensions. Department of Education, Science and Training, Commonwealth of Australia. páginas.

Grout, D. J. and Palisca, C. V., 1988. Historia de la música occidental. Vol I y II. Alianza Música, Madrid. 1112 páginas.

Grups.blanquerna, 2010. História de L'Orgue. http://grups.blanquerna.url.edu/m222/hist.htm [Visitado: 8 de Agosto, 2010]

Ha, T., Chang, Y. and Woo, W., 2007. Usability Test of Immersion for Augmented Reality Based Product Design. Edutainment: 152 161.

Hall, T., Ciolfi, L., Bannon, L., Fraser, M., Benford, S., Bowers, J., Greenhalgh, C., Hellström, S.-O., Izadi, S., Schnädelbach, H. and Flintham, M., 2002. The Visitor as Virtual Archaeologist: Explorations in Mixed Reality Technology to Enhance Educational and Social Interaction in the Museum. ACM 91-96.

Halme, A., Suomela, J. and Savela, M., 1999. Applying telepresence and augmented reality to teleoperate field robots. Robotics and Autonomous Systems, 26(2-3): 117-125.

Hammond-organ, 2010. The Hammond Solovox (1940). http://www.hammond-organ.com/Museum/solovox.htm

[Visitado: 8 de Agosto, 2010]

Harchanko, J., 2003. Spectro-morphology and Structure. An Analysis of Gilles Gobeil's $\quad$ Le Vertige Inconnu\}. http://cec.concordia.ca/econtact/Analyses/Harchanko/index.ht $\underline{\mathrm{ml}}$ [Visitado: 28 de Julio, 2010]

Haro, J., 2004. Arte sonoro: liberación del sonido e hibridación artística. Lucera \#5: 7.

Harrison, J., $1995 . \quad$ Unsound Objects.

http://artsweb.bham.ac.uk/harrison/prognotes.htm [Visitado: 18 Abril 2009].

Harrison, J., 1996. Sound, Space, Sculpture: some thoughts on the 'what', 'how', and (most importantly) 'why' of diffusion...and related topics. Journal of Electroacoustic Music,(Mayo).

Hellerman, W. and Goddard, D., 1983. Sound /Art (Catalogue). Mayo 1-30. T. S. Center. Nueva York, BACA/DCC Gallery. Junio 1-30.

Hernández, P., 2010. La vocación en el video danza. http://www.videodanza.com/textos.htm [Visitado: 25 de Julio, 2010] 
Hetherington, K., 1998. Expressions of Identity: Space, Performance, Politics. The Dictionary of Human Geography. R. J. Johnston, D. Gregory, G. Pratt and M. Watts. London, Sage: 577.

Hicks, J., Flanagan, R., Petrov, P. and Stoyen, A., 2003. Eyekon: Distributed Augmented Reality for Soldier Teams. International Command and Control Research and Technology Symposium (ICCRTS'03), Washingtong, DC.

Hicks, J. D., Flanagan, R. A., Petrov, P. V. and Stoyen, A. D., 2002. Eyekon: augmented reality for battlefield soldiers. Software Engineering Workshop, NASA Goddard/IEEE: 156 - 163 .

Hirst, D., 2004. An analytical methoodology for acousmatic music. International Conference on Music Information Retrieval. Barcelona: 76-112.

HistoriaGlobalOnline, $2010 . \quad$ Macintosh http://historiaglobalonline.com/2009/03/la-apple-macintoshcumple-25-anos/

Hoberman, P., Parés, N. and Parés, R., 1998. El ball del fanalet. http://www.iua.upf.es/ gvirtual/lghtpls/lghtpl c.htm [Visitado: 4 Febrero 2008].

Höllerer, T., Feiner, S., Terauchi, T., Rashid, G. and Hallaway, D., 1999. Exploring MARS: developing indoor and outdoor user interfaces to a mobile augmented reality system. Computers \& Graphics, 23(6): 779-785.

IBM, 2010a. Felt and Tarrant Comptometer. http://www03.ibm.com/ibm/history/exhibits/attic2/attic2_047.html

[Visitado: 8 de Agosto, 2010]

IBM, 2010b. Transistor and printed circuit. http://www03.ibm.com/ibm/history/exhibits/vintage/vintage_4506VV2118. html [Visitado: 8 de Agosto, 2010]

Iges, J., 2010. ARTE SONORO: UN ARTE DE INTERSECCIONES. http://ease.mase.es/?p=123\#more-123 [Visitado: 12 de Agosto, 2010]

IMEB,

2010.

Cybernephone.

http://www.imeb.net/IMEB_v2/index.php?option=com_content \&view=article\&id=513\&/temid=145 [Visitado: 5 de Agosto, 2010]

Infosuionsystems, 2010.

I-CubeX.

http://infusionsystems.com/catalog/info_pages.php/pages_id/1 37 [Visitado: 23 de Julio, 2010]

IntuitiveMusic, 2010. Electronic Music Definition. http://www.intuitivemusic.com/electronic-music-definition

[Visitado: 7 de Agosto, 2010] 
ISMLP, 2010. Musikalisches Würfelspiel, KV Anh. 294d (W. A. Mozart), International Music Score Library Proyect Portal. http://imslp.org/wiki/Musikalisches_Würfelspiel,_KV_Anh._294 d_(Mozart,_Wolfgang_Amadeus) [Visitado: 9 de Agosto, 2010] Jacobs, K. and Loscos, C., 2006. Classification of Illumination Methods for Mixed Reality. Computer Graphics Forum, 25(1).

Janin, A. L., Mizell, D. W. and Caudell, T. P., 1993. Calibration of headmounted displays for augmented reality applications. IEEE Virtual Reality Annual Int. Symp., Seattle, WA: 246-255.

Juan, M. C., Alcañiz, M., Calatrava, J., Zaragoza, I., Baños, R. and Botella, C., 2007. An Optical see-through AR system for the treatment of phobias to small animals. Lecture Notes in Computer Science, ICVR'07, 4563: 651-659.

Juan, M. C., Alcañiz, M., Monserrat, C., Botella, C., Baños, R. M. and Guerrero, B., 2005. Using augmented reality to treat phobias. IEEE Computer Graphics and Applications, 25(6): 31-37.

Juan, M. C., Baños, R., Botella, C., Pérez, D., Alcañiz, M. and Monserrat, C., 2006a. An Augmented Reality System for the Treatment of Acrophobia: The Sense of Presence Using Immersive Photography. Presence: Teleoperators \& Virtual Environments, 15(4): 393-402.

Juan, M. C., Joele, D., Baños, R., Botella, C., Alcañiz, M. and van der Mast, C., 2006b. A Markerless Augmented Reality System for the treatment of phobia to small animals. Presence Conference: 7174 .

Justel, E., 2000. Las estructuras formales en la música de producción electrónica. Tesis doctoral. Universidad de Paris 8, 375 páginas.

Justel, E., 2010. Fundación Destellos, Argentina. http://www.fundestellos.org/Prensa.htm [Visitado: 4 de Agosto, 2010]

Kameda, Y., Takemasa, T. and Ohta, Y., 2004. Outdoor see-through vision utilizing surveillance cameras. Proceedings of the Third IEEE and ACM International Symposium on Mixed and Augmented Reality (ISMAR'04).

Kangas, K. J. and Röning, J., 2002. Using Mobile Code to Create Ubiquitous Augmented Reality. Wireless Networks, 8: 199- 211.

Kantor, T., 1993. A Journey Through Other Spaces, Essays and Manifestos (1944-1990). University of California Press.

Kaufmann, H., 2002. Construct3D: An Augmented Reality Application for Mathematics and Geometry Education. ACE'02: 656- 657.

Kaufmann, H., 2004. Geometry Education with Augmented Reality. Technischen Universität Wien, Viena. 179 páginas. 
Kaufmann, H. and Schmalstieg, D., 2003. Mathematics and geometry education with collaborative augmented reality. Computers \& Graphics, 27(3): 339-345.

Kealy, A. and Scott-Young, S., 2006. A Technology Fusion Approach for Augmented Reality Applications. Transactions in GIS, 10(2).

Kendall, G. S., 2009. Listening to Art: Aura Cognition in Electroacoustic Music. EMS og: 5.

Kennedy, M., 2006. The Oxford Dictionary of Music, Oxford University Press: 1008.

KeyboardMuseum, 2010. The Synket (1964). http://www.keyboardmuseum.com/pre6o/196o/synket.html

[Visitado: 7 de Agosto, 2010]

KhosidWeddingDances, 2010.

http://www.beskydy.net/Listen to Beskydy/khosid wedding dances .html [Visitado: 31 de Julio, 2010]

Kientzy, D., 1990. Saxologie, du potentiel acoustico-expressif des 7 saxophones. Université de Paris VIII, 606 páginas.

King, G. R., Piekarski, W. and Thomas, B. H., 2005. ARVino - Outdoor Augmented Reality Visualisation of Viticulture GIS Data. International Symposium on Mixed and Augmented Reality (ISMAR'05), IEEE Computer Society: 52 - 55.

Klee, P., 1990. Das bildnerische Denken. Schwabe, Leipzig. 555 páginas.

Klopfer, E., Perry, J., Squire, K. and Jan, M.-F., 2005. Collaborative Learning through Augmented Reality Role Playing. Computer Support for Collaborative Learning, Taipei, Taiwan, International Society of the Learning Sciences: 311 - 315.

Koleva, B., Taylor, I., Benford, S., Fraser, M., Greenhalgh, C., Schnädelbach, H., Lehn, D. v., Heath, C., Row-Farr, J. and Adams, M., 2001. Orchestrating a Mixed Reality Performance. CHI'01, ACM, 3 (1): 38 - 45.

Köln, P. W., 1954. Cita para K. Stockhausen. Musik der Zeit Band 2, DuMont: Cologne, 1988.

Konishi, K., Hashizume, M., Nakamoto, M., Kakeji, Y., Yoshino, I., Taketomi, A., Sato, Y., Tamura, S. and Maehara, Y., 2005. Augmented reality navigation system for endoscopic surgery based on three-dimensional ultrasound and computed tomography: Application to 20 clinical cases. International Congress Series, 1281: 537-542.

Kontakte, G. d. P., 2009. http://www.kontakte-percusion.com [Visitado: 12 Enero 2009].

Koop, N., Nicoli, A. and Livingston, G., 2010. Re: John Cage = no entry (no

exit). 
http://www.youtube.com/watch?v=6TogoOO/JyM\&feature=pla yer_embedded [Visitado: 28 de Julio, 2010]

Kuppers, P., 2007. Community Performance: An Introduction. 224 páginas.

Kurzweil, r., 1999. The Age of Spiritual Machines: When Computers Exceed human Intelligence. Penguin, Nueva York. 400 páginas.

Kwon, M., 2004. One Place After Another: Site-SpecificArt and Locational Identity. MIT Press, Massachusetts. 232 páginas.

Lam, A. H. T., Chow, K. C. H., Yau, E. H. H. and Lyu, M. R., 2006. ART: Augmented Reality Table for Interactive Trading Card Game. VRCIA'06, ACM: 357 - 360.

Landy, L., 2007. Understanding the Art of Sound Organization, London. páginas.

Larousse, 2010. Gran Diccionario de la Lengua Española, Larousse.

Larson, R. D., 1985. Musique Fantastique: A Survey of Film Music in the Fantastic Cinema. Metuchen N. J. \& London: Scarecrow Press. 592 páginas.

Lavelock, J., 1979. A New Look ar Life on Earth, Oxford. 176 páginas.

Lecaine, H., 2010. Electronic Sackbut. http://www.hughlecaine.com/en/sackbut.html [Visitado: 7 de Agosto, 2010]

Lee, R., 1986. Mirror Mirror on the Wall. http://www.rescen.net/Rosemary_Lee/rlchoreo1.html

[Visitado: 31 de Julio, 2010]

Lee, R., 2007.2 Lightwalking. http://www.rescen.net/Rosemary_Lee/rlchoreo3.html

[Visitado: 31 de Julio, 2010]

Lee, R., 2010a. Remote Dancing.

http://www.rescen.net/Rosemary_Lee/rlchoreo3.html

[Visitado: 31 de Julio, 2010]

Lee, R., 2010b. Stereo Dances.

http://www.rescen.net/Rosemary_Lee/rlchoreo3.html

[Visitado: 31 de Julio, 2010]

Lee, S. P., Cheok, A. D., James, T. K. S., Debra, G. P. L., Jie, C. W., Chuang, W. and Farbiz, F., 2006. A mobile pet wearable computer and mixed reality system for human-poultry interaction through the internet. Pers Ubiquit Comput, 10: $301-$ 317.

Leipp, E., 1977. La machine à écouter: Essay de Psycho-acoustique. Masson, Paris. 260 páginas.

Leipp, E., 1984. Acoustique et músique. Mason, Paris. 376 páginas.

Lerma García, J. L., 2002. Fotogrametría Moderna: Analítica y Digital. 550 páginas. 
Levin, G., 2006. Computer Vision for Artists and Designers: Pedagogic Tools and Techniques for Novice Programmers. Journal of Artificial Intelligence and Society, 20(4): 462 - 482.

Levin, G. and Collaborators, 2008. Hidden Worlds of Noice and Voice. http://www.flong.com/projects/hwnv/ [Visitado: 19 Febrero 2008].

Lewinsky, J., 2010. http://videodanza.wordpress.com/ [Visitado: 20 de Julio, 2010]

Livingston, M. A., Rosenblum, L. J., Julier, S. J., Brown, D., Baillot, Y., Swan, J. E., Gabbard, J. L. and Hix, D., 2002. An augmented reality system for military operations in urban terrain. Interservice / Industry Training, Simulation, \& Education Conference (I/ITSEC '02), Orlando, FL.

LNME, 2010. http://www.electroacustica.cult.cu/ [Visitado: 17 de Julio, 2010

López, J. M., 1989. Karlheinz Stockhausen. Círculo de Bellas Artes, Madrid. 142 páginas.

LoyolaUniversityChicago, $2006 . \quad$ Pascal's calculator. http://webpages.cs.luc.edu/ mt/CS150/M1.html [Visitado: 8 de Agosto, 2010]

Lu, B., Lim, K., Zheng, J. and Cai, Y., 2004. Learning Molecular Biology By VR Playing, ACM: 168 - 172.

Luening, O., 1975. The Development and Practice of Electronic Music. Prentice Hall Inc., Nueva Jersey. 288 páginas.

MacAuley, G., 2000. Space in Performance. Michigan, University of Michigan Press.

Mackay, W. E., 1998. Augmented Reality: linking real and virtual worlds. A new paradigm for interacting with computers. Advanced visual interfaces (AVI'98), L'Aquila, Italy, ACM Press: 13 - 21.

Manning, P., 1993. Electronic and Computer Music. Oxford University Press. 496 páginas.

Marchand, r. and Chaumette, F., 2002. Virtual Visual Servoing: a framework for real-time augmented reality. Computer Graphics Forum, 21(3).

Mathews, M. V., 1963. The Digital Computer as a Musical Instrument. Science, 142(11): 553-557.

Mathews, M. V., Miller, J., Pierce, J., Moore, R. and Risset, J.-C., 1969. The Technology of Computer Music. The MIT Press, Massachusetts. 196 páginas.

Matysczok, C., Radkowski, R. and Berssenbruegge, J., 2004. ARBowling: Immersive and Realistic Game Play in Real Environments Using Augmented Reality. ACE'04, Singapore, ACM: $269-274$. 
McEvilly, J., 1999. History of Electro-Acoustic Music. Tesis de máster. Queens University, Belfast. páginas.

McKinon, D., 2007. The acousmatic and the language of the technological sublime.

www.emsnetwork.org/IMG/pdf_McKinnonEMSo7.pdf [Visitado: 13 Febrero 2009].

McPherson, K., 2006. Making videodance, Nueva York. 296 páginas.

Mellers, W., 1992. Percussion in the New-Old World. The Musical Times. ??? páginas.

Member.tde,

2010.

Ondioline.

http://members.tde.com/mmckeown/pictures/Ondioline2Done .jpg [Visitado: 8 de Agosto, 2010]

Mey, T. D., 1997. Rosas Danst Rosas. http://www.rosas.be/SubPages/subFilmexpo/subRosasDanstRo sas/RosasDanstRosas/tabid/147/language/nl-BE/Default.aspx [Visitado: 31 de Julio, 2010]

Mey, T. D., 2002. Fase, Four Movements to the Music of Steve Reich. http://www.rosas.be/SubPages/subFilmexpo/subFase/Fase/tabi d/143/language/nl-BE/Default.aspx [Visitado: 31 de Julio, 2010]

Mey, T. D., 2008. Ma Mere L'Oye. http://www.siouxwire.com/2008/o4/thierry-de-meys-ma-mreloye.html [Visitado: 31 de Julio, 2010]

Meyer, L. B., 2001. Emoción y significado en la música. Alianza, Madrid. 312 páginas.

Michels, U., 1982. Atalas de Música. Vol I. Alianza Editorial, Madrid. 282 páginas.

Mila, M., 2003. Breve historia de la Música. Ediciones Península, Barcelona. 652 páginas.

Milgram, P. and Drascic, D., 1997. Perceptual effects in aligning virtual and real objects in augmented reality displays. $41 \mathrm{~s} t$ Annual Meeting of Human Factors and Ergonomics Society.

Milgram, P. and Kishino, F., 1994. A taxonomy of mixed reality visual displays. IEICE Transactions on Networked Reality, E77-D(12): $1321-1329$.

Minsburg, R., 2008. ¿Qué es la acusmática? http://raulminsburg.blogspot.com/2008/02/qu-es-laacusmtica.html [Visitado: 4 de Agosto de 2010]

Miranda, E. R., 2002. Computer Sound Design: Synthesis Techniques and Programming. Focal Press, Oxford. 263 páginas.

Mischkowski, R. A., Zinser, M. J., Kubler, A. C., Krug, B., Seifert, U. and Zoller, J. E., 2006. Application of an augmented reality tool for maxillary positioning in orthognathic surgery - A feasibility study. Journal of Cranio-Maxillofacial Surgery, 34(8): 478-483. 
Molina, M., 2006. Ecos del Arte sonoro en la vanguardia histórica española (1909-1945). I. M. d. a. s. e. MASE. Lucena-Córdoba, Sensxperiment, Ed.

Molina, M., 2007. Sonido, espacio, reverberación, trascendencia, poder... de la intervención realizada por Conchín Darijo, Leopoldo Amigo y Miguel Molina en el antiguo aljibe del Palau Ducal dels Borja. A. a. Palau'07. Gandía (Valencia).

Molina, M., 2008. El Arte Sonoro. ITAMAR, Revista de Investigación Musical: territorios para el Arte. Valencia, PUB \& Rivera Ed.

Morgan, R. P., 1992. Antología de la música del siglo XX, España. 490 páginas.

Mowitt, J., 1987. The Sound of Music in the Era of Its Electronic Reproductibility in Music and Society: The Politics od Composition, Performance and Reception. (Ed. R. L. a. S. McClary). Cambridge University Press, New York.

Music, M., 2010. http://www.misomusic.com/ [Visitado: 17 de Julio, 2010]

Musicalwars,

2007.

Tipos

de

Síntesis.

http://musicalwars.blogspot.com/2007/og/tipos-de-

sntesis.html [Visitado: 4 de Agosto, 2010]

MXR, 2006. Mixed Reality Lab, National University of Singapore, Singapur. http://www.mixedrealitylab.org/ [Visitado: 1 Febrero 2008].

National Research Council Staff, 1994. Virtual Reality : Scientific and Technological Challenges. Washington, DC, USA: National Academies Press. páginas.

Nawab, A., Chintamani, K., Ellis, D., Auner, G. and Pandya, A., 2007. Joystick mapped Augmented Reality Cues for End-Effector controlled Tele-operated Robots. Virtual Reality (VR'07): 263266.

Neumann, U., 2001. STAR: Tracking for Object-Centric Augmented Reality. capítulo 10 in Fundamentals of wearable computers and augmented reality. (Eds. W. Barfield and T. Caudell). Lawrence Erlbaum Associates, Mahwah, New Jersey. páginas: 329-352.

Newman, J., Wagner, M., Pintaric, T., MacWilliams, A., Baver, M., Klinker, G. and Schmlastieg, D., 2003. Fundamentals of Ubiquitous Tracking for Augmented Reality. Viena, TU-Wien: 18.

NI, 2010. Native Instruments. http://www.nativeinstruments.com/\#/en/ [Visitado: 15 de Julio, 2010 ]

Nikou, C., Digioia lii, A. M., Blackwell, M., Jaramaz, B. and Kanade, T., 2000. Augmented reality imaging technology for orthopaedic surgery. Operative Techniques in Orthopaedics, 10(1): 82-86. 
Nintendo,

2010.

Mando

Wii.

http://www.nintendo.es/NOE/es_ES/wii_54.html [Visitado: 10 de Agosto, 2010]

Noctamina,

2009.

El

Theremin. http://www.noctamina.com/tecnologia/el-theremin [Visitado: 8 de Agosto, 2010]

Nunes, E., 1994. Temps et spatialité. L'Espace - Les cahiers de l'IRCAM, recherche et musique, 5 , Paris.

Olimpias, 2010. The Olimpias. http://www-personal.umich.edu/ petra/ [Visitado: 30 de Julio, 2010]

onepointsix, 2010. http://www.onepointsix.com/ [Visitado: 31 de Julio, 2010]

Palmer, C., 1989a. Computer graphics in music performance research. Behavior Research Methods, Instruments, \& Computers, 21(2): 265-270.

Palmer, C., 1989b. Structural representations of music performance. Proceedings of the Eleventh Annual Conference of the Cognitive Science Society, Hillsdale, NJ, Erlbaum.

Palmer, C., 1989c. Timing in Skilled Music Performance. Cornell University, 353 páginas.

Palombini, C., 1993. 'Pierre Schaeffer's Typo-Morphology of Sonic Objects'. PhD thesis. The University of Durham, páginas.

Pan, Z., Cheok, A. D., Yang, H., Zhu, J. and Shi, J., 2006. Virtual reality and mixed reality for virtual learning environments. Computers \& Graphics, 30: $20-28$.

Parallax Inc., 1987. BASIC Stamp. http://www.parallax.com/ [Visitado: 12 Septiembre 2008].

Park, J.-S., Kim, T. and Yoon, J.-H., 2006. AR Table Tennis: A VideoBased Augmented Reality Sports Game. ICAT'06, SpringerVerlag Berlin Heidelberg: 197-206.

Parra i Esteve, H., 2005. Pour une approche créatrice des interrelations structurelles entre les espaces acoustiques et visuels Paris VIII, Paris. 133 páginas.

Patrian, N., 2008. 'Hodoku'. http://hodokuvideodanza.blogspot.com/ [Visitado: 21 de Julio, 2010]

Patton, K., 2007. Morphological notation for interactive electroacoustic music. páginas.

Paul, C., 2003. Digital Art. Thames \& Hudson world of art, 224. páginas.

Paulos, E. and Jenkins, T., 2005. Urban Probes: Encountering Our Emerging Urban Atmospheres. CHI'05, ACM.

Peignot, J., 1960. De la musique concrète à l'acousmatique. Esperit. 280. 
Peitz, J., Björk, S. and Jäppinen, A., 2006. Wizard's Apprentice gameplay-oriented design of a computer-augmented board game. ACE'o6, California, USA, ACM.

Pelletier, J.-M., 2006. cv.jit computer vision for jitter. http://www.iamas.ac.jp/ jovano2/cv/ [Visitado: 8 Febrero 2008].

Pennstate, 2010. History of Electroacoustic Music: The ColumbiaPrinceton Electronic Music Center. http://www.music.psu.edu/Faculty\%20Pages/Ballora/INART55/ columbia-princeton.html [Visitado: 8 de Agosto, 2010]

Pérez, D., Juan, M. C., Alcañiz, M., Baños, R. and Botella, C., 2007. Two similar systems for the treatment of acrophobia. An AR system and a Virtual Reality system. Lecture Notes in Computer Science, ICVR'07: 850-854.

Pérez, M., 1981. El Universo de la Música. Musicalis, Madrid. 672 páginas.

PhotographersDirect, $2010 . \quad \mathrm{J}$ Mager. http://www.photographersdirect.com/buyers/stockphoto.asp?i mageid $=665156$ [Visitado: 8 de Agosto, 2010]

Piekarski, W., 2006. 3D Modeling with the Tinmith Mobile Outdoor Augmented Reality System. IEEE Computer Graphics and Applications. Projects in VR: 14 - 17.

Piekarski, W. and Thomas, B. H., 2003. Augmented reality user interfaces and techniques for outdoor modelling: 225- 226.

Polite, Pablo G., Sánchez, S., El sonido de la velocidad: cine y música electrónica, 2005, Alpha Decay, 363 páginas.

Portalés, C., 2008. Entornos de Realidad Aumentada en el Campo del Arte. Tesis doctoral. Universidad Politécnica de Valencia, Valencia. 508 páginas.

Portalés Ricart, C., 2008. Entornos de Realidad Aumentada en el Campo del Arte. Tesis doctoral. Universidad Politécnica de Valencia, Valencia. 508 páginas.

Prieto, D. and Reyes, J., 2001-2004. Fundamentos de Síntesis de Audio con Granos, CCRMA, Stanford University.

Author, 1990. Max MSP. Edition, Cycling '74. http://www.cycling74.com/products/max5 1990].

Puckette, M., 1997. Fiddle Max MSP external, University of California. http://www.crca.ucsd.edu/ msp [Visitado: 12 Febrero 2008].

Author, 1990. Max MSP. Edition, Cycling '74. http://www.cycling74.com/products/max5 1990].

Punakea, 2010. http://www.nudgenudge.eu/punakea [Visitado: 15 de Julio de 2010] 
R.A.E., 2010a. Gesto. http://www.rae.es/rae.html [Visitado: 3 de Agosto, 2010]

R.A.E., 2010b. Instrumento. http://www.rae.es/rae.html [Visitado: 3 de Agosto, 2010]

R.A.E., 2010c. Intérprete. http://www.rae.es/rae.html [Visitado: 3 de Agosto, 2010]

R.A.E., 2010d. Sintético. http://www.rae.es/rae.html [Visitado: 3 de Agosto, 2010]

Rashid, O., Bamford, W., Coulton, P., Edwards, R. and Sheible, J., 2006. PAC-LAN: Mixed-Reality Gaming with RFID Enabled Mobile Phones. ACM Computers in Entertainment, 4(4).

Reitmayr, G. and Schmalstieg, D., 2004. Scalable Techniques for Collaborative Outdoor Augmented Reality. Viena, TU-WIEN.

Rekalde, J., 2010a.

Gaia. http://www.hamacaonline.net/obra.php?id=29o [Visitado: 17 de Julio, 2010]

Rekalde, J., 2010b. Vuelos Migratorios. http://www.hamacaonline.net/obra.php?id=288 [Visitado: 17 de Julio, 2010

Ricard, J. and Herrera, P., 2004. Morphological sound description: computational model and usability evaluation. Audio Engineering Society Convention Proceedings.

Risset, J.-C., 1997. Composition et diffusion: quelques observations'. Actes III de l'Académie de Bourges.

Roads, C., 1997. Espace musical: virtuel et physique. Actes III de l'Académie de Bourges.

Robert, M., 1999. Pierre Schaeffer: Communication et musique en France entre 1936 et 1986. L'Harmattan, Paris. 416 páginas.

Rocha Iturbide, M., 1991. Acerca de John Cage. La Pus Moderna, México $D F, 3$.

Rolland, J., Davis, L., Ha, Y., Meyer, C., Shaoulov, V., Akcay, A., Zheng, H., Banks, R. and Vento, B. D., 2002. 3D Visualization and Imaging in Distributed Collaborative Environments. IEEE Computer Graphics and Applications. Projects in VR: $11-13$.

Rolland, J. P., Davis, L. D. and Baillot, Y., 2001. A Survey of Tracking Technologies for Virtual Environments. capítulo 3 in Fundamentals of wearable computers and augmented reality. (Eds. W. Barfield and T. Caudell). Lawrence Erlbaum Associates, Mahwah, New Jersey. páginas: 67-112.

Romero, L., Santiago, J. and Correia, N., 2004. Contextual Information Access and Storytelling in Mixed Reality Using Hypermedia. ACM Computers in Entertainment, 2(3). 
Rosenberg, D., 2006. Screendance: the State of the Art. American Dance Festival, Duke University in Durham, NC: 2.

Rosenthal, M., State, A., Lee, J., Hirota, G., Ackerman, J., Keller, K., Pisano, E. D., Jiroutek, M., Muller, K. and Fuchs, H., 2002. Augmented reality guidance for needle biopsies: An initial randomized, controlled trial in phantoms. Medical Image Analysis, 6(3): 313-320.

Roussou, M., 2004. Learning by Doing and Learning Through Play: An Exploration of Interactivity in Virtual Environments for Children. ACM Computers in Entertainment, 2(4): 1 - 23.

Rowe, R., 1993. Interactive Music Systems: Machine Listening and Composing. MIT Press: Cambridge.

Rowe, R., 2010. Página personal. http://homepages.nyu.edu/ rr6/ [Visitado: 8 de Aosto, 2010]

Sadie, S., 1984. The New Grove's Dictionary of Music and Musicians. Londres, MacMillan Press.

Sakonda,

N., 2010.

http://web.me.com/nsakonda/sakoweb/download.html

[Visitado: 12.07.2010

[Visitado: 18 abril 2009].

Sánchez, J. A., 1999. Desviaciones. La inesperada y Cuarta Pared, Cuenca.

Sandor, C. and Klinker, G., 2005. A rapid prototyping software infrastructure for user interfaces in ubiquitous augmented reality. Pers Ubiquit Comput, 9: 169-185.

Sanz-Menendez, L., Bordons, M. and Zulueta, M. A., 2001. Interdisciplinarity as a multidimensional concept: Its measere in three different research areas, Research Evaluation, 10: 47-58.

Scarani, S., 2010. Perg. http://www.stefanoscarani.com/ [Visitado: 17 de Julio, 2010]

Schachtel, E., 1984. Metamorphosis: On the Development of Affect, Perception, Attention, and Memory (Psychoanalysis Examined and Re-Examined). Da Capo Press. 344 páginas.

Schaeffer, P., 1952. À la recherche d'une musique concréte. Éditions du Seuil, Paris. 228 páginas.

Schaeffer, P., 1966. Tratado de los objetos musicales. Alianza Música, Madrid. 337 páginas.

Schechner, R., 1988a. Performance Theory. The Oxford English Dictionary. Routledge, New York, Oxford University Press.

Schechner, R., 1988b. Performance Theory. Routledge. The Oxford English Dictionary (1989). Routledge. New York, Oxford University Press. 
Schmidt, H.-C., 1976. Musik in den Massenmedien Rundfunk und Fernsehen. 339 páginas.

Schnädelbach, H., Koleva, B., Fintham, M., Fraser, M., Izadi, S., Chandler, P., Foster, M., Benford, S., Greenhalgh, C. and Rodden, T., 2002. The Auguroscope: a mixed reality interface for outdoors. CHI'02, 4: 9 - 16.

Schnell,

N., 2010.

Página

pesonal.

http://imtr.ircam.fr/imtr/Norbert Schnell [Visitado: 8 de Agosto, 2010]

Schumacher, F., 2009. Oir sin ver. Revista Resonancias, Insitituro de Música de la Universidad Católica: 6.

Seidle, N., 2006. Wii-mote guts. http://www.sparkfun.com/commerce/tutorial info.php?tutorial s id $=43$ \&page $=$ [Visitado: 17 Abril 2009].

Serra, X., 2010. Perspectivas actuales en la síntesis digital de sonidos musicales. http://www.iva.upf.es/formats/formats1/aozet.htm [Visitado: 4 de Agosto, 2010]

Settel, Z., 1994-98. Jimmies objects library, IRCAM. [Visitado: 13 Agosto 2008].

Shaheen, M., Mallem, M. and Chavand, F., 2001. Visual command of a robot using $3 \mathrm{D}$-scene reconstruction in an augmented reality system. Control Engineering Practice, 9(4): 375-385.

Shaw, J., 1989. The legible city. Manhattan version (1989), Amsterdam version (1990), Karlsruhe version (1991). http://www.jeffreyshaw.net/html_main/show_work.php3?record_id=83 [Visitado: 5 Octubre 2007].

Sherman, W. R. and Craig, A. B., 2003. Understanding virtual reality: interface, application, and design. Morgan Kaufmann, Amsterdam. 582 páginas.

SIGGRAPGH, 2010. SIGGRAPH VIDEO REVIEW. http://www.siggraph.org/publications/video-review/1_36.php [Visitado: 28 de Julio, 2010]

Sloterdijk, P., 2001. Extrañamiento del mundo. Editorial Pre-textos, Valencia. 286 páginas.

Smalley, D., 1982. Master pieces of 2oth-Century Muti-Channel Tape Music.

http://www.music.columbia.edu/masterpieces/notes/smalley/n otes.html [Visitado: 18 abril 2009].

Smalley, D., 1986. Spectromorphology and structuring processes. in The Language of Electroacoustic Music. In S. Emmerson (ed), Basingstoke.

Smalley, D., 1992. The Listening Imagination: Listening in the Electroacoustic Era. capítulo 26 in Companion to Contemporary 
Musical Thought. (Eds. J. Orton, T. Paynter, T. Howell and P. Seymour). Routeledge, London. páginas: 514-554.

Smalley, D., 1997. Spectromorphology: Explaining sound-shapes. Organised Sound. Cambridge University Press. páginas.

Smith, H., 1997. Improvisation hypermedie and the arts since 1945, Amsterdam. 336 páginas.

SpotMeta, 2010. http://www.fluffy.co.uk/spotmeta/ [Visitado: 15 de Julio de 2010]

Stangos, N., 1986. Conceptos de arte moderno, Madrid. 336 páginas.

Stephenson, T., 2006. Poème électronique by Edgard Varèe: Authenticity, reproduction and mediatization. International Journal of Performance Arts and Digital Media,(1).

Stilman, M., Michel, P., Chestnutt, J., Nishiwaki, K., Kagami, S. and Kuffner, J., 2005. Augmented Reality for Robot Development and Experimentation, Robotics Institute, Carnegie Mellon University.

Stravinsky, I., 1961. 8 de Octubre. The Observer.

Supercollider, 2010. Audiosynth. http://www.audiosynth.com/ [Visitado: 8 de Agosto, 2010]

Sutherland, R., 1994. New Perspectives in music. Sun Tavern Fileds. 287 páginas.

Synthése, 2010. http://www.imeb.net/IMEB v2/index.php [Visitado: 17 de Julio, 2010]

Szalavári, Z., Eckstein, E. and Gervautz, M., 1998. Collaborative Gaming in Augmented Reality. VRST'98, Taipei (Taiwan), ACM.

Tangatamanu, 2010. Tangatamanu. http://www.tangatamanu.com/ [Visitado: 17 de Julio, 2010]

Tannenbaum, E., 2010. National Geographic special on computers featuring video artist Ed Tannenbaum. http://www.youtube.com/watch?v=MjpE47LaRcl\&feature=relat ed [Visitado: 28 de Julio, 2010]

Tannenbaum, E., Javril, M. and Payne, M., 1985. Viscous Meanderings. http://il.youtube.com/watch?v=98fvPSNJHpw [Visitado: $28 \mathrm{de}$ Julio, 2010]

Tappert, C. C., Ruocco, A. S., Langdorf, K. A., Mabry, F. J., Heineman, K. J., Brick, T. A., Cross, D. M., Pellissier, S. V. and Kaste, R. C., 2001. Military Applications of Wearable Computers and Augmented Reality. capítulo 20 in Fundamentals of wearable computers and augmented reality. (Eds. W. Barfield and T. Caudell). Lawrence Erlbaum Associates, Mahwah, New Jersey. páginas: $625-648$. 
TheSummitHistoricalSociety, 2004. Edwin Scott Votey. http://www.summitnjhistory.org/Historian_votey.php

[Visitado: 8 de Agosto, 2010]

Thoresen, L., 2007. Spectromorphological analysis of sound objects: an adaptation of Pierre Schaeffer's typomorphology, New York. páginas.

Torpus, J., 2005. lifeClipper. http://www.torpus.com/lifeclipper/ [Visitado: 5 Octubre 2007].

Troillard, C., 2006-2008. OSCulator 2.5.9. http://www.osculator.net/ [Visitado: 12 Enero 2009].

Truax, B., 2001. Acoustic Communication, Westport, Connecticut. 250 páginas.

UVA, 2010. Volume. http://www.uva.co.uk/archives/49 [Visitado: 31 de Julio, 2010]

V.V.-A.A., 1991. IVAECM. Tercer encuentro sobre composición musical.

Vaggione, H., 1991. Jeux d'espaces in (Dohmont, F. L'Espace des sons). Musique et Recherches, Bruxelles. 2.

Vande Gorne, A., 1996. Les mots pour le dire: Lexique des musiques Ėlectroacoustiques. Ars Sonora, 3 (Marzo).

Vandekeybus, W., 2010a. http://www.ultimavez.com/ [Visitado: 31 de Julio, 2010]

Vandekeybus, W., 2010b. Dance \& Short Fiction Films. Format: DVD. C. U. vez.

Varèse, E., 1957-58. Poème Électronique für Tonband. sketch sheet 8,6 $\times 29,8 \mathrm{~cm}$ páginas.

Varèse, E., 1967. The Liberation of Sound in Contemporary Composers on Contemporary Music. (Eds. E. Schwartz, B. Childs and J. Fox, New York. páginas: 195-208.

VoxNovus, 2010. Vox Novus, the new voice in contemporary music. http://www.voxnovus.com/ [Visitado: 28 de Julio, 2010]

Wacker, F. K., Vogt, S., Khamene, A., Sauer, F., Wendt, M., Duerk, J. L., Lewin, J. S. and Wolf, K. J., 2005. MR image-guided needle biopsies with a combination of augmented reality and MRI: A pilot study in phantoms and animals. International Congress Series, 1281: 424-428.

Wagner, M., MacWilliams, A., Baver, M., Klinker, G., Newman, J., Pintaric, T. and Schmalstieg, D., 2004. Fundamentals of Ubiquitous Tracking. Viena, TU-Wien: 6.

Wang, X. and Dunston, P. S., 2006. Compatibility issues in Augmented Reality systems for AEC: An experimental prototype study. Automation in Construction, 15(3): 314-326.

Waves, 2010. Waves Audio Ltd. http://www.waves.com/ [Visitado: 2 de Agosto, 2010] 
Weidenbach, M., Wick, C., Pieper, S., Quast, K. J., Fox, T., Grunst, G. and Redel, D. A., 2000. Augmented Reality Simulator for Training in Two-Dimensional Echocardiography. Computers and Biomedical Research, 33(1): 11-22.

Wikipedia, 2008a. Mobile RFID. http://en.wikipedia.org/wiki/Mobile_RFID [Visitado: 20 Enero 2008].

Wikipedia, 2008b. RFID. http://es.wikipedia.org/wiki/RFID [Visitado: 20 Enero 2008].

Wikipedia, 2010a. Archicembalo.

http://en.wikipedia.org/wiki/Archicembalo [Visitado: 8 de Agosto, 2010]

Wikipedia, 2010b. Audio Units. http://en.wikipedia.org/wiki/Audio Units [Visitado: 1 de Agosto, 2010]

Wikipedia, 2010c. Auriculares. http://es.wikipedia.org/wiki/Auriculares [Visitado: 1 de Agosto, 2010]

Wikipedia, 2010d. Efecto Doppler. http://es.wikipedia.org/wiki/Efecto Doppler [Visitado: 5 de Agosto, 2010]

Wikipedia, 2010e. Historia de la música. http://es.wikipedia.org/wiki/Historia de la música [Visitado: 7 de Agosto, 2010]

Wikipedia, 2010f. Historia de la tecnología. http://es.wikipedia.org/wiki/Historia_de_la_tecnolog\%C3\%ADa [Visitado: 7 de Agosto, 2010]

Wikipedia, 2010g. Historia del registro del sonido. http://es.wikipedia.org/wiki/Historia_del_registro_del_sonido [Visitado: 7 de Agosto, 2010]

Wikipedia, 2010h. Improvisación. http://es.wikipedia.org/wiki/lmprovisación [Visitado: 9 de Agosto, 2010]

Wikipedia, 2010i. Mano Guidoniana. http://es.wikipedia.org/wiki/Mano_guidoniana [Visitado: 8 de Agosto, 2010]

Wikipedia, 2010j.

MassiveAttack. http://es.wikipedia.org/wiki/Massive_Attack [Visitado: 31 de Julio, 2010]

Wikipedia, 2010k. Matemáticas discretas.

http://es.wikipedia.org/wiki/Matemática_discreta [Visitado: 4 de Agosto, 2010]

Wikipedia, 2010l. Mellotron. http://es.wikipedia.org/wiki/Mellotron

[Visitado: 7 de Agosto, 2010] 
Wikipedia, 2010m.

Órgano

Hammond.

http://es.wikipedia.org/wiki/Órgano_Hammond [Visitado: 8 de Agosto, 2010]

Wikipedia, 2010 .

Performance.

http://es.wikipedia.org/wiki/Performance [Visitado: 9 de Agosto, 2010]

Wikipedia, 20100. Sensor. http://es.wikipedia.org/wiki/Sensor

[Visitado: 9 de Agosto, 2010]

Wikipedia, 2010p. Software. http://es.wikipedia.org/wiki/Software

[Visitado: 9 de Agosto, 2010]

Wikipedia, 2010q. The

The Musical

Box.

http://en.wikipedia.org/wiki/Musical box [Visitado: 8 de Agosto, 2010]

Wikipedia, 2010r. TripHop. http://es.wikipedia.org/wiki/Trip-hop [Visitado: 31 de Julio, 2010]

Wilkie, F., 2002. Mapping the Terrain: A Survey of Site Specific Performance in Britain. New Theatre Journal, 18(70 (Mayo)).

Windsor, W. L., 1996. Perception and signification in electroacoustic music. En R. Monelle y C. T. Gray (eds.) in Songs and Signification, chapter 7. (Ed. E. U. F. o. Music páginas: pp.64-74.

Windsor, W. L., 2000. Through and Around the Acoustic: The Interpretation of Electroacoustic Sounds. Ashgate, Aldershot. 735 páginas.

Wishart, T., 1986. Sound Symbols and Landscapes. capítulo 3 in The Language of Electroacoustic Music. (Ed. S. Emmerson). Harwood Academic, New York. páginas: 41-6o.

Wishart, T., 1994. Audible Design: A plain and easy introduction to practical sound composition. Broadfield Publishing. 139 páginas.

Xenakis, I., 2001. Formalized Music: Thought and Mathematics in Composition. Pendragon Press, Hillsdale, NY. 490 páginas.

Xiig190, 2008. Wii Remote orientation $X Y Z$ data values. http://xiig190.wordpress.com/2008/05/23/wii-remoteorientation-xyz-data-values/ [Visitado: 10 de Agosto, 2010]

XSens, 2007. XSens Motion Technologies. http://www.xsens.com/ [Visitado: 2 Febrero 2007].

Xsens, 2007. "Xsens Motion Technologies". [Visitado: Visto el 2 Febrero, 2007, en http://www.xsens.com/.

Zhou, Z., Cheok, A. D., Yang, X. and Qiu, Y., 2004. An experimental study on the role of $3^{D}$ sound in augmented reality environment. Interacting with Computers, 16(6): 1043-1068.

Zin-Lai, W., 2001. Tai Chi: El Ballet de La Felicidad. 128 páginas.

Zlatanova, S., 2001. 3D modelling for augmented reality. Dynamic and Multi-dimensional GIS. Bangkok (Thailand). 